ORP-56321

Revision 0

\title{
Preliminary ILAW Formulation Algorithm Description, 24590 LAW RPT-RT-04-0003, Rev. 1
}

Prepared for the U.S. Department of Energy

Assistant Secretary for Environmental Management

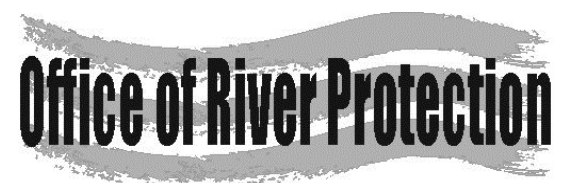

P.O. Box 450

Richland, Washington 99352 
ORP-56321

Revision 0

\section{Preliminary ILAW Formulation Algorithm Description, 24590 LAW RPT-RT-04-0003, Rev. 1}

D. S. Kim

Pacific Northwest National Laboratory

J. D. Vienna

Pacific Northwest National Laboratory
A. A. Kruger

Department of Energy - Office of River Protection

Date Published

November 2012

Prepared for the U.S. Department of Energy

Assistant Secretary for Environmental Management

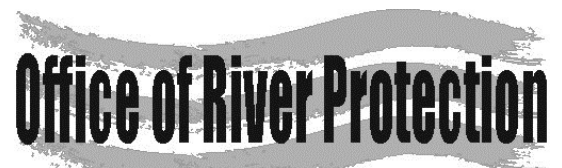

\section{P.O. Box 450}

Richland, Washington 99352

\section{APPROVED}

By Julia Raymer at 11:14 am, Dec 03, 2013 
ORP-56321

Revision 0

TRADEMARK DISCLAIMER

Reference herein to any specific commercial product, process, or service by tradename, trademark, manufacturer, or otherwise, does not necessarily constitute or imply its endorsement, recommendation, or favoring by the United States Government or any agency thereof or its contractors or subcontractors.

This report has been reproduced from the best available copy.

Printed in the United States of America 
Issued by

RPP-WTP ADC

R50027169

ORP-56321, Rev. 0

Preliminary ILAW Formulation Document title: Algorithm Description

Document number: 24590-LAW-RPT-RT-04-0003, Rev 1

Contract number: $\quad$ DE-AC27-01RV14136

Department:

Authors):

Checked by:

Issue status:
Process Technology

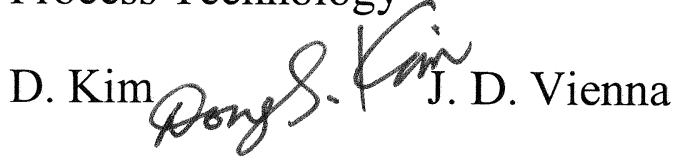

J. L. Nelson Go Burrow

Approved

Approved by:

S. M. Barnes

Approver's position: Manager, Process Technology

Approver's signature:
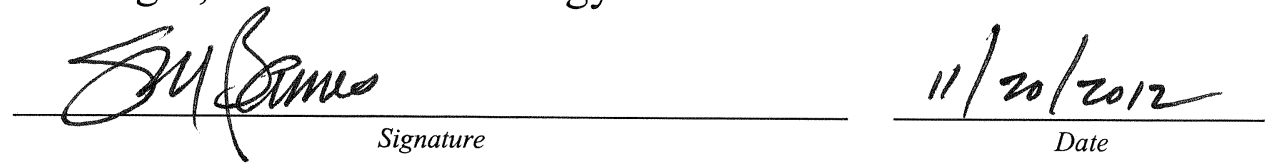

River Protection Project

Waste Treatment Plant

2435 Stevens Center Place

Richland, WA 99354

United States of America

Tel: 5093712000 


\section{History Sheet}

\begin{tabular}{|c|c|c|}
\hline Rev & Reason for revision & Revised by \\
\hline 0 & Initial Issue & JD Vienna \\
\hline 1 & $\begin{array}{l}\text { Major rewrite to incorporate all the changes since Rev } 0 \\
\text { including new glass property models, additional glass } \\
\text { formulation rules, updated constraints, new method of } \\
\text { uncertainty calculation, revised process conditions, and revised } \\
\text { glass formulation steps with example calculations based on } \\
\text { updated waste compositions. The report was also reorganized } \\
\text { to make it consistent with the IHLW formulation algorithm } \\
\text { report. }\end{array}$ & D Kim \\
\hline
\end{tabular}




\section{Contents}

History Sheet

Executive Summary .......................................................................................................................... vii

Abbreviations and Acronyms ............................................................................................. viii

Key Definitions ............................................................................................................................ ix

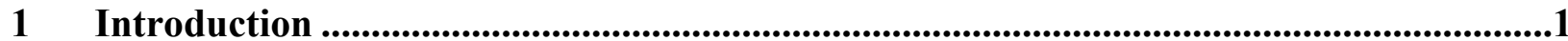

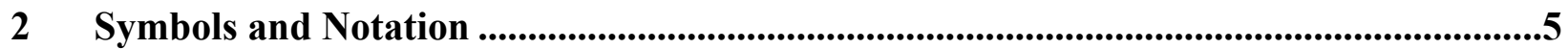

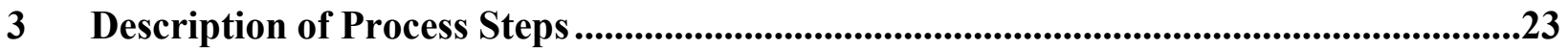

4 Description of Property Predictions, Uncertainties, and Constraints ..............................25

4.1 Property Predictions .........................................................................................................................25

4.2 Uncertainties for Predicted Properties....................................................................................................33

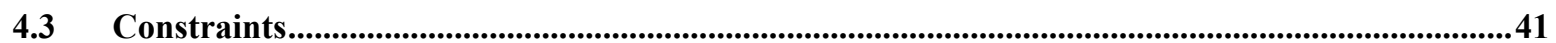

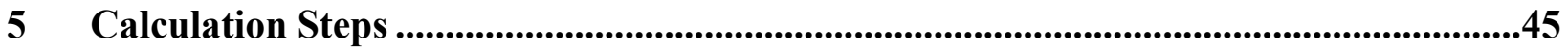

5.1 Step 1 - Glass Formulation and Calculation of LAW Transfer Volume..........................................45

5.2 Step 2 - Calculation of GFC Masses and Dilution Water Volume .................................................79

5.3 Step 3 - Calculation of Final Glass Composition and Properties with Uncertainties .....................8 82

5.4 Step 4 - Comparison of Final Composition and Properties with Constraints .................................93

5.5 Step 5 - Completion of Production Records ....................................................................................93

6 Calculation Examples.......................................................................................................108

6.1 Example Step 1 - Glass Formulation and Calculation of LAW Transfer Volume .....................108

6.2 Example Step 2 - Calculation of GFC Masses and Dilution Water Volume ..................................134

6.3 Example Step 3 - Calculation of Final Glass Composition and Properties with

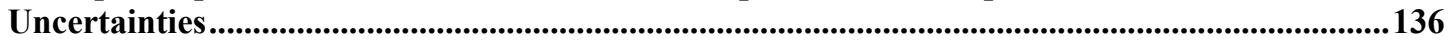

6.4 Example Step 4 - Comparison of Final Composition and Properties with Constraints .............. 140

6.5 Example Step 5 - Completion of Production Records ....................................................................140

7 Summary and Recommendations ....................................................................................147

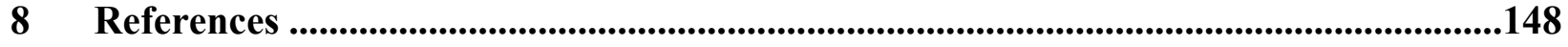

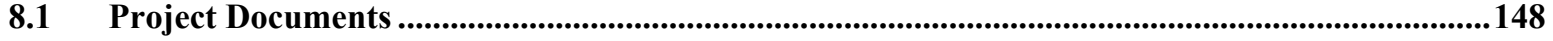

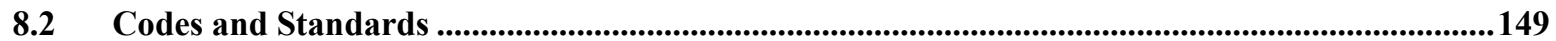

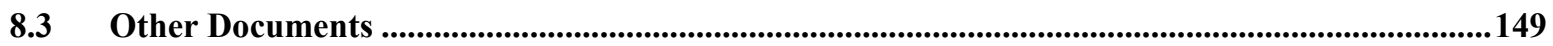




\section{Appendices}

Appendix A -Inputs Used in Calculations............................................................................... A-1

Appendix B -Results of Example Calculations..............................................................................B-1

Appendix C -Summary of Data Requirements........................................................................... C-1

Appendix D -Uncertainties for Waste Transfer Volume Measurements.............................. D-1

Appendix E -Uncertainties for GFC Mass Measurements......................................................E-1

Appendix F -GFC and Sucrose Volume Contributions...............................................................F-1

Appendix G -PERT Distribution ................................................................................................ G-1

\section{Tables}

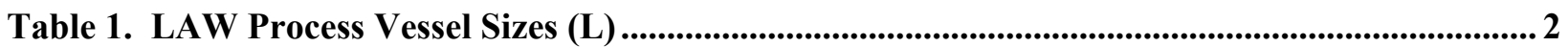

Table 2. Summary of LAW Glass and Melt Constraints Used in ILAW Algorithm ${ }^{(\text {a) }}$......................... 3

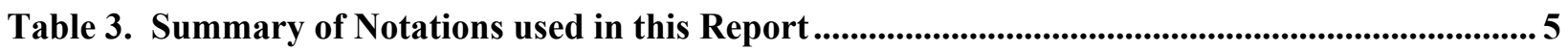

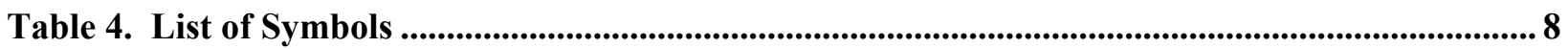

Table 5. PCT Release-Composition Model Coefficients and Selected Statistical Parameters.......... 27

Table 6. VHT Alteration Depth-Composition Model Coefficients and Selected Statistical

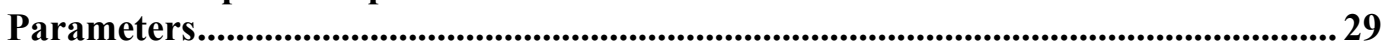

Table 7. Viscosity-Composition Model Coefficients and Selected Statistical Parameters.................. 31

Table 8. Electrical Conductivity-Composition Model Coefficients and Selected Statistical

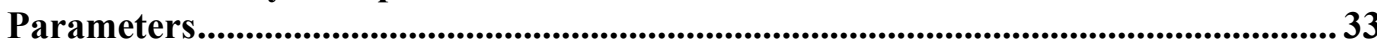

Table 9. Summary of Uncertain Input Values that Are Generated for Mass Balance

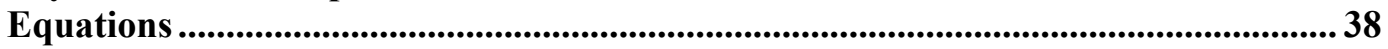

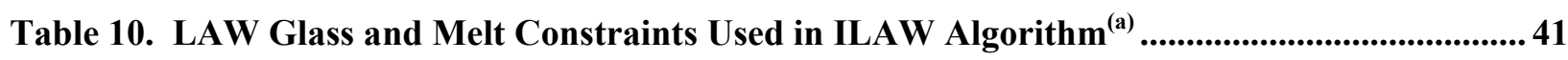

Table 11. Model Validity Range for $\tilde{g}_{i j}^{\text {oxidein }}$ (Single Component Constraints in Mass

Fraction) .................................................................................................................................... 43

Table 12. Model Validity Constraints for Glass and Melt Properties.................................................... 44

Table 13. Model Validity Multiple Component Constraints (in Mass Fraction) ................................. 44

Table 14. CRV-MFPV Line and Sampling Line Flush Nominal Volumes (L) .................................... 62

Table 15. Long Lived Radionuclides Class C Limits ................................................................................. 71

Table 16. Short Lived Radionuclides Class C Limits ................................................................................ 72

Table 17. Summary of Production Records Related Waste Form Specifications (24590-WTP-PL-RT-03-001)

Table 18. Preliminary Target Mass $\left(\dddot{M}_{k, A 101}^{G F C i n, p r e}\right)$ and Target Mass $\left(\dddot{M}_{k, A 101}^{G F C \text {, target }}\right)$ of Each GFC per $g$ Glass for the $A 101^{\text {th }}$ MFPV Batch 
Table 19. Masses of GFCs and Sucrose from Step 1 Calculation for the $A 101^{\text {th }}$ MFPV Batch ...... 121

Table 20. Example Calculation for Predicted PCT Normalized B Release, $P_{A 101}^{p c t B, S t e p 1}$ in $\ln [\mathrm{g} / \mathrm{L}]$

Table 21. Predicted Properties, Uncertainties, and UCCI/LCCI Values for the $A 101^{\text {th }}$

MFPV Batch Compared with the Corresponding Limits

Table 22. Model Validity Constraints for the $A 101^{\text {th }}$ MFPV Batch Compared with the Corresponding Limits.

Table 23. Calculation of Sum of Fractions for Long Lived Radionuclides Class C Limits in the $A 101^{\text {th }}$ MFPV batch

Table 24. Calculation of SD for Sum of Fractions for Long Lived Radionuclides Class C Limits in the $A 101^{\text {th }}$ MFPV batch

Table 25. Calculation of Sum of Fractions for Short Lived Radionuclides Class C Limits in the $A 101^{\text {th }}$ MFPV batch

Table 26. Calculation of SD for Sum of Fractions for Short Lived Radionuclides Class C Limits in the $A 101^{\text {th }}$ MFPV batch

Table 27. Preliminary Target and Target Masses of Each GFC per g Glass for the $A 101^{\text {th }}$ MFPV Batch after Target Glass Composition Adjustment

Table 28. Masses of GFCs and Sucrose from Step 1 Calculation for the $A 101^{\text {th }}$ MFPV Batch after Target Composition Adjustment

Table 29. Predicted Properties, Uncertainties, and UCCI/LCCI Values for the $A 101^{\text {th }}$ MFPV Batch Compared with the Corresponding Limits (After Formulation Adjustment)

Table 30. Additional Constraints for the $A 101^{\text {th }}$ MFPV Batch after Composition Adjustment Compared with the Corresponding Limits

Table 31. Masses of GFCs and Sucrose from Step 2 Calculation for the $A 101^{\text {th }}$ MFPV Batch

Table 32. Assumed Values for the Measured Masses of GFCs and Sucrose in Step 3 Calculation and Calculated GFC/Sucrose Masses per $\mathrm{g}$ Glass for the $\boldsymbol{A 1 0 1}{ }^{\text {th }}$ MFPV Batch 136

Table 33. Predicted Properties, Uncertainties, and UCCI/LCCI Values for Final Composition from Step 3 Calculation of the $A 101^{\text {th }}$ MFPV Batch Compared with the Corresponding Limits. 138

Table 34. Additional Constraints for the Step 3 composition of the $A 101^{\text {th }}$ MFPV Batch Compared with the Corresponding Limits

Table 35. Calculation of Waste $\mathrm{Na}_{2} \mathrm{O}$ loading for the $A 501^{\text {th }}$ and $B 501^{\text {th }}$ Canisters 141

Table 36. Chemical Composition of Glass in the $A 501^{\text {th }}$ and $B 501^{\text {th }}$ Canisters ............................. 142

Table 37. Specific Activities of Radionuclides in the $A 501^{\text {th }}$ and $B 501^{\text {th }}$ Canisters 144

Table 38. Results of Calculating the Quantities for Radionuclide Concentration Limitations in the $\mathrm{A501}^{\text {th }}$ and $\mathrm{B501}^{\text {th }}$ Canisters 145

Table 39. Summary of PCT and VHT Results for the ILAW in the $A 501^{\text {th }}$ and $B 501^{\text {th }}$ Canisters 146 


\section{Figures}

Figure 1. Schematic of the LAW Vitrification Process....................................................................... 1

Figure 2. Preliminary ILAW Product Qualification Process Flow Diagram ...................................... 23

Figure 3. Block Diagram Showing the Sources of Uncertainties Applied To Glass

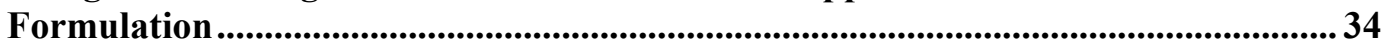

Figure 4. Process Flow Diagram for Algorithm Steps 1 through 5 ..................................................... 45

Figure 5. Process Flow Diagram for Algorithm Step 1 Calculations ...................................................46

Figure 6. Schematic of $\mathrm{Na}_{2} \mathrm{O}-\mathrm{SO}_{3}-\mathrm{K}_{\mathbf{2}} \mathrm{O}$ Rules for $g_{\mathrm{Na}_{2} O, j}^{M M^{2}{ }^{2}}$

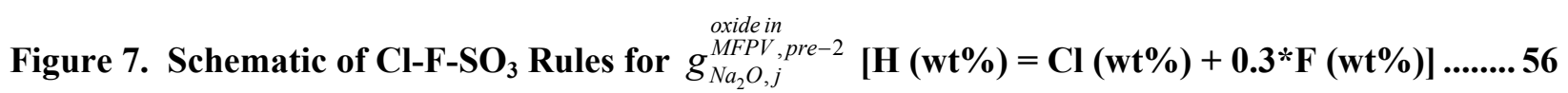

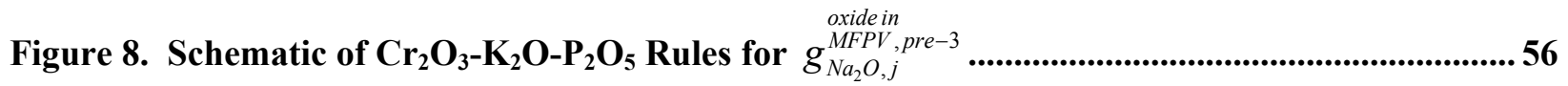

Figure 9. Relationship between Sodium Molarity and Waste Loading for Successful Melter Feed

Figure 10. Schematic of Glass Composition Averaging over MFPV Batches and ILAW Containers

Figure 11. Schematics of Glass Formulation Rules Showing the Initial Glass Composition for the $A 101^{\text {th }}$ MFPV Batch $[\mathrm{H}(\mathrm{wt} \%)=\mathrm{Cl}(\mathrm{wt} \%)+0.3 * \mathrm{~F}(\mathrm{wt} \%)]$

Figure 12. Example Histogram of 5000 Random $V_{A 11,1}^{\text {transwaste }}$ Values (L) for Monte Carlo Simulation

Figure 13. Histogram of 5000 Predicted $P_{A 101}^{p c t B, S t e p 1}$ Values $(\ln [\mathbf{g} / \mathbf{L}])$ from Monte Carlo 


\section{Executive Summary}

This report documents the initial algorithm for use by Hanford Tank Waste Treatment and Immobilization Plant (WTP) in batching low-activity waste (LAW) and glass-forming chemicals (GFCs) in the LAW melter feed preparation vessel (MFPV). Algorithm inputs include the chemical analyses of the pretreated LAW in the concentrate receipt vessel (CRV), the volume of the MFPV heel, and the compositions of individual GFCs. In addition to these inputs, uncertainties in the LAW composition and processing parameters are included in this algorithm.

Using the above inputs, the algorithm calculates the following outputs: 1) the volume of LAW to be transferred from the CRV to the MFPV, 2) the volume of any required dilution water, 3) the mass of each GFC for addition to the MFPV batch, 4) the composition of the glass that will be produced, and 5) the predicted properties, with associated uncertainties, of the resulting immobilized low-activity waste (ILAW) on a batch and lot scale.

The GFC additions are determined using a glass-formulation correlation (Muller et al. 2004) that produces an interpolation using glasses that were successfully demonstrated at pilot scale. Developing the ILAW correlation entailed fitting functions to glasses that met all property constraints and were demonstrated in the Duratek LAW pilot melter (DM3300). Many glass oxide components have constant concentrations in the ILAW glass; i.e., $\left(\mathrm{Al}_{2} \mathrm{O}_{3}\right.$ [6.1 wt\%], $\mathrm{B}_{2} \mathrm{O}_{3}$ [10], $\mathrm{Fe}_{2} \mathrm{O}_{3}$ [5.5], $\mathrm{TiO}_{2}$ [1.4], $\mathrm{ZnO}$ [3.5], and $\left.\mathrm{ZrO}_{2}[3]\right)$. The concentrations of other components $\left(\mathrm{CaO}, \mathrm{Li}_{2} \mathrm{O}\right.$, and $\left.\mathrm{MgO}\right)$ were determined from fitted curves as functions of alkali content of the glass. These glass formulation rules were supplemented by two set of additional rules (Halide, Chromate, and Phosphate Impacts on LAW Glass Salt Limits, CCN 150795), with one set based on the mass fractions of $\mathrm{Cl}, \mathrm{F}$, and $\mathrm{SO}_{3}$ and the other based on the mass fractions of $\mathrm{Cr}_{2} \mathrm{O}_{3}, \mathrm{~K}_{2} \mathrm{O}$, and $\mathrm{P}_{2} \mathrm{O}_{5}$ in the CRV waste transferred to MFPV.

The algorithm also incorporates process measurement and property prediction uncertainties. Estimates of the various process and measurement uncertainties that affect glass compositions and predicted glass properties have been previously estimated (Piepel et al. 2005) and the impact of these estimated uncertainties on the product quality and processing-related properties were evaluated.

The details of work performed to date to develop this preliminary GFC addition and batching algorithm are summarized along with a statement of the required work to achieve a final operational control algorithm. This document will be updated as needed, as new data are available or changes to approaches/constraints are made. 


\section{Abbreviations and Acronyms}

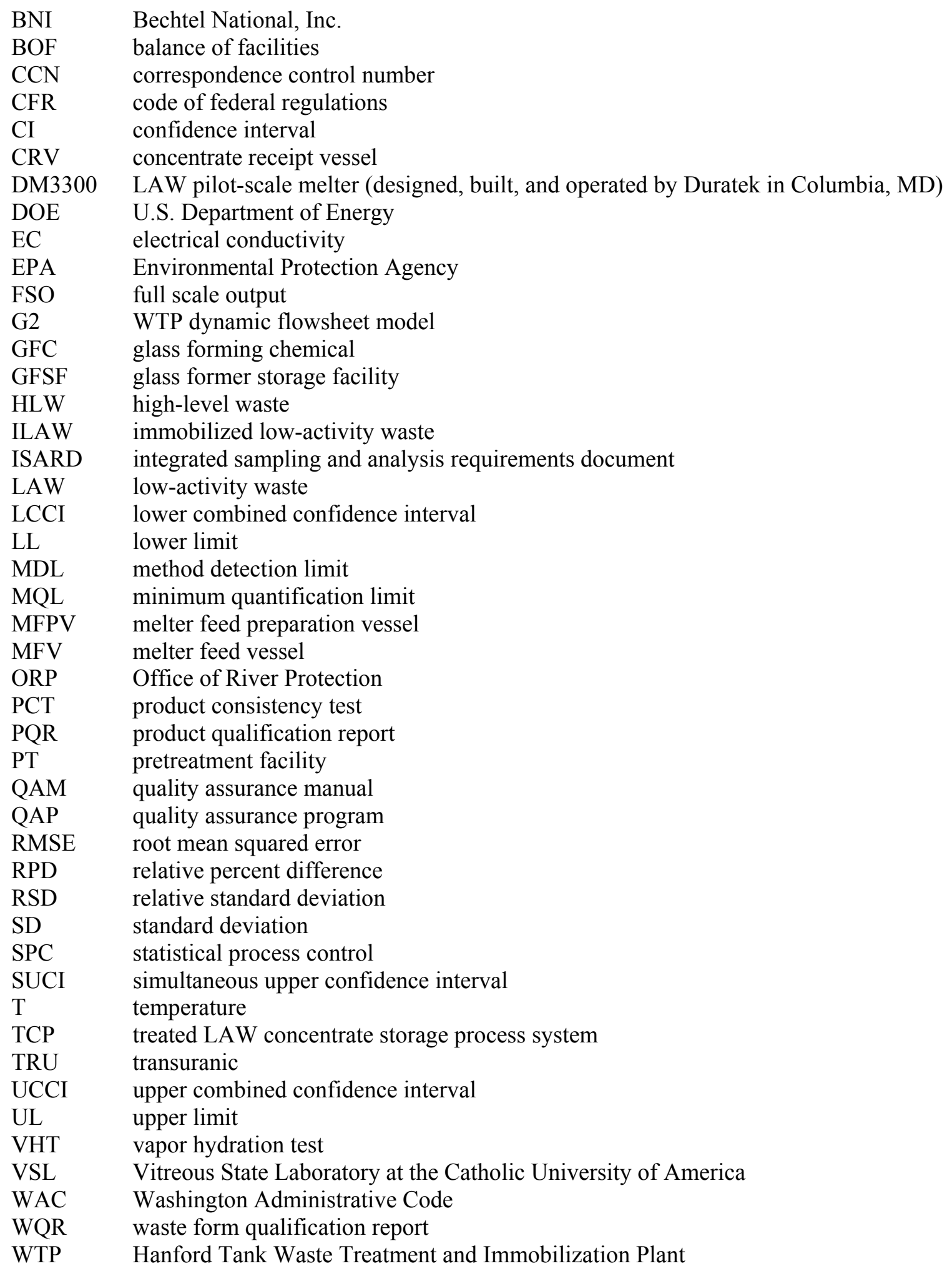




\section{Key Definitions}

Algorithm - a term "algorithm" used in this report signifies the process control methodology to formulate processable and compliant glass composition and generate data for production records.

$\boldsymbol{C L} \%$ - a confidence level percent. This term is used in combination with other terms such as "CL\% confidence interval (CL\% CI)", which is an interval that includes the true mean value of a quantity with CL\% confidence.

$e c$ - electrical conductivity. The "ec" notation is used as a superscript for various symbols to specify that the symbols are for electrical conductivity, e.g., $U_{p r e d}^{e c}$ is the prediction uncertainty for electrical conductivity.

$\boldsymbol{G F C}$ - glass forming chemical(s), solid materials added to the LAW to form a suitable glass when melted and solidified in an ILAW container. Current GFCs include mined minerals (kyanite, wollastonite, olivine, silica, zincite, and zircon) and processed chemicals (boric acid, hematite, sodium carbonate, lithium carbonate, rutile, and sucrose).

GFC components -11 glass components that are supplied from GFCs by design, $\mathrm{Al}_{2} \mathrm{O}_{3}, \mathrm{~B}_{2} \mathrm{O}_{3}, \mathrm{CaO}$, $\mathrm{Fe}_{2} \mathrm{O}_{3}, \mathrm{Li}_{2} \mathrm{O}, \mathrm{MgO}, \mathrm{Na}_{2} \mathrm{O}, \mathrm{SiO}_{2}, \mathrm{TiO}_{2}, \mathrm{ZnO}$, and $\mathrm{ZrO}_{2}$. Every GFC component has one corresponding source GFC although some GFCs may contain additional GFC component(s) as major constituents (e.g., kyanite is a source for $\mathrm{Al}_{2} \mathrm{O}_{3}$ with roughly $57 \mathrm{wt} \% \mathrm{Al}_{2} \mathrm{O}_{3}$ but also contains $41 \mathrm{wt} \% \mathrm{SiO}_{2}$ supplying a portion of $\mathrm{SiO}_{2}$, which is primarily supplied by silica sand). Non-GFC components include all glass oxide components other than 11 GFC components and are originated from the waste (not intentionally added) although some components are supplied as impurities from GFCs (e.g., $\mathrm{Cr}_{2} \mathrm{O}_{3}, \mathrm{~K}_{2} \mathrm{O}$ ).

Glass oxides - a method or convention for reporting the composition of a glass, also called "oxides" in short. The notation used in this report to identify glass composition is to assume single element oxides that are represented in their most prevalent oxidation state (e.g., $\mathrm{Fe}_{2} \mathrm{O}_{3}, \mathrm{Na}_{2} \mathrm{O}, \mathrm{SO}_{3}$ ). Halogens are represented as single, neutrally charged, elements (e.g., Cl, F). This notation is used not to imply structure or local bonding of elements within the glass/melt, but rather, to give a simple, standardized method to identify glass or melter feed composition.

ILAW formulation algorithm - a set of steps to develop a successful LAW MFPV batch composition. A successful MFPV batch composition is one that is processable and results in an acceptable glass when vitrified. The algorithm also produces the data necessary for the glass composition related production records.

MFPV batch - a batch of material, consisting of the waste transferred from the CRV and the glass forming chemicals added, in either of the two melter feed preparation vessels. The Melter Feed Preparation Vessel (MFPV) batch becomes the smallest identifiable batch of melter feed. The MFPV does not completely drain and leaves behind some of the previous MFPV batch, which is called the heel.

Monte Carlo - Monte Carlo methods are a class of computational methods that rely on repeated random sampling to compute their results. Monte Carlo method is often used when simulating physical and mathematical systems; it is used here to estimate the distribution of possible solutions.

pct - product consistency test (PCT). The " $p c t$ " notation is used as a superscript for various symbols to specify that the symbols are for PCT releases, e.g., $U_{\text {pred }}^{p c t B}$ and $U_{\text {pred }}^{p c t N a}$ are the prediction uncertainties for PCT-B and Na normalized releases. 
Processing property - those properties that are used as measures of the ability to process a given glass melt and/or melter feed. These properties typically include melter feed rheology, melt viscosity, melt electrical conductivity, and salt formation.

Product compliance - the activities performed during production to ensure and document compliance with contract and disposal system requirements for the ILAW waste form.

Product quality - those properties that are used as measures of the ability to dispose of the glass once it has been fabricated. These properties typically include chemical durability, regulatory compliance, and related contract requirements.

Production lot - as stated in WTP contract Specification 13, the certification and acceptance of ILAW product will be done on a lot basis. Currently, the proposed lot size is the amount of glass contained in three canisters as discussed in Section 5.5.

$\boldsymbol{R}^{2}$ (after Hrma et al. 1994) $-\mathrm{R}^{2}$ estimates the fraction of the variability in the property data accounted for by the fitted model. $\boldsymbol{R}^{2}$ Adjusted adjusts $\mathrm{R}^{2}$ to the number of terms in the model and the number of data points used to fit the model. It is useful for comparing models fitted with a different number of model terms. $\boldsymbol{R}^{2}$ Prediction is the $\mathrm{R}^{2}$ where each data point is left out of the fit in evaluating how well the model predicts that data point (one-point-at-a-time). It is useful in estimating the fraction of variability that would be explained in predicting new observations drawn from the same model composition region. $\boldsymbol{R}^{2}$ Validation is the $\mathrm{R}^{2}$ calculated using data not used to fit the model. In this report it is taken as the average $\mathrm{R}^{2}$ Validation from 5 individual $\mathrm{R}^{2}$ Validation values calculated from five separate modeling and validation subsets of data. Each modeling and validation subset of data was obtained by taking every fifth data point out of the model fit data set and using them for model validation.

Relative standard deviation - a relative standard deviation (RSD) is a standard deviation divided by a mean value. $\% \mathrm{RSD}=100 \times \mathrm{RSD}$.

Retention factor - a fraction of component mass retained in glass after melting to the mass in the feed that entered the melter.

Root Mean Squared Error - a root mean squared error (RMSE) is the square root of the mean square for error in a model. It estimates the standard deviation of the model random error.

Selected - "Selected" used in the property model equations means that only some of the model terms are included in the model.

Transformed - a term "transformed" used in this report has two meanings. (1) "transformed" property means that the property unit was converted to the natural logarithm of the property unit used by the property models, i.e., $\mathrm{g} / \mathrm{L}$ to $\ln (\mathrm{g} / \mathrm{L})$ for $\mathrm{PCT}, \mathrm{mg} / \mathrm{L}$ to $\ln (\mathrm{mg} / \mathrm{L})$ for TCLP, $\mathrm{P}$ to $\ln (\mathrm{P})$ for viscosity and $\mathrm{S} / \mathrm{cm}$ to $\ln (\mathrm{S} / \mathrm{cm})$ for electrical conductivity, (2) a "transformed" value of component mass fractions means the calculated value of component mass fractions according to the appropriate basis for the specific model terms such as $\mathrm{Al}_{2} \mathrm{O}_{3} \times \mathrm{Al}_{2} \mathrm{O}_{3}, \mathrm{Al}_{2} \mathrm{O}_{3} \times \mathrm{SiO}_{2}, \mathrm{Al}_{2} \mathrm{O}_{3} /(\mathrm{T} / 1000)^{2}$.

Validity range - component concentration range or property value range within which property models are valid.

Variance-covariance matrix - a variance-covariance matrix is calculated for the estimated coefficients of a model fitted by regression according to, $\Sigma^{\text {prop }}=\left(\begin{array}{c}r m s e o f \\ s_{\text {prode }}^{\text {mod }}\end{array}\right)^{2}\left[\left(\mathbf{X}^{\text {prop }}\right)^{\mathbf{T}} \mathbf{X}^{\text {prop }}\right]^{-1}$ where $\Sigma^{\text {prop }}$ is the variance-covariance matrix for the "prop" model, $s_{p r o p}^{\text {model }}$ is the RMSE for the "prop" model, and $\mathbf{X}$ "prop is the matrix of glass composition vectors for all the data points (glasses) used to fit the "prop" model. 
Vector/matrix notation used in this report - the notation in bold face is used in this report to represent vectors and matrices. Vectors are treated as column vectors (a matrix consisting of a single column of elements) in this report. An example of a vector is $\mathbf{x}^{p c t}$ in Equation (8), which represents the vector form of the component mass fraction in glass or transformed value of component mass fractions to the appropriate basis for the model terms in the PCT models. An example of a matrix is $\boldsymbol{\Sigma}^{p c t}$ in Equation(8), which represents the variance-covariance matrix for the PCT normalized release models given in Tables A-7 and A-8.

vis - viscosity. The "vis" notation is used as a superscript for various symbols to specify that the symbols are for viscosity, e.g., $U_{\text {pred }}^{v i s}$ is the prediction uncertainties for viscosity.

Waste glass - a non-crystalline (i.e., vitreous) solid containing waste components chemically bound within the structure of the solid - thereby immobilizing the waste. Typically an alkali-aluminoborosilicate glass is used. The waste is initially dissolved in molten glass that is cooled quickly enough to prevent crystallization. However, some minor amounts of crystals may be present in the glass.

Waste loading - the mass fraction of the glass that originated as waste (e.g., mass of calcined glass oxides originated from waste divided by the glass mass).

Waste sodium - the sodium delivered to the WTP in waste batches from the tank farm system, plus the sodium used in the pretreatment process to perform leaching of the waste solids. 


\section{Introduction}

The U.S. Department of Energy (DOE), Office of River Protection (ORP), has contracted with Bechtel National, Inc. (BNI) to design, construct, and commission the Hanford Tank Waste Treatment and Immobilization Plant (WTP) at the Hanford Site (DOE 2000). This plant is designed to operate for 40 years and treat roughly 50 million gallons of mixed hazardous high-level waste (HLW) stored in 177 underground tanks at the Hanford Site. The process involves separating the high-level and low-activity waste (LAW) fractions through filtration, leaching, Cs ion exchange, and precipitation. Each fraction will be separately vitrified into borosilicate waste glass.

Figure 1 shows a schematic of the LAW vitrification process. The LAW is transferred from the treated LAW concentrate storage process system (TCP) in the pretreatment facility (PT) to one of two concentrate receipt vessels (CRVs) in the LAW vitrification facility. The CRVs are sampled, and samples are analyzed at the WTP laboratory. These analyses are required for batching of glass-forming chemicals (GFCs), and for production records. LAW is transferred from the CRVs to the melter feed preparation vessels (MFPVs) in batches where GFCs are added, and the melter feed is blended. The blended melter feed is then transferred in batches to the melter feed vessels (MFVs), which continuously provide melter feed to the melters. The melt is cast into containers where it cools and solidifies into LAW glass, which is referred to as immobilized LAW (ILAW).

Figure 1. Schematic of the LAW Vitrification Process

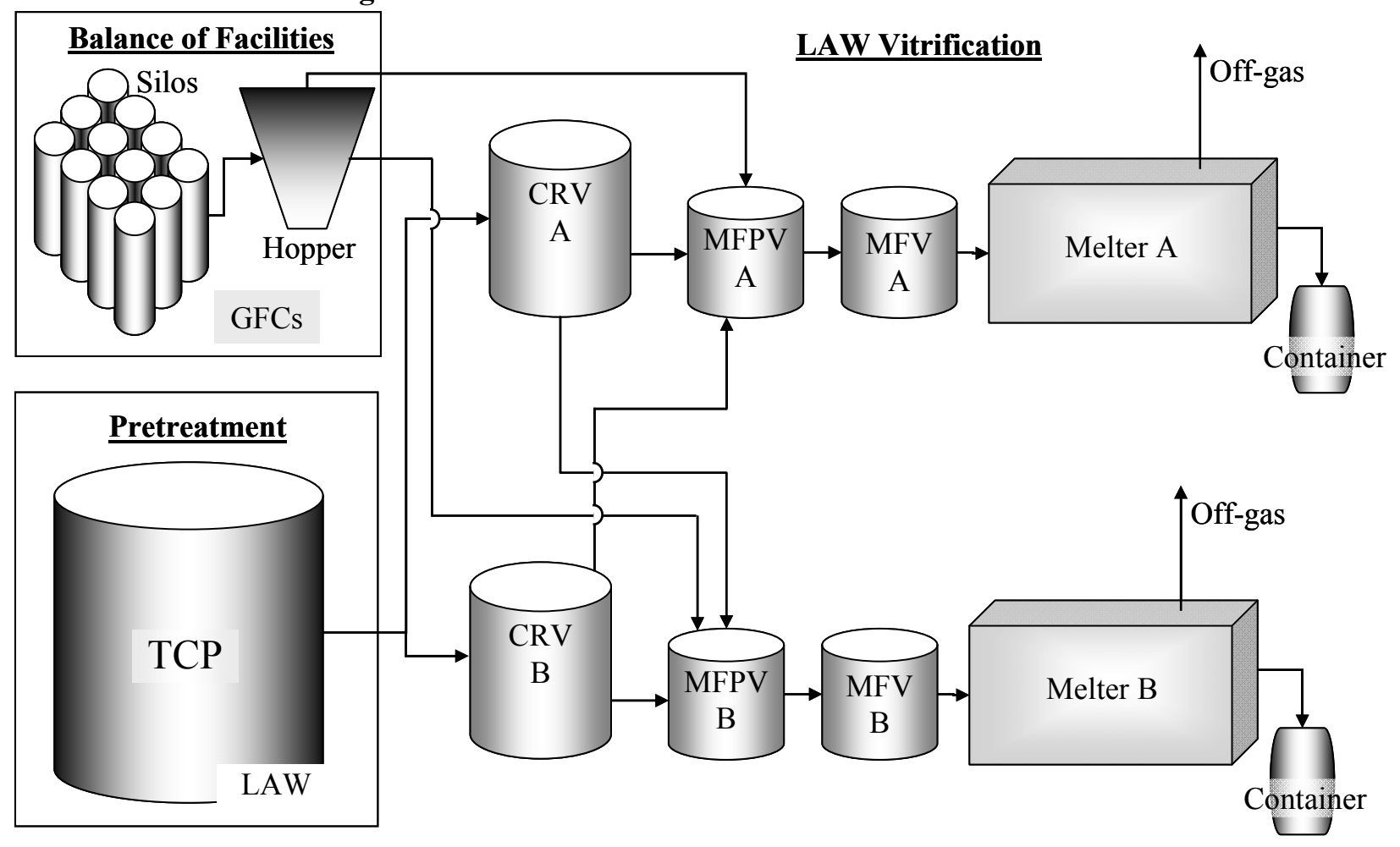


Table 1. LAW Process Vessel Sizes (L)

\begin{tabular}{||l|c|c|c||}
\hline \hline Description & CRV & MFPV & MFV \\
\hline Batch volume (L) & 34,504 & 12,870 & 12,870 \\
\hline Heel volume (L) & 14,157 & 6,556 & 3,698 \\
\hline Working (=Batch+Heel) volume (L) & 48,661 & 19,426 & 16,568 \\
\hline Volume up to overflow (L) & 56,315 & 28,348 & 21,833 \\
\hline Vessel ID & LCP-VSL-00001/2 & LFP-VSL-00001/3 & LFP-VSL-00002/4 \\
\hline Reference & 24590-LAW-M6C- & 24590-LAW-M6C- & 24590-LAW-M6C- \\
& LCP-00001, Rev 1 & LFP-00001, Rev 1 & LFP-00002, Rev 1 \\
\hline
\end{tabular}

CRV: concentrate receipt vessel

MFPV: melter feed preparation vessel

MFV: melter feed vessel

The key process vessel volumes are summarized in Table 1. Each ILAW container contains roughly $5,911 \mathrm{~kg}$ of glass (assuming 94\% fill height, an effective density of $2,627 \mathrm{~kg} / \mathrm{m}^{3}$, and a total fill volume of $2.394 \mathrm{~m}^{3}$ ) (Andre 2004). The mass yield of LAW melter feed ranges from 800 to $960 \mathrm{~g}$ of glass per L of feed with a nominal average value of $880 \mathrm{~g} / \mathrm{L}(\mathrm{CCN} 116150) .{ }^{(1)}$ With a nominal MFPV batch size of $12,870 \mathrm{~L}$, it is expected that roughly 1.88 containers will be generated by each MFPV batch (assuming nominal values). A CRV batch is roughly $34,500 \mathrm{~L}$, which is transferred to MFPV batches at roughly 8,700 L per batch (24590-LAW-M4C-20-00002) producing roughly four MFPV batches on average (may range from 2,300 L to $10,000 \mathrm{~L}$, producing from 3.5 to $15 \mathrm{MFPV}$ batches, depending on sodium molarity and waste loading). Therefore, a CRV batch will generate roughly 7.5 containers of glass (assuming nominal values are achieved, but may range from 6 to 28 containers, depending on sodium molarity and waste loading). The mass of glass in the LAW melter is estimated to be $17,240 \mathrm{~kg}$ of glass (24590-LAWM0D-LMP-00002), which translates to three containers.

The ILAW must meet a series of constraints to be acceptable for disposal in the Hanford Site integrated disposal facility. The waste-acceptance-related constraints are in Specification 2 of the contract (DOE 2000). Additionally, key processing-related constraints will be used to ensure successful processing of the LAW into glass at the design capacity rate. The combined constraint set is summarized in Table 2. Although not listed in Table 2, ILAW must also meet the Dangerous Waste Limitations as specified in the Contract Specification paragraph 2.2.2.20 (DOE 2000). The approach to meeting the Dangerous Waste Limitations is described in detail in the petition for variance to land disposal restrictions (LDR) (24590WTP-RPT-ENV-03-003). The petition was submitted to DOE. After thorough review, DOE will submit the petition to Environmental Protection Agency (EPA) and Washington State Department of Ecology. If successful, the LDR variance will be technology based so the only restrictions would include processing the waste by vitrification as described in the petition. This compliance strategy is specified in the ILAW PCP (24590-WTP-PL-RT-03-001), “... During production, the WTP project will control the vitrification process to adequately treat the waste in accordance with any conditions established as part of the treatability variance." This specification is not listed in Table 2 because there is no calculation required to be performed by the ILAW algorithm under the current compliance strategy.

Along with the constraints listed in Table 2, there are potential issues that are not defined by numeric values, such as corrosion rates of glass contact materials (bubblers, electrodes, refractories, etc.), redox ratio, and salt accumulation. They are the issues that require attention for efficient and safe plant operations but are not currently modeled.

(1) These mass yield values are valid for LAWs with Na molarity close to the current target values of $10 \mathrm{M} N \mathrm{Na}$ for envelopes $\mathrm{A}$ and $\mathrm{C}$ and of $5 \mathrm{M} \mathrm{Na}$ for envelope $\mathrm{B}$. The target values for $\mathrm{Na}$ molarity are not finalized and may change. 
Table 2. Summary of LAW Glass and Melt Constraints Used in ILAW Algorithm ${ }^{(a)}$

\begin{tabular}{|c|c|c|}
\hline Constraint Description & Constraint & Source \\
\hline $\begin{array}{l}\text { Product consistency test (PCT) normalized } \\
\text { releases of } \mathrm{Na}, \mathrm{B} \text {, and } \mathrm{Si}\end{array}$ & $<2\left(\mathrm{~g} / \mathrm{m}^{2}\right)($ for $\mathrm{Na}, \mathrm{B}$, and $\mathrm{Si})$ & $\begin{array}{l}\text { DOE 2000 } \\
\text { (Spec. 2.2.2.17.2) }\end{array}$ \\
\hline $\begin{array}{l}\text { Vapor hydration test (VHT) } 200^{\circ} \mathrm{C} \\
\text { alteration rate }\end{array}$ & $<50\left(\mathrm{~g} / \mathrm{m}^{2} / \mathrm{d}\right)$ & $\begin{array}{l}\text { DOE 2000 } \\
\text { (Spec. 2.2.2.17.3) }\end{array}$ \\
\hline Viscosity at $1100^{\circ} \mathrm{C}$ & $\leq 150(\mathrm{P})^{(\mathrm{b})}$ & $\begin{array}{l}\text { 24590-LAW-3PS-AE00- } \\
\text { T00001, Rev. } 4\end{array}$ \\
\hline Viscosity at $1150^{\circ} \mathrm{C}$ & $\geq 20(\mathrm{P})$ & $\begin{array}{l}\text { 24590-HLW-RPT-RT- } \\
\text { 05-001, Rev. } 0^{\text {(c) }}\end{array}$ \\
\hline Viscosity at $1150^{\circ} \mathrm{C}$ & $\leq 80(\mathrm{P})$ & $\begin{array}{l}\text { 24590-HLW-RPT-RT- } \\
\text { 05-001, Rev. 0 }\end{array}$ \\
\hline Electrical conductivity at $1100^{\circ} \mathrm{C}$ & $\geq 0.1(\mathrm{~S} / \mathrm{cm})$ & $\begin{array}{l}\text { 24590-LAW-3PS-AE00- } \\
\text { T00001, Rev. } 4\end{array}$ \\
\hline Electrical conductivity at $1200^{\circ} \mathrm{C}$ & $\leq 0.7(\mathrm{~S} / \mathrm{cm})$ & $\begin{array}{l}\text { 24590-LAW-3PS-AE00- } \\
\text { T00001, Rev. } 4\end{array}$ \\
\hline Waste loading (wt $\%$ waste $\mathrm{Na}_{2} \mathrm{O}$ in glass) & $\begin{array}{l}>14,3, \text { and } 10(\mathrm{wt} \%) \text { for } \\
\text { envelopes A, B, and C LAW, } \\
\text { respectively }\end{array}$ & $\begin{array}{l}\text { DOE } 2000 \\
\text { (Spec. 2.2.2.2) }\end{array}$ \\
\hline Waste classification & $\begin{array}{l}<\text { Class } C \text { limits as defined in } \\
10 \text { CFR61.55 }\end{array}$ & $\begin{array}{l}\text { DOE 2000 } \\
\text { (Spec. 2.2.2.8) }\end{array}$ \\
\hline${ }^{90} \mathrm{Sr}$ activity per unit volume of glass & $<20\left(\mathrm{Ci} / \mathrm{m}^{3}\right)$ & $\begin{array}{l}\text { DOE 2000 } \\
\text { (Spec. 2.2.2.8) }\end{array}$ \\
\hline $\begin{array}{l}{ }^{137} \text { Cs activity per unit volume of glass } \\
\text { (waste form compliance) }\end{array}$ & $<3\left(\mathrm{Ci} / \mathrm{m}^{3}\right)$ & $\begin{array}{l}\text { DOE 2000 } \\
\text { (Spec. 2.2.2.8) }\end{array}$ \\
\hline $\begin{array}{l}{ }^{137} \mathrm{Cs} \text { activity per unit volume of glass } \\
\text { (system maintenance) }\end{array}$ & $<0.3\left(\mathrm{Ci} / \mathrm{m}^{3}\right)$ & $\begin{array}{l}\text { DOE } 2000 \text { [Section C.7 } \\
\text { (d).(1).(iii)] }\end{array}$ \\
\hline Canister surface dose rate & $\leq 500 \mathrm{mrem} / \mathrm{h}$ & $\begin{array}{l}\text { DOE 2000 } \\
\text { (Spec. 2.2.2.9) }\end{array}$ \\
\hline
\end{tabular}

(a) ILAW must also meet the Dangerous Waste Limitations (Contract Specification paragraph 2.2.2.20, DOE 2000) although this specification is not listed in this table because there is no calculation required to be performed by the ILAW algorithm (see text above this table).

(b) Note that the lower limit of $10 \mathrm{P}$ on viscosity at $1100^{\circ} \mathrm{C}$, specified in 24590-LAW-3PS-AE00-T00001, Rev. 4, is unnecessary given the lower limit of $20 \mathrm{P}$ on viscosity at $1150^{\circ} \mathrm{C}$. This is because viscosity decreases with increasing temperature.

(c) The bases for glass viscosity constraint at $1150^{\circ} \mathrm{C}$ discussed for IHLW algorithm (Appendix G in 24590-HLWRPT-RT-05-001, Rev. 0) also applies to the ILAW algorithm.

The Vitreous State Laboratory (VSL) at the Catholic University of America formulated ILAW glasses for vitrification testing and demonstrations in the Duratek pilot-scale melter (DM-3300). Each formulation was developed to meet all of the constraints listed above. The formulations were then demonstrated to meet all the processing and product-quality constraints at scales up to pilot-scale. These compositions span the range of waste compositions expected during the initial phase of WTP operation, and form the basis of the glass-composition portion of the ILAW formulation algorithm. Following the results of 24590-LAW-M4C-LFP-00002 and 24590-WTP-MRQ-PO-03-033, Muller et al. (2004) fit functions of glass-component concentrations to the ratio of $\mathrm{Na}_{2} \mathrm{O}$ to $\mathrm{SO}_{3}$ in the LAW. ${ }^{(2)}$ The purpose of these

(2) The notation used in this report to identify glass composition is to assume single electropositive element oxides that are represented in their most prevalent oxidation state (e.g., $\mathrm{Fe}_{2} \mathrm{O}_{3}, \mathrm{Na}_{2} \mathrm{O}, \mathrm{SO}_{3}$ ). Halogens are represented as single element concentrations (e.g., Cl, F). This notation is used not to imply structure or local bonding of elements in the glass/melt, but rather, to give a simple, standardized method to uniquely identify composition. 
functions is to interpolate new acceptable glass compositions between glass compositions successfully demonstrated in pilot-scale melter tests.

To implement the glass-batching equations during the LAW vitrification plant operation, several steps are envisioned, including:

- $\quad$ LAW transfer from the TCP in the PT facility to the LAW CRV

- Sampling and chemical analyses of the LAW CRV batch

- Determination of initial ILAW composition

- Estimation of ILAW properties using glass property-composition models

- Comparison of predicted glass properties with limits or constraints

- Calculation of LAW and GFC masses for transfer to the LAW MFPV

- Transfer of LAW and GFCs to the LAW MFPV

- Transfer of the blended LAW melter feed to the LAW MFV

- Determination of final ILAW composition

- Generation of glass-composition-related portions of the ILAW Production Records.

These steps of the formulation algorithm, including the preliminary set of mass-balance equations used for feed batching and compliance with contract specifications, are described in this document. Information relevant to the calculations is included in Appendix A (Inputs Used in Calculations) and Appendix B (Results of Example Calculations). A summary of data requirements for this algorithm to be complete is included in Appendix C. Approaches used to estimate the uncertainties for waste transfer volume and GFC mass measurements are in Appendices D and E. Calculation of GFC and sucrose volume contribution to the MFPV batch volume is described in Appendix F. A discussion on the use PERT distributions for GFC composition and retention factors is in Appendix G.

This document will be updated as needed, as new data are available, or changes to approaches/constraints are made. 


\section{Symbols and Notation}

Due to the large number of variables used in the ILAW formulation algorithm, it was necessary to develop a consistent notation to track the numerous variables. The notation uses base symbols that represent the type of value, with superscripts representing the location or vessel, and subscripts representing an index (e.g., component index, batch index). Table 3 lists the notation components that are incorporated in the symbols used in this report. Table 3 is not a complete list of all subscripts and superscripts used in this report, and includes only those that help to clarify the meaning of specific notations. A list of units is also included in Table 3. The list of specific notations and their definitions are given in Table 4. Vectors and matrices are in bold font. Note that there are changes in notation in Table 4 compared to that in Piepel et al. (2005).

Table 3. Summary of Notations used in this Report

\begin{tabular}{|c|c|}
\hline Notation & Description \\
\hline \multicolumn{2}{|c|}{ Base Symbols } \\
\hline$a$ & activity of radionuclides \\
\hline$A$ & specific activity, i.e., activity per mass of radionuclide \\
\hline$B$ & $\begin{array}{l}\text { confidence interval in transformed predicted property (see Key Definitions section for the } \\
\text { definition of "transformed" properties) }\end{array}$ \\
\hline$c$ & $\begin{array}{l}\text { concentration of individual component, e.g., } c_{i}^{\text {element in }} \text { is the concentration of } i^{\text {th }} \text { elemental } \\
\text { component in CRV }\end{array}$ \\
\hline$C$ & $\begin{array}{l}\text { concentration of total components, e.g., } C^{\text {oxidein }} \text { is the concentration of all glass oxide } \\
\text { components in } \mathrm{CRV}\end{array}$ \\
\hline$d$ & normalized alkali oxides $\left(\mathrm{Na}_{2} \mathrm{O}\right.$ and $\left.\mathrm{K}_{2} \mathrm{O}\right)$ mass fraction \\
\hline$f$ & oxide conversion factor, i.e., glass oxide mass per mass of analyte \\
\hline$F$ & F-distribution \\
\hline$g$ & $\begin{array}{l}\text { mass fraction of component in glass, GFC, or feed. The mass fraction for all glass } \\
\text { components sums to 1, i.e., } \sum_{i=1}^{n} g_{i}=1 \text {. }\end{array}$ \\
\hline$G$ & $\begin{array}{l}\text { mass fraction of feed constituent, such as waste, heel, and various GFCs, in the MFPV batch, } \\
\text { also referred to as "loading", as in "waste loading" and "heel loading" }\end{array}$ \\
\hline$I$ & radionuclide inventory, activity per canister \\
\hline$L$ & limit \\
\hline$m$ & $\begin{array}{l}\text { mass fraction of component in GFC. Used for GFC only, which sometimes includes } \\
\text { volatiles that are not retained in glass ( } \operatorname{such} \text { as } \mathrm{CO}_{2}, \mathrm{H}_{2} \mathrm{O} \text { ), i.e., } \sum_{i=1}^{n} m_{i} \neq 1 \text { for some GFCs } \\
\text { where } i \text { represents glass component. }\end{array}$ \\
\hline$M$ & mass \\
\hline
\end{tabular}




\begin{tabular}{|c|c|}
\hline Notation & Description \\
\hline$M W$ & molecular weight \\
\hline$n$ & number, for example number of samples, number of variables, number of model coefficients \\
\hline$p$ & property model coefficient \\
\hline$P$ & $\begin{array}{l}\text { predicted value of a transformed property (see Key Definitions section for the meaning of } \\
\text { "transformed") }\end{array}$ \\
\hline$Q$ & percentile \\
\hline$r$ & PCT normalized elemental release \\
\hline$R$ & activity per volume \\
\hline$s$ & standard deviation \\
\hline$S F$ & sum of fractions \\
\hline$t$ & t-distribution, target sodium molarity \\
\hline $\mathbf{t}$ & target MFPV batch composition vector \\
\hline$U$ & uncertainty \\
\hline$V$ & volume \\
\hline$w$ & weighting factor \\
\hline$x$ & $\begin{array}{l}\text { mass fraction of model component. The } x \text { is different from } g \text { in that } x \text { is for model } \\
\text { components that includes "Others" as one model component whereas } g \text { is for all components } \\
\text { being tracked. (See Equations ( } 3 \text { ) and (4) for more information.) }\end{array}$ \\
\hline$\varepsilon$ & electrical conductivity \\
\hline$\eta$ & viscosity \\
\hline $\mathbf{H}$ & GFC composition matrix \\
\hline$\lambda$ & dilution factor \\
\hline$v$ & retention factor \\
\hline$\rho$ & density \\
\hline$\Sigma$ & variance-covariance matrix \\
\hline$\omega$ & fraction of waste sodium \\
\hline \multicolumn{2}{|c|}{ Subscripts and Superscripts } \\
\hline $2 s$ & two standard deviations \\
\hline can & within a canister \\
\hline comp & composition, components \\
\hline$d$ & CRV batch index \\
\hline$e$ & canister index \\
\hline$e c$ & electrical conductivity \\
\hline
\end{tabular}




\begin{tabular}{|c|c|}
\hline Notation & Description \\
\hline flush & flush or filter wash water \\
\hline$G F C$ & glass forming chemical \\
\hline$h$ & Model term index \\
\hline$C R V$ & Low-activity waste concentrate receipt vessel \\
\hline$i$ & chemical or radionuclide component (e.g., Al, B, Ca...) index \\
\hline$j$ & MFPV batch index \\
\hline$k$ & GFC (e.g., silica, borax, ...) index \\
\hline$l$ & sample index, analyses index, or lower in case of limits \\
\hline$l c c i$ & lower combined confidence interval \\
\hline$m$ & waste loading limit index \\
\hline$M F P V$ & MFPV batch \\
\hline$M F P V w$ & working MFPV content, i.e., MFPV batch plus heel from the previous working MFPV \\
\hline$p c t B$ & Product Consistency Test normalized boron response \\
\hline $\operatorname{pct} N a$ & Product Consistency Test normalized sodium response \\
\hline pred & prediction \\
\hline prop & property \\
\hline $\mathrm{rad}$ & radionuclide \\
\hline samp & samples of a particular material \\
\hline suci & simultaneous upper confidence interval \\
\hline$T$ & Temperature for viscosity or electrical conductivity \\
\hline$u$ & upper \\
\hline ucci & upper combined confidence interval \\
\hline vis & viscosity \\
\hline \multicolumn{2}{|c|}{ Accent marks } \\
\hline- & used to represent average (above the symbol as in $\bar{g}_{i}$ ) \\
\hline ' & used to indicate that $i \neq i^{\prime}$ in model coefficients for the quadratic model terms ( $P_{i i^{\prime}}^{\text {prop }}$ ) \\
\hline$\sim$ & $\begin{array}{l}\text { used to indicate composition after applying component retention factors (above the symbol as } \\
\text { in } \tilde{g}_{i} \text { ) }\end{array}$ \\
\hline$\wedge$ & $\begin{array}{l}\text { used to represent the activity of radionuclide and its standard deviation per unit volume of } \\
\text { radin } \\
\text { glass instead of unit mass of glass (above the symbol as in } \hat{a}_{i e}^{\text {can }} \text { and } \hat{s}_{i e}^{\text {can }} \text { ) }\end{array}$ \\
\hline
\end{tabular}




\begin{tabular}{|c|c|}
\hline Notation & Description \\
\hline$\cdots$ & used to represent the mass of GFC per g of glass (above the symbol as in $\dddot{M}_{k j}^{G F C \text {, target }}$ ) \\
\hline.. & used to represent the mass of sucrose per liter of waste (above the symbol as in $\ddot{M}_{j}^{\text {Mucros, target }}$ ) \\
\hline \multicolumn{2}{|l|}{ Units $^{(\mathrm{a})}$} \\
\hline${ }^{\circ} \mathrm{C}$ & degree centigrade \\
\hline $\mathrm{Ci}$ & curie \\
\hline $\mathrm{g}$ & gram \\
\hline $\mathrm{h}$ & hour \\
\hline K & Kelvin \\
\hline $\mathrm{L}$ & liter \\
\hline $\ln$ & natural logarithm \\
\hline $\mathrm{m}$ & meter \\
\hline $\mathrm{P}$ & poise \\
\hline S & siemens \\
\hline$w t \%$ & weight percent \\
\hline
\end{tabular}

(a) Non-italic fonts are used to distinguish units from base symbols, subscripts, and superscripts.

Table 4. List of Symbols

\begin{tabular}{|c|c|c|}
\hline Symbol & Description & Equation(s) \\
\hline$a_{i e}^{\text {radin }}$ & specific activity of the $i^{\text {th }}$ radionuclide in the $e^{\text {th }}$ canister (mCi/g glass) & $\begin{array}{l}(125)(127) \\
(128)(130)\end{array}$ \\
\hline$\hat{a}_{i e}^{\text {radin }}$ & $\begin{array}{l}\text { activity of the } i^{\text {th }} \text { radionuclide per unit volume of glass in the } e^{\text {th }} \text { canister } \\
\left(\mathrm{Ci} / \mathrm{m}^{3} \text { glass }\right)\end{array}$ & $(128)(130)$ \\
\hline $\begin{array}{c}\text { rad in } \\
a_{i d m}^{C R V}\end{array}$ & $\begin{array}{l}\text { specific activity of the } i^{\text {th }} \text { radionuclide in the } m^{\text {th }} \text { transfer waste } \\
\text { transferred from the } d^{\text {th }} \text { CRV to MFPV (mCi/g oxides) }\end{array}$ & $\begin{array}{l}(24)(53) \\
(100)(106)\end{array}$ \\
\hline $\begin{array}{l}\operatorname{rad\text {in}} \\
a_{i j}^{M F P V, \text { Step } 1} \\
{ }_{i j}^{\text {rad in }} \\
a_{i j}^{M F P, \text { Step } 3}\end{array}$ & $\begin{array}{l}\text { specific activity of the } i^{\text {th }} \text { radionuclide in the } j^{\text {th }} \text { MFPV batch from } \\
\text { algorithm calculation Step } 1 \text { or Step } 3 \text { before applying component } \\
\text { retention factors ( } \mathrm{mCi} / \mathrm{g} \text { oxides) }\end{array}$ & $\begin{array}{l}(53)(54) \\
(69)(70) \\
(100)(101) \\
(106)(107)\end{array}$ \\
\hline $\begin{array}{l}\text { radin } \\
\tilde{a}_{i j}^{\text {MPPV }, \text { Step } 1} \\
{ }^{\text {rad in }} \\
\tilde{a}_{i j}^{\text {MFPV Step } 3}\end{array}$ & $\begin{array}{l}\text { specific activity of the } i^{\text {th }} \text { radionuclide in the } j^{\text {th }} \text { MFPV batch from } \\
\text { algorithm calculation Step } 1 \text { or Step } 3 \text { after applying the component } \\
\text { retention factors ( } \mathrm{mCi} / \mathrm{g} \text { oxides) }\end{array}$ & $\begin{array}{l}(54)(70) \\
(71)(75) \\
(101)(108) \\
(110)(125)\end{array}$ \\
\hline $\begin{array}{l}\hat{\tilde{a}}_{i j}^{\text {radin }} \\
\hat{\tilde{a}}_{i j}^{\text {MFPV }} \\
\text { MFIn } \text { Step } 3\end{array}$ & $\begin{array}{l}\text { activity of the } i^{\text {th }} \text { radionuclide per unit volume of glass in the } j^{\text {th }} \text { MFPV } \\
\text { batch from algorithm calculation Step } 1 \text { or Step } 3 \text { after applying } \\
\text { retention factors }\left(\mathrm{Ci} / \mathrm{m}^{3} \text { glass) }\right.\end{array}$ & $\begin{array}{l}(71)(73) \\
(74)(75) \\
(76)(83) \\
(108)(110) \\
(111)\end{array}$ \\
\hline$A_{i}$ & specific activity of the $i^{\text {th }}$ radionuclide $(\mathrm{Ci} / \mathrm{g})$ & $(23)$ \\
\hline
\end{tabular}




\begin{tabular}{|c|c|c|}
\hline Symbol & Description & Equation(s) \\
\hline$B_{\text {lcci }}^{\text {prop }}$ & $\begin{array}{l}\text { CL\% lower combined confidence interval for "prop" (applicable only to } \\
\text { "vis" and "ec") }\end{array}$ & $(16)$ \\
\hline $\begin{array}{l}B_{\text {lcci,j }}^{\text {prop }, \text { Step } 1} \\
B_{u c c i, j}^{\text {prop }, \text { Step } 3}\end{array}$ & $\begin{array}{l}\text { CL\% lower combined confidence interval for "prop" for the } j^{\text {th }} \text { MFPV } \\
\text { batch from algorithm calculation Step 1or Step } 3 \text { (applicable only to } \\
\text { "vis" and "ec") }\end{array}$ & $(67)(104)$ \\
\hline$B_{u c c i}^{\text {prop }}$ & CL\% upper combined confidence interval for "prop" & $(16)$ \\
\hline$B_{u c c i, e}^{p c t}, B_{u c c i, e}^{v h t}$ & $\begin{array}{l}\text { CL\% upper combined confidence interval for " } p c t \text { " }\left(\ln \left[r_{\mathrm{B}}, \mathrm{g} / \mathrm{L}\right], \ln \left[r_{\mathrm{Na}} \text {, }\right.\right. \\
\mathrm{g} / \mathrm{L}]) \text { and " } v h t \text { " }(\ln [D, \mu \mathrm{m}]) \text { for the } e^{\text {th }} \text { canister }\end{array}$ & $(134)(135)$ \\
\hline $\begin{array}{l}B_{\text {ucci, }, \text { Step } 1}^{\text {prop }} \\
B_{\text {lcci, }, j}^{\text {prop }, \text { Step } 3}\end{array}$ & $\begin{array}{l}\text { CL\% upper combined confidence interval for "prop" for the } j^{\text {th }} \text { MFPV } \\
\text { batch from algorithm calculation Step } 1\end{array}$ & $\begin{array}{l}(67)(83) \\
(87)(104)\end{array}$ \\
\hline$c_{i d}^{\text {element in }}$ & $\begin{array}{l}\text { concentration of the } i^{\text {th }} \text { element in the } d^{\text {th }} \text { CRV batch associated with the } \\
j^{\text {th }} \text { MFPV batch }(\mathrm{mg} / \mathrm{L})\end{array}$ & $(12)(14)$ \\
\hline $\begin{array}{l}{ }^{\text {element in }} \\
\bar{c}_{i d}^{C R V}\end{array}$ & $\begin{array}{l}\text { concentration of the } i^{\text {th }} \text { component in the waste of the } d^{\text {th }} \text { CRV batch } \\
\text { aversin } \\
\text { averaged over } n_{d}^{C R V} \text { samples analyzed (mg/L waste) }\end{array}$ & $(18)$ \\
\hline$C_{i d m}^{\text {element in }}$ & $\begin{array}{l}\text { concentration of the } i^{\text {th }} \text { component in the } m^{\text {th }} \text { transfer waste transferred } \\
\text { from the } d^{\text {th }} \text { CRV to MFPV (mg/L waste) }\end{array}$ & $\begin{array}{l}(18)(21) \\
(22)(23) \\
(65)(69) \\
(102)(106)\end{array}$ \\
\hline $\begin{array}{l}\text { element in } \\
c_{N a, d m}^{C R V}\end{array}$ & $\begin{array}{l}\text { concentration of } \mathrm{Na} \text { in the } m^{\text {th }} \text { transfer waste transferred from the } d^{\text {th }} \\
\text { CRV to MFPV (mg/L waste) }\end{array}$ & $(62)(92)$ \\
\hline 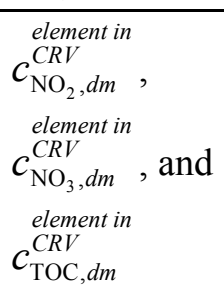 & $\begin{array}{l}\text { concentration of nitrite, nitrate, and total organic carbon in the } m^{\text {th }} \\
\text { transfer waste transferred from the } d^{\text {th }} \text { CRV to MFPV (mg/L LAW) }\end{array}$ & $(59)$ \\
\hline $\begin{array}{c}\text { elementin } \\
c_{i j}^{M F P V w}\end{array}$ & concentration of the $i^{\text {th }}$ element in the $j^{\text {th }}$ working MFPV $(\mathrm{mg} / \mathrm{L})$ & $(120)$ \\
\hline $\begin{array}{l}\text { oxides in } \\
C_{d m}^{C R V}\end{array}$ & $\begin{array}{l}\text { concentration of total glass oxides in the } m^{\text {th }} \text { transfer waste transferred } \\
\text { from the } d^{\text {th }} \text { CRV to MFPV (g oxides per L waste) }\end{array}$ & $\begin{array}{l}(22)(24) \\
(53)(56) \\
(58)(63) \\
(96)(100) \\
(118)(122)\end{array}$ \\
\hline$C_{j}^{\text {oxides in }}$ & concentration of total glass oxides in the $j^{\text {th }}$ MFPV batch (g oxides per L) & $(118)(119)$ \\
\hline$C_{j}^{\text {oxidesin }}$ & $\begin{array}{l}\text { concentration of total glass oxides in the } j^{\text {th }} \text { working MFPV (g oxides per } \\
\text { L) }\end{array}$ & $(119)(120)$ \\
\hline $\begin{array}{l}\text { oxidesin } \\
C_{j-1}^{M F P V w}\end{array}$ & $\begin{array}{l}\text { concentration of total glass oxides in the } j-1^{\text {th }} \text { (previous) working MFPV } \\
\text { (g oxides per L) }\end{array}$ & (119) \\
\hline$d$ & $\mathrm{Na}_{2} \mathrm{O}$ mass fraction plus 0.66 times $\mathrm{K}_{2} \mathrm{O}$ mass fraction & $\begin{array}{l}(40)(41) \\
(42)(43)\end{array}$ \\
\hline $\bar{D}$ & VHT alteration depth $(\mu \mathrm{m})$ & General \\
\hline
\end{tabular}




\begin{tabular}{|c|c|c|}
\hline Symbol & Description & Equation(s) \\
\hline$\overline{f_{i}}$ & $\begin{array}{l}\text { oxide conversion factor, i.e., mass of the } i^{\text {th }} \text { glass oxide per mass of the } \\
i^{\text {th }} \text { element }\end{array}$ & $\begin{array}{l}(12)(21) \\
(22)(65) \\
(69)(102) \\
(106)(120)\end{array}$ \\
\hline 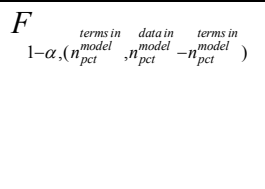 & 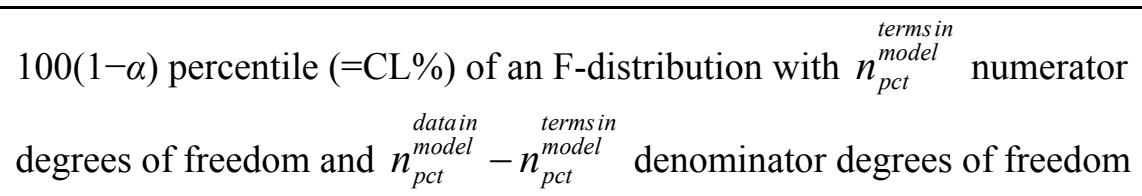 & (8) \\
\hline 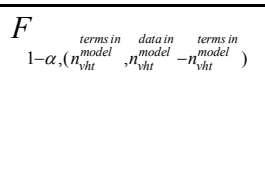 & $\begin{array}{c}100(1-\alpha) \text { percentile }(=\mathrm{CL} \%) \text { of an F-distribution with } n_{v h t}^{\text {termsin }} \text { numerator } \\
\text { datain } \\
\text { degrees of freedom and } n_{v h t}^{\text {model }}-n_{v h t}^{\text {model }} \text { denominator degrees of freedom }\end{array}$ & (9) \\
\hline$g_{i}$ & mass fraction of the $i^{\text {th }}$ glass oxide component in glass & (3) (4) \\
\hline$g_{\text {idm }}^{\text {oxide in }}$ & $\begin{array}{l}\text { mass fraction of the } i^{\text {th }} \text { glass oxide in the } m^{\text {th }} \text { transfer waste transferred } \\
\text { from the } d^{\text {th }} \text { CRV to MFPV (g oxide per g CRV oxides) }\end{array}$ & $\begin{array}{l}\text { (25) through } \\
(30)(32) \\
(33)(40) \\
(44)(21) \\
(47)(50) \\
(51)(68) \\
(98)(105) \\
\end{array}$ \\
\hline $\begin{array}{c}\text { oxidein } \\
g_{\mathrm{Na}_{2} \mathrm{O}(\mathrm{w}), e}^{\text {can }}\end{array}$ & $\begin{array}{l}\text { mass fraction of waste } \mathrm{Na}_{2} \mathrm{O} \text { (waste } \mathrm{Na}_{2} \mathrm{O} \text { loading) in the } e^{\text {th }} \text { canister ( } \mathrm{g} \\
\text { per g glass) }\end{array}$ & $(121)$ \\
\hline $\begin{array}{c}\text { oxidein } \\
g_{i j}^{M F P V}\end{array}$ & $\begin{array}{l}\text { mass fraction of the } i^{\text {th }} \text { glass oxide in the } j^{\text {th }} \text { MFPV batch before applying } \\
\text { component retention factors (g oxide per g MFPV oxides) }\end{array}$ & $(12)(13)$ \\
\hline $\begin{array}{c}\text { oxidein } \\
g_{i j}^{M F P V, \text { initial }}\end{array}$ & $\begin{array}{l}\text { initial mass fraction of the } i^{\text {th }} \text { glass oxide in the } j^{\text {th }} \text { MFPV batch (g oxide } \\
\text { per g MFPV oxides) }\end{array}$ & $\begin{array}{l}\text { (33) through } \\
(45)(46) \\
(84)(84)\end{array}$ \\
\hline $\begin{array}{c}\text { oxidein } \\
g_{i j}^{M F P V \text {,initial ,adj }}\end{array}$ & $\begin{array}{l}\text { adjusted initial mass fraction of the } i^{\text {th }} \text { glass oxide in the } j^{\text {th }} \text { MFPV batch } \\
\text { (g oxide per g MFPV oxides) }\end{array}$ & $(82)$ \\
\hline $\begin{array}{c}\text { oxidein } \\
g_{i j}^{M F P V, \text {,target }}\end{array}$ & $\begin{array}{l}\text { target mass fraction of the } i^{\text {th }} \text { glass oxide in the } j^{\text {th }} \text { MFPV batch (g oxide } \\
\text { per g MFPV oxides) }\end{array}$ & $\begin{array}{l}(46)(47) \\
(82)(84)\end{array}$ \\
\hline$g_{i j}^{\text {oxidein }}$ & $\begin{array}{l}\text { manual adjustment made to satisfy all the constraints for the target mass } \\
\text { fraction of the } i^{\text {th }} \text { glass oxide in the } j^{\text {th }} \text { MFPV batch (g oxide per g MFPV } \\
\text { oxides) }\end{array}$ & $(81)(84)$ \\
\hline $\begin{array}{c}\text { oxidein } \\
g_{i j}^{M P V}, \text {,target-gfc }\end{array}$ & $\begin{array}{l}\text { target mass fraction of the } i^{\text {th }} \text { glass oxide in glass from GFC for the } j^{\text {th }} \\
\text { MFPV batch (g oxide per } g \text { MFPV oxides) }\end{array}$ & (47) (48) \\
\hline $\begin{array}{c}\text { oxide in } \\
g_{\mathrm{Na} a_{2} \mathrm{O}, \mathrm{j}}^{\mathrm{MFPV}}\end{array}$ & $\begin{array}{l}\text { preliminary minimum } \mathrm{Na}_{2} \mathrm{O} \text { mass fraction in the } j^{\text {th }} \text { MFPV batch (g per } \mathrm{g} \\
\text { MFPV oxide) }\end{array}$ & $\begin{array}{l}(25) \text { through } \\
(32)(39) \\
(81)\end{array}$ \\
\hline $\begin{array}{c}\text { oxidein } \\
g_{\mathrm{Na}_{2} \mathrm{O}, \mathrm{j}, \text { initial }}^{M F P}\end{array}$ & $\begin{array}{l}\text { initial mass fraction of } \mathrm{Na}_{2} \mathrm{O} \text { in the } j^{\text {th }} \text { MFPV batch (g oxide per } g \text { MFPV } \\
\text { oxides) }\end{array}$ & $(33)$ \\
\hline $\begin{array}{c}\text { oxidein } \\
g_{\mathrm{Na}_{2} \mathrm{O}, j}^{\mathrm{MFPV} \text {,target }}\end{array}$ & $\begin{array}{l}\text { target mass fraction of } \mathrm{Na}_{2} \mathrm{O} \text { in the } j^{\text {th }} \text { MFPV batch (g oxide per g MFPV } \\
\text { oxides) }\end{array}$ & (61) \\
\hline $\begin{array}{c}\text { oxidein } \\
g_{\mathrm{Na}_{2} \mathrm{O}, \mathrm{j}, \mathrm{adj}}^{\text {MFP }}\end{array}$ & $\begin{array}{l}\text { manual adjustment of } \mathrm{Na}_{2} \mathrm{O} \text { concentration in the } j^{\text {th }} \text { MFPV batch } \\
\text { required to satisfy all the constraints ( } \mathrm{g} \text { per } \mathrm{g} \text { MFPV oxide) }\end{array}$ & $(81)$ \\
\hline
\end{tabular}




\begin{tabular}{|c|c|c|}
\hline Symbol & Description & Equation(s) \\
\hline$\frac{\text { oxidein }}{g_{\mathrm{Na} a_{2} \mathrm{O}, \mathrm{j} \text {, }}^{M F-a d j}}$ & $\begin{array}{l}\text { adjusted preliminary target } \mathrm{Na}_{2} \mathrm{O} \text { concentration in the } j^{\text {th }} \text { MFPV batch ( } \mathrm{g} \\
\text { per } g \text { MFPV oxide) }\end{array}$ & $(81)$ \\
\hline $\begin{array}{l}\text { oxidein } \\
g_{i j}^{\text {MFPV }, \text { Step } 1} \\
\text { oxidein } \\
g_{i j}^{\text {MFPV }, \text { Step } 3}\end{array}$ & $\begin{array}{l}\text { mass fraction of the } i^{\text {th }} \text { glass oxide in the } j^{\text {th }} \text { MFPV batch from algorithm } \\
\text { calculation Step } 1 \text { or Step } 3 \text { before applying component retention factors } \\
\text { (g oxide per g MFPV oxides) }\end{array}$ & $\begin{array}{l}(50)(52) \\
(54)(65) \\
(66)(70) \\
(98)(99) \\
(101)(102) \\
(103)(107) \\
(114)(122) \\
\end{array}$ \\
\hline $\begin{array}{l}\text { oxidein } \\
\tilde{g}_{i j}^{M F P V, \text { Step } 1} \\
\text { oxidein } \\
\tilde{g}_{i j}^{\text {MFPV }, \text { Step } 3}\end{array}$ & $\begin{array}{l}\text { mass fraction of the } i^{\text {th }} \text { glass oxide in the } j^{\text {th }} \text { MFPV batch from algorithm } \\
\text { calculation Step } 1 \text { or Step } 3 \text { after applying the component retention } \\
\text { factors (g oxide per g glass), i.e., mass of } i^{\text {th }} \text { glass oxide that will remain } \\
\text { in glass divided by the total mass of all glass oxides that will remain in } \\
\text { glass }\end{array}$ & $\begin{array}{l}(13)(52) \\
(66)(83) \\
(85)(86) \\
(99)(103) \\
(123)\end{array}$ \\
\hline $\begin{array}{l}\text { oxidein } \\
g_{\mathrm{Na}_{2} \mathrm{O}(\mathrm{W}), \mathrm{Step} 1}^{\text {MFP }} \\
\text { oxidein } \\
g_{\mathrm{Na}_{2} \mathrm{O}(\mathrm{w}), \mathrm{Step} 3}^{\mathrm{MFP}}\end{array}$ & $\begin{array}{l}\text { mass fraction of waste } \mathrm{Na}_{2} \mathrm{O} \text { (waste } \mathrm{Na}_{2} \mathrm{O} \text { loading) in the } j^{\text {th }} \text { MFPV batch } \\
\text { from algorithm calculation Step 1or Step } 3 \text { (g per g glass) }\end{array}$ & $\begin{array}{l}(68)(105) \\
(121)\end{array}$ \\
\hline 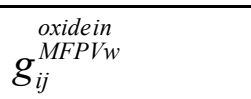 & $\begin{array}{l}\text { mass fraction of the } i^{\text {th }} \text { glass oxide in the } j^{\text {th }} \text { working MFPV (g oxide per } \\
\text { g glass) }\end{array}$ & $(114)(120)$ \\
\hline $\begin{array}{c}\text { oxidein } \\
g_{i, j-1}^{M F P V W}\end{array}$ & $\begin{array}{l}\text { mass fraction of the } i^{\text {th }} \text { glass oxide in the } j-I^{\text {th }} \text { (previous) working MFPV } \\
\text { (g oxide per g glass) }\end{array}$ & $(114)$ \\
\hline$g_{\text {ie }}^{\text {canidein }}$ & mass fraction of the $i^{\text {th }}$ glass oxide in the $e^{\text {th }}$ canister (g per g glass) & $(123)$ \\
\hline $\begin{array}{c}\text { wastein } \\
G_{j}^{M F P V, \text {, nitial }}\end{array}$ & $\begin{array}{l}\text { initial mass fraction of glass oxides originated from waste in the } j^{\text {th }} \\
\text { MFPV batch, i.e. initial waste loading (g per g MFPV oxides) }\end{array}$ & $\begin{array}{l}(32)(33) \\
(40)(44)\end{array}$ \\
\hline$G_{j}^{\text {wastein }}$ & $\begin{array}{l}\text { target mass fraction of glass oxides originated from waste in the } j^{\text {th }} \\
\text { MFPV batch, i.e. target waste loading (g per g MFPV oxides) }\end{array}$ & $\begin{array}{l}(47)(50) \\
(51)(56) \\
(58)(63) \\
(68)\end{array}$ \\
\hline $\begin{array}{l}\text { wastein } \\
G_{j}^{M F P V, \text { Step } 1} \\
\text { wastein } \\
G_{j}^{M F P V, \text { Step } 3}\end{array}$ & $\begin{array}{l}\text { mass fraction of glass oxides originated from waste in the } j^{\text {th }} \text { MFPV } \\
\text { batch from algorithm calculation Step } 1 \text { or Step 3, i.e. waste loading (g } \\
\text { per g MFPV oxides) }\end{array}$ & $\begin{array}{l}(51)(53) \\
(96)(97) \\
(98)(100) \\
(105)(118)\end{array}$ \\
\hline$I_{\text {ie }}^{\text {radin }}$ & inventory of the $i^{\text {th }}$ radionuclide in the $e^{\text {th }}$ canister $(\mathrm{Ci})$ & $(127)$ \\
\hline$k^{\text {rad }}$ & expansion factor for radionuclide concentration specification & $\begin{array}{l}(73)(74) \\
(79)(80) \\
(83)\end{array}$ \\
\hline$L_{u}^{\text {prop }}$ and $L_{l}^{\text {prop }}$ & $\begin{array}{l}\text { upper and lower property limit for predicted "prop" transformed } \\
\text { property value }\end{array}$ & General \\
\hline$L_{u}^{a_{i}}$ & upper limit for specific activity of the $i^{\text {th }}$ radionuclide (nCi/g glass) & $\begin{array}{l}(75)(77) \\
(110)(112) \\
(130)(132)\end{array}$ \\
\hline
\end{tabular}




\begin{tabular}{|c|c|c|}
\hline Symbol & Description & Equation(s) \\
\hline$L_{u}^{\hat{\tilde{a}}_{i}}$ & $\begin{array}{l}\text { upper limit for the activity of the } i^{\text {th }} \text { radionuclide per unit glass volume } \\
\left(\mathrm{Ci} / \mathrm{m}^{3} \text { glass }\right)\end{array}$ & $\begin{array}{l}(75)(76) \\
(77)(78) \\
(110)(111) \\
(112)(113) \\
(130)(131) \\
(132)(133)\end{array}$ \\
\hline$m_{i k}^{\text {oxide in }}$ & $\begin{array}{l}\text { mass fraction of the } i^{\text {th }} \text { glass oxide in the } k^{\text {th }} \text { GFC (g oxide per g GFC } \\
\text { including volatiles) }\end{array}$ & $\begin{array}{l}(12)(48) \\
(50)(51) \\
(65)(68) \\
(69)(96) \\
(97)(98) \\
(102)(105) \\
(106)(122) \\
\end{array}$ \\
\hline $\mathbf{m}_{j}$ & 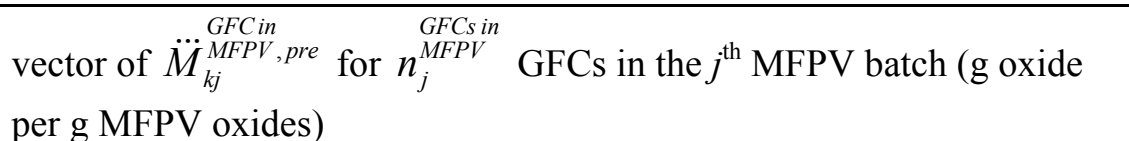 & $(48)$ \\
\hline$M_{k j}^{G F P V}$ & mass of the $k^{\text {th }}$ GFC to add to the $j^{\text {th }}$ MFPV batch (g) & $(12)$ \\
\hline 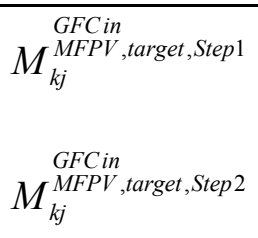 & $\begin{array}{l}\text { target mass of } k^{\text {th }} \text { GFC to add to the } j^{\text {th }} \text { MFPV batch resulted from } \\
\text { algorithm calculation Step } 1 \text { or Step } 2(\mathrm{~g})\end{array}$ & $\begin{array}{l}(57)(63) \\
(65)(69) \\
(89)\end{array}$ \\
\hline 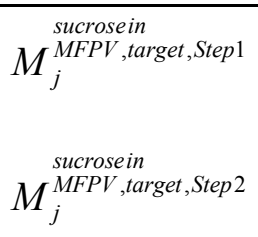 & $\begin{array}{l}\text { target mass of sucrose to add to the } j^{\text {th }} \text { MFPV batch resulted from } \\
\text { algorithm calculation Step } 1 \text { or Step } 2(\mathrm{~g})\end{array}$ & $(64)(90)$ \\
\hline $\begin{array}{c}\text { GFCin } \\
M_{k j}^{M F P V, \text { measured }}\end{array}$ & measured mass of $k^{\text {th }}$ GFC added to the $j^{\text {th }}$ MFPV batch $(\mathrm{g})$ & $\begin{array}{l}(96)(97) \\
(102)(106) \\
(116)(122)\end{array}$ \\
\hline $\begin{array}{c}\text { sucrosein } \\
M_{j}^{M F P V, \text { measured }}\end{array}$ & measured mass of sucrose added to the $j^{\text {th }}$ MFPV batch $(\mathrm{g})$ & $(117)$ \\
\hline$\dddot{M}_{k j}^{\text {GFCPV }}$ & $\begin{array}{l}\text { preliminary target mass of the } k^{\text {th }} \text { GFC per } g \text { of glass to add to the } j^{\text {th }} \\
\text { MFPV batch (g per g MFPV oxides) }\end{array}$ & $(48)(49)$ \\
\hline$\dddot{M}_{k j}^{M F C P V, \text { target }}$ & $\begin{array}{l}\text { target mass of the } k^{\text {th }} \text { GFC per } g \text { of glass to add to the } j^{\text {th }} \text { MFPV batch ( } g \\
\text { per } g \text { MFPV oxides) }\end{array}$ & $\begin{array}{l}(49)(50) \\
(51)(56) \\
(58)(63) \\
(68)\end{array}$ \\
\hline $\begin{array}{l}\ddot{M}_{j}^{M F P V}, \text { target } \\
\text { sucrosein }\end{array}$ & target mass of sucrose required per L of waste $(\mathrm{g} / \mathrm{L})$ & $\begin{array}{l}(59)(60) \\
(64)\end{array}$ \\
\hline$\dddot{M}_{k j}^{G F C \text { in }} M$ & $\begin{array}{l}\text { mass of the } k^{\text {th }} \text { GFC per } g \text { of glass in the } j^{\text {th }} \text { MFPV batch from algorithm } \\
\text { calculation Step } 3 \text { (g per } g \text { MFPV oxides) }\end{array}$ & $\begin{array}{l}(97)(98) \\
(105)\end{array}$ \\
\hline 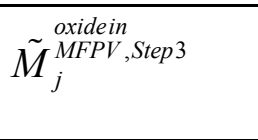 & $\begin{array}{l}\text { mass of total glass oxides in the } j^{\text {th }} \text { MFPV batch after applying the } \\
\text { component retention factors from algorithm calculation Step } 3(\mathrm{~g})\end{array}$ & $\begin{array}{l}(121)(122) \\
(123)(124) \\
(125)(126)\end{array}$ \\
\hline
\end{tabular}




\begin{tabular}{|c|c|c|}
\hline Symbol & Description & Equation(s) \\
\hline $\begin{array}{c}\text { glassin } \\
M_{e}^{\text {can }} \\
\end{array}$ & mass of glass in the $e^{\text {th }}$ canister $(\mathrm{kg})$ & $(127)$ \\
\hline$M W_{\mathrm{C}_{12} \mathrm{H}_{22} \mathrm{O}_{11}}$ & molecular mass of sucrose $(\mathrm{g} /$ mole $)$ & $(59)$ \\
\hline$M W_{\mathrm{Na}}$ & atomic mass of sodium $(\mathrm{g} / \mathrm{mole})$ & $(62)(92)$ \\
\hline $\begin{array}{l}M W_{\mathrm{NO}_{2}}, \\
M W_{\mathrm{NO}_{3}} \text {, and } \\
M W_{\mathrm{C}}\end{array}$ & molecular masses of nitrite, nitrate, and carbon ( $\mathrm{g} / \mathrm{mole})$ & $(59)$ \\
\hline $\begin{array}{c}\text { compsin } \\
n_{e c}^{\text {model }}\end{array}$ & number of model components in the "ec" model & (7) (11) \\
\hline $\begin{array}{c}\text { compsin } \\
n_{p c t}^{\text {model }}\end{array}$ & number of model components in the " $p c t$ " model & (2) (8) \\
\hline $\begin{array}{c}\text { compsin } \\
n_{v h t}^{\text {model }}\end{array}$ & number of model components in the " $v h t$ " model & (5) (9) \\
\hline $\begin{array}{c}\underbrace{\text { coms }}_{\text {compsin }} \\
n_{v i s}^{\text {model }}\end{array}$ & number of model components in the "vis" model & (6) (10) \\
\hline $\begin{array}{c}\text { datain } \\
n_{e c}^{\text {model }}\end{array}$ & number of data points used to fit the "ec" model & $(11)$ \\
\hline $\begin{array}{c}\text { datain } \\
n_{p c t}^{\text {model }}\end{array}$ & number of data points used to fit the " $p c t$ " model & $(8)$ \\
\hline $\begin{array}{c}\text { datain } \\
n_{\text {vht }}^{\text {model }}\end{array}$ & number of data points used to fit the " $v h t$ " model & (9) \\
\hline $\begin{array}{c}\text { datain } \\
n_{\text {vis }}^{\text {model }}\end{array}$ & number of data points used to fit the "vis" model & $(10)$ \\
\hline 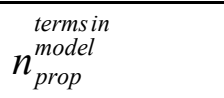 & number of model terms in the "prop" model & (1) \\
\hline $\begin{array}{c}\text { termsin } \\
n_{e c}^{\text {model }}\end{array}$ & number of model terms in the "ec" model & (7) (11) \\
\hline $\begin{array}{c}\text { termsin } \\
n_{p c t}^{\text {model }}\end{array}$ & number of model terms in the " $p c t$ " model & (2) (8) \\
\hline $\begin{array}{c}\text { termsin } \\
n_{v h t}^{\text {model }}\end{array}$ & number of model terms in the " $v h t$ " model & (5) (9) \\
\hline $\begin{array}{c}\text { termsin } \\
n_{v i s}^{\text {model }}\end{array}$ & number of model terms in the "vis" model & (6) (10) \\
\hline$n_{d}^{\text {oxides in }}$ & number of glass oxides tracked in the $d^{\text {th }}$ CRV batch & $\begin{array}{l}(12)(21) \\
(22)(65) \\
(102)\end{array}$ \\
\hline$n_{d}^{\text {samps in }}$ & number of samples analyzed in the $d^{\text {th }} \mathrm{CRV}$ batch & $\begin{array}{l}(14)(69) \\
(106)\end{array}$ \\
\hline$n_{k}^{\text {oxides in }}$ & number of glass oxides in the $k^{\text {th }} \mathrm{GFC}$ & $\begin{array}{l}(96)(97) \\
(122)\end{array}$ \\
\hline
\end{tabular}




\begin{tabular}{|c|c|c|}
\hline Symbol & Description & Equation(s) \\
\hline$n_{j}^{\text {GFCsin }}$ & number of GFCs used in the $j^{\text {th }}$ MFPV batch & $\begin{array}{l}(12)(50) \\
(51)(56) \\
(58)(65) \\
(68)(69) \\
(96)(97) \\
(98)(102) \\
(105)(106) \\
(122)\end{array}$ \\
\hline $\begin{array}{l}\text { oxidesin } \\
n_{j}^{M F P V}\end{array}$ & $\begin{array}{l}\text { number of glass oxides tracked in the mass balance calculations for the } \\
j^{\text {th }} \text { MFPV batch }\end{array}$ & $\begin{array}{l}(45)(12) \\
(13)(50) \\
(51)(52) \\
(54)(65) \\
(66)(68) \\
(70)(96) \\
(99)(101) \\
(102)(103) \\
(105)(106) \\
(107)(122)\end{array}$ \\
\hline$n_{e}^{\text {MFPVSin }}$ & number of MFPV batches that are assumed to be in the $e^{\text {th }}$ canister & $\begin{array}{l}(121)(123) \\
(124)(125) \\
(126)\end{array}$ \\
\hline$p_{h}^{\text {prop }}$ & coefficient of the $h^{\text {th }}$ model term for the "prop" model & $(1)$ \\
\hline$p_{h}^{e c}$ & $\begin{array}{l}\text { coefficient of the } h^{\text {th }} \text { model term for the "ec" model }(\mathrm{S} / \mathrm{cm}) \cdot p_{h}^{e c} \\
\text { represents all forms of the model term, i.e., } p_{i}^{e c}, p_{i i^{\prime}}^{e c}(\text { selected }) \text {, and } \\
p_{i}^{e c, T}\end{array}$ & (7) \\
\hline$p_{h}^{p c t}$ & $\begin{array}{l}\text { coefficient of the } h^{\text {th }} \text { model term for the " } p c t " \text { model }(\ln [\mathrm{g} / \mathrm{L}]) . p_{h}^{p c t} \\
\text { represents all forms of the model term, i.e., } p_{i}^{p c t}, p_{i i}^{p c t}(\text { selected }), \text { and } \\
p_{i i '}^{p c t}(\text { selected })\end{array}$ & (2) \\
\hline$p_{h}^{v h t}$ & $\begin{array}{l}\text { coefficient of the } h^{\text {th }} \text { model term for the " } v h t^{\text {" }} \text { model }(\ln [\mathrm{g} / \mathrm{L}]) . p_{h}^{v h t} \\
\text { represents all forms of the model term, i.e., } p_{i}^{v h t}, p_{i i}^{v h t}(\text { selected }), \text { and } \\
p_{i i^{v}}^{v h t}(\text { selected })\end{array}$ & $(5)$ \\
\hline$p_{h}^{v i s}$ & $\begin{array}{l}\text { coefficient of the } h^{\text {th }} \text { model term for the "vis" model }(\mathrm{P}) . p_{h}^{v i s} \text { represents } \\
\text { all forms of the model term, i.e., } p_{i}^{v i s}, p_{i i}^{v i s}(\text { selected }), p_{i i}^{v i s}(\text { selected }), \\
\text { and } p_{i}^{v i s, T} \text { (selected) }\end{array}$ & (6) \\
\hline$p_{i}^{e c}$ & $\begin{array}{l}\text { coefficient of the } i^{\text {th }} \text { model component in the "ec" model (represents } \\
\mathrm{Al}_{2} \mathrm{O}_{3} \text { through Others terms in Table 8) }\end{array}$ & (7) \\
\hline$p_{i i^{\prime}}^{e c}($ selected $)$ & $\begin{array}{l}\text { coefficients for the selected quadratic model terms in the "ec" model. } \\
\text { "Selected" means that only some of the terms in curly brackets are } \\
\text { included in the model. (represent } \mathrm{CaO} \times \mathrm{Li}_{2} \mathrm{O}, \mathrm{CaO} \times \mathrm{Na}_{2} \mathrm{O} \text {, and } \\
\mathrm{Li}_{2} \mathrm{O} \times \mathrm{Na}_{2} \mathrm{O} \text { terms in Table } 8 \text { ) }\end{array}$ & (7) \\
\hline
\end{tabular}




\begin{tabular}{|c|c|c|}
\hline Symbol & Description & Equation(s) \\
\hline$p_{i}^{e c, T}$ & $\begin{array}{l}\text { coefficient of the } i^{\text {th }} \text { model component for the model terms involving } \\
\text { temperature in the "ec" model. (represents } \mathrm{A}_{2} \mathrm{O}_{3} /(\mathrm{T} / 1000) \text { through } \\
\text { Others/(T/1000) terms in Table 8) }\end{array}$ & $(7)$ \\
\hline$p_{i}^{p c t}$ & $\begin{array}{l}\text { coefficient of the } i^{\text {th }} \text { model component for the " } p c t \text { " model }(\ln [\mathrm{g} / \mathrm{L}]) \\
\text { (represents } \mathrm{Al}_{2} \mathrm{O}_{3} \text { through Others terms in Table 5) }\end{array}$ & $(2)$ \\
\hline $\begin{array}{l}p_{i i}^{p c t}(\text { selected }) \\
p_{i i^{\prime}}^{p c t}(\text { selected })\end{array}$ & $\begin{array}{l}\text { coefficients for the selected quadratic model terms. "Selected" means } \\
\text { that only some of the terms in curly brackets are included in the model } \\
(\ln [\mathrm{g} / \mathrm{L}])\left(\text { represent } \mathrm{CaO} \times \mathrm{Li}_{2} \mathrm{O} \text { through }\left(\mathrm{K}_{2} \mathrm{O}\right)^{2} \text { terms in Table 5) }\right.\end{array}$ & $(2)$ \\
\hline$p_{i}^{v h t}$ & $\begin{array}{l}\text { coefficient of the } i^{\text {th }} \text { model component for the " } v h t \text { " model }(\ln [\mathrm{g} / \mathrm{L}]) \\
\left.\text { (represents } \mathrm{Al}_{2} \mathrm{O}_{3} \text { through Others terms in Table } 6\right)\end{array}$ & $(5)$ \\
\hline $\begin{array}{l}p_{i i i}^{v h t}(\text { selected }) \\
p_{i i i^{\prime}}^{v h t}(\text { selected }) \\
p_{i i^{\prime \prime} i^{\prime}}^{v h t}(\text { selected })\end{array}$ & $\begin{array}{l}\text { coefficients for the selected cubic model terms. "Selected" means that } \\
\text { only some of the terms in curly brackets are included in the model } \\
(\ln [\mathrm{g} / \mathrm{L}])\left(\text { represent }\left(\mathrm{K}_{2} \mathrm{O}\right)^{2} \times \mathrm{Na}_{2} \mathrm{O} \text { through } \mathrm{B}_{2} \mathrm{O}_{3} \times \mathrm{CaO} \times \mathrm{Na}_{2} \mathrm{O} \text { terms in }\right. \\
\text { Table 6) }\end{array}$ & $(5)$ \\
\hline$p_{i}^{v i s}$ & $\begin{array}{l}\text { coefficient of the } i^{\text {th }} \text { model component in the "vis" model (represents } \\
\mathrm{Al}_{2} \mathrm{O}_{3} \text { through Others terms in Table 7) }\end{array}$ & (6) \\
\hline $\begin{array}{l}p_{i i}^{v i s}(\text { selected }) \\
p_{i i i^{\prime}}^{v i s}(\text { selected })\end{array}$ & $\begin{array}{l}\text { coefficients for the selected quadratic model terms in the "vis" model. } \\
\text { "Selected" means that only some of the terms in curly brackets are } \\
\text { included in the model. (represent } \mathrm{Al}_{2} \mathrm{O}_{3} \times \mathrm{SiO}_{2} \text { through }\left(\mathrm{Li}_{2} \mathrm{O}\right)^{2} \text { terms in } \\
\text { Table 7) }\end{array}$ & $(6)$ \\
\hline$p_{i}^{v i s, T}($ selected $)$ & $\begin{array}{l}\text { coefficient of the selected } i^{\text {th }} \text { model component for the model terms } \\
\text { involving temperature in the "vis" model. "Selected" means that only } \\
\text { some of the terms in curly brackets are included in the model. } \\
\left.\left.\text { (represents } \mathrm{Al}_{2} \mathrm{O}_{3} /(\mathrm{T} / 1000)^{2} \text { through Others/(T/1000) }\right)^{2} \text { terms in Table } 7\right)\end{array}$ & (6) \\
\hline$P^{p c t}$ & $\begin{array}{l}\text { transformed normalized release }\left(=\ln \left[r_{\mathrm{B}}, \mathrm{g} / \mathrm{L}\right] \text { and } \ln \left[r_{\mathrm{Na}}, \mathrm{g} / \mathrm{L}\right]\right) \text { for } p c t= \\
\text { pctB and pctNa respectively }\end{array}$ & $(2)$ \\
\hline$P^{v h t}$ & transformed VHT alteration depth $(\ln [D, \mu \mathrm{m}])$ & $(5)$ \\
\hline$P^{\text {prop }}$ & $\begin{array}{l}\text { transformed property "prop", which includes } \ln \left(r_{\mathrm{B}}, \mathrm{g} / \mathrm{L}\right), \ln \left(r_{\mathrm{Na}}, \mathrm{g} / \mathrm{L}\right) \text {, } \\
\ln (D, \mu \mathrm{m}), \ln \left(\eta_{T}, \mathrm{P}\right) \text {, and } \ln \left(\varepsilon_{T}, \mathrm{~S} / \mathrm{cm}\right)\end{array}$ & (1) (16) \\
\hline$P_{e}^{p c t}, P_{e}^{v h t}$ & $\begin{array}{l}\text { predicted transformed property for " } p c t \text { " }\left(\ln \left[r_{\mathrm{B}}, \mathrm{g} / \mathrm{L}\right], \ln \left[r_{\mathrm{Na}}, \mathrm{g} / \mathrm{L}\right]\right) \text { and } \\
\text { " } v h t "(\ln [D, \mu \mathrm{m}]) \text { for the } e^{\text {th }} \text { canister }\end{array}$ & $(134)(135)$ \\
\hline $\begin{array}{l}P_{j}^{\text {prop }, \text { Step } 1} \\
P_{j}^{\text {prop ,Step3 }}\end{array}$ & $\begin{array}{l}\text { predicted transformed property "prop" for the } j^{\text {th }} \text { MFPV batch from } \\
\text { algorithm calculation Step } 1 \text { or Step 3, which includes } \ln \left(r_{\mathrm{B}}, \mathrm{g} / \mathrm{L}\right), \ln \left(r_{\mathrm{Na}} \text {, }\right. \\
\mathrm{g} / \mathrm{L}), \ln (D, \mu \mathrm{m}), \ln \left(\eta_{T}, \mathrm{P}\right) \text {, and } \ln \left(\varepsilon_{T}, \mathrm{~S} / \mathrm{cm}\right)\end{array}$ & $(67)(104)$ \\
\hline $\mathbf{p}^{\text {prop }}$ & 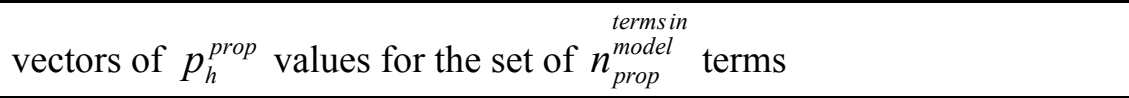 & $(1)$ \\
\hline$Q_{C L \%}^{p r o p}$ & $\begin{array}{l}\mathrm{CL} \%[=100(1-\alpha)] \text { percentile of the distribution of } n^{\text {runs of }} \text { simation } \\
\text { values }\end{array}$ & $(15)$ \\
\hline$Q_{50 \%}^{\text {prop }}$ & $\begin{array}{l}\text { median predicted property value or CL\% }=50 \% \text { percentile of the } \\
\text { distribution of } n^{\text {runsof of }} \text { sition } \\
\text { property values }\end{array}$ & $(15)$ \\
\hline$r_{\mathrm{B}}$ & PCT normalized boron release $(\mathrm{g} / \mathrm{L})$ & General \\
\hline$r_{\mathrm{Na}}$ & PCT normalized sodium release $(\mathrm{g} / \mathrm{L})$ & General \\
\hline$r_{\mathrm{Si}}$ & PCT normalized silicon release $(\mathrm{g} / \mathrm{L})$ & General \\
\hline$r_{e}^{\text {dosein } \text {,max }, \text { measured }}$ & measured maximum surface dose rate from $e^{\text {th }}$ canister $(\mathrm{mrem} / \mathrm{h})$ & General \\
\hline
\end{tabular}




\begin{tabular}{|c|c|c|}
\hline Symbol & Description & Equation(s) \\
\hline $\bar{R}_{i d}^{\text {rad in }}$ & $\begin{array}{l}\text { activity (per unit volume) of the } i_{\text {samps in }}^{\text {th }} \text { radionuclide in the waste of the } d^{\text {th }} \\
\text { CRV averaged over } n_{d}^{C R V} \text { samples analyzed (mCi/L) }\end{array}$ & $\begin{array}{l}(23)(24) \\
(53)(69) \\
(100)\end{array}$ \\
\hline $\begin{aligned} \text { element in } \\
R S D_{\text {anal }, i}^{C R V}\end{aligned}$ & $\begin{array}{l}\text { relative standard deviation (RSD) in the concentration of the } i^{\text {th }} \text { element } \\
\text { for chemical analysis in CRV batch }\end{array}$ & (14) \\
\hline $\begin{array}{c}\text { element in } \\
R S D_{\text {mix\&samp }, i}^{C R V}\end{array}$ & $\begin{array}{l}\text { RSD in the concentration of the } i^{\text {th }} \text { element for mixing and sampling in } \\
\text { CRV batch }\end{array}$ & (14) \\
\hline $\begin{array}{r}\text { element in } \\
R S D_{\text {biascorr }, i}^{C R V}\end{array}$ & $\begin{array}{l}\text { RSD in the concentration of the } i^{\text {th }} \text { element for correction of mixing and } \\
\text { sampling biases in CRV batch }\end{array}$ & (14) \\
\hline$s_{i d}^{\text {element in }}$ & $\begin{array}{l}\text { standard deviation in the concentration of the } i^{\text {th }} \text { element in the } d^{\text {th }} \mathrm{CRV} \\
\text { batch }(\mathrm{mg} / \mathrm{L})\end{array}$ & (14) \\
\hline $\begin{array}{c}\text { oxidein } \\
\tilde{S}_{i j}^{M F P V, \text { Step } 3}\end{array}$ & $\begin{array}{l}\text { SD for the mass fraction of the } i^{\text {th }} \text { glass oxide in the } j^{\text {th }} \text { MFPV batch after } \\
\text { applying the component retention factors from algorithm calculation } \\
\text { Step } 3 \text { (g per g glass) }\end{array}$ & $(124)(126)$ \\
\hline$S_{i e}^{\text {oxidein }}$ & $\begin{array}{l}\text { SD for the mass fraction of the } i^{\text {th }} \text { glass oxide in the } e^{\text {th }} \text { canister (g per g } \\
\text { glass) }\end{array}$ & (124) \\
\hline $\begin{array}{l}\text { radin } \\
\tilde{S}_{i j}^{M F P V, S t e p 1} \\
\tilde{s}_{i j}^{\text {radin }} \\
\text { MFP Step3 }^{\text {MF }}\end{array}$ & $\begin{array}{l}\text { SD for the specific activity of the } i^{\text {th }} \text { radionuclide in the } j^{\text {th }} \text { MFPV batch } \\
\text { from algorithm calculation Step } 1 \text { or Step } 3 \text { after applying retention } \\
\text { factors (mCi/g glass) }\end{array}$ & $\begin{array}{l}(72)(77) \\
(109)(112) \\
(126)\end{array}$ \\
\hline $\begin{array}{l}\hat{\tilde{S}}_{i j}^{\text {radin }} \\
\hat{\tilde{S}}_{i j}^{\text {radin }} \\
\text { MPV Stetep } 3\end{array}$ & $\begin{array}{l}\text { SD for the activity of the } i^{\text {th }} \text { radionuclide per unit volume of glass in the } \\
j^{\text {th }} \text { MFPV batch from algorithm calculation Step lor Step } 3 \text { after } \\
\text { applying retention factors ( } \mathrm{Ci} / \mathrm{m}^{3} \text { glass) }\end{array}$ & $\begin{array}{l}(72)(73) \\
(74)(78) \\
(83)(109) \\
(112)\end{array}$ \\
\hline$S_{i e}^{\text {radin }}$ & $\begin{array}{l}\text { SD for the specific activity of the } i^{\text {th }} \text { radionuclide in the } e^{\text {th }} \text { canister } \\
\text { (mCi/g glass) }\end{array}$ & $\begin{array}{l}(126)(129) \\
(132)\end{array}$ \\
\hline $\begin{array}{c}\text { radin } \\
\hat{s}_{i e}^{\text {can }}\end{array}$ & $\begin{array}{l}\text { SD for the activity of the } i^{\text {th }} \text { radionuclide per unit volume of glass in the } \\
e^{\text {th }} \text { canister }\left(\mathrm{Ci} / \mathrm{m}^{3} \text { glass }\right)\end{array}$ & $\begin{array}{l}(129)(132) \\
(133)\end{array}$ \\
\hline 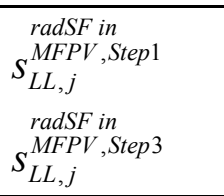 & $\begin{array}{l}\text { SD for the sum of fractions of activity to the limit of each radionuclide } \\
\text { for long-lived radionuclides for Class C limit determination in the } j^{\text {th }} \\
\text { MFPV batch from algorithm calculation Step } 1 \text { or Step } 3\end{array}$ & $\begin{array}{l}(77)(79) \\
(83)(112)\end{array}$ \\
\hline 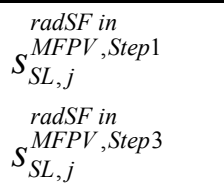 & $\begin{array}{l}\text { SD for the sum of fractions of activity to the limit of each radionuclide } \\
\text { for short-lived radionuclides for Class C limit determination in the } j^{\text {th }} \\
\text { MFPV batch from algorithm calculation Step } 1 \text { or Step } 3\end{array}$ & $\begin{array}{l}(78)(80) \\
(83)(113)\end{array}$ \\
\hline $\begin{array}{l}\text { radSF in } \\
S_{L L, e}^{c a n}\end{array}$ & $\begin{array}{l}\text { SD for the sum of fractions of activity to the limit of each radionuclide } \\
\text { for long-lived radionuclides for Class C limit determination in the } e^{\text {th }} \\
\text { canister }\end{array}$ & $(132)$ \\
\hline $\begin{array}{l}\text { radSF in } \\
S_{S L, e}^{c a n}\end{array}$ & $\begin{array}{l}\text { SD for the sum of fractions of activity to the limit of each radionuclide } \\
\text { for short-lived radionuclides for Class C limit determination in the } e^{\text {th }} \\
\text { canister }\end{array}$ & (133) \\
\hline $\begin{array}{l}\text { rad in } \\
S F_{L L, j}^{M F P V, \text { Step } 1} \\
\quad \text { rad in } \\
S F_{L L, j}^{M F P V, S t e p 3}\end{array}$ & $\begin{array}{l}\text { sum of fractions of activity to the limit of each radionuclide for long- } \\
\text { lived radionuclides for Class C limit determination in the } j^{\text {th }} \text { MFPV batch } \\
\text { from algorithm calculation Step } 1 \text { or Step } 3\end{array}$ & $\begin{array}{l}(75)(79) \\
(83)(110)\end{array}$ \\
\hline
\end{tabular}




\begin{tabular}{|c|c|c|}
\hline Symbol & Description & Equation(s) \\
\hline $\begin{array}{l}\text { rad in } \\
S F_{S L, j}^{M F P V, S t e p 1} \\
\quad \text { rad in } \\
S F_{S L, j}^{M F P V, S t e p 3}\end{array}$ & $\begin{array}{l}\text { sum of fractions of activity to the limit of each radionuclide for short- } \\
\text { lived radionuclides for Class C limit determination in the } j^{\text {th }} \text { MFPV batch } \\
\text { from algorithm calculation Step } 1\end{array}$ & $\begin{array}{l}(76)(80) \\
(83)(111)\end{array}$ \\
\hline$S F_{L L, e}^{\text {rad in }}$ & $\begin{array}{l}\text { sum of fractions of activity to the limit of each radionuclide for long- } \\
\text { lived radionuclides for Class } C \text { limit determination in the } e^{\text {th }} \text { canister }\end{array}$ & $(130)$ \\
\hline$S F_{S L, e}^{\text {rad in }}$ & $\begin{array}{l}\text { sum of fractions of activity to the limit of each radionuclide for short- } \\
\text { lived radionuclides for Class } C \text { limit determination in the } e^{\text {th }} \text { canister }\end{array}$ & $(131)$ \\
\hline$t_{[N a], j}$ & target sodium molarity of the melter feed (M) & $\begin{array}{l}(61)(62) \\
(92)\end{array}$ \\
\hline $\mathbf{t}_{j}$ & $\begin{array}{l}\text { oxidein } \\
\text { vector of } g_{i j}^{M F P V, \text { target-g } f c} \text { for } n_{j}^{\text {oxidesin }} \text { components in the } j^{\text {th }} \text { MFPV batch } \\
\text { (g oxide per g MFPV oxides) }\end{array}$ & $(48)$ \\
\hline 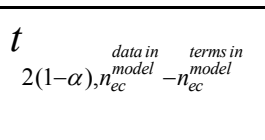 & $\begin{array}{l}100(1-\alpha) \text { percentile (=CL\%) of a two-sided t-distribution with } \\
\text { datain } \\
n_{e c}^{\text {termsin }}-n_{e c}^{\text {model }} \text { degrees of freedom }\end{array}$ & (11) \\
\hline 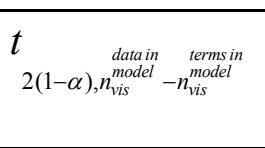 & $\begin{array}{l}100(1-\alpha) \text { percentile }(=\mathrm{CL} \%) \text { of a two-sided t-distribution with } \\
\text { datain } \\
n_{v i s}^{\text {model }}-n_{\text {vis }}^{\text {model }} \\
\text { megrees of freedom }\end{array}$ & $(10)$ \\
\hline$T$ & absolute temperature in Kelvin $(\mathrm{K})$ & (6) (7) \\
\hline$U_{\text {comp }}^{\text {prop }}$ & $\begin{array}{l}\text { composition uncertainty for "prop", i.e., uncertainty in predicted "prop" } \\
\text { due to glass composition uncertainty (in property model units) }\end{array}$ & $(15)(16)$ \\
\hline $\begin{array}{l}U_{\text {comp }, j}^{\text {prop }, \text { Step } 1} \\
U_{\text {comp }, j}^{\text {prop }, \text { Step } 3}\end{array}$ & $\begin{array}{l}\text { composition uncertainty for "prop" for the } j^{\text {th }} \text { MFPV batch from } \\
\text { algorithm calculation Step } 1 \text { or Step } 3 \text { (in property model units) }\end{array}$ & $(67)(104)$ \\
\hline $\begin{array}{l}U_{c o m p, e}^{p c t} \\
U_{c o m p, e}^{v h t}\end{array}$ & $\begin{array}{l}\text { composition uncertainty for " } p c t \text { " }\left(\ln \left[r_{\mathrm{B}}, \mathrm{g} / \mathrm{L}\right], \ln \left[r_{\mathrm{Na}}, \mathrm{g} / \mathrm{L}\right]\right) \text { and " } v h t \text { " } \\
(\ln [D, \mu \mathrm{m}]) \text { for the } e^{\text {th }} \text { canister }\end{array}$ & $(134)(135)$ \\
\hline$U_{\text {pred }}^{\text {prop }}$ & $\begin{array}{l}\text { model prediction uncertainty for "prop" (calculated per Section 4.2.1) } \\
\text { (in property model units) }\end{array}$ & $(16)$ \\
\hline$U_{\text {pred }}^{e c}$ & $\begin{array}{l}\text { prediction uncertainty for electrical conductivity (in } \ln [\mathrm{S} / \mathrm{cm}] \text { ) model, } \\
\text { which is given as a model uncertainty half width for a CL\% two-sided } \\
\text { CI }\end{array}$ & (11) \\
\hline$U_{\text {pred }}^{p c t}$ & $\begin{array}{l}\text { prediction uncertainty for PCT response (PCT-B or Na normalized } \\
\text { release, in } \ln [\mathrm{g} / \mathrm{L}] \text { ) model, which is given as a model uncertainty half } \\
\text { width for a CL\% SUCI }\end{array}$ & $(8)$ \\
\hline$U_{\text {pred }}^{v h t}$ & $\begin{array}{l}\text { prediction uncertainty for VHT alteration depth (in } \ln [\mu \mathrm{m}]) \text { model, } \\
\text { which is given as a model uncertainty half width for a CL\% SUCI }\end{array}$ & (9) \\
\hline$U_{\text {pred }}^{\text {vis }}$ & $\begin{array}{l}\text { prediction uncertainty for viscosity (in } \ln [\mathrm{P}] \text { ) model, which is given as a } \\
\text { model uncertainty half width for a CL\% two-sided CI }\end{array}$ & $(10)$ \\
\hline $\begin{array}{l}U_{p \text { pred }, j}^{\text {prop }, \text { Step } 1} \\
U_{\text {pred }, j}^{\text {prop }, \text { Step } 3}\end{array}$ & $\begin{array}{l}\text { model prediction uncertainty for "prop" for the } j^{\text {th }} \text { MFPV batch from } \\
\text { algorithm calculation Step } 1 \text { or Step } 3 \text { (in property model units) }\end{array}$ & $(67)(104)$ \\
\hline$U_{\text {pred,e }}^{\text {pct }}, U_{\text {pred,e }}^{v h t}$ & $\begin{array}{l}\text { model prediction uncertainty for " } p c t \text { " }\left(\ln \left[r_{\mathrm{B}}, \mathrm{g} / \mathrm{L}\right], \ln \left[r_{\mathrm{Na}}, \mathrm{g} / \mathrm{L}\right]\right) \text { and } \\
\text { " } v h t \text { " }(\ln [D, \mu \mathrm{m}]) \text { for the } e^{\text {th }} \text { canister }\end{array}$ & $(134)(135)$ \\
\hline
\end{tabular}




\begin{tabular}{|c|c|c|}
\hline Symbol & Description & Equation(s) \\
\hline $\begin{array}{l}\text { heel } \\
V_{d}^{C R V}\end{array}$ & $\begin{array}{l}\text { volume of the } d^{\text {th }} \text { CRV heel required for normal operation (L). The } \\
\text { neel } \\
\left.\text { nominal value of } V^{C R V} \text { is } 15,581 \mathrm{~L} \text { (Table } 1\right) \text {. }\end{array}$ & $(20)$ \\
\hline$V_{d}^{\text {working }}$ & $\begin{array}{l}\text { working volume of the } d^{\text {th }} \mathrm{CRV} \text { measured before the sampling line flush } \\
\text { working } \\
\text { water is added to the CRV (T). The nominal value of } V^{C R V} \text { is } 50,085 \\
\left.\text { CRV heel volume ( } V_{d}^{C R V}\right) \text { required for normal operation plus the CRV } \\
\text { batch } \\
\text { batch volume }\left(V_{d}^{C R V}\right) \text { transferred from TCP. }\end{array}$ & (19) \\
\hline$V_{d}^{\text {sampflush }}$ & volume of the sampling line flush water used for the $d^{\text {th }} \mathrm{CRV}$ batch (L) & (19) \\
\hline $\begin{array}{c}\text { current } \\
V_{d, m-1}^{C R V}\end{array}$ & $\begin{array}{l}\text { current volume of the } d^{\text {th }} \text { CRV measured after the } m-l^{\text {th }} \text { (previous) waste } \\
\text { transfer to MFPV }(\mathrm{L}) .\end{array}$ & $(19)(20)$ \\
\hline $\begin{array}{l}\text { transflush } \\
V_{d, m-1}^{C R V}\end{array}$ & $\begin{array}{l}\text { volume of the CRV-MFPV transfer line flush water used for the } d^{\text {th }} \text { CRV } \\
\text { after the } m-1^{\text {th }} \text { (previous) waste transfer to MFPV (L). }\end{array}$ & $(19)$ \\
\hline $\begin{array}{l}\text { transwaste } \\
V_{d, m-1}^{C R V}\end{array}$ & $\begin{array}{l}\text { volume of the } m-1^{\text {th }} \text { (previous) transfer waste transferred from the } d^{\text {th }} \\
\text { CRV to MFPV (L). }\end{array}$ & $(20)$ \\
\hline $\begin{array}{l}\text { transwaste } \\
V_{d m}^{C R V}\end{array}$ & $\begin{array}{l}\text { volume of the } m^{\text {th }} \text { transfer waste to be transferred from the } d^{\text {th }} \text { CRV to } \\
\text { MFPV (L). }\end{array}$ & $\begin{array}{l}(55)(56) \\
(58)(60) \\
(62)(63) \\
(64)(65) \\
(69)(89) \\
(90)(91) \\
(93)(94)\end{array}$ \\
\hline$V_{j}^{\text {working }}$ & $\begin{array}{l}\text { working volume for the } j^{\text {th }} \text { MFPV batch }(\mathrm{L}) . \text { The MFPV working } \\
\text { volume includes the MFPV heel volume }\left(V_{j}^{M F P V}\right) \text { required for normal } \\
\text { operation plus the MFPV batch volume }\left(V_{j}^{\text {batch }}\right) \text { prepared. } \\
\quad \text { working } \\
V_{j}^{M F P V, \text { nominal }}=12,444 \mathrm{~L}\end{array}$ & $(55)$ \\
\hline $\begin{array}{c}\text { batch } \\
V_{j}^{M F P V}\end{array}$ & volume of the $j^{\text {th }}$ MFPV batch (L) & $\begin{array}{l}(114)(115) \\
(118)(119)\end{array}$ \\
\hline $\begin{array}{l}{ }_{j}^{G F C} \\
{ }_{j}^{M F P V, \text { Step } 1} \\
V_{j}^{\text {GFC }} \\
{ }^{M F V, \text { Step } 2} \\
V_{j}^{\text {GFP }} \\
\end{array}$ & 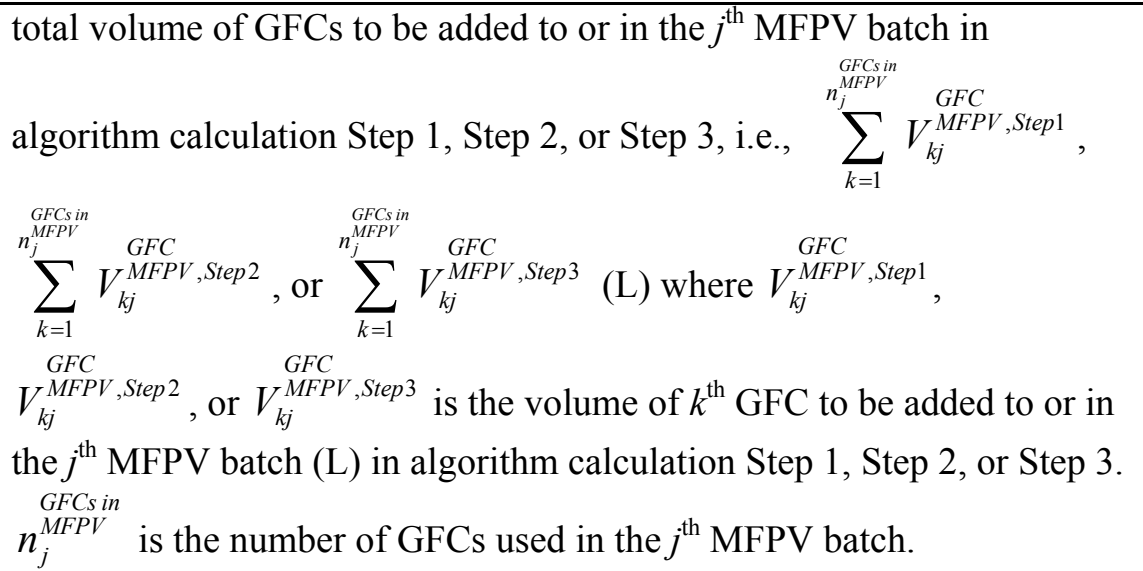 & $\begin{array}{l}(55)(56) \\
(93)(95) \\
(115)(116)\end{array}$ \\
\hline
\end{tabular}




\begin{tabular}{|c|c|c|}
\hline Symbol & Description & Equation(s) \\
\hline $\begin{array}{l}\text { dust } \\
V_{j}^{M F P V, \text { Step } 1} \\
{ }_{j}^{\text {dust }} \\
V_{j}^{M F P V, \text { Step } 2}\end{array}$ & $\begin{array}{l}\text { volume of water added to control GFC dusting in the } j^{\text {th }} \text { MFPV batch in } \\
\text { algorithm calculation Step } 1 \text { or Step } 2 \text { (L) }\end{array}$ & $\begin{array}{l}(55)(57) \\
(58)(62) \\
(91)(92) \\
(95)\end{array}$ \\
\hline $\begin{array}{c}\text { dust } \\
V_{j}^{M F P V, \text { measured }}\end{array}$ & $\begin{array}{l}\text { measured volume of water added to control GFC dusting in the } j^{\text {th }} \text { MFPV } \\
\text { batch }\end{array}$ & $(115)$ \\
\hline 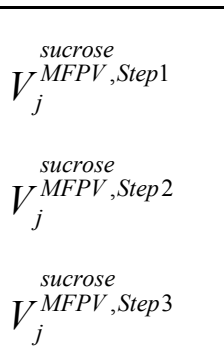 & $\begin{array}{l}\text { volume of sucrose addition to the } j^{\text {th }} \text { MFPV batch (L) in algorithm } \\
\text { calculation Step 1, Step 2, o Step } 3(\mathrm{~L})\end{array}$ & $\begin{array}{l}(55)(60) \\
(94)(95) \\
(115)(117)\end{array}$ \\
\hline $\begin{array}{l}\text { heel } \\
V_{j}^{M F P V}\end{array}$ & $\begin{array}{l}\text { volume of heel in the } j^{\text {th }} \text { MFPV batch measured prior to waste transfer } \\
\text { (L) }\end{array}$ & $\begin{array}{l}(55)(95) \\
(114)(119)\end{array}$ \\
\hline$V_{j}^{\text {transflush }}$ & $\begin{array}{l}\text { volume of water used to flush the CRV-MFPV transfer line in the } j^{\text {th }} \\
\text { MFPV batch (L) }\end{array}$ & $(55)(62)$ \\
\hline $\begin{array}{c}\text { transflush } \\
V_{j}^{M F P V, \text { measured }}\end{array}$ & $\begin{array}{l}\text { measured volume of water used to flush the CRV-MFPV transfer line in } \\
\text { the } j^{\text {th }} \text { MFPV batch (L) }\end{array}$ & $\begin{array}{l}(92)(95) \\
(115)\end{array}$ \\
\hline $\begin{array}{c}\text { sampflush } \\
V_{j}^{M F P V}\end{array}$ & $\begin{array}{l}\text { volume of water used to flush the MFPV sampling line in the } j^{\text {th }} \text { MFPV } \\
\text { batch (L) }\end{array}$ & $\begin{array}{l}(55)(62) \\
(92)(95)\end{array}$ \\
\hline $\begin{array}{c}\text { sampflush } \\
V_{j}^{M F P V} \text {,measured } \\
\end{array}$ & $\begin{array}{l}\text { measured volume of water used to flush the MFPV sampling line in the } \\
j^{\text {th }} \text { MFPV batch (L) }\end{array}$ & $(115)$ \\
\hline 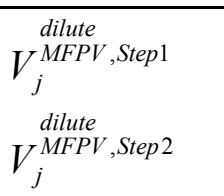 & $\begin{array}{l}\text { volume of dilution water required to maintain satisfactory melter-feed } \\
\text { rheological properties in the } j^{\text {th }} \text { MFPV batch in algorithm calculation } \\
\text { Step } 1 \text { or Step } 2 \text { (L) }\end{array}$ & $\begin{array}{l}(55)(62) \\
(92)(95)\end{array}$ \\
\hline $\begin{array}{c}\text { dilute } \\
V_{j}^{M F P V, \text { measured }} \\
\end{array}$ & $\begin{array}{l}\text { measured volume of dilution water added to maintain satisfactory } \\
\text { melter-feed rheological properties in the } j^{\text {th }} \text { MFPV batch }\end{array}$ & $(115)$ \\
\hline $\begin{array}{c}\text { waste } \\
V_{j}^{M F P V}\end{array}$ & volume of waste transferred from CRV to the $j^{\text {th }}$ MFPV (L) & $\begin{array}{l}(12)(89) \\
(90)(91) \\
(92)(93) \\
(94)(95) \\
(96)(102) \\
(106)(115) \\
(118)(122) \\
\end{array}$ \\
\hline$W_{j}^{\text {initial }}$ & 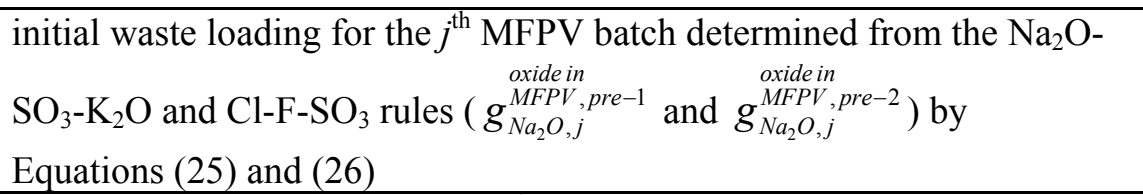 & $(27)(28)$ \\
\hline$W_{j}^{\min , K}$ & $\begin{array}{l}\text { minimum waste loading for the } j^{\text {th }} \text { MFPV batch when } 0.54 \mathrm{wt} \% \text { of } \mathrm{K}_{2} \mathrm{O} \\
\text { limit is assumed }\end{array}$ & $(27)(29)$ \\
\hline$W_{j}^{\min , C r}$ & $\begin{array}{l}\text { minimum waste loading for the } j^{\text {th }} \text { MFPV batch when } 0.08 \mathrm{wt} \% \text { of } \mathrm{Cr}_{2} \mathrm{O}_{3} \\
\text { limit is assumed }\end{array}$ & $(27)(30)$ \\
\hline
\end{tabular}




\begin{tabular}{|c|c|c|}
\hline Symbol & Description & Equation(s) \\
\hline$x_{h}^{e c}$ & $\begin{array}{l}\text { component mass fraction in glass or transformed value of component } \\
\text { mass fractions to the appropriate basis for the } h^{\text {th }} \text { model term in the " } e c \text { " } \\
\text { model }\end{array}$ & (7) \\
\hline$x_{h}^{p c t}$ & $\begin{array}{l}\text { component mass fraction in glass or transformed value of component } \\
\text { mass fractions to the appropriate basis for the } h^{\text {th }} \text { model term in the " } p c t \text { " } \\
\text { model }\end{array}$ & (2) \\
\hline$x_{h}^{\text {prop }}$ & $\begin{array}{l}\text { component mass fraction in glass or transformed value of component } \\
\text { mass fractions to the appropriate basis for the } h^{\text {th }} \text { model term in the } \\
\text { "prop" model }\end{array}$ & (1) \\
\hline$x_{h}^{v h t}$ & $\begin{array}{l}\text { component mass fraction in glass or transformed value of component } \\
\text { mass fractions to the appropriate basis for the } h^{\text {th }} \text { model term in the " } v h t \text { " } \\
\text { model }\end{array}$ & (5) \\
\hline$x_{h}^{v i s}$ & $\begin{array}{l}\text { component mass fraction in glass or transformed value of component } \\
\text { mass fractions to the appropriate basis for the } h^{\text {th }} \text { model term in the "vis" } \\
\text { model }\end{array}$ & (6) \\
\hline$x_{i}^{e c}$ & $\begin{array}{l}\text { mass fraction of the } i^{\text {th }} \text { model component in glass for the "ec" model, } \\
\text { compsin } \\
\sum_{i=1}^{\text {model }} \text { od } \\
\sum_{i=1}^{e c} x_{i}^{e c}=1\end{array}$ & (7) \\
\hline$x_{i}^{p c t}$ & 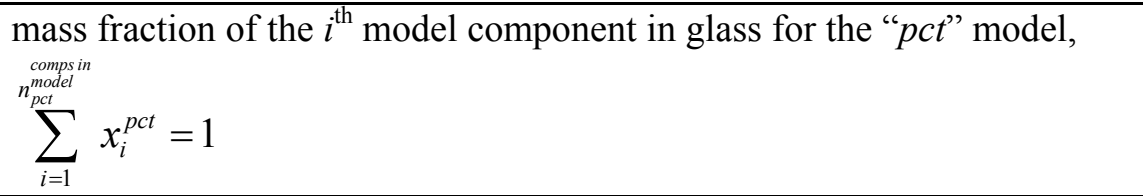 & (2) \\
\hline$x_{i}^{\text {prop }}$ & mass fraction of the $i^{\text {th }}$ model component in glass for the "prop" model & (3) \\
\hline$x_{\text {Others }}^{\text {prop }}$ & $\begin{array}{l}\text { mass fraction of the "Others" model component in glass for the "prop" } \\
\text { model }\end{array}$ & (4) \\
\hline$x_{i}^{v h t}$ & 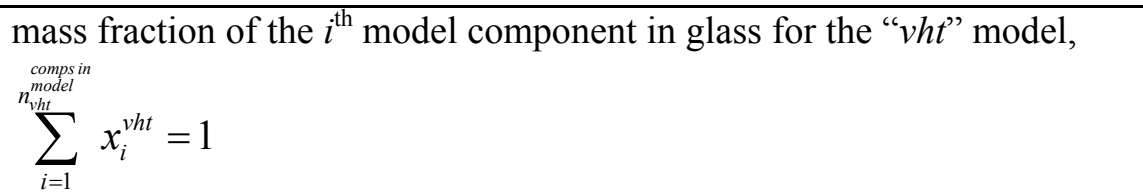 & (5) \\
\hline$x_{h}^{v i s}$ & 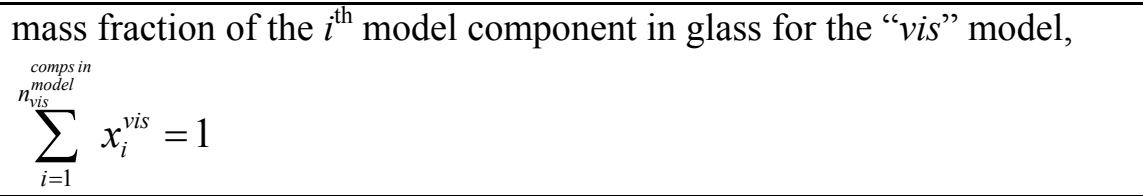 & (6) \\
\hline $\mathbf{x}^{e c}$ & $\begin{array}{l}\text { termsin } \\
\text { vector of } x_{h}^{e c} \text { values for the set of } n_{e c}^{\text {model }} \text { terms, where } x_{h}^{e c} \text { is } \\
\text { component mass fraction in glass or transformed value of component } \\
\text { mass fractions to the appropriate basis for the } h^{\text {th }} \text { model term in the "ec" } \\
\text { model (note that } \mathbf{x}^{e c} \text { is temperature dependent) }\end{array}$ & (11) \\
\hline $\mathbf{x}^{p c t}$ & $\begin{array}{l}\text { vector of } x_{h}^{p c t} \text { values for the set of } n_{p c t}^{\text {termsin }} \text { terms, where } x_{h}^{p c t} \text { is } \\
\text { component mass fraction in glass or transformed value of component } \\
\text { mass fractions to the appropriate basis for the } h^{\text {th }} \text { model term in the " } p c t \text { " } \\
\text { model }\end{array}$ & (8) \\
\hline $\mathbf{x}^{\text {prop }}$ & 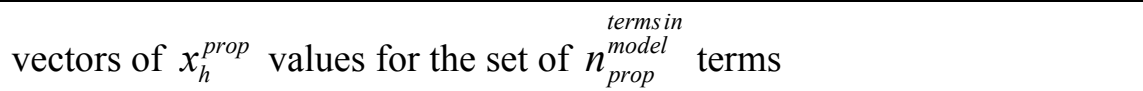 & (1) \\
\hline
\end{tabular}




\begin{tabular}{|c|c|c|}
\hline Symbol & Description & Equation(s) \\
\hline $\mathbf{x}^{v h t}$ & $\begin{array}{l}\text { vector of } x_{h}^{\text {termsin }} \text { values for the set of } n_{v h t}^{\text {model }} \text { terms, where } x_{h}^{v h t} \text { is } \\
\text { component mass fraction in glass or transformed value of component } \\
\text { mass fractions to the appropriate basis for the } h^{\text {th }} \text { model term in the " } v h t \text { " } \\
\text { model }\end{array}$ & (9) \\
\hline $\mathbf{x}^{v i s}$ & $\begin{array}{l}\text { termsin } \\
\text { vector of } x_{h}^{v i s} \text { values for the set of } n_{v i s}^{\text {model }} \text { terms, where } x_{h}^{v i s} \text { is } \\
\text { component mass fraction in glass or transformed value of component } \\
\text { mass fractions to the appropriate basis for the } h^{\text {th }} \text { model term in the "vis" } \\
\text { model (note that } \mathbf{x}^{v i s} \text { is temperature dependent) }\end{array}$ & $(10)$ \\
\hline$\alpha$ & $\begin{array}{l}\text { a small fraction typically less than or equal to } 0.1 \text { used to represent the } \\
\text { probability that a "100(1- } \alpha) \text { confidence interval" does not contain the } \\
\text { true value }\end{array}$ & General \\
\hline$\delta$ & $\begin{array}{l}\text { a unitless constant larger than zero and typically smaller than } 0.01 \\
\text { introduced to accommodate the variations resulting from Monte Carlo } \\
\text { calculation of composition uncertainties }\end{array}$ & $\begin{array}{l}(83)(85) \\
(86)(87)\end{array}$ \\
\hline$\varepsilon_{1100}$ & melt electrical conductivity at $1100^{\circ} \mathrm{C}(\mathrm{S} / \mathrm{cm})$ & General \\
\hline$\varepsilon_{1200}$ & melt electrical conductivity at $1200^{\circ} \mathrm{C}(\mathrm{S} / \mathrm{cm})$ & General \\
\hline$\eta_{1100}$ & melt viscosity at $1100^{\circ} \mathrm{C}(\mathrm{P})$ & General \\
\hline$\eta_{1150}$ & melt viscosity at $1150^{\circ} \mathrm{C}(\mathrm{P})$ & General \\
\hline$\varepsilon_{T}$ & electrical conductivity $(\mathrm{S} / \mathrm{cm})$ at temperature $T(\mathrm{~K})$ & (7) \\
\hline$\eta_{T}$ & viscosity $(\mathrm{P})$ at temperature $T(\mathrm{~K})$ & (6) \\
\hline $\mathbf{H}$ & $\begin{array}{l}11 \times 11 \text { matrix of } m_{i k}^{\text {oxidein }} \text { GFC } \\
\mathrm{CaO}, \mathrm{Fe}_{2} \mathrm{O}_{3}, \mathrm{Li}_{2} \mathrm{O}, \mathrm{MgO}, \mathrm{Na}_{2} \mathrm{O}, \mathrm{SiO}_{2}, \mathrm{TiO}_{2}, \mathrm{ZnO} \text {, and } \mathrm{ZrO}_{2} \text {, with a } \\
\text { corresponding GFC per each glass oxide component, g per g GFC } \\
\text { including volatiles) }\end{array}$ & $(48)$ \\
\hline$\lambda_{d m}$ & $\begin{array}{l}\text { dilution factor caused by the addition of flush waters for the } m^{\text {th }} \text { transfer } \\
\text { waste transferred from the } d^{\text {th }} \text { CRV to MFPV }\end{array}$ & $\begin{array}{l}(18)(23) \\
(24)(53) \\
(69)(100) \\
\end{array}$ \\
\hline$\lambda_{d, m-1}$ & $\begin{array}{l}\text { dilution factor caused by the addition of flush waters for the } m-I^{\text {th }} \\
\text { (previous) transfer waste transferred from the } d^{\text {th }} \text { CRV batch to MFPV } \\
\text { (dilution factor for the waste transferred previously) }\end{array}$ & (19) \\
\hline$v_{i}$ & retention factor for the $i^{\text {th }}$ component (fraction) & $\begin{array}{l}(13)(52) \\
(54)(66) \\
(68)(70) \\
(99)(101) \\
(103)(105) \\
(107)(122)\end{array}$ \\
\hline$\rho_{e}^{\text {glass in }}$ & density of glass in the $e^{\text {th }}$ canister $(\mathrm{g} / \mathrm{L})$ & $(128)(129)$ \\
\hline$\rho_{j}^{\substack{\text { glass in } \\
\text { MFPV }}}$ & density of glass in the $j^{\text {th }}$ MFPV batch (g/L glass) & $\begin{array}{l}(71)(72) \\
(108)\end{array}$ \\
\hline$\rho_{k}$ & particle density of the $k^{\text {th }}$ GFC $(\mathrm{g} / \mathrm{L})$ & $(56)(116)$ \\
\hline$\rho_{\text {sucrose }}$ & particle density of sucrose $(\mathrm{g} / \mathrm{L})$ & $(60)(117)$ \\
\hline$\Sigma^{e c}$ & variance-covariance matrix for the " $e c$ " model & (11) \\
\hline
\end{tabular}




\begin{tabular}{|l|l|l|}
\hline Symbol & Description & Equation(s) \\
\hline $\boldsymbol{\Sigma}^{p c t}$ & variance-covariance matrix for the " $p c t$ " model & $(8)$ \\
\hline $\boldsymbol{\Sigma}^{\text {vht }}$ & variance-covariance matrix for the " $v h t^{\text {" model }}$ & $(9)$ \\
\hline $\boldsymbol{\Sigma}^{v i s}$ & variance-covariance matrix for the "vis" model & $(10)$ \\
\hline$\omega_{d}$ & $\begin{array}{l}\text { fraction of the sodium in the } d^{\text {th }} \text { CRV batch that is classified as waste } \\
\text { sodium (unitless) }\end{array}$ & $(68)(105)$ \\
\hline
\end{tabular}




\section{Description of Process Steps}

Figure 2 is a preliminary process flow diagram for the ILAW product compliance process.

Figure 2. Preliminary ILAW Product Qualification Process Flow Diagram

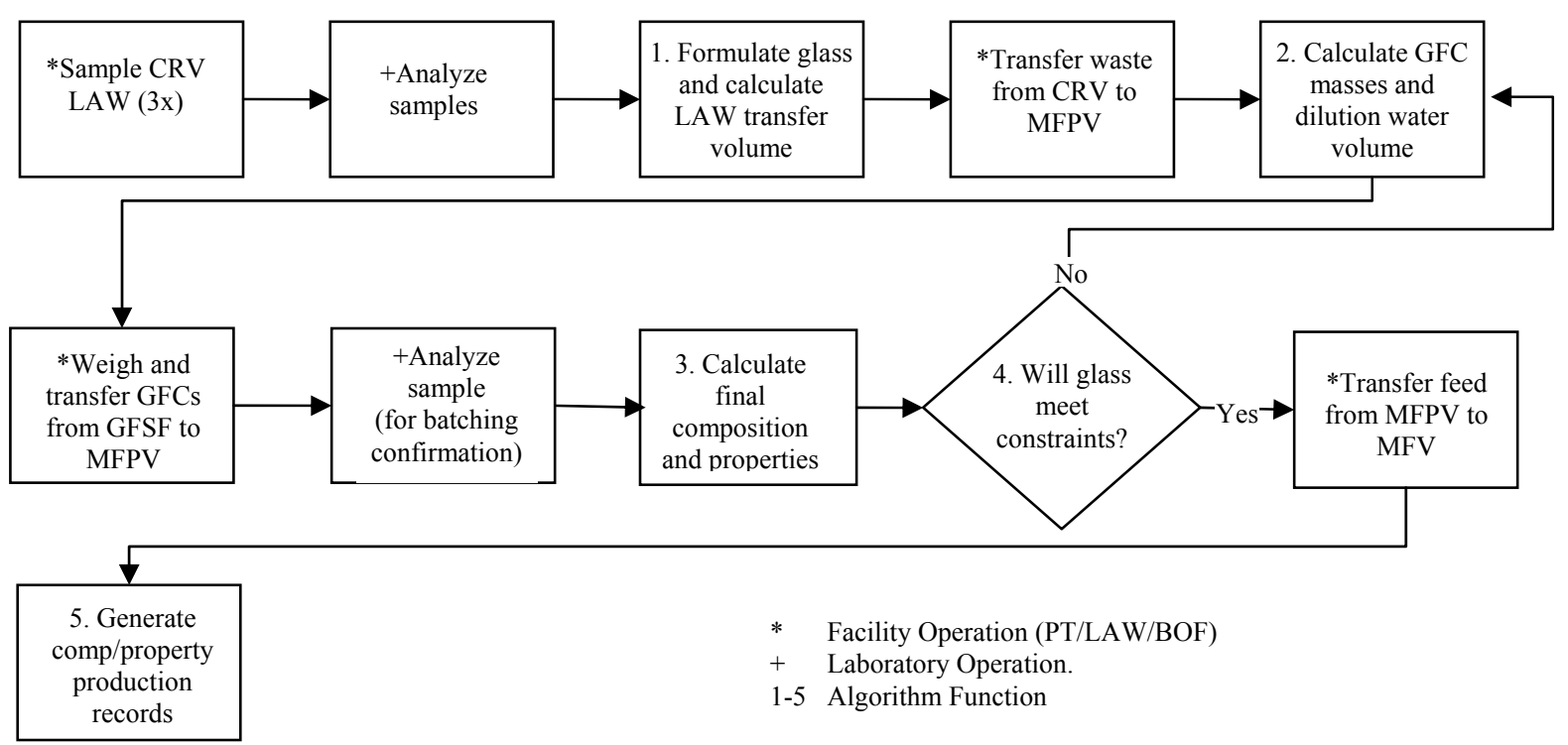

The ILAW formulation algorithm steps (those numbered activities in Figure 2) are highlighted below.

1. In the first step of the ILAW product compliance process, analytical data from the LAW CRV samples will be screened and evaluated prior to calculating glass formulation. The data screening should include, at a minimum, outlier identification, and trending evaluation. The analytical data given in concentration of chemical elements and activity of radionuclides will be converted to the forms used in glass formulation.

Glass formulation will be performed based on the composition of CRV waste and the composition of GFCs. Glass formulation does not include the content of the heel from a previous MFPV batch. The target glass composition will be calculated following the glass formulation rules described in Section 5.1.3. The glass properties with uncertainties will be calculated from the target glass formulation and compared with the constraints. The formulation will also be checked to make sure that it meets all the constraints described in Section 4.3. The resulting glass formulation will be used to calculate volume of waste transfer and the mass of GFCs including sucrose. The volume relation will be solved to calculate the waste transfer volume. The output of Step 1 calculation is the waste transfer volume.

2. In the second step, after waste transfer to the MFPV, the actual measured waste transfer volume will be used to calculate the masses of GFCs based on glass formulation completed in Step 1 (i.e., glass formulation is not performed in this step, instead the Step 1 formulation results are used to calculate the GFC masses.) The volume of dilution water will also be recalculated after accounting for changes in other process water volumes.

3. The final glass-composition estimate associated with a completed MFPV batch will be made in Step 3 . The actual measured volume of waste transfer, actual measured volumes of various process waters, and 
the actual measured masses of GFCs are used to calculate the final composition and predict the properties of the glass with uncertainties using glass composition-property models.

The MFPV contents including heel and newly added MFPV batch will be sampled and analyzed for major glass components to confirm proper GFC addition, but this is not a process hold point. Trending analyses will be performed on the differences between the analytical results and calculated values to detect potential errors in the MFPV batch preparation.

4. In Step 4, the projected LAW glass composition and predicted properties (corresponding to the MFPV batch) will be statistically compared (i.e., accounting for uncertainties) to composition and property constraints summarized in Section 4.3. If the constraints are met, then the MFPV batch will be transferred to the MFV for processing. If any constraint is not met then an operator will be alerted for intervention. If a product quality constraint is not met then the process may return to Step 2.

5. In Step 5, the appropriate waste form compliance quantities will be recorded for inclusion in the Production Records for ILAW containers within the current lot.

The calculation logic and equations required to implement Steps 1 through 5 are presented in detail in Section 5 and illustrated in Section 6. 


\section{Description of Property Predictions, Uncertainties, and Constraints}

The objective of glass formulation for a given waste is to calculate the acceptable glass composition that meets various processing and product-quality related constraints. For LAW, the initial glass composition is estimated using the glass formulation rules developed by Muller et al. (2004) and supplemented by CCN 150795, described in Section 5.1.3. Several of the processing and product-quality related constraints are based on LAW glass properties implemented by property-composition models. The following subsections present the property predictions, associated uncertainty calculations, and constraints used to meet the key ILAW formulation algorithm steps, as described in Section 3.

The mass balance equations and statistical methods and formulas used in several steps of the formulation algorithm are based on compliance strategy development work in Piepel et al. (2005) and estimates of variation and uncertainty in Piepel et al. (2006). Citations are given to specific sections of those documents in subsequent sections of this report for those who want additional details contained in those documents.

\subsection{Property Predictions}

The melter feed should be both processable and yield an adequate product, i.e., the resultant glass should have properties within acceptable ranges. Therefore, the properties of the target glass are predicted using glass-composition property models.

The property-composition models were developed for processing and product-quality properties of LAW glasses and melts, including (Piepel et al. 2007):

- $\quad$ Normalized B and Na releases by PCT ( $r_{\mathrm{B}}$ and $\left.r_{\mathrm{Na}}\right)$

- $\quad$ Alteration depth by VHT at $200^{\circ} \mathrm{C}(D)$

- $\quad$ Viscosity as a function of temperature $\left(\eta_{T}\right)$

- $\quad$ Electrical conductivity as a function of temperature $\left(\varepsilon_{T}\right)$

A general form of all the property-composition models above is given as:

$$
P^{\text {prop }}=\sum_{h=1}^{\substack{\text { terms in } \\ \text { prod } \text { prop }}} p_{h}^{\text {prop }} x_{h}^{\text {prop }}=\left(\mathbf{p}^{\text {prop }}\right)^{\mathbf{T}} \mathbf{x}^{\text {prop }}
$$

where

$$
\begin{aligned}
n_{\text {prop }}^{\text {termsin }} & =\text { number of model terms in the "prop" model } \\
p_{h}^{\text {prop }} & =\text { coefficient of the } h^{\text {th }} \text { model term for the "prop" model } \\
x_{h}^{\text {prop }} & =\begin{array}{l}
\text { component mass fraction in glass or transformed value of component mass } \\
\text { fractions to the appropriate basis for the } h^{\text {th }} \text { model term in the "prop" model }
\end{array}
\end{aligned}
$$




$$
\mathbf{p}^{\text {prop }} \text { and } \mathbf{x}^{\text {prop }}=\text { vectors of } p_{h}^{\text {prop }} \text { and } x_{h}^{\text {prop }} \text { values for the set of } n_{\text {prop }}^{\text {termsin }} \text { terms }
$$

The property models are valid only over the region of component mass fractions where experimental data were available to develop them. Thus, extrapolation beyond currently tested compositional bounds will not be done and the model validity ranges become constraints for formulating acceptable glass composition discussed in Section 4.3. Refer to Piepel et al. (2007) for detailed information on the data and methods used to develop the models and the limitations that need to be considered when using these models.

\subsubsection{Product Consistency Test}

The model for PCT normalized releases as a function of LAW glass composition is [Piepel et al. 2007, see Equation (5.2)]:

$$
\begin{aligned}
& \ln \left(r_{B}, r_{N a}\right)=\sum_{h=1}^{\substack{\text { termsin } \\
\text { nod } \\
\text { poct }}} p_{h}^{p c t} x_{h}^{p c t}=P^{p c t}
\end{aligned}
$$

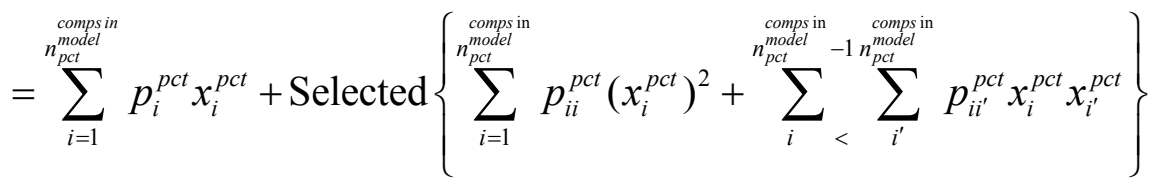

where

$$
\begin{aligned}
& r_{B}, r_{N a}=\text { normalized release for } \mathrm{B} \text { or } \mathrm{Na}(\mathrm{g} / \mathrm{L}) \\
& P^{p c t}=\begin{array}{l}
\text { transformed normalized release }\left(=\ln \left[r_{\mathrm{B}}, \mathrm{g} / \mathrm{L}\right] \text { and } \ln \left[r_{\mathrm{Na}}, \mathrm{g} / \mathrm{L}\right]\right) \text { for } p c t=\operatorname{pctB} \\
\text { and pctNa respectively }
\end{array}
\end{aligned}
$$

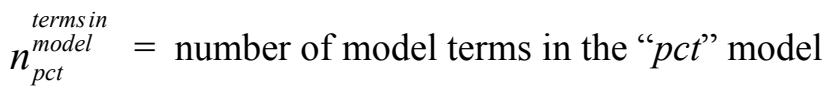

$$
\begin{aligned}
& p_{h}^{p c t}=\begin{array}{l}
\text { coefficient of the } h^{\text {th }} \text { model term for the " } p c t \text { " model }(\ln [\mathrm{g} / \mathrm{L}]) . p_{h}^{p c t} \text { represents } \\
\text { all forms of the model term, i.e., } p_{i}^{p c t}, p_{i i}^{p c t}(\text { selected }), \text { and } p_{i i^{\prime}}^{p c t}(\text { selected })
\end{array} \\
& x_{h}^{p c t}=\begin{array}{l}
\text { component mass fraction in glass or transformed value of component mass } \\
\text { fractions to the appropriate basis for the } h^{\text {th }} \text { model term in the " } p c t \text { " model }
\end{array} \\
& n_{p c t}^{\text {compsin }} \text { model }=\text { number of model components in the " } p c t \text { " model } \\
& p_{i}^{p c t}=\begin{array}{l}
\text { coefficient of the } i^{\text {th }} \text { model component for the " } p c t \text { " model }(\ln [\mathrm{g} / \mathrm{L}]) \\
\text { (represents } \mathrm{Al}_{2} \mathrm{O}_{3} \text { through Others terms in Table 5) }
\end{array}
\end{aligned}
$$

$p_{i i}^{p c t}$ (selected) coefficients for the selected quadratic model terms. "Selected" means that

$p_{i i^{\prime}}^{p c t}($ selected $)=\begin{aligned} & \text { only some of the terms in curly brackets are included in the model }(\ln [\mathrm{g} / \mathrm{L}]) \\ & \left(\text { represent } \mathrm{CaO} \times \mathrm{Li}_{2} \mathrm{O} \text { through }\left(\mathrm{K}_{2} \mathrm{O}\right)^{2} \text { terms in Table 5) }\right.\end{aligned}$

mass fraction of the $i^{\text {th }}$ model component in glass for the " $p c t$ " model,

$$
x_{i}^{p c t}=\sum_{i=1}^{\substack{\text { comps in } \\ \text { pod } \\ \text { pod }}} x_{i}^{p c t}=1
$$


Existing data has shown that the $r_{S i}$ values are always below the $r_{B}$ and $r_{N a}$ values due to Si solubility limits in the leaching solution (Piepel et al. 2007). Therefore, $r_{S i}$ is predicted to be less than the minimum of $r_{B}$ and $r_{N a}$ and the models for the $r_{S i}$ values are not needed.

The PCT model coefficients $\left(p_{h}^{p c t}\right)$ are listed in Table 5 (from Table 5.9 and Table 5.14 in Piepel et al.

2007). Table 5 also lists the model statistics including $\mathrm{R}^{2}$ statistics, $s_{\text {pct }}^{\text {rmseof }}$ (root mean squared error

[RMSE] for the model), and $n_{\text {pct }}^{\text {datain }}$ (number of data points used to fit the model).

For all "prop" models, the mass fraction of the $i^{\text {th }}$ model component is given as the mass fraction of the $i^{\text {th }}$ glass oxide component in glass (g oxide per g glass) for all model components except for "Others"

component, i.e.,

$$
x_{i}^{\text {prop }}=g_{i}(i \neq \text { Others })
$$

where $x_{i}^{\text {prop }}$ is the mass fraction of the $i^{\text {th }}$ model component in glass for the "prop" model and $g_{i}$ is the mass fraction of the $i^{\text {th }}$ glass oxide component in glass. The mass fraction of "Others" component is a sum of mass fractions of remaining components not included in the model components and is calculated as:

$$
x_{\text {Others }}^{\text {prop }}=1-\sum_{i=1}^{\substack{\text { comps sin } \\ n_{\text {mordel }}^{\text {mor }}-1}} g_{i} \text {. }
$$

where $x_{\text {Others }}^{\text {prop }}$ is the mass fraction of the "Others" model component in glass for the "prop" model.

\begin{tabular}{|c|c|c|}
\hline \multirow{2}{*}{ Model Term } & \multicolumn{2}{|c|}{ Model Coefficients } \\
\hline & $\ln \left(r_{\mathrm{B}}, \mathrm{g} / \mathrm{L}\right)$ & $\ln \left(r_{\mathrm{Na}}, \mathrm{g} / \mathrm{L}\right)$ \\
\hline $\mathrm{Al}_{2} \mathrm{O}_{3}$ & -31.3612 & -20.7142 \\
\hline $\mathrm{B}_{2} \mathrm{O}_{3}$ & 11.8101 & -6.5489 \\
\hline $\mathrm{CaO}$ & -13.8404 & 0.0151 \\
\hline $\mathrm{Fe}_{2} \mathrm{O}_{3}$ & -16.5948 & -8.4617 \\
\hline $\mathrm{K}_{2} \mathrm{O}$ & 7.9687 & -0.8724 \\
\hline $\mathrm{Li}_{2} \mathrm{O}$ & 83.3036 & 44.7604 \\
\hline $\mathrm{MgO}$ & -21.2343 & -13.8667 \\
\hline $\mathrm{Na}_{2} \mathrm{O}$ & 46.1599 & 9.9942 \\
\hline $\mathrm{P}_{2} \mathrm{O}_{5}$ & -19.254 & -14.5324 \\
\hline $\mathrm{SiO}_{2}$ & -1.6161 & -4.8834 \\
\hline $\mathrm{ZrO}_{2}$ & -6.6289 & -0.62 \\
\hline Others & -5.169 & 3.345 \\
\hline $\mathrm{CaO} \times \mathrm{Li}_{2} \mathrm{O}$ & -251.2654 & -232.1695 \\
\hline $\mathrm{CaO} \times \mathrm{Fe}_{2} \mathrm{O}_{3}$ & 212.0947 & 182.6191 \\
\hline $\mathrm{B}_{2} \mathrm{O}_{3} \times \mathrm{MgO}$ & 488.8612 & 437.4267 \\
\hline $\mathrm{B}_{2} \mathrm{O}_{3} \times \mathrm{Li}_{2} \mathrm{O}$ & -374.9533 & $\mathrm{~N} / \mathrm{A}$ \\
\hline $\mathrm{Na}_{2} \mathrm{O} \times \mathrm{SiO}_{2}$ & -74.3462 & N/A \\
\hline $\mathrm{B}_{2} \mathrm{O}_{3} \times \mathrm{Na}_{2} \mathrm{O}$ & $\mathrm{N} / \mathrm{A}$ & 87.6716 \\
\hline$\left(\mathrm{K}_{2} \mathrm{O}\right)^{2}$ & N/A & 315.6867 \\
\hline
\end{tabular}

Table 5. PCT Release-Composition Model Coefficients and Selected Statistical Parameters 


\begin{tabular}{|c|c|c|}
\hline Statistic & Value & Value \\
\hline $\mathrm{R}^{2}$ & 0.866 & 0.870 \\
\hline $\mathrm{R}^{2}$ Adjusted & 0.857 & 0.861 \\
\hline $\mathrm{R}^{2}$ Predicted & 0.835 & 0.840 \\
\hline $\mathrm{R}^{2}$ Validation $^{(\mathrm{a})}$ & 0.769 & 0.804 \\
\hline$S_{p c t}^{\substack{\text { rmse of } \\
\text { model }}}, \ln (\mathrm{g} / \mathrm{L})$ & 0.291 & 0.255 \\
\hline$n_{p c t}^{\text {compsin }}$ & 12 & 12 \\
\hline$n_{p c t}^{\text {termsin }}$ & 17 & 17 \\
\hline $\begin{array}{l}\text { datain } \\
n_{\text {pct }}^{\text {model }} \\
\end{array}$ & 244 & 244 \\
\hline
\end{tabular}

N/A: not applicable

(a) Based on data splitting method (see Table 5.9 and Table 5.14 in Piepel et al. 2007).

\subsubsection{Vapor Hydration Test}

The model for VHT alteration depth as a function of LAW glass composition is [Piepel et al. 2007, Equation (6.4) without the partial quadratic model terms]:

$$
\begin{aligned}
& \ln (D)=\sum_{h=1}^{\substack{\text { termsin } \\
\text { vhlodel } \\
\text { vht }}} p_{h}^{v h t} x_{h}^{v h t}=P^{v h t}
\end{aligned}
$$

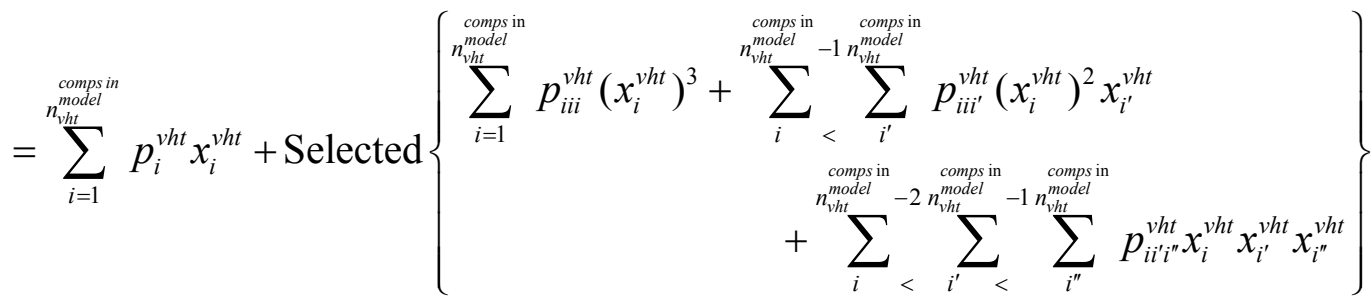

where

$$
D=\text { VHT alteration depth }(\mu \mathrm{m})
$$$$
P^{v h t}=\text { transformed VHT alteration depth }(\ln [D, \mu \mathrm{m}])
$$

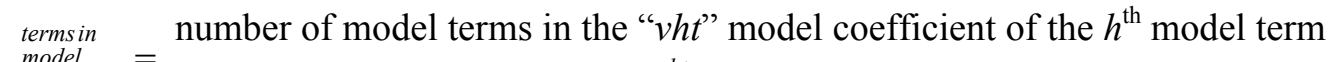
$n_{v h t}^{\text {model }}=$ for the " $v h t$ " model $(\ln [\mathrm{g} / \mathrm{L}]) p_{h}^{v h t}$ represents all forms of the model

$$
\begin{aligned}
p_{h}^{v h t}= & \text { term, i.e., } p_{i}^{v h t}, p_{i i i}^{v h t}(\text { selected }), p_{i i i^{\prime}}^{v h t}(\text { selected }), \text { and } p_{i i^{\prime} i^{\prime \prime}}^{v h t}(\text { selected }) \\
x_{h}^{v h t}= & \begin{array}{l}
\text { component mass fraction in glass or transformed value of component mass } \\
\text { fractions to the appropriate basis for the } h^{\text {th }} \text { model term in the "vht" model }
\end{array}
\end{aligned}
$$$$
n_{v h t}^{\text {compsin }} \text { model }=\text { number of model components in the " } v h t \text { " model }
$$

$$
p_{i}^{v h t}=\begin{aligned}
& \text { coefficient of the } i^{\text {th }} \text { model component for the " } v h t^{\prime} \text { model }(\ln [\mathrm{g} / \mathrm{L}]) \\
& \text { (represents } \mathrm{Al}_{2} \mathrm{O}_{3} \text { through Others terms in Table 6) }
\end{aligned}
$$


$p_{i i i}^{v h t}($ selected $)$

coefficients for the selected cubic model terms. "Selected" means that only

$p_{i i i^{\prime}}^{v \text { }}($ selected $)=$ some of the terms in curly brackets are included in the model $(\ln [\mathrm{g} / \mathrm{L}])$

$p_{i i^{\prime} i^{\prime \prime}}^{v h t}($ selected $)$ (represent $\left(\mathrm{K}_{2} \mathrm{O}\right)^{2} \times \mathrm{Na}_{2} \mathrm{O}$ through $\mathrm{B}_{2} \mathrm{O}_{3} \times \mathrm{CaO} \times \mathrm{Na}_{2} \mathrm{O}$ terms in Table 6)

$$
\begin{aligned}
& \text { mass fraction of the } i^{\text {th }} \text { model component in glass for the " } v h t \text { " model, }
\end{aligned}
$$

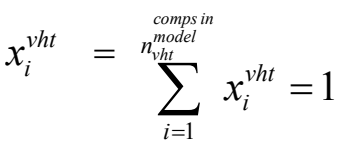

The VHT model coefficients $\left(p_{h}^{\text {vht }}\right)$ are listed in Table 6 (from Table 6.11 in Piepel et al. 2007). Table 6 also lists the model statistics including $\mathrm{R}^{2}$ statistics, $s_{v h t}^{\text {rmseof }}$ (root mean squared error [RMSE] for the model), and $n_{v h t}^{\substack{\text { datain } \\ \text { model }}}$ (number of data points used to fit the model).

Table 6. VHT Alteration Depth-Composition Model Coefficients and Selected Statistical Parameters

\begin{tabular}{|c|c|}
\hline Model Term & $\begin{array}{c}\text { Coefficient, } \\
\ln (D, \mu \mathrm{m})\end{array}$ \\
\hline $\mathrm{Al}_{2} \mathrm{O}_{3}$ & 19.5685 \\
\hline $\mathrm{B}_{2} \mathrm{O}_{3}$ & 18.5336 \\
\hline $\mathrm{CaO}$ & 38.2412 \\
\hline $\mathrm{Fe}_{2} \mathrm{O}_{3}$ & -8.4126 \\
\hline $\mathrm{K}_{2} \mathrm{O}$ & -39.3124 \\
\hline $\mathrm{Li}_{2} \mathrm{O}$ & -17.8250 \\
\hline $\mathrm{MgO}$ & -8.3068 \\
\hline $\mathrm{Na}_{2} \mathrm{O}$ & -20.6518 \\
\hline $\mathrm{SiO}_{2}$ & -0.5137 \\
\hline $\mathrm{ZrO}_{2}$ & -62.8457 \\
\hline Others & -0.4293 \\
\hline$\left(\mathrm{K}_{2} \mathrm{O}\right)^{2} \times \mathrm{Na}_{2} \mathrm{O}$ & 10138.2817 \\
\hline$\left(\mathrm{Na}_{2} \mathrm{O}\right)^{3}$ & 872.6563 \\
\hline $\mathrm{Li}_{2} \mathrm{O} \times \mathrm{Na}_{2} \mathrm{O} \times \mathrm{SiO}_{2}$ & 2139.8048 \\
\hline $\mathrm{B}_{2} \mathrm{O}_{3} \times \mathrm{CaO} \times \mathrm{Na}_{2} \mathrm{O}$ & -1943.0687 \\
\hline Statistic & Value \\
\hline $\mathrm{R}^{2}$ & 0.744 \\
\hline $\mathrm{R}^{2}$ Adjusted & 0.720 \\
\hline $\mathrm{R}^{2}$ Predicted & 0.696 \\
\hline $\mathrm{R}^{2}$ Validation $^{(\mathrm{a})}$ & 0.677 \\
\hline$s_{p c t}^{\substack{r m s e o f \\
\text { model }}}, \ln (\mathrm{g} / \mathrm{L})$ & 0.848 \\
\hline$n_{p c t}^{\text {compsin }}$ & 11 \\
\hline $\begin{array}{c}\text { termsin } \\
n_{p c t}^{\text {model }} \\
\end{array}$ & 15 \\
\hline $\begin{array}{c}\text { datain } \\
n_{\text {pct }}^{\text {model }}\end{array}$ & 165 \\
\hline
\end{tabular}

(a) Based on data splitting method (see Table 6.11 in Piepel et al. 2007). 


\subsubsection{Melt Viscosity}

The model for viscosity as a function of melt temperature and LAW melt composition can be expressed as [Piepel et al. 2007, see Equation (8.2)]:

$$
\begin{aligned}
& \ln \left(\eta_{T}\right)=\sum_{h=1}^{\substack{\text { termsin } \\
n_{v i s}^{\text {mol }} \\
\sum_{h}}} p_{h}^{v i s} x_{h}^{v i s}=P^{v i s}
\end{aligned}
$$

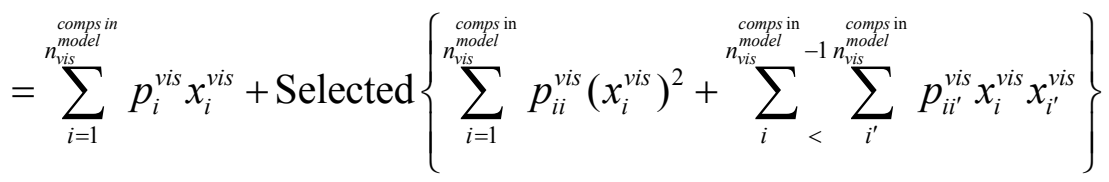

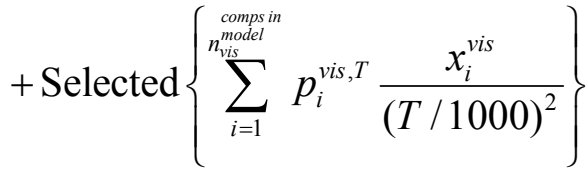

where

$$
\begin{aligned}
& \eta_{T}=\text { viscosity }(\mathrm{P}) \text { at temperature } T(\mathrm{~K}) \\
& P^{v i s}=\text { transformed viscosity at temperature } T(\mathrm{~K})(\ln [\mathrm{P}])
\end{aligned}
$$

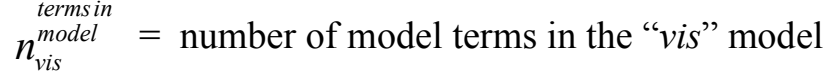

$$
\begin{aligned}
& \text { coefficient of the } h^{\text {th }} \text { model term for the "vis" model }(\ln [\mathrm{P}]) \cdot p_{h}^{v i s} \text { represents } \\
& p_{h}^{v i s}=\text { all forms of the model term, i.e., } p_{i}^{v i s}, p_{i i}^{v i s} \text { (selected), } p_{i i^{\prime}}^{v i s}(\text { selected), and } \\
& p_{i}^{v i s, T}(\text { selected }) \\
& x_{h}^{v i s}=\begin{array}{l}
\text { component mass fraction in glass or transformed value of component mass } \\
\text { fractions to the appropriate basis for the } h^{\text {th }} \text { model term in the "vis" model }
\end{array}
\end{aligned}
$$

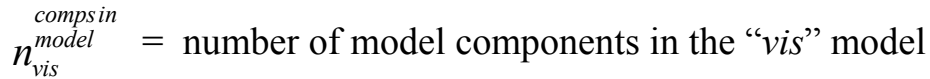

$$
\begin{aligned}
& p_{i}^{v i s}=\begin{array}{l}
\text { coefficient of the } i^{\text {th }} \text { model component in the "vis" model (represents } \mathrm{Al}_{2} \mathrm{O}_{3} \\
\text { through "Others" terms in Table 7) }
\end{array} \\
& p_{i i}^{v i s} \text { (selected) coefficients for the selected quadratic model terms in the "vis" model. } \\
& =\text { "Selected" means that only some of the terms in curly brackets are included } \\
& p_{i i}^{v i s} \text { (selected) in the model. (represent } \mathrm{Al}_{2} \mathrm{O}_{3} \times \mathrm{SiO}_{2} \text { through }\left(\mathrm{Li}_{2} \mathrm{O}\right)^{2} \text { terms in Table 7) } \\
& \text { coefficient of the selected } i^{\text {th }} \text { model component for the model terms involving } \\
& p_{i}^{v i s, T}(\text { selected })=\begin{array}{l}
\text { temperature in the "vis" model. "Selected" means that only some of the } \\
\text { terms in curly brackets are included in the model. (represents }
\end{array} \\
& \left.\mathrm{Al}_{2} \mathrm{O}_{3} /(\mathrm{T} / 1000)^{2} \text { through Others/(T/1000) }\right)^{2} \text { terms in Table 7) } \\
& \text { mass fraction of the } i^{\text {th }} \text { model component in glass for the "vis" model, } \\
& x_{i}^{v i s}=\sum_{i=1}^{\substack{\text { compsin } \\
n_{\text {visel }}^{\text {node }}}} x_{i}^{\text {vis }}=1 \\
& T=\text { absolute temperature in Kelvin }(\mathrm{K})
\end{aligned}
$$


The viscosity model coefficients $\left(p_{h}^{v i s}\right)$ are listed in Table 7 (from Table 8.8 in Piepel et al. 2007). Note that some of the model terms $\left(x_{h}^{v i s}\right)$ are temperature dependent so that the viscosity is estimated as a function of

temperature. Table 7 also lists the model statistics including $\mathrm{R}^{2}$ statistics, $s_{v i s}^{\text {rmseof }}$ (RMSE for the model), and

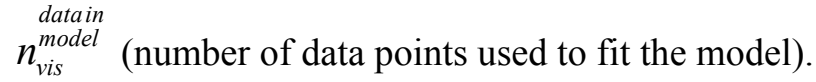

Table 7. Viscosity-Composition Model Coefficients and Selected Statistical Parameters

\begin{tabular}{|c|c|}
\hline Model Term & $\begin{array}{c}\text { Coefficient, } \\
\ln \left(\eta_{T}, P\right)\end{array}$ \\
\hline $\mathrm{Al}_{2} \mathrm{O}_{3}$ & 5.5124 \\
\hline $\mathrm{B}_{2} \mathrm{O}_{3}$ & -42.3772 \\
\hline $\mathrm{CaO}$ & -10.6445 \\
\hline $\mathrm{Fe}_{2} \mathrm{O}_{3}$ & -4.6220 \\
\hline $\mathrm{K}_{2} \mathrm{O}$ & -0.8689 \\
\hline $\mathrm{Li}_{2} \mathrm{O}$ & 10.9390 \\
\hline $\mathrm{MgO}$ & -5.6188 \\
\hline $\mathrm{Na}_{2} \mathrm{O}$ & 0.9073 \\
\hline $\mathrm{P}_{2} \mathrm{O}_{5}$ & -0.8081 \\
\hline $\mathrm{SiO}_{2}$ & 1.5575 \\
\hline $\mathrm{ZrO}_{2}$ & -12.0741 \\
\hline Others & -9.3903 \\
\hline$\left(\mathrm{B}_{2} \mathrm{O}_{3}\right)^{2}$ & 198.7360 \\
\hline$\left(\mathrm{Li}_{2} \mathrm{O}\right)^{2}$ & 133.6906 \\
\hline $\mathrm{Al}_{2} \mathrm{O}_{3} \times \mathrm{Li}_{2} \mathrm{O}$ & -136.5095 \\
\hline$(\mathrm{MgO})^{2}$ & -179.8249 \\
\hline $\mathrm{Al}_{2} \mathrm{O}_{3} /(T / 1000)^{2}$ & 24.6423 \\
\hline $\mathrm{CaO} /(T / 1000)^{2}$ & 13.7793 \\
\hline $\mathrm{Fe}_{2} \mathrm{O}_{3} /\left(T / 1000^{2}\right.$ & 15.2036 \\
\hline $\mathrm{Li}_{2} \mathrm{O} /(T / 1000)^{2}$ & -82.4815 \\
\hline $\mathrm{MgO} /(T / 1000)^{2}$ & 22.7608 \\
\hline $\mathrm{Na}_{2} \mathrm{O} /(T / 1000)^{2}$ & -14.5621 \\
\hline $\mathrm{P}_{2} \mathrm{O}_{5} /(T / 1000)^{2}$ & 24.0339 \\
\hline $\mathrm{SiO}_{2} /(T / 1000)^{2}$ & 24.4077 \\
\hline $\mathrm{ZrO}_{2} /(T / 1000)^{2}$ & 48.2286 \\
\hline Others/(T/1000) $)^{2}$ & 17.3800 \\
\hline
\end{tabular}

\begin{tabular}{||l|c||}
\hline \multicolumn{1}{|c|}{ Statistic } & Value \\
\hline $\mathrm{R}^{2}$ & 0.988 \\
\hline $\mathrm{R}^{2}$ Validation $^{(\mathrm{a})}$ & 0.983 \\
\hline $\begin{array}{c}\text { rmse of } \\
s_{\text {vis }}^{\text {model }}, \ln (\mathrm{P})\end{array}$ & 0.147 \\
\hline $\begin{array}{c}\text { compsin } \\
n_{\text {vis }}^{\text {model }}\end{array}$ & 12 \\
\hline $\begin{array}{c}\text { termsin } \\
n_{\text {vis }}^{\text {model }}\end{array}$ & 171 \\
\hline $\begin{array}{c}\text { datain } \\
n_{\text {vis }}^{\text {model }}\end{array}$ & 26 \\
\hline \hline
\end{tabular}

(b) Based on data splitting method (see Table 8.8 in Piepel et al. 2007). 


\subsubsection{Melt Electrical Conductivity}

The model for glass melt electrical conductivity as a function of melt temperature and glass composition can be expressed as [Piepel et al. 2007, see Equation (7.2)]:

$$
\begin{aligned}
& \ln \left(\varepsilon_{T}\right)=\sum_{h=1}^{\substack{\text { termssin } \\
\text { noc } \\
e c d}} p_{h}^{e c} x_{h}^{e c}=P^{e c}
\end{aligned}
$$

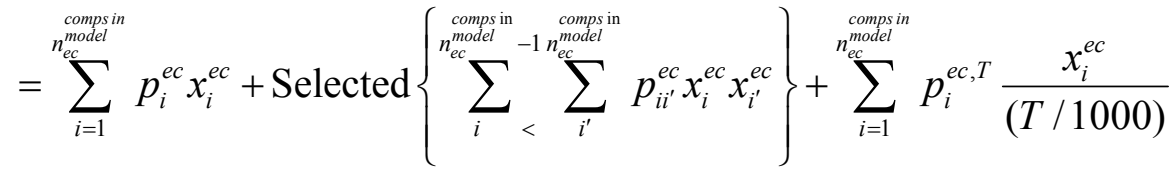

where

$$
\begin{aligned}
& \varepsilon_{T}=\text { electrical conductivity }(\mathrm{S} / \mathrm{cm}) \text { at temperature } T(\mathrm{~K}) \\
& P^{e c}=\text { transformed electrical conductivity at temperature } T(\mathrm{~K})(\ln [\mathrm{S} / \mathrm{cm}]) \\
& n_{e c}^{\substack{\text { termsin } \\
\text { model }}}=\text { number of model terms in the "ec" model } \\
& p_{h}^{e c}=\begin{array}{l}
\text { coefficient of the } h^{\text {th }} \text { model term for the "ec" model }(\mathrm{S} / \mathrm{cm}) \cdot p_{h}^{e c} \text { represents all } \\
\text { forms of the model term, i.e., } p_{i}^{e c}, p_{i i^{\prime}}^{e c}(\text { selected }), \text { and } p_{i}^{e c, T}
\end{array} \\
& x_{h}^{e c}=\begin{array}{l}
\text { component mass fraction in glass or transformed value of component mass } \\
\text { fractions to the appropriate basis for the } h^{\text {th }} \text { model term in the "ec" model }
\end{array}
\end{aligned}
$$

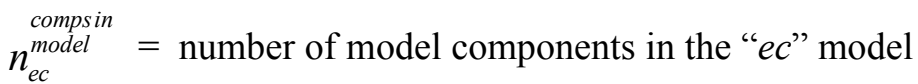

$$
\begin{aligned}
& p_{i}^{e c}=\begin{array}{l}
\text { coefficient of the } i^{\text {th }} \text { model component in the "ec" model (represents } \mathrm{Al}_{2} \mathrm{O}_{3} \\
\text { through Others terms in Table 8) }
\end{array} \\
& \text { coefficients for the selected quadratic model terms in the "ec" model. }
\end{aligned}
$$

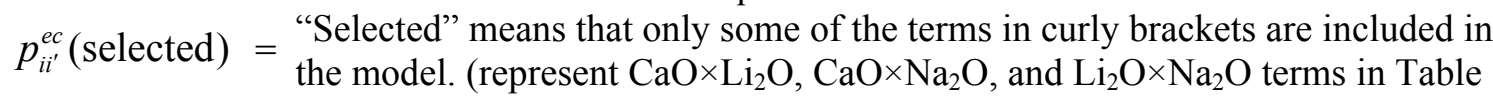
8)

coefficient of the $i^{\text {th }}$ model component for the model terms involving

$p_{i}^{e c, T}=$ temperature in the "ec" model. (represents $\mathrm{A}_{2} \mathrm{O}_{3} /(\mathrm{T} / 1000)$ through Others/(T/1000) terms in Table 8)

$x_{i}^{e c}=$ mass fraction of the $i^{\text {th }}$ model component in glass for the " $e c$ " model, $\sum_{i=1}^{\substack{c o m p s i n \\ n_{e c}^{\text {model }}}} x_{i}^{e c}=1$

$T=$ absolute temperature in Kelvin $(\mathrm{K})$

The electrical conductivity model coefficients $\left(p_{h}^{e c}\right)$ are listed in Table 8 (from Table 7.10 in Piepel et al. 2007). Note that some of the model terms $\left(x_{h}^{e c}\right)$ are temperature dependent so that the electrical 
conductivity is estimated as a function of temperature. Table 8 also lists the model statistics including $\mathrm{R}^{2}$ statistics, $s_{e c}^{\substack{\text { rmseof } \\ \text { model }}}$ (RMSE for the "ec" model), and $n_{e c}^{\begin{array}{c}\text { datain } \\ \text { model }\end{array}}$ (number of data points used to fit the "ec" model).

Table 8. Electrical Conductivity-Composition Model Coefficients and Selected Statistical Parameters

\begin{tabular}{|c|c|}
\hline Model Term & $\begin{array}{l}\text { Coefficient, } \\
\ln \left(\varepsilon_{T}, S / \mathbf{c m}\right)\end{array}$ \\
\hline $\mathrm{Al}_{2} \mathrm{O}_{3}$ & 2.3854 \\
\hline $\mathrm{B}_{2} \mathrm{O}_{3}$ & 7.9750 \\
\hline $\mathrm{CaO}$ & 5.2093 \\
\hline $\mathrm{Fe}_{2} \mathrm{O}_{3}$ & 4.3935 \\
\hline $\mathrm{K}_{2} \mathrm{O}$ & 7.6774 \\
\hline $\mathrm{Li}_{2} \mathrm{O}$ & 4.2464 \\
\hline $\mathrm{MgO}$ & 15.1675 \\
\hline $\mathrm{Na}_{2} \mathrm{O}$ & -2.0291 \\
\hline $\mathrm{SiO}_{2}$ & 3.6811 \\
\hline $\mathrm{ZrO}_{2}$ & 7.8740 \\
\hline Others & 11.2069 \\
\hline $\mathrm{CaO} \times \mathrm{Li}_{2} \mathrm{O}$ & 144.9519 \\
\hline $\mathrm{CaO} \times \mathrm{Na}_{2} \mathrm{O}$ & 79.0190 \\
\hline $\mathrm{Li}_{2} \mathrm{O} \times \mathrm{Na}_{2} \mathrm{O}$ & -130.1441 \\
\hline $\mathrm{Al}_{2} \mathrm{O}_{3} /(T / 1000)$ & -9.0593 \\
\hline $\mathrm{B}_{2} \mathrm{O}_{3} /(T / 1000)$ & -11.0983 \\
\hline $\mathrm{CaO} /(T / 1000)$ & -30.6535 \\
\hline $\mathrm{Fe}_{2} \mathrm{O}_{3} /(T / 1000)$ & -9.2407 \\
\hline $\mathrm{K}_{2} \mathrm{O} /(T / 1000)$ & -11.5299 \\
\hline $\mathrm{Li}_{2} \mathrm{O} /(T / 1000)$ & 30.4827 \\
\hline $\mathrm{MgO} /(T / 1000)$ & -25.0634 \\
\hline $\mathrm{Na}_{2} \mathrm{O} /(T / 1000)$ & 12.3822 \\
\hline $\mathrm{SiO}_{2} /(T / 1000)$ & -10.1563 \\
\hline $\mathrm{ZrO}_{2} /(T / 1000)$ & -16.5390 \\
\hline Others/(T/1000) & -17.7117 \\
\hline
\end{tabular}

\begin{tabular}{|l|c|}
\hline \multicolumn{1}{|c|}{ Statistic } & Value \\
\hline $\mathrm{R}^{2}$ & 0.951 \\
\hline $\mathrm{R}^{2}$ Validation \\
\hline $\begin{array}{c}\text { rmse of } \\
s_{\text {vis }}^{\text {model }},\end{array}, \ln (\mathrm{P})$ & 0.936 \\
\hline $\begin{array}{c}\text { compsin } \\
n_{\text {vis }}^{\text {model }}\end{array}$ & 0.151 \\
\hline $\begin{array}{c}\text { termsin } \\
n_{\text {vis }}^{\text {model }}\end{array}$ & 11 \\
\hline $\begin{array}{c}\text { datain } \\
n_{\text {model }}^{\text {modi }}\end{array}$ & 171 \\
\hline \hline
\end{tabular}

(a) Based on data splitting method (see Table 7.10 in Piepel et al. 2007).

\subsection{Uncertainties for Predicted Properties}

The use of the property-composition models introduces model prediction uncertainties $\left(U_{\text {pred }}^{\text {prop }}\right)$ and composition uncertainties ( $U_{\text {comp }}^{\text {prop }}$ ) that must be accounted for in comparing the predicted properties to their limits ( $L^{\text {prop }}$ ). The following subsections present the equations used to calculate prediction uncertainties of property-composition models and composition uncertainties, expressed in property units, resulting from uncertain values used to estimate the glass composition. The total uncertainty combining model prediction uncertainty and composition uncertainty is also presented. A block diagram in Figure 3 summarizes the 
prediction and composition uncertainties and the sources of composition uncertainties discussed in the following subsections.

Figure 3. Block Diagram Showing the Sources of Uncertainties Applied To Glass Formulation

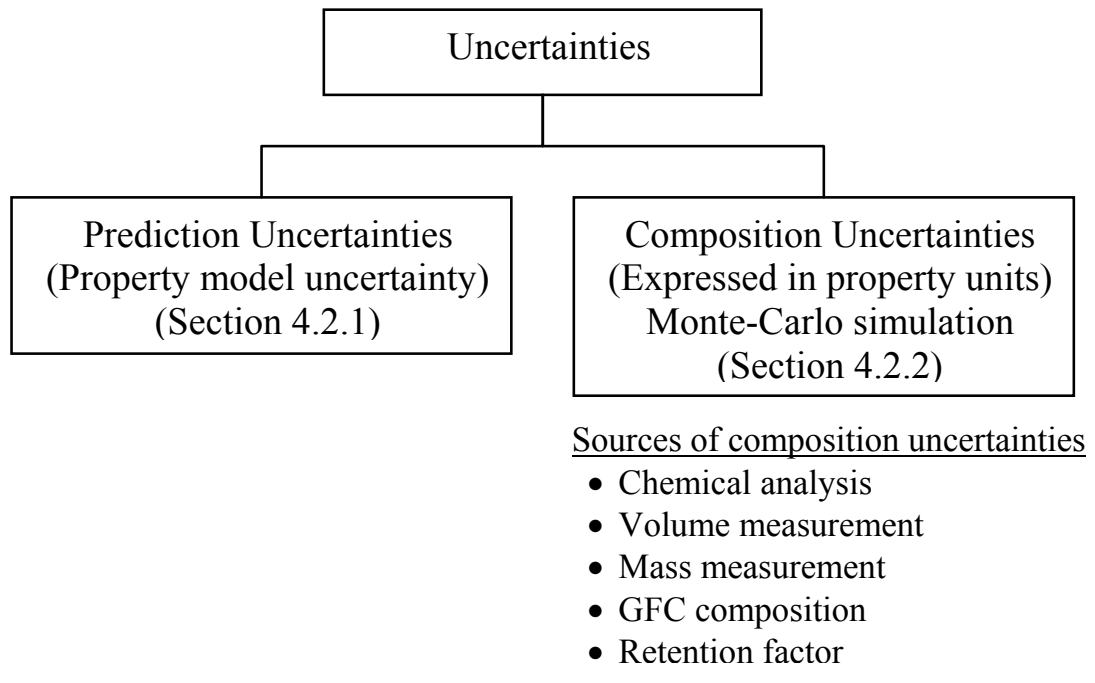

\subsubsection{Prediction Uncertainties for Predicted Properties}

A confidence level percent (CL\%) simultaneous confidence interval (SUCI) is used to account for prediction uncertainties for PCT and VHT as discussed in Piepel et al. (2005). A CL\% two-sided confidence interval (CI) is used for viscosity and electrical conductivity that have both upper and lower limits. In summary, two types of confidence interval methods are used:

- Model uncertainty half width for a CL\% simultaneous upper confidence interval (CL\% SUCI) for PCT an VHT (Piepel et al. 2005, Section 5.4.3.2)

- Model uncertainty half width for a CL\% two-sided confidence interval (CL\% two-sided CI) for viscosity and electrical conductivity

The prediction uncertainty for PCT is calculated:

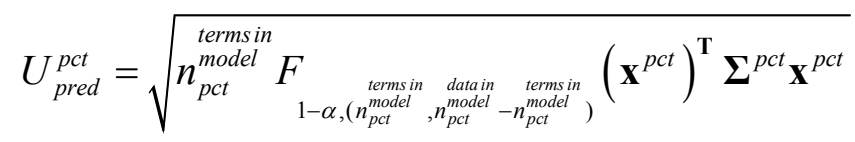

where

prediction uncertainty for PCT response (PCT-B or Na normalized

where

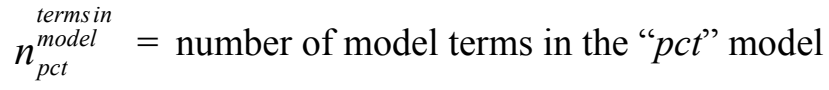

$$
\begin{aligned}
& n_{p c t}^{\text {datain }} \text { model }=\text { number of data points used to fit the " } p c t \text { " model }
\end{aligned}
$$

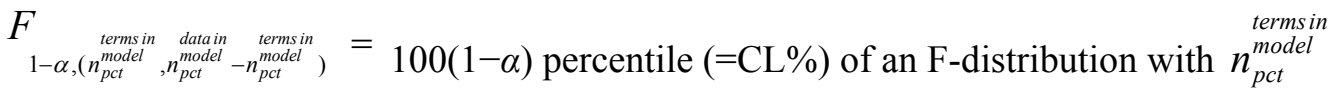




$$
\begin{aligned}
& \text { numerator degrees of freedom and } n_{p c t}^{\text {datain }} \begin{array}{c}
\text { termsin } \\
\text { model }
\end{array}-n_{p c t}^{\text {model }} \text { denominator degrees } \\
& \text { of freedom } \\
& \text { a small fraction typically less than or equal to } 0.1 \text { used to represent the } \\
& \alpha=\text { probability that a " } 100(1-\alpha) \text { confidence interval" does not contain the } \\
& \text { true value } \\
& \text { vector of } x_{h}^{p c t} \text { values for the set of } n_{p c t}^{\substack{\text { termsin } \\
\text { model }}} \text { terms, where } x_{h}^{p c t} \text { is } \\
& \mathbf{x}^{p c t}=\text { component mass fraction in glass or transformed value of component } \\
& \text { mass fractions to the appropriate basis for the } h^{\text {th }} \text { model term in the } \\
& \text { " } p c t \text { " model } \\
& \boldsymbol{\Sigma}^{p c t}=\text { variance-covariance matrix for the " } p c t \text { " model }
\end{aligned}
$$

A variance-covariance matrix, $\Sigma^{\text {prop }}$, is calculated for the estimated coefficients of a model fitted by regression according to, $\Sigma^{\text {prop }}=\left(\begin{array}{c}\text { rmseof } \\ s_{\text {prop }}^{\text {model }}\end{array}\right)^{2}\left[\left(\mathbf{X}^{\text {prop }}\right)^{\mathbf{T}} \mathbf{X}^{\text {prop }}\right]^{-1}$ where $s_{\text {prop }}^{\text {model }}$ is the RMSE for the "prop" model, and $\mathbf{X}^{\text {prop }}$ is the matrix of glass composition vectors for all the data points (glasses) used to fit the "prop" model (Piepel et al. 2008). The variance-covariance matrices for PCT models $\left(\boldsymbol{\Sigma}^{p c t B}, \boldsymbol{\Sigma}^{p c t N a}\right)$ are listed in Tables A-7 and A-8 of Appendix A.

The prediction uncertainty for VHT is calculated:

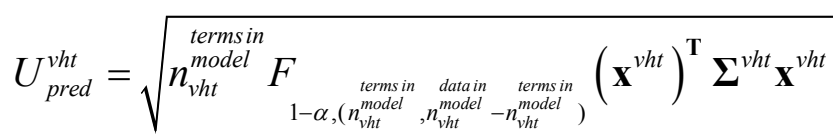

where

$$
\begin{aligned}
& U_{\text {pred }}^{v h t}=\begin{array}{l}
\text { prediction uncertainty for VHT alteration depth (in } \ln [\mu \mathrm{m}]) \text { model, } \\
\text { which is given as a model uncertainty half width for a CL\% SUCI }
\end{array}
\end{aligned}
$$

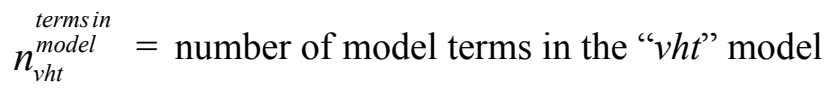

$$
\begin{aligned}
& n_{v h t}^{\text {datain }}=\text { number of data points used to fit the "vht" model }
\end{aligned}
$$

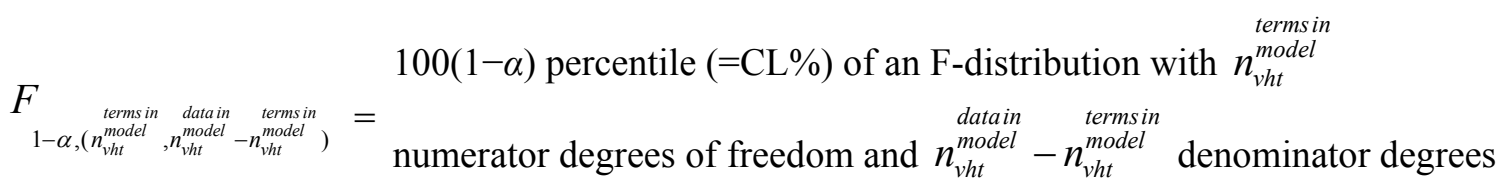

$$
\begin{aligned}
& \text { of freedom } \\
& \text { a small fraction typically less than or equal to } 0.1 \text { used to represent the } \\
& \alpha=\text { probability that a " } 100(1-\alpha) \text { confidence interval" does not contain the } \\
& \text { true value }
\end{aligned}
$$

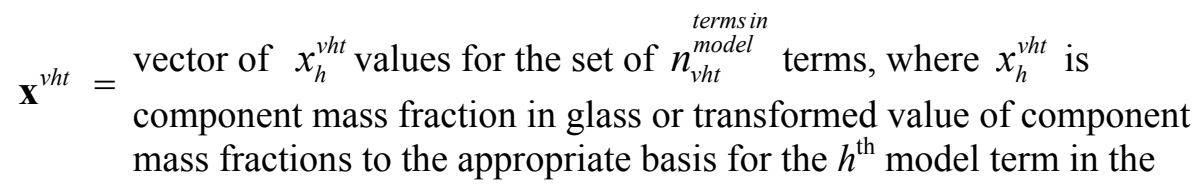




$$
\begin{gathered}
\text { "vht" model } \\
\Sigma^{v h t}=\text { variance-covariance matrix for the " } v h t " \text { model }
\end{gathered}
$$

The variance-covariance matrix for VHT model $\left(\boldsymbol{\Sigma}^{v h t}\right)$ is listed in Table A-9.

The prediction uncertainty for viscosity as a function of temperature is calculated:

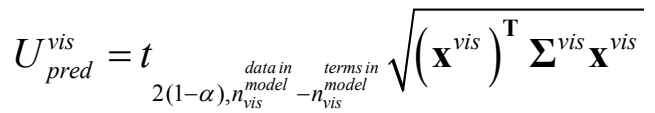

where

$$
\begin{aligned}
& U_{\text {pred }}^{v i s}=\begin{array}{l}
\text { prediction uncertainty for viscosity (in } \ln [\mathrm{P}]) \text { model, which is given as a } \\
\text { model uncertainty half width for a CL\% two-sided CI }
\end{array} \\
& n_{v i s}^{\text {datain }}=\text { number of data points used to fit the "vis" model }
\end{aligned}
$$

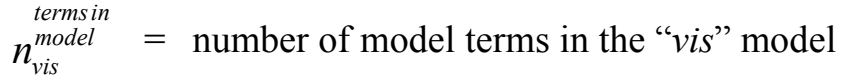

$$
\begin{aligned}
& t \quad 100(1-\alpha) \text { percentile }(=\mathrm{CL} \%) \text { of a two-sided } t \text {-distribution with }
\end{aligned}
$$

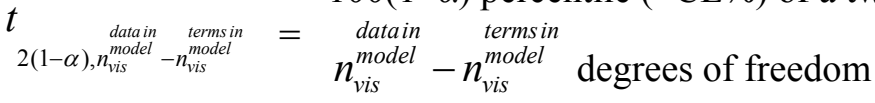

$$
\begin{aligned}
& \text { vector of } x_{h}^{v i s} \text { values for the set of } n_{v i s}^{\substack{\text { termsin } \\
\text { model }}} \text { terms, where } x_{h}^{v i s} \text { is component } \\
& \mathbf{x}^{v i s}=\text { mass fraction in glass or transformed value of component mass fractions to } \\
& \text { the appropriate basis for the } h^{\text {th }} \text { model term in the "vis" model (note that } \mathbf{x}^{\text {vis }} \\
& \text { is temperature dependent) } \\
& \boldsymbol{\Sigma}^{v i s}=\text { variance-covariance matrix for the "vis" model }
\end{aligned}
$$

The variance-covariance matrix for viscosity model $\left(\boldsymbol{\Sigma}^{v i s}\right)$ is given in Table A-10.

The prediction uncertainty for electrical conductivity as a function of temperature is calculated:

$$
U_{\text {pred }}^{e c}=t \underset{\substack{\text { datain } \\ 2(1-\alpha), n_{e c}^{\text {model }}-n_{e c}^{\text {termsin in }}}}{\sqrt{\left(\mathbf{x}^{e c}\right)^{\mathbf{T}} \boldsymbol{\Sigma}^{e c} \mathbf{x}^{e c}}}
$$

where

$$
\begin{aligned}
& \left.U_{\text {pred }}^{e c}=\text { prediction uncertainty for electrical conductivity (in } \ln [\mathrm{S} / \mathrm{cm}]\right) \text { model, which } \\
& \text { is given as a model uncertainty half width for a CL\% two-sided CI } \\
& n_{e c}^{\text {datain }}=\text { number of data points used to fit the "ec" model }
\end{aligned}
$$

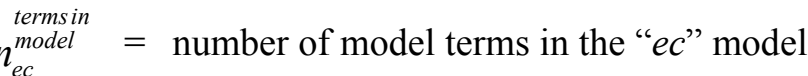

$$
\begin{aligned}
& 100(1-\alpha) \text { percentile }(=\mathrm{CL} \%) \text { of a two-sided t-distribution with }
\end{aligned}
$$

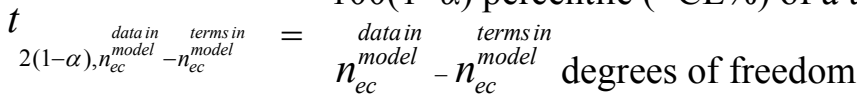

$$
\begin{aligned}
& \text { vector of } x_{h}^{e c} \text { values for the set of } n_{e c}^{\substack{\text { termsin } \\
\text { model }}} \text { terms, where } x_{h}^{e c} \text { is component } \\
& \mathbf{x}^{e c}=\text { mass fraction in glass or transformed value of component mass fractions to } \\
& \text { the appropriate basis for the } h^{\text {th }} \text { model term in the " } e c \text { " model (note that } \mathbf{x}^{e c} \\
& \text { is temperature dependent) }
\end{aligned}
$$




$$
\Sigma^{e c}=\text { variance-covariance matrix for the "ec" model }
$$

The variance-covariance matrix for electrical conductivity model $\left(\boldsymbol{\Sigma}^{e c}\right)$ is given in Table A-11.

\subsubsection{Composition Uncertainties for Predicted Properties}

Glass properties are calculated from glass composition(s) based on estimated feed composition in two different steps of algorithm process steps described in Section 3: (1) Step 1 - Formulate glass and calculate LAW transfer and dilution water volumes (more specifically, sub-steps 1b, 1c, 1e, and 1f in Figure 4) and (2) Step 3 - Calculate final glass composition and properties from waste transfer and GFC masses (sub-steps 3a and $3 b$ in Figure 4). A mass balance equation is used in Steps 1 and 3 of the algorithm to calculate the glass composition from the volume and composition of waste and mass and composition of GFCs. The composition uncertainty results from uncertain values used in the mass balance equation and is calculated using Monte Carlo simulation. The glass property models are applied to determine the impacts of the uncertain composition on property estimates.

The mass balance equations for glass formulation for the $j^{\text {th }}$ MFPV batch are given by:

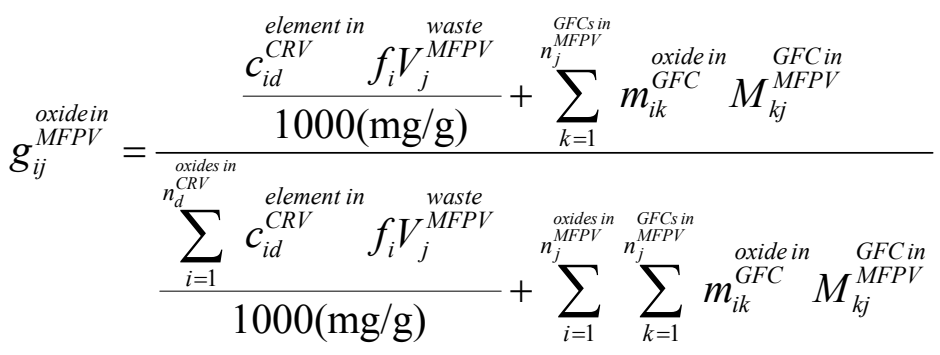

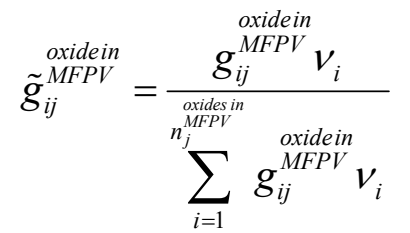

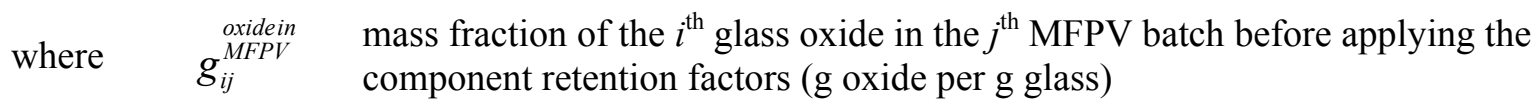

mass fraction of the $i^{\text {th }}$ glass oxide in the $j^{\text {th }}$ MFPV batch after applying the $\tilde{g}_{i j}^{\text {oxide in }}=\begin{aligned} & \text { component retention factors (g oxide per g glass), i.e., mass of } i^{\text {th }} \text { glass oxide that } \\ & \text { will remain in glass divided by the total mass of all glass oxides that will remain }\end{aligned}$ in glass

$c_{i d}^{c^{\text {element in }}}=\begin{aligned} & \text { concentration of the } i^{\text {th }} \text { element in the } d^{\text {th }} \mathrm{CRV} \text { batch associated with the } j^{\text {th }} \text { MFPV } \\ & \text { batch }(\mathrm{mg} / \mathrm{L})\end{aligned}$

$f_{i}=$ oxide conversion factor, i.e., mass of the $i^{\text {th }}$ glass oxide per mass of the $i^{\text {th }}$ element

$\stackrel{\substack{\text { waste } \\ V_{j}^{M F P V}}}{=}=$ volume of waste transferred from CRV to the $j^{\text {th }}$ MFPV (L)

$n_{j}^{M F P V}=$ number of GFCs used in the $j^{\text {th }}$ MFPV batch 


$$
\begin{aligned}
& m_{i k}^{\text {oxides in }}=\begin{array}{l}
\text { mass fraction of the } i^{\text {th }} \text { glass oxide in the } k^{\text {th }} \text { GFC (g oxide per g GFC including } \\
\text { volatiles) }
\end{array} \\
& M_{k j}^{G F P V}=\text { mass of the } k^{\text {th }} \text { GFC to add to the } j^{\text {th }} \text { MFPV batch (g) } \\
& v_{i}=\text { retention factor for the } i^{\text {th }} \text { component (fraction) (listed in Table A-3) } \\
& n_{d}^{\text {oxides in }}=\begin{array}{l}
\text { number of glass oxides tracked in the } d^{\text {th }} \text { CRV batch (currently up to 64, listed in } \\
\text { Table A-1) }
\end{array} \\
& { }_{M F P}^{\text {oxides in }} \text { - number of glass oxides tracked in the mass balance calculations for the GFCs used } \\
& n_{j}^{M F P V}=\text { in the } j^{\text {th }} \text { MFPV batch }
\end{aligned}
$$

As many of the parameters of this mass balance [Equations (12) and (13)] are uncertain, the resulting composition is uncertain. The various sources of uncertainty are briefly described in Table 9 . The complexity of the mass balance precludes an analytical solution to the uncertainties (see Piepel et al. 2005 for more discussion). Therefore, Monte Carlo analyses of uncertainties will be used after the work of Piepel et al. (2005). Monte Carlo methods are a class of computational methods that rely on repeated random sampling to compute their results. The Monte Carlo method is often used when simulating physical and mathematical systems; it is used here to estimate the distribution of possible solutions (see Section 3.4.2 of Piepel et al. (2005) for more details on Monte Carlo analyses).

Table 9. Summary of Uncertain Input Values that Are Generated for Mass Balance Equations

\begin{tabular}{||c|l|c|l||}
\hline $\begin{array}{c}\text { Input } \\
\text { Values }\end{array}$ & \multicolumn{1}{|c||}{ Sources of Uncertainty } & $\begin{array}{c}\text { Uncertainty } \\
\text { Distribution }\end{array}$ & $\begin{array}{c}\text { Uncertainty } \\
\text { Values } \\
\text { Location }\end{array}$ \\
\hline $\begin{array}{c}\text { element in } \\
c_{i d}^{C R V}\end{array}$ & $\begin{array}{l}\text { chemical analyses, mixing and sampling of the CRV } \\
\text { waste, and bias correction for mixing and sampling biases }\end{array}$ & Normal & Table A-2 \\
\hline$V_{j}^{\text {waste }}$ & $\begin{array}{l}\text { vessel volume estimates (from calibrated level } \\
\text { measurements) }\end{array}$ & Normal & Appendix D \\
\hline $\begin{array}{c}\text { oxides in } \\
m_{k}^{G F C}\end{array}$ & GFC composition certificates from vendors & PERT & Table A-4 \\
\hline $\begin{array}{c}G F C \text { in } \\
M_{k j}^{M F P V}\end{array}$ & GFC mass measurement and transfer & Normal & Appendix E \\
\hline$v_{i}$ & $\begin{array}{l}\text { amount of material lost from the melter from R\&T testing } \\
\text { and production melter mass balance testing }\end{array}$ & PERT & Table A-3 \\
\hline
\end{tabular}

For each of the uncertain input values listed in Table 9 a series of, $n^{\text {rimulation }}$, random numbers in normal or PERT distributions around the "estimated" (measured) values are generated with the standard deviations for the uncertainties. A discussion on the use of PERT distributions for GFC composition and retention factors is in Appendix G. The uncertainties for $c_{i d}^{\text {element in }}$ include the impacts of analytical uncertainties, mixing/sampling uncertainties, and uncertainties in correction for potential mixing/sampling biases, as an example for $c_{i d}^{\text {element in }}$ : 


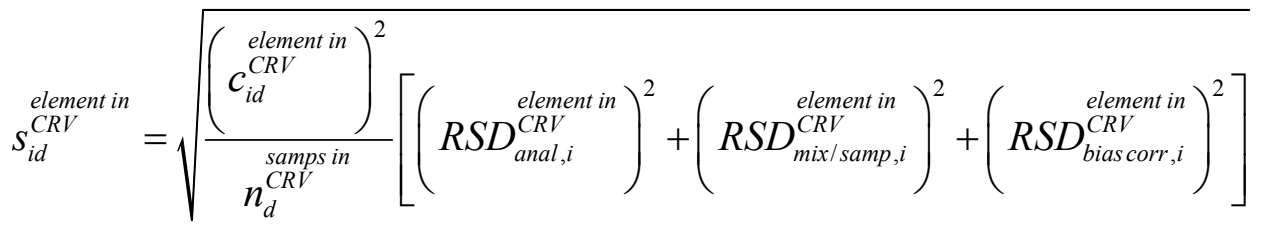

where

$$
\begin{aligned}
& S_{i d}^{{ }_{\text {element in }}^{C R V}}=\begin{array}{l}
\text { standard deviation in the concentration of the } i^{\text {th }} \text { element in the } d^{\text {th }} \text { CRV batch } \\
(\mathrm{mg} / \mathrm{L})
\end{array}
\end{aligned}
$$

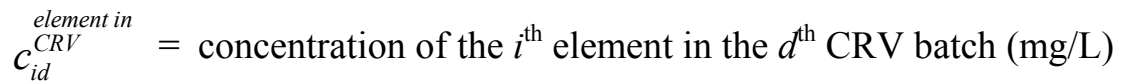

$$
\begin{aligned}
& \begin{array}{l}
R_{S D_{\text {anal }, i}^{C R V}}^{\text {element in }} \\
\text { chemical analysis in CRV batch }
\end{array}
\end{aligned}
$$

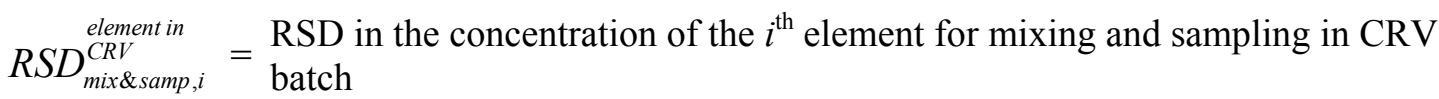

$$
\begin{aligned}
& R S D_{\text {biascorr }, i}^{\text {element in }}=\operatorname{RSD} \text { in the concentration of the } i^{\text {th }} \text { element for correction of biases in } c_{i d}^{C R V} \\
& n_{d}^{\text {sampsin }}=\text { number of samples analyzed in the } d^{\text {th }} \mathrm{CRV} \text { batch }
\end{aligned}
$$

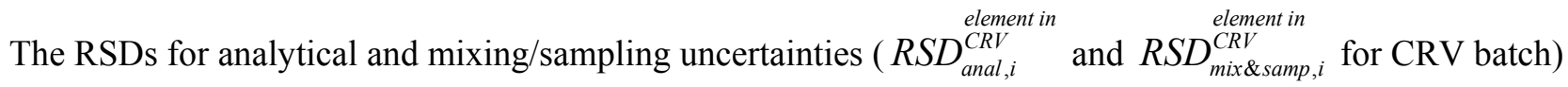
are given Table A-2. However, it was assumed that there are no biases on the analytical results used for example calculations in this report. Each of the $n^{\text {rimulation }}$ sets of values are used to calculate a glass composition with Equations (12) and (13). The resulting $n^{\text {runsulation }}$ glass compositions are then used to calculate the standard deviation in each component mass fraction in the glass.

The $n^{\substack{\text { runs of } \\ \text { simulation }}}$ glass compositions are also used to predict the properties of the glasses using the property models described in Section 4.1, yielding $n^{\substack{\text { runsim of } \\ \text { sination }}}$ predicted property values. These property values are then used to quantify the composition uncertainty half widths in property units. As long as $n^{\begin{array}{c}\text { runs of } \\ \text { simulation }\end{array}}$ is sufficient, and the random number distributions are close to the targeted distributions, excellent representations of the true composition uncertainties (in property units) are obtained (Piepel et al. 2005). Example calculations using RiskAMP ${ }^{\circledR}$ (as part of this work) and S-Plus ${ }^{\circledR}$ (Piepel et al. 2005) showed that runs of $n^{\text {simulation }} \geq 5000$ were adequate for implementing this method. The composition uncertainty is given by:

$$
U_{\text {comp }}^{\text {prop }}=Q_{C L \%}^{\text {prop }}-Q_{50 \%}^{\text {prop }} \text { or } Q_{50 \%}^{\text {prop }}-Q_{100-C L \%}^{\text {prop }}
$$

where $U_{\text {comp }}^{\text {prop }}=\begin{aligned} & \text { composition uncertainty for "prop", i.e., uncertainty in predicted "prop" due to glass } \\ & \text { composition uncertainty (in property model units) }\end{aligned}$ 


$$
\begin{aligned}
& Q_{C L \%}^{\text {prop }}=\mathrm{CL} \%[=100(1-\alpha)] \text { percentile of the distribution of } n^{\text {simulation }} \text { property values } \\
& Q_{50 \%}^{\text {prop }}=\begin{array}{c}
\text { median predicted property value or CL\% } \%=50 \% \text { percentile of the distribution of } \\
n^{\text {sumulation }} \text { property values }
\end{array}
\end{aligned}
$$

\subsubsection{CL\% Combined Confidence Interval for Predicted Properties}

Ultimately, model prediction uncertainty and composition uncertainty must be combined to obtain the total uncertainty associated with estimates of property values for LAW glass corresponding to a single MFPV batch. The method used to do this is a CL\% combined confidence interval, discussed in Sections 5.4.3.2 of Piepel et al. (2005). The formula for a CL\% upper combined confidence interval (UCCI) and lower combined confidence interval (LCCI) are given by:

$$
B_{\text {ucci }}^{\text {prop }}=P^{\text {prop }}+U_{\text {pred }}^{\text {prop }}+U_{\text {comp }}^{\text {prop }} \text { and } B_{\text {lcci }}^{\text {prop }}=P^{\text {prop }}-U_{\text {pred }}^{\text {prop }}-U_{\text {comp }}^{\text {prop }}
$$

where $\quad B_{u c c i}^{\text {prop }}=\mathrm{CL} \%$ upper combined confidence interval for "prop"

$$
\begin{aligned}
& B_{\text {lcci }}^{\text {prop }}= \begin{array}{l}
\mathrm{CL} \% \text { lower combined confidence interval for "prop" (applicable only to "vis" and } \\
\text { "ec" }
\end{array} \\
& P^{\text {prop }}=\begin{array}{l}
\text { transformed property "prop", which includes } \ln \left(r_{\mathrm{B}}, \mathrm{g} / \mathrm{L}\right), \ln \left(r_{\mathrm{Na}}, \mathrm{g} / \mathrm{L}\right), \ln (D, \mu \mathrm{m}), \ln \left(\eta_{T},\right. \\
\mathrm{P}), \text { and } \ln \left(\varepsilon_{T}, \mathrm{~S} / \mathrm{cm}\right)(\text { calculated per Section } 4.1)
\end{array} \\
& U_{\text {pred }}^{\text {prop }}=\text { model prediction uncertainty for "prop" (calculated per Section 4.2.1) } \\
& U_{\text {comp }}^{\text {prop }}=\text { composition uncertainty for "prop" (calculated per Section 4.2.2) }
\end{aligned}
$$

Note that CL\% UCCIs ( $B_{u c c i}^{\text {prop }}$ ) and LCCIs ( $B_{l c c i}^{\text {prop }}$ ) as well as model prediction uncertainty $\left(U_{\text {pred }}^{\text {prop }}\right)$ and composition uncertainty $\left(U_{\text {comp }}^{\text {prop }}\right)$ are expressed in the units of the model used to predict a property $(\ln [\mathrm{g} / \mathrm{L}]$ for PCT responses, $\ln [\mu \mathrm{m}]$ for VHT response, $\ln [\mathrm{P}]$ for melt viscosity, and $\ln [\mathrm{S} / \mathrm{cm}]$ for melt electrical condcutivity). Hence, they can be used to assess whether property constraints (as discussed in Section 4.3) are met.

\subsubsection{Assumed Levels of Uncertainties for Predicted Properties}

There are currently no mandatory requirements that direct the required confidence levels for the ILAW product or processing properties. The acceptable levels of uncertainties assumed for example calculations in this preliminary algorithm are $90 \%$ CL (i.e. $\alpha=0.1$, see Section 4.2 .1 ) for all properties, i.e., PCT, VHT, viscosity, and electrical conductivity. This $90 \% \mathrm{CL}$ used in this report is preliminary and may be revised as directed by DOE.

a small fraction typically less than or equal to 0.1 used to represent the probability that a " $100(1-\alpha)$ confidence interval" does not contain the true value. 


\subsection{Constraints}

A glass formulation is calculated to meet a set of requirements previously summarized in Table 2 in Section 1. Table 10 summarizes the glass and melt constraints for LAW, which is the same as Table 2, but with constraints expressed using symbols and units converted to those used in this report from those used in the source documents.

All the quantities for the constraints listed in Table 10 will be calculated for each MFPV batch during glass formulation (Section 5.1) to ensure that the MFPV batch meets all the waste-acceptance-related and key processing-related constraints before the batch is transferred to MFV. The calculation for each MFPV also includes the model validities described in Section 4.3.1 to ensure that all predicted properties and estimated uncertainties are valid. For canistered glass waste form, only the quantities for the waste-acceptance-related constraints (i.e., excluding viscosity and electrical conductivity from Table 10) are calculated to complete the production records (Section 5.5). The model validities are not calculated for the canistered glass waste form because they are already met for all MFPV batches that constitute the canistered glass.

Table 10. LAW Glass and Melt Constraints Used in ILAW Algorithm ${ }^{(a)}$

\begin{tabular}{|c|c|c|}
\hline Constraint Description & Constraint $^{(\mathbf{b})}$ & Source \\
\hline PCT normalized B release & $B_{u c c i}^{p c t B}<\ln [4(\mathrm{~g} / \mathrm{L})]$ & $\begin{array}{l}\text { DOE } 2000 \\
\text { (Spec. } 2.2 .2 .17 .2)\end{array}$ \\
\hline PCT normalized Na release & $B_{u c c i}^{p c t N a}<\ln [4(\mathrm{~g} / \mathrm{L})]$ & $\begin{array}{l}\text { DOE 2000 } \\
\text { (Spec. 2.2.2.17.2) }\end{array}$ \\
\hline VHT alteration depth & $B_{u c c i}^{v h t}<\ln [453(\mu \mathrm{m})]$ & $\begin{array}{l}\text { DOE 2000 } \\
\text { (Spec. 2.2.2.17.3) }\end{array}$ \\
\hline Viscosity at $1100^{\circ} \mathrm{C}$ & $B_{u c c i}^{v i s 1100} \leq \ln [150(\mathrm{P})]$ & $\begin{array}{l}\text { 24590-LAW-3PS- } \\
\text { AE00-T00001, Rev. } 4\end{array}$ \\
\hline Viscosity at $1150^{\circ} \mathrm{C}$ & $B_{l c c i}^{v i s 1150} \geq \ln [20(\mathrm{P})]$ & $\begin{array}{l}\text { 24590-HLW-RPT-RT- } \\
\text { 05-001, Rev. } 0\end{array}$ \\
\hline Viscosity at $1150^{\circ} \mathrm{C}$ & $B_{u c c i}^{v i s 1150} \leq \ln [80(\mathrm{P})]$ & $\begin{array}{l}\text { 24590-HLW-RPT-RT- } \\
\text { 05-001, Rev. } 0\end{array}$ \\
\hline $\begin{array}{l}\text { Electrical conductivity at } \\
1100^{\circ} \mathrm{C}\end{array}$ & $B_{l c c i}^{e c 1100} \geq \ln [0.1(\mathrm{~S} / \mathrm{cm})]$ & $\begin{array}{l}\text { 24590-LAW-3PS- } \\
\text { AE00-T00001, Rev. } 4\end{array}$ \\
\hline $\begin{array}{l}\text { Electrical conductivity at } \\
1200^{\circ} \mathrm{C}\end{array}$ & $B_{u c c i}^{e c 1200} \leq \ln [0.7(\mathrm{~S} / \mathrm{cm})]$ & $\begin{array}{l}\text { 24590-LAW-3PS- } \\
\text { AE00-T00001, Rev. } 4\end{array}$ \\
\hline Waste $\mathrm{Na}_{2} \mathrm{O}$ loading & $\begin{array}{c}\begin{array}{c}\text { oxidein } \\
M F P V\end{array} \\
g_{\mathrm{Na}_{2} \mathrm{O}(\mathrm{w})}>14,3 \text {, and } 10(\mathrm{wt} \%) \text { for } \\
\text { envelopes } \mathrm{A}, \mathrm{B} \text {, and C LAW, respectively }\end{array}$ & $\begin{array}{l}\text { DOE } 2000 \\
\text { (Spec. 2.2.2.2) }\end{array}$ \\
\hline Waste classification & $\begin{array}{c}<\text { Class C limits as defined in 10CFR61.55 } \\
\qquad F_{L}+k^{r a d} S S_{L}<1 \\
S F_{S}+k^{r a d} S^{S F_{S}}<1\end{array}$ & $\begin{array}{l}\text { DOE } 2000 \\
\text { (Spec. 2.2.2.8) }\end{array}$ \\
\hline${ }^{90} \mathrm{Sr}$ activity in glass & 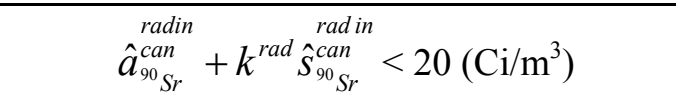 & $\begin{array}{l}\text { DOE 2000 } \\
\text { (Spec. 2.2.2.8) }\end{array}$ \\
\hline $\begin{array}{l}{ }^{137} \text { Cs activity in glass } \\
\text { (waste form compliance) }\end{array}$ & 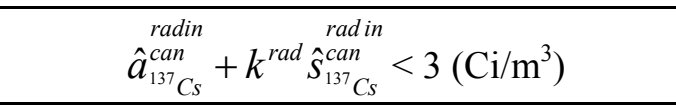 & $\begin{array}{l}\text { DOE 2000 } \\
(\text { Spec. 2.2.2.8) }\end{array}$ \\
\hline $\begin{array}{l}{ }^{137} \mathrm{Cs} \text { activity in glass } \\
\text { (system maintenance) }\end{array}$ & 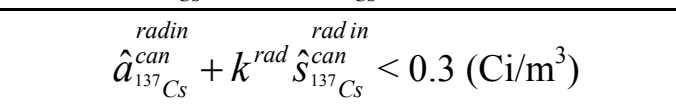 & $\begin{array}{l}\text { DOE } 2000 \text { [Section } \\
\text { C.7 (d).(1).(iii)] }\end{array}$ \\
\hline Canister surface dose rate & $\begin{array}{l}\text { dosein } \\
r^{\text {can,max }, \text { measured }} \leq 500(\mathrm{mrem} / \mathrm{h})\end{array}$ & $\begin{array}{l}\text { DOE 2000 } \\
\text { (Spec. 2.2.2.9) }\end{array}$ \\
\hline
\end{tabular}


(a) ILAW must also meet the Dangerous Waste Limitations (Contract Specification paragraph 2.2.2.20, DOE 2000) although this specification is not listed in this table because there is no calculation required to be performed by the ILAW algorithm (See Section 1).

(b) See Section 4.1.1 for justification to exclude the PCT Si release from the constraints.

\subsubsection{Constraints Related to Glass Properties and Model Validities}

For PCT, the contract (DOE 2000) Specification 2.2.2.17 requires normalized releases of Na, B, and Si to be below $2 \mathrm{~g} / \mathrm{m}^{2}$, which is equivalent to $4 \mathrm{~g} / \mathrm{L}$. The conversion from $\mathrm{g} / \mathrm{m}^{2}$ to $\mathrm{g} / \mathrm{L}$ is described in ASTM (2002). The values calculated by the model are in $\ln (\mathrm{g} / \mathrm{L})$. See Section 4.1 .1 for justification to exclude the PCT Si release from the constraints. For VHT, the contract (DOE 2000) Specification 2.2.2.17 requires that the $200^{\circ} \mathrm{C}$ alteration rate be below $50 \mathrm{~g} / \mathrm{m}^{2} / \mathrm{d}$. The values calculated by the model are the natural logarithm of the alteration layer thickness $(D)$ in $\ln (\mu \mathrm{m})$. The alteration rate limit is converted to the alteration layer thickness according to:

$$
50\left[\frac{\mathrm{g}(\text { glass })}{\mathrm{m}^{2}(\text { glass }) \times \text { day }}\right] \cdot 24(\text { day }) \cdot \frac{1}{2.65}\left[\frac{\left.\mathrm{cm}^{3} \text { (glass }\right)}{\mathrm{g}(\text { glass })}\right] \cdot\left(\frac{\mu \mathrm{m} \cdot \mathrm{m}^{2}}{\mathrm{~cm}^{3}}\right)=453 \mu \mathrm{m}
$$

because the model data were based on 24-day VHT with glasses showing a mean density of roughly $2.65 \mathrm{~g} / \mathrm{cm}^{3}$.

Although not required by the contract, key processing-related constraints on viscosity and electrical conductivity of glass melt are used to ensure successful processing of the LAW into glass at the design capacity rate. The viscosity constraint at $1100^{\circ} \mathrm{C}$ and the electrical conductivity constraints at 1100 and $1200^{\circ} \mathrm{C}$ are specified in Engineering Specification for Low Activity Waste Melters, 24590-LAW-3PS-AE00T00001, Rev. 4. The bases for glass viscosity constraint at $1150^{\circ} \mathrm{C}$ discussed for IHLW algorithm (Appendix G in 24590-HLW-RPT-RT-05-001, Rev. 0) also applies to the ILAW algorithm. The viscosity constraint is in the form of two ranges with upper and lower limits $\left(20 \mathrm{P} \leq \eta_{1150} \leq 80 \mathrm{P}\right.$ and $10 \mathrm{P} \leq \eta_{1100} \leq 150$ $\mathrm{P})$. Since viscosity increases with decreasing temperature, a glass meeting the lower viscosity limit at $1150^{\circ} \mathrm{C}$ of $20 \mathrm{P}$ cannot fail the lower viscosity limit at $1100^{\circ} \mathrm{C}$ of $10 \mathrm{P}$. Therefore, only three of the four constraints need to be calculated. The electrical conductivity constraint is in the form of a range with an upper and lower limit over a range of temperatures $\left(0.1 \mathrm{~S} / \mathrm{cm} \leq \varepsilon_{1100} \leq 0.7 \mathrm{~S} / \mathrm{cm}\right.$ and $0.1 \mathrm{~S} / \mathrm{cm} \leq \varepsilon_{1200} \leq 0.7$ $\mathrm{S} / \mathrm{cm}$ ). Only the two extremes: $0.1 \mathrm{~S} / \mathrm{cm} \leq \varepsilon_{1100}$ and $\varepsilon_{1200} \leq 0.7 \mathrm{~S} / \mathrm{cm}$ are considered because conductivity increases with temperature.

The constraints related to glass properties (PCT, VHT, viscosity, and electrical conductivity) are expressed based on UCCI or LCCI, $B_{u c c i}^{\text {prop }}$ or $B_{u c c i}^{\text {prop }}$, discussed in Section 4.2.3. The equations for property predictions and uncertainties needed to calculate the UCCI or LCCI were given in Sections 4.1 and 4.2.

The UCCI or LCCI for glass properties in Table 10 are calculated using the glass property-composition models, which are subject to the model validity constraints. Three types of model validity constraints were developed by Piepel et al. (2007): single component, glass property, and multiple components.

Table 11 summarizes the model validity range for glass composition in the MFPV batch $\left(\tilde{g}_{i j}^{\text {oxidein }}\right.$ MFV , expressed as single component concentrations after applying retention factors $\left(v_{i}\right)$.

Table 11 also includes a column for constraints already imposed by formulating glasses following the glass formulation rules discussed in Section 5.1.3. For many components the glass formulation rules limit the target concentration to a fixed value or range of values, which is within the model validity range, and therefore the model validity constraint is not applicable. The last column in specifies applicability of the 
model validity constraint depending on the model validity range and constraints predetermined by glass formulation rules.

In addition to the lower and upper bounds on the LAW glass components in Table 11, the multiple component and glass and melt property constraints restrict the composition region of validity for LAW glass property models. The glass and melt property model validity constraints given in Table 12 indirectly constrain the valid LAW glass composition region. Note that the glass and melt property model validity constraints are expressed without considering uncertainties, i.e., in terms of property values ( $P^{\text {prop }}$ ) not UCCI or LCCI ( $B_{u c c i}^{\text {prop }}$ or $B_{u c c i}^{\text {prop }}$ ). The multiple component model validity constraints given in Table 13 specify the allowable combinations of glass components in the composition region of validity for LAW glass property models. Some of these property and multiple component model validity constraints in Table 12 and Table 13 do not restrict the composition region (last columns) beyond that defined by the constraints in .

Table 11. Model Validity Range for $\tilde{g}_{i j}^{\text {oxide in }}$ (Single Component Constraints in Mass Fraction)

\begin{tabular}{|c|c|c|c|c|}
\hline \multirow{2}{*}{ Component } & \multicolumn{2}{|c|}{ Model validity } & \multirow{2}{*}{$\begin{array}{l}\text { Constraint by glass } \\
\text { formulation rules }\end{array}$} & \multirow{2}{*}{$\begin{array}{c}\text { Model validity } \\
\text { constraint } \\
\text { applicable? }\end{array}$} \\
\hline & Min & Max & & \\
\hline $\mathrm{Al}_{2} \mathrm{O}_{3}$ & 0.035 & 0.090 & Min at 0.061 & Yes \\
\hline $\mathrm{B}_{2} \mathrm{O}_{3}$ & 0.060 & 0.131 & Fixed at 0.100 & No \\
\hline $\mathrm{CaO}$ & 0 & 0.105 & Max at 0.070 & No \\
\hline $\mathrm{Cl}$ & 0 & 0.0091 & Max at 0.015 & Yes \\
\hline $\mathrm{Cr}_{2} \mathrm{O}_{3}$ & 0 & 0.0059 & Max at 0.0063 & Yes \\
\hline $\mathrm{F}$ & 0 & 0.0035 & Max at 0.049 & Yes \\
\hline $\mathrm{Fe}_{2} \mathrm{O}_{3}$ & 0 & 0.080 & Fixed at 0.055 & No \\
\hline $\mathrm{K}_{2} \mathrm{O}$ & 0 & 0.054 & Max at 0.050 & No \\
\hline $\mathrm{Li}_{2} \mathrm{O}$ & 0 & 0.058 & Max at 0.043 & No \\
\hline $\mathrm{MgO}$ & 0 & 0.050 & Max at 0.029 & $\mathrm{No}$ \\
\hline $\mathrm{Na}_{2} \mathrm{O}$ & 0.025 & 0.230 & $\begin{array}{l}\text { Min at } 0.054 \\
\text { Max at } 0.210\end{array}$ & No \\
\hline $\mathrm{P}_{2} \mathrm{O}_{5}$ & 0 & 0.030 & $\mathrm{~N} / \mathrm{A}$ & Yes \\
\hline $\mathrm{SiO}_{2}$ & 0.384 & 0.521 & $\mathrm{~N} / \mathrm{A}$ & Yes \\
\hline $\mathrm{SO}_{3}$ & 0 & 0.010 & Max at 0.0077 & No \\
\hline $\mathrm{TiO}_{2}$ & 0 & 0.030 & Fixed at 0.014 & No \\
\hline $\mathrm{ZnO}$ & 0.010 & 0.054 & Fixed at 0.035 & $\mathrm{No}$ \\
\hline $\mathrm{ZrO}_{2}$ & 0 & 0.050 & Fixed at 0.030 & No \\
\hline Sum of Minors ${ }^{(a)}$ & 0 & 0.0028 & $\mathrm{~N} / \mathrm{A}$ & Yes \\
\hline
\end{tabular}

N/A: not applicable

(a) Sum of all components not listed individually in this table 
Table 12. Model Validity Constraints for Glass and Melt Properties

\begin{tabular}{||c|c|c||}
\hline \multicolumn{1}{||}{ Property } & Constraint & $\begin{array}{c}\text { Model validity } \\
\text { constraint } \\
\text { applicable? }\end{array}$ \\
\hline PCT-B & $P^{p c t B} \leq \ln [2.7(\mathrm{~g} / \mathrm{L})]$ & Yes \\
\hline PCT-Na & $P^{p c t N a} \leq \ln [2.7(\mathrm{~g} / \mathrm{L})]$ & Yes \\
\hline VHT & $P^{v h t} \leq \ln [1100(\mu \mathrm{m})]$ & No \\
\hline Viscosity at $T\left({ }^{\circ} \mathrm{C}\right)$ & $-5.65+\frac{9259.90}{T} \leq P^{v i s, T} \leq-7.75+\frac{14705.60}{T}(\ln [\mathrm{P}])$ & No \\
\hline Electrical at $T\left({ }^{\circ} \mathrm{C}\right)$ & $3.75-\frac{7311.55}{T} \leq P^{e c, T} \leq 4.10-\frac{4869.65}{T}(\ln [\mathrm{S} / \mathrm{cm}])$ & No \\
\hline
\end{tabular}

Table 13. Model Validity Multiple Component Constraints (in Mass Fraction)

\begin{tabular}{|c|c|c|}
\hline $\begin{array}{l}\text { Composition } \\
\text { Components }\end{array}$ & Constraint & $\begin{array}{c}\text { Model validity } \\
\text { constraint } \\
\text { applicable? }\end{array}$ \\
\hline $\mathrm{Li}_{2} \mathrm{O}$ and $\mathrm{Na}_{2} \mathrm{O}$ & 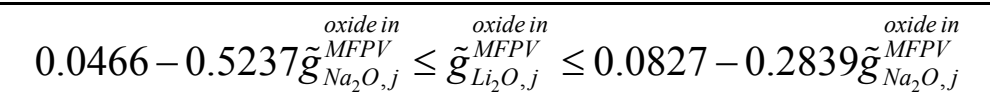 & Yes \\
\hline $\mathrm{Cr}_{2} \mathrm{O}_{3}$ and $\mathrm{P}_{2} \mathrm{O}_{5}$ & $-0.0018+0.2102 \tilde{g}_{P_{2} O_{5}, j}^{\text {oxide in }} \leq \tilde{g}_{C_{2} O_{3}, j}^{\text {oxide in }} \leq 0.0017+0.3226 \tilde{g}_{P_{2} O_{5}, j}^{M F P V}$ & Yes \\
\hline $\mathrm{Na}_{2} \mathrm{O}$ and $\mathrm{CaO}$ & 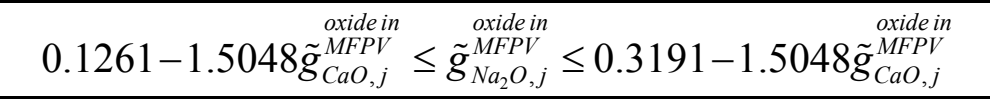 & Yes \\
\hline $\mathrm{Li}_{2} \mathrm{O}$ and $\mathrm{CaO}$ & $\tilde{g}_{\mathrm{Li}_{2} \mathrm{O}, j}^{\text {oxide in }} \leq 0.0282+0.4565 \tilde{g}_{\mathrm{CaO}, j}^{\text {oxide in }}$ & Yes \\
\hline $\mathrm{Na}_{2} \mathrm{O}$ and $\mathrm{SO}_{3}$ & 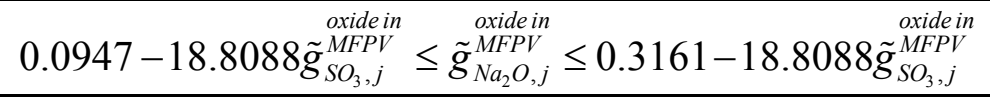 & Yes \\
\hline $\mathrm{Li}_{2} \mathrm{O}$ and $\mathrm{SO}_{3}$ & 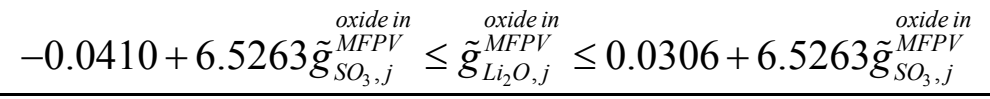 & Yes \\
\hline $\mathrm{Na}_{2} \mathrm{O}$ and $\mathrm{SiO}_{2}$ & $\begin{array}{c}\text { oxide in } \\
0.6024-1.3287 \tilde{g}_{\mathrm{SiO}_{2}, j}^{\mathrm{MFPV}} \leq \tilde{g}_{\mathrm{Na}_{2} \mathrm{Oxide}, \mathrm{in}}^{\mathrm{MFPV}} \leq 0.8050-1.3287 \tilde{g}_{\mathrm{SiO}_{2}, j}^{\text {oxide in }} \\
\end{array}$ & Yes \\
\hline
\end{tabular}

\subsubsection{Constraints Not Related to Glass Properties}

Additional constraints not related to glass properties include waste $\mathrm{Na}_{2} \mathrm{O}$ loading (Specification 2.2.2.2), radionuclide concentration [waste classification and activities of ${ }^{90} \mathrm{Sr}$ and ${ }^{137} \mathrm{Cs}$ in glass; Specification 2.2.2.8 and contract Section C.7 (d).(1).(iii)], and canister surface dose rate (Specification 2.2.2.9). The equations for these constraints will be derived later in Section 5.1.6 after introducing all the equations needed. The details of the relevant contract Specifications will also be discussed in Section 5.1.6. 


\section{Calculation Steps}

The following subsections present the detailed calculation steps discussed in Section 3. Figure 4 shows the detailed process flow diagram for algorithm Steps 1 through 5 discussed in this section.

Figure 4. Process Flow Diagram for Algorithm Steps 1 through 5

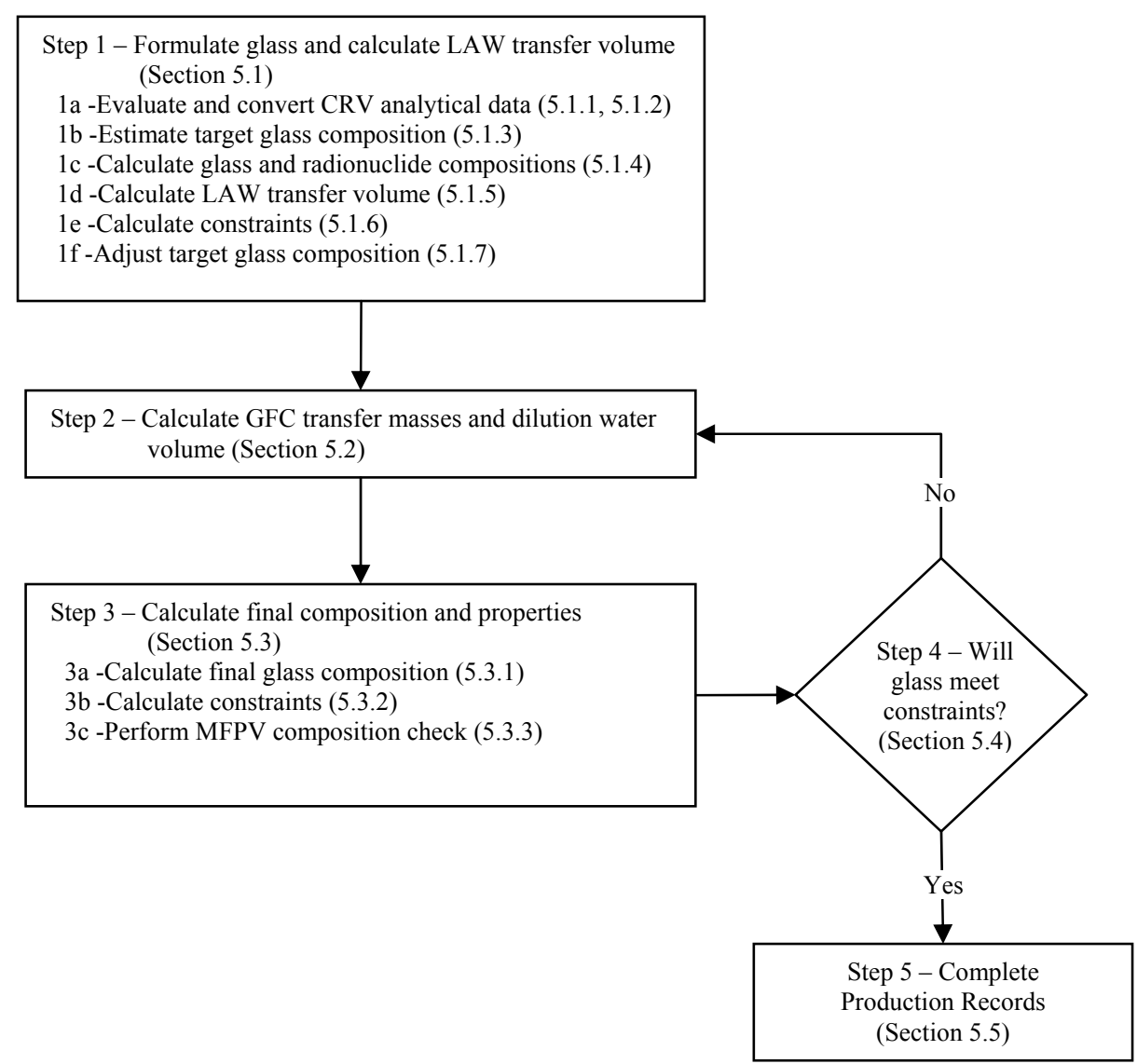

The solution of the equations described in this Section and their application to processing and product quality determination are illustrated in Section 6 for example waste compositions.

\subsection{Step 1 - Glass Formulation and Calculation of LAW Transfer Volume}

Step 1 uses the composition of CRV waste, volume of heel from the previous MFPV batch, and composition of GFCs to calculate the volume of waste to transfer from the CRV to the MFPV.

Figure 5 shows the detailed process flow diagram for algorithm Step 1 calculations. The target glass composition is formulated (5.1.3) from the waste composition data (Sections 5.1.1 and 5.1.2). The resulting target glass composition is used to further calculate Step 1 glass and radionuclide compositions (Section 5.1.4) and LAW transfer volume (Section 5.1.5). The Step 1 glass and radionuclide compositions and LAW transfer volume are then used to calculate all constraint quantities discussed in Section 4.3 (Section 5.1.6). If all constraints are met, the calculated LAW transfer volume based on the corresponding target glass 
composition is provided to the operators of the LAW Vitrification facility so that the waste from the CRV can be transferred to the MFPV. If any of the constraints is not met, the target composition is adjusted (Section 5.1.7) and calculations described in Sections 5.1.4 through 5.1.6 are performed again to formulate the glass that meets all constraints so that the waste transfer from CRV to MFPV can be initiated.

Figure 5. Process Flow Diagram for Algorithm Step 1 Calculations

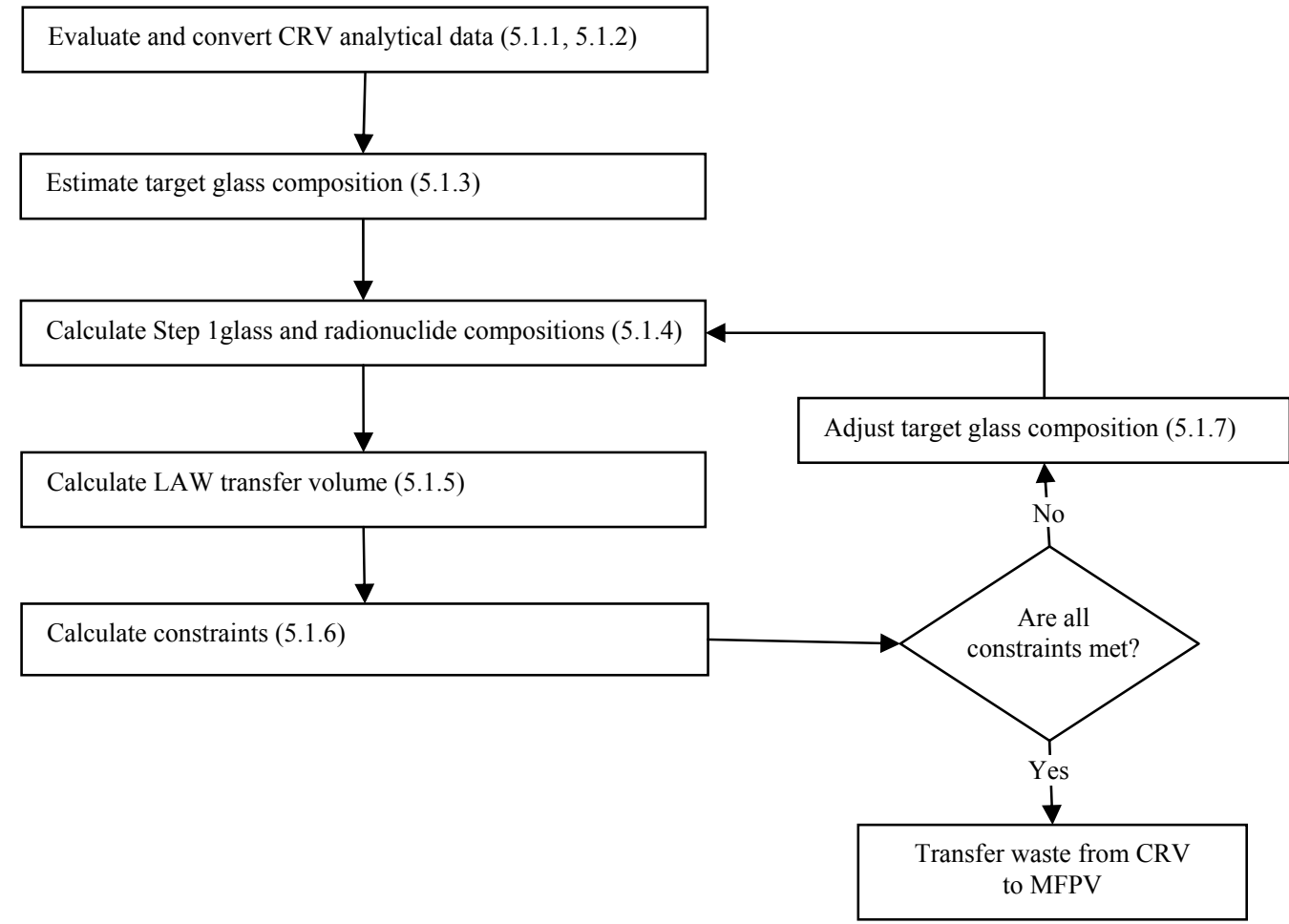

\subsubsection{CRV Analytical Data Screening and Evaluation}

The LAW is transferred from the TCP in the pretreatment facility to one of two CRVs in the LAW vitrification facility. The CRV is then sampled, and samples are analyzed at the analytical laboratory. The analytical data from the LAW CRV samples are screened and evaluated prior to calculating glass formulation. The evaluation of results from blanks and standards will be performed at the analytical laboratory according to their procedures (not yet developed) (Integrated Sampling and Analysis Requirements Document (ISARD), Dodd and Arakali 2008, 24590-WTP-PL-PR-04-0001). The analytical data will then be screened before they are averaged and entered to the LAW formulation algorithm. The data screening will include, at a minimum,

- Outlier Identification - According to current plans (System Description for LAW Concentrate Receipt Process (LCP), Taki and Hirzel 2004, 24590-LAW-3YD-LCP-00001, Rev 1) three samples will be taken from each CRV batch and analyzed for each analyte. Standard statistical tests for outlying data will be used.

- Trending Evaluation-The trending analyses are not calculated in this report. It is assumed that prepackaged statistical process control (SPC) software will be used during production.

An operator will be alerted for intervention if there are any potential concerns. 
The LAW in CRV is analyzed in two steps (Dodd and Arakali 2008): LAW 1a sample is first analyzed for major components/radionuclides and then LAW $1 \mathrm{~b}$ sample is analyzed later for minor components. The LAW $1 \mathrm{~b}$ analytical results are not required for glass formulation, but will be used if available.In the event that the LAW $1 \mathrm{~b}$ analyses are not available, the glass formulation will be performed based on LAW 1a analyses, but the production records will be completed using both LAW 1a and 1b samples.

\subsubsection{CRV Analytical Data Conversion}

The analytical data from the CRV samples will be obtained from the laboratory information management system in the form of chemical analyte concentrations and radionuclide activities per unit volume. The mass of component $i$ per unit volume of the $d^{\text {th }} \mathrm{CRV}$ batch is given by $c_{i d}^{\text {element in }}$ (in $\mu \mathrm{g} / \mathrm{mL} \equiv \mathrm{mg} / \mathrm{L}$ ). The activity of radionuclide analyte $i$ per unit volume of the $d^{\text {th }} \mathrm{CRV}$ batch is given by $R_{i d}^{\text {rad in }}$ (in $\left.\mu \mathrm{Ci} / \mathrm{mL} \equiv \mathrm{mCi} / \mathrm{L}\right)$.

Concentrations of some LAW components will be measured both chemically and radiochemically (then, element in $c_{i d}^{C R V}$ is a sum of concentrations of all isotopes). The data for such components will be compared to the method detection limits (MDL) and minimum quantification limits (MQL) for the individual analytes. If the mass of an element, $i$, (e.g., $i=$ uranium) from chemical analyses is greater than its MQL mass, then the chemical analyses results will be used in the mass balance for that element regardless of the accuracy of the radiochemical analyses results. Further, for consistency that concentration will be used to rescale the concentrations of each isotope of that element measured by radiochemistry (e.g., $i={ }^{232} \mathrm{U},{ }^{233} \mathrm{U},{ }^{234} \mathrm{U},{ }^{235} \mathrm{U} \ldots$ ) using the ratio of each isotope. If the chemical analysis result is below the MDL and the radiochemical analyses results are above the MDL, then the chemical component's concentration will be set to the sum of the concentrations of the isotopes (converted to mass units). Finally, if the chemical analysis result is between the MDL and the MQL and the radiochemical analyses results are above the MDL, then the values with the lowest associated uncertainties will be used. ${ }^{(3)}$ For analytes with concentrations reported as less than the $M D L$, a concentration of zero will be used in the mass balance equations. All components with concentrations reported below the MQL but above the MDL will use analytical results with the appropriate flags assigned to them.

Multiple samples (currently three samples) are collected and analyzed for each CRV batch. The algorithm uses the average concentrations from multiple samples analyzed ${ }^{(4)}$. As discussed in Section 1, each CRV batch will generate roughly from 3.5 to $15 \mathrm{MFPV}$ batches depending on sodium molarity of waste and waste loading in glass. The CRV waste becomes diluted by the addition of two types of flush water added to the CRV. The sample line flush water is added after samples are taken from CRV, which is performed once per each CRV batch. The CRV-MFPV line flush is performed after each waste transfer. Then, the composition of CRV batch after accounting for the flush water additions is given as:

$$
c_{i d m}^{\text {element in }}=\bar{c}_{i d}^{\text {element in }} \lambda_{d m}
$$

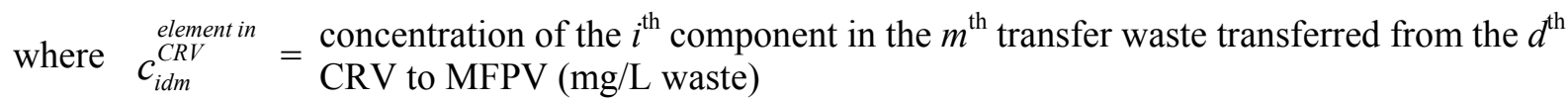

(3) This analytical data "sorting" is done outside of the ILAW formulation algorithm, i.e., the chemical and radiochemical data are "sorted" before they are entered into the algorithm.

(4) The averaging of analytical data is performed outside of the ILAW formulation algorithm and the average values are entered into the algorithm. 


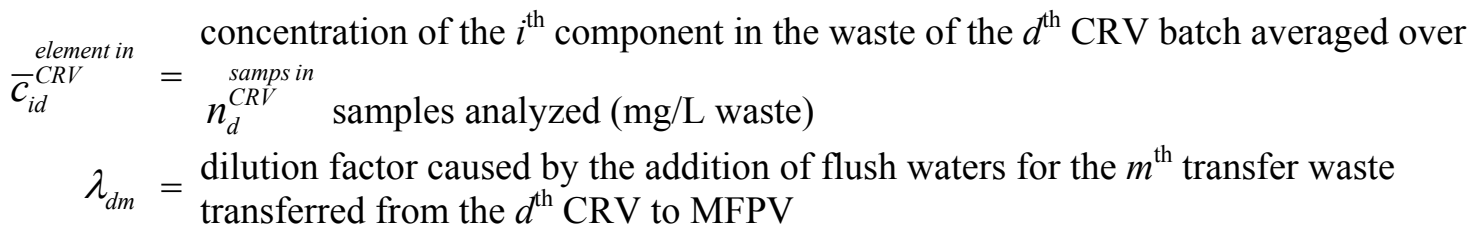

The dilution factor is calculated from:

$$
\begin{aligned}
& \lambda_{d m}=\frac{V_{d}^{\text {working }}}{V_{d}^{\text {working }}{ }^{\text {sampflush }}+V_{d}^{C R V}} \quad \text { for } m=1 \\
& \lambda_{d m}=\lambda_{d, m-1} \frac{\begin{array}{c}
\text { current } \\
V_{d, m-1}^{C R V}
\end{array}}{\operatorname{current}_{d, m-1}^{C R V}+V_{d, m-1}^{\text {transflush }}} \text { for } m \geq 2
\end{aligned}
$$

where $\underset{V^{C R V}}{\text { working }}=$ working volume of the $d^{\text {th }} \mathrm{CRV}$ measured before the sampling line flush water is $V_{d}^{C R V} \quad$ added to the CRV (L). The nominal value of $V^{\text {working }}$ is $50,085 \mathrm{~L}$ (Table 1). The CRV working volume for each CRV batch includes the CRV heel volume $\left(V_{d}^{\text {hel }}{ }^{\text {CR }}\right)$ required for normal operation plus the CRV batch volume $\left(V_{d}^{\text {batch }}\right)$ transferred from TCP.

$V_{d}^{\text {sampfflush }}=$ volume of the sampling line flush water used for the $d^{\text {th }} \mathrm{CRV}$ batch (L) dilution factor caused by the addition of flush waters for the $m-1^{\text {th }}$ transfer waste $\lambda_{d, m-1}=$ transferred from the $d^{\text {th }} \mathrm{CRV}$ batch to MFPV (dilution factor for the waste transferred previously) $\underset{d, m-1}{V_{\text {current }}^{C R V}}=$ current volume of the $d^{\text {th }} \mathrm{CRV}$ measured after the $m-l^{\text {th }}$ waste transfer to MFPV (L) $\begin{aligned} & { }_{\text {transflush }}^{C R V} \\ & V_{d, m-1}^{C R V}\end{aligned}=\begin{aligned} & \text { volume of the CRV-MFPV transfer line flush water used for the } d^{\text {th }} \text { CRV after the } m \text { - } \\ & I^{\text {th }} \text { waste transfer to MFPV (L) }\end{aligned}$ The waste transfer from the CRV will continue until the volume of remaining current CRV waste $\left(\begin{array}{c}\text { current } \\ V_{d, m-1}^{C R V}\end{array}\right)$ is less than the volume required for next transfer (assuming the same volume used in the previous transfer) plus nominal CRV heel volume (15581 L, see Table 1). The waste from the other CRV will be used if

$$
\begin{gathered}
\text { current } \\
V_{d, m-1}^{C R V}
\end{gathered} V_{d, m-1}^{\text {transwaste }}+V^{\text {heel }}
$$

where $\quad V_{d, m-1}^{c \text { current }}=$ current volume of the $d^{\text {th }}$ CRV measured after the $m-I^{\text {th }}$ waste transfer to MFPV (L) 


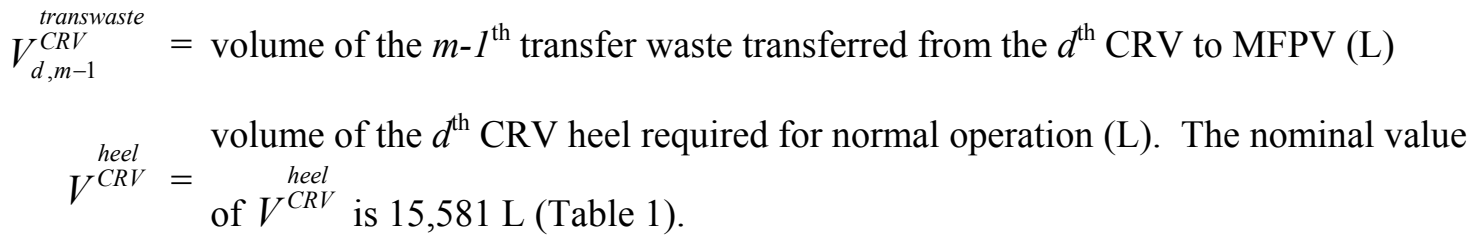

The ILAW formulation algorithm uses waste compositions in the form of mass fractions of glass oxides. The analytical data are converted from $\mathrm{mg} / \mathrm{L}$ to the mass fraction of a glass oxide by:

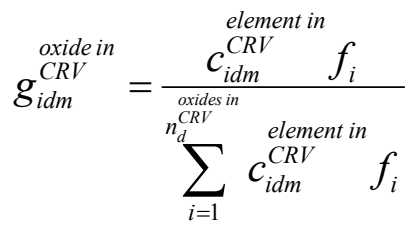

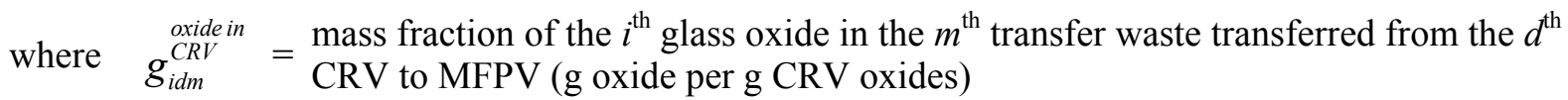

$f_{i}=\begin{aligned} & \text { oxide conversion factor, i.e., mass to the } i^{\text {th }} \text { glass oxide per mass of the } i^{\text {th }} \text { element, } \\ & \text { listed in Table A-1 (unitless) }\end{aligned}$

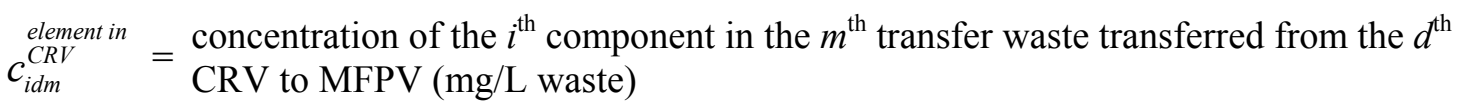
$n_{d}^{\text {oxidesin }}=$ number of glass oxides tracked in the $d^{\text {th }} \mathrm{CRV}$ batch

The concentration of total glass oxides in the waste is given by:

$$
C_{d m}^{C R V}=\frac{\sum_{i=1}^{\substack{C R \text { des in } \\ n_{d}^{C R V}}} c_{i d m}^{\substack{\text { oxdesin } \\ \text { element in }}} f_{i}}{1000(\mathrm{mg} / \mathrm{g})}
$$

where $C_{d m}^{\text {oxides in }}$ is the concentration of total glass oxides in the $m^{\text {th }}$ transfer waste transferred from the $d^{\text {th }}$ CRV to MFPV (g oxides per L waste) and the remaining notations are as defined in Equation (21).

A chemical component will be carried through the mass balance equations for each of the elements present in the radiochemical analyses. The concentration of each individual isotope, however, will be calculated on an activity per mass of glass basis.

For radionuclides, specific activities $\left(A_{i}\right)$ are used to convert radionuclide activities to masses for inclusion in the mass balance:

$$
c_{i d m}^{\text {element in }}=\frac{\bar{R}_{i d}^{C R V} \lambda_{d m}^{\text {rad in }}}{A_{i}}
$$


where

$$
\begin{aligned}
& c_{i d m}^{\text {element in }}=\begin{array}{l}
\text { concentration of the } i^{\text {th }} \text { radionuclide in the } m^{\text {th }} \text { transfer waste transferred from the } d^{\text {th }} \\
\text { CRV to MFPV }(\mathrm{mg} / \mathrm{L})
\end{array} \\
& \bar{R}_{i d}^{\text {rad in }}=\begin{array}{l}
\text { activity (per unit volume) of the } i^{\text {th }} \text { radionuclide in the waste of the } d^{\text {th }} \mathrm{CRV} \text { averaged } \\
\text { over } n_{d}^{C R V} \text { samples analyzed }(\mathrm{mCi} / \mathrm{L})
\end{array} \\
& \lambda_{d m}=\text { dilution factor for the } m^{\text {th }} \text { transfer waste transferred from the } d^{\text {th }} \mathrm{CRV} \text { to MFPV. } \\
& A_{i}= \text { specific activity of the } i^{\text {th }} \text { radionuclide, listed in Table A-1 }(\mathrm{Ci} / \mathrm{g})
\end{aligned}
$$

The resulting $c_{i d m}^{\text {element in }}$ values are converted to mass fractions of glass oxides by Equation (21). The mass fractions of glass oxides in waste are then used for subsequent calculations. The radionuclides that have nonradioactive elements analyzed chemically are already included in the chemical components.

For all radionuclides, the average activity per unit volume of the CRV batch $\left(\bar{R}_{\text {id }}^{\text {rad in }}\right.$ in $\left.\mathrm{mCi} / \mathrm{L}\right)$ is converted to the activity per unit mass of glass oxides in waste by

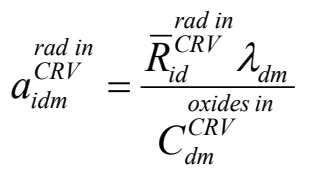

where $a_{i d m}^{C R V}$ is the specific activity of the $i^{\text {th }}$ radionuclide in the $m^{\text {th }}$ transfer waste transferred from the $d^{\text {th }}$ CRV to MFPV (mCi/g oxides) and the remaining notations are as previously defined.

\subsubsection{Estimation of Target Glass Composition}

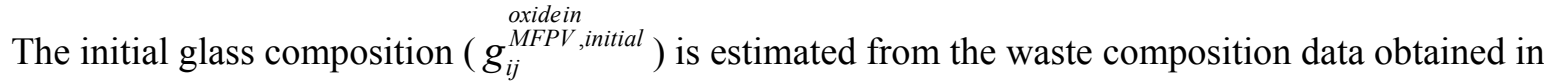
Sections 5.1.1 and 5.1.2 using the methods defined by Muller et al. (2004) and supplemented by CCN 150795. The glass formulation rules generate a unique glass composition based on waste composition, which calculates the maximum $\mathrm{Na}_{2} \mathrm{O}$ concentration from waste in LAW glass that satisfies all the rules. The basis of the method by Muller et al. (2004) is interpolation using previous successful glass compositions. Fifteen glass compositions that were formulated by Vitreous State Laboratory for the immobilization of a full range of Hanford LAW streams are the basis for interpolation. Each of these glasses met all glass quality and processability constraints and was successfully processed at increasing scales, up to the Duratek pilot melter. These glasses not only met the numerical constraints (Table 2), but were also successfully processed at pilot scale; thereby demonstrating that non-constrained variables were appropriate for largescale, continuous, production. The key parameters for this method include the mass fractions of $\mathrm{Na}_{2} \mathrm{O}, \mathrm{SO}_{3}$, and $\mathrm{K}_{2} \mathrm{O}$ in the CRV waste transferred to MFPV. These glass formulation rules were supplemented by two sets of additional rules described in $\mathrm{CCN} 150795$, with one set based on the mass fractions of $\mathrm{Cl}, \mathrm{F}$, and $\mathrm{SO}_{3}$ and the other based on the mass fractions of $\mathrm{Cr}_{2} \mathrm{O}_{3}, \mathrm{~K}_{2} \mathrm{O}$, and $\mathrm{P}_{2} \mathrm{O}_{5}$ in the CRV waste transferred to MFPV. 
The first step in this method (Muller et al. 2004) determines the acceptable concentration of $\mathrm{Na}_{2} \mathrm{O}$ in the final glass $\left(\begin{array}{c}\text { oxide in } \\ \mathrm{Na}_{2} \mathrm{O}, j\end{array}\right)$ by the following rules (Figure 6 through Figure 8$)$ (concentration in target ${ }^{(5)} \mathrm{wt} \%$ in glass):

$\underline{\mathrm{Na}_{2}} \underline{\mathrm{O}-\mathrm{SO}_{3}}-\mathrm{K}_{2} \mathrm{O}$ rules (Muller et al. 2004) (concentration in target wt $\%$ in glass)

1. $\mathrm{Na}_{2} \mathrm{O}$ must be at or below $21 \mathrm{wt} \%$ in glass.

2. $\mathrm{Na}_{2} \mathrm{O}$ must be at or below the value of $35.875 \mathrm{wt} \%$ minus 42.5 times $\mathrm{SO}_{3} \mathrm{wt} \%$ in glass.

3. $\mathrm{SO}_{3}$ must be at or below $0.77 \mathrm{wt} \%$ in glass.

4. $\mathrm{Na}_{2} \mathrm{O}$ plus 0.66 times $\mathrm{K}_{2} \mathrm{O}$ must be at or below $21.5 \mathrm{wt} \%$ in glass. ${ }^{(6)}$

$\underline{\mathrm{Cl}-\mathrm{F}-\mathrm{SO}_{3}}$ rules (CCN 150795) (concentration in target $\mathrm{wt} \%$ in glass)

5. $\mathrm{Cl}$ plus 0.3 times $\mathrm{F}$ must be at or below the value $1.4656 \mathrm{wt} \%$ minus 2.1111 times $\mathrm{SO}_{3} \mathrm{wt} \%$ in glass if $\mathrm{SO}_{3}$ in glass is at or below $0.59 \mathrm{wt} \%$.

6. $\mathrm{Cl}$ plus 0.3 times $\mathrm{F}$ must be at or below $0.22 \mathrm{wt} \%$ in glass if $\mathrm{SO}_{3}$ in glass is above $0.59 \mathrm{wt} \%$.

$\underline{\mathrm{Cr}_{2}} \underline{\mathrm{O}_{3}}-\underline{\mathrm{K}_{2}} \underline{\underline{\mathrm{O}}-\mathrm{P}_{2}} \underline{\mathrm{O}_{5}}$ rules $(\mathrm{CCN} 150795)$ (concentration in target $\mathrm{wt} \%$ in glass)

7. $\mathrm{Cr}_{2} \mathrm{O}_{3}$ in glass must be at or below $0.63 \mathrm{wt} \%$ and $\mathrm{K}_{2} \mathrm{O}$ in glass must be at or below and $5 \mathrm{wt} \%$.

8. If $\mathrm{P}_{2} \mathrm{O}_{5}$ in glass is below $2.79 \mathrm{wt} \%$, and $\mathrm{K}_{2} \mathrm{O}$ in glass is at or below $0.54 \mathrm{wt} \%, \mathrm{Cr}_{2} \mathrm{O}_{3}$ in glass must be at or below $0.63 \mathrm{wt} \%$.

9. If $\mathrm{P}_{2} \mathrm{O}_{5}$ in glass is below $2.79 \mathrm{wt} \%$ and $\mathrm{K}_{2} \mathrm{O}$ in glass is between $0.54 \mathrm{wt} \%$ and $5 \mathrm{wt} \%, \mathrm{Cr}_{2} \mathrm{O}_{3}$ in glass must be at or below $0.08 \mathrm{wt} \%$.

The preliminary minimum $\mathrm{Na}_{2} \mathrm{O}$ mass fractions in glass from the $\mathrm{Na}_{2} \mathrm{O}-\mathrm{SO}_{3}-\mathrm{K}_{2} \mathrm{O}$ rules $\left(g_{\mathrm{Na}_{2} \mathrm{O}, j}^{M F P V \text {, pre-1 }}\right)$ and

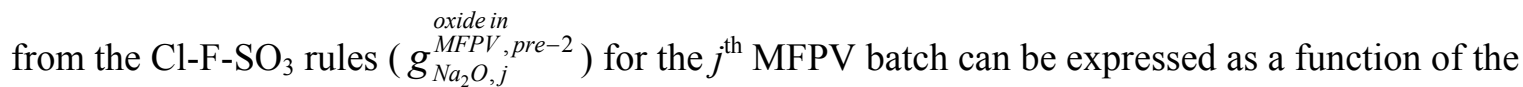
component mass fractions in the CRV waste:

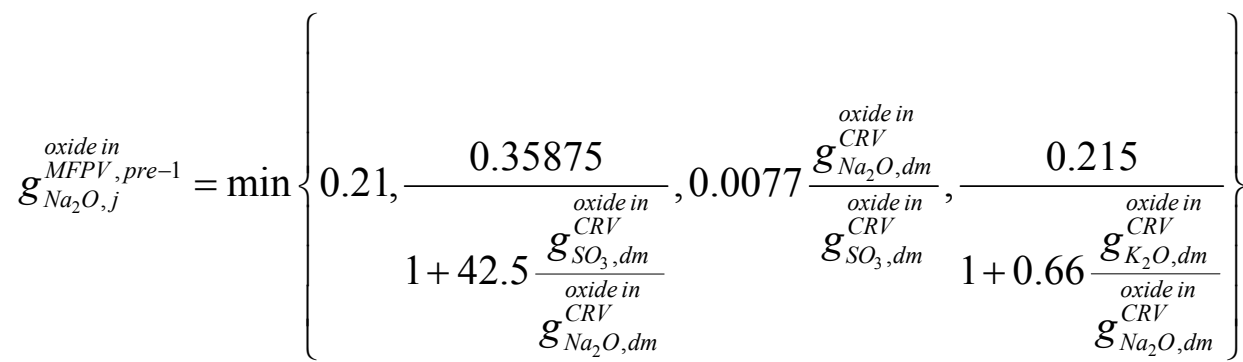

(5) The term "target" was used to note that the concentrations are based on assumed $100 \%$ retention in glass.

(6) The 0.66 scale factor is meant to adjust for differences in molecular masses of $\mathrm{Na}_{2} \mathrm{O}$ and $\mathrm{K}_{2} \mathrm{O}$. 


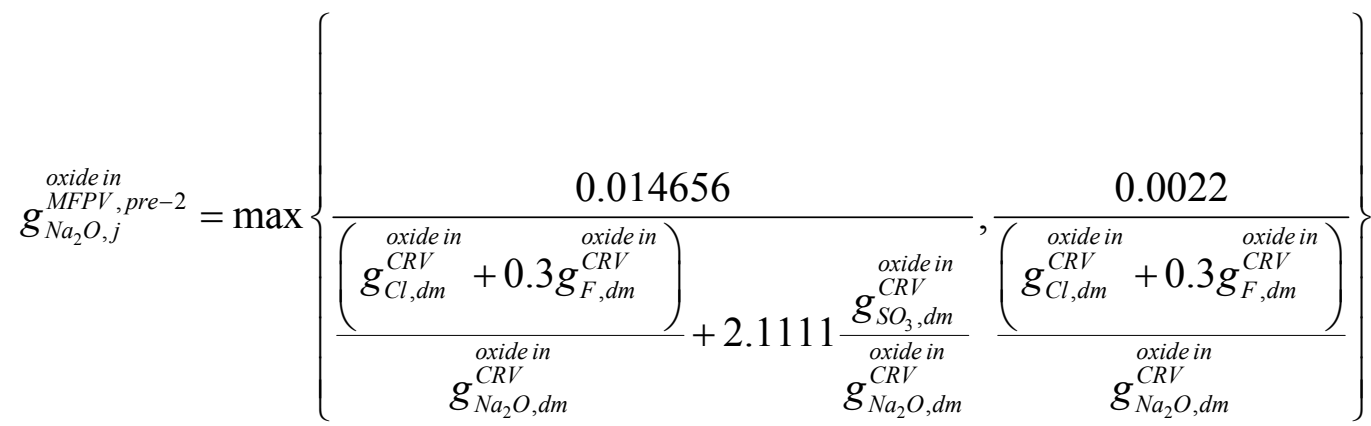

where $g_{i d m}^{\text {oxidein }}$ is the mass fraction of the $i^{\text {th }}$ glass oxide in the $m^{\text {th }}$ transfer waste transferred from the $d^{\text {th }} \mathrm{CRV}$ to MFPV (g oxide per g CRV oxides), which supplies waste to the $j^{\text {th }}$ MFPV batch. The preliminary

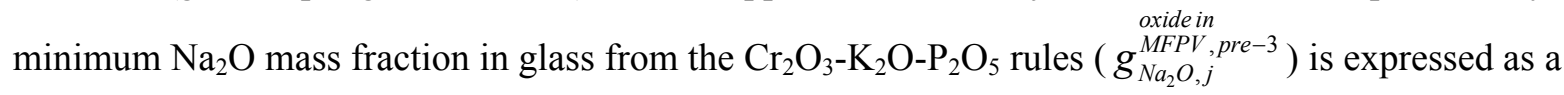
function of component mass fractions following the logics defined by the rules 7 through 9 :

$$
\begin{aligned}
& g_{\mathrm{Na}_{2} \mathrm{O}, \mathrm{j}}^{\text {oxide in }}
\end{aligned}
$$

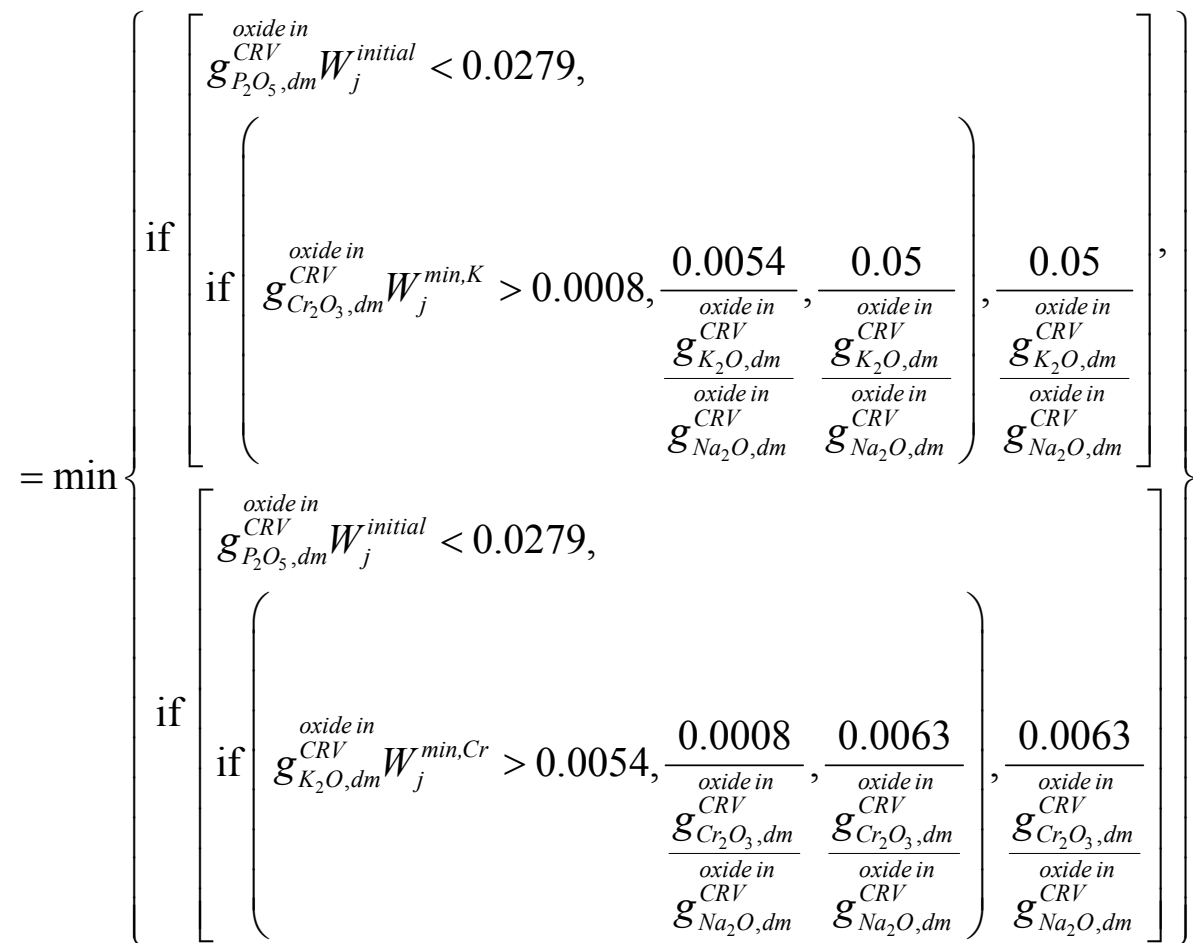

where $W_{j}^{\text {initial }}$ is the initial waste loading for the $j^{\text {th }}$ MFPV batch determined from the $\mathrm{Na}_{2} \mathrm{O}-\mathrm{SO}_{3}-\mathrm{K}_{2} \mathrm{O}$ and

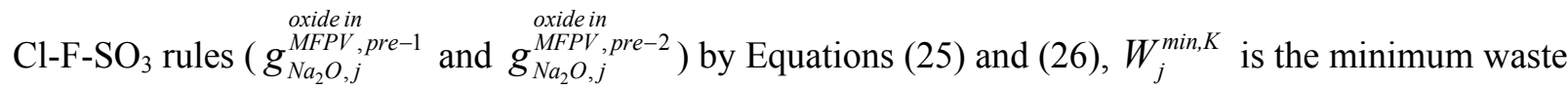

(7) The output of if(A, B, C) function is given as: if(A, B, C) equals B if the logical test $\mathrm{A}$ is true and if(A, B, C) equals $\mathrm{C}$ if the logical test $\mathrm{A}$ is false. 
loading for the $j^{\text {th }}$ MFPV batch when $0.54 \mathrm{wt} \%$ of $\mathrm{K}_{2} \mathrm{O}$ limit is assumed, and $W_{j}^{\min , C r}$ is the minimum waste loading for the $j^{\text {th }}$ MFPV batch when $0.08 \mathrm{wt} \%$ of $\mathrm{Cr}_{2} \mathrm{O}_{3}$ limit is assumed, which are calculated as:
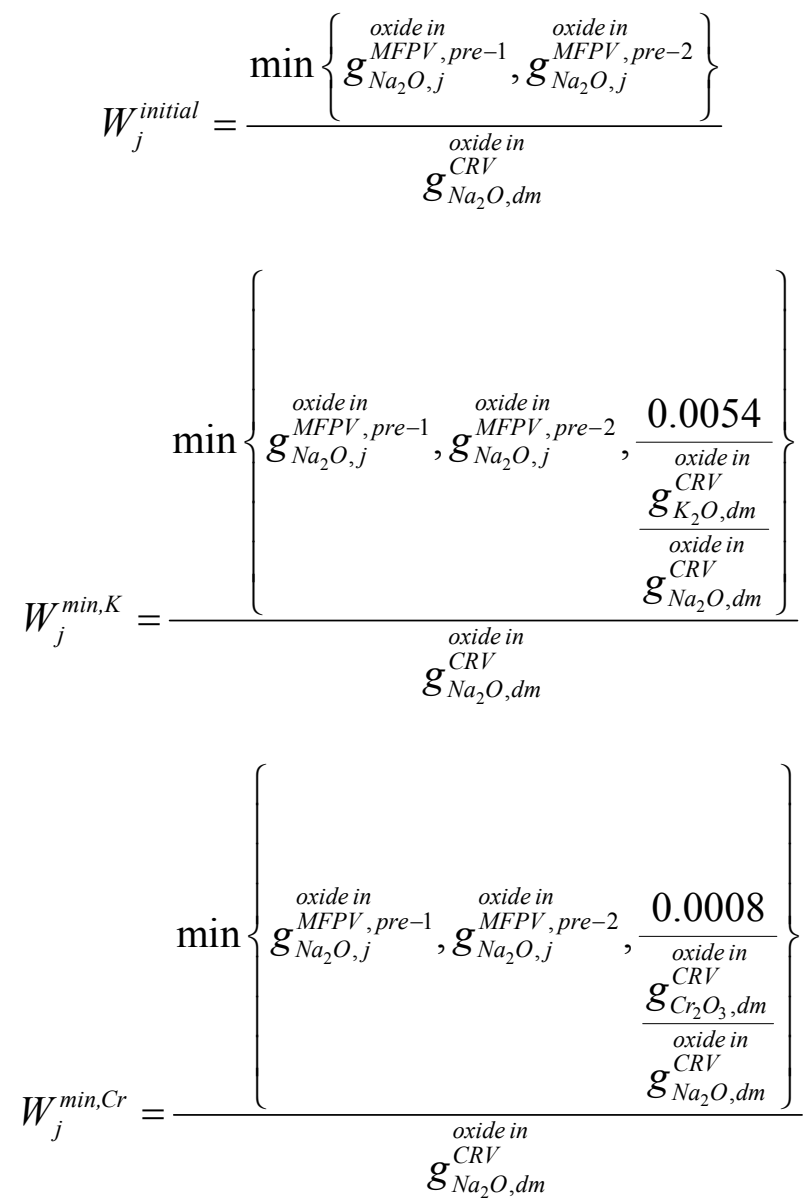

Then, the preliminary minimum $\mathrm{Na}_{2} \mathrm{O}$ mass fraction in glass determined from all the formulation rules is given as:

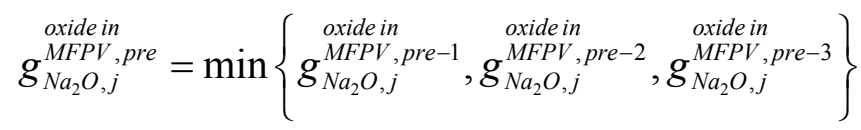

The waste loading is defined as the mass fraction of glass that originated from the material in the CRV. The initial waste loading $\left(G_{j}^{\text {wastein }}\right.$,initial $)$ is calculated according to:

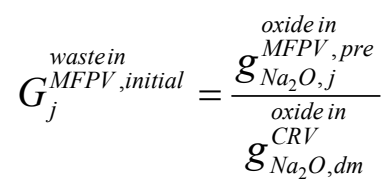

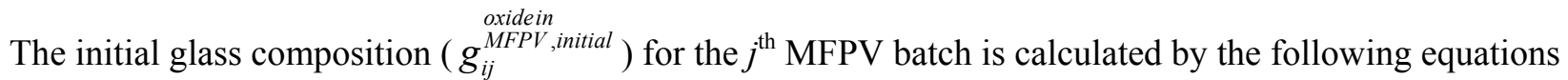
(Muller et al. 2004): 


$$
\begin{aligned}
& g_{A l_{2} \mathrm{O}_{3}, j}^{\substack{\text { oxidein } \\
M F P V \text { initial }}}=\max \left\{0.061, G_{j}^{\text {wastein }} \begin{array}{l}
\text { oxPV,initial in } \\
g_{\mathrm{Al}_{2} \mathrm{O}_{3}, \mathrm{dm}}^{C R V}
\end{array}\right\}
\end{aligned}
$$

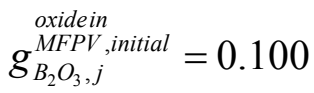

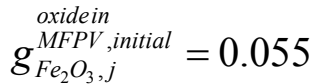

$$
\begin{aligned}
& g_{\text {TiO2,j }}^{\text {oxidein }}=0.014 \\
& g_{\mathrm{ZnO,j}}^{\substack{\text { oxidein } \\
M F P V \text { initial }}}=0.035 \\
& g_{\mathrm{ZrO}_{2}, j}^{\text {oxidein }} \text { MFIitial }^{\text {M. }}=0.030
\end{aligned}
$$

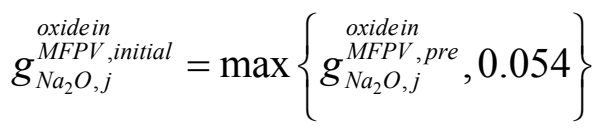

$$
\begin{aligned}
& d=g_{N a_{2} O, j}^{\substack{\text { oxidein } \\
M F P V, \text { initial }}}+0.66 G_{j}^{\text {wastein }} \stackrel{\text { initial }}{\text { oxide in }} \underset{K_{2} \mathrm{O}, \mathrm{dm}}{\mathrm{CRV}} \\
& g_{C a O, j}^{\substack{\text { oxidein } \\
M F P V i t i a l}}=0.015+\frac{0.055}{1+\exp \left(\frac{d-0.17}{0.02}\right)}
\end{aligned}
$$

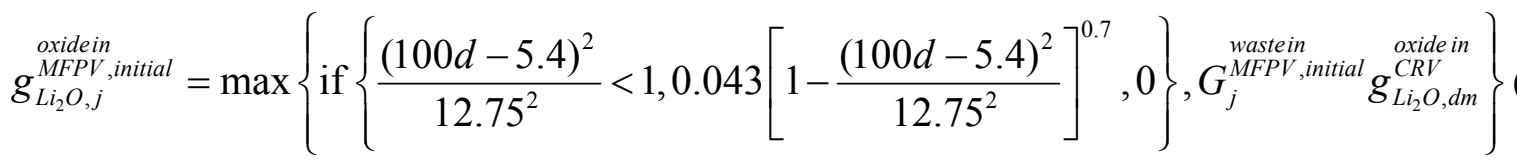

$$
\begin{aligned}
& g_{M g O, j}^{\substack{\text { oxidein } \\
M F P V \text { initial }}}=0.0148+\frac{0.0149}{1+\exp (100 d-9)}
\end{aligned}
$$

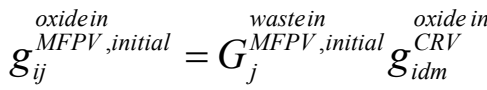

$$
\begin{aligned}
& \left\{i \neq \mathrm{Al}_{2} \mathrm{O}_{3}, \mathrm{~B}_{2} \mathrm{O}_{3}, \mathrm{CaO}, \mathrm{Fe}_{2} \mathrm{O}_{3}, \mathrm{Li}_{2} \mathrm{O}, \mathrm{MgO}, \mathrm{Na}_{2} \mathrm{O}, \mathrm{SiO}_{2}, \mathrm{TiO}_{2}, \mathrm{ZnO}, \mathrm{ZrO}_{2}\right\}
\end{aligned}
$$

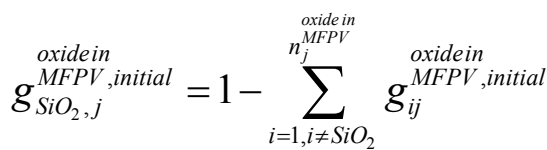


where $n_{j}^{\text {oxidesin }}$ is the number of glass oxides tracked in the mass balance calculations for the $j^{\text {th }}$ MFPV batch.

It is assumed that the radionuclide constraints will be met through the WTP process control strategy (24590WTP-3YD-50-00002). The algorithm will confirm this assumption for each MFPV batch by calculating the constraint quantities from analyzed activities of radionuclides in the CRV and comparing them with the limits.

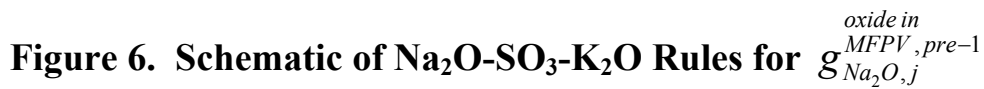

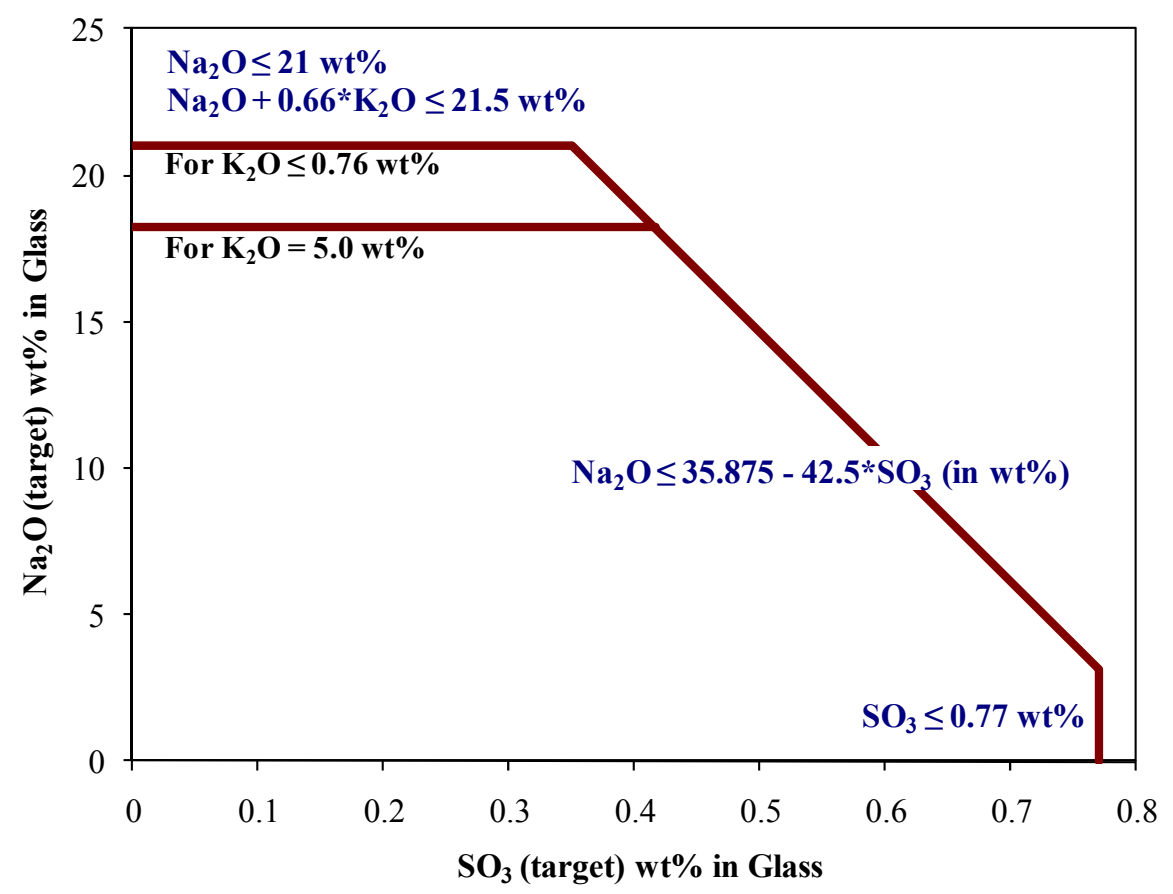


Figure 7. Schematic of Cl-F-SO Rules for $g_{\mathrm{Na}_{2} O, j}^{\substack{\text { oxidein } \\ \mathrm{MF}, \mathrm{pre}-2}}[\mathbf{H}(\mathbf{w t} \%)=\mathbf{C l}(\mathbf{w t} \%)+\mathbf{0 . 3} * \mathbf{F}(\mathbf{w t} \%)]$

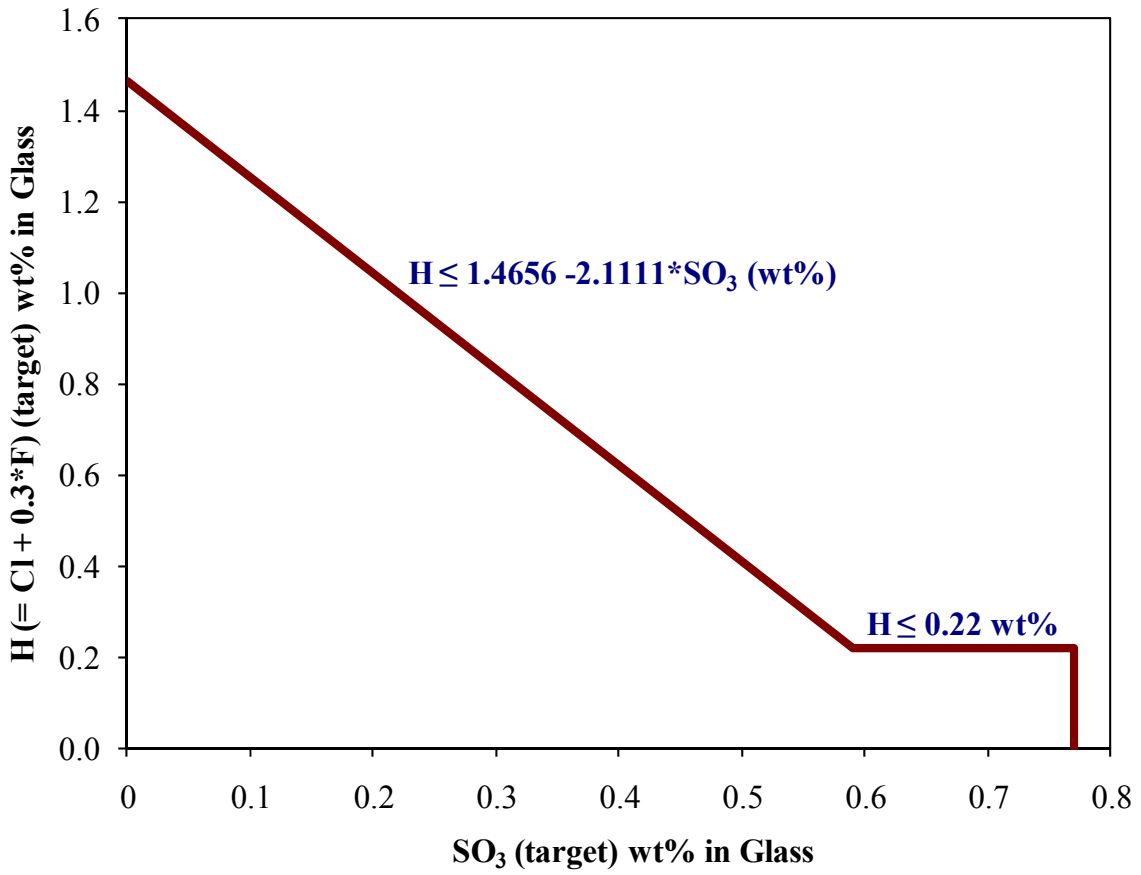

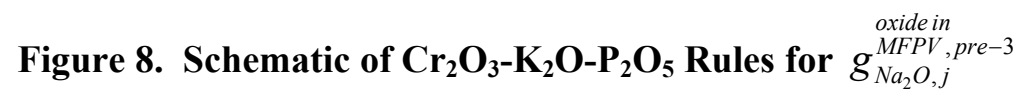

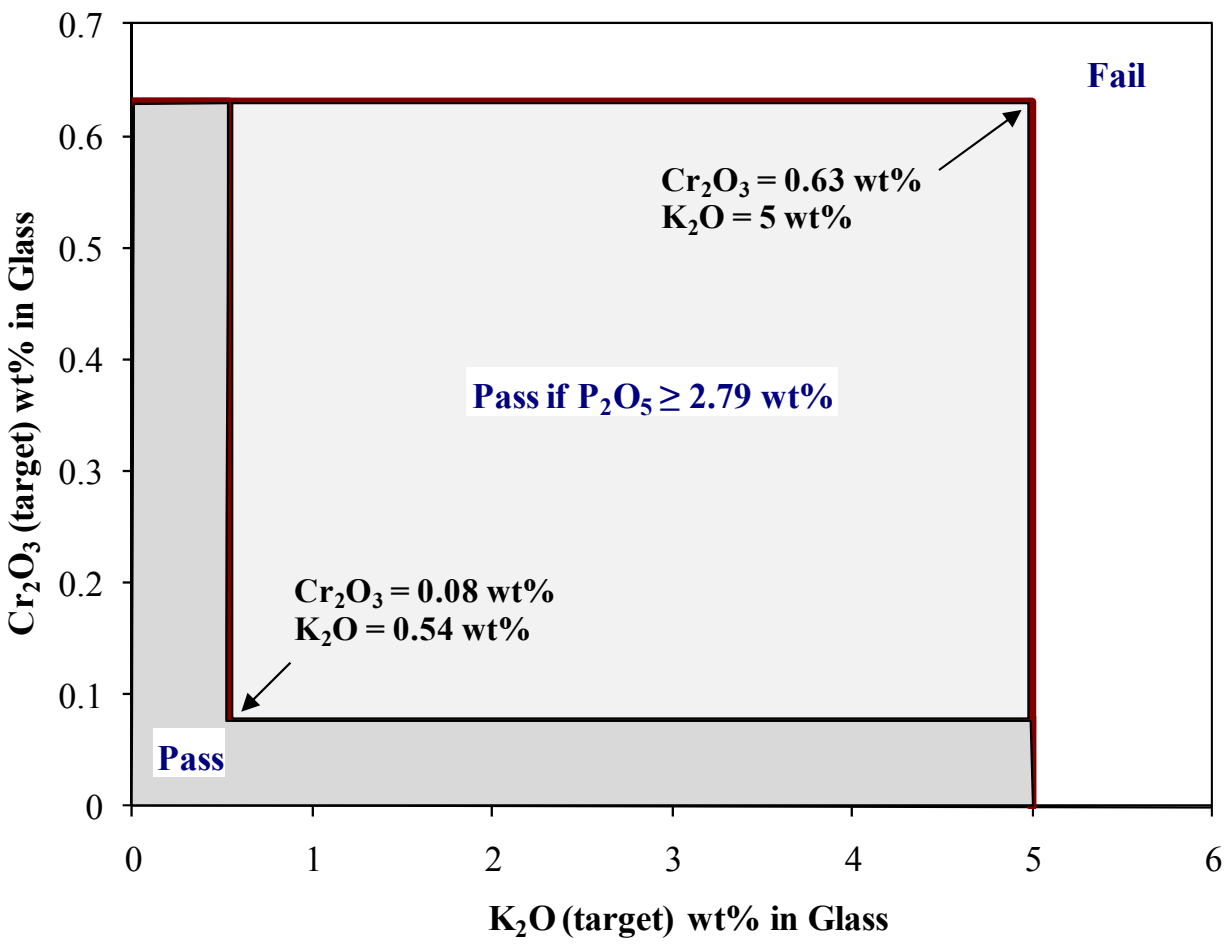


The resulting initial composition is set to target composition $\left(g_{i j}^{M F P V \text {,target }}\right)$ for all components, i.e.

$$
g_{i j}^{\stackrel{\text { oxidein }}{M F P V, \text { target }}}=g_{i j}^{\stackrel{\text { oxidein }}{M F P V, \text { initial }}}
$$

and used to calculate the Step 1 glass and radionuclide compositions (Section 5.1.4) and waste transfer volume (Section 5.1.5). The resulting GFC masses and waste transfer volume are used to calculate the constraint quantities and compare them with the limits (Section 5.1.6).

\subsubsection{Calculation of Step 1 Glass and Radionuclide Compositions}

The target mass fractions for 11 GFC components are used to calculate the mass of each GFC required. First, the contribution from waste to the concentration of GFC components is subtracted from the target concentration in glass to obtain the target mass fractions to be supplied from GFCs according to

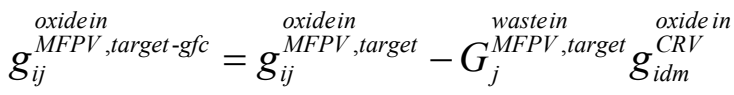

$$
\begin{aligned}
& \left\{i=\mathrm{Al}_{2} \mathrm{O}_{3}, \mathrm{~B}_{2} \mathrm{O}_{3}, \mathrm{CaO}, \mathrm{Fe}_{2} \mathrm{O}_{3}, \mathrm{Li}_{2} \mathrm{O}, \mathrm{MgO}, \mathrm{Na}_{2} \mathrm{O}, \mathrm{SiO}_{2}, \mathrm{TiO}_{2}, \mathrm{ZnO}, \mathrm{ZrO}_{2}\right\}
\end{aligned}
$$

where $g_{i j}^{\substack{\text { oxidein } \\ M F P V \text {,target-gfc }}}$ is the target mass fraction of the $i^{\text {th }}$ glass oxide in glass from GFC for the $j^{\text {th }}$ MFPV batch (g per g MFPV oxides).

Define the GFC composition vector $\mathbf{t}_{j}=g_{i j}^{\text {oxidein } \text {,target-gfc }}$ ( $g$ per g MFPV oxides), the $11 \times 11$ matrix of GFC composition $\mathbf{H}=m_{i k}^{\substack{\text { oxidein } \\ G F C}}$ (for $i=\mathrm{Al}_{2} \mathrm{O}_{3}, \mathrm{~B}_{2} \mathrm{O}_{3}, \mathrm{CaO}, \mathrm{Fe}_{2} \mathrm{O}_{3}, \mathrm{Li}_{2} \mathrm{O}, \mathrm{MgO}, \mathrm{Na}{ }_{2} \mathrm{O}, \mathrm{SiO}_{2}, \mathrm{TiO}_{2}, \mathrm{ZnO}$, and $\mathrm{ZrO}_{2}$, g per g GFC including volatiles), and the preliminary GFC mass vector $\mathbf{m}_{j}=\dddot{M}_{k j}^{G F P V, p r e}$ (g GFC per g MFPV oxides) is calculated as.

$$
\mathbf{m}_{j}=\left(\mathbf{H}^{\mathrm{T}} \mathbf{H}\right)^{-1} \mathbf{H}^{\mathrm{T}} \mathbf{t}_{j}
$$

where $\quad \begin{aligned} \mathbf{m}_{j}= & \begin{array}{l}\text { vector of } \dddot{M}_{k j}^{G F P V} \text {,pre } \\ \text { MFPV oxides) }\end{array} \\ \dddot{M}_{k j}^{G F C \text { in }} n_{j}^{M F P V} \text {,pre } & =\begin{array}{l}\text { preliminary target mass of the } k^{\text {th }} \text { GFC per g of glass to add to the } j^{\text {th }} \text { MFPV } \\ \text { batch (g per g MFPV oxides) }\end{array}\end{aligned}$

$$
\begin{aligned}
\mathbf{H}=\begin{array}{l}
11 \times 11 \text { matrix of } m_{i k}^{G F C} \\
\mathrm{Fe}_{2} \mathrm{O}_{3}, \mathrm{Li}_{2} \mathrm{O}, \mathrm{MgO}, \mathrm{Na}_{2} \mathrm{O}, \mathrm{SiO}_{2}, \mathrm{TiO}_{2}, \mathrm{ZnO}, \text { and } \mathrm{ZrO}_{2}, k=\text { corresponding } \mathrm{GFC} \\
\text { per each glass oxide component, } \mathrm{g} \text { per } \mathrm{g} \text { GFC including volatiles) }
\end{array} \\
\begin{array}{l}
\text { oxides in } \\
m_{i k}^{G F C}
\end{array}=\begin{array}{l}
\text { mass fraction of the } i^{\text {th }} \text { glass oxide in the } k^{\text {th }} \mathrm{GFC} \text { (g oxide per g GFC including } \\
\text { volatiles) }
\end{array}
\end{aligned}
$$




$$
\begin{aligned}
& \mathbf{t}_{j}=\text { vector of } g_{i j}^{\substack{\text { oxidein } \\
M P V \text {,target-gfc }}} \text { for } n_{j}^{\text {oxidesin }} \text { components in the } j^{\text {th }} \text { MFPV batch (g } \\
& \text { oxide per g MFPV oxides) }
\end{aligned}
$$

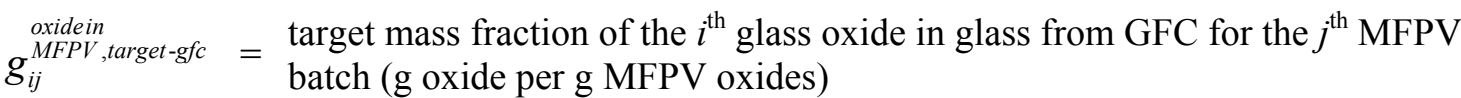

Then, the target mass of GFC per $\mathrm{g}$ glass is given as ${ }^{(8)}$

$$
\dddot{M}_{k j}^{G F C \text {, target }}=\max \left\{\dddot{M}_{k j}^{G F P V, \text { pre }}, 0\right\}
$$

Because of $\mathrm{Na}_{2} \mathrm{O}$ and $\mathrm{Li}_{2} \mathrm{O}$ (not required from glass formulation rules) and some non-GFC components added as impurities from other GFCs, calculation of glass composition for all components requires normalization. The glass composition before applying the component retention factors is given by:

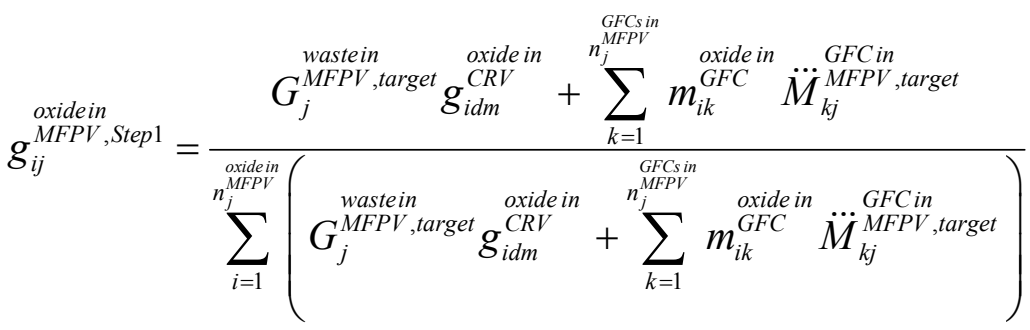

where

$$
\begin{aligned}
& \text { oxidein mass fraction of the } i^{\text {th }} \text { glass oxide in the } j^{\text {th }} \text { MFPV batch from algorithm } \\
& \begin{aligned}
g_{i j}^{\text {MFPV }, \text { Step } 1}= & \text { calculation Step } 1 \text { before applying component retention factors (g oxide per } \mathrm{g} \\
& \text { MFPV oxides) }
\end{aligned} \\
& \begin{array}{l}
\text { wastein } \\
G_{j}^{M F P V \text {, target }}
\end{array}=\begin{array}{l}
\text { target mass fraction of glass oxides originated from waste in the } j^{\text {th }} \text { MFPV batch } \\
\text { (g oxides per g glass) }
\end{array} \\
& { }_{C R V}^{\text {oxidein }}=\text { mass fraction of the } i^{\text {th }} \text { glass oxide in the } m^{\text {th }} \text { transfer waste transferred from the } \\
& g_{\text {idm }}^{C R V}=d^{\text {th }} \text { CRV to MFPV (g oxide per g CRV oxides) } \\
& n_{j}^{G F P C P V}=\text { number of GFCs in the } j^{\text {th }} \text { MFPV batch } \\
& \dddot{M}_{k j}^{\text {GFC , target }}=\begin{array}{l}
\text { target mass of } k^{\text {th }} \text { GFC per g of glass to add to the } j^{\text {th }} \text { MFPV batch (g GFC per } \mathrm{g} \\
\text { glass) }
\end{array}
\end{aligned}
$$

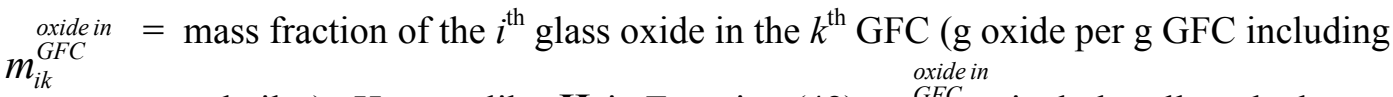

$$
\begin{aligned}
& \text { volatiles). Here, unlike } \mathbf{H} \text { in Equation (48), } m_{i k}^{\text {oxide in }} \text { includes all tracked }
\end{aligned}
$$

(8) For some formulations, the mass fraction of GFC from Equation (48) becomes negative if the target mass fraction in glass is zero (applicable to $\mathrm{Na}_{2} \mathrm{O}$ and $\mathrm{Li}_{2} \mathrm{O}$ only-target mass fraction is greater than zero for all other GFC components) when there are GFCs that contain these as impurities. For simplicity, an after-linear-regression constraint of $\dddot{M}_{k j}^{G F P V \text {,target }} \geq 0$ was used in this case rather than a "constrained least squares" method. A comparison of the two methods showed little impact for the current GFC matrix, which has relatively small $\mathrm{Na}_{2} \mathrm{O}$ and $\mathrm{zero} \mathrm{Li}_{2} \mathrm{O}$ impurities. However, if GFCs were to include more significant impurities of these components then this evaluation needs to be repeated or the "constrained least squares" methods may need to be adopted. 
components beyond the 11 GFC components.

$n_{j}^{\text {oxidesin }}=\begin{aligned} & \text { number of glass oxides tracked in the mass balance calculations for the } j^{\text {th }} \text { MFPV } \\ & \text { batch }\end{aligned}$

From Equation (50), the final waste loading in glass for the $j^{\text {th }}$ MFPV batch from algorithm calculation Step 1 after including the impurities from GFC is given as:

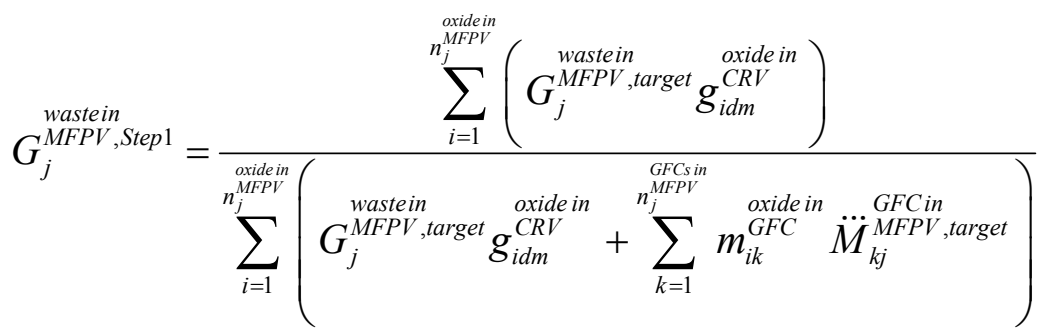

where $G_{j}^{\text {Mastein }}$ MFtep 1 is the mass fraction of glass oxides originated from waste in the $j^{\text {th }}$ MFPV batch from algorithm calculation Step 1, i.e., waste loading (g per g MFPV oxides).

Since many radionuclides and chemical components are partially lost to the offgas during melting, their concentration in glass would be overestimated if it were assumed that the melt retained $100 \%$ of their mass in the melter feed. A portion of the fraction emitted from the melter is captured in the offgas system and recycled back to pretreatment. This recycling process will increase the concentration of such species in the incoming feed, further exaggerating their estimated concentrations in glass. To help improve the estimate of glass composition, a retention factor $\left(v_{i}\right)$, equal to the fraction retained in the melt, is applied. The glass composition after applying the component retention factors is:

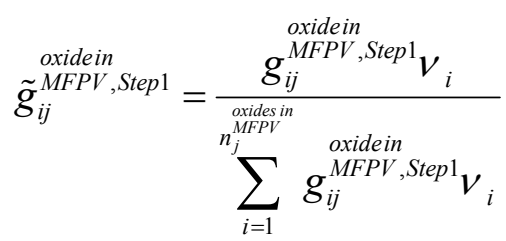

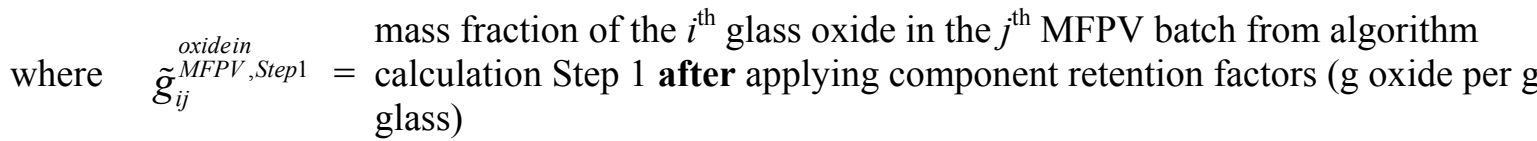

$$
\begin{aligned}
& \text { oxidein mass fraction of the } i^{\text {th }} \text { glass oxide in the } j^{\text {th }} \text { MFPV batch from algorithm } \\
& g_{i j}^{\text {MFPV ,Step } 1}=\underset{\text { calculation Step } 1 \text { before applying component retention factors ( } \mathrm{g} \text { oxide per } \mathrm{g}}{\text { glass) }} \\
& n_{j}^{\frac{\text { oxidesin }}{M F P V}}=\begin{array}{l}
\text { number of glass oxides tracked in the mass balance calculations for the } j^{\text {th }} \text { MFPV } \\
\text { batch }
\end{array} \\
& v_{i}=\text { retention factor for the } i^{\text {th }} \text { component (fraction) (listed in Table A-3) }
\end{aligned}
$$

The activity of radionuclides per unit mass of glass oxides in the $j^{\text {th }}$ MFPV batch before applying component retention factors is given as: 


$$
\begin{aligned}
& a_{i j}^{\text {rad in }}{ }^{M F P V, \text { Step } 1}=a_{i d m}^{\text {rad in }} G_{j}^{\text {wastein }} G^{M F P V \text { Step } 1} \\
& =\frac{\bar{R}_{i d}^{\text {rad in }} \lambda_{d m} G_{j}^{\text {wastein }} \text { MFP } \text { Step } 1}{C_{d m}^{\text {oxides in }}}
\end{aligned}
$$

where $\quad \begin{aligned} & \text { rad in } \\ & a_{i j}^{M F P V, S t e p 1}=\end{aligned}=\begin{aligned} & \text { specific activity of the } i^{\text {th }} \text { radionuclide in the } j^{\text {th }} \text { MFPV batch from algorithm } \\ & \text { calculation Step } 1 \text { before applying component retention factors (mCi/g oxides) }\end{aligned}$

$a_{i d m}^{C R V}=\begin{aligned} & \text { rad in } \\ & \text { the } d^{\text {th }} \mathrm{CRV} \text { to MFPV (mCi/g oxides) }\end{aligned}$

$$
\text { the } d \text { CRV to MFPV (mCi/g oxides) }
$$

(final) mass fraction of glass oxides originated from waste in the $j^{\text {th }}$ MFPV batch

$\begin{aligned} G_{j}^{\text {wastein }} & \begin{array}{l}\text { (final) mass fraction of glass oxides originated from waste in the } j \text { MFPV } \\ \text { from algorithm calculation Step 1, i.e. (final) waste loading (g per g MFPV } \\ \text { oxides) }\end{array}\end{aligned}$

$\bar{R}_{i d}^{\text {rad in }}=$ activity (per unit volume) of the $i^{\text {th }}$ radionuclide in the waste of the $d^{\text {th }} \mathrm{CRV}$

$\bar{R}_{i d}^{C R V}={ }_{\text {averaged over }} n_{d}^{\text {samps in }}$ samples analyzed $(\mathrm{mCi} / \mathrm{L})$

$\lambda_{d m}=$ dilution factor for the $m^{\text {th }}$ transfer waste transferred from the $d^{\text {th }}$ CRV to MFPV

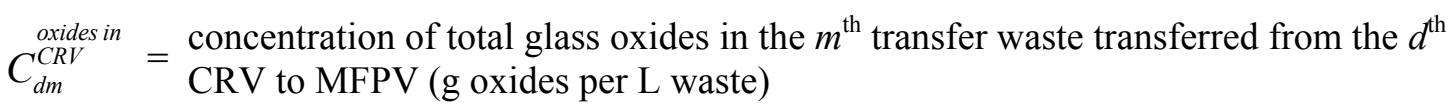

The specific activity after applying retention factors is given as:

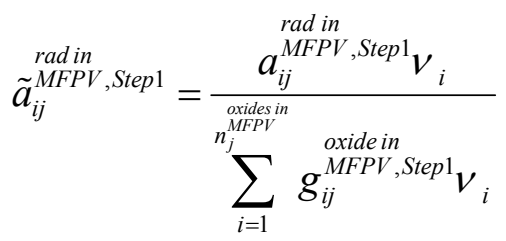

where $\tilde{a}_{i j}^{\text {MFPV,Step } 1}$ is the specific activity of the $i^{\text {th }}$ radionuclide in the $j^{\text {th }}$ MFPV batch from algorithm calculation Step 1 after applying component retention factors ( $\mathrm{mCi} / \mathrm{g}$ oxides) and $v_{i}$ is the retention factor for the $i^{\text {th }}$ radionuclide (fraction).

\subsubsection{Calculation of LAW Transfer Volume}

The two key variables considered in material transfer to the MFPV for each batch are glass composition and vessel volume. The concentrated LAW is transferred from the TCP (in PT) to one of two CRVs in the LAW vitrification facility. Each CRV has a working volume of 13,231 gal (50,085 L) and a nominal batch size of 9,115 gal $(34,504 \mathrm{~L})$. LAW is transferred from the CRVs into each of two MFPVs in roughly four 2,300 gal (8,700 L) batches (24590-LAW-3YD-LCP-00001, 24590-LAW-M4C-20-00002). Each MFPV has a nominal working volume of 5,132 gal (19,426 L), which is a sum of the nominal batch of 3,400 gal (12,870 L) and nominal heel of $1,732 \mathrm{gal}(6,556 \mathrm{~L})$. The target LAW transfer volume $\left(V_{d m}^{\text {transwaste }}\right)$ from the CRV to the MFPV is determined by comparing the anticipated melter feed volume with the remaining operating 
capacity of the vessel. The determination of waste transfer volume $\left(V_{d m}^{\text {transwaste }}\right.$ ) from CRV to MFPV needs to account for the volumes of:

- $\operatorname{MFPV}$ heel $\left(V_{j}^{\text {MFPV }}\right)$,

- CRV-MFPV transfer line flush water $\left(V_{j}^{\text {transflush }}\right.$ MFPV,

- MFPV sampling line flush water $\left(V_{j}^{\text {sampflush }}\right)$,

- $\operatorname{GFCs}\left(V_{j}^{G F C}\right)$

- $\operatorname{GFC}$ dust control water $\left(V_{j}^{M F P V}\right)$,

- $\operatorname{Sucrose}\left(V_{j}^{\text {sucrose }}\right)$,

- Dilution water $\left(V_{j}^{\text {dilute }}\right.$ MFPV

so that the combined volumes equal to the MFPV working volume $\left(V_{j}^{\text {wFrking }}{ }^{M F P}\right)$.

The volume contributions to the MFPV batch can be subdivided into three categories 1) the volumes independent of $V_{d m}^{\text {transwaste }}$ such as $V_{j}^{M F P V}, V_{j}^{\text {transflush }} \begin{array}{c}\text { sampflush } \\ \text { MFPV }\end{array}$ and $\left.V_{j}^{M F P V}, 2\right)$ the volumes dependent on $V_{d m}^{\text {transwaste }}$

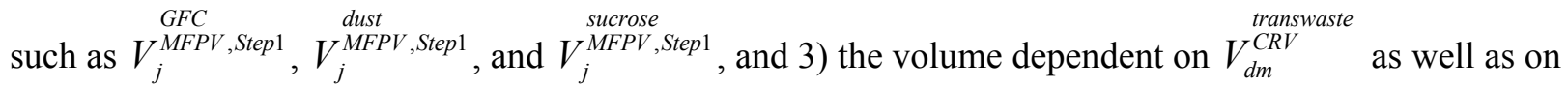

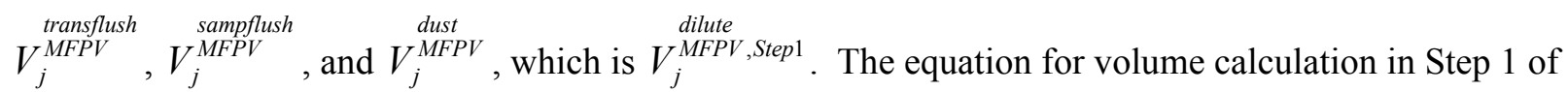
ILAW algorithm is given as:

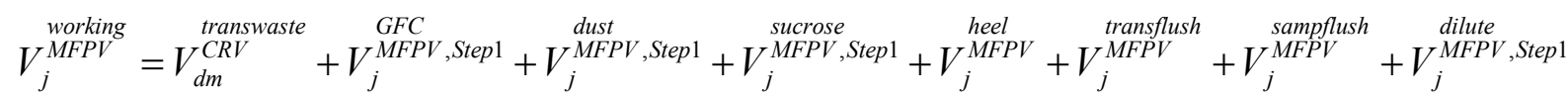

where $V_{j}^{\text {MFPV }}$ working $=$ working volume for the $j^{\text {th }}$ MFPV batch (L). The MFPV working volume includes the MFPV heel volume $\left(V_{j}^{M F P V}\right)$ required for normal operation plus the MFPV

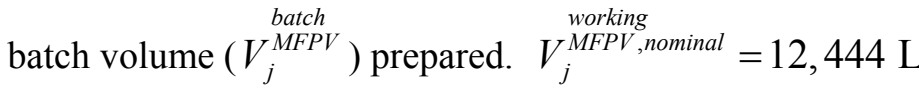

$V_{d m}^{\text {transwaste }}=$ volume of the $m^{\text {th }}$ transfer waste to be transferred from the $d^{\text {th }}$ CRV to MFPV (L).

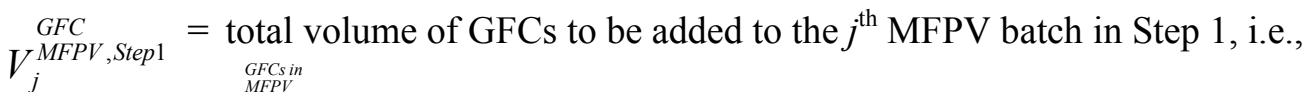
${ }_{n_{j}^{M F P V V}}^{G F C \text { sin }} G F C$ $\sum_{k=1}^{n_{j}} V_{k j}^{G F C}{ }^{G F V, S t e p 1}$ (L) where $V_{k j}^{G F C}{ }^{M F P, S t e p 1}$ is the volume of $k^{\text {th }}$ GFC to be added to the $j^{\text {th }}$ MFPV batch (L) in Step 1 and $n_{j}^{G F P V}$ is the number of GFCs used in the $j^{\text {th }}$ MFPV batch. 


$$
\begin{aligned}
& \begin{array}{l}
\text { dust } \\
V_{j}^{M F P V \text { Step } 1}
\end{array}=\text { volume of water added to control GFC dusting in the } j^{\text {th }} \text { MFPV batch in Step } 1 \text { (L) } \\
& V_{j}^{\text {sucrose }} \text { MFPV,Step } 1=\text { volume of sucrose addition to the } j^{\text {th }} \text { MFPV batch in Step } 1 \text { (L) } \\
& \begin{array}{c}
\text { heel } \\
V_{j}^{M F P V}
\end{array}=\text { volume of heel in the } j^{\text {th }} \text { MFPV batch measured prior to waste transfer (L) } \\
& \begin{array}{l}
\text { transflush } \\
V_{j}^{M F P V}
\end{array}=\begin{array}{l}
\text { volume of water used to flush the CRV-MFPV transfer line in the } j^{\text {th }} \text { MFPV batch } \\
(\mathrm{L})
\end{array}
\end{aligned}
$$

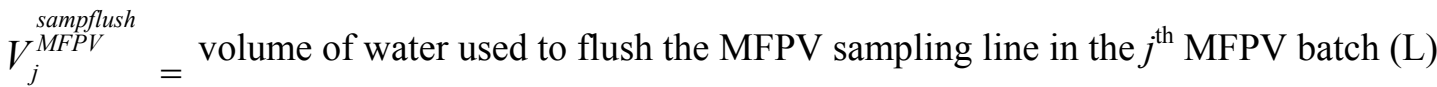

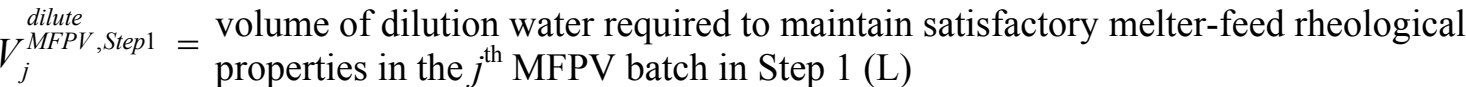

Equation (55) assumes ideal mixing between slurry (waste and heel) and water (flush, dust control, and dilution), i.e., the discrepancy by nonideal mixing of a small volume of water added to the large volume of slurry is negligible.

Solving Equation (55) requires estimates of the various volumes. The $V_{j}^{\text {wFPV }}$ is given by heel 24590-LAW-M6C-LFP-00001, Rev 1 as 19,426 L. The heel volume $V_{j}^{M F P V}$ will be measured before each transfer but has a nominal value of 6,556 L (24590-LAW-M6C-LFP-00001, Rev 1). The nominal $V_{j}^{\text {transflush }}$ and $V_{j}^{\text {sampflush }}$ values depend on the MFPV and CRV vessels used and are summarized in Table 14 (24590LAW-M4C-20-00002, Rev. 0). These nominal flush volumes are used for example calculations in this report but the measured values will be used in the algorithm for plant operation. MFPV to MFV and MFV to melter line flushes are not counted because they do not contribute to the MFPV volume.

Table 14. CRV-MFPV Line and Sampling Line Flush Nominal Volumes (L)

\begin{tabular}{||c|c|c||}
\hline \hline MFPV AND CRV VESSELS & $\begin{array}{c}\text { transflush } \\
V_{j}^{M F P V}\end{array}$ & $\begin{array}{c}\text { sampflush } \\
V_{j}^{M F P V}\end{array}$ \\
\hline For LFP-VSL-00001 from LCP-VSL-00001 & 37.5 & 175.3 \\
\hline For LFP-VSL-00001 from LCP-VSL-00002 & 28.4 & 175.3 \\
\hline For LFP-VSL-00003 from LCP-VSL-00001 & 66.2 & 247.2 \\
\hline For LFP-VSL-00003 from LCP-VSL-00002 & 40.5 & 247.2 \\
\hline
\end{tabular}

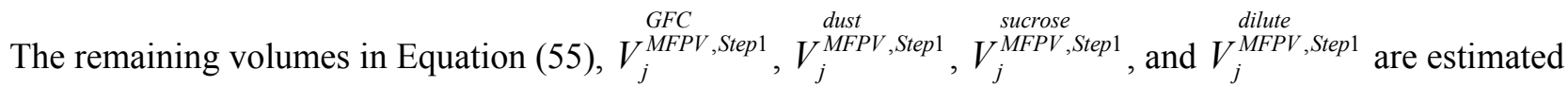
as a function of $V_{d m}^{\text {transwaste }}$ as described below. 
Section 5.1.3 describes the general method of determining the target mass fraction of glass oxides originated

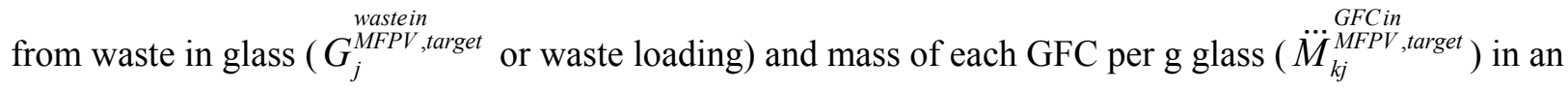
MFPV batch required to calculate the $V_{j}^{M F C V \text {,Step } 1}$ value:

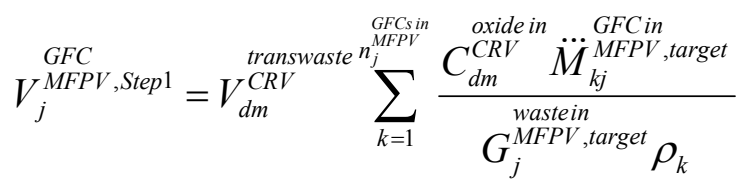

where

$$
\begin{aligned}
C_{d m}^{\text {oxidein }} & =\begin{array}{l}
\text { concentration of total glass oxides in the } m^{\text {th }} \text { transfer waste transferred from the } \\
d^{\text {th }} \text { CRV to MFPV, calculated by Equation (22) (g oxide per L LAW) }
\end{array} \\
\dddot{M}_{k j}^{\text {GFC in } \text {,target }} & =\text { target mass of } k^{\text {th }} \text { GFC per g glass to add to the } j^{\text {th }} \text { MFPV batch (g per g glass) } \\
G_{j}^{\text {wastein }} \text { MFPV,target } & =\begin{array}{l}
\text { target mass fraction of glass oxides originated from waste from CRV in glass } \\
\text { for the } j^{\text {th }} \text { MFPV batch (g oxides per g glass) }
\end{array} \\
\rho_{k} & =\text { particle density of the } k^{\text {th }} \text { GFC }(\mathrm{g} / \mathrm{L}) \\
n_{j}^{G F C P V} & =\text { the number of GFCs in the } j^{\text {th }} \text { MFPV batch }
\end{aligned}
$$

Equation (56) assumes that the volume of GFC in the MFPV slurry is equal to the specific volume $\left(1 / \rho_{k}\right)$ of each GFC particle multiplied by its mass (see Appendix F for details).

Water is added to control dusting of the GFCs at a constant ratio (4 wt $\%)$ to total GFC mass (24590-LAWM4C-20-00002, Rev 0). Since the dust control water volume depends on the mass of GFCs, it is also dependent on the volume of HLW transfer to the MFPV, as shown in the following equations.

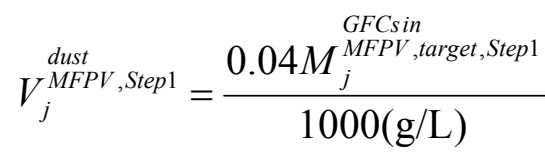

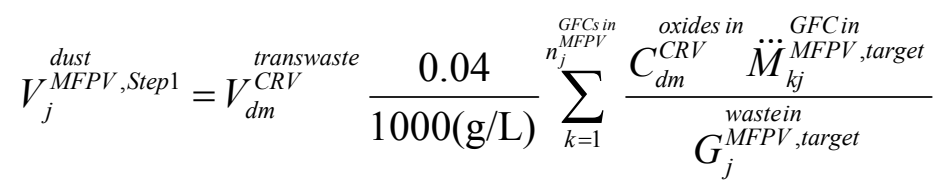

where $M_{j}^{\text {GFCSIn } \text {,target,Step } 1}$ is the total target mass of GFCs in the $j^{\text {th }}$ MFPV batch from algorithm calculation Step $1(\mathrm{~g})$ and the remaining symbols are as previously defined.

Sucrose is used to control redox chemistry and ensure proper processing conditions in the melter. The amount of sucrose is determined by setting the target ratio of carbon moles (from sucrose and total organic carbon in the waste) to nitrogen moles (from nitrate and nitrite) equal to $0.75\left(\mathrm{C} / \mathrm{NO}_{\mathrm{x}}=0.75\right)$. The target mass of sucrose is calculated according to Matlack et al. (2005): 


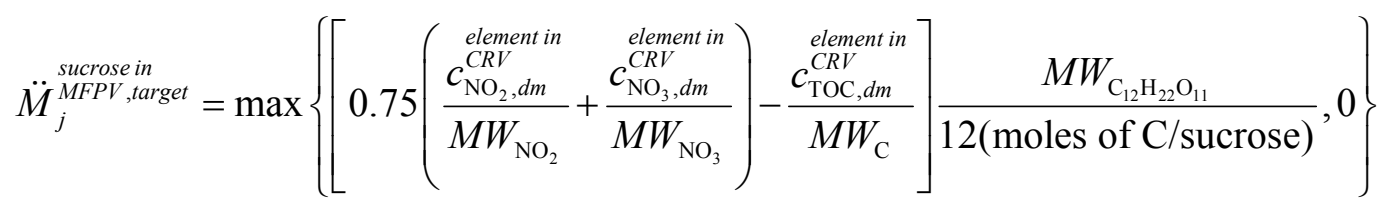

where

$$
\ddot{M}_{j}^{M F P V \text {,target }}=\text { target mass of sucrose required per L of waste }(\mathrm{g} / \mathrm{L})
$$

$$
\begin{gathered}
\begin{array}{c}
\text { element in } \\
c_{\mathrm{NO}_{2}, d m}^{C R V}, c_{\mathrm{NO}_{3}, d m}^{\text {element in }} \\
c^{C R V}
\end{array} \text {, and } c_{\mathrm{TOC}, d m}^{C R V}=\begin{array}{l}
\text { element in } \\
\text { concentration of nitrite, nitrate, and total organic carbon in the } m^{\text {th }} \\
\text { transfer waste transferred from the } d^{\text {th }} \mathrm{CRV} \text { to MFPV }(\mathrm{g} / \mathrm{L} \mathrm{LAW})
\end{array} \\
M W_{\mathrm{NO}_{2}}, M W_{\mathrm{NO}_{3}}, \text { and } M W_{\mathrm{C}}=\text { molecular masses of nitrite, nitrate, and carbon }(\mathrm{g} / \mathrm{mole}) \\
M W_{\mathrm{C}_{12} \mathrm{H}_{22} \mathrm{O}_{11}}=\text { molecular mass of sucrose }(\mathrm{g} / \mathrm{mole})
\end{gathered}
$$

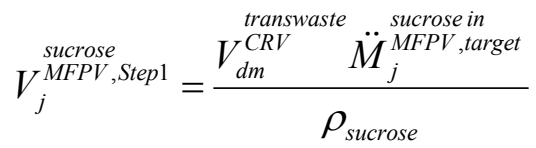

where $\rho_{\text {sucrose }}$ is the particle density of sucrose $(\mathrm{g} / \mathrm{L})$ and the remaining symbols are as previously defined. The particle densities of sucrose $\left(\rho_{\text {sucrose }}\right)$ and $\operatorname{GFCs}\left(\rho_{k}\right)$ are listed in Table A-12.

Dilution water may be required to lower the risk of cementation of the blended melter feed in the MFPV and/or MFV. At low waste loading and high sodium molarities, the LAW melter feed was found to harden and not be mixable or pumpable (Poloski et al. 2004, CCN 116150). To avoid this failure of the melter feed preparation system, the WTP (CCN 116150) developed an empirical correlation between waste loading, represented by waste $\mathrm{Na}_{2} \mathrm{O}$ mass fraction in glass, and sodium molarity ([Na]) in melter feed. Satisfactory melter-feed rheological properties were found in feeds that followed the trend in Figure 9. This trend line is used as a preliminary estimate of dilution water required to maintain the sodium molarity at the target $\left(t_{[N a]}\right)$ or below in melter feed:

$$
t_{[\mathrm{Na}], j}=\frac{g_{\mathrm{Na}_{2} \mathrm{O}, j}^{\text {oxidein }} \mathrm{MFPV \text {target }}+0.0047}{0.0249}
$$

where $g_{\mathrm{Na}_{2} \mathrm{O}, j}^{\substack{\text { oxidein } \\ \mathrm{MFPV} \text {,target }}}$ is the target $\mathrm{Na}_{2} \mathrm{O}$ mass fraction in the $j^{\text {th }}$ MFPV batch, given by Equation (46).

The target $\mathrm{Na}_{2} \mathrm{O}$ loading and total volume of water in a given MFPV vessel is then used to estimate the required volume of dilution water $\left(V_{j}^{\text {MFPV }}\right.$,pre $)$.

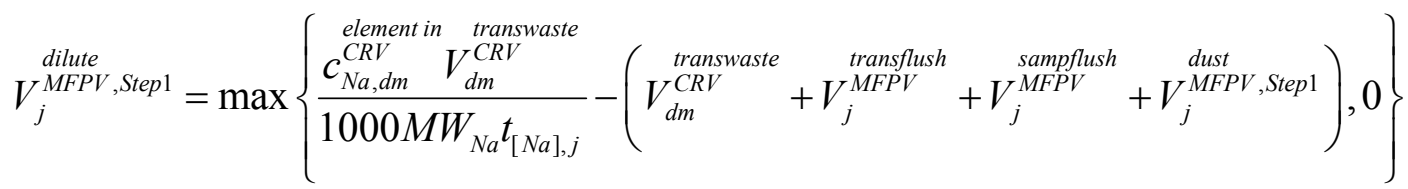


where $c_{N a, d m}^{\text {element in }}$ is the sodium concentration in the $m^{\text {th }}$ transfer waste transferred from the $d^{\text {th }} \mathrm{CRV}$ to MFPV (mg/L waste), $M W_{\mathrm{Na}}$ is the molecular mass of sodium (=22.98977 $\left.\mathrm{g} / \mathrm{mole}\right)$, and the remaining notations are as previously defined in Equation (55) and (61). This preliminary empirical correlation should be updated, and is meant to reduce risk of an agitated MFPV system exceeding allowable rheological properties. Other controls would be required to reduce the risk of MFPV system failure if agitation were not supplied.

Figure 9. Relationship between Sodium Molarity and Waste Loading for Successful Melter Feed

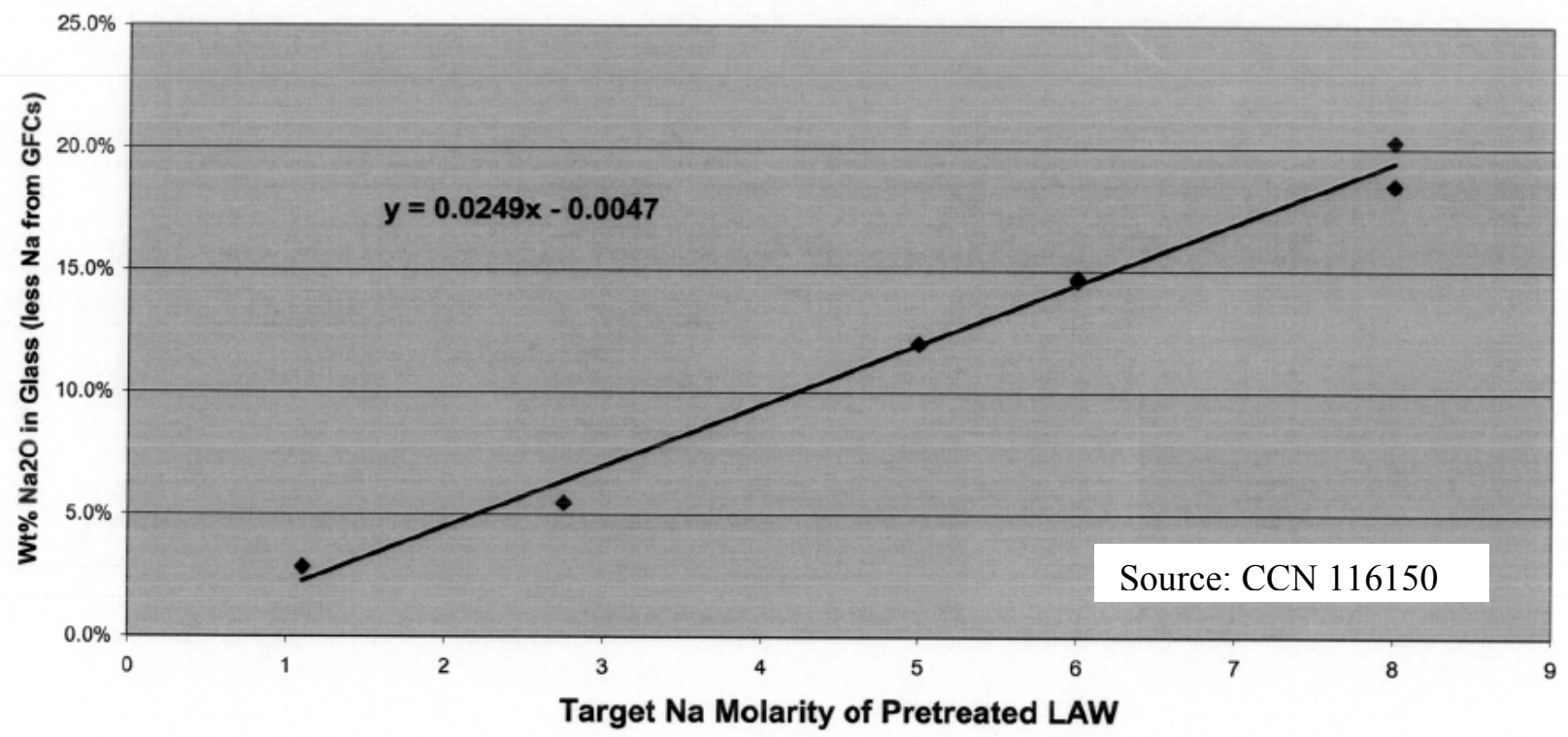

The waste transfer volume $\left(V_{d m}^{\text {transwaste }}\right.$ CRV $)$ is obtained by solving Equations (55) through (62) iteratively.

From the waste transfer volume, the target masses of GFCs and sucrose are calculated

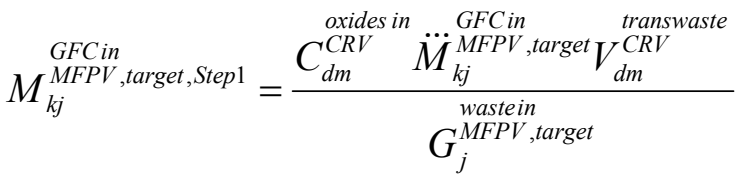

$$
\begin{aligned}
& M_{j}^{M F P V, \text { target, Step } 1}=\ddot{M}_{j}^{\text {sucrosein }}{ }^{\text {sucrosein }} \underbrace{\text { transwaste }}_{d m}
\end{aligned}
$$
where $\quad M_{k j}^{\text {GFCin } \text { MFV,target,Step } 1}=\begin{aligned} & \text { target mass of } k^{\text {th }} \text { GFC to add to the } j^{\text {th }} \text { MFPV batch resulted from } \\ & \text { algorithm calculation Step } 1(\mathrm{~g})\end{aligned}$

$$
\begin{aligned}
\begin{array}{c}
\text { oxidesin } \\
C_{d m}^{C R V}
\end{array} & \begin{array}{l}
\text { concentration of total glass oxides in the } m^{\text {th }} \text { transfer waste transferred } \\
\text { from the } d^{\text {th }} \text { CRV to MFPV, calculated by Equation }(22) \text { (g oxide per L } \\
\text { LAW) }
\end{array} \\
\dddot{M}_{k j}^{G F C \text { in }} \text {,target }= & \begin{array}{l}
\text { target mass of } k^{\text {th }} \text { GFC per g glass to add to the } j^{\text {th }} \text { MFPV batch (g per } \mathrm{g} \\
\text { glass) }
\end{array}
\end{aligned}
$$




$$
\begin{aligned}
& V_{d m}^{\text {transwaste }}=\text { volume of the } m^{\text {th }} \text { transfer waste to be transferred from the } d^{\text {th }} \mathrm{CRV} \text { to } \\
& \text { MFPV (L). Result of algorithm calculation Step } 1 . \\
& G_{j}^{\text {wFP }, \text { target }}=\text { target mass fraction of glass oxides originated from waste from CRV in } \\
& G_{j}^{M F P, \text { target }}=\text { glass for the } j^{\text {th }} \text { MFPV batch (g oxides per g glass) }
\end{aligned}
$$

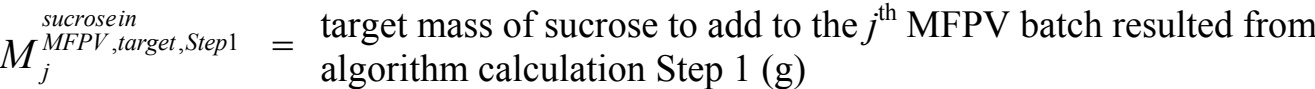

$$
\begin{aligned}
& \ddot{M}_{j}^{\text {sucrosein }} \text {,arget }=\text { target mass of sucrose required per } \mathrm{L} \text { of waste }(\mathrm{g} / \mathrm{L})
\end{aligned}
$$

These target masses of GFCs and sucrose are used to calculate the GFCs and sucrose masses in algorithm Step 2 using the measured waste transfer volume.

\subsubsection{Calculation of Constraints for Algorithm Step 1}

The equations to calculate the quantities for all constraints listed in Table 10 through Table 13 for algorithm Step 1 are described in this section.

\subsubsection{Glass Property and Model Validity Constraints}

The constraints related to glass properties and model validities were discussed in Section 4.3.1. For property predictions and calculations of prediction uncertainties, the $g_{i}$ for $x_{i}^{\text {prop }}$ and $x_{\text {Others }}^{\text {prop }}$ in Equations (3) and (4) is given by $\tilde{g}_{i j}^{\text {oxidein }}{ }^{M F P V \text { Step } 1}$ from Equation (52). The model validity constraints are also calculated based on $\tilde{g}_{i j}^{\text {oxidein }}$ MFPV Step 1 . Then, these $x_{i}^{\text {prop }}$ values are used in Equations (2), (5), (6), and (7) to calculate $P^{\text {prop }}$ and Equations (8) through (11) to calculate $U_{\text {pred }}^{\text {prop }}$. Composition uncertainty $\left(U_{\text {comp }}^{\text {prop }}\right)$ is calculated following the methods described in Section 4.2.2. For $U_{\text {comp }}^{\text {prop }}$ calculation the mass balance equations given by Equation (12) and (13) are rewritten based on the values for Step 1 calculation:

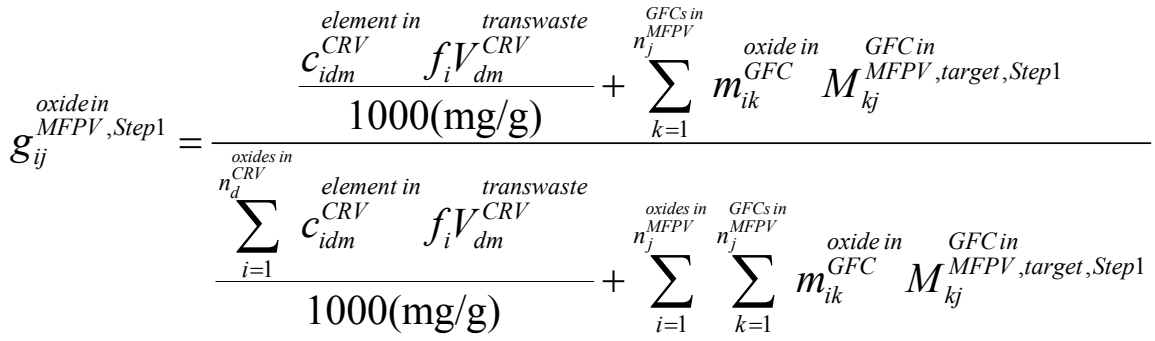

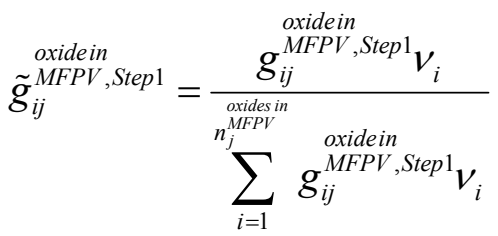


where

$$
\begin{aligned}
& \text { oxidein mass fraction of the } i^{\text {th }} \text { glass oxide in the } j^{\text {th }} \text { MFPV batch from algorithm } \\
& g_{i j}^{M F P V, \text { Step } 1}=\underset{\text { calculation Step } 1 \text { after applying component retention factors (g oxide per } \mathrm{g}}{\text { glass }} \\
& \text { oxidein mass fraction of the } i^{\text {th }} \text { glass oxide in the } j^{\text {th }} \text { MFPV batch from algorithm } \\
& \tilde{g}_{i j}^{M F P V, \text { Step } 1}=\text { calculation Step } 1 \text { after applying component retention factors (g oxide per } \mathrm{g} \\
& \text { glass) } \\
& { }_{C R V}^{\text {element in }}=\text { concentration of the } i^{\text {th }} \text { component in the } m^{\text {th }} \text { transfer waste transferred from } \\
& c_{i d m}^{C R V}=\text { the } d^{\text {th }} \mathrm{CRV} \text { to MFPV (mg/L waste) } \\
& f_{i}=\begin{array}{l}
\text { oxide conversion factor, i.e., mass of the } i^{\text {th }} \text { glass oxide per mass of the } i^{\text {th }} \\
\text { element }
\end{array} \\
& \begin{array}{ll}
V_{d m}^{\text {transwaste }} & =\text { volume of the } m^{\text {th }} \text { transfer waste to be transferred from the } d^{\text {th }} \mathrm{CRV} \text { to MFPV } \\
& (\mathrm{L})
\end{array} \\
& n_{j}^{G F P V}=\text { number of GFCs used in the } j^{\text {th }} \text { MFPV batch } \\
& \text { mass fraction of the } i^{\text {th }} \text { glass oxide in the } k^{\text {th }} \mathrm{GFC} \text { (g oxide per g GFC } \\
& m_{i k}^{\substack{\text { oxide in } \\
G F C}}=\text { including volatiles). Here, unlike } \mathbf{H} \text { in Equation (48), } m_{i k}^{\substack{\text { oxide in } \\
G F C}} \text { includes all } \\
& \text { tracked components beyond the } 11 \text { GFC components. } \\
& M_{k j}^{\text {GFCin } \text {,target,Step } 1}=\begin{array}{l}
\text { target mass of } k^{\text {th }} \text { GFC to add to the } j^{\text {th }} \text { MFPV batch resulted from algorithm } \\
\text { calculation Step } 1(\mathrm{~g})
\end{array} \\
& v_{i}=\text { retention factor for the } i^{\text {th }} \text { component (fraction) } \\
& n_{d}^{\text {oxides in }}=\begin{array}{l}
\text { number of glass oxides tracked in the mass balance calculations for the } d^{\text {th }} \\
\text { CRV batch }
\end{array} \\
& n_{j}^{\stackrel{\text { oxides in }}{M F P V}}=\begin{array}{l}
\text { number of glass oxides tracked in the mass balance calculations for the } j^{\text {th }} \\
\text { MFPV batch }
\end{array}
\end{aligned}
$$

The results of $P^{\text {prop }}, U_{\text {pred }}^{\text {prop }}$, and $U_{\text {comp }}^{\text {prop }}$ are used to calculate CL\% UCCI or LCCI ( $B_{u c c i}^{\text {prop }}$ or $B_{u c c i}^{\text {prop }}$ ) for glass properties (PCT, VHT, viscosity, and electrical conductivity) according to Equation (16) discussed in Section 4.2.3.

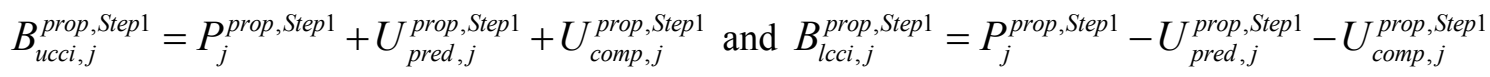

where $\quad B_{u c c i, j}^{\text {prop }, \text { Step } 1}=\begin{aligned} & \mathrm{CL} \% \text { upper combined confidence interval for predicted "prop" } \mathrm{s} \text { for the } j^{\text {th }} \mathrm{MFPV} \\ & \text { batch from algorithm calculation Step } 1 \text { (in property model units) }\end{aligned}$

$$
\begin{aligned}
& \text { CL\% lower combined confidence interval for "prop" for the } j^{\text {th }} \text { MFPV batch from } \\
& B_{l c c i, j}^{\text {prop Step } 1}=\underset{\text { units) }}{\text { algorithm calculation Step } 1 \text { (applicable only to "vis" and "ec") (in property model }} \\
& \text { predicted "prop" transformed property values for the } j^{\text {th }} \text { MFPV batch from } \\
& P_{j}^{\text {prop,Step } 1}=\text { algorithm calculation Step } 1 \text {, which includes } \ln \left(r_{\mathrm{B}}, \mathrm{g} / \mathrm{L}\right), \ln \left(r_{\mathrm{Na}}, \mathrm{g} / \mathrm{L}\right), \ln (D, \mu \mathrm{m}) \text {, } \\
& \ln \left(\eta_{T}, \mathrm{P}\right) \text {, and } \ln \left(\varepsilon_{T}, \mathrm{~S} / \mathrm{cm}\right)
\end{aligned}
$$




$$
\begin{aligned}
U_{\text {pred }, j}^{\text {prop }, \text { Ste } 1} & =\begin{array}{l}
\text { model prediction uncertainty for "prop" for the } j^{\text {th }} \text { MFPV batch from algorithm } \\
\text { calculation Step } 1 \text { (in property model units) }
\end{array} \\
U_{\text {comp }, j}^{\text {prop }, j}= & \begin{array}{l}
\text { composition uncertainty for "prop" for the } j^{\text {th }} \text { MFPV batch from algorithm } \\
\text { calculation Step } 1 \text { (in property model units) }
\end{array}
\end{aligned}
$$

Note that CL\% UCCIs and LCCIs are expressed in the units of the model used to predict a property (e.g., $\ln [\mathrm{g} / \mathrm{L}]$ for PCT responses). Hence, they can be used to assess whether property constraints (as discussed in Section 4.3) are met.

In addition, the SD values for glass component mass fractions $\left(\tilde{s}_{i j}^{\text {oxidein }}\right.$ STtep 1 for algorithm calculation Step 1 after applying retention factors are obtained by Monte Carlo simulations of Equation (66).

\subsubsection{Waste $\mathrm{Na}_{2} \mathrm{O}$ Loading Constraint}

The Contract (DOE 2000) Specification 2.2.2.2 requires that the $\mathrm{Na}_{2} \mathrm{O}$ mass fraction in glass that came from waste $\mathrm{Na}_{2} \mathrm{O}$ be above 14, 3, and $10 \mathrm{wt} \%$, for Envelopes A, B, and $\mathrm{C}$ waste products, respectively. The waste $\mathrm{Na}_{2} \mathrm{O}$ loading in the $j^{\text {th }}$ MFPV batch from algorithm calculation Step $1, g_{\mathrm{Na}_{2} \mathrm{O}(w), j}^{M F P(S t) p 1}$, is calculated as:

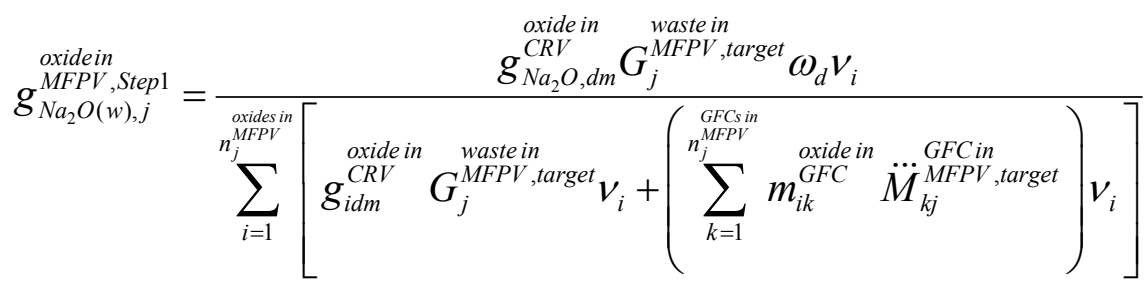

where

$$
\begin{aligned}
& \underset{g_{N a_{2} O(w), j}^{\text {oxidein }}}{M F P V \text { Step } 1}=\begin{array}{l}
\text { mass fraction of waste } \mathrm{Na}_{2} \mathrm{O} \text { (waste } \mathrm{Na}_{2} \mathrm{O} \text { loading) in the } j^{\text {th }} \text { MFPV batch from } \\
\text { algorithm calculation Step } 1 \text { (g per g glass) }
\end{array} \\
& g_{\mathrm{Na}_{2} \mathrm{O}, d m}^{\text {oxide in }}=\begin{array}{l}
\text { mass fraction of } \mathrm{Na}_{2} \mathrm{O} \text { in the } m^{\text {th }} \text { transfer waste transferred from the } d^{\text {th }} \mathrm{CRV} \text { to } \\
\text { MFPV (g oxide per g CRV oxides) }
\end{array}
\end{aligned}
$$

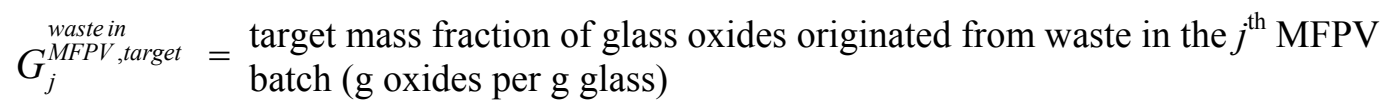

$$
\begin{aligned}
& \omega_{d}=\begin{array}{l}
\text { fraction of the sodium in the } d^{\text {th }} \mathrm{CRV} \text { batch that is classified as waste sodium } \\
\text { (unitless) }
\end{array} \\
& v_{i}=\text { retention factor for the } i^{\text {th }} \text { component (fraction) } \\
& n_{j}^{\stackrel{\text { oxides in }}{M F P V}}=\begin{array}{l}
\text { number of glass oxides tracked in the mass balance calculations for the } j^{\text {th }} \\
\text { MFPV batch }
\end{array} \\
& g_{\text {idm }}^{\text {oxide in }}=\begin{array}{l}
\text { mass fraction of the } i^{\text {th }} \text { glass oxide in the } m^{\text {th }} \text { transfer waste transferred from } \\
\text { the } d^{\text {th }} \text { CRV to MFPV (g oxide per g CRV oxides) }
\end{array} \\
& n_{j}^{G F C P V}=\text { number of GFCs in the } j^{\text {th }} \text { MFPV batch } \\
& \dddot{M}_{k j}^{G F C \text {, target }}=\underset{\text { target mass of } k^{\text {th }} \text { GFC per g of glass to add to the } j^{\text {th }} \text { MFPV batch (g GFC per }}{\text { g glass) }}
\end{aligned}
$$




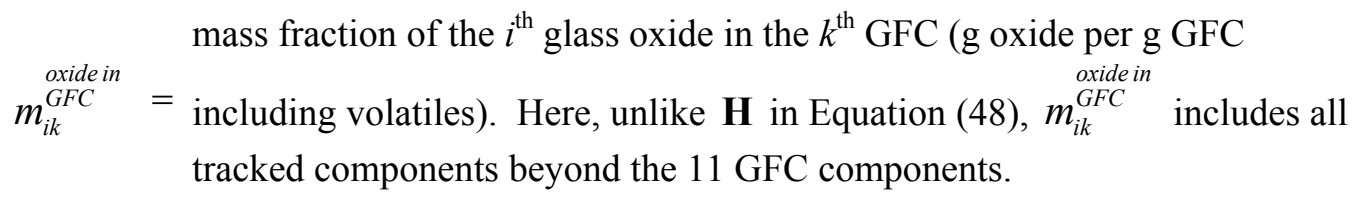

The fraction of waste $\mathrm{Na}_{2} \mathrm{O}$ includes that originating from receipt of waste from the tank farm operator and that used to wash and leach the HLW fraction of the waste in the PT facility. All other sources of chemically added sodium (including that from GFCs) are non-waste $\mathrm{Na}_{2} \mathrm{O}$. The operator must enter both $\omega_{d}$ and the waste envelope from which the glass is produced to calculate $\underset{\mathrm{Na}_{2} \mathrm{O}(w), j}{\mathrm{MFPV}}$ and compare it to the lower limit of waste $\mathrm{Na}_{2} \mathrm{O}, L_{l}^{W_{N a}}$.

\subsubsection{Radionuclide Concentration Constraints}

The Contract (DOE 2000) Specification 2.2.2.8 requires that the radionuclide concentrations in glass do not exceed Class $\mathrm{C}$ limits as defined in 10CFR61.55 and the average glass concentrations of ${ }^{137} \mathrm{Cs}$ and ${ }^{90} \mathrm{Sr}$ be lower than 3 and $20 \mathrm{Ci} / \mathrm{m}^{3}$, respectively. The Contract (DOE 2000) Section C.7 (d).(1).(iii) further requires that the pretreatment unit operation remove ${ }^{137} \mathrm{Cs}$ from the filtered supernatant to achieve $0.3 \mathrm{Ci} / \mathrm{m}^{3}$ to facilitate the maintenance concept established for the ILAW melter system.

The constraints related to radionuclide concentration limitations also need to consider uncertainties originated from uncertain values used in mass balance equations. The specific activity of radionuclide in glass is calculated by

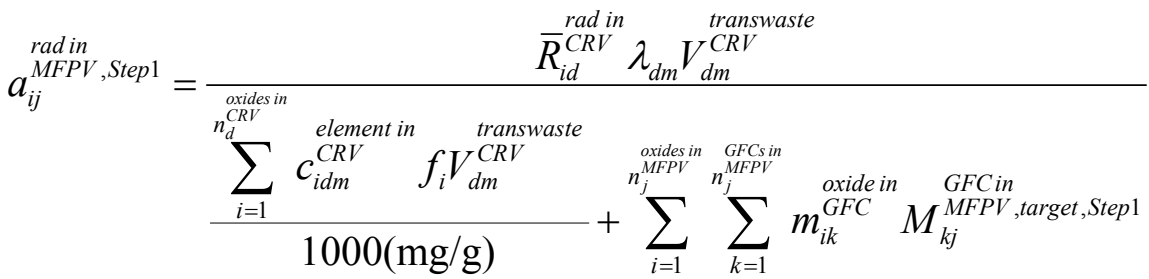

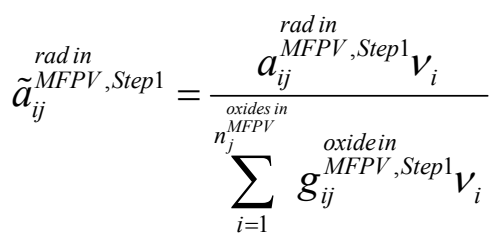
where $\quad a_{i j}^{\operatorname{radin}} \operatorname{MFPV}_{\text {Step } 1}=\begin{aligned} & \text { specific activity of the } i^{\text {th }} \text { radionuclide in the } j^{\text {th }} \text { MFPV batch from algorithm } \\ & \text { calculation Step } 1 \text { before applying retention factors ( } \mathrm{mCi} / \mathrm{g} \text { glass) }\end{aligned}$

$$
\begin{aligned}
& \text { rad in activity (per unit volume) of the } i^{\text {th }} \text { radionuclide in the waste of the } d^{\text {th }} \mathrm{CRV} \\
& \bar{R}_{i d}^{C R V}=\text { averaged over } n_{d}^{\text {sampsin }} \text { samples analyzed }(\mathrm{mCi} / \mathrm{L}) \\
& \lambda_{d m}=\begin{array}{l}
\text { dilution factor for the } m^{\text {th }} \text { transfer waste transferred from the } d^{\text {th }} \text { CRV to } \\
\text { MFPV }
\end{array} \\
& \begin{array}{l}
V_{d m}^{\text {transwaste }} \\
V_{d m}^{\text {CR }}
\end{array}=\begin{array}{l}
\text { volume of the } m^{\text {th }} \text { transfer waste to be transferred from the } d^{\text {th }} \text { CRV to MFPV } \\
(\mathrm{L})
\end{array}
\end{aligned}
$$




$$
\begin{aligned}
& n_{d}^{\text {oxides in }}=\begin{array}{l}
\text { number of glass oxides tracked in the mass balance calculations for the } d^{\text {th }} \\
\text { CRV batch }
\end{array}
\end{aligned}
$$

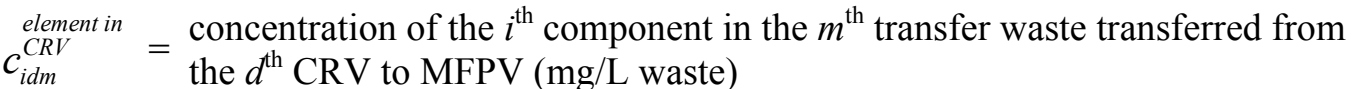

$$
\begin{aligned}
& f_{i}=\begin{array}{l}
\text { oxide conversion factor, i.e., mass of the } i^{\text {th }} \text { glass oxide per mass of the } i^{\text {th }} \\
\text { element }
\end{array} \\
& n_{j}^{\stackrel{\text { oxides in }}{M F P V}}=\begin{array}{l}
\text { number of glass oxides tracked in the mass balance calculations for the } j^{\text {th }} \\
\text { MFPV batch }
\end{array} \\
& n_{j}^{G F P V}=\text { number of GFCs used in the } j^{\text {th }} \text { MFPV batch } \\
& \underset{m_{i k}^{\text {oxidein }}}{\text { GFC }}=\begin{array}{l}
\text { mass fraction of the } i^{\text {th }} \text { glass oxide in the } k^{\text {th }} \text { GFC (g oxide per g GFC } \\
\text { including volatiles). }
\end{array} \\
& M_{k j}^{\text {GFCin } \text {,target,Step } 1}=\begin{array}{l}
\text { target mass of } k^{\text {th }} \text { GFC to add to the } j^{\text {th }} \text { MFPV batch resulted from algorithm } \\
\text { calculation Step } 1(\mathrm{~g})
\end{array} \\
& \tilde{a}_{i j}^{\text {radin }} \text { MFPV,Step } 1=\text { specific activity of the } i^{\text {th }} \text { radionuclide in the } j^{\text {th }} \text { MFPV batch from algorithm } \\
& v_{i}=\text { retention factor for the } i^{\text {th }} \text { component (fraction) } \\
& \text { oxidein mass fraction of the } i^{\text {th }} \text { glass oxide in the } j^{\text {th }} \text { MFPV batch from algorithm } \\
& g_{i j}^{M P P V, \text { Step } 1}=\underset{\text { calculation Step } 1 \text { after applying component retention factors (g oxide per } \mathrm{g}}{ }
\end{aligned}
$$

Here, Equation (69) is used instead of Equation (53) so that the SD of specific activity of radionuclide in glass can be calculated based on uncertain input values summarized in Table 9. The SD values for specific activity of radionuclide $\left(\tilde{S}_{i j}^{M F P V, \text { Step } 1}\right)$ for algorithm calculation Step 1 after applying retention factors are obtained by Monte Carlo simulations of Equation (70).

The radionuclide concentration limits are based on the activity of each radionuclide either per unit glass mass or per unit glass volume. The specific activity of radionuclides from Equation (54) and its SD are converted to per unit glass volume using:

$$
\begin{aligned}
& \hat{\tilde{a}}_{i j}^{\text {radin }} \begin{array}{l}
\text { radin } \\
\text { rad }
\end{array}=\tilde{a}_{i j}^{M F P V, \text { Step } 1} \rho_{j}^{\text {glass in }}
\end{aligned}
$$

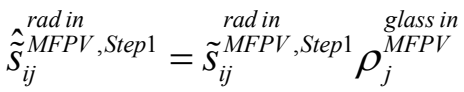

where $\quad \hat{\tilde{a}}_{i j}^{\text {radin }}$ MFV,Step $1=\begin{aligned} & \text { activity of the } i^{\text {th }} \text { radionuclide per unit volume of glass in the } j^{\text {th }} \text { MFPV batch from } \\ & \text { algorithm calculation Step } 1 \text { after applying retention factors }\left(\mathrm{Ci} / \mathrm{m}^{3} \text { glass }\right)\end{aligned}$

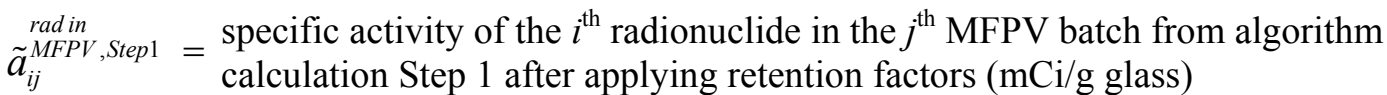

$$
\rho_{j}^{\substack{\text { glass in } \\ M F P V}}=\text { density of glass in the } j^{\text {th }} \text { MFPV batch }(\mathrm{g} / \mathrm{L})
$$




$$
\begin{aligned}
\begin{aligned}
& \text { SD for the activity of the } i^{\text {th }} \text { radionuclide per unit volume of glass in the } j^{\text {th }} \text { MFPV } \\
& \tilde{\tilde{S}}_{i j}^{M F P V, S t e p 1}= \text { batch from algorithm calculation Step } 1 \text { after applying retention factors }\left(\mathrm{Ci} / \mathrm{m}^{3}\right. \\
&\text { glass }) \\
& \tilde{s}_{i j}^{\text {radin }} \text { SD for the specific activity of the } i^{\text {th }} \text { radionuclide in the } j^{\text {th }} \text { MFPV batch from } \\
& \text { algorithm calculation Step } 1 \text { after applying retention factors (mCi/g glass) }
\end{aligned}
\end{aligned}
$$

The relation between uncertainty and standard deviation is in general given as $U=k s$ where $U$ is the uncertainty, $s$ is the standard deviation, and $k$ is the expansion factor. The expansion factor for various specifications ("spec"), $k^{\text {spec }}$ is a function of the confidence level (CL), i.e., the $k$ value is 1 for $68.27 \%$ CL, 1.645 for $90 \%$ CL, 1.960 for $95 \%$ CL, 2 for $95.45 \%$ CL, 2.576 for $99 \%$ CL, 3 for $99.73 \%$ CL, etc. ${ }^{(9)}$ The requirements for ${ }^{137} \mathrm{Cs}$ and ${ }^{90} \mathrm{Sr}$ are satisfied if the following conditions are satisfied:

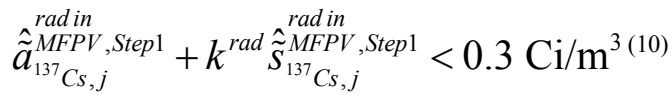

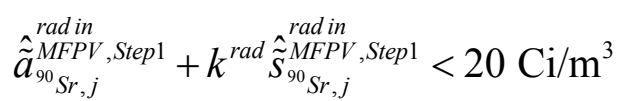

\begin{tabular}{|c|c|c|}
\hline Radionuclide (i) & $L_{u}^{\hat{a}_{i}}, \mathbf{C i} / \mathbf{m}^{3}$ & $L_{u}^{a_{i}}, \mathbf{n C i} \mathbf{i g}$ \\
\hline${ }^{99} \mathrm{Tc}$ & 3 & \\
\hline${ }^{129} \mathrm{I}$ & 0.08 & \\
\hline $\mathrm{TRU}^{(\mathrm{a})}$ & & 100 \\
\hline${ }^{241} \mathrm{Pu}$ & & 3,500 \\
\hline${ }^{242} \mathrm{Cm}$ & & 20,000 \\
\hline \multicolumn{3}{|c|}{$\begin{array}{l}\text { (a) Alpha emitting transuranic nuclides with half-life greater } \\
\text { than } 5 \text { years for Hanford LAW }(24590 \text {-WTP-PL-RT-03-001) } \\
={ }^{237} \mathrm{~Np},{ }^{238} \mathrm{Pu},{ }^{239} \mathrm{Pu},{ }^{240} \mathrm{Pu},{ }^{241} \mathrm{Am},{ }^{242} \mathrm{Pu},{ }^{243} \mathrm{Am},{ }^{243} \mathrm{Cm} \text {, and } \\
{ }^{244} \mathrm{Cm} \text {. The total alpha counting measured in LAW 1a } \\
\text { sample will be used instead of TRU activity calculated as } \\
\text { sum of acitivities of these nuclides measured in LAW 1b } \\
\text { sample. }\end{array}$} \\
\hline
\end{tabular}

where $k^{\text {rad }}$ is the expansion factor for radionuclide concentration specification.

To demonstrate that the waste meets the classification of Class C waste or below, limiting values for $\stackrel{\tilde{\tilde{a}}}{i j}^{\text {radin }}$ and $\underset{a_{i j}^{M F P V}}{\stackrel{\text { radin }}{M F P}}$; listed in Table 15 and Table 16, are used.

Table 15. Long Lived Radionuclides Class C Limits

(9) The Contract Specification 2.2.2.8 and Section C.7 (d).(1).(iii) do not specify the required confidence level.

(10) The lower of two requirements, $3 \mathrm{Ci} / \mathrm{m}^{3}$ for Contract (DOE 2000) Specification 2.2.2.8 and 0.3 Ci $/ \mathrm{m}^{3}$ for Contract (DOE 2000) Section C.7 (d).(1).(iii), is applied. 
Table 16. Short Lived Radionuclides Class C Limits

\begin{tabular}{|l|c|}
\hline \hline Radionuclide $(\boldsymbol{j})$ & $L_{u}^{\hat{a}_{i}}, \mathbf{C i} / \mathbf{m}^{\mathbf{3}}$ \\
\hline${ }^{63} \mathrm{Ni}$ & 700 \\
\hline${ }^{90} \mathrm{Sr}$ & 7,000 \\
\hline${ }^{137} \mathrm{Cs}$ & 4,600 \\
\hline
\end{tabular}

According to 10 CFR 61.55:

(3) (iv) For wastes containing mixtures of radionuclides listed in [Table 15], the total concentration shall be determined by the sum of fractions rule described in paragraph (a)(7) of [10CFR61.55].

(4) Classification determined by short lived radionuclides. If radioactive waste does not contain any of the radionuclides listed in [Table 15], classification shall be determined based on the concentrations shown in [Table 16] ...

(5) Classification determined by both long-and short-lived radionuclides. If radioactive waste contains a mixture of radionuclides, some of which are listed in [Table 15], and some of which are listed in [Table 16], classification shall be determined as follows: (i) If the concentration of a nuclide listed in [Table 15] does not exceed 0.1 times the value listed in [Table 15], the class shall be determined by the concentration of nuclides listed in [Table 16]. (ii) If the concentration of a nuclide listed in [Table 15] exceeds 0.1 times the value listed in [Table 15] the waste shall be Class $C$, provided the concentration does not exceed the value shown in... [Table 16].

The first step to classification is then to determine if there are any radionuclides with measurable concentrations ( $\tilde{\tilde{a}}_{i j}^{\text {radin }}{ }^{M F V \text { Step } 1}$ for ${ }^{99} \mathrm{Tc},{ }^{129} \mathrm{I},{ }^{63} \mathrm{Ni},{ }^{90} \mathrm{Sr}$, and ${ }^{137} \mathrm{Cs}$, or $\tilde{a}_{i j}^{\text {radin }}{ }^{M F P V \text { Step } 1}$ for TRU, ${ }^{241} \mathrm{Pu}$, and ${ }^{242} \mathrm{Cm}$ ). If non-zero values are present for radionuclides only in Table 15 or only in Table 16, then only those tables are used for classification. If there are non-zero values for both tables, then Table 15 is used for classification if any one radionuclide from Table 15 is greater than $10 \%$ of its associated limit. If no Table 15 radionuclide has a concentration greater than or equal to its associated limit, then Table 16 is used for classification. The sum of fractions rule is used for classification:

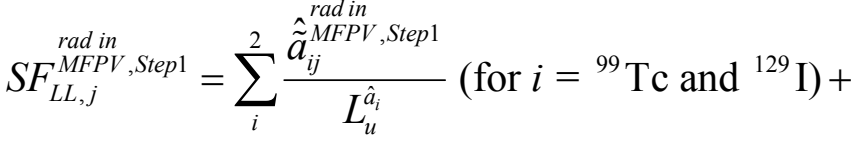

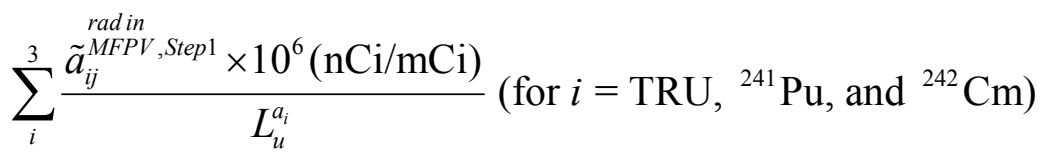

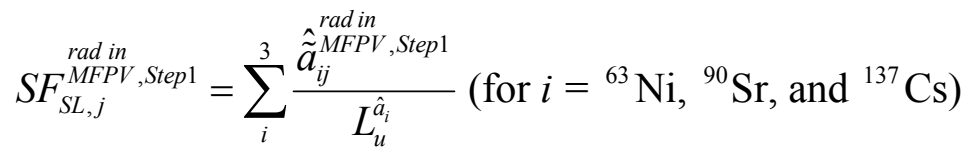

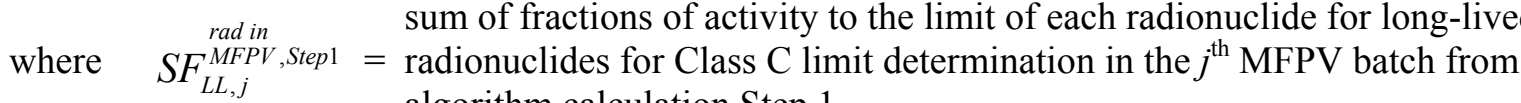
algorithm calculation Step 1

$$
\begin{aligned}
& \text { rad in sum of fractions of activity to the limit of each radionuclide for short-lived } \\
& S F_{S L, j}^{M F P V, S t e p 1}=\text { radionuclides for Class C limit determination in the } j^{\text {th }} \text { MFPV batch from } \\
& \text { algorithm calculation Step } 1
\end{aligned}
$$




$$
\begin{aligned}
\begin{aligned}
\text { radin } \\
\tilde{\tilde{a}}_{i j}^{M F P V, S t e p 1}
\end{aligned} & \begin{array}{l}
\text { activity of the } i^{\text {th }} \text { radionuclide per unit volume of glass in the } j^{\text {th }} \text { MFPV batch } \\
\text { from algorithm calculation Step } 1 \text { after applying retention factors }\left(\mathrm{Ci} / \mathrm{m}^{3} \text { glass }\right)
\end{array} \\
\tilde{a}_{i j}^{\text {radin }} & =\begin{array}{l}
\text { specific activity of the } i^{\text {th }} \text { radionuclide in the } j^{\text {th }} \text { MFPV batch from algorithm } \\
\text { calculation Step } 1 \text { after applying retention factors ( } \mathrm{mCi} / \mathrm{g} \text { glass) }
\end{array} \\
L_{u}^{\hat{a}_{i}}= & \begin{array}{l}
\text { upper limit for the activity of the } i^{\text {th }} \text { radionuclide per unit glass volume }\left(\mathrm{Ci} / \mathrm{m}^{3}\right. \\
\text { glass) }
\end{array} \\
L_{u}^{a_{i}}= & \text { upper limit for specific activity of the } i^{\text {th }} \text { radionuclide (nCi/g glass) }
\end{aligned}
$$

The standard deviations for $S F_{L L, j}^{\text {rad in }}$,Step 1 and $S F_{S L, j}^{\text {rad in }}$,Step 1 are given as:

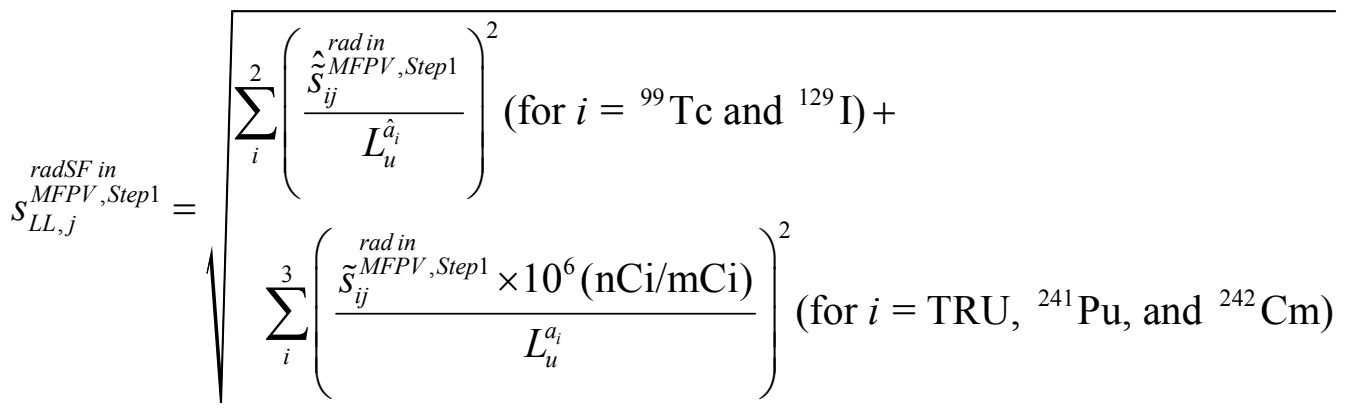

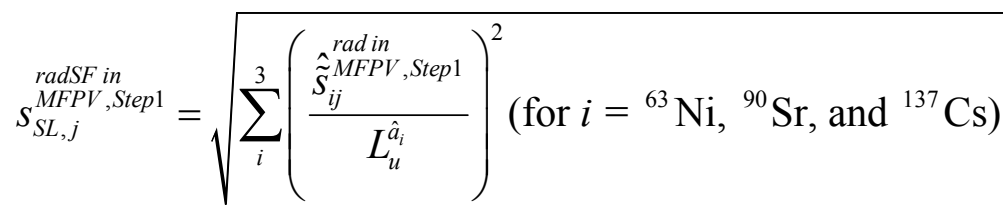

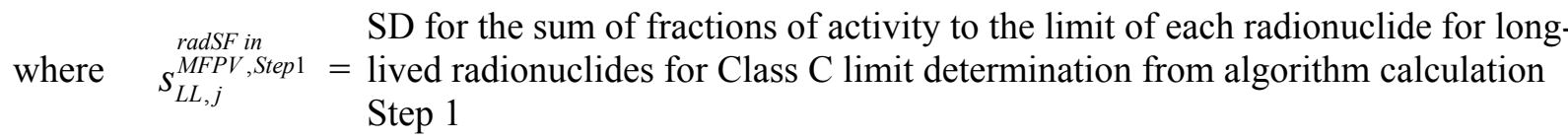

radSF in $\quad$ SD for the sum of fractions of activity to the limit of each radionuclide for short-

$s_{S L, j}^{M F P V, S t e p 1}=$ lived radionuclides for Class C limit determination from algorithm calculation Step 1

radin SD for the activity of the $i^{\text {th }}$ radionuclide per unit volume of glass in the $j^{\text {th }}$ MFPV $\hat{\tilde{s}}_{i j}^{M F P V, \text { Step } 1}=\begin{aligned} & \text { batch from algorithm calculation Step } 1 \text { after applying retention factors }\left(\mathrm{Ci} / \mathrm{m}^{3}\right. \\ & \text { glass })\end{aligned}$

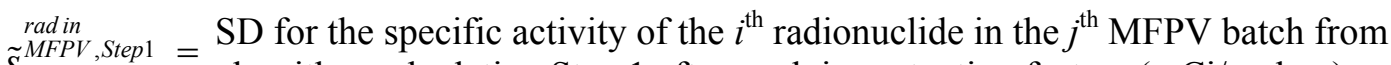

$\tilde{s}_{i j}^{M F P V, S t e p 1}=$ algorithm calculation Step 1 after applying retention factors (mCi/g glass)

$L_{u}^{\hat{a}_{i}}=\begin{aligned} & \text { upper limit for the activity of the } i^{\text {th }} \text { radionuclide per unit glass volume }\left(\mathrm{Ci} / \mathrm{m}^{3}\right. \\ & \text { glass }\end{aligned}$

$L_{u}^{a_{i}}=$ upper limit for specific activity of the $i^{\text {th }}$ radionuclide (nCi/g glass)

The Class C limit is satisfied as long as the following two conditions are satisfied: 


$$
\begin{aligned}
& S F_{L L, j}^{\text {rad in }}{ }^{M F P V, \text { Step } 1}+k^{\text {rad }} S_{L L, j}^{\text {MFPV }, \text { Step } 1}<1
\end{aligned}
$$

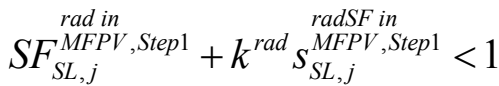

\subsubsection{Surface Dose Rate Constraint}

The Contract (DOE 2000) Specification 2.2.2.9 requires that the surface dose rate of the canister be at or lower than $500 \mathrm{mrem} / \mathrm{h}$. The ILAW PCP (24590-WTP-PL-RT-03-001) specifies that the compliance for this constraint will be confirmed by monitoring the surface dose rate of each ILAW container using handheld instrumentation or automated monitoring equipment prior to transfer for disposal. The surface dose rate calculation will not be performed by ILAW formulation algorithm.

\subsubsection{Adjustment of Target Glass Composition}

If all constraints (with uncertainties factored in) calculated from the initial glass formulation in Section 5.1.3 are met, the result of waste transfer volume calculation in Section 5.1.5 becomes the final output of Step 1 calculation.

The original glass formulation rules developed by Muller et al. (2004), Equations (25) and (32) through (45), were designed so that all the glasses formulated within these rules would pass all property requirements. It was recently discovered that some glasses formulated by applying both the Muller et al. (2004) rules and new rules (CCN 150795) fail the property and model validity constraints when applied to the present algorithm (Piepel et al. 2007). There are three changes that are likely to contribute to this: (1) new models with new model validity ranges (Piepel et al. 2007) have been implemented compared to the preliminary models and model validity ranges used to formulate the Muller et al. (2004) rules, (2) new glass formulation rules (CCN 150795) have been added, and (3) there have been changes in the projected composition of wastes from those used as a basis for the development of the Muller et al. (2004) rules.

A glass formulation study was performed to identify the constraints that fail when formulated following the steps described in Section 5.1.3 and then to develop the approach to adjust the target glass composition (i.e., deviate from the Muller et al. (2004) rules) using one set of the projected waste compositions. The same waste compositions as used for example calculations in Section 6 were used (see Section 6 for detailed description of the projected waste compositions). The results of this study are described below.

If the formulation fails one of the constraints, target $\mathrm{Na}_{2} \mathrm{O}$ loading or target glass composition needs to be adjusted depending on which constraint is failed. The constraints that failed and the required adjustment for each failed constraint are:

1. Single component model validity constraint for $\mathrm{F}$ (decrease $\mathrm{Na}_{2} \mathrm{O}$ loading)

2. Radionuclide concentration limits for ${ }^{90} \mathrm{Sr}$ and ${ }^{137} \mathrm{Cs}$ and Class $\mathrm{C}$ limit for long lived radionuclides caused by TRU concentration (decrease $\mathrm{Na}_{2} \mathrm{O}$ loading)

3. Multi-component model validity constraint for $\mathrm{Na}_{2} \mathrm{O}-\mathrm{SiO}_{2}$ (decrease $\mathrm{Na}_{2} \mathrm{O}$ loading)

4. Multi-component model validity constraint for $\mathrm{P}_{2} \mathrm{O}_{5}-\mathrm{Cr}_{2} \mathrm{O}_{3}$ (decrease $\mathrm{Na}_{2} \mathrm{O}$ loading)

5. Multi-component model validity constraint for $\mathrm{Li}_{2} \mathrm{O}-\mathrm{SO}_{3}$ (decrease $\mathrm{Li}_{2} \mathrm{O}$ target concentration)

6. Multi-component model validity constraint for $\mathrm{Na}_{2} \mathrm{O}-\mathrm{SO}_{3}$ (increase $\mathrm{Na}_{2} \mathrm{O}$ target concentration from GFC)

7. Upper limit for electrical conductivity at $1200^{\circ} \mathrm{C}$ (decrease $\mathrm{Na}_{2} \mathrm{O}$ loading)

8. Upper limit for viscosity at $1150^{\circ} \mathrm{C}$ (increase $\mathrm{Li}_{2} \mathrm{O}$ target concentration) 
There are waste compositions that fail additional constraints after the first adjustment of target $\mathrm{Na}_{2} \mathrm{O}$ loading or glass composition to meet the initial constraint that failed. After each adjustment of target $\mathrm{Na}_{2} \mathrm{O}$ loading or glass composition, the calculation of waste transfer volume and predicted properties with uncertainties and all constraint quantities are calculated for adjusted formulation before next adjustment is calculated.

The adjustment of target $\mathrm{Na}_{2} \mathrm{O}$ loading or glass composition described above, which may not work for different set of waste compositions, should be regarded as an intermediate solution. It is desirable to revise the glass formulation rules or expand the model validity range so that compliant glasses can be formulated without adjustment for all expected waste compositions, especially for those wastes that require significant decrease of $\mathrm{Na}_{2} \mathrm{O}$ loading (i.e., waste loading). The decrease of waste loading increases the overall waste treatment cost and for some wastes a large decrease of waste loading may lead to a failure of a contract waste loading requirement. The equations used to adjust the target $\mathrm{Na}_{2} \mathrm{O}$ loading or glass composition are described below.

If the initial formulation fails the constraints other than above listed or the adjustment described below does not lead to a compliant formulation an interruption by qualified staff is required.

\subsubsection{Adjustment of Target $\mathrm{Na}_{2} \mathrm{O}$ Loading}

For the case of decreasing the target $\mathrm{Na}_{2} \mathrm{O}$ loading $\left(\# 1,2,3,4\right.$, and 7), the adjusted preliminary target $\mathrm{Na}_{2} \mathrm{O}$ concentration in glass $\left(\begin{array}{c}\text { oxidein } \\ \mathrm{NFPV}^{\mathrm{MF}, \mathrm{pre}-\mathrm{adj}}\end{array}\right)$ is given as:

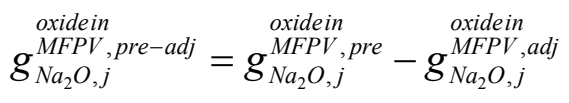

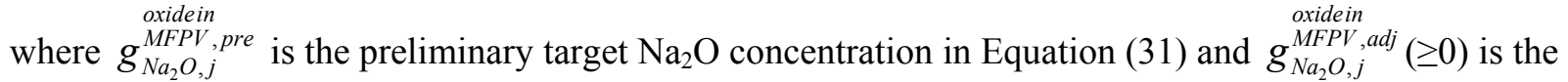

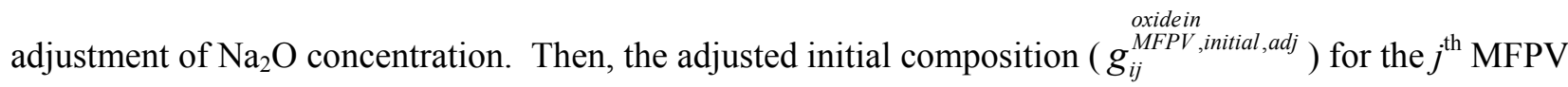
batch is obtained by applying Equations (32) through (45) in Section 5.1.3 after replacing $g_{\mathrm{Na}_{2} O, j}^{M P V, p r e}$ with $g_{\mathrm{Na}_{2} \mathrm{O}, j}^{\mathrm{Mxidein} \text {,pre-adj }}$ and the superscript "initial" is replaced by "initial,adj". The adjusted initial glass composition

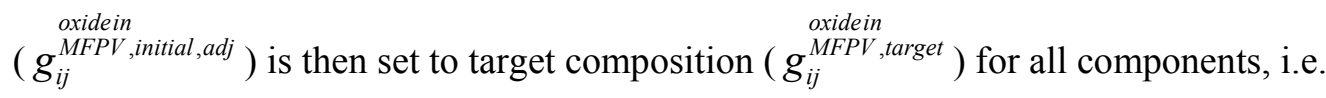

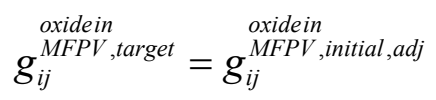

and used to calculate the Step 1 glass and radionuclide compositions (Section 5.1.4) and waste transfer volume (Section 5.1.5). The glass and radionuclide compositions and waste transfer volume are used to calculate the constraint quantities and compare them with the limits (Section 5.1.6).

Equation (83) computes the ratios of loading and predicted properties (with their uncertainties) to their corresponding limits (constraints) and ensures this ratio (after applying $\delta$ ) is less than one. The method of target $\mathrm{Na}_{2} \mathrm{O}$ loading adjustment is to find the $g_{\mathrm{Na}_{2} \mathrm{O}, j}^{\mathrm{MFPV}, \mathrm{dadj}}$ value that satisfies the following equation through iterative calculations: 


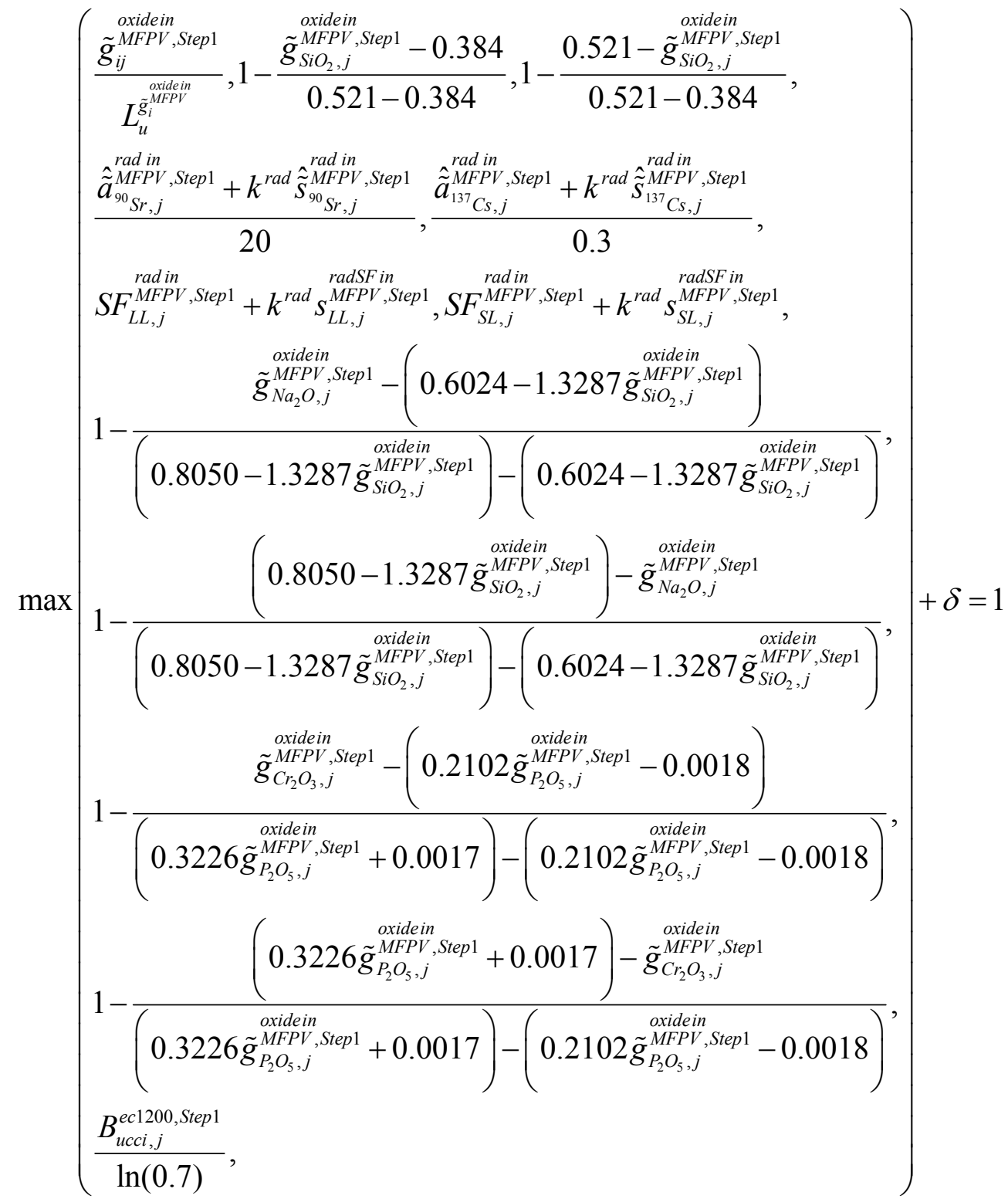

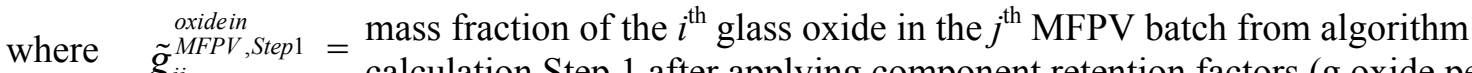
$\tilde{g}_{i j}^{M F P V, S t e p 1}=$ calculation Step 1 after applying component retention factors (g oxide per g glass) model validity upper limit for the mass fraction of the $i^{\text {th }}$ glass oxide after $L_{u}^{\substack{\text { oxidein } \\ \tilde{g}_{i}^{M F P V}}}=\begin{aligned} & \text { applying component retention factors (g oxide per g glass) for } i=\mathrm{Al}_{2} \mathrm{O}_{3}, \mathrm{Cl} \text {, } \\ & \mathrm{Cr}_{2} \mathrm{O}_{3}, \mathrm{~F}, \mathrm{P}_{2} \mathrm{O}_{5} \text {, and Sum of Minors as given in }\end{aligned}$ Table 11

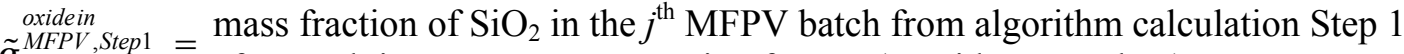
$\tilde{g}_{\mathrm{SiO}_{2}, j}^{\mathrm{M}}=$ after applying component retention factors (g oxide per g glass) $k^{\text {rad }}=$ expansion factor for radionuclide concentration specification 


$$
\begin{aligned}
& \text { rad in activity of the } i^{\text {th }} \text { radionuclide }\left(i={ }^{90} \mathrm{Sr} \text { or }{ }^{137} \mathrm{Cs}\right) \text { per unit volume of glass in the } j^{\text {th }} \\
& \hat{\tilde{a}}_{i j}^{M F P V, S t e p 1}=\text { MFPV batch from algorithm calculation Step } 1 \text { after applying retention factors } \\
& \left(\mathrm{Ci} / \mathrm{m}^{3} \text { glass }\right) \\
& \text { rad in SD for the activity of the } i^{\text {th }} \text { radionuclide }\left(i={ }^{90} \mathrm{Sr} \text { or }{ }^{137} \mathrm{Cs}\right) \text { per unit volume of } \\
& \hat{\tilde{s}}_{90}^{M F P V, \text { Step } 1}=\text { glass in the } j^{\text {th }} \text { MFPV batch from algorithm calculation Step } 1 \text { after applying } \\
& \text { retention factors }\left(\mathrm{Ci} / \mathrm{m}^{3} \text { glass }\right) \\
& \text { rad in sum of fractions of activity to the limit of each radionuclide for long-lived } \\
& S F_{L L, j}^{M F P V, S t e p 1}=\text { radionuclides for Class C limit determination in the } j^{\text {th }} \text { MFPV batch from } \\
& \text { algorithm calculation Step } 1 \\
& \text { radSF in } \quad \mathrm{SD} \text { for the sum of fractions of activity to the limit of each radionuclide for long- } \\
& s_{L L, j}^{M F P V, S t e p 1}=\text { lived radionuclides for Class } \mathrm{C} \text { limit determination from algorithm calculation } \\
& \text { Step } 1 \\
& \text { rad in sum of fractions of activity to the limit of each radionuclide for short-lived } \\
& S F_{S L, j}^{M F P V, S t e p 1}=\text { radionuclides for Class C limit determination in the } j^{\text {th }} \text { MFPV batch from } \\
& \text { algorithm calculation Step } 1 \\
& \text { radSF in } \quad \mathrm{SD} \text { for the sum of fractions of activity to the limit of each radionuclide for short- } \\
& s_{S L, j}^{M F P V, S t e p 1}=\text { lived radionuclides for Class C limit determination from algorithm calculation } \\
& \text { Step } 1 \\
& B_{u c c i, j}^{e c 1200, S t e p 1}=\begin{array}{l}
\mathrm{CL} \% \text { upper combined confidence interval for predicted "ec1200" for the } j^{\text {th }} \text { MFPV } \\
\text { batch from algorithm calculation Step } 1 \text { (in property model units) }
\end{array} \\
& \text { a unitless constant larger than zero and typically smaller than } 0.01^{11} \text { introduced to } \\
& \delta=\text { accommodate the variations resulting from Monte Carlo calculation of } \\
& \text { composition uncertainties }
\end{aligned}
$$

If all constraints calculated from the adjusted target composition described above are met, the result of waste transfer volume calculation in Section 5.1.5 becomes the final output of Step 1 calculation.

\subsubsection{Adjustment of Target $\mathrm{Li}_{2} \mathrm{O}$ or $\mathrm{Na}_{2} \mathrm{O}$ Concentration}

For the case of adjusting target concentration of $\mathrm{Li}_{2} \mathrm{O}$ or $\mathrm{Na}_{2} \mathrm{O}\left(\# 5,6\right.$, and 8), the Equation (46) for $\mathrm{Li}_{2} \mathrm{O}$ or $\mathrm{Na}_{2} \mathrm{O}$ is replaced by:

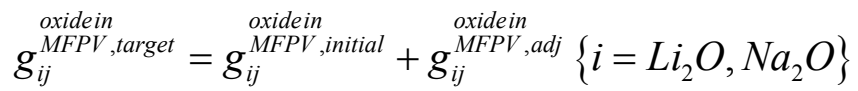

$$
\begin{aligned}
& \text { where } g_{i j}^{\substack{\text { oxidein } \\
\text { MFPV target }}}=\begin{array}{l}
\text { target mass fraction of the } i^{\text {th }} \text { glass oxide in the } j^{\text {th }} \text { MFPV batch (g oxide per } g \\
\text { MFPV oxides) }
\end{array}
\end{aligned}
$$

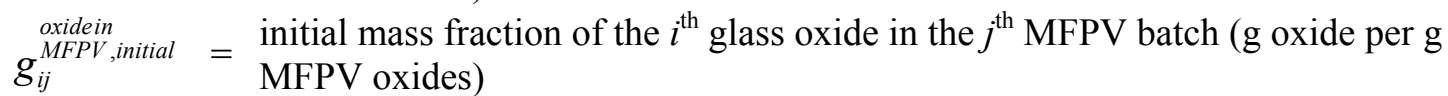

$$
\begin{aligned}
& \text { adjustment made to the target mass fraction of the } i^{\text {th }} \text { glass oxide in the } j^{\text {th }} \text { MFPV }
\end{aligned}
$$

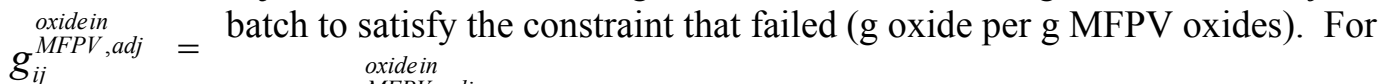

$$
\begin{aligned}
& \mathrm{Na}_{2} \mathrm{O}\left(g_{\mathrm{Na}_{2} \mathrm{O}, j}^{\mathrm{MFPV}, \mathrm{adj}} \geq 0\right) \text { the increase of } \mathrm{Na}_{2} \mathrm{O} \text { is supplied from GFC not from waste. }
\end{aligned}
$$

\footnotetext{
${ }^{11}$ The required value of $\delta$ depends on the number of simulations used in Monte Carlo calculation of composition uncertainties. The value of 0.01 was sufficiently large for 5000 simulations.
} 
The method of target $\mathrm{Li}_{2} \mathrm{O}$ concentration adjustment to meet the multi-component model validity constraint for $\mathrm{Li}_{2} \mathrm{O}-\mathrm{SO}_{3}$ is to find the $g_{L_{2} O, j}^{M F P V, a d j}$ value that satisfies the following equation through iterative calculations:

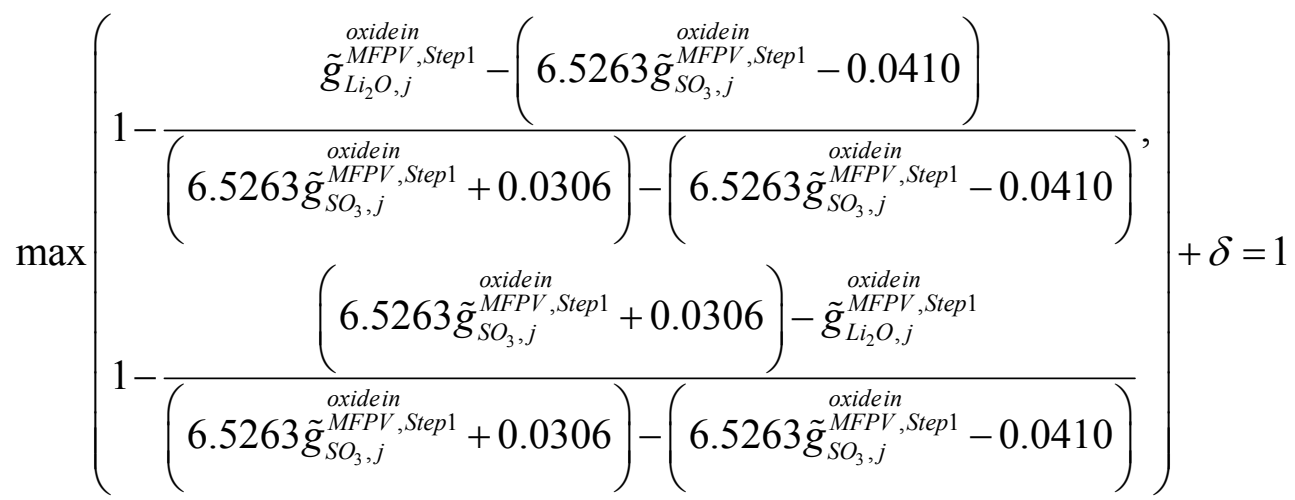

where $\tilde{g}_{i j}^{\text {oxidein }}{ }_{i j}^{\text {MFV Step } 1}$ is the mass fraction of the $i^{\text {th }}$ glass oxide in the $j^{\text {th }}$ MFPV batch from algorithm calculation Step 1 after applying component retention factors (g oxide per g glass) and $\delta$ is a unitless constant larger than zero and typically smaller than 0.01 introduced to accommodate the variations resulting from Monte Carlo calculation of composition uncertainties.

The method of target $\mathrm{Na}_{2} \mathrm{O}$ concentration adjustment to meet the multi-component model validity constraint

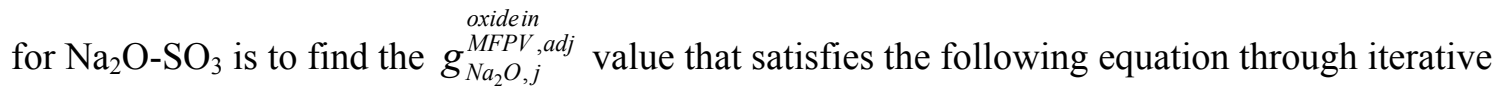
calculations:

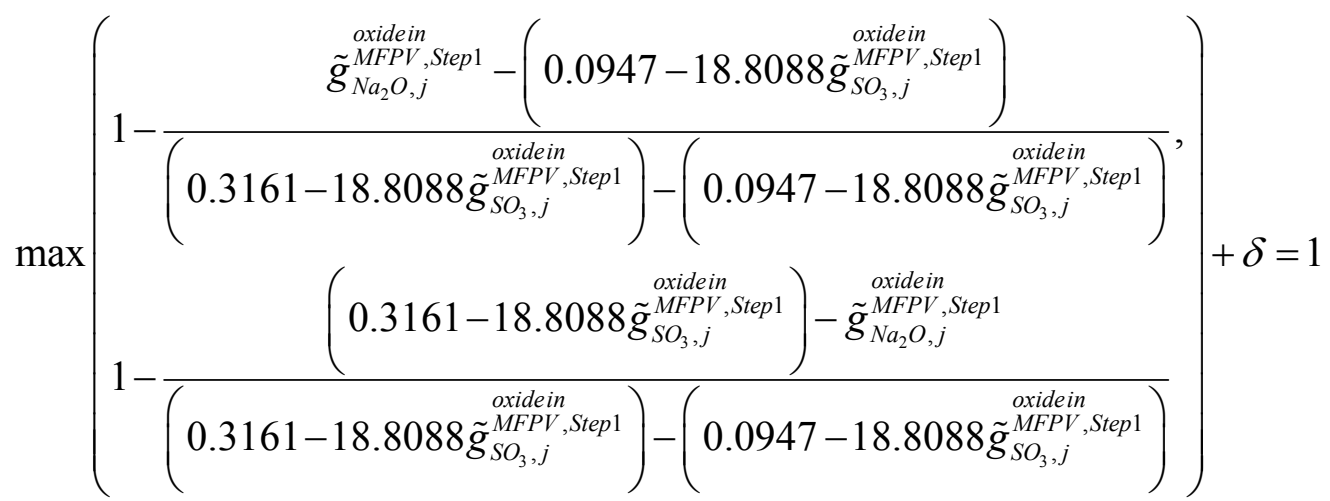

The method of target $\mathrm{Li}_{2} \mathrm{O}$ concentration adjustment to meet the upper limit for viscosity at $1150^{\circ} \mathrm{C}$ is to find the $g_{L i_{2} O, j}^{M M^{O} \text {,adj }}$ value that satisfies the following equation through iterative calculations:

$$
\frac{\exp \left(B_{u c c i, j}^{v i s 1150, \text { Step } 1}\right)}{80}+\delta=1
$$


where $B_{u c c i, j}^{v i s 150, \text { Step } 1}$ is the CL\% upper combined confidence interval for predicted "vis 1150 " for the $j^{\text {th }}$ MFPV batch from algorithm calculation Step 1 (in property model units).

There are no changes in the waste loading and in target concentrations for all components other than that being adjusted $\left(\mathrm{Li}_{2} \mathrm{O}\right.$ or $\left.\mathrm{Na}_{2} \mathrm{O}\right)$ and $\mathrm{SiO}_{2}$. The change in the target concentration of the component being adjusted is given by Equation (84), which results in the change of $\mathrm{SiO}_{2}$ target concentration as:

$$
g_{\mathrm{SiO}_{2}, j}^{\mathrm{MFPV, \text {target }}}=g_{\mathrm{SiO}_{2}, j}^{\stackrel{\text { oxidein }}{M F P V i t i a l}}-g_{i j}^{\stackrel{\text { oxidein }}{M F P V, \text { adj }}}\left\{i=\mathrm{Li}_{2} \mathrm{O}, \mathrm{Na} \mathrm{O}_{2} \mathrm{O}\right\}
$$

$$
\begin{aligned}
& \text { where } \frac{\substack{\text { oxidein } \\
M F P V, \text { target }}}{\mathrm{SiO}_{2}, j}=\text { target mass fraction of } \mathrm{SiO}_{2} \text { in the } j^{\text {th }} \text { MFPV batch (g oxide per } \mathrm{g} \text { MFPV oxides) }
\end{aligned}
$$

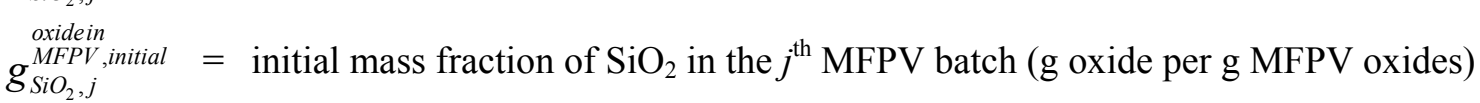

$$
\begin{aligned}
& \text { adjustment made to the target mass fraction of the } i^{\text {th }} \text { glass oxide in the } j^{\text {th }} \text { MFPV } \\
& { }_{M F P V, a d j}^{o x i d e i n}=\text { batch to satisfy the constraint that failed (g oxide per g MFPV oxides). For } \\
& g_{i j}^{M F P V, a d j}=\quad \text { oxidein } \\
& \mathrm{Na}_{2} \mathrm{O}\left(g_{\mathrm{Na}_{2} \mathrm{O}, j}^{\mathrm{MFPV}, \text { adj }} \geq 0\right) \text { the increase of } \mathrm{Na}_{2} \mathrm{O} \text { is supplied from GFC not from waste. }
\end{aligned}
$$

If all constraints calculated from Section 5.1.6 based on the adjusted target composition described above are met, the result of waste transfer volume calculation in Section 5.1.5 becomes the final output of Step 1 calculation.

\subsection{Step 2 - Calculation of GFC Masses and Dilution Water Volume}

The actual waste volume $\left(V_{j}^{\text {waste }}\right.$ ) added to the MFPV is obtained based on the volume change in the MFPV as described in Appendix D. In Step 2, the measured waste transfer volume is used to calculate the masses of GFCs and sucrose to add to the MFPV:

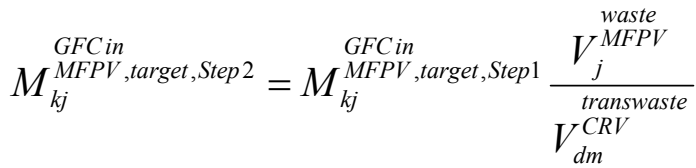

$$
\begin{aligned}
& M_{j}^{\substack{\text { sucrosein } \\
\text { MFPV,target,Step 2 }}}=M_{j}^{\substack{\text { sucrosein } \\
\text { MFPV,target ,Step } 1}} \frac{\begin{array}{c}
\text { waste } \\
\text { MFPV }
\end{array}}{V_{d m}^{\text {transwaste }}}
\end{aligned}
$$

where $M_{k j}^{G F P \text {, target,Step } 2}=\begin{aligned} & \text { target mass of } k^{\text {th }} \text { GFC to add to the } j^{\text {th }} \text { MFPV batch in algorithm calculation } \\ & \text { Step } 2(\mathrm{~g})\end{aligned}$

$$
\begin{aligned}
& M_{k j}^{\text {GFC , target,Step } 1}=\begin{array}{l}
\text { target mass of } k^{\text {th }} \text { GFC to add to the } j^{\text {th }} \text { MFPV batch resulted from algorithm } \\
\text { calculation Step } 1(\mathrm{~g})
\end{array}
\end{aligned}
$$

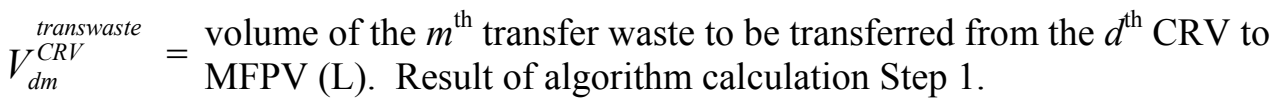




$$
\begin{aligned}
\qquad \begin{array}{l}
\text { waste } \\
V_{j}^{M F P V}
\end{array} & =\text { measured volume of waste transferred from CRV to the } j^{\text {th }} \text { MFPV (L) } \\
M_{j}^{\text {sucrosein }} \text { MFPV target,Step } 2 & =\begin{array}{l}
\text { target mass of sucrose to add to the } j^{\text {th }} \text { MFPV batch in algorithm calculation } \\
\text { Step } 2(\mathrm{~g})
\end{array} \\
M_{j}^{\text {sucrosein } \text {,target, Step } 1} & =\begin{array}{l}
\text { target mass of sucrose to add to the } j^{\text {th }} \text { MFPV batch resulted from algorithm } \\
\text { calculation Step } 1(\mathrm{~g})
\end{array}
\end{aligned}
$$

If the volume of waste transferred is different from that calculated in Step 1, the volume of dilution water also needs to be recalculated after accounting for changes in other process water volumes, including the CRV-MFPV line flush water and dust control water (no change for MFPV sampling line flush water). After waste is transferred from CRV to MFPV the CRV-MFPV line is flushed and the flush water is added to MFPV. The actual amount of CRV-MFPV line flush water $\left(V_{j}^{\text {transflush }} \begin{array}{l}\text { MFPV } \\ \text { measured }\end{array}\right)$, which can be different from the nominal values given in Table 14, is recorded and used for dilution water calculation. The volume of dust control water is calculated from the result of Step 1:

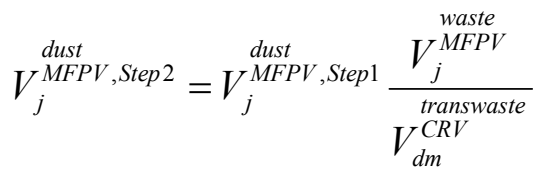

where $\quad V_{j}^{\text {dust }}$ MFPV,Step $2=\begin{aligned} & \text { volume of water added to control GFC dusting in the } j^{\text {th }} \text { MFPV batch in } \\ & \text { algorithm calculation Step 2(L) }\end{aligned}$

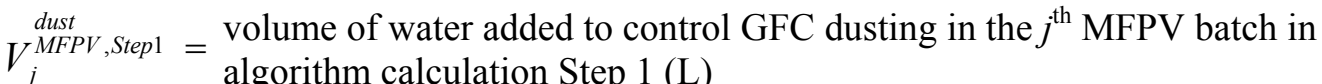
algorithm calculation Step 1 (L)

$V_{d m}^{\text {transwaste }}=\begin{aligned} & \text { volume of the } m^{\text {th }} \text { transfer waste to be transferred from the } d^{\text {th }} \text { CRV to MFPV } \\ & (\mathrm{L}) \text {. Result of algorithm calculation Step } 1 .\end{aligned}$

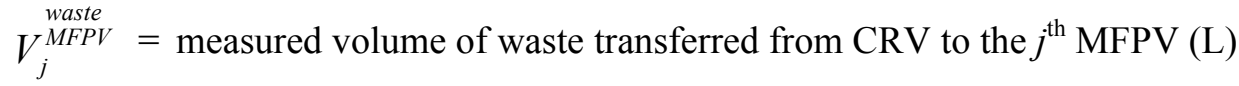

The volume of dilution water is calculated following Equation (62) using the actual waste volume ( $V_{j}^{M F P V}$ ),

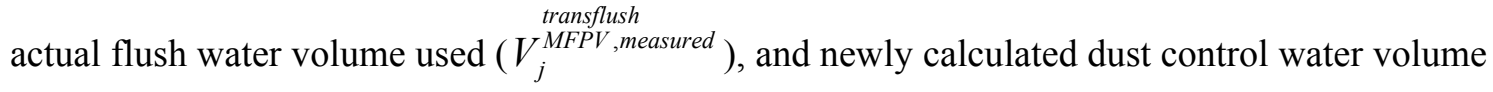
$\left(\begin{array}{l}\text { dust } \\ \left(V_{j}^{M F P V, S t e p 2}\right)\end{array}\right)$

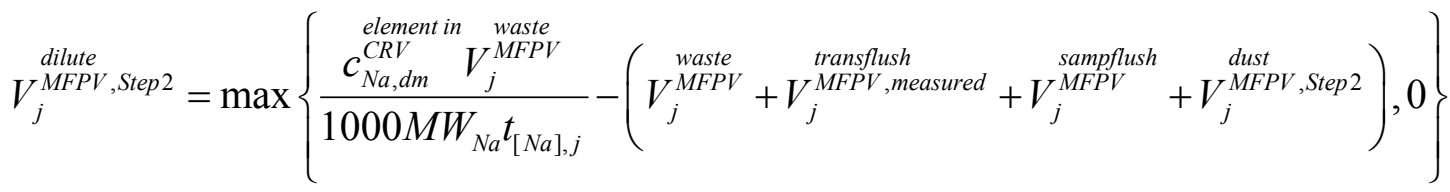

where $\quad \begin{aligned} & \text { dilute } \\ & V_{j}^{M F P V, \text { Step } 2}=\begin{array}{l}\text { volume of dilution water required to maintain satisfactory melter-feed } \\ \text { rheological properties in the } j^{\text {th }} \text { MFPV batch in algorithm calculation }\end{array}\end{aligned}$ 


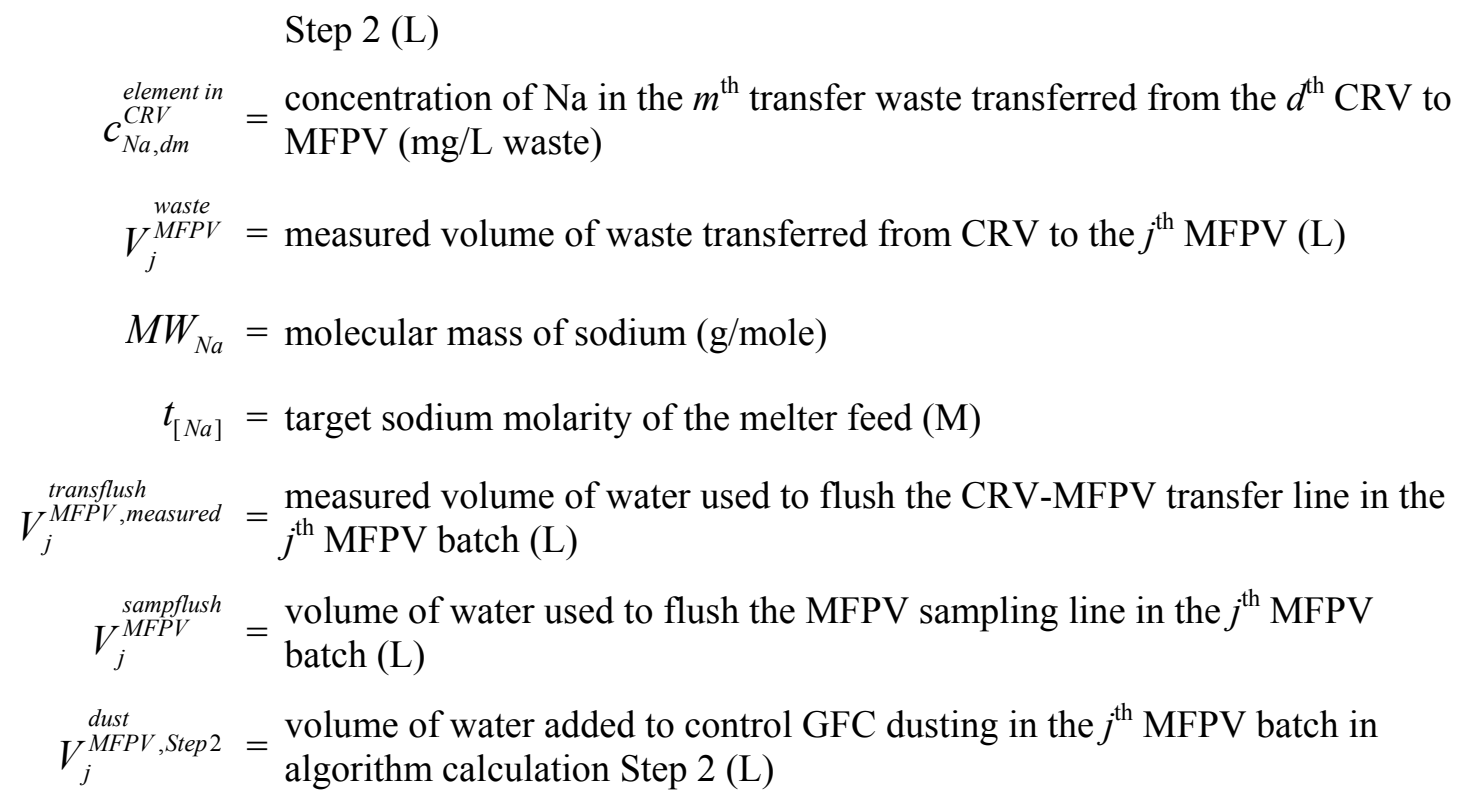

The volume contributions of GFCs and sucrose are calculated from the ratio of target and actual waste transfer volumes:

$$
\begin{aligned}
& V_{j}^{G F C} \begin{array}{c}
G F C, \text { Step 2 } \\
\text { MFC }
\end{array}=V_{j}^{M F P, \text { Step } 1} \frac{\begin{array}{c}
\text { waste } \\
\text { MFPV }
\end{array}}{V_{d m}^{\text {transwaste }}} \\
& V_{j}^{\begin{array}{c}
\text { sucrose } \\
\text { MFPV Step 2 }
\end{array}=V_{j}^{M F P V, \text { Step } 1} \frac{V_{j}^{\text {sucroste }}}{\text { transwaste }}}
\end{aligned}
$$

The nominal working volume of MFPV is $19,426 \mathrm{~L}$ which includes nominal heel volume $(6,556 \mathrm{~L})$ and nominal batch volume $(12,870 \mathrm{~L})$. If $V_{j}^{\text {waste }}>V_{d m}^{\text {transwaste }}$, the total volume of MFPV contents will increase and need to make sure that the total volume is within the allowable volume increase. It is assumed that the maximum allowable volume increase is the "High Operator Response" defined in 24590-LAW-M6C-LFP00001 , Rev 1 , which is $3,331 \mathrm{~L}\left(\mathrm{dV}_{11}=880 \mathrm{gal}\right) .{ }^{(12)}$ For the purpose of the preliminary algorithm, the allowable increase of the MFPV volume over the nominal working volume caused by the accidentally increased waste transfer volume is assumed to be a half of this $3,331 \mathrm{~L}$ or $1,666 \mathrm{~L}{ }^{(13)}$ Then, the total increase of volume originated from increased waste transfer volume is expressed as:

${ }^{(12)}$ This does not include the "Instrument Uncertainty" volume, $\mathrm{dV}_{10}$ of 156 gal (591 L) in 24590-LAW-M6C-LFP00001, Rev 1.

(13) This is a preliminary assumption. The uncertainty in the volume transfer is not established yet. The current design is to control the volume transfer based on the level measurements in CRV and MFPV. However, WTP is evaluating the use of flow meter (to be installed primarily to check the flow to protect the pump) to control the waste transfer volume. Once the control method is established, the waste transfer volume uncertainty can be accurately estimated and it is likely that the waste volume transfer will be maintained within the nominal value. 


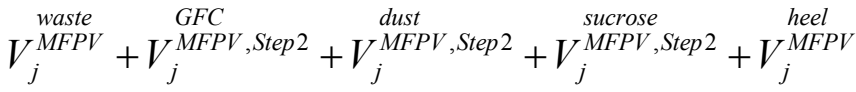

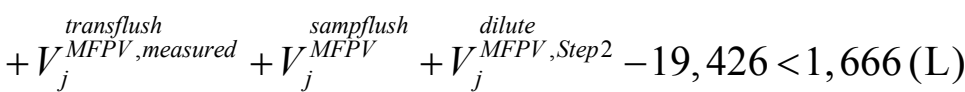

If the actual waste transfer volume was large enough to cause the total MFPV volume increase over the allowable $1,666 \mathrm{~L}$ then the operator will be alerted for intervention. ${ }^{(14)}$

Half of this 3,331 L of "High Operator Response" volume is reserved for the volume uncertainty that originates from estimating volume contributions from GFCs and sucrose. The volume contribution of GFC materials and sucrose, different from that calculated based on particle density of materials, will depend on the solubility in water, adhered or embedded air, and non-ideality of mixing soluble species. Appendix F compiles and evaluates the volume contribution for the test slurry feeds found in the literature. Based on the results of this evaluation it is likely that the half of the "High Operator Response" volume of 3,331 L, 1,666 L, is sufficiently conservative to make sure that the MFPV working volume does not increase over the "High Operator Response". If Step 3 (below) indicates a GFC adjustment is necessary, the remaining half of the "High Operator Response" volume (1,666 L) may be used for this purpose.

\subsection{Step 3 - Calculation of Final Glass Composition and Properties with Uncertainties}

The actual measured volume of waste transfer, actual measured volumes of flush, batch control, and dilution water, and the actual measured masses of GFCs are used to calculate the final composition and properties.

5.3.1 Final Glass Composition to Calculate the Final Glass Composition, the Final Waste Loading $\left(G_{j}^{M F P V, S t e p 3}\right)$ and GFC Mass per g Glass $\left(\dddot{M}_{k j}^{G F C P V, S t e p 3}\right)$ are First Calculated:

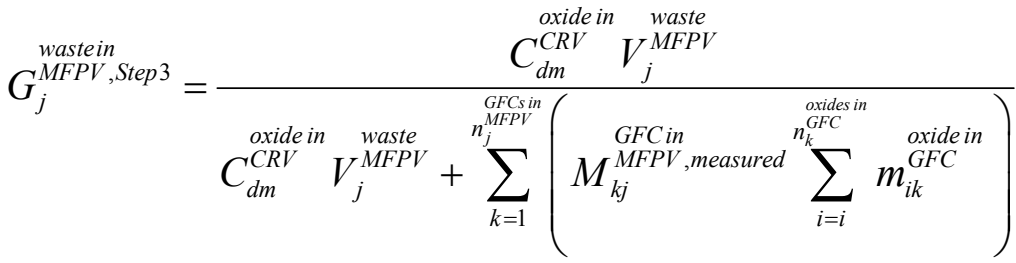

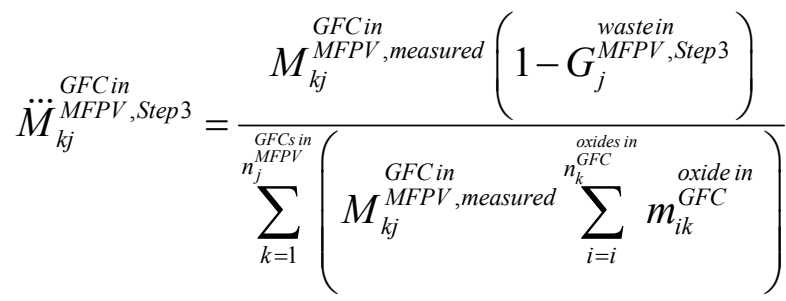

where $\quad G_{j}^{\text {wastein }} \begin{aligned} & \text { MFPV,Step } 3 \\ & \text { mass fraction of glass oxides originated from waste in the } j^{\text {th }} \text { MFPV batch from } \\ & \text { algorithm calculation Step 3, i.e. waste loading (g per g MFPV oxides) }\end{aligned}$

\footnotetext{
${ }^{(14)}$ It is unlikely that the MFPV volume increase by actual waste transfer volume increase would reach the allowable
} 1,666 L during normal operation. 


$$
\begin{aligned}
& C^{\text {oxides in }}=\text { concentration of total glass oxides in the } m^{\text {th }} \text { transfer waste transferred from the } \\
& C_{d m}^{C R V}=d^{\text {th }} \text { CRV to MFPV (g oxides per L waste) } \\
& V_{j}^{\text {Maste }}=\text { volume of waste transferred from CRV to the } j^{\text {th }} \text { MFPV (L) } \\
& n_{j}^{G F C S V}=\text { number of GFCs used in the } j^{\text {th }} \text { MFPV batch } \\
& M_{k j}^{\text {GFPV , measured }}=\text { measured mass of } k^{\text {th }} \text { GFC added to the } j^{\text {th }} \text { MFPV batch (g) } \\
& \underset{m_{i k}^{\text {oxides in }}}{\text { GFC }}=\begin{array}{l}
\text { mass fraction of the } i^{\text {th }} \text { glass oxide in the } k^{\text {th }} \text { GFC (g oxide per g GFC including } \\
\text { volatiles) }
\end{array} \\
& n_{k}^{\text {oxides in }}=\text { number of glass oxides in the } k^{\text {th }} \text { GFC } \\
& \dddot{M}_{k j}^{\text {GFC in }} \text { Mtep } 3=\begin{array}{l}
\text { mass of the } k^{\text {th }} \text { GFC per g of glass in the } j^{\text {th }} \text { MFPV batch from algorithm } \\
\text { calculation Step } 3 \text { (g per g MFPV oxides) }
\end{array}
\end{aligned}
$$

Then, the glass composition is given as:

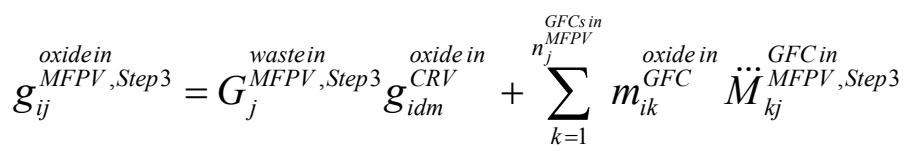

where $g_{i j}^{\substack{\text { oxidein } \\ M F P V \text { Step } 3}}$ is the mass fraction of the $i^{\text {th }}$ glass oxide in the $j^{\text {th }}$ MFPV batch from algorithm calculation Step 3 before applying component retention factors (g oxide per g MFPV oxides) and the remaining notations are as previously defined in Equations (96) and (97).

The glass composition after applying retention factors $\left(\tilde{g}_{i j}^{\text {oxidein }}{ }^{M F P t e p 3}\right.$ ) is given as:

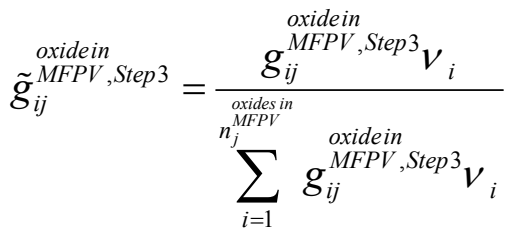

The activity of radionuclides per unit mass of glass oxides in the MFPV batch $\left(a_{i j}^{\text {rad in }}{ }^{\mathrm{MFV}, \text { Step } 3}\right)$ is given as:

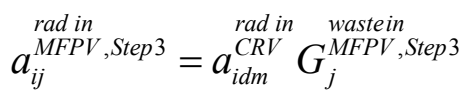

$$
\begin{aligned}
& =\frac{\bar{R}_{i d}^{\text {rad in }} \lambda_{d m} G_{j}^{\text {wastein }, \text { Step } 3}}{\text { oxides in }}
\end{aligned}
$$


where

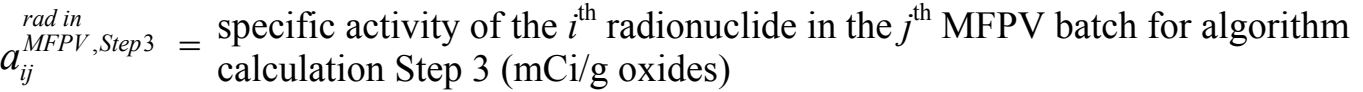

$$
\begin{aligned}
& a_{i d m}^{\text {rad in }}=\begin{array}{l}
\text { specific activity of the } i^{\text {th }} \text { radionuclide in the } m^{\text {th }} \text { transfer waste transferred from } \\
\text { the } d^{\text {th }} \text { CRV to MFPV (mCi/g oxides) }
\end{array} \\
& G_{j}^{\text {wastein }} \begin{array}{l}
\text { mass frep } 3 \\
G_{j}
\end{array}=\begin{array}{l}
\text { maction of glass oxides originated from waste in the } j^{\text {th }} \text { MFPV batch from } \\
\text { algorithm calculation Step 3, i.e. waste loading (g per g MFPV oxides) }
\end{array} \\
& \text { rad in activity (per unit volume) of the } i^{\text {th }} \text { radionuclide in the waste of the } d^{\text {th }} \mathrm{CRV} \\
& \bar{R}_{i d}^{\text {rad in }}={ }_{\text {averaged over }}^{\text {sampsin }} n_{d}^{C R V} \text { samples analyzed }(\mathrm{mCi} / \mathrm{L}) \\
& \lambda_{d m}=\text { dilution factor for the } m^{\text {th }} \text { transfer waste transferred from the } d^{\text {th }} \text { CRV to MFPV } \\
& \begin{array}{l}
C_{d m}^{\text {oxides in }} \\
C^{C R V}
\end{array}=\begin{array}{l}
\text { concentration of total glass oxides in the } m^{\text {th }} \text { transfer waste transferred from the } \\
d^{\text {th }} \text { CRV to MFPV (g oxides per L waste) }
\end{array}
\end{aligned}
$$

The specific activity after applying retention factors $\left(\tilde{a}_{i j}^{\text {oxidein }}\right.$ MFP,Step 33$)$ is given as:

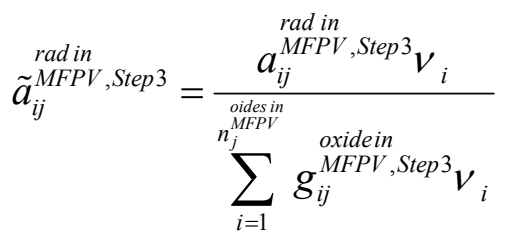

\subsubsection{Constraints for Algorithm Step 3}

The equations to calculate the quantities for all constraints listed in Table 10 through Table 13 for algorithm Step 3 are described in this section. The same equations derived in Section 5.1.6 for algorithm Step 1 are also employed using the symbols corresponding to algorithm Step 3.

\subsubsection{Glass Property and Model Validity Constraints}

For property predictions and calculations of prediction uncertainties, the $g_{i}$ for $x_{i}^{\text {prop }}$ and $x_{\text {Others }}^{\text {prop }}$ in Equations (3) and (4) is given by $\tilde{g}_{i j}^{\text {oxidein }}$ MFPVStep 3 from Equation (99). The model validity constraints are also calculated based on $\tilde{g}_{i j}^{\text {oxidein }}$ MFP Step 3 . Then, these $x_{i}^{\text {prop }}$ values are used in Equations (2), (5), (6), and (7) to calculate $P^{\text {prop }}$ and Equations (8) through (11) to calculate $U_{\text {pred }}^{\text {prop }}$. Composition uncertainty $\left(U_{\text {comp }}^{\text {prop }}\right)$ is calculated following the methods described in Section 4.2.2. For $U_{\text {comp }}^{\text {prop }}$ calculation the mass balance equations given by Equation (12) and (13) are rewritten based on the values for Step 3 calculation: 


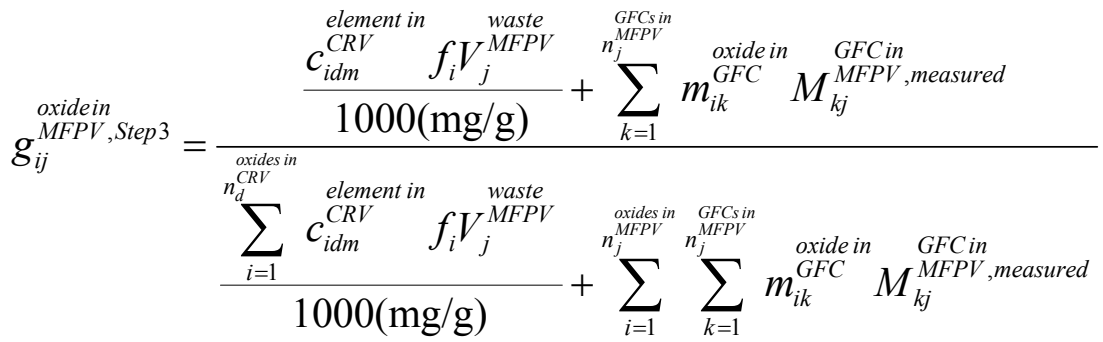

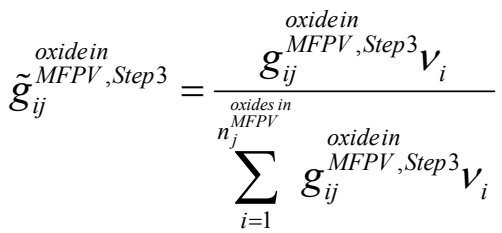

where

$$
\begin{aligned}
& \text { mass fraction of the } i^{\text {th }} \text { glass oxide in the } j^{\text {th }} \text { MFPV batch from algorithm } \\
& g_{i j}^{M F P V, \text { Step } 3}=\underset{\text { calculation Step } 3 \text { after applying component retention factors (g oxide per } \mathrm{g}}{\text { glass) }} \\
& \text { oxidein mass fraction of the } i^{\text {th }} \text { glass oxide in the } j^{\text {th }} \text { MFPV batch from algorithm } \\
& \tilde{g}_{i j}^{M F P V, S t e p 3}=\text { calculation Step } 3 \text { after applying component retention factors (g oxide per } \mathrm{g} \\
& \text { glass) } \\
& c_{C R V}^{\text {element in }}=\text { concentration of the } i^{\text {th }} \text { component in the } m^{\text {th }} \text { transfer waste transferred from } \\
& c_{i d m}^{C R V}=\text { the } d^{\text {th }} \mathrm{CRV} \text { to MFPV (mg/L waste) } \\
& f_{i}=\begin{array}{l}
\text { oxide conversion factor, i.e., mass of the } i^{\text {th }} \text { glass oxide per mass of the } i^{\text {th }} \\
\text { element }
\end{array} \\
& V_{j}^{\text {waste }}=\text { volume of waste transferred from CRV to the } j^{\text {th }} \text { MFPV (L) } \\
& n_{j}^{G F P V}=\text { number of GFCs used in the } j^{\text {th }} \text { MFPV batch } \\
& \text { mass fraction of the } i^{\text {th }} \text { glass oxide in the } k^{\text {th }} \text { GFC (g oxide per g GFC } \\
& m_{i k}^{\text {oxide in }} \text { GFC }=\text { including volatiles). Here, unlike } \mathbf{H} \text { in Equation (48), } m_{i k}^{\text {oxidein }} \text { includes all } \\
& \text { tracked components beyond the } 11 \text { GFC components. }
\end{aligned}
$$

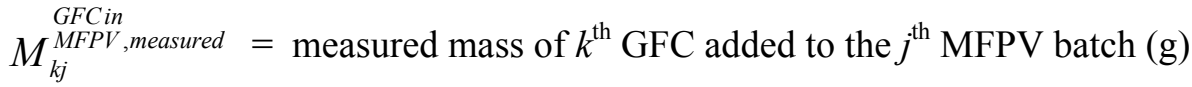

$$
\begin{aligned}
& v_{i}=\text { retention factor for the } i^{\text {th }} \text { component (fraction) } \\
& n_{d}^{\text {oxides in }}=\text { number of glass oxides tracked in the } d^{\text {th }} \text { CRV batch } \\
& n_{j}^{\text {oxides in }}=\begin{array}{l}
\text { number of glass oxides tracked in the mass balance calculations for the } j^{\text {th }} \\
\text { MFPV batch }
\end{array}
\end{aligned}
$$


The results of $P^{\text {prop }}, U_{\text {pred }}^{\text {prop }}$, and $U_{\text {comp }}^{\text {prop }}$ are used to calculate CL\% UCCI or LCCI ( $B_{u c c i}^{\text {prop }}$ or $\left.B_{u c c i}^{\text {prop }}\right)$ for glass properties (PCT, VHT, viscosity, and electrical conductivity) according to Equation (16) discussed in Section 4.2.3.

$$
B_{u c c i, j}^{\text {prop,Step } 3}=P_{j}^{\text {prop }, \text { Step } 3}+U_{\text {pred }, j}^{\text {prop }, \text { Step } 3}+U_{\text {comp }, j}^{\text {prop }, \text { tep } 3} \text { and } B_{\text {lcci, }, j}^{\text {prop }, \text { Step } 3}=P_{j}^{\text {prop,Step } 3}-U_{\text {pred }, j}^{\text {prop,Step } 3}-U_{\text {comp }, j}^{\text {prop }, \text { Step } 3}
$$

where $B_{u c c i, j}^{\text {prop }, \text { Step } 3}=\begin{aligned} & \mathrm{CL} \% \text { upper combined confidence interval for predicted " } p r o p \text { " } \mathrm{s} \text { for the } j^{\text {th }} \text { MFPV } \\ & \text { batch from algorithm calculation Step } 3\end{aligned}$

$$
\begin{aligned}
& B_{l c c i, j}^{\text {prop }, \text { tep } 3}=\begin{array}{l}
\text { CL\% lower combined confidence interval for "prop" for the } j^{\text {th }} \text { MFPV batch from } \\
\text { algorithm calculation Step } 3 \text { (applicable only to "vis" and "ec") }
\end{array} \\
& \text { predicted "prop" transformed property values for the } j^{\text {th }} \text { MFPV batch from } \\
& P_{j}^{\text {prop,Step } 3}=\text { algorithm calculation Step 3, which includes } \ln \left(r_{\mathrm{B}}, \mathrm{g} / \mathrm{L}\right), \ln \left(r_{\mathrm{Na}}, \mathrm{g} / \mathrm{L}\right), \ln (D, \mu \mathrm{m}) \text {, } \\
& \ln \left(\eta_{T}, \mathrm{P}\right) \text {, and } \ln \left(\varepsilon_{T}, \mathrm{~S} / \mathrm{cm}\right) \\
& U_{\text {pred }, j}^{\text {prop }, \text { tep } 3}=\begin{array}{l}
\text { model prediction uncertainty for " } p r o p \text { " for the } j^{\text {th }} \text { MFPV batch from algorithm } \\
\text { calculation Step } 3
\end{array} \\
& U_{\text {comp }, j}^{\text {prop }, \text { tep } 3}=\begin{array}{l}
\text { composition uncertainty for "prop" for the } j^{\text {th }} \text { MFPV batch from algorithm } \\
\text { calculation Step } 3
\end{array}
\end{aligned}
$$

The CL\% UCCIs and LCCIs, expressed in the units of the model used to predict a property (e.g., $\ln [\mathrm{g} / \mathrm{L}]$ for PCT responses), are used to assess whether property constraints (as discussed in Section 4.3) are met.

\subsubsection{Waste $\mathrm{Na}_{2} \mathrm{O}$ Loading Constraint}

The waste $\mathrm{Na}_{2} \mathrm{O}$ loading in the $j^{\text {th }}$ MFPV batch from algorithm calculation Step 3 is calculated as:

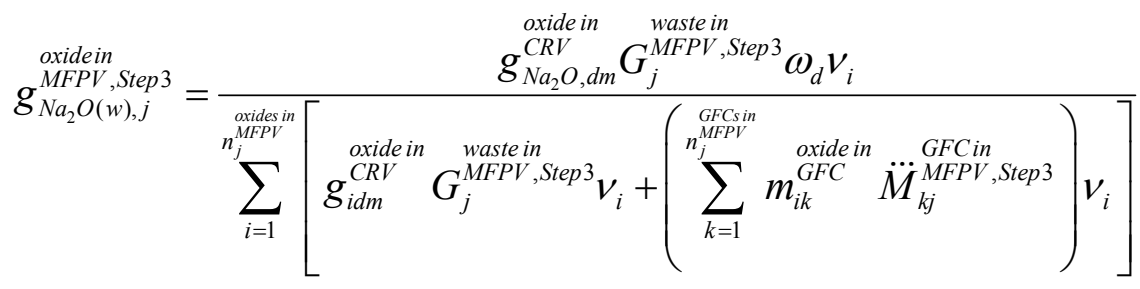

where

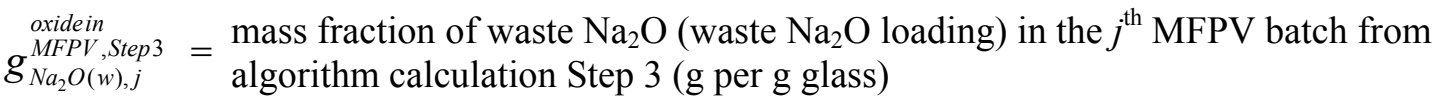

$$
\begin{aligned}
& g_{\mathrm{Na}_{2} \mathrm{O}, \mathrm{dm}}^{\mathrm{c} \text { oxide in }}=\begin{array}{l}
\text { mass fraction of } \mathrm{Na}_{2} \mathrm{O} \text { in the } m^{\text {th }} \text { transfer waste transferred from the } d^{\text {th }} \mathrm{CRV} \text { to } \\
\text { MFPV (g oxide per g CRV oxides) }
\end{array} \\
& \begin{array}{l}
G_{j}^{\text {waste in }} \text { MFPV Step } 3 \\
\text { from algorithm calculation Step 3, i.e. waste loading (g per g MFPV oxides) }
\end{array} \\
& \omega_{d}=\begin{array}{l}
\text { fraction of the sodium in the } d^{\text {th }} \mathrm{CRV} \text { batch that is classified as waste sodium } \\
\text { (unitless) }
\end{array} \\
& v_{i}=\text { retention factor for the } i^{\text {th }} \text { component (fraction) } \\
& n_{j}^{\stackrel{\text { oxides in }}{M F P V}}=\begin{array}{l}
\text { number of glass oxides tracked in the mass balance calculations for the } j^{\text {th }} \\
\text { MFPV batch }
\end{array}
\end{aligned}
$$




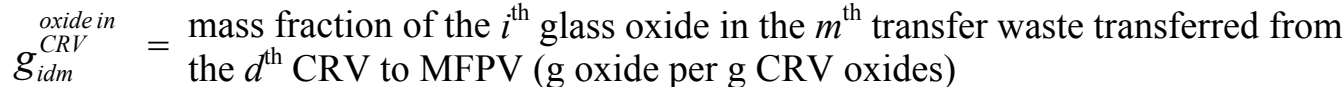

$$
\begin{aligned}
& n_{j}^{G F C \operatorname{MF} i n}=\text { number of GFCs in the } j^{\text {th }} \text { MFPV batch } \\
& \dddot{M}_{k j}^{G F C \text { in }} \text { MFIep } 3=\begin{array}{l}
\text { mass of the } k^{\text {th }} \text { GFC per } \mathrm{g} \text { of glass in the } j^{\text {th }} \text { MFPV batch from algorithm } \\
\text { calculation Step } 3 \text { (g per g MFPV oxides) }
\end{array} \\
& \text { mass fraction of the } i^{\text {th }} \text { glass oxide in the } k^{\text {th }} \text { GFC (g oxide per g GFC } \\
& m_{i k}^{\substack{\text { oxide in } \\
\text { GFC }}}=\text { including volatiles). Here, unlike } \mathbf{H} \text { in Equation (48), } m_{i k}^{\substack{\text { oxide in } \\
G F C}} \text { includes all } \\
& \text { tracked components beyond the } 11 \text { GFC components. }
\end{aligned}
$$

The $g_{\mathrm{Na}_{2} \mathrm{O}(\mathrm{W}(\mathrm{W}), j}^{\text {oxidein } 3}$ value is compared to $L_{l}^{\mathrm{N} N a}$ to confirm that each MFPV batch meets the waste $\mathrm{Na}_{2} \mathrm{O}$ loading constraint.

\subsubsection{Radionuclide Concentration Constraints}

The specific activity of radionuclide in glass is calculated by

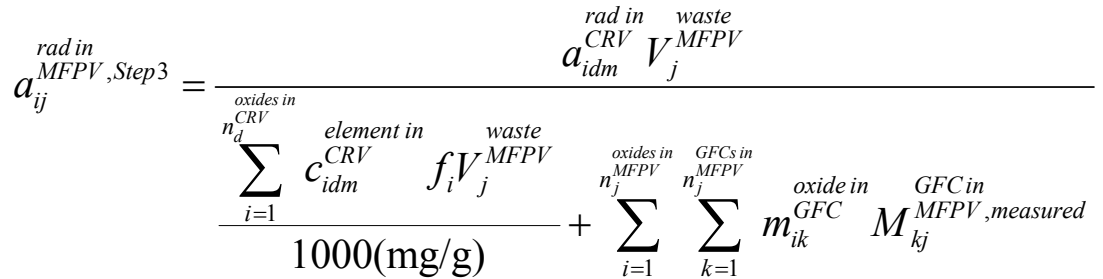

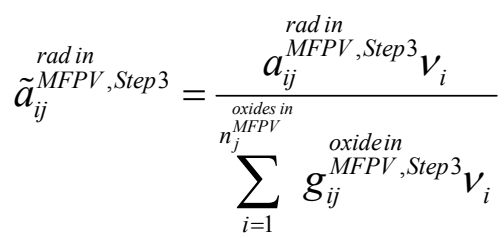

where

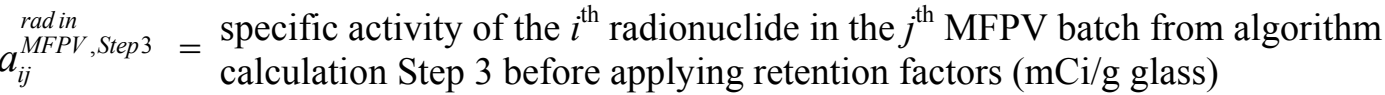

$$
\begin{aligned}
& a_{i d m}^{\text {rad in }}=\text { specific activity of the } i^{\text {th }} \text { radionuclide in the } m^{\text {th }} \text { transfer waste transferred } \\
& V_{j}^{\text {waste }}=\text { volume of waste transferred from CRV to the } j^{\text {th }} \text { MFPV (L) } \\
& \begin{array}{l}
n_{d}^{\text {oxides in }} \\
\text { CRV batch }
\end{array} \\
& f_{i}=\begin{array}{l}
\text { oxide conversion factor, i.e., mass of the } i^{\text {th }} \text { glass oxide per mass of the } i^{\text {th }} \\
\text { element }
\end{array}
\end{aligned}
$$




$$
\begin{aligned}
& n_{j}^{\text {oxides in }}=\begin{array}{l}
\text { number of glass oxides tracked in the mass balance calculations for the } j^{\text {th }} \\
\text { MFPV batch }
\end{array} \\
& n_{j}^{G F P C \text { in }}=\text { number of GFCs used in the } j^{\text {th }} \text { MFPV batch }
\end{aligned}
$$

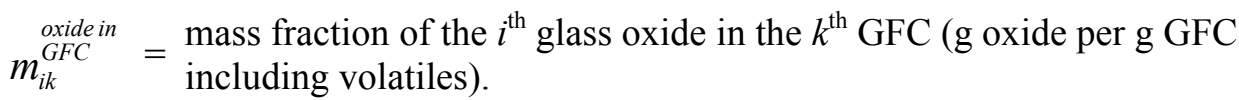

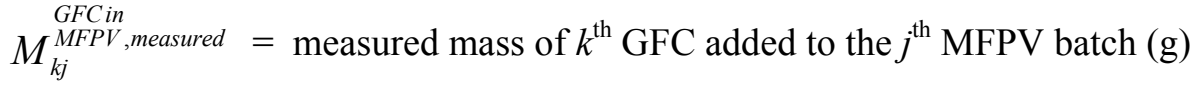

$$
\begin{aligned}
& \begin{array}{l}
\text { radin } \\
\tilde{a}_{i j}^{M F P V, S t e p 3} 3
\end{array}=\begin{array}{l}
\text { specific activity of the } i^{\text {th }} \text { radionuclide in the } j^{\text {th }} \text { MFPV batch from algorithm } \\
\text { calculation Step } 3 \text { after applying retention factors (mCi/g glass) }
\end{array} \\
& v_{i}=\text { retention factor for the } i^{\text {th }} \text { component (fraction) } \\
& \begin{array}{l}
\text { mass fraction of the } i^{\text {th }} \text { glass oxide in the } j^{\text {th }} \text { MFPV batch from algorithm } \\
g_{i j}^{M F P V, \text { Step } 3}=\begin{array}{l}
\text { calculation Step } 3 \text { after applying component retention factors (g oxide per } g \\
\text { glass) }
\end{array}
\end{array}
\end{aligned}
$$

The SD values for glass component mass fractions $\left(\tilde{s}_{i j}^{\text {oxidein }}\right.$,Step 3 ) and radionuclide concentrations $\left(\tilde{s}_{i j}^{\text {radin }}\right.$ MFP ,Step 3 ) for algorithm calculation Step 3 after applying retention factors are obtained by Monte Carlo simulations of Equations (103) and (107) respectively.

The specific activity of radionuclides from Equation (101) and its SD are converted to per unit glass volume using:

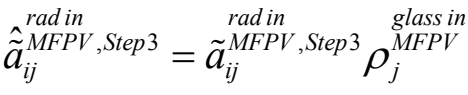

$$
\begin{aligned}
& \hat{\tilde{s}}_{i j}^{\text {radin }}{ }^{M F P V, \text { Step } 3}=\tilde{s}_{i j}^{\text {radin }}{ }^{M F P V, \text { Step } 3} \rho_{j}^{\text {glass in }}
\end{aligned}
$$
where $\quad \tilde{\tilde{a}}_{i j}^{\text {radin }}$ MFV Step $3=\begin{aligned} & \text { activity of the } i^{\text {th }} \text { radionuclide per unit volume of glass in the } j^{\text {th }} \mathrm{MFPV} \text { batch from } \\ & \text { algorithm calculation Step } 3 \text { after applying retention factors }\left(\mathrm{Ci} / \mathrm{m}^{3} \text { glass }\right)\end{aligned}$

radin
$\tilde{a}_{i j}^{M F P V, S t e p 3}=$
calculation Step 3 after applying retention factors (mCi/g glass)

$$
\rho_{j}^{\substack{\text { glass in } \\ M F P V}}=\text { density of glass in the } j^{\text {th }} \text { MFPV batch }(\mathrm{g} / \mathrm{L})
$$

$\begin{aligned} \text { radin } & \text { SD for the activity of the } i^{\text {th }} \text { radionuclide per unit volume of glass in the } j^{\text {th }} \text { MFPV } \\ \hat{\tilde{s}}_{i j}^{M F P V, S t e p 3}= & \text { batch from algorithm calculation Step } 3 \text { after applying retention factors }\left(\mathrm{Ci} / \mathrm{m}^{3}\right. \\ & \text { glass })\end{aligned}$

$\tilde{S}_{i j}^{\text {radin }}$ MFPV Step $3=\begin{aligned} & \text { SD for the specific activity of the } i^{\text {th }} \text { radionuclide in the } j^{\text {th }} \text { MFPV batch from } \\ & \text { algorithm calculation Step } 3 \text { after applying retention factors (mCi/g glass) }\end{aligned}$ 


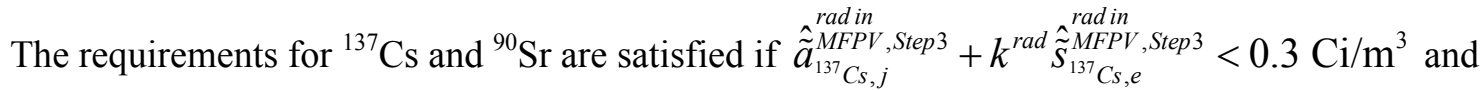

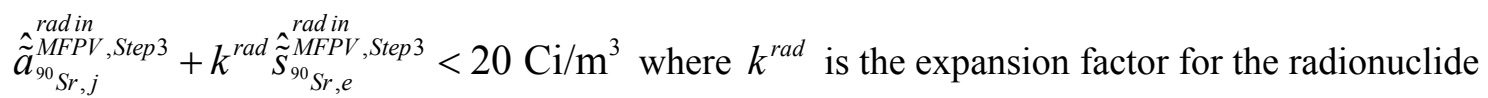
concentration specification.

To demonstrate that the waste meets the classification of Class $\mathrm{C}$ waste or below, limiting values for $\hat{\tilde{a}}_{i j}^{\text {radin }}$

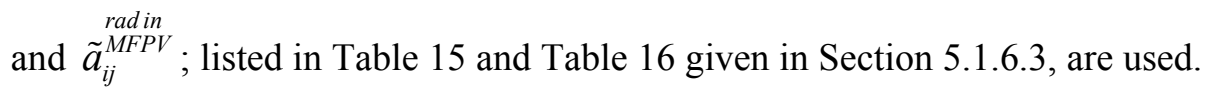

The first step to classification is then to determine if there are any radionuclides with measurable concentrations ( $\tilde{\tilde{a}}_{i j}^{\text {radin }}$,Step 3 for ${ }^{99} \mathrm{Tc},{ }^{129} \mathrm{I},{ }^{63} \mathrm{Ni},{ }^{90} \mathrm{Sr}$, and ${ }^{137} \mathrm{Cs}$, or $\tilde{a}_{i j}^{\text {radin }}{ }^{M F P V \text { Step } 3}$ for TRU, ${ }^{241} \mathrm{Pu}$, and ${ }^{242} \mathrm{Cm}$ ). If non-zero values are present for radionuclides only in Table 15 or only in Table 16, then only those tables are used for classification. If there are non-zero values for both tables, then Table 15 is used for classification if any one radionuclide from Table 15 is greater than $10 \%$ of its associated limit. If no Table 15 radionuclide has a concentration greater than or equal to its associated limit, then Table 16 is used for classification. The sum of fractions rule for algorithm calculation Step 3 is given as:

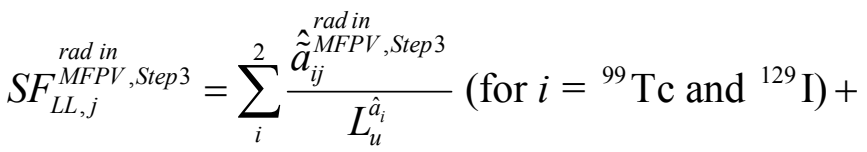

$$
\begin{aligned}
& \sum_{i}^{3} \frac{\tilde{a}_{i j}^{\text {MFPV } \text { Step } 3} \times 10^{6}(\mathrm{nCi} / \mathrm{mCi})}{L_{u}^{a_{i}}}\left(\text { for } i=\mathrm{TRU},{ }^{241} \mathrm{Pu}, \text { and }{ }^{242} \mathrm{Cm}\right)
\end{aligned}
$$

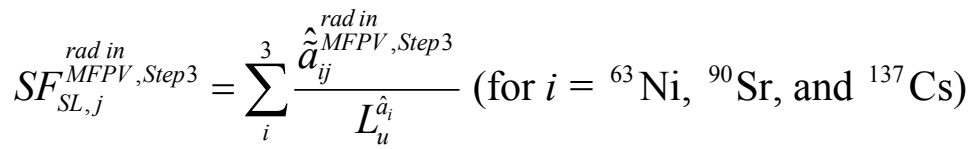

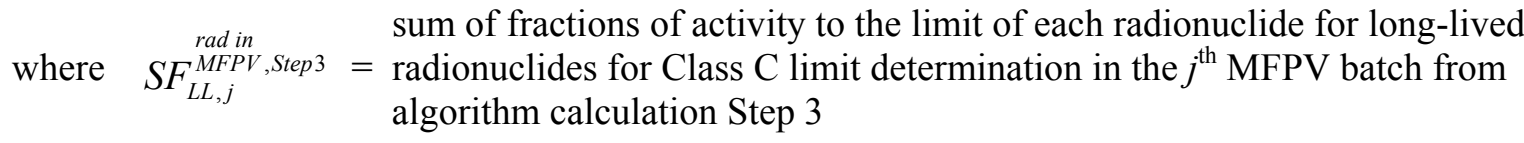

$$
\begin{aligned}
& \begin{aligned}
\stackrel{\text { radin }}{\text { ratsep }}= & \text { sum of fractions of activity to the limit of each radionuclide for short-lived } \\
S F_{S L, j}^{M F P V, S t e p}= & \text { radionuclides for Class C limit determination in the } j^{\text {th }} \text { MFPV batch from } \\
& \text { algorithm calculation Step } 3
\end{aligned} \\
& \stackrel{\tilde{a}_{i j}^{M F P, S t e p} 3}{\text { radin }}=\underset{\text { activity of the } i^{\text {th }}}{\text { radionuclide per unit volume of glass in the } j^{\text {th }} \text { MFPV batch }} \\
& \underset{\tilde{a}_{i j}^{\text {MFPV Step } 3}}{\text { ran }}=\begin{array}{l}
\text { specific activity of the } i^{\text {th }} \text { radionuclide in the } j^{\text {th }} \text { MFPV batch from algorithm } \\
\text { calculation Step } 3 \text { after applying retention factors (mCi/g glass) }
\end{array}
\end{aligned}
$$

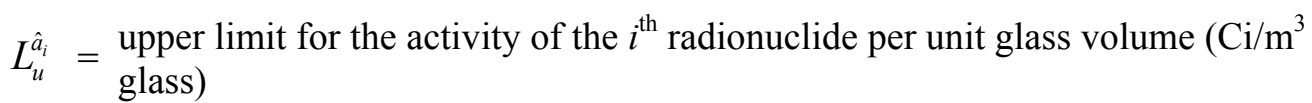

$$
\begin{aligned}
& L_{u}^{a_{i}}=\text { upper limit for specific activity of the } i^{\text {th }} \text { radionuclide (nCi/g glass) }
\end{aligned}
$$




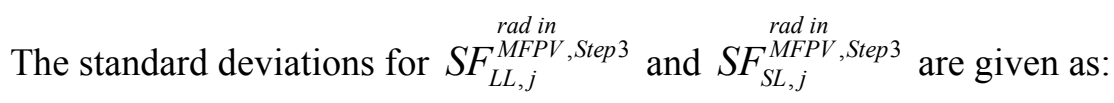

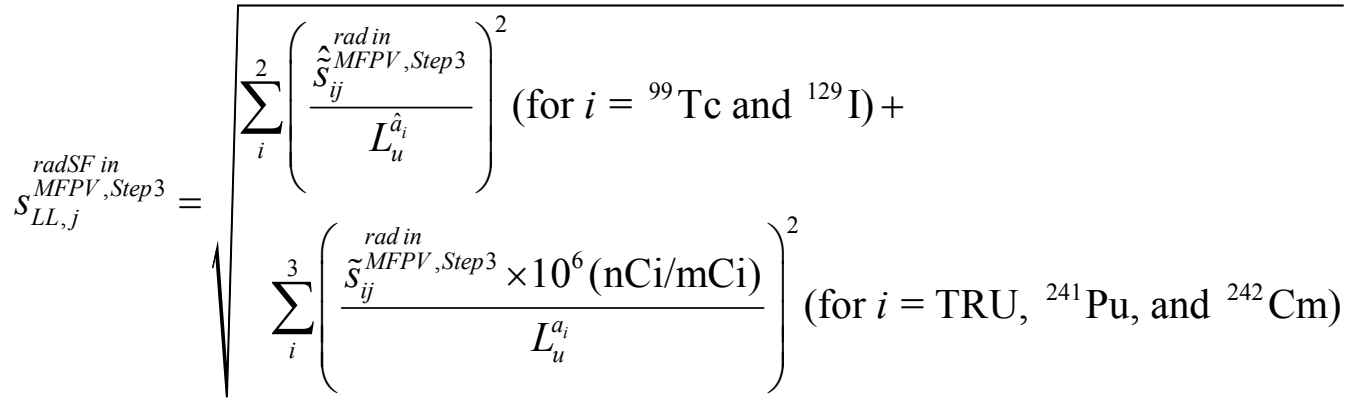

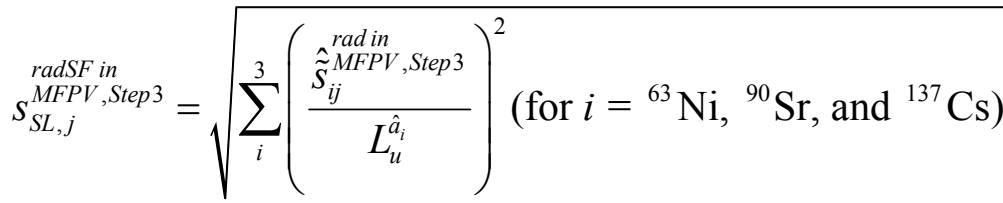

where

radSF in SD for the sum of fractions of activity to the limit of each radionuclide for long$\begin{aligned} S_{L L, j}^{M F P V, S t e p 3}= & \text { lived radionuclides for Class C limit determination in the } j^{\text {th }} \text { MFPV batch from } \\ & \text { algorithm calculation Step } 3\end{aligned}$

radSF in $\quad$ SD for the sum of fractions of activity to the limit of each radionuclide for short$s_{S L, j}^{M F P V, S t e p 3}=$ lived radionuclides for Class C limit determination in the $j^{\text {th }}$ MFPV batch from algorithm calculation Step 3

radin SD for the activity of the $i^{\text {th }}$ radionuclide per unit volume of glass in the $j^{\text {th }}$ MFPV $\hat{\tilde{s}}_{i j}^{\text {MFPV Step } 3}=$ batch from algorithm calculation Step 3 after applying retention factors $\left(\mathrm{Ci} / \mathrm{m}^{3}\right.$ glass)

$\tilde{s}^{\text {radin }}$ MFV Step $3=$ SD for the specific activity of the $i^{\text {th }}$ radionuclide in the $j^{\text {th }}$ MFPV batch from $\tilde{s}_{i j}^{M F P V, S t e p 3}=\begin{aligned} & \text { algorithm calculation Step } 3 \text { after applying retention factors ( } \mathrm{mCi} / \mathrm{g} \text { glass) } \\ & \text { al }\end{aligned}$

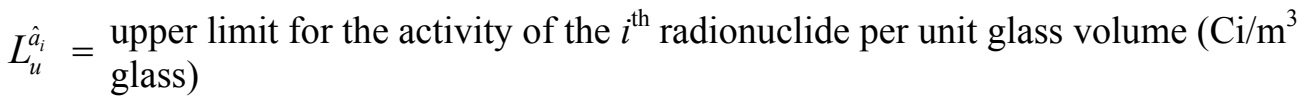
$L_{u}^{a_{i}}=$ upper limit for specific activity of the $i^{\text {th }}$ radionuclide (nCi/g glass)

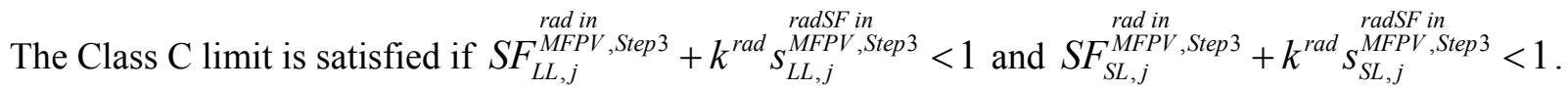

\subsubsection{Surface Dose Rate Constraint}

As mentioned in Section 5.1.6.4, the surface does rate calculation will not be performed by ILAW formulation algorithm.

\subsubsection{MFPV Composition Check}

The MFPV contents including heel and newly added MFPV batch will be sampled and analyzed for major glass components (ISARD sample point = LAW6). The glass composition of working MFPV (batch + heel) is calculated as: 


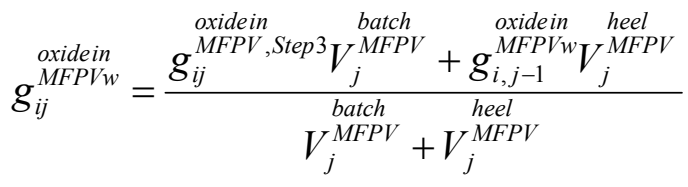

where $\quad g_{i j}^{\text {oxidein }}$ MFPVW $=$ mass fraction of the $i^{\text {th }}$ glass oxide in the $j^{\text {th }}$ working MFPV (g oxide per g glass)

$$
\begin{aligned}
& \text { oxidein mass fraction of the } i^{\text {th }} \text { glass oxide in the } j^{\text {th }} \text { MFPV batch from algorithm } \\
& \begin{aligned}
g_{i j}^{\text {MFPV } \text { Step } 3}= & \text { calculation Step } 3 \text { before applying component retention factors (g oxide per } \mathrm{g} \\
& \text { MFPV oxides) }
\end{aligned} \\
& \begin{array}{c}
\text { batch } \\
V_{j}^{M F P V}
\end{array}=\text { volume of the } j^{\text {th }} \text { MFPV batch (L) } \\
& g_{i, j-1}^{\substack{\text { oxidein } \\
M F P V}}=\text { mass fraction of the } i^{\text {th }} \text { glass oxide in the } j-1^{\text {th }} \text { working MFPV (g oxide per } g \text { glass) } \\
& V_{j}^{\text {heel }}=\text { volume of heel in the } j^{\text {th }} \text { MFPV batch measured prior to waste transfer (L) }
\end{aligned}
$$

The MFPV batch volume is calculated as a sum of measured waste transfer volume $\left(V_{j}^{\text {waste }}\right.$, measured

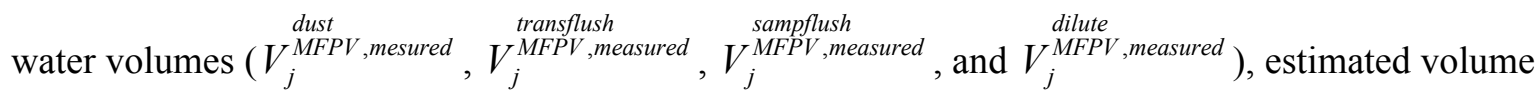

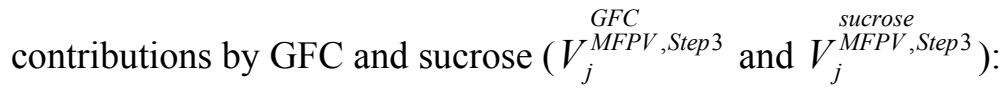

$$
\begin{gathered}
\text { batch } \\
V_{j}^{M F P V}=V_{j}^{\text {waste }} \\
\end{gathered}
$$

Volume contributions by GFC and sucrose are estimated from measured GFC and sucrose masses

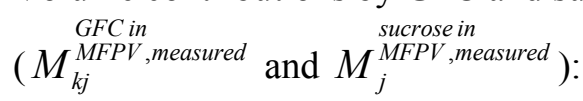

$$
\begin{aligned}
& V_{j}^{M F C P V, \text { Step } 3}=\sum_{k=1}^{\substack{G F C \text { in } \\
n_{j}^{M F P V}}} \frac{\begin{array}{c}
G F C \text { in } \\
\text { MFPV }
\end{array}}{\rho_{k}}
\end{aligned}
$$

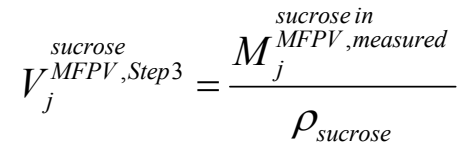

where $\rho_{k}$ and $\rho_{\text {sucrose }}$ are the densities of $k^{\text {th }}$ GFC and sucrose, respectively. 
The estimated glass oxides content in the MFPV (after completing batch preparation, "estimated" because the volume contributions of GFCs and sucrose are estimated) is given as:

$$
C_{j}^{\text {oxides in }}=\frac{C_{d m}^{\text {oxides in }} V_{j}^{\text {waste }}}{G_{j}^{\text {MFPV }}}
$$

where $\quad C_{j}^{\text {oxides in }}=$ concentration of total glass oxides in the $j^{\text {th }}$ MFPV batch $(\mathrm{g}$ oxides per $\mathrm{L})$

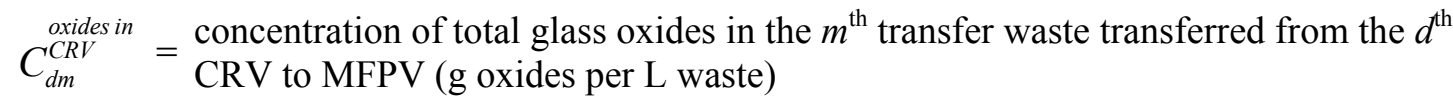

$V_{j}^{\text {waste }}=$ volume of waste transferred from CRV to the $j^{\text {th }}$ MFPV (L)

$G_{j}^{\text {wastein }}$ MFP Step $3=\begin{aligned} & \text { mass fraction of glass oxides originated from waste in the } j^{\text {th }} \text { MFPV batch from } \\ & \text { algorithm calculation Step 3, i.e. waste loading (g per g MFPV oxides) }\end{aligned}$

$\begin{gathered}\text { batch } \\ V_{j}^{M F P V}\end{gathered}=$ volume of the $j^{\text {th }}$ MFPV batch (L)

Then, the estimated glass oxides content $\left(C_{j}^{\text {oxidesin }} \begin{array}{c}\text { MFPW } \\ \text { elementin }\end{array}\right)$ and elemental composition $\left(c_{i j}^{M F P V w}\right.$ in the working MFPV is given as:

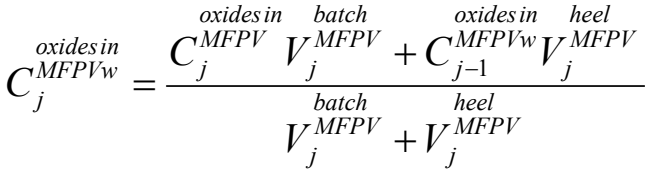

$$
\begin{aligned}
& c_{i j}^{\text {elementin }}{ }^{M F P V w}=\frac{g_{i j}^{\text {oxidein }}{ }^{M F P V w} C_{j}^{\text {oxidesin }}}{f_{i}}
\end{aligned}
$$

where $\quad C_{j}^{\text {oxidesin }}=$ concentration of total glass oxides in the $j^{\text {th }}$ working MFPV (g oxides per L)

$C_{j}^{\text {oxides in }}=$ concentration of total glass oxides in the $j^{\text {th }}$ MFPV batch (g oxides per $\mathrm{L}$ )

$\begin{gathered}\text { batch } \\ V_{j}^{M F P V}\end{gathered}=$ volume of the $j^{\text {th }}$ MFPV batch (L)

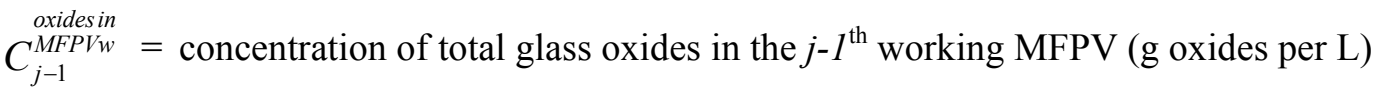

$\stackrel{\substack{\text { heel } \\ V_{j}^{M F P V}}}{=}$ volume of heel in the $j^{\text {th }}$ MFPV batch measured prior to waste transfer (L) 


$$
\begin{aligned}
\begin{aligned}
\text { elementin } \\
c_{i j}^{M F P V W}
\end{aligned} & =\text { concentration of the } i^{\text {th }} \text { element in the } j^{\text {th }} \text { working MFPV }(\mathrm{mg} / \mathrm{L}) \\
g_{i j}^{\text {oxidein }} & =\text { mass fraction of the } i^{\text {th }} \text { glass oxide in the } j^{\text {th }} \text { working MFPV (g oxide per g glass) } \\
f_{i} & =\text { oxide conversion factor, i.e., mass of the } i^{\text {th }} \text { glass oxide per mass of the } i^{\text {th }} \text { element }
\end{aligned}
$$

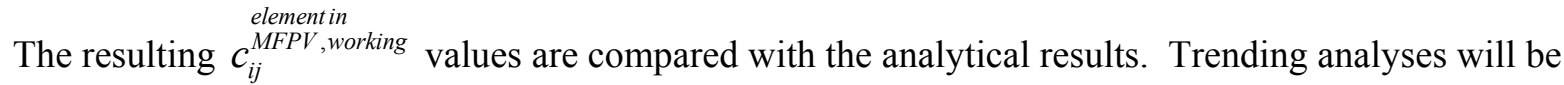
performed on the differences between the analytical results and calculated values to detect potential errors in the MFPV batch preparation, e.g., weighing of GFCs. The trending analyses are not calculated in this report. It is assumed that prepackaged statistical process control (SPC) software will be used during production.

\subsection{Step 4 - Comparison of Final Composition and Properties with Constraints}

The resulting constraint quantities are compared to their limits discussed in Section 4.3. If any of the constraints is not met, an operator will be alerted for intervention. For product quality related properties (e.g., those properties required to meet Contract Specification 2) this comparison is a hold point for transfer of melter feed to the MFV. Once the comparison is successful, the hold point is lifted.

\subsection{Step 5 - Completion of Production Records}

The production records for ILAW will include portions related to the container, the waste form, and the containerized waste form. This section discusses the calculations required to generate those portions of the production records related to the waste form.

Production records document the composition of the waste forms and demonstrate that they meet all the related specifications from the WTP Contract (DOE 2000). The specifications and an overview of the WTP project's strategy for complying with the specifications are contained in the ILAW Product Compliance Plan (PCP) (24590-WTP-PL-RT-03-001). Piepel et al. (2005) developed statistical methods for implementing the compliance strategies to meet several specifications. Those equations and methods were adapted in several parts of the formulation algorithm.

ILAW product requirements are listed in Specification 2.2.2 of the contract (DOE 2000). A series of calculations are performed based on the final glass composition for each MFPV batch. Those requirements, which are not described here (2.2.2.1, 2.2.2.3 through 2.2.2.5, 2.2.2.10 through 2.2.2.16, 2.2.2.18, and 2.2.2.20 through 2.2.2.22), are not related to the glass composition and so are not addressed through these calculations (24590-WTP-PL-RT-03-001).

The requirements that will be satisfied, at least partially, by the production records are listed in Table 17. The calculations used to generate these parts of the production records are discussed in the following subsections. Each subsection starts by quoting the PCP for "during production compliance activities". All specifications related to waste form are based on the content of canistered glass. 
Table 17. Summary of Production Records Related Waste Form Specifications (24590-WTP-PL-RT-03-001)

\begin{tabular}{||l|l|l||}
\hline $\begin{array}{l}\text { Contract } \\
\text { Specification } \\
\text { Number }\end{array}$ & Description & $\begin{array}{l}\text { Section in } \\
\text { This Report }\end{array}$ \\
\hline 2.2 .2 .2 & Waste Loading & 5.5 .1 \\
\hline 2.2 .2 .6 & Chemical Composition Documentation & 5.5 .2 \\
\hline 2.2 .2 .7 & Radiological Composition Documentation & 5.5 .3 \\
\hline 2.2 .2 .8 & Radionuclide Concentration Limitations & 5.5 .4 \\
\hline 2.2 .2 .9 & Surface Dose Rate Limitations & 5.5 .5 \\
\hline 2.2 .2 .17 & Waste Form Testing & 5.5 .6 \\
\hline 2.2 .2 .23 & Manifesting & 5.5 .7 \\
\hline
\end{tabular}

The composition of LAW glass generated from a single MFPV batch and its properties are calculated as described in Section 5.3. However, the production records are based on a canistered glass as discussed above. It should be noted that the melter feed making up each individual MFPV batch doesn't necessarily correspond to the glass in any particular canister. Rather, there is blending of batches by the material within the MFPV (with heel from previous MFPV), within the MFV (which is continually fed to the melter), and within the melter itself. This blending occurs because the vessels (MFPV, MFV, and melter) are well mixed so rather than "plug flow" of material from the MFPV to the canister, there is material blending of several MFPV batches to make up a container. Implicit to this strategy is the assumption that blending MFPV batches and heels that have been correctly formulated will yield a blended glass formulation meeting all constraints. A complication related to container composition averaging is that the compositions must be available for the Production Records at the time the container is transferred to DOE or the contractor.

Therefore, a moving average is used that does not include MFPV batches analyzed after the time of individual container production. The composition is averaged over five MFPV batches (since this is roughly equivalent to three melter volumes of glass) and is then assigned to the glasses in three consecutive canisters. There is an offset between time of the $j^{\text {th }}$ MFPV batch and its associated containers. The time is roughly 2 days to process the amount of glass in one MFPV batch, one MFV batch, and one-half the mass of glass in the melter at the nominal operating rate of $15,000 \mathrm{~kg}$ of glass per day. In summary, the average composition from five MFPV batches are assigned to the glasses in three canisters with the time off-set of 2 days between the start of feed transfer from the first MFPV batch of five to the MFV and the start of pour to the first canister of three. Figure 10 illustrates the contribution and timing of various CRV and MFPV batches, which MFPV batches contribute to the composition of which containers, and the general timing of the process.

WTP contract Specification 13.2.1 (as of M153 of DOE 2000) specifies that: ... The certification and acceptance of ILAW product shall be done on a lot basis. The lot size shall be proposed by the Contractor, and agreed to by DOE. ... Currently, the proposed lot size is the amount of glass contained in three canisters that have the same composition calculated from five MFPV batches discussed above. 
Figure 10. Schematic of Glass Composition Averaging over MFPV Batches and ILAW Containers

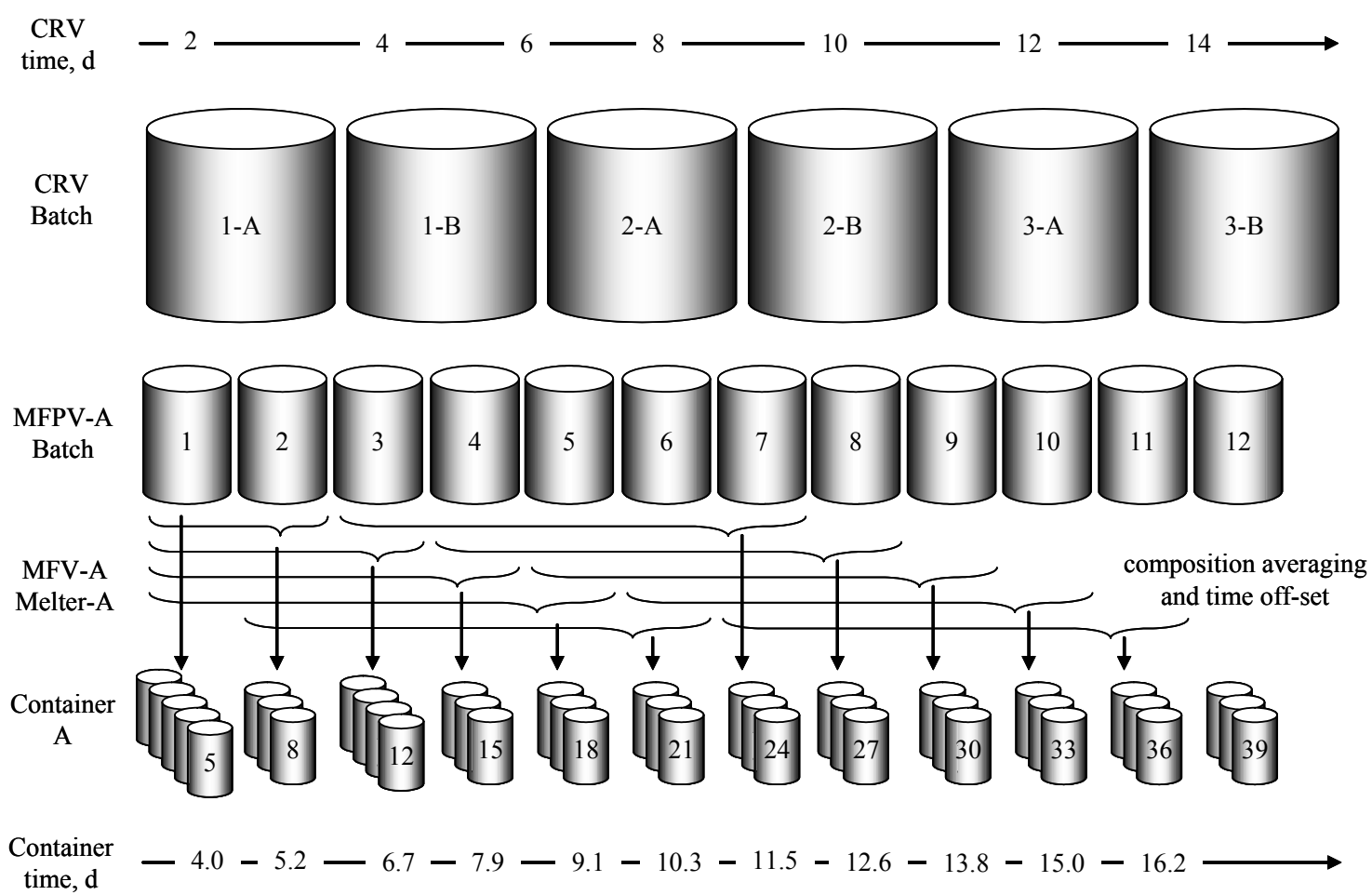

Through normal operation, these equations adequately address the changing composition of glass in canisters. However, at the beginning of hot commissioning operation, the residual glass in the melter from cold commissioning must be taken into account. This will be performed by assuming that the melter is perfectly mixed and MFPV batches are added to the melter after each container is cast with equal equivalent glass mass as the container just filled. The residual cold commissioning glass will be diluted away as the melter feed is added. The calculation for the initial hot commissioning glass is not included in the ILAW formulation algorithm and needs to be performed separately. There will be initial hot commissioning glass containers that do not meet the waste loading requirement identified in Specification 2.2.2.2. Current WTP contract specifies that ...DOE will accept these containers and provide credit for these containers in the Hot Commissioning Capacity Test... (Specification 13.2.2, as of M152 of DOE 2000)

\subsubsection{Specification 2.2.2.2 - Waste Loading}

Waste Loading: The loading of waste sodium from Envelope A in the ILAW glass shall be greater than 14 weight percent based on $\mathrm{Na}_{2} \mathrm{O}$. The loading of waste sodium from Envelope $B$ in the ILAW glass shall be greater than 3.0 weight percent based on $\mathrm{Na}_{2} \mathrm{O}$. The loading of waste sodium from Envelope C in the ILAW glass shall be greater than 10 weight percent (wt\%) based on $\mathrm{Na}_{2} \mathrm{O}$.

According to the ILAW PCP (24590-WTP-PL-RT-03-001):

[PCP Section 4.1.2: Waste Loading] ... During production operations, the WTP project expects to perform the following activities:

- Control the LAW vitrification process such that prepared LAW melter feed matches a target composition that is formulated to meet or exceed sodium loading while complying with specifications. (A, D, T) 
- Determine the total $\mathrm{Na}_{2} \mathrm{O}$ loading based on sampling and analysis of each LAW feed batch and measurements of the GFCs masses added. These determinations may be confirmed infrequently by chemical analysis of ILAW product samples. $(A, T)$

- Non-waste sodium additions (such as ultrafilter cleaning and ion exchange column regeneration) will be recorded and included in mass balance calculations. The LAW feed analysis will be adjusted by mass balance to account for average non-waste sodium introduced during feed processing. This adjustment will provide the waste sodium loading. (A)

- Report the waste $\mathrm{Na}_{2} \mathrm{O}$ loading in the ILAW production documentation for all ILAW produced from a production lot. (D, A)

The ILAW production documentation will include identification of the LAW feed envelope, the metric tons of ILAW produced per metric ton of sodium feed, and the calculated waste $\mathrm{Na}_{2} \mathrm{O}$ loading in the ILAW glass product.

According to this specification, the $\mathrm{Na}_{2} \mathrm{O}$ mass fraction in glass that came from waste $\mathrm{Na}_{2} \mathrm{O}\left(g_{\mathrm{Na}_{2} \mathrm{O}(w)}^{\text {oxidein }}\right)$ must be above the limit ( $L_{l}^{W_{N a}}$ ), i.e., $L_{l}^{W_{N a}}<g_{\mathrm{Na}_{2} \mathrm{O}(w)}^{\text {oxidein }}$. The limit is $14 \mathrm{wt} \%$, 3, and 10, for Envelopes A, B, and C waste products, respectively. The method of demonstrating that this specification is met during production is to calculate and report $g_{\mathrm{Na}_{2} \mathrm{O}(w), j}^{\mathrm{MFPI} V}$ and the waste envelope in the Production Records.

The waste $\mathrm{Na}_{2} \mathrm{O}$ loading in each MFPV batch is calculated by Equation (105). The mass weighted average over a group of MFPV batches is given by:

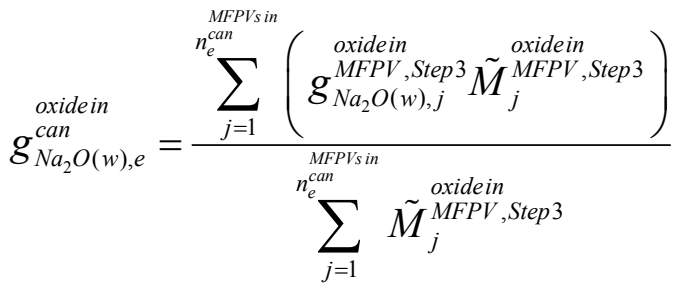

where

$$
\begin{aligned}
& \underset{g_{\mathrm{Na}_{2} \mathrm{O}(w), e}^{\text {caxidein }}}{\text { can }}=\begin{array}{l}
\text { mass fraction of waste } \mathrm{Na}_{2} \mathrm{O} \text { (waste } \mathrm{Na}_{2} \mathrm{O} \text { loading) in the } e^{\text {th }} \text { canister (g per } \mathrm{g} \\
\text { glass) }
\end{array} \\
& \underset{g_{N a_{2} \mathrm{O}(w), j}^{\text {oxidein }}}{\mathrm{MFPtep}}=\begin{array}{l}
\text { mass fraction of waste } \mathrm{Na}_{2} \mathrm{O} \text { (waste } \mathrm{Na}_{2} \mathrm{O} \text { loading) in the } j^{\text {th }} \text { MFPV batch from } \\
\text { algorithm calculation Step } 3 \text { (g per g glass) }
\end{array} \\
& n_{e}^{\text {MFPVSin }}=\text { number of MFPV batches that are assumed to be in the } e^{\text {th }} \text { canister }
\end{aligned}
$$

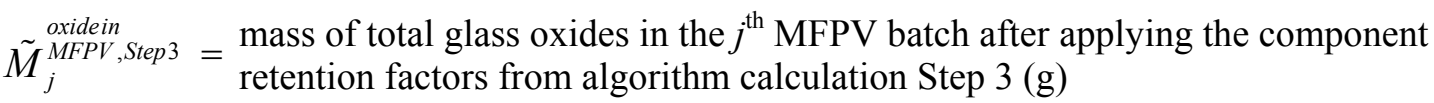

The summation is performed over $n_{e}^{\text {MFPVSin }}$ batches within a group, $j, j-1, j-2 \ldots$ and $j-\left(n_{e}^{\text {MFPVIsin }}-1\right)$. The mass of total glass oxides in the $j^{\text {th }}$ MFPV batch after applying the component retention factors from algorithm

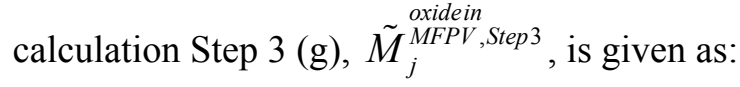




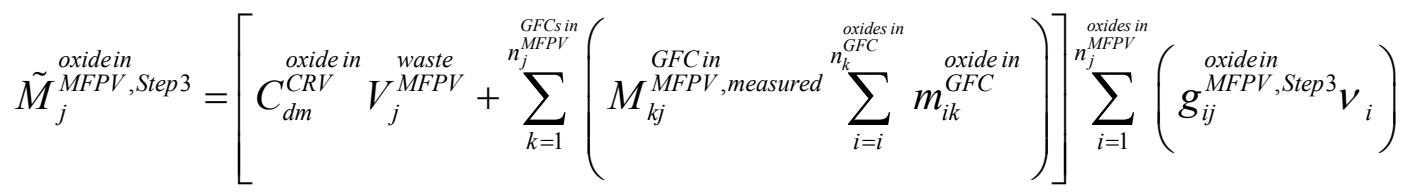

where

$$
\begin{aligned}
& C_{d m}^{\text {oxide in }}=\begin{array}{l}
\text { mass fraction of waste } \mathrm{Na}_{2} \mathrm{O} \text { (waste } \mathrm{Na}_{2} \mathrm{O} \text { loading) in the } j^{\text {th }} \text { MFPV batch from } \\
\text { algorithm calculation Step } 3 \text { (g per g glass) }
\end{array} \\
& \stackrel{\text { waste }}{V_{j}^{M F P V}}=\text { volume of waste transferred from CRV to the } j^{\text {th }} \text { MFPV (L) } \\
& n_{j}^{G F C \sin }=\text { number of GFCs in the } j^{\text {th }} \text { MFPV batch }
\end{aligned}
$$

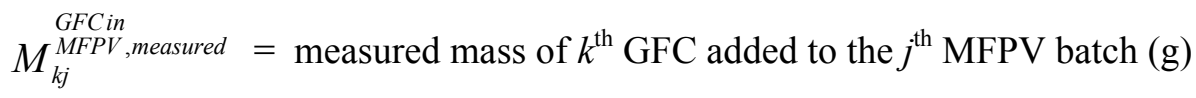

$$
\begin{aligned}
& n_{k}^{\text {oxides in }}=\text { number of glass oxides in the } k^{\text {th }} \text { GFC } \\
& \text { mass fraction of the } i^{\text {th }} \text { glass oxide in the } k^{\text {th }} \text { GFC (g oxide per g GFC }
\end{aligned}
$$

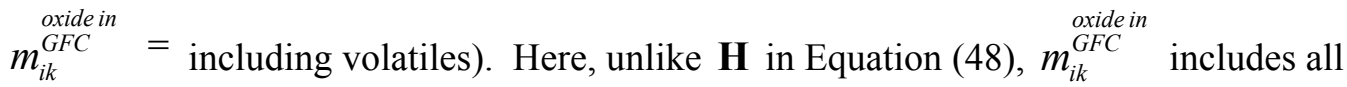

$$
\begin{aligned}
& \text { tracked components beyond the } 11 \text { GFC components. } \\
& n_{j}^{\text {oxides in }}=\begin{array}{l}
\text { number of glass oxides tracked in the mass balance calculations for the } j^{\text {th }} \\
\text { MFPV batch }
\end{array} \\
& \text { oxidein mass fraction of the } i^{\text {th }} \text { glass oxide in the } j^{\text {th }} \text { MFPV batch from algorithm } \\
& g_{i j}^{M F P V, S t e p 3}=\text { calculation Step } 3 \text { before applying component retention factors (g oxide per } \mathrm{g} \\
& \text { MFPV oxides) } \\
& v_{i}=\text { retention factor for the } i^{\text {th }} \text { component (fraction) }
\end{aligned}
$$

\subsubsection{Specification 2.2.2.6 - Chemical Composition Documentation}

Chemical Composition Documentation: The chemical composition of the waste form, filler, and package shall be identified.

2.2.2.6.2 Chemical Composition During Production: The production documentation

(Table C.5-1.1, Deliverable 6.7) shall provide the chemical composition of each waste form, optional filler, and package. The reported composition shall include elements (excluding oxygen) present in concentrations greater than 0.5 percent by weight and elements and compounds required to meet regulatory or Contract requirements.

According to the ILAW PCP (24590-WTP-PL-RT-03-001):

[PCP Section 4.1.6.2: Chemical Composition During Production] ... During production operations, the WTP project expects to perform the following characterization and reporting activities:

- Qualified sampling, test methods, analytical techniques, and models will be used to demonstrate compliance with this requirement during production. As new methods become available, they may be evaluated for development and qualification for use in ILAW production. (A, D, T)

- The WTP project's Quality Assurance Manual (QAM), 24590-WTP-QAM-QA-06-001, requires the GFC supplier facility to follow a WTP project approved $Q A$ program $(Q A P)$ and perform 
audit and surveillance activities at the WTP vitrification facility to ensure that quality materials are used in GFC addition. GFC suppliers will be required to certify the compositions and uncertainties of GFCs (major components as well as impurities) and to provide chemical analysis data. $(A, I)$

- The impurities in GFCs will be kept to a minimum by requiring the vendor to supply the material at a specific purity level and certify it with material test reports. If the glass forming chemical (for example, $\mathrm{Fe} 2 \mathrm{O3}$ ) contains Al2O3 as a major impurity, it will be accounted for in the calculation of the amount of GFC to be added to the waste batch. (A, I)

- ILAW chemical composition will be controlled during production operations by sampling and chemically analyzing $L A W$ feed, and calculating required additions of GFCs necessary to yield ILAW satisfying all WTP contract and processing requirements. In addition, volume transfers of $C R V$ batches and mass of GFCs transferred to the MFPV will be verified within measurement uncertainties. (A, D, I, T)

- The product control aspects of the strategy for compliance with this requirement will be implemented as part of a larger process control system for $L A W$ vitrification. Aspects of the product control system that are part of the compliance strategy will be conducted according to NQA-1 (ASME 2000) requirements and documented in the ILAW production documentation. The process will be operated within control limits based on parameters and results from qualification activities. (A, D, T)

- The means and standard deviations of reportable glass components will be calculated over the chemical composition determinations of ILAW produced as a given production lot is being processed. Standard deviations will be computed to account for multiple sources of variation and uncertainty. $(A, I)$

The following information will be reported in the ILAW production documentation:

- The estimated composition of the ILAW glass. The estimated composition will be calculated using a mass balance based upon the analyses of LAW feed samples, the volume of waste transferred from the CRV to the MFPV, the composition of the GFCs as provided in the vendor certifications, and the masses of GFCs added (as measured in the glass former batching facility), as well as the estimated volume and composition of the tank heels in the MFPV. The reported compositions will span several ILAW containers corresponding to a production lot. If a shard sample is taken from an individual container and analyzed, that composition will also be reported for that container. Reportable glass components will include those at concentrations greater than $0.5 \mathrm{wt} \%$ in the glass plus those necessary to meet regulatory or contract requirements.

- The chemical composition of any optional filler material and the quantity added to each filled container, if any.

- The materials of construction for the ILAW container.

The mass weighted average composition over a group of MFPV batches is given by:

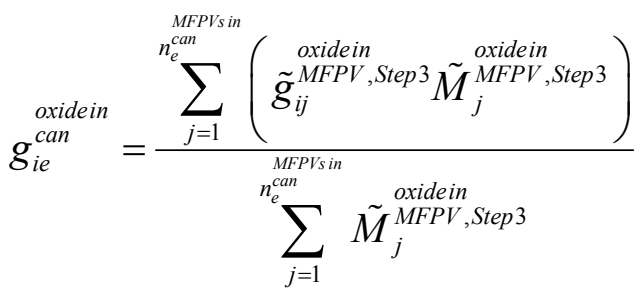


where

$$
\begin{aligned}
& g_{i e}^{\text {caidein }}=\text { mass fraction of the } i^{\text {th }} \text { glass oxide in the } e^{\text {th }} \text { canister (g per g glass) } \\
& \text { mass fraction of the } i^{\text {th }} \text { glass oxide in the } j^{\text {th }} \text { MFPV batch from algorithm } \\
& \tilde{g}_{i j}^{\text {MFidein }, \text { Step } 3}=\begin{array}{l}
\text { calculation Step } 3 \text { after applying the component retention factors (g oxide per } \mathrm{g} \\
\text { glass), i.e., mass of } i^{\text {th }} \text { glass oxide that will remain in glass divided by the total }
\end{array} \\
& \text { mass of all glass oxides that will remain in glass } \\
& n_{e}^{\text {MFPV }}{ }^{\text {can }}=\text { number of MFPV batches that are assumed to be in the } e^{\text {th }} \text { canister }
\end{aligned}
$$

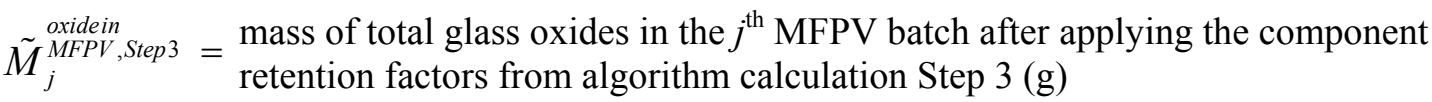

The summation is performed over $n_{e}^{\text {MFPVSin }}$ batches within a group, $j, j-1, j-2 \ldots$ and $j-\left(n_{e}^{\text {MFPVIsin }}-1\right)$.

The mass weighted SD of glass composition is

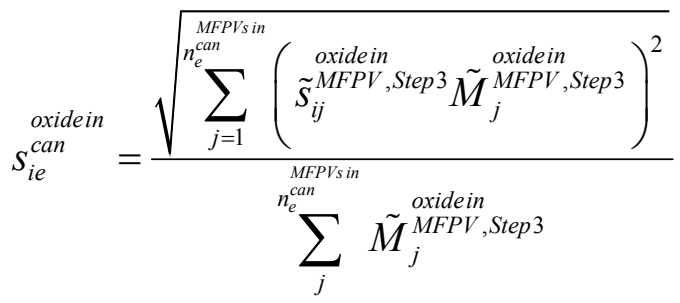

where $\quad s_{i e}^{\text {oxidein }}=\mathrm{SD}$ for the mass fraction of the $i^{\text {th }}$ glass oxide in the $e^{\text {th }}$ canister (g per g glass)

SD for the mass fraction of the $i^{\text {th }}$ glass oxide in the $j^{\text {th }}$ MFPV batch after applying

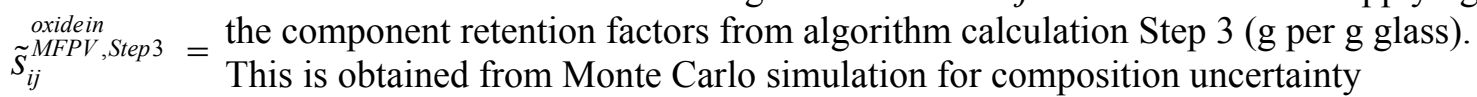
calculation discussed in Section 4.2.2.

$n_{e}^{\text {MFPV }}{ }^{\text {can }}=$ number of MFPV batches that are assumed to be in the $e^{\text {th }}$ canister $\tilde{M}_{j}^{\text {oxidein }}$ MFPV, Step $3=\begin{aligned} & \text { mass of total glass oxides in the } j^{\text {th }} \text { MFPV batch after applying the component } \\ & \text { retention factors from algorithm calculation Step } 3(\mathrm{~g})\end{aligned}$

The waste form composition is documented during production by reporting the $g_{i e}^{\text {caxidein }}$ values from Equation (123) and $s_{i e}^{\text {caidein }}$ values from Equation (124) in the Production Records. Currently, it is planned to calculate oxidein $g_{\text {ie }}^{\text {can }} \quad$ values for all components $(i)$ for which analytical data are available for a particular container. However, it may be advantageous to trim the number of components to only those with concentrations greater than $0.5 \mathrm{wt} \%$ plus those associated with other limits and specifications. In any case, only the appropriate subset of $i$ will be reported in the Production Records. 
The addition of optional filler material and production of the final ILAW container data package are not part of the ILAW formulation algorithm.

\subsubsection{Specification 2.2.2.7—Radiological Composition Documentation}

Radiological Composition Documentation: The radionuclide composition of the waste form shall be documented. Radionuclides shall be identified that are significant as defined in NUREG/BR0204 and $49 C F R 172.101$ (Table 2). Technetium-99 $\left({ }^{99} \mathrm{Tc}\right.$ ) shall be considered to be significant at concentrations greater than $0.003 \mathrm{Ci} / \mathrm{m}^{3}$ in the ILAW form. The inventories shall be indexed to December 31, 2002. The documentation shall be consistent with the radiological description format described in NUREG/BR-0204.

2.2.2.7.2 Radionuclide Composition During Production: The ILAW production documentation (Table C.5-1.1, Deliverable 6.7) shall identify the radionuclide inventory in each ILAW package produced. The actual inventory indexed at the month of product transfer and the inventory indexed to December 31, 2002, shall be reported.

According to the ILAW PCP (24590-WTP-PL-RT-03-001):

[PCP Section 4.1.7: Radiological Composition Documentation] ... During production operations, the WTP project expects to conduct the following activities to comply with this requirement:

- Collect and perform radiochemical analysis on process samples to determine the concentrations of significant radionuclides as defined in NUREG/BR-0204 (NRC 1995b) and 49 CFR 172.101, Table 2. (D, T)

- Apply the ratio method to estimate radionuclide concentrations for those radionuclides not directly measured, if necessary. (A)

- Calculate the means and standard deviations of the radionuclide inventory determinations for ILAW containers produced from a given LAW production lot for each significant radionuclide. (A)

- Calculate radionuclide inventories indexed to the month of product transfer and to 31 December 2002 using a computer code (for example, MicroShield ${ }^{\mathrm{TM}}$ [Grove 1996]) for each significant radionuclide. (A)

Inventories of reported radionuclides in Ci per container based on CRV analyses will be included in the ILAW production documentation for each significant radionuclide. The documentation will be consistent with the radiological description format described in NUREG/BR-0204 (NRC 1995b).

Indexing of radionuclide data to a specified date will be performed by the laboratory, before entering into the ILAW formulation algorithm. The mass weighted average specific activity of radionuclides over a group of MFPV batches is given by

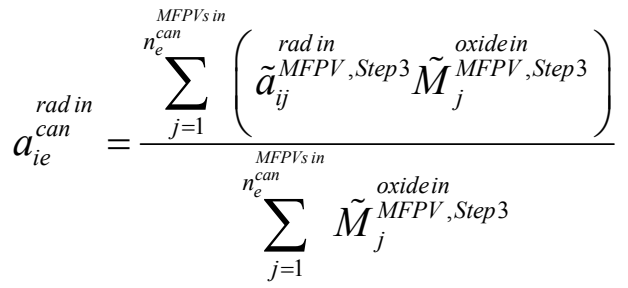

where $\quad a_{i e}^{\text {cadin }}=$ specific activity of the $i^{\text {th }}$ radionuclide in the $e^{\text {th }}$ canister ( $\mathrm{mCi} / \mathrm{g}$ glass) 


$$
\begin{aligned}
& \tilde{a}_{i j}^{\text {rad in }} \text { MFPV,Step } 3=\begin{array}{l}
\text { specific activity of the } i^{\text {th }} \text { radionuclide in the } j^{\text {th }} \text { MFPV batch after applying the } \\
\text { component retention factors for algorithm calculation Step } 3 \text { (mCi/g oxides) }
\end{array} \\
& n_{e}^{\text {can }}=\text { number of MFPV batches that are assumed to be in the } e^{\text {th }} \text { canister }
\end{aligned}
$$

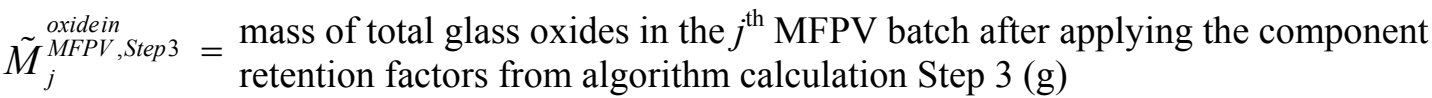

The mass weighted SD of specific activity is

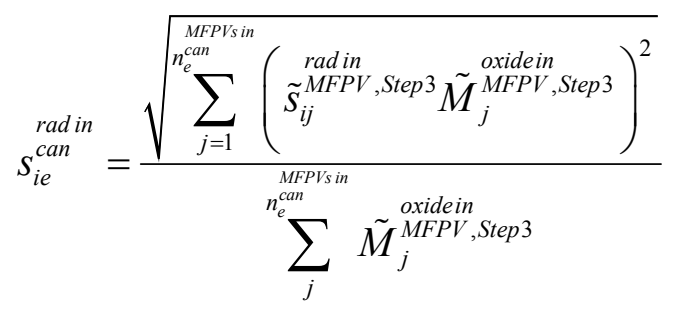

where $\quad s_{i e}^{\text {cad in }}=\mathrm{SD}$ for the specific activity of the $i^{\text {th }}$ radionuclide in the $e^{\text {th }}$ canister (mCi/g glass)

SD for the specific activity of the $i^{\text {th }}$ radionuclide in the $j^{\text {th }}$ MFPV batch after

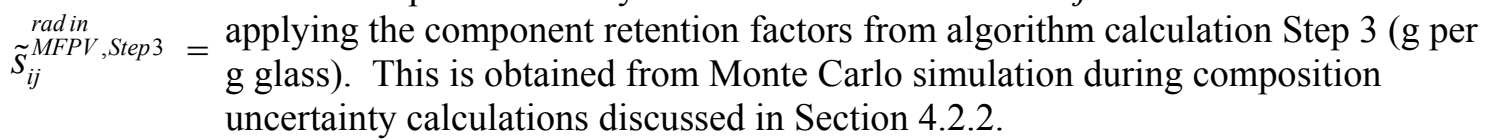
$n_{e}^{\text {can }}=$ number of MFPV batches that are assumed to be in the $e^{\text {th }}$ canister $\tilde{M}_{j}^{\text {oxidein }}$ MFV Step $3=\begin{aligned} & \text { mass of total glass oxides in the } j^{\text {th }} \text { MFPV batch after applying the component } \\ & \text { retention factors from algorithm calculation Step } 3(\mathrm{~g})\end{aligned}$

The inventory of each radionuclide in each canister of LAW glass (the reporting quantity) is given by:

$$
I_{i e}^{\text {radin }}=a_{i e}^{\text {radin }} M_{e}^{\text {glassin }}
$$

where

$$
\begin{aligned}
I_{i e}^{\text {can }} & =\text { inventory of the } i^{\text {th }} \text { radionuclide in the } e^{\text {th }} \text { canister }(\mathrm{Ci}) \\
a_{i e}^{\text {can }} & =\text { specific activity of the } i^{\text {th }} \text { radionuclide in the } e^{\text {th }} \text { canister (mCi/g glass) } \\
M_{e}^{\text {glassin }} & =\text { mass of glass in the } e^{\text {th }} \text { canister }(\mathrm{kg})
\end{aligned}
$$

The mass of glass in the container is assumed to be $M_{e}^{\text {glassin }}=5,911 \mathrm{~kg}$ (the average value measured in the full-scale container filling experiments [Andre 2004]). During plant operation, $M_{e}^{\text {glassin }}$ will be obtained from direct measurement or correlation with fill height. 
The inventories and concentrations of radionuclides will be calculated for all radionuclides with measured values from the laboratory samples. For those radionuclides with "less-than" values reported by the laboratory, the detection limit will be used in calculations of concentration and an appropriate flag will be carried with the results. The Production Records will report only those values required (e.g., those radionuclides with concentrations considered significant according to the specification above).

\subsubsection{Specification 2.2.2.8 - Radionuclide Concentration Limitations}

Radionuclide Concentration Limitations: The radionuclide concentration of the ILAW form shall not exceed Class $C$ limits as defined in 10CFR61.55. In addition, the average glass concentrations of Cesium-137 $\left({ }^{137} \mathrm{Cs}\right)$, Strontium-90 $\left({ }^{90} \mathrm{Sr}\right)$ shall be limited as follows: ${ }^{137} \mathrm{Cs}<3 \mathrm{Ci} / \mathrm{m}^{3}$ and ${ }^{90} \mathrm{Sr}<$ $20 \mathrm{Ci} / \mathrm{m}^{3}$. The method used to perform concentration averaging should be identified in the ILAW Product Compliance Plan.

According to the ILAW PCP (24590-WTP-PL-RT-03-001):

[PCP Section 4.1.8: Radiological Concentration Limitations] ... During production, the WTP project expects to perform the following activities:

- Determine the radionuclide concentrations in the ILAW product through analysis of a combination of process samples, flowsheet calculations, or periodic confirmatory product samples. Radionuclide concentrations will be determined routinely based upon samples taken from the ILAW CRVS. $(A, T)$

- Verify that radionuclide concentrations are less than Class C limits as defined in 10 CFR 61.55 and as described in the Nuclear Regulatory Commission's Branch Technical Position on Concentration Averaging and Encapsulation (NRC 1995a). (A, I, T)

- Verify that the average concentrations for the following radionuclides are below their respective concentration limits: $137 \mathrm{Cs}<3 \mathrm{Ci} / \mathrm{m} 3,90 \mathrm{Sr}<20 \mathrm{Ci} / \mathrm{m} 3$, and $\mathrm{TRU}<100 \mathrm{nCi} / \mathrm{g}$. The average concentrations will be determined by calculating the means of radionuclide concentrations, measured in process or confirmatory product samples, for all containers submitted for acceptance. $(A, I, T)$

- Calculate a running average of radionuclide concentrations by summing the actual inventories of each radionuclide in the ILAW product presented to date and dividing by the total volume of waste in these containers. (A)

Inventories of reported radionuclides in Ci per container based on CRV analyses will be included in the ILAW production documentation for each significant radionuclide. The WTP project will also report running averages of radionuclide concentrations over all ILAW product containers presented to date for acceptance on a waste type basis in the ILAW production documentation.

The radionuclide concentration limits are based on the activity of each radionuclide either per unit glass mass or per unit glass volume. The specific activity of radionuclides and its SD from Equations (125) and (126) are converted to per unit glass volume using:

$$
\begin{gathered}
\hat{a}_{i e}^{\text {rad in }}=a_{i e}^{\text {cad }} \rho_{e}^{\text {can }} \rho^{\text {class in }} \\
\hat{s}_{i e}^{\text {rad in }}=s_{i e}^{\text {can }} \rho_{e}^{\text {ran }}{ }^{\text {glass in }}
\end{gathered}
$$


where

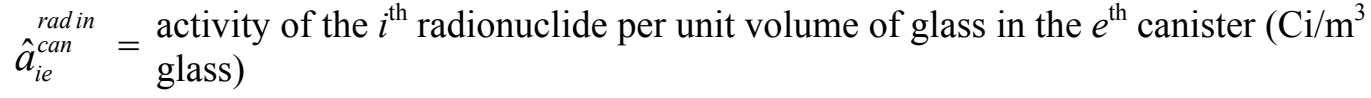

$$
\begin{aligned}
& a_{i e}^{\text {radin }}=\text { specific activity of the } i^{\text {th }} \text { radionuclide in the } e^{\text {th }} \text { canister ( } \mathrm{mCi} / \mathrm{g} \text { glass) } \\
& \rho_{e}^{\text {glass in }}=\text { density of glass in the } e^{\text {th }} \text { canister }(\mathrm{g} / \mathrm{L})
\end{aligned}
$$

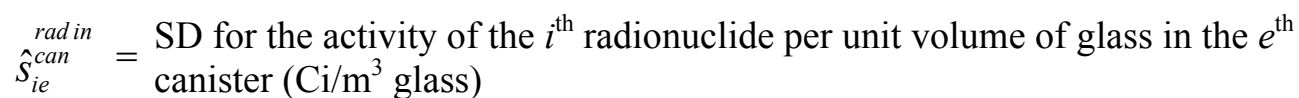

$$
\begin{aligned}
& s_{i e}^{\text {cadin }}=\mathrm{SD} \text { for the specific activity of the } i^{\text {th }} \text { radionuclide in the } e^{\text {th }} \text { canister ( } \mathrm{mCi} / \mathrm{g} \text { glass) }
\end{aligned}
$$

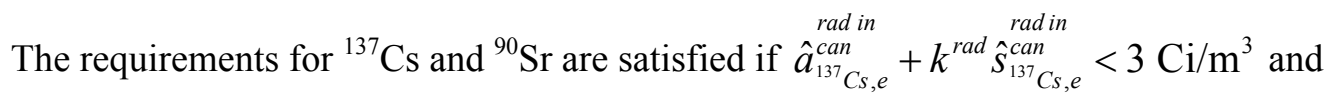

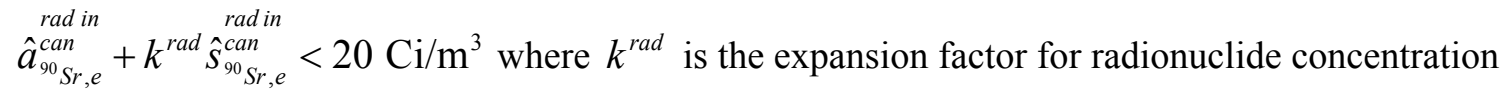
specification. Note that the Contract (DOE 2000) Section C.7 (d).(1).(iii) requirement of $0.3 \mathrm{Ci} / \mathrm{m}^{3137} \mathrm{Cs}$ is not relevant to product compliance and not required in the production records.

To demonstrate that the waste meets the classification of Class $\mathrm{C}$ waste or below, limiting values for $\hat{a}_{i e}^{\text {radin }}$ and $a_{i e}^{\text {radin }}$; listed in Table 15 and Table 16 given in Section 5.1.6.3, are used.

The first step to classification is then to determine if there are any radionuclides with measurable concentrations ( $\hat{a}_{i e}^{\text {rad in }}$ for ${ }^{99} \mathrm{Tc},{ }^{129} \mathrm{I},{ }^{63} \mathrm{Ni},{ }^{90} \mathrm{Sr}$, and ${ }^{137} \mathrm{Cs}$, or $a_{i e}^{\text {rad in }}$ for TRU, ${ }^{241} \mathrm{Pu}$, and ${ }^{242} \mathrm{Cm}$ ). If non-zero values are present for radionuclides only in Table 15 or only in Table 16, then only those tables are used for classification. If there are non-zero values for both tables, then Table 15 is used for classification if any one radionuclide from Table 15 is greater than $10 \%$ of its associated limit. If no Table 15 radionuclide has a concentration greater than or equal to its associated limit, then Table 16 is used for classification. The sum of fractions rule is given as:

$$
\begin{aligned}
& S F_{L L, e}^{\text {rad in }}{ }^{\text {can }}=\sum_{i}^{2} \frac{\hat{a}_{i e}^{\text {rad in }}}{L_{u}^{\hat{a}_{i}}}\left(\text { for } i={ }^{99} \mathrm{Tc} \text { and }{ }^{129} \mathrm{I}\right)+
\end{aligned}
$$

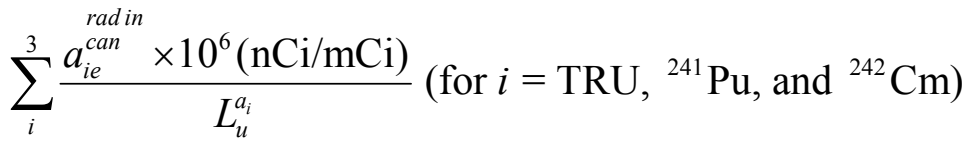

$$
\begin{aligned}
& S F_{S L, e}^{\text {rad in }}=\sum_{i}^{3} \frac{\hat{a}_{i e}^{\text {can }}}{\text { cadin }_{\hat{\theta}_{i}}}\left(\text { for } i={ }^{63} \mathrm{Ni},{ }^{90} \mathrm{Sr} \text {, and }{ }^{137} \mathrm{Cs}\right)
\end{aligned}
$$

$\quad S_{L L, e}^{\text {rad in }}=\begin{aligned} & \text { sum of fractions of activity to the limit of each radionuclide for long-lived } \\ & \text { where } \quad \text { radionuclides for Class C limit determination in the } e^{\text {th }} \text { canister }\end{aligned}$ 


$$
\begin{aligned}
S F_{S L, e}^{\text {can in }} & =\begin{array}{l}
\text { sum of fractions of activity to the limit of each radionuclide for short-lived } \\
\text { radionuclides for Class C limit determination in the } e^{\text {th }} \text { canister }
\end{array} \\
\hat{a}_{i e}^{\text {can }} & =\begin{array}{l}
\text { activity of the } i^{\text {th }} \text { radionuclide per unit volume of glass in the } e^{\text {th }} \text { canister }\left(\mathrm{Ci} / \mathrm{m}^{3}\right. \\
\text { glass) } \\
\hat{a}_{i e}^{\text {radin }}
\end{array}=\text { specific activity of the } i^{\text {th }} \text { radionuclide in the } e^{\text {th }} \text { canister (mCi/g glass) } \\
L_{u}^{a_{i}} & =\text { upper limit for specific activity of the } i^{\text {th }} \text { radionuclide (nCi/g glass) } \\
L_{u}^{\hat{a}_{i}} & =\text { upper limit for the activity of the } i^{\text {th }} \text { radionuclide per unit glass volume }\left(\mathrm{Ci} / \mathrm{m}^{3}\right.
\end{aligned}
$$

The standard deviations for $S F_{L L, e}^{\text {rad in }}$ and $S F_{S L, e}^{\text {rad in }}$ are given as:

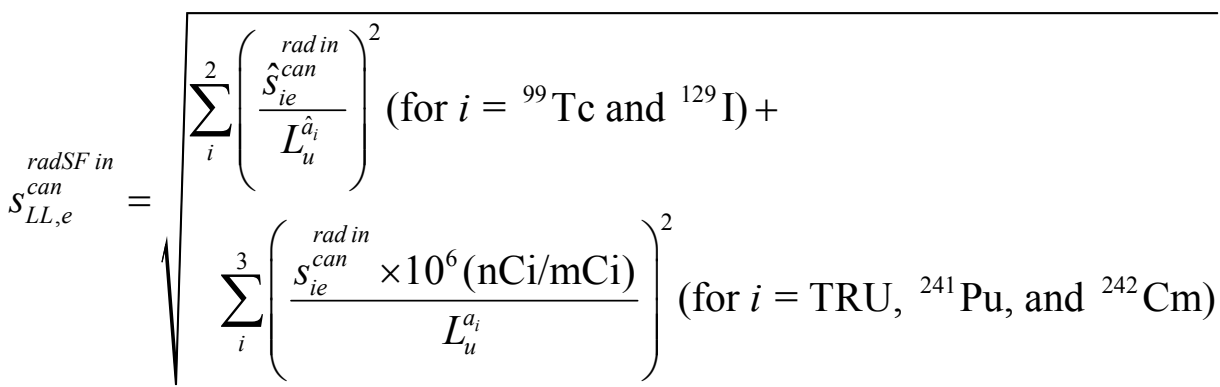

$$
\begin{aligned}
& S F_{S}=\sqrt{\sum_{i}^{3}\left(\frac{\hat{S}_{i e}^{\text {radin }}}{L_{u}^{\hat{\tilde{\theta}}_{i}}}\right)^{2}\left(\text { for } i={ }^{63} \mathrm{Ni},{ }^{90} \mathrm{Sr} \text {, and }{ }^{137} \mathrm{Cs}\right)}
\end{aligned}
$$

where $\quad s_{L a n}^{\text {radSF in }}=$ SD for the sum of fractions of activity to the limit of each radionuclide for long$s_{L L, e}^{c a n}=$ lived radionuclides for Class $\mathrm{C}$ limit determination in the $e^{\text {th }}$ canister ${ }_{S}^{\mathrm{rad} S \mathrm{Can}}$ in $=\mathrm{SD}$ for the sum of fractions of activity to the limit of each radionuclide for short$s_{S L, e}^{c a n}=$ lived radionuclides for Class $\mathrm{C}$ limit determination in the $e^{\text {th }}$ canister $\hat{S}^{\text {cadin }}{ }^{\text {can }}=\mathrm{SD}$ for the activity of the $i^{\text {th }}$ radionuclide per unit volume of glass in the $e^{\text {th }}$ $\hat{s}_{i e}^{\text {can }}=$ canister $\left(\mathrm{Ci} / \mathrm{m}^{3}\right.$ glass $)$

$s_{i e}^{\text {cad in }}=\mathrm{SD}$ for the specific activity of the $i^{\text {th }}$ radionuclide in the $e^{\text {th }}$ canister ( $\mathrm{mCi} / \mathrm{g}$ glass)

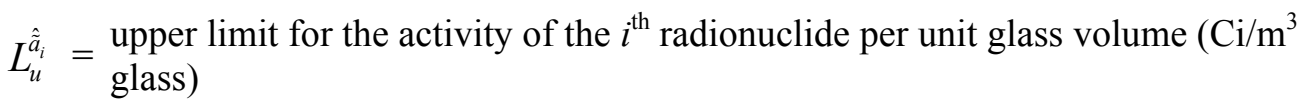
$L_{u}^{a_{i}}=$ upper limit for specific activity of the $i^{\text {th }}$ radionuclide (nCi/g glass)

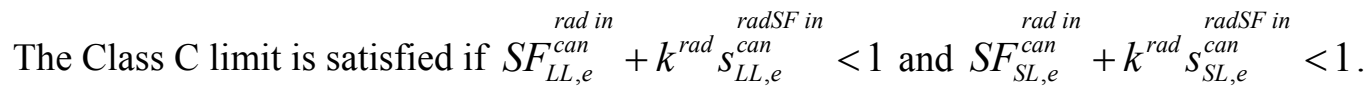




\subsubsection{Specification 2.2.2.9-Surface Dose Rate Limitations}

Surface Dose Rate Limitations: The dose rate at any point on the external surface of the package shall not exceed $500 \mathrm{mrem} / \mathrm{hr}$.

According to the ILAW PCP (24590-WTP-PL-RT-03-001):

[PCP Section 4.1.9: Surface Dose Rate Limitations] ... During production, the WTP project expects to perform the following activities:

- Check radionuclide concentrations projected for compliance with WTP contract Specification 2.2.2.7, Radiological Composition Documentation, to verify that they will be lower in the ILAW product than the maximum used to demonstrate compliance with this specification. (A)

- Confirm compliance with this requirement by monitoring the surface dose rate of each ILAW container using handheld instrumentation or automated monitoring equipment prior to transfer for disposal. (I)

Surface dose rates measured for each container will be reported in the ILAW production documentation.

No calculation is needed by ILAW formulation algorithm.

\subsubsection{Specification 2.2.2.17-Waste form Testing}

Waste form Testing:

2.2.2.17.2 Product Consistency Test: The normalized mass loss of sodium, silicon, and boron shall be measured using a seven day product consistency test run at $90^{\circ} \mathrm{C}$ as defined in ASTM C1285-98. The test shall be conducted with a glass to water ratio of 1 gram of glass $(-100+200$ mesh) per 10 milliliters of water. The normalized mass loss shall be less than 2.0 grams $/ \mathrm{m}^{2}$. Qualification testing shall include glass samples subjected to representative waste form cooling curves. The product consistency test shall be conducted on waste form samples that are statistically representative of the production glass.

2.2.2.17.3 Vapor Hydration Test: The glass corrosion rate shall be measured using at least a seven day vapor hydration test run at $200^{\circ} \mathrm{C}$ as defined in the DOE concurred upon ILAW Product Compliance Plan. The measured glass alteration rate shall be less than 50 grams $/\left(\mathrm{m}^{2} \cdot\right.$ day). Qualification testing shall include glass samples subjected to representative waste form cooling curves. The vapor hydration test shall be conducted on waste form samples that are representative of the production glass.

According to the ILAW PCP (24590-WTP-PL-RT-03-001):

[PCP Section 4.1.17: Waste Form Testing] ... During production operations, the WTP project expects to perform the following characterization and reporting activities:

- The chemical composition of the ILAW product will be determined and controlled as described in the response to WTP contract Specification 2.2.2.6. (A, $I, T$ )

- The PCT and VHT property composition models will be applied using the ILAW glass chemical composition determinations for each MFPV batch. The outcomes will be predicted PCT and $V H T$ values, and calculated uncertainties of the predictions for each chemical composition determination. (A)

- The predicted PCT and VHT values for glasses produced over a production lot will be used to calculate means, standard deviations, and statistical intervals. The calculations will account for 
variations and uncertainties in the predicted property values due to variations in glass composition, as well as uncertainties due to glass sampling, glass chemical analyses, other measurement uncertainties and the PCT and VHT property composition models. Statistical variance and error propagation methods will be used, and will be discussed in detail in the ILAW PQR after they are developed and applied. (A)

The ILAW production documentation will include the chemical composition of ILAW glass as oxides as calculated from CRV samples and masses of GFCs added and the predicted PCT and VHT calculated from PCT and VHT glass property composition models.

The glass properties will be calculated for the final estimated composition of canistered glass using the glass property models described in Section 4.1. The predicted properties for PCT normalized releases ( $P^{p c t}$, $\ln \left[r_{\mathrm{B}}, \mathrm{g} / \mathrm{L}\right]$ and $\left.\ln \left[r_{\mathrm{Na}}, \mathrm{g} / \mathrm{L}\right]\right)$ and VHT alteration depth $\left(P^{v h t}, \ln [D, \mu \mathrm{m}]\right)$ are calculated using Equations (2) and (5) with model coefficients ( $p_{h}^{p c t}$ and $p_{h}^{\text {vht }}$ ) given in Table 5 and Table 6 and glass composition (for $x_{h}^{p c t}$ and $\left.x_{h}^{v h t}\right)$ given by Equation (123). The prediction uncertainties $\left(U_{p r e d}^{p c t}\right.$ and $\left.U_{p r e d}^{v h t}\right)$ are calculated using Equations (8) and (9) and the same composition (for $\mathbf{x}^{p c t}$ and $\mathbf{x}^{\text {vht }}$ ) given by Equation (123). The composition uncertainties ( $U_{\text {comp }}^{p c t}$ and $U_{\text {comp }}^{\text {vht }}$ ) are calculated using Monte Carlo simulation method described in Section 4.2.2 based on nominal glass composition given by Equation (123) with SD given by Equation (124).

The UCCIs for PCT normalized releases and VHT alteration depths are given as:

$$
\begin{aligned}
& B_{u c c i, e}^{p c t}=P_{e}^{p c t}+U_{p r e d, e}^{p c t}+U_{c o m p, e}^{p c t} \\
& B_{u c c i, e}^{v h t}=P_{e}^{v h t}+U_{p r e d, e}^{v h t}+U_{c o m p, e}^{v h t}
\end{aligned}
$$

where $\quad B^{p c t}, B^{v h t}=\mathrm{CL} \%$ upper combined confidence interval for " $p c t$ " $\left(\ln \left[r_{\mathrm{B}}, \mathrm{g} / \mathrm{L}\right], \ln \left[r_{\mathrm{Na}}\right.\right.$, $\mathrm{g} / \mathrm{L}])^{(15)}$ and " $v h t^{\prime}$ " $(\ln [D, \mu \mathrm{m}])$ for the $e^{\text {th }}$ canister

$$
P_{e}^{p c t}, P_{e}^{v h t}=\text { predicted transformed property for " } p c t \text { " }\left(\ln \left[r_{\mathrm{B}}, \mathrm{g} / \mathrm{L}\right], \ln \left[r_{\mathrm{Na}}, \mathrm{g} / \mathrm{L}\right]\right) \text { and " } v h t \text { " }
$$
$(\ln [D, \mu \mathrm{m}])$ for the $e^{\text {th }}$ canister (calculated per Section 4.1) $U_{p c t, e}^{p c t}, U_{p r e d, e}^{v h t}=$ model prediction uncertainty for " $p c t$ " $\left(\ln \left[r_{\mathrm{B}}, \mathrm{g} / \mathrm{L}\right], \ln \left[r_{\mathrm{Na}}, \mathrm{g} / \mathrm{L}\right]\right)$ and " $v h t$ " pred,e $(\ln [D, \mu \mathrm{m}])$ for the $e^{\text {th }}$ canister (calculated per Section 4.2.1) $U_{c o m p, e}^{p c t}, U_{c o m p, e}^{v h t}=\begin{aligned} & \text { composition uncertainty for " } p c t \text { " }\left(\ln \left[r_{\mathrm{B}}, \mathrm{g} / \mathrm{L}\right], \ln \left[r_{\mathrm{Na}}, \mathrm{g} / \mathrm{L}\right]\right) \text { and " } v h t \text { " }(\ln [D, \\ & \left.\mu \mathrm{m}]) \text { for the } e^{\text {th }} \text { canister (calculated per Section } 4.2 .2\right)\end{aligned}$

\subsubsection{Specification 2.2.2.23-Manifesting}

Manifesting: A shipping manifest shall be prepared for delivery with each shipment of ILAW product. Information on the manifest shall satisfy the requirements in DOE Manual 435.1-1, Chapter IV, Section I.(2), and NUREG/BR-0204. Any package containing dangerous waste must be labeled and manifested in accordance with WAC 173-303-370 and the Dangerous Waste Portion of the Resource Conservation and Recovery Act Permit for the Treatment, Storage, and Disposal of Dangerous Wastes (Permit No. WA 7890008967).

According to the ILAW PCP (24590-WTP-PL-RT-03-001):

${ }^{(15)}$ See Section 4.1.1 for justification to exclude the PCT Si release from the constraints. 
[PCP Section 4.1.23: Manifesting] ... During production operations, the WTP project expects to perform the following activities:

- Prepare the documentation necessary to transfer the ILAW from the WTP to the onsite ILAW disposal site. Information needed to complete the radioactive shipping records will be available from

- Sampling and analysis (T)

- Process knowledge (I)

- Maintain and make available for inspection transportation records as required by DOE, Ecology, and DOT. (I)

During production, documentation satisfying the requirements of this specification and confirmation that the ILAW product meets radioactive shipment record requirements will be provided with each shipment of ILAW to the disposal site.

Waste composition and radionuclide concentrations/inventories will be put in the Production Records. The equations required to manifest the waste are taken from above subsections. 


\section{Calculation Examples}

To demonstrate the calculation steps described in Section 5 and aid in understanding how they are solved, an example set of waste compositions is carried through most of the calculations. The wastes needed to have both chemical and radionuclide information available and would benefit from having waste composition variations. For this purpose, the waste compositions generated by the WTP Dynamic Flowsheet Model (G2) were chosen (24590-WTP-RPT-PO-07-002, Rev. 0). The G2 model run selected for example calculations (MRQ07-0003 as described in 24590-WTP-MDD-PR-01-002, Rev. $9^{(16)}$ ) represents one of many recent G2 runs. The G2 model output data in the form of chemical snapshots of the CRV contents were used.

The selected G2 run produced total 4998 CRV batches with 2499 batches per each CRV: LCP-VSL-00001 (designated as CRV-A in this report) and LCP-VSL-00002 (CRV-B). The order of CRV batches is $A 1, B 1$, $A 2, B 2, \ldots, A 2499, B 2499$. The eight sequential datasets, representing the $A 10^{\text {th }}$ through $B 13^{\text {th }}$ CRV batches, are given in Table B.1 in Appendix B and are used for example calculations in this report. The composition is reported in the format of mass of each of 96 (non-zero) analytes and a total batch volume. The mass values per batch were converted to concentration units that would be reported by the WTP laboratory during operation (in elemental concentrations and radionuclide activities per unit volume of CRV waste). ${ }^{(17)}$ The G2 data on CRV batch are taken as the average analytical results of three replicate CRV samples $\left(\bar{c}_{i d}^{\text {element in }}\right.$ for chemical components and $\bar{R}_{i d}^{\text {rad in }}$ fRV for radionuclides).

The G2 data on CRV batch composition includes the trace components that will not be analyzed from the CRV samples. For components that are listed for both chemical analyte and radionuclide(s), the data on chemical elements are used for oxide conversion because for $\mathrm{G} 2$ data the concentration of chemical element includes all isotopes. Note that this approach is solely for example calculations in this report using the G2 output. During WTP operation, the analytical data conversion procedures described in Section 5.1.2 are used.

The volume of CRV was from 53033 to $53279 \mathrm{~L}$ within the first $250 \mathrm{CRV}$ batches, which are higher than the present design of working volume of CRV $(48661 \mathrm{~L})$. For example calculations, the volume for each CRV batch was randomly generated based on the uncertainty estimation $(\mathrm{SD}=724.3 \mathrm{~L})$ described in Appendix D around the nominal working volume of $48661 \mathrm{~L}$. Similarly the heel volume for the calculation of each MFPV batch was also randomly generated based on the uncertainty estimation ( $\mathrm{SD}=447.2 \mathrm{~L}$ ) described in Appendix D around the nominal working volume of $6556 \mathrm{~L}$. The resulting working volume of the $A 11^{\text {th }}$ CRV was $48709 \mathrm{~L}$ and the heel volume for the $A 101^{\text {th }}$ MFPV batch was $6712 \mathrm{~L}$.

\subsection{Example Step 1 - Glass Formulation and Calculation of LAW Transfer Volume}

The waste compositions of CRV used to perform the calculations was that of the $A 11^{\text {th }} \mathrm{CRV}$ batch as estimated by the mentioned G2 run. The laboratory will screen the data and scale the radionuclide concentrations to the appropriate date, per their procedures.

(16) The same G2 run was used for IHLW algorithm example calculations and IHLW WQR calculations and will be used for ILAW PQR calculations.

(17) The methods of converting the G2 composition data into laboratory units are not relevant to the scope of this report and will not be discussed here. 


\subsubsection{CRV Analytical Data Screening and Evaluation}

The analytical data from the LAW CRV samples are screened and evaluated prior to calculating glass formulation. No examples are given in this report for data screening and evaluation, which will be performed using the dedicated SPC software during production.

\subsubsection{CRV Analytical Data Conversion}

This subsection illustrates the calculations for the G2 example to convert analytical data into the appropriate form for glass formulation calculations, discussed in Section 5.1.2. The formulation algorithm uses waste compositions in the form of mass fractions of glass oxides. The analytical data are converted from $\mathrm{mg} / \mathrm{L}$ or $\mathrm{mCi} / \mathrm{L}$ of analytes to mass fraction of glass oxide by Equations (21) and (23). With the $f_{i}$ and $A_{i}$ values listed in Table A-1, the analytical $\bar{c}_{i, A 11}^{\text {element in }}$ and $\bar{R}_{i, A 11}^{\text {rad in }}$ values listed in Table B-1 are converted to the correct format for glass formulation. Table B-2 lists the glass oxide mass fractions for all 64 components in the $A 11^{\text {th }} \mathrm{CRV}$ for the $1^{\text {st }}$ waste transfer $(d=A 11$ and $m=1)$. For $\mathrm{NO}_{2}, \mathrm{NO}_{3}$, and TOC (treated as elements in $\bar{c}_{i d}^{\text {element in }}$ format), the concentrations per waste volume are still used after converting them from $\mathrm{mg} / \mathrm{L}$ to $\mathrm{g} / \mathrm{L}$. For radionuclides, the specific activities are calculated using Equation (24).

The first step is to obtain the dilution factor according to Equation (19):

$$
\lambda_{A 11,1}=\frac{V_{A 11}^{\text {working }}}{V_{A 11}^{C R V}+V_{A 11}^{C R V}}=\frac{48,709(\mathrm{~L})}{48,709(\mathrm{~L})+71.2(\mathrm{~L})}=0.99854
$$

Then, use the result to calculate the $c_{i, A 11,1}^{\text {element in }}$ values from $\bar{c}_{i, A 11}^{\text {element in }}$ according to Equation (18):

$$
c_{i, A 11,1}^{\text {element in }}=\bar{c}_{i, A 11}^{\text {element in }} \quad \lambda_{A 11,1}
$$

To provide examples, concentrations of $\mathrm{Al}$ and $\mathrm{Cs}$ and activities of $\mathrm{Cs}$ isotopes were taken from the $A 11^{\text {th }}$ CRV composition in Table B- 1 to calculate the mass fractions of the glass oxides $\mathrm{Al}_{2} \mathrm{O}_{3}$ and $\mathrm{Cs}_{2} \mathrm{O}$. It was assumed that the first waste transfer from the $A 11^{\text {th }} \mathrm{CRV}$ batch in Table B-1 represents the feed stream for the $A 101^{\text {th }}$ MFPV batch.

Combining Equations (18), (21), and (22) for $\mathrm{Al}$ and Cs yields:

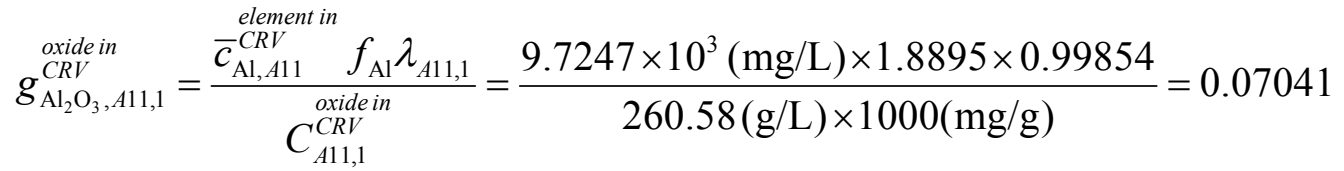

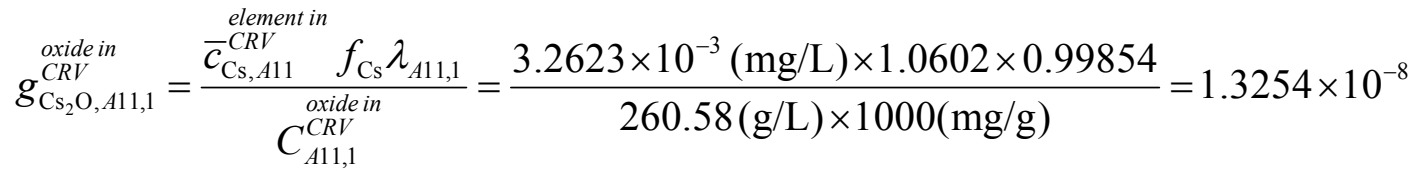


For Cs isotopes, the activity data are converted to elemental concentrations following Equation (23):

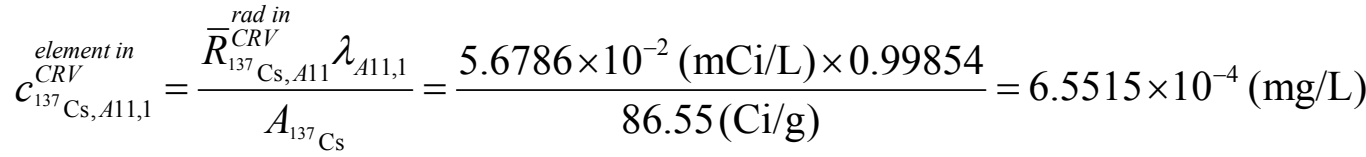

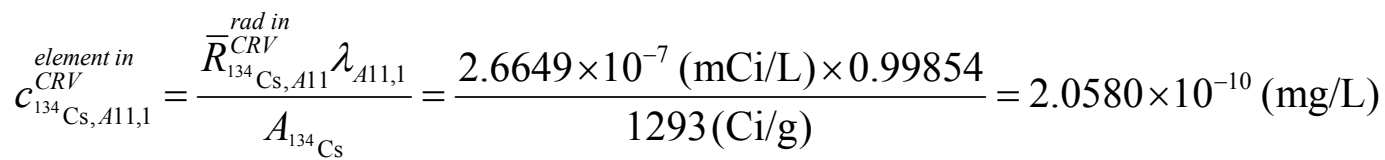

Combining Equations (21) and (22) for ${ }^{137} \mathrm{Cs}$ and ${ }^{134} \mathrm{Cs}$ yields:

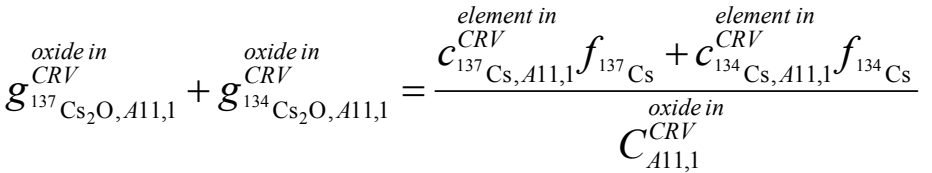

$$
\begin{aligned}
& =\frac{6.5515 \times 10^{-4}(\mathrm{mg} / \mathrm{L}) \times 1.0584+2.0580 \times 10^{-10}(\mathrm{mg} / \mathrm{L}) \times 1.0597}{260.58(\mathrm{~g} / \mathrm{L}) \times 1000(\mathrm{mg} / \mathrm{g})}=2.661 \times 10^{-9}
\end{aligned}
$$

The combined $g_{\mathrm{Cs}_{2} \mathrm{O}, A 11,1}^{\text {oxidein }}$ value of $2.6661 \times 10^{-9}$ from ${ }^{137} \mathrm{Cs}$ and ${ }^{134} \mathrm{Cs}$ is smaller than the value obtained from the concentration of chemical Cs, $1.3254 \times 10^{-8}$, which includes all isotopes.

The specific activities of ${ }^{137} \mathrm{Cs}$ and ${ }^{134} \mathrm{Cs}$ are calculated using Equation (24):

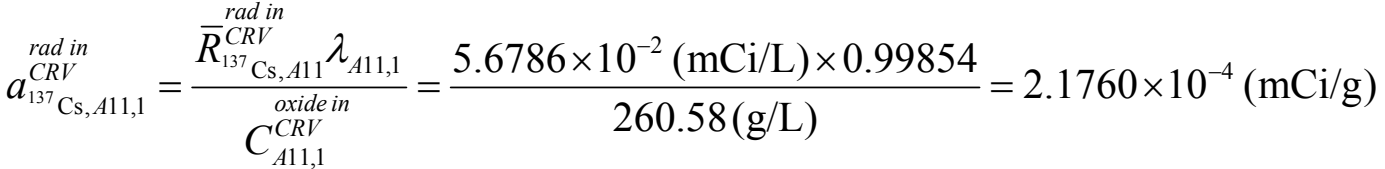

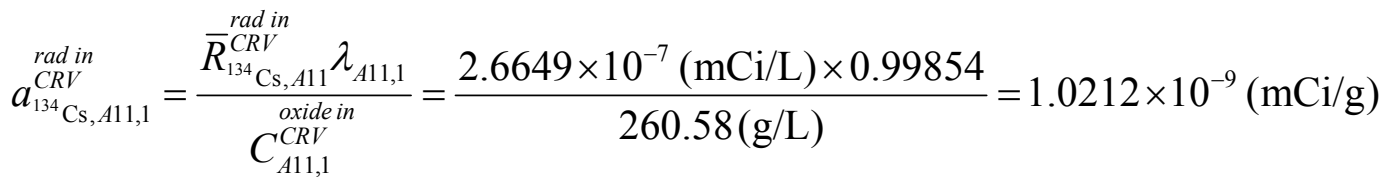

In the examples above, the total glass oxide concentration $\left(C_{A 11,1}^{\text {oxidein }}\right.$ ) of $260.58 \mathrm{~g} / \mathrm{L}$ was obtained by summing over all 64 glass oxide components tracked in the calculations according to Equation (22):

$$
C_{A 11,1}^{\begin{array}{c}
\text { oxides in } \\
C R V
\end{array}}=\frac{\sum_{i=1}^{64} c_{i, A 11,1}^{\text {element in }} f_{i}^{C R V}}{1000(\mathrm{mg} / \mathrm{g})}
$$

The composition of the $1^{\text {st }}$ transfer waste transferred from the $A 11^{\text {th }} \mathrm{CRV}$ in the format for glass formulation is given in Table B-2. 


\subsubsection{Estimation of Target Glass Composition}

The first step is to obtain the preliminary minimum $\mathrm{Na}_{2} \mathrm{O}$ mass fraction that meets the glass formulation rules defined by Muller et al. (2004) and CCN 150795 from Equations (25) through (31). From Equation (25) for the $\mathrm{Na}_{2} \mathrm{O}-\mathrm{SO}_{3}-\mathrm{K}_{2} \mathrm{O}$ rules for the $A 101^{\text {th }} \mathrm{MFPV}$ batch to obtain $g_{\mathrm{Na}_{2} \mathrm{O}, A 101}^{\mathrm{MFPl}^{2} \text {,pre-1 }}$ :

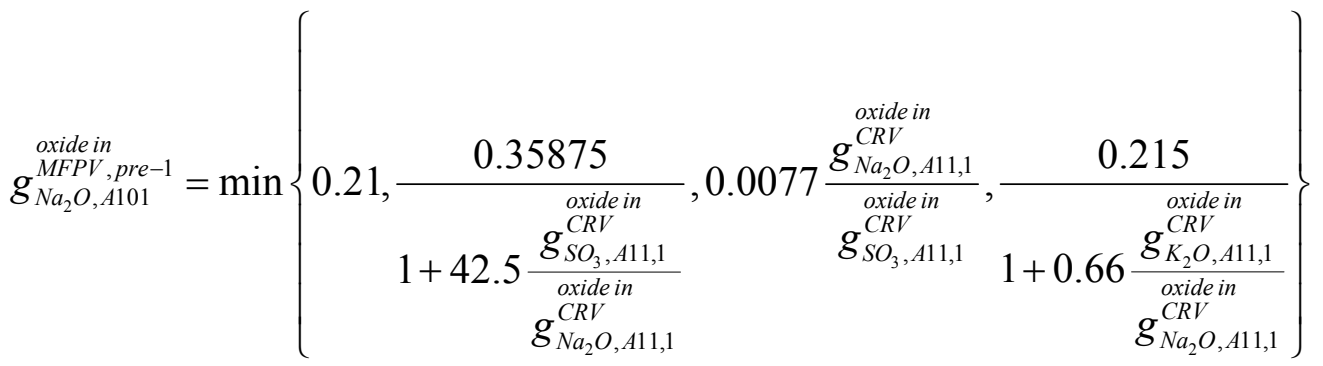

$$
\begin{aligned}
& =\min \left\{0.21, \frac{0.35875}{1+42.5 \frac{1.5515 \times 10^{-2}}{8.2030 \times 10^{-1}}}, 0.0077 \frac{8.2030 \times 10^{-1}}{1.5515 \times 10^{-2}}, \frac{0.215}{1+0.66 \frac{6.2008 \times 10^{-2}}{8.2030 \times 10^{-1}}}\right\} \\
& =\min \{0.21,0.1989,0.4071,0.2048\} \\
& =0.1989
\end{aligned}
$$

From Equation (26) for the Cl-F-SO $\mathrm{SO}_{3}$ rules for the $A 101^{\text {th }}$ MFPV batch to obtain $g_{\mathrm{Na}_{2} \mathrm{O}, A 101}^{\substack{\text { oxide in } \\ M F r e-2}}$ :

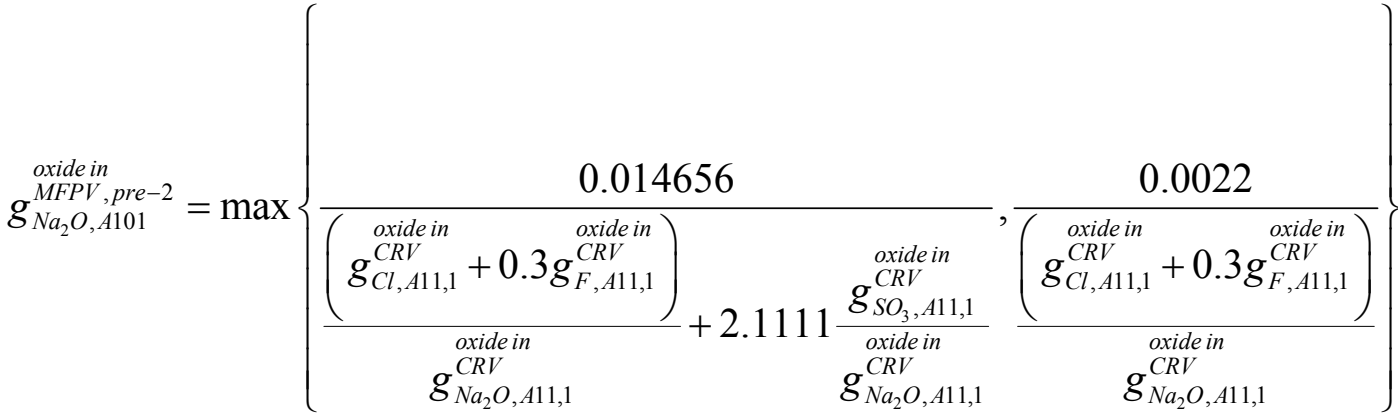

$$
\begin{aligned}
& =\max \left\{\begin{array}{l}
\frac{0.014656}{\frac{\left(1.0657 \times 10^{-2}+0.3 \times 4.4190 \times 10^{-3}\right)}{8.2030 \times 10^{-1}}+2.1111 \frac{1.5515 \times 10^{-2}}{8.2030 \times 10^{-1}}}, \\
\frac{0.0022}{\frac{\left(1.0657 \times 10^{-2}+0.3 \times 4.4190 \times 10^{-3}\right)}{8.2030 \times 10^{-1}}}
\end{array}\right\} \\
& =\max \{0.2687,0.1506\} \\
& =0.2687
\end{aligned}
$$


The preliminary minimum $\mathrm{Na}_{2} \mathrm{O}$ mass fraction in glass for the $A 101^{\text {th }}$ MFPV batch from the $\mathrm{Cr}_{2} \mathrm{O}_{3}-\mathrm{K}_{2} \mathrm{O}-\mathrm{P}_{2} \mathrm{O}_{5}$ oxide in rules $\left(g_{\mathrm{Na}_{2} \mathrm{O}, A 101}^{\mathrm{MFPV}, \mathrm{pre}-3}\right)$ is obtained following the logics defined by the rules 7 through 9 in Section 5.1.3. To obtain the $g_{\mathrm{Na}_{2} \mathrm{O}, A 101}^{\substack{\text { xidein } \\ M P V}}$ value, the $W_{A 101}^{\text {initial }}, W_{A 101}^{\operatorname{min,K}}$, and $W_{A 101}^{\min , \mathrm{Cr}}$ values need to be first calculated from Equations (28) through (30) as below:

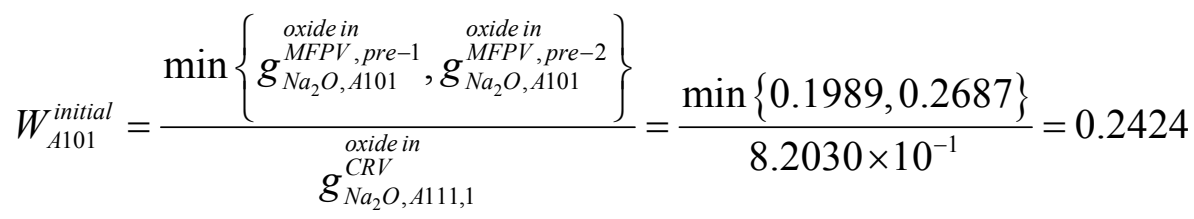
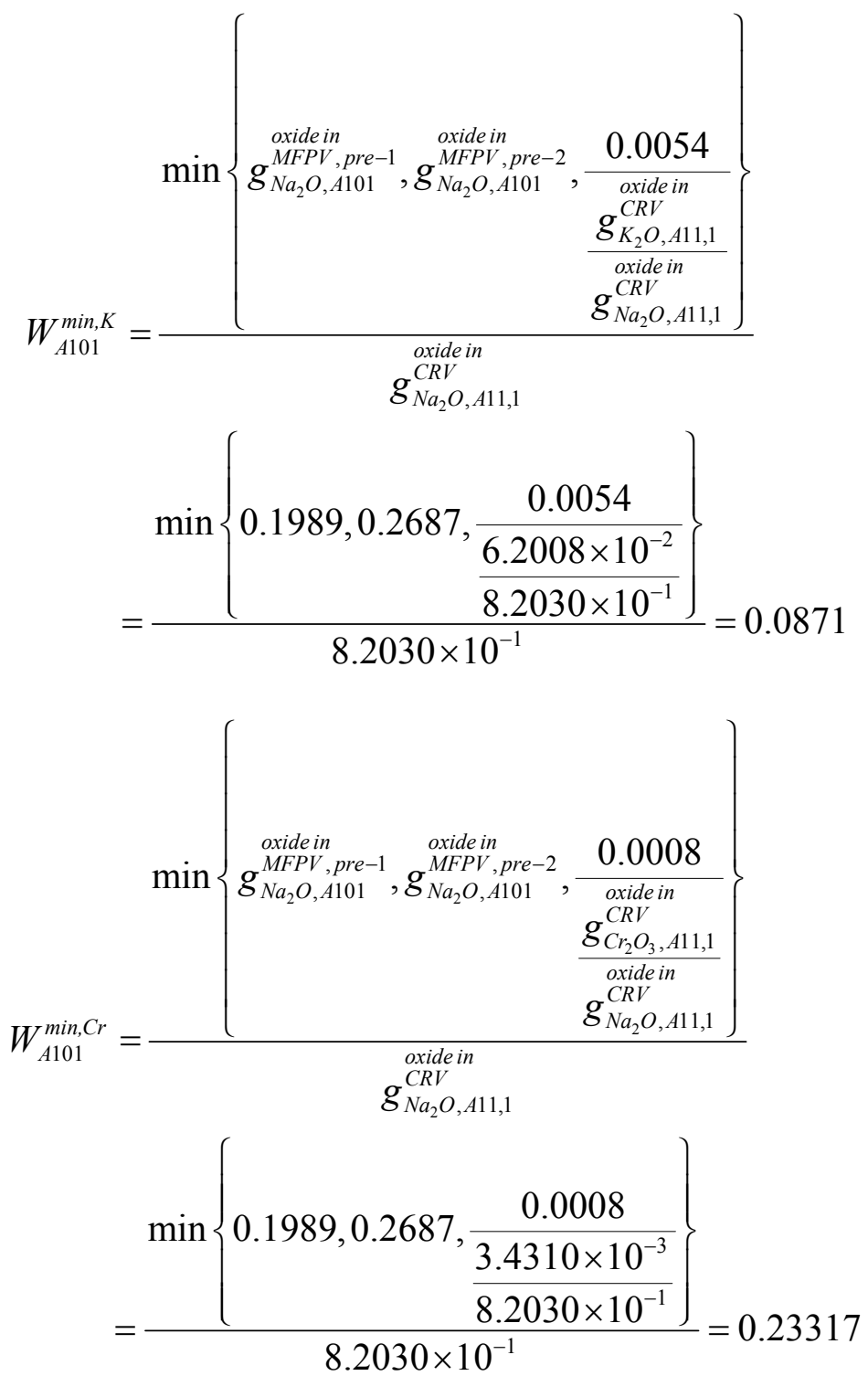


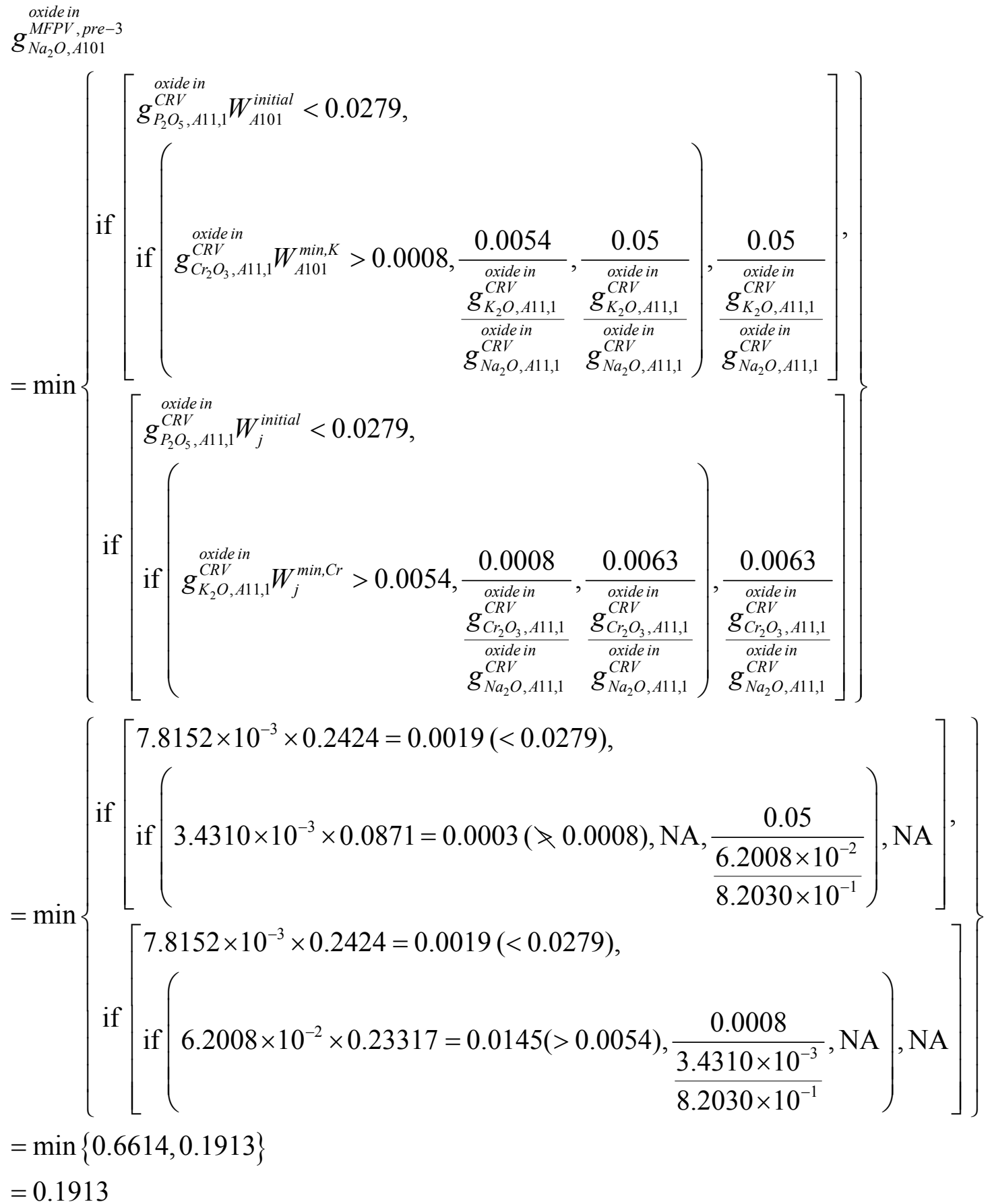

where "NA" represents "not applicable" because the corresponding logic test is false. Equation (151)

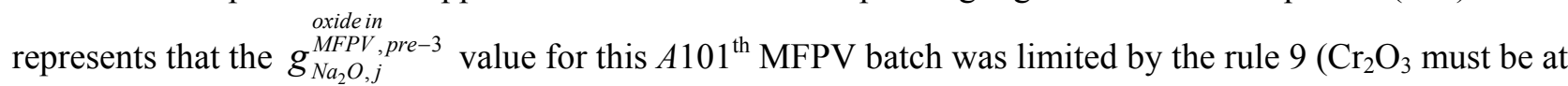
or below $0.08 \mathrm{wt} \%$ if $\mathrm{K}_{2} \mathrm{O}$ in glass is above $0.54 \mathrm{wt} \%$ but at or below $5 \mathrm{wt} \%$ and $\mathrm{P}_{2} \mathrm{O}_{5}$ in glass is below 2.79 $w t)$.

Then, the preliminary minimum $\mathrm{Na}_{2} \mathrm{O}$ mass fraction in glass for the $A 101^{\text {th }}$ MFPV batch after applying all glass formation rules is determined by Equation (31): 


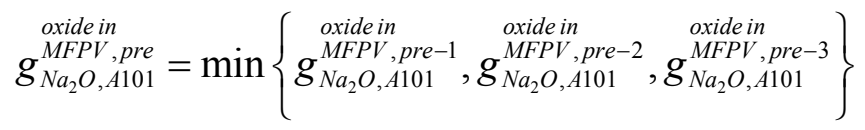

$$
\begin{aligned}
& =\min \{0.1989,0.2687,0.1913\} \\
& =0.1913
\end{aligned}
$$

Figure 11 shows the schematics of glass formulation rules showing the data point for the initial composition in three plots for $\mathrm{Na}_{2} \mathrm{O}-\mathrm{SO}_{3}-\mathrm{K}_{2} \mathrm{O}$ rules, Cl-F-SO $\mathrm{SO}_{3}$ rules, and $\mathrm{Cr}_{2} \mathrm{O}_{3}-\mathrm{K}_{2} \mathrm{O}-\mathrm{P}_{2} \mathrm{O}_{5}$ rules. It can be seen from Figure 11 that the waste loading was limited by $\mathrm{Cr}_{2} \mathrm{O}_{3}$ concentration to meet the $\mathrm{Cr}_{2} \mathrm{O}_{3}-\mathrm{K}_{2} \mathrm{O}-\mathrm{P}_{2} \mathrm{O}_{5}$ rules.

Figure 11. Schematics of Glass Formulation Rules Showing the Initial Glass Composition for the $A 101^{\text {th }}$ MFPV Batch $[\mathrm{H}(\mathrm{wt} \%)=\mathrm{Cl}(\mathrm{wt} \%)+0.3 * \mathrm{~F}(\mathrm{wt} \%)]$
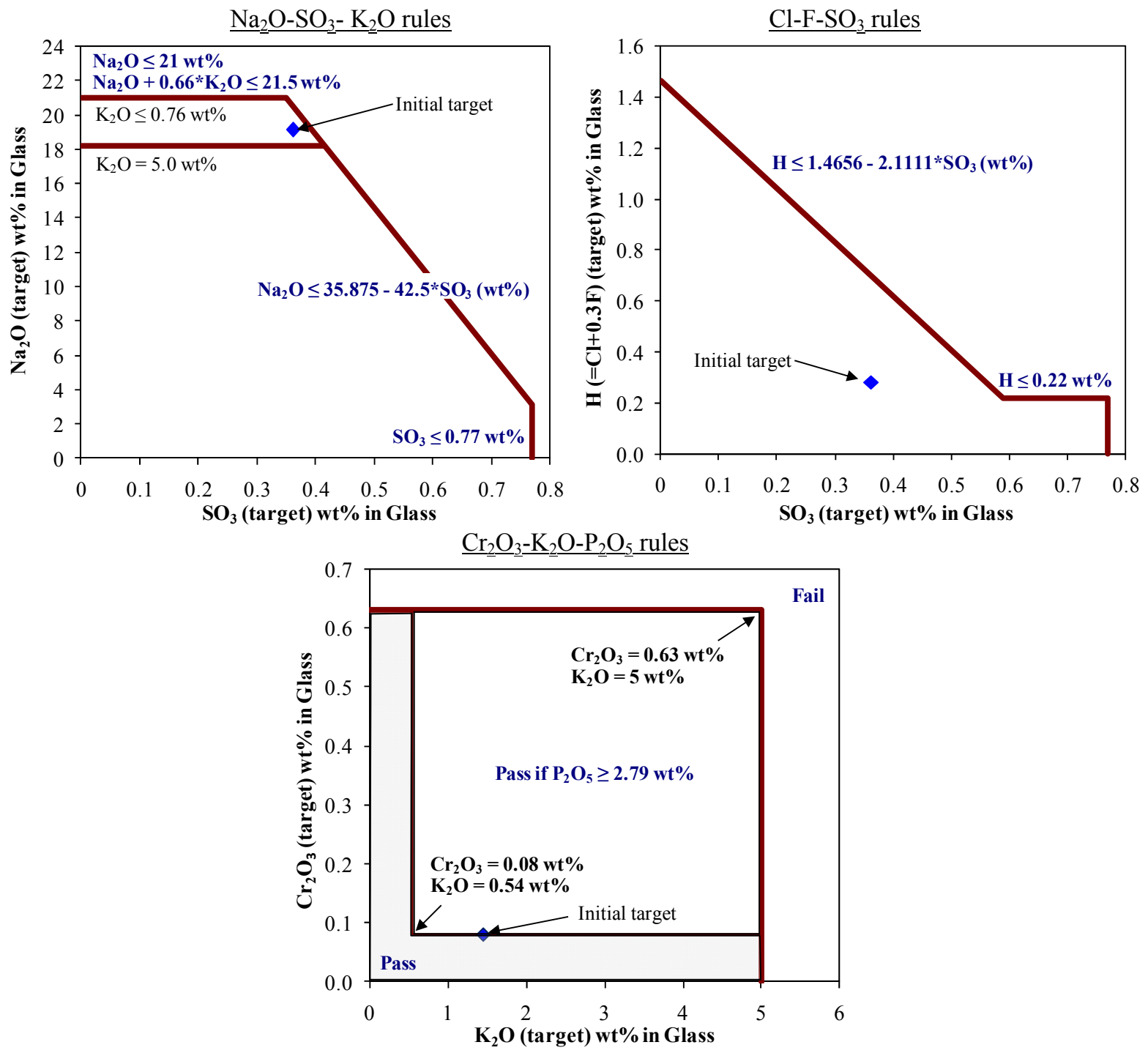

The initial waste loading ( $G_{j}^{\text {MFPST,initial }}$ ) for the $A 101^{\text {th }}$ MFPV batch is calculated using Equation (32): 


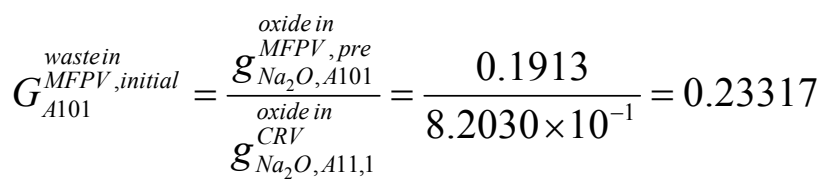

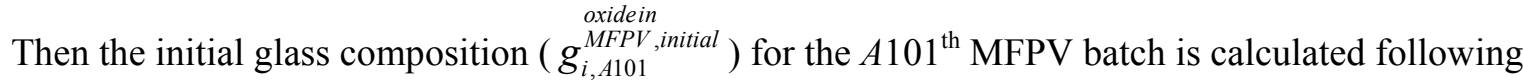

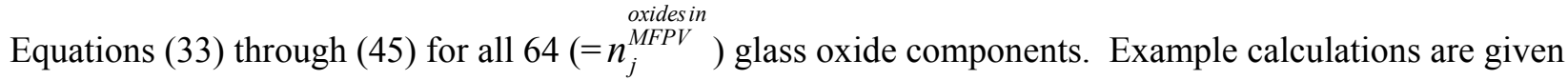
below for $\mathrm{Al}_{2} \mathrm{O}_{3}, \mathrm{Na}_{2} \mathrm{O}, \mathrm{CaO}, \mathrm{Li}_{2} \mathrm{O}, \mathrm{MgO}, \mathrm{Cr}_{2} \mathrm{O}_{3}$ (an example for non-GFC component), and $\mathrm{SiO}_{2}$ :

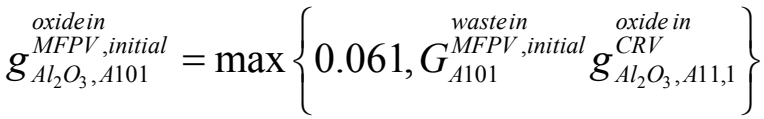

$$
\begin{aligned}
& =\max \left\{0.061,0.23317 \times 7.0410 \times 10^{-2}\right\}=\max \{0.061,0.0164\}=0.061 \\
& g_{N a_{2} O, A 101}^{M F P V, \text { initial }}=\max \left\{\begin{array}{c}
\text { oxidein } \\
g_{N a_{2} O, A 101}^{M F P V, p r e}
\end{array}, 0.054\right\}=\max \{0.1913,0.054\}=0.1913 \\
& d=g_{N a_{2} O, A 101}^{\substack{\text { oxidein } \\
M F P V \text {,initial }}}+0.66 G_{A 101}^{\text {wastein }} \stackrel{\text { initial }}{\text { oxidein }} g_{K_{2} O, A 11,1}^{C R V} \\
& =0.1913+0.66 \times 0.23317 \times 6.2008 \times 10^{-2}=0.2008 \\
& g_{C a O, A 101}^{\substack{\text { oxidein } \\
\text { MFPV }, \text { initial }}}=0.015+\frac{0.055}{1+\exp \left(\frac{d-0.17}{0.02}\right)}=0.015+\frac{0.055}{1+\exp \left(\frac{0.2008-0.17}{0.02}\right)}=0.0247 \\
& g_{L i_{2} O, A 101}^{\substack{\text { oxidein } \\
M F P V \text {,inial }}}=0.043\left[1-\frac{(100 d-5.4)^{2}}{12.75^{2}}\right]^{0.7} \\
& =0.043\left[1-\frac{(100 \times 0.2008-5.4)^{2}}{12.75^{2}}\right]^{0.7}=0.043[1-1.32566]^{0.7}=0 \\
& g_{M g O, \text {, } 101}^{\substack{\text { oxidein } \\
M F P V i t i a l}}=0.0148+\frac{0.0149}{1+\exp (100 d-9)} \\
& =0.0148+\frac{0.0149}{1+\exp (100 \times 0.2008-9)}=0.0148
\end{aligned}
$$

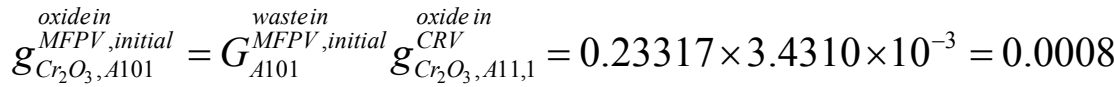

$$
\begin{aligned}
& \left\{i \neq \mathrm{Al}_{2} \mathrm{O}_{3}, \mathrm{~B}_{2} \mathrm{O}_{3}, \mathrm{CaO}, \mathrm{Fe}_{2} \mathrm{O}_{3}, \mathrm{Li}_{2} \mathrm{O}, \mathrm{MgO}, \mathrm{Na}_{2} \mathrm{O}, \mathrm{SiO}_{2}, \mathrm{TiO}_{2}, \mathrm{ZnO}, \mathrm{ZrO} \mathrm{O}_{2}\right\}
\end{aligned}
$$

\footnotetext{
${ }^{(18)}$ Imaginary result was set to zero.
} 


$$
g_{S i O_{2}, A 101}^{\substack{\text { oxidein } \\ M F P V}}=1-\sum_{i=1, i \neq S i O_{2}}^{\substack{\text { oxide in } \\ n_{j}^{M F P V}}} g_{i, A 101}^{\text {MFPV , initial }}=1-0.5502=0.4498
$$

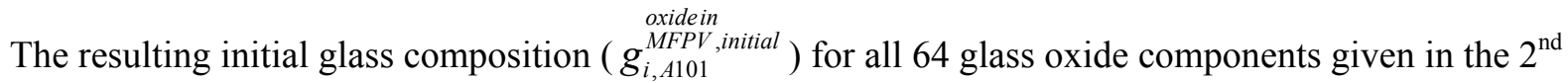
column of Table B-3 is set to the target composition following Equation (46):

$$
g_{i, A 101}^{\text {oxidein }} \stackrel{\substack{\text { oxidein } \\ \text { MFPV } \text {,arget }}}{\text { MFPV, } \text { initial }}
$$

This target composition is used to calculate the GFC masses and Step 1 compositions (Section 6.1.4) and LAW transfer volume (Section 6.1.5). The resulting GFC masses and waste transfer volume are used to calculate the constraint quantities and compare them with the limits (Section 6.1.6).

\subsubsection{Calculation of Step 1 Glass and Radionuclide Compositions}

The target mass fractions for $11 \mathrm{GFC}$ components are used to calculate the target mass fractions to be supplied from GFCs using Equation (47):

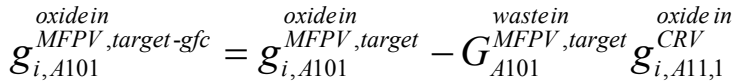

$$
\begin{aligned}
& \left\{i=\mathrm{Al}_{2} \mathrm{O}_{3}, \mathrm{~B}_{2} \mathrm{O}_{3}, \mathrm{CaO}, \mathrm{Fe}_{2} \mathrm{O}_{3}, \mathrm{Li}_{2} \mathrm{O}, \mathrm{MgO}, \mathrm{Na}_{2} \mathrm{O}, \mathrm{SiO}_{2}, \mathrm{TiO}_{2}, \mathrm{ZnO}, \mathrm{ZrO}_{2}\right\}
\end{aligned}
$$

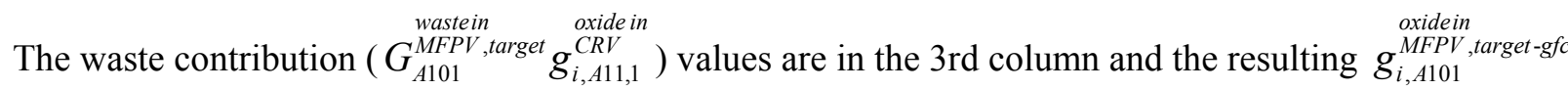
values for 11 GFC components are in the $4^{\text {th }}$ column of Table B-3. These $g_{i, A 101}^{\text {oxidein }}$,target-gfc $v$ values $\left(\mathbf{t}_{A 101}\right)$ and $\mathbf{H}\left(11 \times 11\right.$ matrix of $m_{i k}^{\text {oxidein }}$ given in Table A-6) are used to calculate the preliminary target mass of each

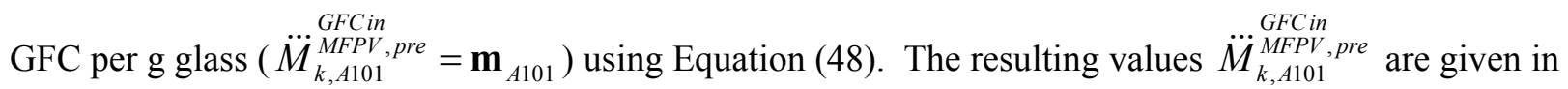
Table 18. Then, the target mass of GFC per g glass is calculated using Equation (49) and also given in Table 18.

Table 18. Preliminary Target Mass $\left(\dddot{M}_{k, A 101}^{G F C i n}\right.$ ) and Target Mass $\left(\dddot{M}_{k, A 101}^{G F C \text {, target }}\right)$ of Each GFC per g Glass for the $A 101^{\text {th }}$ MFPV Batch

\begin{tabular}{||c|c|c||}
\hline GFC $(\boldsymbol{k})$ & $\dddot{M}_{k, A 101}^{\text {GFCin }}$ & $\dddot{M}_{k, A 101}^{G F C \text {, }}$, target \\
\hline Kyanite & $7.5092 \mathrm{E}-02$ & $7.5092 \mathrm{E}-02$ \\
\hline Boric Acid & $1.7684 \mathrm{E}-01$ & $1.7684 \mathrm{E}-01$ \\
\hline Wollastonite & $5.1734 \mathrm{E}-02$ & $5.1734 \mathrm{E}-02$ \\
\hline Hematite & $5.3216 \mathrm{E}-02$ & $5.3216 \mathrm{E}-02$ \\
\hline Li carbonate & $-4.3225 \mathrm{E}-18$ & 0 \\
\hline Olivine & $3.0508 \mathrm{E}-02$ & $3.0508 \mathrm{E}-02$ \\
\hline Na carbonate & $-5.6791 \mathrm{E}-04$ & 0 \\
\hline
\end{tabular}




\begin{tabular}{||c|c|c||}
\hline Silica & $3.6491 \mathrm{E}-01$ & $3.6491 \mathrm{E}-01$ \\
\hline Rutile & $1.4190 \mathrm{E}-02$ & $1.4190 \mathrm{E}-02$ \\
\hline Zincite & $3.5051 \mathrm{E}-02$ & $3.5051 \mathrm{E}-02$ \\
\hline Zircon & $4.5078 \mathrm{E}-02$ & $4.5078 \mathrm{E}-02$ \\
\hline
\end{tabular}

Then the full composition of GFCs are used to calculate the glass composition from Step 1 calculation following Equation (50):

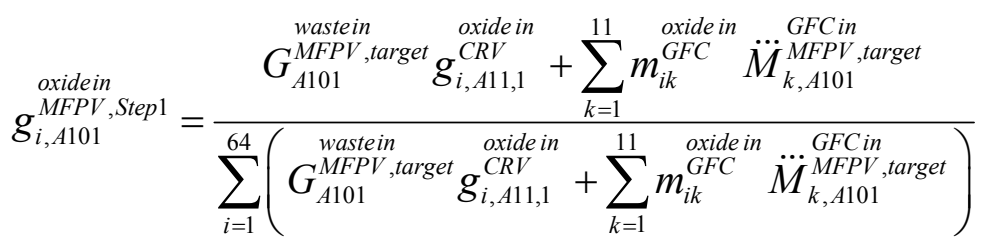

Table B-4a shows the waste contribution $\left(G_{A 101}^{\text {wastein }} \begin{array}{c}\text { oxidein } \\ \text { MFV }\end{array} g_{i, A 11,1}^{C R V}\right)\left(2^{\text {nd }}\right.$ column, the same as the $3^{\text {rd }}$ column of

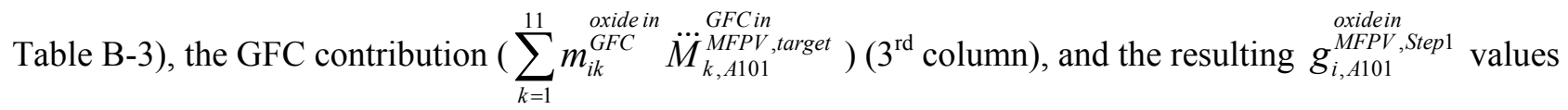
( $4^{\text {th }}$ column) for the $A 101^{\text {th }}$ MFPV Batch. From Table B-4a the denominator of Equation (164) is given as:

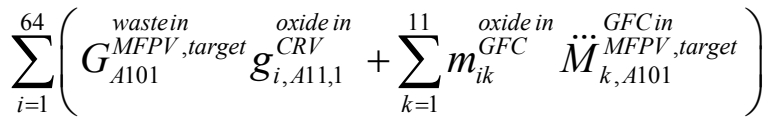

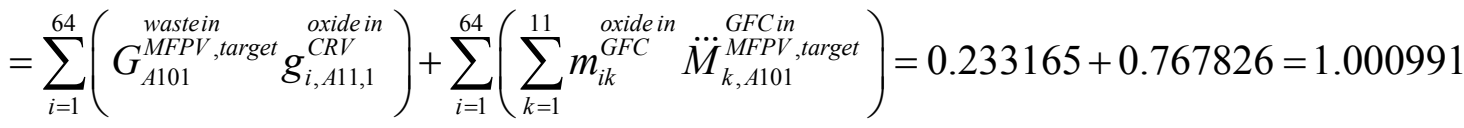

Then, the resulting waste loading in glass of the $A 101^{\text {th }}$ MFPV Batch after including the GFC impurities is calculated from Equation (51):

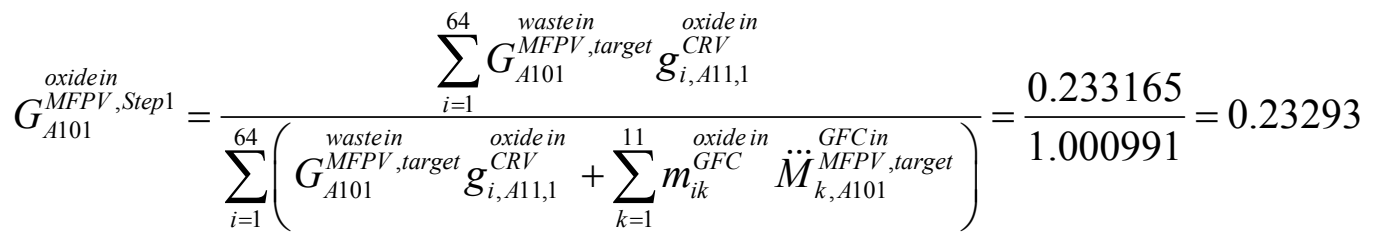

The final composition after applying retention factors is calculated using Equation (52):

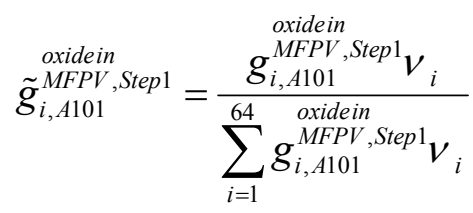




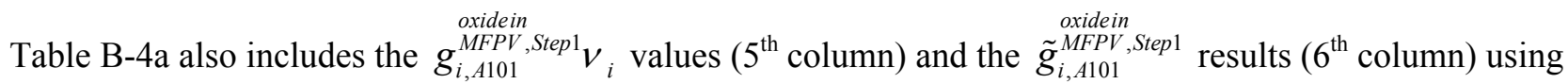
$\sum_{i=1}^{64} g_{i, A 101}^{\text {oxidein }} \stackrel{\text { Step } 1}{v_{i}}=0.99410$.

The specific activity (activity per unit mass of glass oxides) of radionuclides in the $A 101^{\text {th }}$ MFPV batch

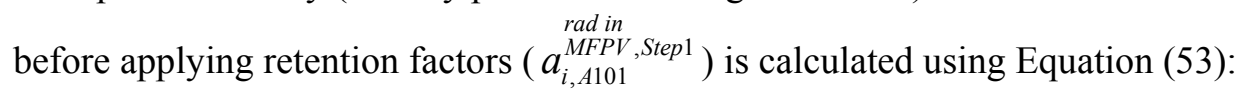

$$
\begin{aligned}
& a_{i, A 101}^{\stackrel{\text { rad in }}{M F P V, \text { Step } 1}}=a_{i, A 11,1}^{\text {rad in }} G_{A 101}^{\text {wastein }}
\end{aligned}
$$

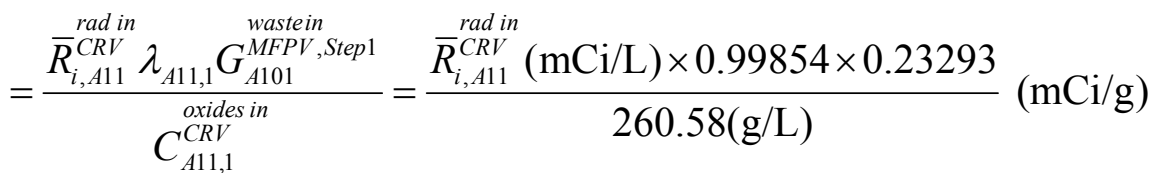

The specific activity after applying retention factors $\left(\begin{array}{c}\text { oxidein } \\ \left.\tilde{a}_{i, A 101}^{M F P V, S t e p 1}\right)\end{array}\right)$ is calculated using Equation (54):

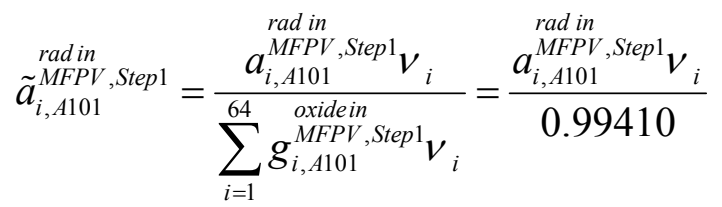

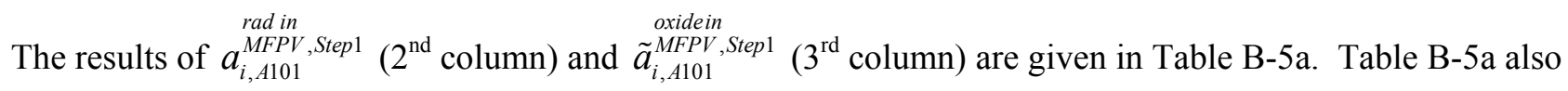

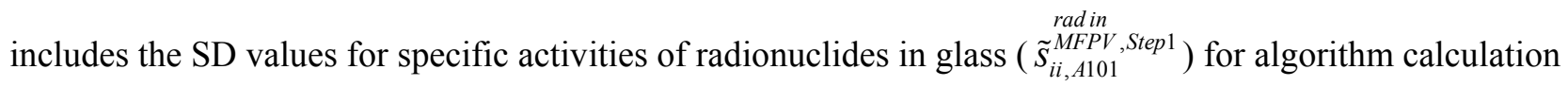
Step 1 after applying retention factors obtained from Monte Carlo simulations of Equation (70).

\subsubsection{Calculation of LAW Transfer Volume}

The volumes involved in Equation (55) for the $A 101^{\text {th }}$ MFPV batch is given below. From Table 1 the target working volume is:

$$
V_{A 101}^{\stackrel{\text { working }}{M F P V}}=19,426 \mathrm{~L}
$$

As mentioned earlier, the $A 101^{\text {th }}$ MFPV batch, the volume of heel was assumed as $6,712 \mathrm{~L}$, i.e.,

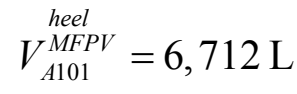

From Table 14, for the LFP-VSL-00001 (MFPV-A) from LCP-VSL-00001 (CRV-A), the CRV-MFPV line flush and sampling flush volumes are given as:

$$
V_{A 101}^{\text {transflush }}=37.5 \mathrm{~L}
$$




$$
V_{A 101}^{\text {sampflush }}=175.3 \mathrm{~L}
$$

During plant operation the actual measured volume of these flush waters will be used. For the example calculation in this report, the nominal values are used instead of random generation similar to CRV working and MFPV heel volumes for simplicity.

The rest of volumes are calculated based on the glass formulation described in Section 6.1.3. The volume occupied by GFCs is expressed as function of waste transfer volume using Equation (56):

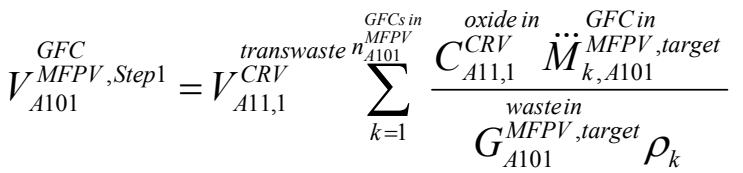

$$
\begin{aligned}
& =V_{A 11,1}^{\text {transwaste }} \sum_{k=1}^{11} \frac{260.58(\mathrm{~g} / \mathrm{L}) \times \dddot{M}_{k, A 101}^{\text {GFC target }}(\mathrm{g} / \mathrm{g} \text { glass })}{0.23317(\mathrm{~g} / \mathrm{g} \text { glass }) \times \rho_{k}(\mathrm{~g} / \mathrm{L})} \\
& =0.37472 V_{A 11,1}^{\text {transwast }}
\end{aligned}
$$

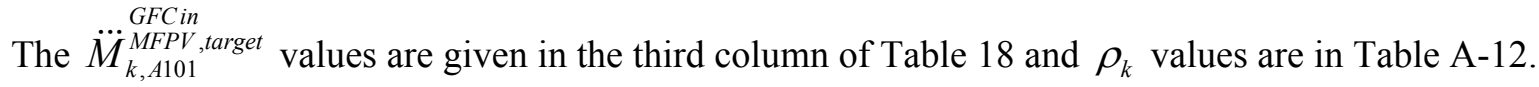

The dust control water volume is calculated using Equation (58):

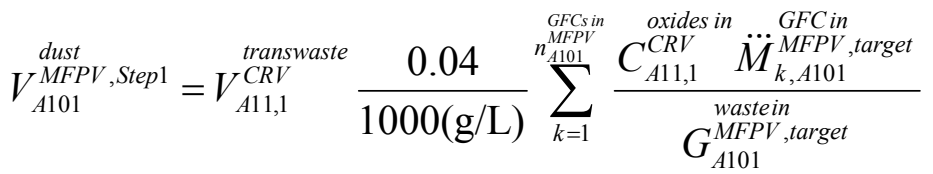

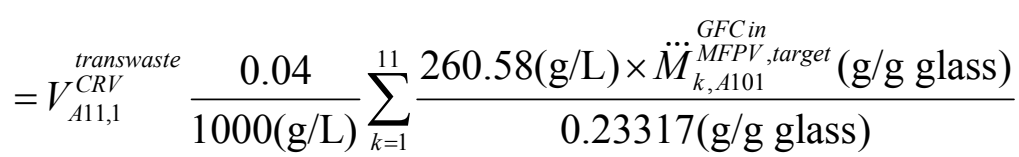

$$
\begin{aligned}
& =V_{A 11,1}^{\text {transwaste }} \frac{0.04 \times 946.165}{1000(\mathrm{~g} / \mathrm{L})} \\
& =0.037847 V_{A 11,1}^{\text {trans }}
\end{aligned}
$$

The target mass of sucrose is calculated using Equation (59):

$$
\begin{aligned}
& \ddot{M}_{A 101}^{\text {sucrosein } \text {,target }}=\max \left\{\left[0.75\left(\frac{c_{\mathrm{NO}_{2}, A 11,1}^{C R V}}{M W_{\mathrm{NO}_{2}}}+\frac{c_{\mathrm{NO}_{3}, A 11,1}^{C R V}}{M W_{\mathrm{NO}_{3}}}\right)-\frac{c_{\mathrm{TOC}, A 11,1}^{C R V}}{M W_{\mathrm{C}}}\right] \frac{M W_{\mathrm{C}_{12} \mathrm{H}_{22} \mathrm{O}_{11}}}{12(\text { moles of C/sucrose })}, 0\right\} \\
& \quad=\max \left\{\left[0.75\left(\frac{27.981}{46.0055}+\frac{73.780}{62.0049}\right)-\frac{1.1356(\mathrm{~g} / \mathrm{L})}{12.0110(\mathrm{~g} / \mathrm{mole})}\right] \frac{342.3001(\mathrm{~g} / \mathrm{mole})}{12(\text { moles of C/sucrose })}, 0\right\} \\
& \quad=\max \{35.7714,0\}=35.7714(\mathrm{~g} / \mathrm{L} \text { waste })
\end{aligned}
$$


Then the volume of sucrose is calculated using Equation (60):

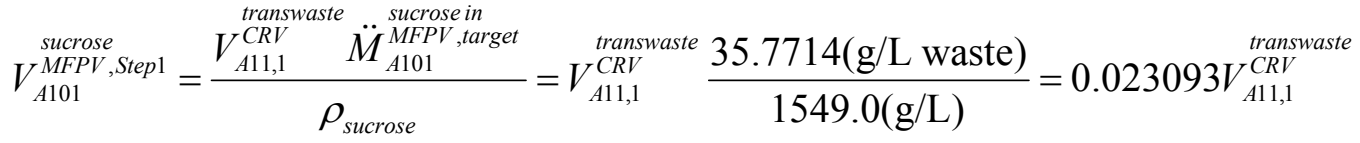

For the required volume of dilution water calculation, the target sodium molarity is first calculated using Equation (61):

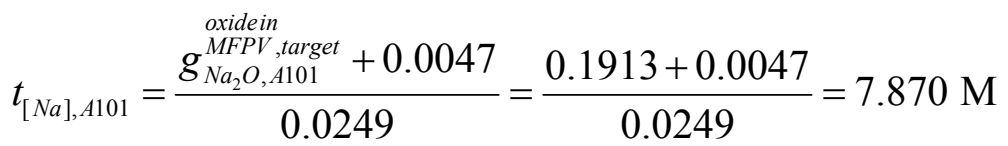

Then, dilution water volume is calculated from Equation (62):

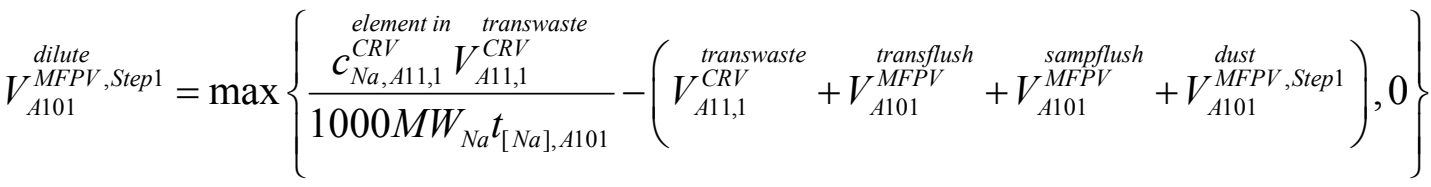

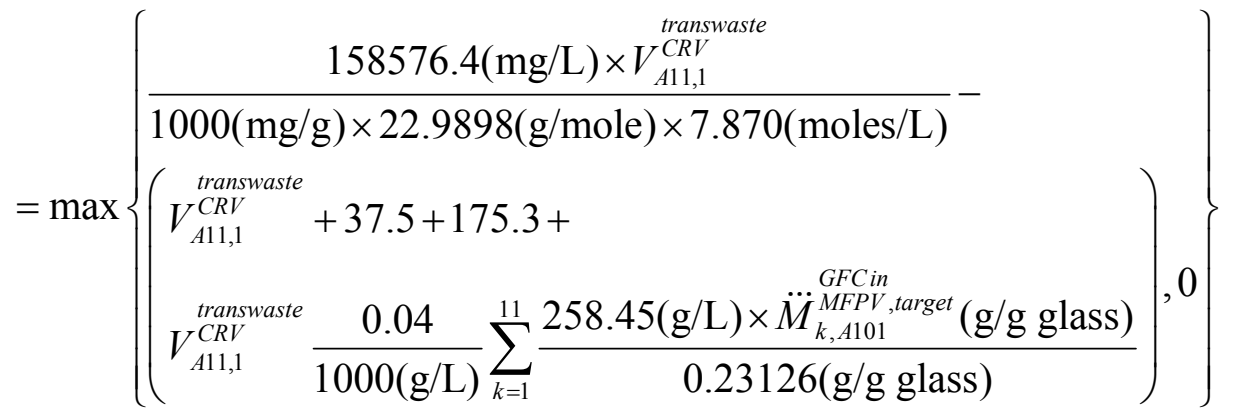

$$
\begin{aligned}
& =\max \left\{0.87644 V_{A 11,1}^{\text {transwaste }}-\left(V_{A 11,1}^{\text {transwaste }}+37.5+175.3+0.037847 V_{A 11,1}^{\text {transwaste }}{ }^{C R V}\right), 0\right\} \\
& =\max \left\{-0.161404 V_{A 11,1}^{\text {transwaste }}-212.7,0\right\}
\end{aligned}
$$

Equations (170) through (179) provide the volume values or express them in terms of the waste transfer volume $\left(V_{d m}^{\text {transwaste }}\right.$ ) for all the volumes involved in Equation (55) for the $A 101^{\text {th }}$ MFPV batch. Then, Equation (55) is written as: 


$$
\begin{aligned}
& V_{A 101}^{\text {working }}=19426(\mathrm{~L})
\end{aligned}
$$

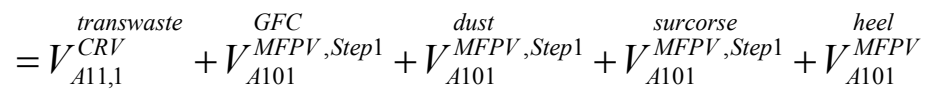

$$
\begin{aligned}
& +V_{A 101}^{\text {transflush }} \stackrel{\text { sampflush }}{\text { silute }}+V_{A 101}^{M F P V}+V_{A 101}^{M F P, \text { Step } 1} \\
& =V_{A 11,1}^{\text {transwaste }}+{ }^{\text {transwaste }}+0.37472 V_{A 11,1}^{C R V}+0.037847 V_{A 11,1}^{\text {transwaste }}+0.023093 V_{A 11,1}^{C R V}+6712.0 \\
& +37.5+175.3+\max \left\{-0.161404 V_{A 11,1}^{\text {transwaste }}-212.7,0\right\}
\end{aligned}
$$

Equation (180) was solved iteratively to obtain the waste transfer volume $\left(V_{d m}^{\text {transwaste }}{ }^{\text {CRV }}\right)$ of $8707.7 \mathrm{~L}$. This

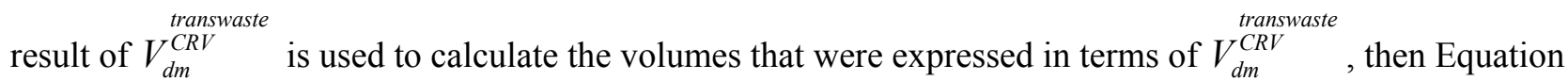
(180) is rewritten as:

$$
19426(\mathrm{~L})=8707.7+3262.9+329.6+201.1+6712.0+37.5+175.3+0.0(\mathrm{~L})
$$

This $V_{d m}^{\text {transwaste }}$ value is used for calculation of composition uncertainties required for the calculation of Step 1 constraints in Section 6.1.6.

From the waste transfer volume, the target masses of GFCs and sucrose are calculated using Equations (63) and (64):

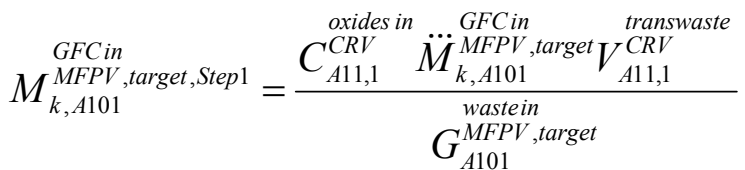

$$
\begin{aligned}
& =\frac{260.58(\mathrm{~g} / \mathrm{L}) \times \dddot{M}_{k, A 101}^{M F P V \text { target }}(\mathrm{g} / \mathrm{g} \text { glass }) \times 8707.7(\mathrm{~L})}{0.23317} \\
& M_{A 101}^{\substack{\text { sucrosein } \\
M F P V \text {,target,Step } 1}}=\ddot{M}_{A 101}^{\text {sucrosein }{ }^{M F P V t} V_{A 1,1}^{\text {transwaste }}}=35.77(\mathrm{~g} / \mathrm{L} \text { waste }) \times 8707.7(\mathrm{~L})=311.49(\mathrm{~kg})
\end{aligned}
$$

\begin{tabular}{|c|c|}
\hline GFC $(k) /$ sucrose & $\begin{array}{c}\text { GFCin } \\
M_{k, A 101}^{M F P V, \text { target }, \text { Step } 1}, \mathbf{k g}\end{array}$ \\
\hline Kyanite & 730.77 \\
\hline Boric Acid & 1720.90 \\
\hline Wollastonite & 503.45 \\
\hline Hematite & 517.88 \\
\hline
\end{tabular}

Table 19 summarizes the resulting masses of GFCs and sucrose from Step 1 calculation for the $A 101^{\text {th }}$ MFPV Batch.

Table 19. Masses of GFCs and Sucrose from Step 1 Calculation for the $A 101^{\text {th }}$ MFPV Batch 


\begin{tabular}{|c|c|}
\hline Lithium carbonate & 0 \\
\hline Olivine & 296.89 \\
\hline Sodium carbonate & 0 \\
\hline Silica & 3551.14 \\
\hline Rutile & 138.09 \\
\hline Zincite & 341.10 \\
\hline Zircon & 438.69 \\
\hline Sucrose & 311.49 \\
\hline Total & 8550.39 \\
\hline
\end{tabular}

\subsubsection{Calculation of Constraints for Algorithm Step 1}

Example calculations for each constraint or each group of constraints are provided in the following subsections.

\subsubsection{Glass Property and Model Validity Constraints}

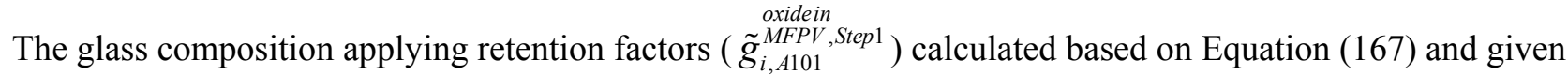
in the last column of Table B-4a is used for calculation of glass property and model validity constraints. Predicted glass properties including PCT normalized B and Na releases, VHT alteration depth, melt viscosity, and melt electrical conductivity are calculated using the composition-property models described in Section 4.1. The equations required for calculating prediction and composition uncertainties and CL\% combined confidence intervals for predicted properties are given in Sections 4.2.1 through 4.2.3. Calculations for PCT normalized B release are provided below as an example. Calculations for all other properties follow the same methods.

Equation (2) and the model coefficients ( $p_{h}^{p c t B}$ ) given in Table 5 are used to calculate the predicted PCT response of the glass as demonstrated in Table 20 for PCT normalized B release.

Table 20. Example Calculation for Predicted PCT Normalized B Release, $P_{A 101}^{p c t B, S t e p 1}$ in $\ln [\mathbf{g} / \mathbf{L}]$

\begin{tabular}{|c|c|c|c||}
\hline Model Term $=\boldsymbol{h}$ & $p_{h}^{p c t B}$ & $x_{h, A 101}^{p c t B, \text { tep } 1}$ & $p_{h}^{p c t B} x_{h, A 101}^{p c t B, \text { Step } 1}$ \\
\hline $\mathrm{Al}_{2} \mathrm{O}_{3}$ & -31.3612 & $6.1232 \mathrm{E}-02$ & $-1.9203 \mathrm{E}+00$ \\
\hline $\mathrm{B}_{2} \mathrm{O}_{3}$ & 11.8101 & $9.9457 \mathrm{E}-02$ & $1.1746 \mathrm{E}+00$ \\
\hline $\mathrm{CaO}$ & -13.8404 & $2.4801 \mathrm{E}-02$ & $-3.4326 \mathrm{E}-01$ \\
\hline $\mathrm{Fe}_{2} \mathrm{O}_{3}$ & -16.5948 & $5.5187 \mathrm{E}-02$ & $-9.1583 \mathrm{E}-01$ \\
\hline $\mathrm{K}_{2} \mathrm{O}$ & 7.9687 & $1.4030 \mathrm{E}-02$ & $1.1180 \mathrm{E}-01$ \\
\hline $\mathrm{Li}_{2} \mathrm{O}$ & 83.3036 & $3.0512 \mathrm{E}-07$ & $2.5418 \mathrm{E}-05$ \\
\hline $\mathrm{MgO}_{\mathrm{Na}} \mathrm{O}$ & -21.2343 & $1.4871 \mathrm{E}-02$ & $-3.1577 \mathrm{E}-01$ \\
\hline $\mathrm{P}_{2} \mathrm{O}_{5}$ & 46.1599 & $1.9088 \mathrm{E}-01$ & $8.8110 \mathrm{E}+00$ \\
\hline $\mathrm{SiO}_{2}$ & -19.254 & $1.9766 \mathrm{E}-03$ & $-3.8057 \mathrm{E}-02$ \\
\hline $\mathrm{ZrO}_{2}$ & -1.6161 & $4.5172 \mathrm{E}-01$ & $-7.3002 \mathrm{E}-01$ \\
\hline $\mathrm{Others}_{2}$ & -6.6289 & $3.0143 \mathrm{E}-02$ & $-1.9981 \mathrm{E}-01$ \\
\hline $\mathrm{CaO} \times \mathrm{Li}_{2} \mathrm{O}$ & -5.169 & $5.5705 \mathrm{E}-02$ & $-2.8794 \mathrm{E}-01$ \\
\hline $\mathrm{B}_{2} \mathrm{O}_{3} \times \mathrm{MgO}^{\mathrm{MgO}}$ & -251.2654 & $7.5675 \mathrm{E}-09$ & $-1.9014 \mathrm{E}-06$ \\
\hline $\mathrm{B}_{2} \mathrm{O}_{3} \times \mathrm{Li}{ }_{2} \mathrm{O}$ & 488.8612 & $1.4790 \mathrm{E}-03$ & $7.2303 \mathrm{E}-01$ \\
\hline & -374.9533 & $3.0346 \mathrm{E}-08$ & $-1.1379 \mathrm{E}-05$ \\
\hline
\end{tabular}




\begin{tabular}{|c|c|c|c||}
\hline $\mathrm{Na}_{2} \mathrm{O} \times \mathrm{SiO}_{2}$ & -74.3462 & $8.6223 \mathrm{E}-02$ & $-6.4104 \mathrm{E}+00$ \\
\hline $\mathrm{CaO} \times \mathrm{Fe}_{2} \mathrm{O}_{3}$ & 212.0947 & $1.3687 \mathrm{E}-03$ & $2.9030 \mathrm{E}-01$ \\
\hline $\mathrm{Sum}$ & N/A & N/A & -0.0507 \\
\hline
\end{tabular}

N/A: not applicable

The prediction uncertainty corresponding to a $90 \%$ SUCI for PCT normalized B release is calculated following Equation (8):

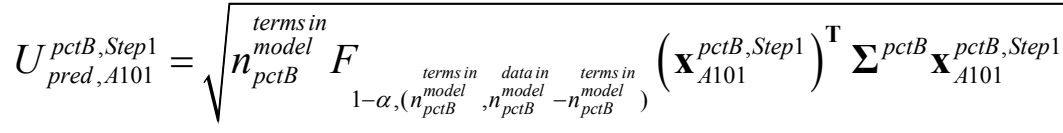

$$
\begin{aligned}
& =\sqrt{17 \times 1.28991 \times 0.0012984}=0.1687 \ln (\mathrm{g} / \mathrm{L})
\end{aligned}
$$

As described in Section 4.2.2, composition uncertainties are estimated using Monte Carlo simulation of mass balance equations given by Equations (65) and (66) for the $A 101^{\text {th }}$ MFPV batch:

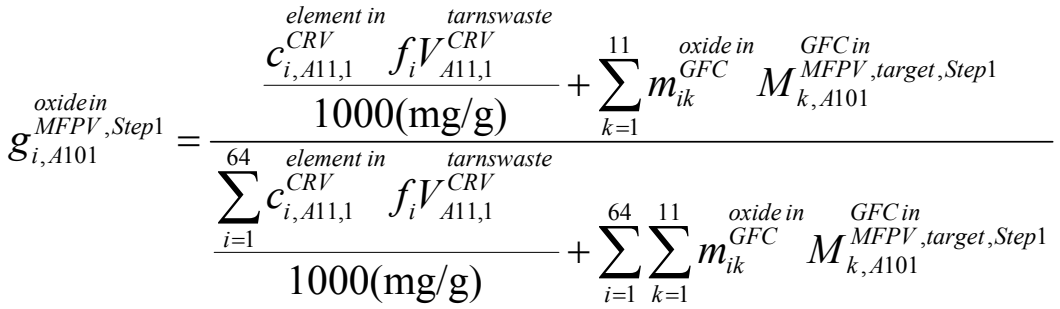

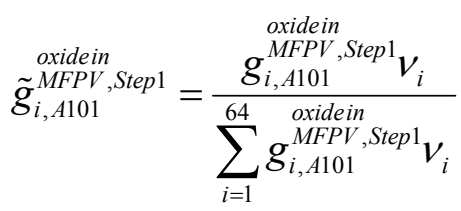

In this method, the uncertain variables in the mass balance equations are given random values (5000 "simulations" for this example) that conform to a certain statistical distribution as summarized here:

- volume of waste to be transferred from CRV to MFPV (normal distribution based on nominal value of 8707.7 L from Section 6.1.5 and SD of 447.2 L from Appendix D)

- concentration of each element in the CRV (normal distribution based on nominal values in Table B1 and SD values calculated by Equation (14) using RSD values given in Table A-2)

- mass of each GFC to be added to the MFPV (normal distribution based on nominal values given in Table 19 and SD values calculated following the methods described in Appendix E)

- concentration of each oxide in each GFC (PERT distribution based on minimum, most likely, and maximum values given in Table A-4)

- retention factor of each component (calculated from PERT distribution of $\ln (\mathrm{DF})$ based on Min, Median, and Max $\ln (\mathrm{DF})$ values in Table A-3)

Figure 12 shows an example distribution for 5000 random values of $V_{A 11,1}^{\text {transwaste }}$ based on a nominal volume of 8707.7 L and SD of 447.2 L. Likewise four other uncertain variables listed above are given 5000 random values from associated statistical distributions. The result is 5000 glass compositions, which are used to 
calculate 5000 predicted values for all properties. An example distribution of 5000 PCT normalized B release values $\left(P_{A 101}^{p c t B, S t e p 1}\right.$ in $\left.\ln [\mathrm{g} / \mathrm{L}]\right)$ is given in Figure 13.

Figure 12. Example Histogram of 5000 Random $V_{A 11,1}^{\text {transwaste }}$ Values (L) for Monte Carlo Simulation

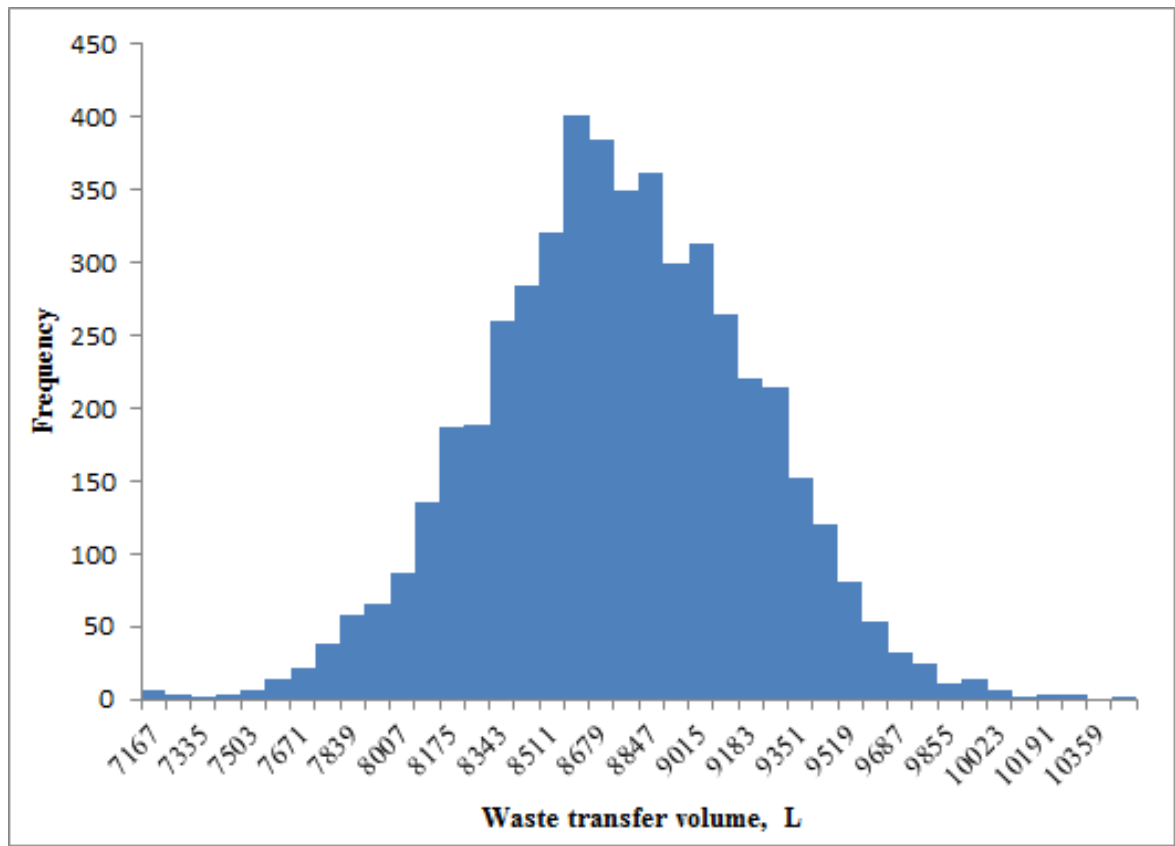

Figure 13. Histogram of 5000 Predicted $P_{A 101}^{p c t B, S t e p 1}$ Values (ln[g/L]) from Monte Carlo Simulation

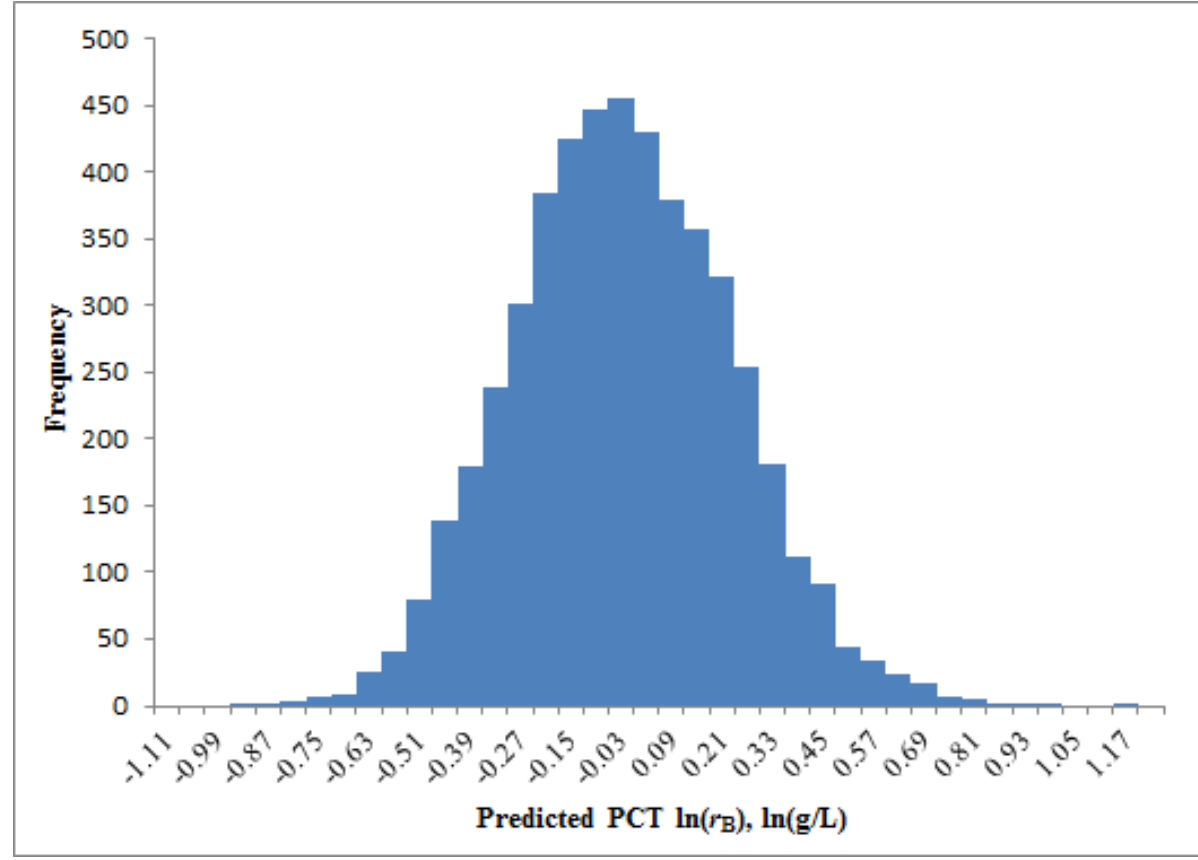

The composition uncertainty of the PCT normalized B release for the $A 101^{\text {th }}$ MFPV batch is calculated using Equation (15): 


$$
U_{\text {comp }, A 101}^{p c t B, \text { Step } 1}=Q_{90 \%, A 101}^{p c t B, \text { Step } 1}-Q_{50 \%, A 101}^{p c t B, \text { Step } 1}=0.2749-(-0.0607)=0.3356
$$

Then, the UCCI of the PCT normalized B release for the $A 101^{\text {th }}$ MFPV batch is calculated using Equation (16):

$$
\begin{aligned}
B_{u c c i, A 101}^{p c t B, \text { Step } 1} & =P_{A 101}^{p c t B, \text { Step } 1}+U_{p r e d, A 101}^{p c t B, \text { Step } 1}+U_{\text {comp }, A 101}^{p c t B, \text { tep } 1} \\
& =-0.0507+0.1687+0.3356 \\
& =0.4536
\end{aligned}
$$

Table 21 summarizes the predicted properties, uncertainties, and UCCI/LCCI values for the $A 101^{\text {th }}$ MFPV batch compared with the corresponding limits. As shown in Table 21, all constraints were satisfied except for the upper limit for viscosity at $1150^{\circ} \mathrm{C}\left(L_{u}^{v i s 1150}=4.3820 \ln [\mathrm{g} / \mathrm{L}]\right)$. The failure to meet the upper limit for viscosity at $1150^{\circ} \mathrm{C}$ requires that the glass formulation needs to be adjusted, which will be done in Section

\begin{tabular}{|c|c|c|c|c|c|c|c|}
\hline Property & Unit & $P_{A 101}^{\text {prop Step } 1}$ & $\begin{array}{c}U_{\text {pred }, A 101}^{\text {prop }, \text { Step } 1} \\
\end{array}$ & $\begin{array}{l}U_{\text {comp }, A 101}^{\text {prop }, \text { Step } 1} \\
\end{array}$ & \multicolumn{2}{|c|}{ 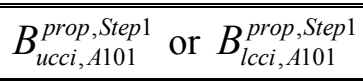 } & $L_{u}^{\text {prop }}$ or $L_{l}^{\text {prop }}$ \\
\hline $\ln \left(r_{B}\right)$ & $\ln [\mathrm{g} / \mathrm{L}]$ & -0.0507 & 0.1687 & 0.3356 & 0.4536 & $<$ & 1.3863 \\
\hline $\ln \left(r_{N a}\right)$ & $\ln [\mathrm{g} / \mathrm{L}]$ & -0.1406 & 0.1759 & 0.2868 & 0.3221 & $<$ & 1.3863 \\
\hline $\ln (D)$ & $\ln [\mu \mathrm{m}]$ & 2.2926 & 0.7076 & 1.2235 & 4.2237 & $<$ & 6.1159 \\
\hline $\ln \left(\eta_{1100}\right), u$ & $\ln [\mathrm{P}]$ & 4.7126 & 0.0361 & 0.2552 & 5.0039 & $\leq$ & 5.0106 \\
\hline $\ln \left(\eta_{1150}\right), l$ & $\ln [\mathrm{P}]$ & 4.2092 & 0.0363 & 0.2301 & 3.9428 & $\geq$ & 2.9957 \\
\hline $\ln \left(\eta_{1150}\right), u$ & $\ln [\mathrm{P}]$ & 4.2092 & 0.0363 & 0.2355 & 4.4811 & $\leq$ & 4.3820 \\
\hline $\ln \left(\varepsilon_{1100}\right), l$ & $\ln [\mathrm{S} / \mathrm{cm}]$ & -1.0720 & 0.0346 & 0.1822 & -1.2888 & $\geq$ & -2.3026 \\
\hline $\ln \left(\varepsilon_{1200}\right), u$ & $\ln [\mathrm{S} / \mathrm{cm}]$ & -0.7157 & 0.0352 & 0.1621 & -0.5184 & $\leq$ & -0.3567 \\
\hline
\end{tabular}
6.1.7.

Table 21. Predicted Properties, Uncertainties, and UCCI/LCCI Values for the $A 101^{\text {th }}$ MFPV Batch Compared with the Corresponding Limits

Shaded row represents the property that does not meet the limit

Table 22 summarizes the model validity constraint values for the $A 101^{\text {th }}$ MFPV batch compared with the corresponding limits. As shown in Table 22, all model validity constraints were satisfied.

Table 22. Model Validity Constraints for the $A 101^{\text {th }}$ MFPV Batch Compared with the Corresponding Limits

\begin{tabular}{|c|c|c|c||}
\hline Constraint & Value & Lower Limit & Upper Limit \\
\hline \multicolumn{4}{||c|}{$\begin{array}{c}\text { oxidein } \\
\text { Model validity single component constraints }\left(\tilde{g}_{i, A 101}^{M F P V, \text { Step } 1}\right)\end{array}$} \\
\hline $\mathrm{Al}_{2} \mathrm{O}_{3}$ & 0.06123 & 0.035 & 0.0900 \\
\hline $\mathrm{Cl}$ & 0.00136 & 0 & 0.0091 \\
\hline $\mathrm{Cr}_{2} \mathrm{O}_{3}$ & 0.00086 & 0 & 0.0059 \\
\hline $\mathrm{F}$ & 0.00076 & 0 & 0.0035 \\
\hline $\mathrm{P}_{2} \mathrm{O}_{5}$ & 0.00198 & 0 & 0.030 \\
\hline $\mathrm{SiO}_{2}$ & 0.45172 & 0.384 & 0.521 \\
\hline
\end{tabular}




\begin{tabular}{|c|c|c|c|}
\hline Constraint & Value & Lower Limit & Upper Limit \\
\hline Sum of Minors & 0.00051 & 0 & 0.0028 \\
\hline \multicolumn{4}{|l|}{ Model validity PCT constraints } \\
\hline$P_{A 101}^{p c t B, \text { Step } 1}(\ln [\mathrm{g} / \mathrm{L}])$ & -0.0507 & NA & 0.9933 \\
\hline$P_{A 101}^{p c t N a, S t e p 1}(\ln [\mathrm{g} / \mathrm{L}])$ & -0.1406 & NA & 0.9933 \\
\hline \multicolumn{4}{|c|}{$\begin{array}{l}\text { Model validity multiple component constraints (based on } \tilde{g}_{i, A 101}^{\text {Oxidein }}, \text {, lower and upper limits ar } \\
\text { a function of concentration of other component) }\end{array}$} \\
\hline $\mathrm{Li}_{2} \mathrm{O}$ function of $\mathrm{Na}_{2} \mathrm{O}$ & 0.00000 & -0.05336 & 0.02851 \\
\hline $\mathrm{Cr}_{2} \mathrm{O} 3$ function of $\mathrm{P}_{2} \mathrm{O}_{5}$ & 0.00086 & -0.00138 & 0.00234 \\
\hline $\mathrm{Na}_{2} \mathrm{O}$ function of $\mathrm{CaO}$ & 0.19088 & 0.08878 & 0.28178 \\
\hline $\mathrm{Li}_{2} \mathrm{O}$ function of $\mathrm{CaO}$ & 0.00000 & 0.00000 & 0.03952 \\
\hline $\mathrm{Na}_{2} \mathrm{O}$ function of $\mathrm{SO}_{3}$ & 0.19088 & 0.03647 & 0.25787 \\
\hline $\mathrm{Li}_{2} \mathrm{O}$ function of $\mathrm{SO}_{3}$ & 0.00000 & -0.02079 & 0.05081 \\
\hline $\mathrm{Na}_{2} \mathrm{O}$ function of $\mathrm{SiO}_{2}$ & 0.19088 & 0.00220 & 0.20480 \\
\hline
\end{tabular}

NA: not applicable

\subsubsection{Waste $\mathrm{Na}_{2} \mathrm{O}$ Loading Constraint}

The waste $\mathrm{Na}_{2} \mathrm{O}$ loading in the $A 101^{\text {th }}$ MFPV batch from algorithm calculation Step 1 is calculated using Equation (68):

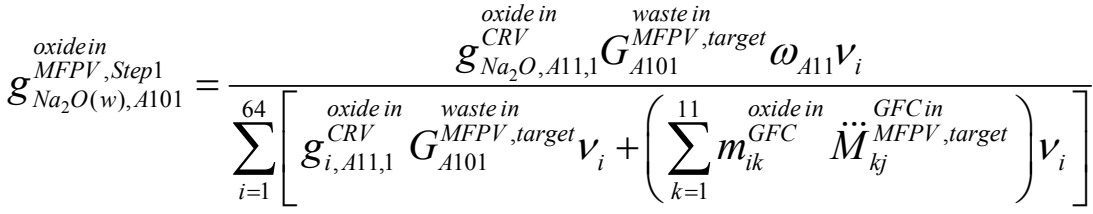

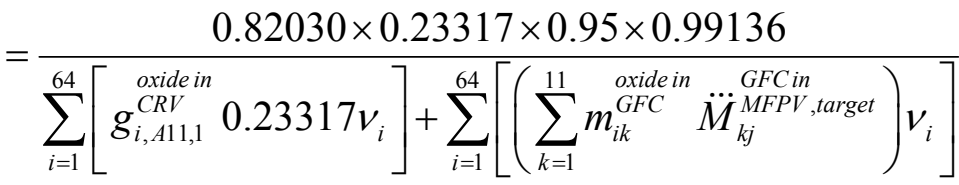

$$
\begin{aligned}
& =\frac{0.18013}{0.22893+0.76616}=0.18102
\end{aligned}
$$

For this example calculation, it was assumed that the $A 11^{\text {th }} \mathrm{CRV}$ waste was designated as Envelope A with $\omega_{A 11}=0.95$ (where $\omega_{A 11}$ is the fraction of the sodium in the $A 11^{\text {th }} \mathrm{CRV}$ batch that is classified as waste

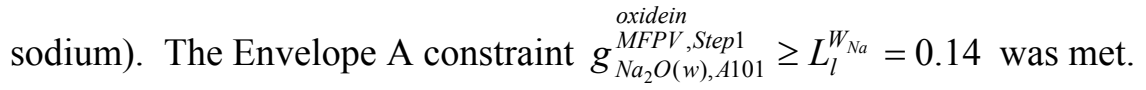

\subsubsection{Radionuclide Concentration Constraints}

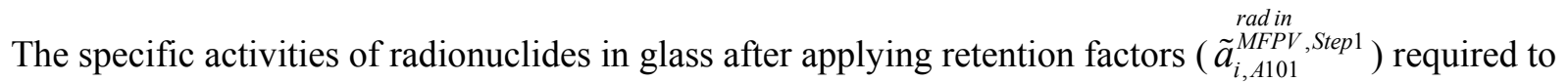
calculate the constraints pertinent to radionuclide concentrations were given in the $3^{\text {rd }}$ column of Table B-5a from Section 6.1.4. The SD values for specific activities of radionuclides in glass $\left(\tilde{s}_{i i, A 101}^{\text {radin }}\right.$,Step 1$)$ for algorithm 
calculation Step 1 after applying retention factors were obtained by Monte Carlo simulations of Equation (70) and given in the $4^{\text {th }}$ column of Table B-5a. These values are used to calculate the constraints for ${ }^{137} \mathrm{Cs}$ and ${ }^{90} \mathrm{Sr}$ according to Equations (73) and (74) as below:

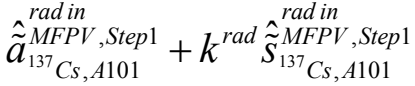

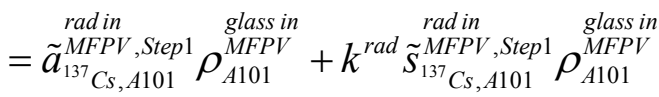

$$
\begin{aligned}
& =4.48192 \mathrm{E}-05(\mathrm{mCi} / \mathrm{g}) \times 2730(\mathrm{~g} / \mathrm{L})+2 \times 5.15875 \mathrm{E}-06(\mathrm{mCi} / \mathrm{g}) \times 2730(\mathrm{~g} / \mathrm{L}) \\
& =0.1505\left(\mathrm{Ci} / \mathrm{m}^{3}\right)<0.3 \mathrm{Ci} / \mathrm{m}^{3}
\end{aligned}
$$

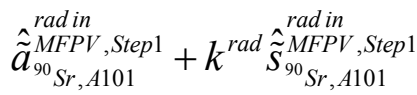

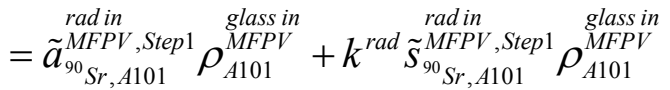

$$
\begin{aligned}
& =5.57167 \mathrm{E}-04(\mathrm{mCi} / \mathrm{g}) \times 2730(\mathrm{~g} / \mathrm{L})+2 \times 2.87069 \mathrm{E}-05(\mathrm{mCi} / \mathrm{g}) \times 2730(\mathrm{~g} / \mathrm{L}) \\
& =1.6778\left(\mathrm{Ci} / \mathrm{m}^{3}\right)<20 \mathrm{Ci} / \mathrm{m}^{3}
\end{aligned}
$$

where $k^{\text {rad }}$ is the expansion factor for radionuclide concentration specification.

\begin{tabular}{|c|c|c|c|c|c|}
\hline $\begin{array}{c}\text { Radio- } \\
\text { nuclide }(i)\end{array}$ & $\begin{array}{c}L_{u}^{\hat{a}_{i}}, \\
\mathbf{C i} / \mathbf{m}^{3}\end{array}$ & $\begin{array}{c}L_{u}^{a_{i}} \\
\mathbf{n C i} / \mathbf{g}\end{array}$ & $\begin{array}{c}\hat{\tilde{a}}_{i, A 101}^{\text {radin }}, \text { Step } 1 \\
\mathbf{C i} / \mathbf{m}^{\mathbf{3}}\end{array}$ & $\begin{array}{c}\tilde{a}_{i, A 101}^{\text {radin }}, \text { Step } 1 \\
\quad \mathbf{n C i} / \mathbf{g}\end{array}$ & $\frac{\hat{\tilde{a}}_{i, A 101}^{\text {radin }}}{L_{u}^{\hat{a}_{i}}}$ or $\frac{\tilde{a}_{i, A 101}^{\text {radin }}}{{ }^{M F P V, S t e p 1}}$ \\
\hline${ }^{99} \mathrm{Tc}$ & 3 & & 0.06123 & & 0.02041 \\
\hline${ }^{129} \mathrm{I}$ & 0.08 & & $1.487 \mathrm{E}-04$ & & 0.00186 \\
\hline $\mathrm{TRU}^{(\mathrm{a})}$ & & 100 & & 1.2026 & 0.01203 \\
\hline${ }^{241} \mathrm{Pu}$ & & 3,500 & & 1.2257 & $3.502 \mathrm{E}-04$ \\
\hline${ }^{242} \mathrm{Cm}$ & & 20,000 & & 0.00271 & $1.354 \mathrm{E}-07$ \\
\hline \multicolumn{5}{|c|}{$\begin{array}{c}\text { rad in } \\
S F_{L L, A 101}^{M F P V, S t e p 1}\end{array}$} & 0.03465 \\
\hline
\end{tabular}

Table 23. Calculation of Sum of Fractions for Long Lived Radionuclides Class C Limits in the $A 101^{\text {th }}$ MFPV batch

(a) Alpha emitting transuranic nuclides with half-life greater than 5 years for Hanford LAW (24590-WTP-PL-RT$03-001)={ }^{237} \mathrm{~Np},{ }^{238} \mathrm{Pu},{ }^{239} \mathrm{Pu},{ }^{240} \mathrm{Pu},{ }^{241} \mathrm{Am},{ }^{242} \mathrm{Pu},{ }^{243} \mathrm{Am},{ }^{243} \mathrm{Cm}$, and ${ }^{244} \mathrm{Cm}$. These are quantified by total alpha measurement.

\begin{tabular}{|c|c|c|c|c|c|}
\hline $\begin{array}{c}\text { Radio- } \\
\text { nuclide }(i)\end{array}$ & $\begin{array}{c}L_{u}^{\hat{a}_{i}}, \\
\mathbf{C i} / \mathbf{m}^{3}\end{array}$ & $\begin{array}{c}L_{u}^{a_{i}} \\
\mathbf{n C i} / \mathbf{g}\end{array}$ & $\begin{array}{c}\hat{\tilde{s}}_{i, A 101}^{\text {radin }}, \text { Step } 1 \\
\mathbf{C i} / \mathbf{m}^{\mathbf{3}}\end{array}$ & $\begin{array}{c}\text { radin } \\
\tilde{S}_{i, A 101}^{M F P V, \text { Step } 1}, \\
\mathbf{n C i} / \mathbf{g}\end{array}$ & 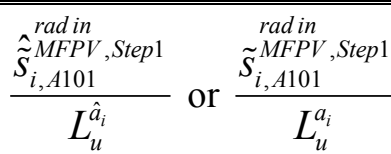 \\
\hline${ }^{99} \mathrm{Tc}$ & 3 & & 0.02136 & & 0.00712 \\
\hline${ }^{129} \mathrm{I}$ & 0.08 & & $5.299 \mathrm{E}-05$ & & 0.00066 \\
\hline $\operatorname{TRU}^{(\mathrm{a})}$ & & 100 & & 0.0472 & 0.00047 \\
\hline${ }^{241} \mathrm{Pu}$ & & 3,500 & & 0.1157 & $3.356 \mathrm{E}-05$ \\
\hline
\end{tabular}

Table 24. Calculation of SD for Sum of Fractions for Long Lived Radionuclides Class C Limits in the $A 101^{\text {th }}$ MFPV batch 


\begin{tabular}{||c|c|c|c||}
\hline \hline${ }^{242} \mathrm{Cm}$ & 20,000 & 0.000196 & $9.813 \mathrm{E}-09$ \\
\hline \multicolumn{3}{|c|}{$\begin{array}{c}\text { radSF in } \\
S_{L L, A 101}^{M F P V}, \text { tep }\end{array}$} & 0.00717 \\
\hline
\end{tabular}

(a) Alpha emitting transuranic nuclides with half-life greater than 5 years for Hanford LAW (24590-WTP-PL-RT$03-001)={ }^{237} \mathrm{~Np},{ }^{238} \mathrm{Pu},{ }^{239} \mathrm{Pu},{ }^{240} \mathrm{Pu},{ }^{241} \mathrm{Am},{ }^{242} \mathrm{Pu},{ }^{243} \mathrm{Am},{ }^{243} \mathrm{Cm}$, and ${ }^{244} \mathrm{Cm}$. These are quantified by total alpha measurement.

Table 25. Calculation of Sum of Fractions for Short Lived Radionuclides Class C Limits in the $\boldsymbol{A 1 0 1}^{\text {th }}$ MFPV batch

\begin{tabular}{|c|c|c|c|}
\hline Radionuclide (j) & $L_{u}^{\hat{a}_{i}}, \mathbf{C} \mathbf{i} / \mathbf{m}^{3}$ & $\hat{\tilde{a}}_{i, A 101}^{\text {radin }}$, Step $1, \mathbf{C i} / \mathbf{m}^{\mathbf{3}}$ & $\frac{\hat{\tilde{a}}_{i, A 101}^{\text {radin }}}{L_{u}^{\hat{a}_{i}}}$ \\
\hline${ }^{63} \mathrm{Ni}$ & 700 & 0.08494 & $1.213 \mathrm{E}-04$ \\
\hline${ }^{90} \mathrm{Sr}$ & 7,000 & 1.52106 & $2.173 \mathrm{E}-04$ \\
\hline${ }^{137} \mathrm{Cs}$ & 4,600 & 0.12236 & $2.660 \mathrm{E}-05$ \\
\hline \multicolumn{3}{|c|}{$\begin{array}{c}\text { rad in } \\
S F_{S L, A 101}^{M F P V, \text { Step } 1}\end{array}$} & 3.652E-04 \\
\hline
\end{tabular}

Table 26. Calculation of SD for Sum of Fractions for Short Lived Radionuclides Class C Limits in the $A_{101}{ }^{\text {th }}$ MFPV batch

\begin{tabular}{|c|c|c|c|}
\hline Radionuclide (j) & $L_{u}^{\hat{a}_{i}}, \mathbf{C i} / \mathbf{m}^{3}$ & 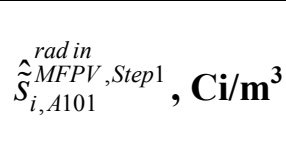 & $\frac{\hat{\tilde{S}}_{i, A 101}^{\text {radin }}}{L_{u}^{\hat{a}_{i}}}$ \\
\hline${ }^{63} \mathrm{Ni}$ & 700 & 0.00604 & $8.624 \mathrm{E}-06$ \\
\hline${ }^{90} \mathrm{Sr}$ & 7,000 & 0.07837 & $1.120 \mathrm{E}-05$ \\
\hline${ }^{137} \mathrm{Cs}$ & 4,600 & 0.01408 & $3.062 \mathrm{E}-06$ \\
\hline \multicolumn{3}{|c|}{$\begin{array}{c}\text { radSF in } \\
S_{S L, A 101}^{M F P V}, \text { Step } 1\end{array}$} & $1.446 \mathrm{E}-05$ \\
\hline
\end{tabular}

The Class C limit is satisfied as long as the two conditions by Equations (79) and (80) are satisfied:

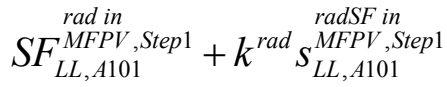

$$
\begin{aligned}
& =0.03465+2 \times 0.00717=0.04898<1
\end{aligned}
$$

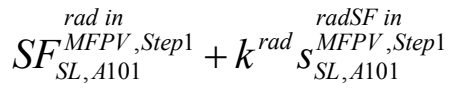

$$
\begin{aligned}
& =3.654 \mathrm{E}-04+2 \times 1.446 \mathrm{E}-05=3.942 \mathrm{E}-04<1
\end{aligned}
$$

\subsubsection{Surface Dose Rate Constraint}

The surface dose rate calculation is not performed by ILAW formulation algorithm.

\subsubsection{Adjustment of Target Glass Composition}

The initial target formulation for the example $A 101^{\text {th }}$ MFPV Batch failed the upper limit for viscosity at $1150^{\circ} \mathrm{C}$ as discussed in Section 6.1.6, which requires an increase of $\mathrm{Li}_{2} \mathrm{O}$ target concentration according to 
the approach described in Section 5.1.7.2. The required adjustment of $\mathrm{Li}_{2} \mathrm{O}$ target concentration is obtained by solving Equation (87) using the $\delta$ value of 0.005 :

$$
\frac{\exp \left(B_{u c c i, A 101}^{v i s 150, \text { Step } 1}\right)}{80}+0.005=1
$$

The $\frac{\exp \left(B_{u c c i, j}^{v i s 150, \text { Step } 1}\right)}{80}$ value before adjustment was 1.104 and becomes 0.995 (this value will change slightly after Monte-Carlo run based on new target composition) when the $g_{\mathrm{Li}_{2} O, A 101}^{\mathrm{MFPV}, \text { adj }}$ is 0.0019 . Then, Equation (88) is used to calculate adjusted $\mathrm{Li}_{2} \mathrm{O}$ target concentration:

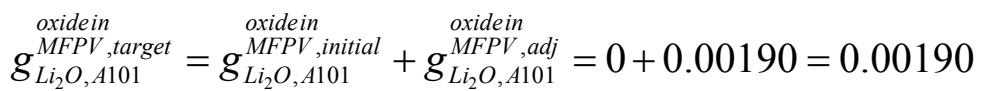

The above adjustment of target $\mathrm{Li}_{2} \mathrm{O}$ mass fraction affects the target mass fraction of $\mathrm{SiO}_{2}$ only i.e., there is no change for all other components and waste loading. The target $\mathrm{SiO}_{2}$ mass fraction is calculated using Equation (88), i.e., by subtracting the adjusted $\mathrm{Li}_{2} \mathrm{O}$ mass fraction from the initial $\mathrm{SiO}_{2}$ as below:

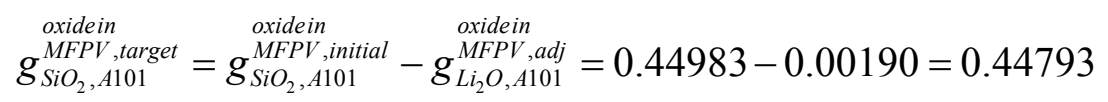

For all other components and waste loading,

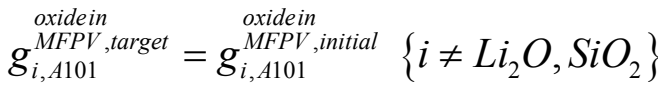

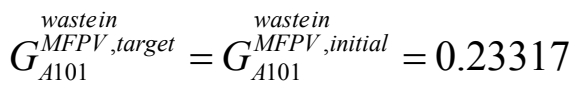

The Step 1 glass and radionuclide compositions (Section 5.1.4), waste transfer volume (Section 5.1.5), and Step 1 constraints (Section 5.1.6) are calculated following the same methods illustrated in Sections 6.1.4, 6.1.5, and 6.1.6. The results of these calculations are summarized below.

\subsubsection{Calculation of Step 1 Glass and Radionuclide Compositions after Target Glass Composition Adjustment}

There is no change in the waste contribution $\left(G_{A 101}^{\text {wastein }} \begin{array}{c}\text { oxide in } \\ \text { ofrget }\end{array} g_{i, A 11,1}^{C R V}\right)$ to the Step 1 glass composition given in the $6^{\text {th }}$ column of Table B-3 compared to that before target glass composition adjustment given in the $3^{\text {rd }}$ column. The adjusted target composition is given in the $5^{\text {th }}$ column and the resulting target GFC

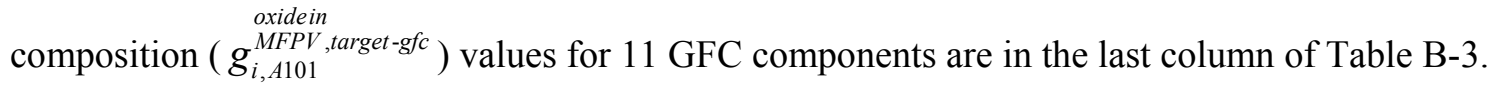




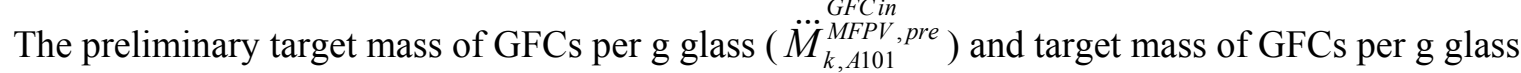
GFCin

$\left(\dddot{M}_{k, A 101}^{M F P V \text {,target }}\right.$ ) are given in Table 27 (corresponding to Table 18 given before target glass composition adjustment).

Table 27. Preliminary Target and Target Masses of Each GFC per g Glass for the $\boldsymbol{A 1 0 1}^{\text {th }}$ MFPV Batch after Target Glass Composition Adjustment

\begin{tabular}{||c|c|c||}
\hline GFC $(\boldsymbol{k})$ & $\dddot{M}_{k, A 101}^{G F C P V}$, pre & $\dddot{M}_{k, A 101}^{G F C \text {,target }}$ \\
\hline Kyanite & $7.5098 \mathrm{E}-02$ & $7.5098 \mathrm{E}-02$ \\
\hline Boric Acid & $1.7684 \mathrm{E}-01$ & $1.7684 \mathrm{E}-01$ \\
\hline Wollastonite & $5.1698 \mathrm{E}-02$ & $5.1698 \mathrm{E}-02$ \\
\hline Hematite & $5.3216 \mathrm{E}-02$ & $5.3216 \mathrm{E}-02$ \\
\hline Li carbonate & $4.7256 \mathrm{E}-03$ & $4.7256 \mathrm{E}-03$ \\
\hline Olivine & $3.0507 \mathrm{E}-02$ & $3.0507 \mathrm{E}-02$ \\
\hline Na carbonate & $-5.7320 \mathrm{E}-04$ & $0.0000 \mathrm{E}+00$ \\
\hline Silica & $3.6302 \mathrm{E}-01$ & $3.6302 \mathrm{E}-01$ \\
\hline Rutile & $1.4191 \mathrm{E}-02$ & $1.4191 \mathrm{E}-02$ \\
\hline Zincite & $3.5051 \mathrm{E}-02$ & $3.5051 \mathrm{E}-02$ \\
\hline Zircon & $4.5078 \mathrm{E}-02$ & $4.5078 \mathrm{E}-02$ \\
\hline
\end{tabular}

Table B-4b shows the waste contribution $\left(G_{A 101}^{\text {wastein }} \begin{array}{c}\text { oxide in } \\ \text { orrget }\end{array} g_{i, A 11,1}^{C R V}\right)\left(2^{\text {nd }}\right.$ column), the GFC contribution

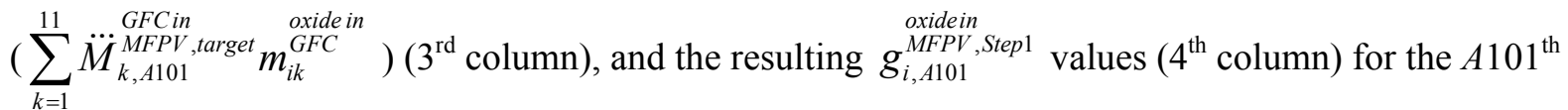
MFPV Batch after target composition adjustment. Table B-4b also includes the $g_{i, A 101}^{\text {oxidein }}{ }^{M F P V} v_{i}$ values $\left(5^{\text {th }}\right.$ column) and the $\tilde{g}_{i, A 101}^{\text {Mxidein }, \text { Step } 1}$ results $\left(6^{\text {th }}\right.$ column $)$ using $\sum_{i=1}^{64} g_{i, A 101}^{\text {oxidein }}{ }^{\text {MFtep } 1} v_{i}=0.994096$. The specific activity of

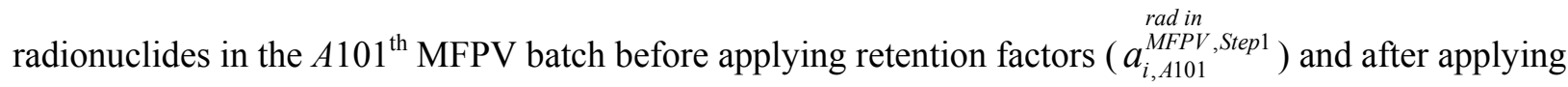

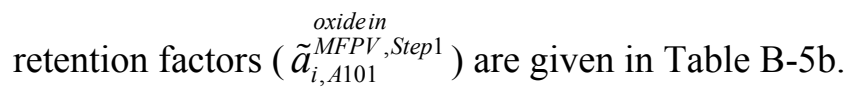

\subsubsection{Calculation of LAW Transfer Volume after Target Glass Composition Adjustment}

The GFC and dust water control volumes per unit volume of LAW and the volume of dilution water change after the target adjustment. Equation (180) for the $A 101^{\text {th }}$ MFPV batch is rewritten with the volumes changed after target glass composition adjustment: 


$$
\begin{aligned}
& V_{A 101}^{\stackrel{\text { working }}{M F P V}}=19426(\mathrm{~L}) \\
& \begin{array}{c}
\text { transwaste } \\
=V_{A 11,1}^{C R V}
\end{array} \\
& +V_{A 101}^{\text {transflush }}+V_{A 101}^{\text {sampflush }} \stackrel{\text { dilute }}{M F P V}+V_{A 101}^{M F P V \text { Step } 1}
\end{aligned}
$$

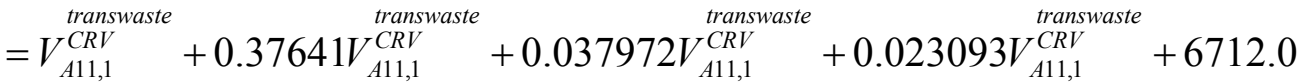

$$
\begin{aligned}
& +37.5+175.3+\max \left\{-0.161529 V_{A 11,1}^{\text {transwaste }}-212.7,0\right\}
\end{aligned}
$$

Equation (199) was solved iteratively to obtain the waste transfer volume $\left(V_{d m}^{C R V}\right)$ of $8696.7 \mathrm{~L}$ compared to the result of $8707.7 \mathrm{~L}$ before the target composition adjustment. This result of $V_{d m}^{C R V}$ is used to calculate the volumes that were expressed in terms of $V_{d m}^{\text {transwaste }}$, then Equation (199) is rewritten as:

$$
19426(\mathrm{~L})=8696.7+3273.5+330.2+200.8+6712.0+37.5+175.3+0.0(\mathrm{~L})
$$

This $V_{d m}^{\text {transwaste }}$ value is used for calculation of composition uncertainties required for the calculation of Step 1 constraints in Section 6.1.10.

The target masses of GFCs and sucrose are calculated from the waste transfer volume. Table 28 summarizes the resulting masses of GFCs and sucrose from Step 1 calculation for the $A 101^{\text {th }}$ MFPV Batch after target composition adjustment.

Table 28. Masses of GFCs and Sucrose from Step 1 Calculation for the $A 101^{\text {th }}$ MFPV Batch after Target Composition Adjustment

\begin{tabular}{|c|c||}
\hline GFC $(\boldsymbol{k}) / \mathbf{s u c r o s e}$ & $\begin{array}{c}\text { GFCin } \\
M_{k, A 101}^{M F P V, \text { target, Step } 1}\end{array}$ \\
\hline Kyanite & 729.90 \\
\hline Boric Acid & 1718.73 \\
\hline Wollastonite & 502.47 \\
\hline Hematite & 517.23 \\
\hline Lithium carbonate & 45.93 \\
\hline Olivine & 296.51 \\
\hline Sodium carbonate & 0 \\
\hline Silica & 3528.27 \\
\hline Rutile & 137.92 \\
\hline Zincite & 340.67 \\
\hline Zircon & 438.13 \\
\hline Sucrose & 311.09 \\
\hline Total & 8566.83 \\
\hline \hline
\end{tabular}




\subsubsection{Calculation of Constraints for Algorithm Step 1 after Target Glass Composition Adjustment}

The same calculations of the constraints described in Section 6.1.6 are performed with adjusted target glass and radionuclide compositions. Table 29 summarizes the predicted properties, uncertainties, and $\mathrm{UCCI} / \mathrm{LCCI}$ values for the Step 1 composition of the $A 101^{\text {th }}$ MFPV batch after composition adjustment and applying the retention factors compared with the corresponding limits. Table 29 shows that all the property constraints are met after composition adjustments.

Table 29. Predicted Properties, Uncertainties, and UCCI/LCCI Values for the $A 101^{\text {th }}$ MFPV Batch Compared with the Corresponding Limits (After Formulation Adjustment)

\begin{tabular}{|c|c|c|c|c|c|c|c|}
\hline Property & Unit & $P_{A 101}^{\text {prop,Step } 1}$ & $U_{\text {pred,A101 }}^{\text {prop,Step } 1}$ & $U_{\text {comp }, A 101}^{\text {prop,Step } 1}$ & \multicolumn{2}{|c|}{$B_{u c c i, A 101}^{\text {prop }, \text { Step } 1}$ or $B_{l c c i, A 101}^{\text {prop }, \text { Step } 1}$} & $L_{u}^{\text {prop }}$ or $L_{l}^{\text {prop }}$ \\
\hline $\ln \left(r_{B}\right)$ & $\ln [\mathrm{g} / \mathrm{L}]$ & 0.0551 & 0.1537 & 0.3585 & 0.5674 & $<$ & 1.3863 \\
\hline $\ln \left(r_{N a}\right)$ & $\ln [\mathrm{g} / \mathrm{L}]$ & -0.0571 & 0.1651 & 0.3016 & 0.4096 & $<$ & 1.3863 \\
\hline $\ln (D)$ & $\ln [\mu \mathrm{m}]$ & 2.6093 & 0.6303 & 1.2962 & 4.5358 & $<$ & 6.1159 \\
\hline $\ln \left(\eta_{1100}\right), u$ & $\ln [\mathrm{P}]$ & 4.6071 & 0.0326 & 0.2520 & 4.8916 & $\leq$ & 5.0106 \\
\hline $\ln \left(\eta_{1150}\right), l$ & $\ln [\mathrm{P}]$ & 4.1112 & 0.0328 & 0.2414 & 3.8370 & $\geq$ & 2.9957 \\
\hline $\ln \left(\eta_{1150}\right), u$ & $\ln [\mathrm{P}]$ & 4.1112 & 0.0328 & 0.2323 & 4.3763 & $\leq$ & 4.3820 \\
\hline $\ln \left(\varepsilon_{1100}\right), l$ & $\ln [\mathrm{S} / \mathrm{cm}]$ & -1.0550 & 0.0321 & 0.1773 & -1.2644 & $\geq$ & -2.3026 \\
\hline $\ln \left(\varepsilon_{1200}\right), u$ & $\ln [\mathrm{S} / \mathrm{cm}]$ & -0.7025 & 0.0327 & 0.1649 & -0.5049 & $\leq$ & -0.3567 \\
\hline
\end{tabular}


Table 30 summarizes the calculation results for additional constraints for the Step 1 composition of the $A 101^{\text {th }}$ MFPV batch after composition adjustment and applying the retention factors compared with the corresponding limits. Table 30 shows that all the model validity, waste $\mathrm{Na}_{2} \mathrm{O}$ loading, and radionuclide concentration constraints are met.

Table 30. Additional Constraints for the $A 101^{\text {th }}$ MFPV Batch after Composition Adjustment Compared with the Corresponding Limits

\begin{tabular}{|c|c|c|c|}
\hline Constraint & Value & Lower Limit & Upper Limit \\
\hline \multicolumn{4}{|c|}{ Model validity single component constraints $\left(\tilde{g}_{i, A 101}^{\text {oxidein }}\right.$, Step1 $)$} \\
\hline $\mathrm{Al}_{2} \mathrm{O}_{3}$ & 0.06123 & 0.035 & 0.090 \\
\hline $\mathrm{Cl}$ & 0.00136 & 0 & 0.0091 \\
\hline $\mathrm{Cr}_{2} \mathrm{O}_{3}$ & 0.00086 & 0 & 0.0059 \\
\hline $\mathrm{F}$ & 0.00076 & 0 & 0.0035 \\
\hline $\mathrm{P}_{2} \mathrm{O}_{5}$ & 0.00198 & 0 & 0.030 \\
\hline $\mathrm{SiO}_{2}$ & 0.44981 & 0.384 & 0.521 \\
\hline Sum of Minors & 0.00051 & 0 & 0.0028 \\
\hline \multicolumn{4}{|l|}{ Model validity PCT constraints } \\
\hline$P_{A 101}^{p c t B, \text { Step } 1}(\ln [\mathrm{g} / \mathrm{L}])$ & 0.0551 & NA & 0.9933 \\
\hline$P_{A 101}^{p c t N a, \text { Step } 1}(\ln [\mathrm{g} / \mathrm{L}])$ & -0.0571 & NA & 0.9933 \\
\hline \multicolumn{4}{|c|}{\begin{tabular}{|l} 
Model validity multiple component constraints (based on $\tilde{g}_{i, A 101}^{\text {Oxidein }}{ }^{\text {MFtep } 1}$, lower and upper limits are \\
a function of concentration of other component)
\end{tabular}} \\
\hline $\mathrm{Li}_{2} \mathrm{O}$ function of $\mathrm{Na}_{2} \mathrm{O}$ & 0.00190 & -0.05337 & 0.02851 \\
\hline $\mathrm{Cr}_{2} \mathrm{O} 3$ function of $\mathrm{P}_{2} \mathrm{O}_{5}$ & 0.00086 & -0.00138 & 0.00234 \\
\hline $\mathrm{Na}_{2} \mathrm{O}$ function of $\mathrm{CaO}$ & 0.19088 & 0.08878 & 0.28178 \\
\hline $\mathrm{Li}_{2} \mathrm{O}$ function of $\mathrm{CaO}$ & 0.00190 & 0.00000 & 0.03952 \\
\hline $\mathrm{Na}_{2} \mathrm{O}$ function of $\mathrm{SO}_{3}$ & 0.19088 & 0.03645 & 0.25785 \\
\hline $\mathrm{Li}_{2} \mathrm{O}$ function of $\mathrm{SO}_{3}$ & 0.00190 & -0.02079 & 0.05081 \\
\hline $\mathrm{Na}_{2} \mathrm{O}$ function of $\mathrm{SiO}_{2}$ & 0.19088 & 0.00474 & 0.20734 \\
\hline \multicolumn{4}{|l|}{ Waste $\mathrm{Na}_{2} \mathrm{O}$ loading constraint } \\
\hline $\begin{array}{c}\text { oxidein } \\
g_{\mathrm{Na}_{2} O(w), A 101}^{M P V, S t e p 1}\end{array}$ & 0.1810 & 0.14 & NA \\
\hline \multicolumn{4}{|c|}{ Radionuclide Concentration Constraints } \\
\hline 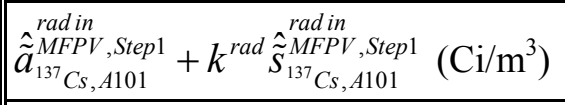 & 0.1503 & NA & 0.3 \\
\hline 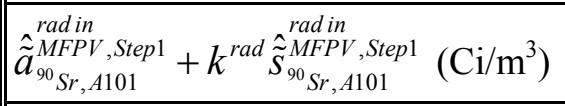 & 1.6796 & NA & 20 \\
\hline 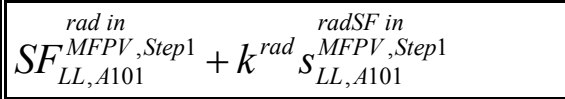 & 0.04869 & NA & 1 \\
\hline 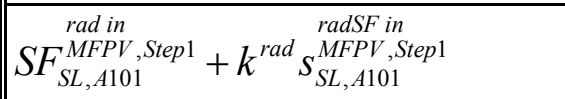 & 0.00039 & NA & 1 \\
\hline
\end{tabular}

NA: not applicable

(a) It was assumed that the fraction of sodium in the $A 11^{\text {th }} \mathrm{CRV}$ that is classified as waste sodium $\left(\omega_{A 11}\right)$ was 95\% and waste in the $A 11^{\text {th }} \mathrm{CRV}$ was designated as Envelope A. 


\subsection{Example Step 2 - Calculation of GFC Masses and Dilution Water Volume}

The waste transfer volume calculated in Section from Step 1 is provided to the operators of the LAW Vitrification and Pretreatment facilities so that they can initiate the waste transfer from the CRV to the MFPV. After transferring the waste, the actual waste volume $\left(V_{j}^{\text {waste }}\right.$ ) added to the MFPV is obtained and used to calculate the GFC/sucrose masses and dilution water volume in Step 2 calculation. For the purpose of this example calculation, it was assumed that the actual waste volume $\left(V_{A 101}^{M F P S T}\right)$ was $8957.6 \mathrm{~L}, 3 \%$ higher than the target of $8696.7 \mathrm{~L}$. The masses of GFCs and sucrose to add to the MFPV are calculated using Equations (89) and (90):

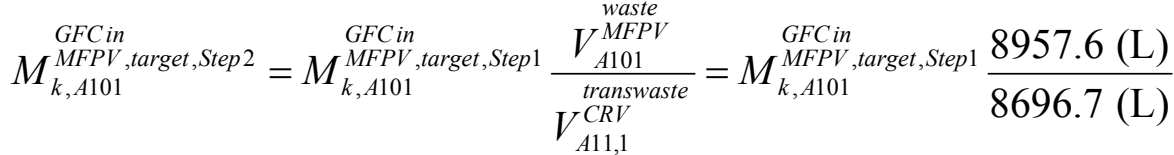

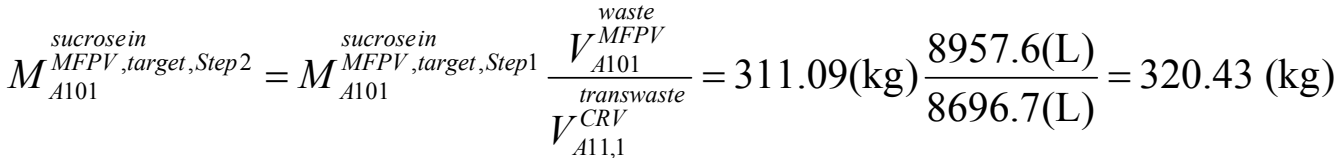

The results of the Step 2 calculations are included in Table 31.

Table 31. Masses of GFCs and Sucrose from Step 2 Calculation for the $A 101^{\text {th }}$ MFPV Batch

\begin{tabular}{|c|c|}
\hline GFC $(k) /$ sucrose & $\begin{array}{c}\text { GFCin } \\
M_{k, A 101}^{\text {MFPV } \text {,target,Step } 2}\end{array}$ \\
\hline Kyanite & 751.80 \\
\hline Boric Acid & 1770.30 \\
\hline Wollastonite & 517.54 \\
\hline Hematite & 532.74 \\
\hline Lithium carbonate & 47.31 \\
\hline Olivine & 305.40 \\
\hline Sodium carbonate & 0.00 \\
\hline Silica & 3634.13 \\
\hline Rutile & 142.06 \\
\hline Zincite & 350.89 \\
\hline Zircon & 451.28 \\
\hline Sucrose & 320.43 \\
\hline Total & 8823.88 \\
\hline
\end{tabular}


The volumes of dust control water and dilution water for Step 2 are calculated based on actual volume of waste transferred using Equations (91) and (92):

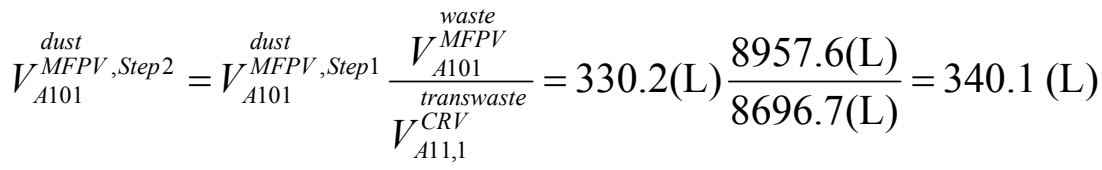

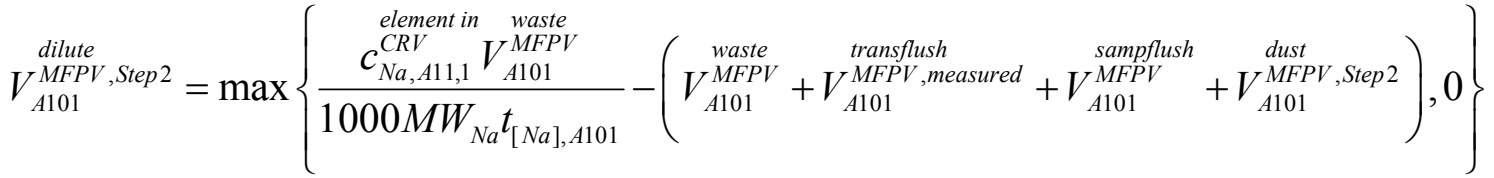

$$
\begin{aligned}
& =\max \left\{\begin{array}{l}
\frac{158576.4(\mathrm{mg} / \mathrm{L}) \times 8957.6}{1000(\mathrm{mg} / \mathrm{g}) \times 22.9898(\mathrm{~g} / \mathrm{mole}) \times 7.870(\mathrm{moles} / \mathrm{L})}- \\
(8957.6+37.5+175.3+340.1), 0
\end{array}\right\} \\
& =\max \{-1659.7,0\}=0
\end{aligned}
$$

The volume contributions of GFCs and sucrose are calculated using Equations (93) and (94):

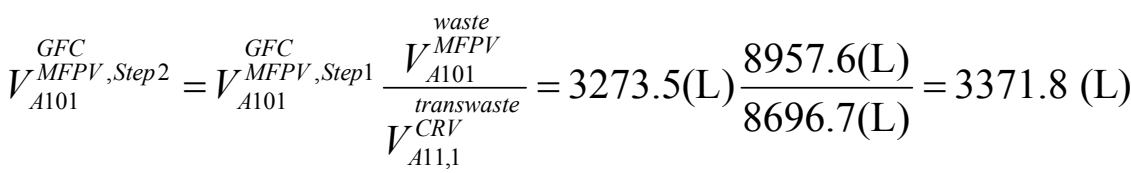

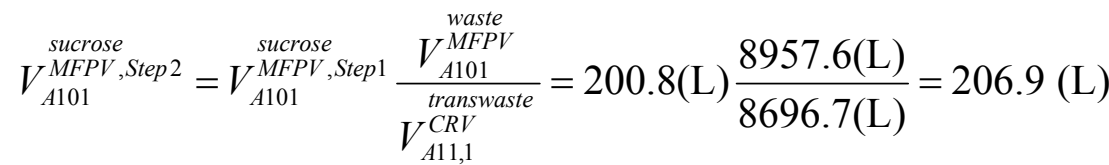

Then, the total increase of volume originated from increased waste transfer volume is calculated using Equation (95) as:

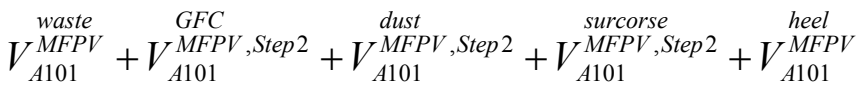

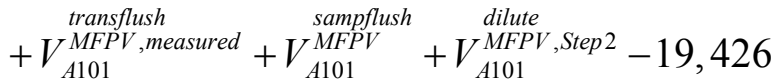

$$
\begin{aligned}
& =8957.6+3371.8+340.1+206.9+6712+37.5+175.3+0-19,426 \\
& =19,801.1-19,426 \\
& =375.1<1,666(\mathrm{~L})
\end{aligned}
$$

In this example, because the actual waste transfer volume increase was small enough not to cause the total MFPV volume increase over the allowable $1,666 \mathrm{~L}$, it is safe to continue normal operation. 


\subsection{Example Step 3 - Calculation of Final Glass Composition and Properties with Uncertainties}

The actual measured volume of waste transfer, actual measured volumes of flush, batch control, and dilution water, and the actual measured masses of GFCs are used to calculate the final composition and properties. For example calculations, the actual measured masses of GFCs and sucrose were random generated based on the SD values discussed in Appendix E and given in the $2^{\text {nd }}$ column of Table 32.

Table 32. Assumed Values for the Measured Masses of GFCs and Sucrose in Step 3 Calculation and Calculated GFC/Sucrose Masses per $g$ Glass for the $A 101^{\text {th }}$ MFPV Batch

\begin{tabular}{|c|c|c|c|c|}
\hline GFC & $\begin{array}{c}G F C \text { in } \\
M_{k, A 101}^{M F P V, \text { measured }} \\
\mathbf{k g}\end{array}$ & $\sum_{i=1}^{64} m_{i k}^{\text {oxide in }}$ & 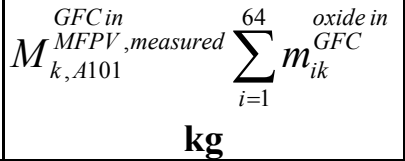 & $\begin{array}{l}\dddot{M}_{k, A 101}^{G F C \text { in }}{ }^{M F P V}, \text { } 3 \\
\text { g/g glass }\end{array}$ \\
\hline Kyanite & 752.1 & 0.99665 & 749.6 & 0.07505 \\
\hline Boric Acid & 1770.0 & 0.56527 & 1000.5 & 0.17663 \\
\hline Wollastonite & 517.7 & 0.99135 & 513.2 & 0.05166 \\
\hline Hematite & 532.6 & 1.00546 & 535.5 & 0.05315 \\
\hline Lithium carbonate & 47.4 & 0.40702 & 19.3 & 0.00473 \\
\hline Olivine & 305.3 & 0.98994 & 302.2 & 0.03047 \\
\hline Sodium carbonate & 0.0 & 0.58420 & 0.0 & 0.00000 \\
\hline Silica & 3634.4 & 0.99891 & 3630.5 & 0.36268 \\
\hline Rutile & 142.1 & 0.98793 & 140.4 & 0.01418 \\
\hline Zincite & 350.7 & 0.99829 & 350.1 & 0.03500 \\
\hline Zircon & 451.2 & 0.98731 & 445.5 & 0.04503 \\
\hline Sucrose & 320.3 & NA & NA & NA \\
\hline Total & 8823.8 & NA & 7686.8 & NA \\
\hline
\end{tabular}

NA: not applicable 


\subsubsection{Final Glass Composition}

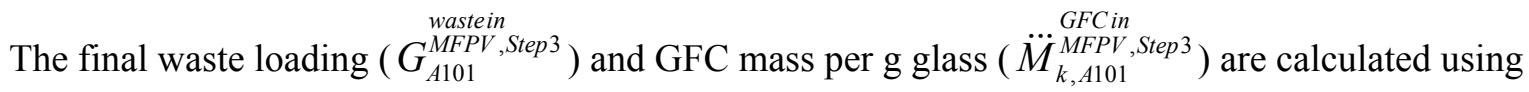
Equations (96) and (97):

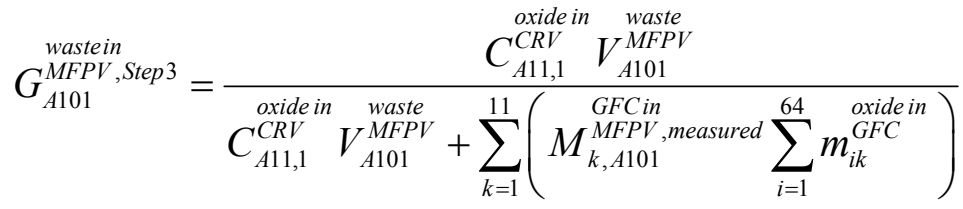

$$
\begin{aligned}
& =\frac{260.58(\mathrm{~g} / \mathrm{L}) \times 8957.6(\mathrm{~L})}{260.58(\mathrm{~g} / \mathrm{L}) \times 8957.6(\mathrm{~L})+\sum_{k=1}^{11}\left(M_{k, A 101}^{G F C \text { in }} \text {, measured } \sum_{i=1}^{64} m_{i k}^{\text {oxide in }}\right)} \\
& =\frac{2334.2(\mathrm{~kg})}{2334.2(\mathrm{~kg})+7686.8(\mathrm{~kg})}=0.23293
\end{aligned}
$$

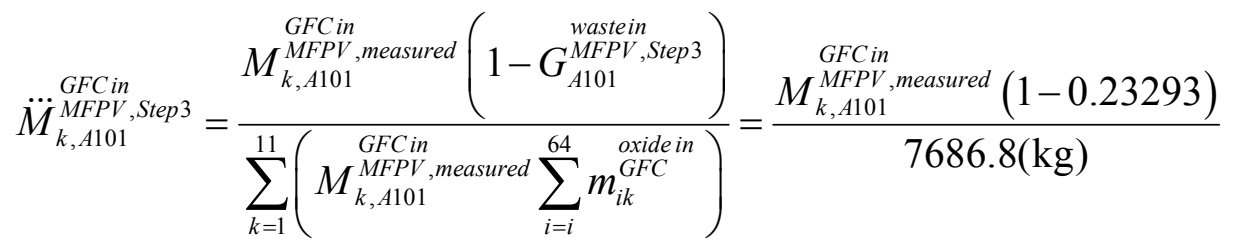

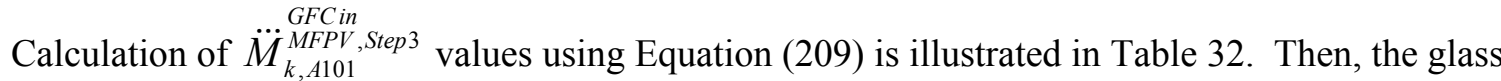
composition is calculated using Equation (98):

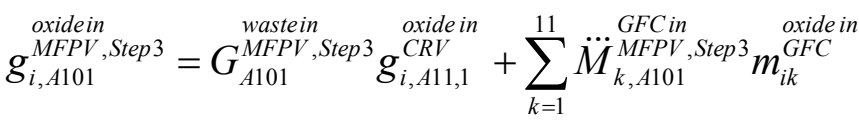

$$
\begin{aligned}
& =0.23293 \times g_{i, A 11,1}^{\text {oxide in }}+\sum_{k=1}^{11} \dddot{M}_{k, A 101}^{G F C \text { in }}{ }^{M F t e p 3} m_{i k}^{\text {oxide in }}
\end{aligned}
$$

The $g_{i, A 11,1}^{\substack{\text { oxidein } \\ C R V}}$ values are given in Table B-2, $\dddot{M}_{k, A 101}^{G F P V \text {,Step } 3}$ values are in Table 32, and $m_{i k}^{\text {oxidein }}$ values are in Table A-5. Table B-6 show the waste contribution $\left(G_{A 101}^{\text {wastein }} \begin{array}{l}\text { MFItep } 3 \\ g_{i, A 11,1}^{C R V}\end{array}\right)\left(2^{\text {nd }}\right.$ column $)$, the GFC contribution

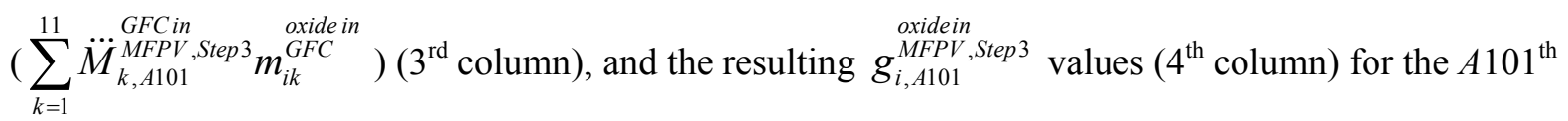
MFPV Batch. The glass composition after applying retention factors $\left(\tilde{g}_{i, A 101}^{\text {oxidein }}{ }_{\text {Step } 3}\right)$ is calculated using Equation (99): 


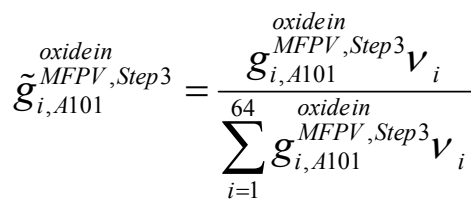

Table B-6 also includes the $g_{i, A 101}^{\text {oxidein }}{ }^{M F P V}{ }_{i}$ values $\left(5^{\text {th }}\right.$ column $)$ and the $\tilde{g}_{i, A 101}^{\text {oxidein }}$ results $\left(6^{\text {th }}\right.$ column $)$ using $\sum_{i=1}^{64} g_{i, A 101}^{\substack{\text { oxidein } \\ M F P V, \text { Step } 3}} v_{i}=0.99410$.

The activity of radionuclides per unit mass of glass oxides in the $A 101^{\text {th }}$ MFPV batch $\left(a_{i, A 101}^{\text {rad in }}{ }^{\text {MFPV } 3}\right)$ is calculated using Equation (100):

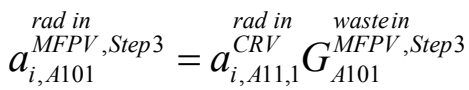

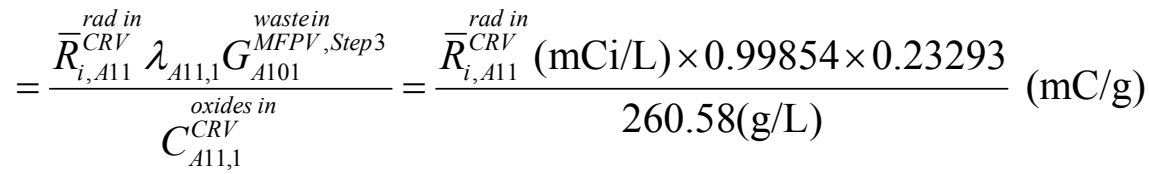

The specific activity after applying retention factors $\left(\tilde{a}_{i, A 101}^{\text {oxidein }}\right.$ MFtep 3 ) is calculated using Equation (101):

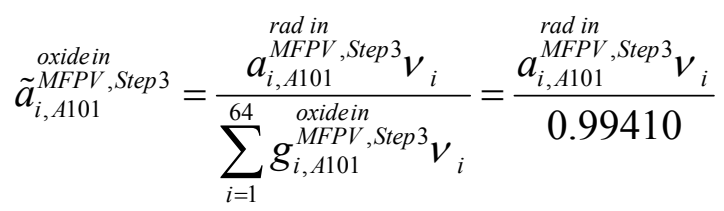

The results of $a_{i, A 101}^{\text {rad in }}$,Step 3 and $\tilde{a}_{i, A 101}^{\text {oxidein }}$ Step 3 are in Table B-7.

\subsubsection{Final Predicted Properties and Uncertainties}

The glass composition given in Table B-6 is used to calculate the final predicted properties with uncertainties.

Table 33 summarizes the predicted properties, uncertainties, and UCCI/LCCI values for the Step 3 composition of the $A 101^{\text {th }}$ MFPV batch after applying the retention factors compared with the corresponding limits. As expected, Table 33 shows that all the property constraints are met.

Table 33. Predicted Properties, Uncertainties, and UCCI/LCCI Values for Final Composition from Step 3 Calculation of the $A 101^{\text {th }}$ MFPV Batch Compared with the Corresponding Limits

\begin{tabular}{||l|c|c|c|c|c|c|c||}
\hline \hline Property & Unit & $P^{\text {prop }}$ & $U_{\text {pred }}^{\text {prop }}$ & $U_{\text {comp }}^{\text {prop }}$ & \multicolumn{2}{|c||}{$B_{\text {ucci,lcci }}^{\text {prop }}$} & $L^{\text {prop }}$ \\
\hline $\ln \left(r_{B}\right)$ & $\ln [\mathrm{g} / \mathrm{L}]$ & 0.0540 & 0.1537 & 0.3366 & 0.5443 & $<$ & 1.3863 \\
\hline $\ln \left(r_{N a}\right)$ & $\ln [\mathrm{g} / \mathrm{L}]$ & -0.0579 & 0.1651 & 0.2852 & 0.3924 & $<$ & 1.3863 \\
\hline
\end{tabular}




\begin{tabular}{|l|c|c|c|c|c|c|c||}
\hline $\ln (D)$ & $\ln [\mu \mathrm{m}]$ & 2.6105 & 0.6303 & 1.2035 & 4.4442 & $<$ & 6.1159 \\
\hline $\ln \left(\eta_{1100}\right), u$ & $\ln [\mathrm{P}]$ & 4.6076 & 0.0326 & 0.2523 & 4.8925 & $<$ & 5.0106 \\
\hline $\ln \left(\eta_{1150}\right), l$ & $\ln [\mathrm{P}]$ & 4.1117 & 0.0328 & 0.2254 & 3.8536 & $>$ & 2.9957 \\
\hline $\ln \left(\eta_{1150}\right), u$ & $\ln [\mathrm{P}]$ & 4.1117 & 0.0328 & 0.2333 & 4.3779 & $<$ & 4.3820 \\
\hline $\ln \left(\varepsilon_{1100}\right), l$ & $\ln [\mathrm{S} / \mathrm{cm}]$ & -1.0551 & 0.0321 & 0.1766 & -1.2638 & $>$ & -2.3026 \\
\hline $\ln \left(\varepsilon_{1200}\right), u$ & $\ln [\mathrm{S} / \mathrm{cm}]$ & -0.7026 & 0.0327 & 0.1528 & -0.5172 & $<$ & -0.3567 \\
\hline
\end{tabular}

Table 34 summarizes the calculation results for additional constraints given in Table 10 through Table 13 for the Step 3 composition of the $A 101^{\text {th }}$ MFPV batch compared with the corresponding limits. There are no or only minor differences between the results from Step 1(Table 30) and Step 3 (Table 34) calculations, resulting from formulation different caused by the differences in the target and measured GFC masses.

Table 34. Additional Constraints for the Step 3 composition of the $A 101^{\text {th }}$ MFPV Batch Compared with the Corresponding Limits

\begin{tabular}{|c|c|c|c|}
\hline Constraint & Value & "Lower Limit & "Upper Limit \\
\hline \multicolumn{4}{|c|}{\begin{tabular}{|c} 
Model validity single component constraints $\left(\tilde{g}_{i, A 101}^{M F P V, S t e p 3}\right)$ \\
Mode
\end{tabular}} \\
\hline $\mathrm{Al}_{2} \mathrm{O}_{3}$ & 0.06125 & 0.035 & 0.090 \\
\hline $\mathrm{Cl}$ & 0.00136 & 0 & 0.0091 \\
\hline $\mathrm{Cr}_{2} \mathrm{O}_{3}$ & 0.00086 & 0 & 0.0059 \\
\hline $\mathrm{F}$ & 0.00076 & 0 & 0.0035 \\
\hline $\mathrm{P}_{2} \mathrm{O}_{5}$ & 0.00198 & 0 & 0.030 \\
\hline $\mathrm{SiO}_{2}$ & 0.44984 & 0.384 & 0.521 \\
\hline Sum of Minors & 0.00051 & 0 & 0.0028 \\
\hline \multicolumn{4}{|l|}{ Model validity PCT constraints } \\
\hline$P_{A 101}^{p c t B, \text { Step } 3}(\ln [\mathrm{g} / \mathrm{L}])$ & 0.0540 & NA & 0.9933 \\
\hline$P_{A 101}^{p c t N a, \text { Step } 3}(\ln [\mathrm{g} / \mathrm{L}])$ & -0.0579 & NA & 0.9933 \\
\hline \multicolumn{4}{|c|}{\begin{tabular}{||l} 
Model validity multiple component constraints (based on $\tilde{g}_{i, A 101}^{\text {oxidein }}$ \\
a function 3 , lower and upper limits are
\end{tabular}} \\
\hline $\mathrm{Li}_{2} \mathrm{O}$ function of $\mathrm{Na}_{2} \mathrm{O}$ & 0.00191 & -0.05336 & 0.02851 \\
\hline $\mathrm{Cr}_{2} \mathrm{O}_{3}$ function of $\mathrm{P}_{2} \mathrm{O}_{5}$ & 0.00086 & -0.00138 & 0.00234 \\
\hline $\mathrm{Na}_{2} \mathrm{O}$ function of $\mathrm{CaO}$ & 0.19088 & 0.08877 & 0.28177 \\
\hline $\mathrm{Li}_{2} \mathrm{O}$ function of $\mathrm{CaO}$ & 0.00191 & 0.00000 & 0.03953 \\
\hline $\mathrm{Na}_{2} \mathrm{O}$ function of $\mathrm{SO}_{3}$ & 0.19088 & 0.03645 & 0.25785 \\
\hline $\mathrm{Li}_{2} \mathrm{O}$ function of $\mathrm{SO}_{3}$ & 0.00191 & -0.02079 & 0.05081 \\
\hline $\mathrm{Na}_{2} \mathrm{O}$ function of $\mathrm{SiO}_{2}$ & 0.19088 & 0.00469 & 0.20729 \\
\hline \multicolumn{4}{|l|}{ Waste $\mathrm{Na}_{2} \mathrm{O}$ loading constraint } \\
\hline $\begin{array}{c}\text { oxidein } \\
g_{N a_{2} O(w), A 101}^{M F P V, S t e p 3} \text { (a) }\end{array}$ & 0.1810 & 0.14 & NA \\
\hline \multicolumn{4}{|c|}{ Radionuclide Concentration Constraints } \\
\hline 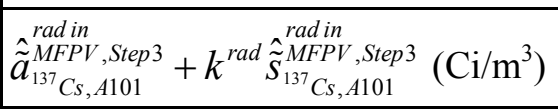 & 0.1501 & NA & 0.3 \\
\hline
\end{tabular}




\begin{tabular}{|c|c|c|c|}
\hline Constraint & Value & "Lower Limit & "Upper Limit \\
\hline 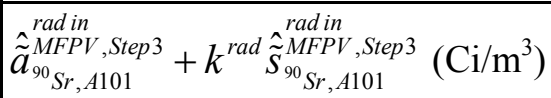 & 1.6777 & NA & 20 \\
\hline 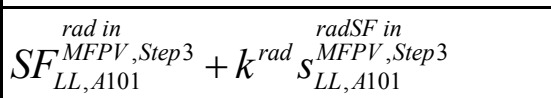 & 0.04843 & NA & 1 \\
\hline $\begin{array}{c}\text { rad in } \\
\text { radSF in } \\
S F_{S L, A 101}^{M F P V, S t e p 3}+k^{\text {rad }} S_{S L, A 101}^{M F P V, S t e p 3}\end{array}$ & 0.00039 & NA & 1 \\
\hline
\end{tabular}

NA: not applicable

(a) It was assumed that the fraction of sodium in the $A 11^{\text {th }} \mathrm{CRV}$ that is classified as waste sodium $\left(\omega_{A 11}\right)$ was $95 \%$ and waste in the $A 11^{\text {th }} \mathrm{CRV}$ was designated as Envelope $\mathrm{A}$.

\subsection{Example Step 4-Comparison of Final Composition and Properties with Constraints}

Table 33 and Table 34 already compared the predicted properties with uncertainties and additional constraint quantities to their limits and confirmed that all the constraints are met for the $A 101^{\text {th }}$ MFPV batch.

If prediction plus composition uncertainty for any property is outside the range of acceptability, an operator will be alerted for intervention. For product quality related properties (e.g., those properties required to meet Contract Specification 1) this comparison is a hold point for transfer of melter feed to the MFV. Once the comparison is successful, the hold point is lifted.

\subsection{Example Step 5 - Completion of Production Records}

As discussed in Section 5.5, the productions records are calculated per glass canister basis. With the canister compositions and masses, compliance with the product requirements is demonstrated. These requirements are discussed in the same order as in Section 5.5.

The example calculations given in Section 6.1 through 6.4 through were performed for one MFPV batch (assumed as $A 101^{\text {th }}$ MFPV) based on the $1^{\text {st }}$ transfer waste transferred from the $A 11^{\text {th }} \mathrm{CRV}$. Similar calculations were also performed for the next 9 MFPV batches for a total of 10 , from $A 101^{\text {th }}$ to $B 105^{\text {th }}$, MFPV batches. These 10 MFPV batches required three CRV batches, A11, B11, and A12. The compositions of these CRV batches are given in Table B-1 in the units that would be reported by the WTP laboratory.

During these calculations, to simulate the use of actual measured data, the following values were random generated:

- Actual CRV working volume around the nominal value of $48661 \mathrm{~L}$

- Actual MFPV heel volume around the nominal value of $6556 \mathrm{~L}$

- Actual waste transfer volume around the Step 1 target value

- Actual GFC masses around the Step 2 target values

The actual water volumes for flush waters, dust control water, and dilution water were assumed to be the same as nominal or target values.

The results of above calculations are in Tables B-8 through B-10. Table B-8 summarizes the input data and results of various processing parameters, Table B-9 waste and final glass compositions and SD for glass composition, and Table B-10 results on various constraint quantities including glass properties and uncertainties. Calculations of quantities for production records based on these 10 MFPV batches are given 
in the following subsections. It was assumed that the $A 501^{\text {th }}$ through $A 503^{\text {th }}$ canisters consist of five MFPVA batches (MFPV- $A 101, A 102, A 103, A 104$, and $A 105)$ and $B 501^{\text {th }}$ through $B 503^{\text {th }}$ canisters consist of five MFPV-B batches (MFPV-B101, $B 102, B 103, B 104$, and $B 105$ ).

\subsubsection{Specification 2.2.2.2 -Waste Loading}

The mass weighted average composition over 5 MFPV batches is calculated using Equation (121):

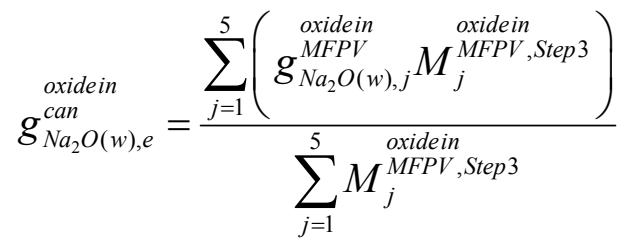

The waste $\mathrm{Na}_{2} \mathrm{O}$ loading $\left(\begin{array}{c}\text { oxidein } \\ \mathrm{NFP}_{2} \mathrm{O}(w), j\end{array}\right)$ data are given in Table B-10 and the total glass oxides mass $\left(M_{j}^{\substack{\text { oxidein } \\ M F P V \text { Step } 3}}\right)$ data are in Table B-8. Table 35 summarizes the calculation of waste $\mathrm{Na}_{2} \mathrm{O}$ loading for the $A 501^{\text {th }}$ and $B 501^{\text {th }}$ canisters.

Table 35. Calculation of Waste $\mathrm{Na}_{2} \mathrm{O}$ loading for the $A 501^{\text {th }}$ and $B 501^{\text {th }}$ Canisters

\begin{tabular}{|c|c|c|c|c|c||}
\hline MFPV batch & $\begin{array}{c}\text { Waste Na } \mathbf{O} \\
\text { loading }\end{array}$ & $\begin{array}{c}\text { Mass of glass } \\
\text { before retention } \\
\text { factor } \\
\text { adjustment, kg }\end{array}$ & MFPV batch & $\begin{array}{c}\text { Waste Na } \mathbf{O} \\
\text { loading }\end{array}$ & $\begin{array}{c}\text { Mass of glass } \\
\text { before } \\
\text { retention factor } \\
\text { adjustment, kg }\end{array}$ \\
\hline MFPV-A101 & 0.181 & 10021.0 & MFPV-B101 & 0.181 & 9888.9 \\
\hline MFPV-A102 & 0.181 & 9952.3 & MFPV-B102 & 0.188 & 9872.2 \\
\hline MFPV-A103 & 0.188 & 9727.5 & MFPV-B103 & 0.188 & 9537.2 \\
\hline MFPV-A104 & 0.162 & 10562.6 & MFPV-B104 & 0.162 & 10431.4 \\
\hline MFPV-A105 & 0.162 & 10508.8 & MFPV-B105 & 0.162 & 10510.9 \\
\hline $\begin{array}{c}\text { Result for } A 501^{\text {th }} \\
\text { canister }\end{array}$ & 0.174 & $\begin{array}{c}\text { Result for } B 501^{\text {th }} \\
\text { canister }\end{array}$ & 0.176 & \\
\hline \hline
\end{tabular}

\subsubsection{Specification 2.2.2.6 - Chemical Composition Documentation}

The composition of canister glass is calculated using Equation (123) and its SD using Equation (124):

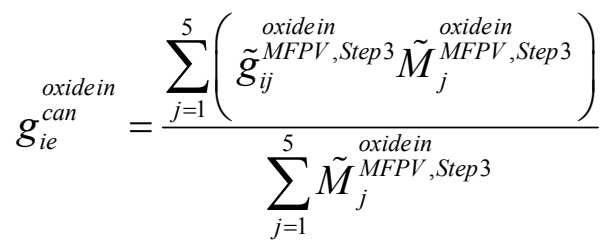




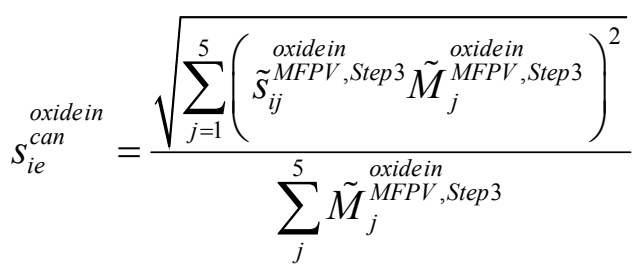

oxidein oxidein oxidein The $g_{i e}^{\text {can }}$ and $s_{i e}^{\text {can }}$ values are given in Table B-9 and $\tilde{M}_{j}^{M F P V, \text { Step } 3}$ values are in Table B-8. The results of above calculations for the $A 501^{\text {th }}$ and $B 501^{\text {th }}$ Canisters are listed in Table 36 .

Table 36. Chemical Composition of Glass in the $A 501^{\text {th }}$ and $B 501^{\text {th }}$ Canisters

\begin{tabular}{|c|c|c|c|c|}
\hline \multirow{2}{*}{$\begin{array}{c}\text { Canister } \\
\text { Comp }\end{array}$} & \multicolumn{2}{|c|}{ Canister- $A 501$} & \multicolumn{2}{|c|}{ Canister-B501 } \\
\hline & $g_{i, A 501}^{\substack{\text { oxidein } \\
\text { can }}}$ & $\begin{array}{c}\text { oxidein } \\
S_{i, A 501}^{\text {can }} \\
\end{array}$ & $g_{i, B 501}^{\substack{\text { oxidein } \\
\text { can }}}$ & 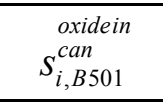 \\
\hline $\mathrm{Ac} 2 \mathrm{O} 3$ & $5.9378 \mathrm{E}-14$ & $1.8996 \mathrm{E}-15$ & $5.9962 \mathrm{E}-14$ & $1.9402 \mathrm{E}-15$ \\
\hline Ag2O & $2.8932 \mathrm{E}-07$ & $1.5987 \mathrm{E}-08$ & $2.9145 \mathrm{E}-07$ & $1.6180 \mathrm{E}-08$ \\
\hline $\mathrm{Al} 2 \mathrm{O} 3$ & $6.1237 \mathrm{E}-02$ & $5.2295 \mathrm{E}-04$ & $6.1228 \mathrm{E}-02$ & $5.2893 \mathrm{E}-04$ \\
\hline $\mathrm{Am} 2 \mathrm{O} 3$ & $1.7190 \mathrm{E}-10$ & $5.8095 \mathrm{E}-12$ & $1.7157 \mathrm{E}-10$ & $5.7174 \mathrm{E}-12$ \\
\hline As2O5 & $1.2226 \mathrm{E}-06$ & $1.4387 \mathrm{E}-07$ & $1.2263 \mathrm{E}-06$ & $1.4256 \mathrm{E}-07$ \\
\hline $\mathrm{B} 2 \mathrm{O} 3$ & $9.9444 \mathrm{E}-02$ & $7.2539 \mathrm{E}-04$ & $9.9453 \mathrm{E}-02$ & $7.2445 \mathrm{E}-04$ \\
\hline $\mathrm{BaO}$ & $2.5847 \mathrm{E}-07$ & $1.1210 \mathrm{E}-08$ & $2.5919 \mathrm{E}-07$ & $1.1157 \mathrm{E}-08$ \\
\hline $\mathrm{BeO}$ & $1.2236 \mathrm{E}-06$ & $2.8384 \mathrm{E}-08$ & $1.2356 \mathrm{E}-06$ & $2.8349 \mathrm{E}-08$ \\
\hline $\mathrm{Bi} 2 \mathrm{O} 3$ & $4.4129 \mathrm{E}-06$ & $1.6742 \mathrm{E}-07$ & $4.4083 \mathrm{E}-06$ & $1.7576 \mathrm{E}-07$ \\
\hline $\mathrm{CaO}$ & $2.9011 \mathrm{E}-02$ & $3.4698 \mathrm{E}-04$ & $2.8492 \mathrm{E}-02$ & $3.4140 \mathrm{E}-04$ \\
\hline $\mathrm{CdO}$ & $4.2937 \mathrm{E}-06$ & $5.9074 \mathrm{E}-07$ & $4.3022 \mathrm{E}-06$ & $5.9677 \mathrm{E}-07$ \\
\hline $\mathrm{Ce} 2 \mathrm{O} 3$ & $2.4914 \mathrm{E}-07$ & $1.6798 \mathrm{E}-08$ & $2.4860 \mathrm{E}-07$ & $1.6625 \mathrm{E}-08$ \\
\hline $\mathrm{Cl}$ & $1.3292 \mathrm{E}-03$ & $1.6680 \mathrm{E}-04$ & $1.3408 \mathrm{E}-03$ & $1.6885 \mathrm{E}-04$ \\
\hline $\mathrm{Cm} 2 \mathrm{O} 3$ & $9.6195 \mathrm{E}-14$ & $3.9052 \mathrm{E}-15$ & $9.6934 \mathrm{E}-14$ & $3.8902 \mathrm{E}-15$ \\
\hline $\mathrm{CoO}$ & $4.4360 \mathrm{E}-07$ & $2.9839 \mathrm{E}-08$ & $4.4810 \mathrm{E}-07$ & $3.0450 \mathrm{E}-08$ \\
\hline $\mathrm{Cr} 2 \mathrm{O} 3$ & $8.6126 \mathrm{E}-04$ & $2.8340 \mathrm{E}-05$ & $8.6122 \mathrm{E}-04$ & $2.8233 \mathrm{E}-05$ \\
\hline $\mathrm{Cs} 2 \mathrm{O}$ & $2.7260 \mathrm{E}-09$ & $1.7125 \mathrm{E}-10$ & $2.7438 \mathrm{E}-09$ & $1.7203 \mathrm{E}-10$ \\
\hline $\mathrm{CuO}$ & $8.1441 \mathrm{E}-07$ & $5.5070 \mathrm{E}-08$ & $8.2091 \mathrm{E}-07$ & $5.5109 \mathrm{E}-08$ \\
\hline $\mathrm{Eu} 2 \mathrm{O} 3$ & $3.1195 \mathrm{E}-11$ & $6.7517 \mathrm{E}-13$ & $3.1421 \mathrm{E}-11$ & $6.7438 \mathrm{E}-13$ \\
\hline $\mathrm{F}$ & $7.5395 \mathrm{E}-04$ & $6.1782 \mathrm{E}-05$ & $7.6445 \mathrm{E}-04$ & $6.2504 \mathrm{E}-05$ \\
\hline $\mathrm{Fe} 2 \mathrm{O} 3$ & $5.5174 \mathrm{E}-02$ & 4.2994E-04 & 5.5182E-02 & $4.2662 \mathrm{E}-04$ \\
\hline $\mathrm{Gd} 2 \mathrm{O} 3$ & $0.0000 \mathrm{E}+00$ & $0.0000 \mathrm{E}+00$ & $0.0000 \mathrm{E}+00$ & $0.0000 \mathrm{E}+00$ \\
\hline $\mathrm{HgO}$ & $0.0000 \mathrm{E}+00$ & $0.0000 \mathrm{E}+00$ & $0.0000 \mathrm{E}+00$ & $0.0000 \mathrm{E}+00$ \\
\hline $\mathrm{I}$ & $3.0867 \mathrm{E}-07$ & 4.8554E-08 & $3.1179 \mathrm{E}-07$ & $4.9280 \mathrm{E}-08$ \\
\hline $\mathrm{K} 2 \mathrm{O}$ & $1.3455 \mathrm{E}-02$ & $3.3878 \mathrm{E}-04$ & $1.3584 \mathrm{E}-02$ & 3.4094E-04 \\
\hline $\mathrm{La} 2 \mathrm{O} 3$ & $3.8107 \mathrm{E}-07$ & $1.2274 \mathrm{E}-08$ & 3.8314E-07 & $1.2332 \mathrm{E}-08$ \\
\hline $\mathrm{Li} 2 \mathrm{O}$ & $3.2768 \mathrm{E}-03$ & $2.7670 \mathrm{E}-05$ & $2.8425 \mathrm{E}-03$ & $2.7580 \mathrm{E}-05$ \\
\hline $\mathrm{MgO}$ & $1.4867 \mathrm{E}-02$ & $1.3234 \mathrm{E}-04$ & $1.4871 \mathrm{E}-02$ & $1.3027 \mathrm{E}-04$ \\
\hline $\mathrm{MnO}$ & $1.4259 \mathrm{E}-04$ & $1.5348 \mathrm{E}-05$ & $1.4154 \mathrm{E}-04$ & $1.5291 \mathrm{E}-05$ \\
\hline $\mathrm{MoO} 3$ & $1.2206 \mathrm{E}-05$ & $4.0822 \mathrm{E}-07$ & $1.2263 \mathrm{E}-05$ & 4.0999E-07 \\
\hline $\mathrm{Na} 2 \mathrm{O}$ & $1.8394 \mathrm{E}-01$ & $5.1260 \mathrm{E}-03$ & $1.8533 \mathrm{E}-01$ & $5.1083 \mathrm{E}-03$ \\
\hline $\mathrm{Nb} 2 \mathrm{O} 5$ & $8.3341 \mathrm{E}-09$ & $2.6933 \mathrm{E}-10$ & $8.5801 \mathrm{E}-09$ & $2.7462 \mathrm{E}-10$ \\
\hline $\mathrm{Nd} 2 \mathrm{O} 3$ & $1.1843 \mathrm{E}-06$ & $5.1378 \mathrm{E}-08$ & $1.1937 \mathrm{E}-06$ & $5.1858 \mathrm{E}-08$ \\
\hline $\mathrm{NiO}$ & $1.4190 \mathrm{E}-04$ & $7.7801 \mathrm{E}-06$ & $1.4230 \mathrm{E}-04$ & $7.8159 \mathrm{E}-06$ \\
\hline $\mathrm{NpO} 2$ & $1.1719 \mathrm{E}-07$ & $2.6984 \mathrm{E}-09$ & $1.1762 \mathrm{E}-07$ & $2.7010 \mathrm{E}-09$ \\
\hline $\mathrm{P} 2 \mathrm{O} 5$ & $1.9503 \mathrm{E}-03$ & $5.9577 \mathrm{E}-05$ & $1.9600 \mathrm{E}-03$ & $5.9579 \mathrm{E}-05$ \\
\hline $\mathrm{Pa} 2 \mathrm{O} 5$ & $2.6611 \mathrm{E}-10$ & $3.4933 \mathrm{E}-11$ & $2.6869 \mathrm{E}-10$ & $3.5179 \mathrm{E}-11$ \\
\hline $\mathrm{PbO}$ & $3.1368 \mathrm{E}-05$ & $1.3514 \mathrm{E}-06$ & $3.1727 \mathrm{E}-05$ & $1.3573 \mathrm{E}-06$ \\
\hline
\end{tabular}




\begin{tabular}{|c|c|c|c|c|}
\hline \multirow{2}{*}{$\begin{array}{c}\text { Canister } \\
\text { Comp }\end{array}$} & \multicolumn{2}{|c|}{ Canister- $A 501$} & \multicolumn{2}{|c|}{ בCanister-B501 } \\
\hline & $g_{i, A 501}^{\text {oxidein }}$ & $S_{i, A 501}^{\text {oxidein }}$ & $g_{i, B 501}^{\text {oxidein }}$ & $S_{i, B 501}^{\text {oxidein }}$ \\
\hline $\mathrm{PdO}$ & $7.2034 \mathrm{E}-06$ & $3.1064 \mathrm{E}-07$ & $7.2748 \mathrm{E}-06$ & $3.1521 \mathrm{E}-07$ \\
\hline Pr2O3 & $1.0322 \mathrm{E}-08$ & $4.4436 \mathrm{E}-10$ & $1.0420 \mathrm{E}-08$ & $4.5572 \mathrm{E}-10$ \\
\hline $\mathrm{PuO} 2$ & $8.6271 \mathrm{E}-09$ & $1.9720 \mathrm{E}-10$ & $8.6252 \mathrm{E}-09$ & $1.9725 \mathrm{E}-10$ \\
\hline $\mathrm{RaO}$ & $3.5087 \mathrm{E}-12$ & $4.1045 \mathrm{E}-13$ & $3.5429 \mathrm{E}-12$ & $4.1531 \mathrm{E}-13$ \\
\hline $\mathrm{Rb} 2 \mathrm{O}$ & $1.4284 \mathrm{E}-06$ & $9.7181 \mathrm{E}-08$ & $1.4422 \mathrm{E}-06$ & $9.8079 \mathrm{E}-08$ \\
\hline $\mathrm{Rh} 2 \mathrm{O} 3$ & $3.2300 \mathrm{E}-06$ & 7.4843E-08 & $3.2628 \mathrm{E}-06$ & $7.4920 \mathrm{E}-08$ \\
\hline $\mathrm{RuO} 2$ & $1.5279 \mathrm{E}-05$ & $3.7936 \mathrm{E}-07$ & $1.5453 \mathrm{E}-05$ & $3.8069 \mathrm{E}-07$ \\
\hline SO3 & $3.0764 \mathrm{E}-03$ & $1.4671 \mathrm{E}-04$ & $3.0794 \mathrm{E}-03$ & $1.4718 \mathrm{E}-04$ \\
\hline $\mathrm{Sb} 2 \mathrm{O} 3$ & $2.6523 \mathrm{E}-07$ & $3.1000 \mathrm{E}-08$ & $2.6529 \mathrm{E}-07$ & $3.1142 \mathrm{E}-08$ \\
\hline $\mathrm{SeO} 2$ & $2.1375 \mathrm{E}-06$ & $2.4905 \mathrm{E}-07$ & 2.1492 E-06 & $2.5179 \mathrm{E}-07$ \\
\hline $\mathrm{SiO} 2$ & $4.5186 \mathrm{E}-01$ & $3.1904 \mathrm{E}-03$ & $4.5123 \mathrm{E}-01$ & $3.1694 \mathrm{E}-03$ \\
\hline $\mathrm{Sm} 2 \mathrm{O} 3$ & $6.8520 \mathrm{E}-08$ & $3.8034 \mathrm{E}-09$ & $6.8750 \mathrm{E}-08$ & $3.8067 \mathrm{E}-09$ \\
\hline $\mathrm{SnO} 2$ & $6.0563 \mathrm{E}-08$ & $2.6412 \mathrm{E}-09$ & $6.0942 \mathrm{E}-08$ & $2.6088 \mathrm{E}-09$ \\
\hline $\mathrm{SrO}$ & $1.3040 \mathrm{E}-07$ & $3.0325 \mathrm{E}-09$ & $1.3035 \mathrm{E}-07$ & $3.0178 \mathrm{E}-09$ \\
\hline Ta2O5 & 4.2542E-08 & $1.8486 \mathrm{E}-09$ & $4.2965 \mathrm{E}-08$ & $1.8618 \mathrm{E}-09$ \\
\hline Tc2O7 & $2.0510 \mathrm{E}-06$ & $3.1509 \mathrm{E}-07$ & $2.0595 \mathrm{E}-06$ & $3.1741 \mathrm{E}-07$ \\
\hline $\mathrm{TeO} 2$ & $1.0220 \mathrm{E}-07$ & $1.1941 \mathrm{E}-08$ & $1.0324 \mathrm{E}-07$ & $1.2142 \mathrm{E}-08$ \\
\hline ThO2 & $4.0771 \mathrm{E}-06$ & $2.7557 \mathrm{E}-07$ & $4.0830 \mathrm{E}-06$ & $2.7580 \mathrm{E}-07$ \\
\hline $\mathrm{TiO} 2$ & $1.4033 \mathrm{E}-02$ & $1.2383 \mathrm{E}-04$ & $1.4035 \mathrm{E}-02$ & $1.2085 \mathrm{E}-04$ \\
\hline $\mathrm{T} 12 \mathrm{O}$ & $7.3309 \mathrm{E}-07$ & $7.3726 \mathrm{E}-08$ & $7.3046 \mathrm{E}-07$ & $7.3822 \mathrm{E}-08$ \\
\hline UO3 & $5.8464 \mathrm{E}-05$ & $1.9327 \mathrm{E}-06$ & 5.8712E-05 & $1.9627 \mathrm{E}-06$ \\
\hline V2O5 & $5.9802 \mathrm{E}-05$ & $8.7013 \mathrm{E}-06$ & $5.9827 \mathrm{E}-05$ & $8.7866 \mathrm{E}-06$ \\
\hline WO3 & $1.2019 \mathrm{E}-05$ & $2.7741 \mathrm{E}-07$ & $1.2135 \mathrm{E}-05$ & $2.7847 \mathrm{E}-07$ \\
\hline Y2O3 & $6.6051 \mathrm{E}-07$ & 4.4754E-08 & $6.6695 \mathrm{E}-07$ & $4.5200 \mathrm{E}-08$ \\
\hline $\mathrm{ZnO}$ & $3.5079 \mathrm{E}-02$ & $2.5230 \mathrm{E}-04$ & $3.5091 \mathrm{E}-02$ & $2.4900 \mathrm{E}-04$ \\
\hline $\mathrm{ZrO} 2$ & $3.0136 \mathrm{E}-02$ & $2.2882 \mathrm{E}-04$ & $3.0139 \mathrm{E}-02$ & $2.2709 \mathrm{E}-04$ \\
\hline SUM & $1.0000 \mathrm{E}+00$ & NA & $1.0000 \mathrm{E}+00$ & NA \\
\hline
\end{tabular}

The waste form composition is documented during production by reporting the $g_{i e}^{\substack{\text { oxidein } \\ \text { can }}}$ values from Equation (123) in the Production Records. Currently, it is planned to calculate $g_{i e}^{\text {caidein }}$ values for all components $(i)$ for which analytical data are available for a particular container. However, it may be advantageous to trim the number of components to only those with concentrations greater than $0.5 \mathrm{wt} \%$ plus those associated with other limits and specifications. In any case, only the appropriate subset of $i$ will be reported in the Production Records.

The addition of optional filler material and production of the final ILAW container data package are not part of the ILAW formulation algorithm.

\subsubsection{Specification 2.2.2.7—Radiological Composition Documentation}

The specific activity of radionuclides in each canister is calculated using Equation (125) and its SD using Equation (126): 


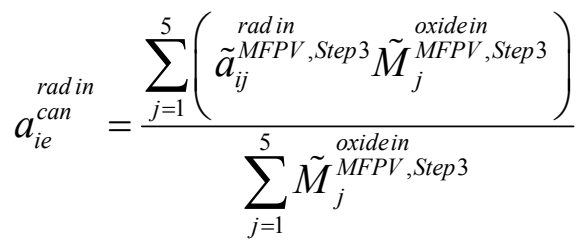

$$
\begin{aligned}
& S_{i e}^{\text {rad in }}=\frac{\left.\sqrt{\sum_{j=1}^{5}\left(\tilde{S}_{i j}^{\text {radin }}{ }^{M F P V, \text { Step } 3} \tilde{M}_{j}^{\text {MFPV }, \text { Step } 3}\right)^{\text {oxidein }}}\right)^{2}}{\sum_{j}^{5} \tilde{M}_{j}^{\text {oxidein }} \text { MFP Step } 3}
\end{aligned}
$$

The $a_{i e}^{\text {radin }}$ and $s_{i e}^{\text {radin }}$ can values are given Table B-9 and $\tilde{M}_{j}^{\text {oxidein }}{ }^{M F P V \text { Step } 3}$ values are in Table B-8. The results of above calculations for the $A 501^{\text {th }}$ and $B 501^{\text {th }}$ Canisters are listed in Table 37.

Table 37. Specific Activities of Radionuclides in the $\boldsymbol{A 5 0 1}^{\text {th }}$ and $B 501^{\text {th }}$ Canisters

\begin{tabular}{|c|c|c|c|c||}
\hline Canister & \multicolumn{2}{|c|}{ Canister-A501 } & \multicolumn{2}{c||}{ Canister-B501 } \\
\hline Comp & $\begin{array}{c}\text { rad in } \\
a_{i, A 501}^{\text {can }}\end{array}$ & $\begin{array}{c}\text { rad } \\
\text { can } \\
\text { Cad }\end{array}$ & $\begin{array}{c}\text { rad in } \\
a_{i, B 5}^{\text {can }}\end{array}$ & $S_{i, B 501}^{\text {can }}$ \\
\hline Unit & mCi/g glass & mCi/g glass & mCi/g glass & mCi/g glass \\
\hline $59 \mathrm{Ni}$ & $3.3472 \mathrm{E}-07$ & $1.0736 \mathrm{E}-08$ & $3.3777 \mathrm{E}-07$ & $1.0848 \mathrm{E}-08$ \\
\hline $60 \mathrm{Co}$ & $5.3639 \mathrm{E}-07$ & $1.2425 \mathrm{E}-08$ & $5.3858 \mathrm{E}-07$ & $1.2392 \mathrm{E}-08$ \\
\hline $63 \mathrm{Ni}$ & $3.0508 \mathrm{E}-05$ & $9.8276 \mathrm{E}-07$ & $3.0785 \mathrm{E}-05$ & $9.9130 \mathrm{E}-07$ \\
\hline $79 \mathrm{Se}$ & $9.9416 \mathrm{E}-07$ & $9.9396 \mathrm{E}-08$ & $9.9679 \mathrm{E}-07$ & $9.9626 \mathrm{E}-08$ \\
\hline $90 \mathrm{Sr}$ & $5.4680 \mathrm{E}-04$ & $1.2710 \mathrm{E}-05$ & $5.5065 \mathrm{E}-04$ & $1.2632 \mathrm{E}-05$ \\
\hline $90 \mathrm{Y}$ & $5.2940 \mathrm{E}-04$ & $1.2267 \mathrm{E}-05$ & $5.3313 \mathrm{E}-04$ & $1.2272 \mathrm{E}-05$ \\
\hline $93 \mathrm{mNb}$ & $1.3901 \mathrm{E}-03$ & $4.4922 \mathrm{E}-05$ & $1.4311 \mathrm{E}-03$ & $4.5802 \mathrm{E}-05$ \\
\hline $93 \mathrm{Zr}$ & $8.1602 \mathrm{E}-06$ & $2.6273 \mathrm{E}-07$ & $8.2091 \mathrm{E}-06$ & $2.6361 \mathrm{E}-07$ \\
\hline $99 \mathrm{Tc}$ & $2.2407 \mathrm{E}-05$ & $3.4423 \mathrm{E}-06$ & $2.2500 \mathrm{E}-05$ & $3.4676 \mathrm{E}-06$ \\
\hline $106 \mathrm{Ru}$ & $4.7546 \mathrm{E}-10$ & $2.1079 \mathrm{E}-11$ & $4.7403 \mathrm{E}-10$ & $2.0994 \mathrm{E}-11$ \\
\hline $113 \mathrm{mCd}$ & $6.0358 \mathrm{E}-06$ & $1.9477 \mathrm{E}-07$ & $6.0562 \mathrm{E}-06$ & $1.9595 \mathrm{E}-07$ \\
\hline $125 \mathrm{Sb}$ & $1.1587 \mathrm{E}-06$ & $1.1275 \mathrm{E}-07$ & $1.1552 \mathrm{E}-06$ & $1.1337 \mathrm{E}-07$ \\
\hline $126 \mathrm{Sn}$ & $1.3712 \mathrm{E}-06$ & $5.9796 \mathrm{E}-08$ & $1.3797 \mathrm{E}-06$ & $5.9064 \mathrm{E}-08$ \\
\hline $129 \mathrm{I}$ & $5.4573 \mathrm{E}-08$ & $8.5840 \mathrm{E}-09$ & $5.5124 \mathrm{E}-08$ & $8.7124 \mathrm{E}-09$ \\
\hline $134 \mathrm{Cs}$ & $2.1221 \mathrm{E}-10$ & $1.7332 \mathrm{E}-11$ & $2.1315 \mathrm{E}-10$ & $1.7270 \mathrm{E}-11$ \\
\hline $137 \mathrm{mBa}$ & $8.7747 \mathrm{E}-02$ & $2.0433 \mathrm{E}-03$ & $8.8181 \mathrm{E}-02$ & $2.0330 \mathrm{E}-03$ \\
\hline $137 \mathrm{Cs}$ & $4.4909 \mathrm{E}-05$ & $2.2913 \mathrm{E}-06$ & $4.5169 \mathrm{E}-05$ & $2.2978 \mathrm{E}-06$ \\
\hline $151 \mathrm{Sm}$ & $1.5561 \mathrm{E}-03$ & $8.6375 \mathrm{E}-05$ & $1.5614 \mathrm{E}-03$ & $8.6452 \mathrm{E}-05$ \\
\hline $152 \mathrm{Eu}$ & $2.6729 \mathrm{E}-07$ & $6.2017 \mathrm{E}-09$ & $2.6774 \mathrm{E}-07$ & $6.1346 \mathrm{E}-09$ \\
\hline $154 \mathrm{Eu}$ & $5.4817 \mathrm{E}-06$ & $1.2746 \mathrm{E}-07$ & $5.5288 \mathrm{E}-06$ & $1.2759 \mathrm{E}-07$ \\
\hline $155 \mathrm{Eu}$ & $2.4642 \mathrm{E}-06$ & $5.7108 \mathrm{E}-08$ & $2.4731 \mathrm{E}-06$ & $5.7128 \mathrm{E}-08$ \\
\hline $226 \mathrm{Ra}$ & $3.2344 \mathrm{E}-09$ & $3.7852 \mathrm{E}-10$ & $3.2659 \mathrm{E}-09$ & $3.8302 \mathrm{E}-10$ \\
\hline $227 \mathrm{Ac}$ & $3.8837 \mathrm{E}-09$ & $1.2425 \mathrm{E}-10$ & $3.9219 \mathrm{E}-09$ & $1.2690 \mathrm{E}-10$ \\
\hline $228 \mathrm{Ra}$ & $1.2977 \mathrm{E}-09$ & $2.1289 \mathrm{E}-10$ & $1.2991 \mathrm{E}-09$ & $2.1196 \mathrm{E}-10$ \\
\hline $229 \mathrm{Th}$ & $1.8629 \mathrm{E}-10$ & $2.4561 \mathrm{E}-11$ & $1.8562 \mathrm{E}-10$ & $2.4442 \mathrm{E}-11$ \\
\hline $231 \mathrm{~Pa}$ & $1.0714 \mathrm{E}-08$ & $1.4064 \mathrm{E}-09$ & $1.0817 \mathrm{E}-08$ & $1.4163 \mathrm{E}-09$ \\
\hline $232 \mathrm{Th}$ & $3.9270 \mathrm{E}-10$ & $1.2706 \mathrm{E}-11$ & $3.9326 \mathrm{E}-10$ & $1.2679 \mathrm{E}-11$ \\
\hline
\end{tabular}




\begin{tabular}{||c|c|c|c|c||}
\hline \hline Canister & \multicolumn{2}{|c|}{ Canister-A501 } & \multicolumn{2}{c|}{ Canister-B501 } \\
\hline \multirow{2}{*}{ Comp } & $\begin{array}{c}\text { radin } \\
a_{i, A 501}^{\text {can }}\end{array}$ & $\begin{array}{c}\text { radin } \\
S_{i, A 501}^{\text {can }}\end{array}$ & $\begin{array}{c}\text { radin } \\
a_{i, B 501}^{\text {can }}\end{array}$ & $\begin{array}{c}\text { rad in } \\
{ }_{i, B 501}\end{array}$ \\
\hline $232 \mathrm{U}$ & $5.2612 \mathrm{E}-10$ & $1.2171 \mathrm{E}-11$ & $5.2662 \mathrm{E}-10$ & $1.2163 \mathrm{E}-11$ \\
\hline $233 \mathrm{U}$ & $2.4604 \mathrm{E}-08$ & $5.7071 \mathrm{E}-10$ & $2.4719 \mathrm{E}-08$ & $5.7249 \mathrm{E}-10$ \\
\hline $234 \mathrm{U}$ & $1.4153 \mathrm{E}-08$ & $3.2624 \mathrm{E}-10$ & $1.4250 \mathrm{E}-08$ & $3.2647 \mathrm{E}-10$ \\
\hline $235 \mathrm{U}$ & $5.3477 \mathrm{E}-10$ & $1.7169 \mathrm{E}-11$ & $5.3831 \mathrm{E}-10$ & $1.7253 \mathrm{E}-11$ \\
\hline $236 \mathrm{U}$ & $9.8127 \mathrm{E}-10$ & $2.2759 \mathrm{E}-11$ & $9.8869 \mathrm{E}-10$ & $2.2862 \mathrm{E}-11$ \\
\hline $237 \mathrm{~Np}$ & $7.2759 \mathrm{E}-08$ & $1.6754 \mathrm{E}-09$ & $7.3028 \mathrm{E}-08$ & $1.6770 \mathrm{E}-09$ \\
\hline $238 \mathrm{Pu}$ & $3.7893 \mathrm{E}-08$ & $8.7870 \mathrm{E}-10$ & $3.7946 \mathrm{E}-08$ & $8.7215 \mathrm{E}-10$ \\
\hline $238 \mathrm{U}$ & $1.0577 \mathrm{E}-08$ & $3.4113 \mathrm{E}-10$ & $1.0646 \mathrm{E}-08$ & $3.4241 \mathrm{E}-10$ \\
\hline $239 \mathrm{Pu}$ & $4.4142 \mathrm{E}-07$ & $1.0291 \mathrm{E}-08$ & $4.4133 \mathrm{E}-07$ & $1.0285 \mathrm{E}-08$ \\
\hline $240 \mathrm{Pu}$ & $1.0764 \mathrm{E}-07$ & $3.4720 \mathrm{E}-09$ & $1.0759 \mathrm{E}-07$ & $3.4945 \mathrm{E}-09$ \\
\hline $241 \mathrm{Am}$ & $5.3429 \mathrm{E}-07$ & $1.8087 \mathrm{E}-08$ & $5.3326 \mathrm{E}-07$ & $1.7799 \mathrm{E}-08$ \\
\hline $241 \mathrm{Pu}$ & $1.2268 \mathrm{E}-06$ & $5.3282 \mathrm{E}-08$ & $1.2250 \mathrm{E}-06$ & $5.2798 \mathrm{E}-08$ \\
\hline $242 \mathrm{Cm}$ & $2.7044 \mathrm{E}-09$ & $8.6873 \mathrm{E}-11$ & $2.7068 \mathrm{E}-09$ & $8.6997 \mathrm{E}-11$ \\
\hline $242 \mathrm{Pu}$ & $1.1876 \mathrm{E}-11$ & $3.8190 \mathrm{E}-13$ & $1.1873 \mathrm{E}-11$ & $3.7935 \mathrm{E}-13$ \\
\hline $243 \mathrm{Am}$ & $8.6297 \mathrm{E}-11$ & $3.7908 \mathrm{E}-12$ & $8.6537 \mathrm{E}-11$ & $3.8211 \mathrm{E}-12$ \\
\hline $243 \mathrm{Cm}$ & $3.1863 \mathrm{E}-10$ & $1.3825 \mathrm{E}-11$ & $3.2100 \mathrm{E}-10$ & $1.3892 \mathrm{E}-11$ \\
\hline $244 \mathrm{Cm}$ & $6.4958 \mathrm{E}-09$ & $2.8185 \mathrm{E}-10$ & $6.5463 \mathrm{E}-09$ & $2.8067 \mathrm{E}-10$ \\
\hline$T R U$ & $1.2009 \mathrm{E}-06$ & $2.1183 \mathrm{E}-08$ & $1.2001 \mathrm{E}-06$ & $2.0939 \mathrm{E}-08$ \\
\hline \hline
\end{tabular}

\subsubsection{Specification 2.2.2.8 - Radionuclide Concentration Limitations}

The specific activity data given in Table 37 are used to calculate the quantities for radionuclide concentration limitations. For those radionuclides with limits expressed in $\mathrm{Ci} / \mathrm{m}^{3}$ unit, the specific activities and their SD's are converted to the activities per unit glass volume using Equations (128) and (129). The sum of fractions of activity values are calculated using Equations (130) and (131) based on the Class C limits for each radionuclide given in Table 15 and Table 16. The $k^{\text {rad }}$ was assumed to be 2, which represents $95.45 \%$ confidence level. The results of these calculations are summarized in Table 38.

Table 38. Results of Calculating the Quantities for Radionuclide Concentration Limitations in the $A 501^{\text {th }}$ and $B 501^{\text {th }}$ Canisters

\begin{tabular}{|c|c|c|}
\hline Constraint & 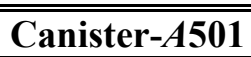 & בCanister-B501 \\
\hline 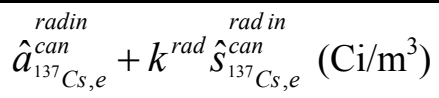 & 0.1351 & 0.1359 \\
\hline 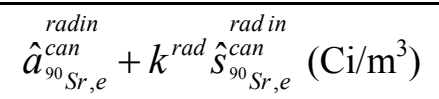 & 1.5621 & 1.5722 \\
\hline $\begin{array}{c}\text { rad in } \\
S F_{L L, e}^{\text {can }}+k^{\text {rad }} S_{L L, e}^{\text {cadSF in }} \\
\text { can }\end{array}$ & 0.04092 & 0.04106 \\
\hline $\begin{array}{c}\text { rad in } \\
S F_{S L, e}^{\text {can }}+k^{\text {rad }} S_{S L, e}^{\text {radSF in }} \\
\text { can }\end{array}$ & 0.00037 & 0.00037 \\
\hline
\end{tabular}

\subsubsection{Specification 2.2.2.9-Surface Dose Rate Limitations}

As mentioned in Section 5.5.5, the surface dose rate calculation is not performed but the measured dose rate will be included in the production records. 


\subsubsection{Specification 2.2.2.17-Waste form Testing}

The glass composition and its SD values given in Table 36 are used to calculate the predicted PCT and VHT responses and uncertainties. The results of calculations described in Section 5.5.6 are summarized in Table 39.

Table 39. Summary of PCT and VHT Results for the ILAW in the $A 501^{\text {th }}$ and $B 501^{\text {th }}$ Canisters

\begin{tabular}{||l|c|c|c|c||}
\hline \hline Property & $\boldsymbol{P}^{\text {prop }}$ & $U_{\text {pred }}^{\text {prop }}$ & $U_{\text {comp }}^{\text {prop }}$ & $B_{\text {ucci,lcci }}^{\text {prop }}$ \\
\hline \multicolumn{5}{|c||}{ Canister-A501 } \\
\hline $\ln \left(r_{B}\right)$ & -0.0263 & 0.1469 & 0.1289 & 0.2495 \\
\hline $\ln \left(r_{N a}\right)$ & -0.1087 & 0.1567 & 0.1093 & 0.1573 \\
\hline $\ln (D)$ & 2.3468 & 0.6200 & 0.4598 & 3.4266 \\
\hline \multicolumn{5}{|c|}{ Canister-B501 } \\
\hline $\ln \left(r_{B}\right)$ & -0.0134 & 0.1478 & 0.1268 & 0.2630 \\
\hline $\ln \left(r_{N a}\right)$ & -0.0996 & 0.1583 & 0.1086 & 0.1672 \\
\hline $\ln (D)$ & 2.3706 & 0.6246 & 0.4833 & 3.4785 \\
\hline
\end{tabular}

\subsubsection{Specification 2.2.2.17- Manifesting}

The data required for manifesting of the glass composition and radionuclide concentrations were all demonstrated above. Those required elements will be included in the waste manifest that accompanies the Production Records. 


\section{Summary and Recommendations}

This report documents the current ILAW formulation algorithm. The algorithm is still preliminary; a number of WTP plant performance assumptions (e.g. analytical uncertainty, see Appendix C) were made because of a lack of data. These assumptions need to be updated as data become available. The equations required to meet the entire product compliance-related constraints, along with a few key processing constraints, are described in some detail. Additional detail is available in Piepel et al. (2005) for equations that were used or adapted from that document. The inputs to the equations are values measured during processing of waste at WTP and values obtained through design, research, and testing before production. Preliminary values for the constants currently available are documented in Appendix A. A detailed example is followed through most of the equations, with the results described in the text and tabulated in Appendix B. A summary of data requirements for this algorithm to be complete is included in Appendix C.

It is recommended that the approach and equations described in this document be used to calculate 1) target glass compositions, 2) LAW transfers to the MFPV, 3) GFC mass additions to the MFPV, 4) resulting glass compositions, 5) glass properties, and 6) uncertainties in glass composition and properties until it is updated with plant performance data or changes to the processing and/or qualification approach. It is further recommended that those values listed as preliminary or described as a value to be updated be tracked and updated when possible. This document will be updated as needed, as new data are available or changes to approaches/constraints are made.

This set of equations will make a suitable starting point for the development of plant control and waste form compliance software. In addition, sufficient data to perform an initial check of any to-be-developed software are included in Appendix B. 


\section{References}

\subsection{Project Documents}

24590-BOF-3YD-GFR-00001, Rev 0. System Description for the WTP Glass Formers Reagent System (GFR).

24590-HLW-RPT-RT-05-001, Rev. 0, Preliminary IHLW Formulation Algorithm Description.

24590-LAW-3PS-AE00-T00001, Rev. 4, Engineering Specification for Low Activity Waste Melters.

24590-LAW-3YD-LCP-00001, Rev. 2, System Description for the LAW Concentrate Receipt Process $(L C P)$.

24590-LAW-3 YD-LFP-00001, Rev. 2, System Description for the Low-Activity Waste Melter Feed Process System (LFP).

24590-LAW-M0D-LMP-00002, Rev. 1, Data Sheet Low Activity Waste Melter 2.

24590-LAW-M4C-20-00002, Rev. 0, LAW LCP and LFP Batch Volumes (LCP-VSL-00001,-00002, LFPVSL-00001, -00002, -00003, -00004).

24590-LAW-M4C-LFP-00002, Rev. B WTP Calculation Sheet: Determining the LAW Glass Former Constituents and Amounts for G2 and ACM Models.

24590-LAW-M6C-LCP-00001, Rev. 1, Concentrate Receipt Vessels LCP-VSL-00001/00002 Sizing.

24590-LAW-M6C-LFP-00001, Rev. 1, LFP-VSL-00001 and LFP-VSL-00003 Sizing.

24590-LAW-M6C-LFP-00002, Rev. 1, LFP-VSL-00002 and LFP-VSL-00004 Sizing.

24590-LAW-RPT-RT-10-001, Rev. 0, Component Partitioning between Glass and Offgas Streams in Low-Activity Waste Melters.

24590-LAW-RPT-RT-11-001, Rev. 0, Evaluation of Mixing, Sampling, and Level Uncertainties for ILAW Glass Qualification.

24590-WTP-3PS-JL10-T0002, Rev 0, Engineering Specification for Radar Level Measurement.

24590-WTP-3YD-50-00002, Rev. 0, WTP Integrated Process Strategy Description.

24590-WTP-MDD-PR-01-002, Rev. 9, Dynamic (G2) Model Model Design Document.

24590-WTP-MRQ-PO-03-033, Rev. 0, Update RAM Data for the LMP System, Appendix A.

24590-WTP-PL-PR-04-0001, Rev. 2, Integrated Sampling and Analysis Requirements Document.

24590-WTP-PL-RT-03-001, Rev. 4, ILAW Product Compliance Plan.

24590-WTP-RPT-ENV-03-003, Rev. 1, Land Disposal Restriction Treatability Variance Petition for Hanford Tank Waste.

24590-WTP-RPT-PO-07-002, Rev. 0, Dynamic (G2) Flowsheet Assessment of the Effect of M-12 Modifications on Pretreatment Capacity.

CCN 111456. Memorandum, David Dodd/Bruce Kaiser to JD Vienna: Estimated Analytical Measurement Uncertainties for Selected Analytes.

CCN 116150. Memorandum, JM Perez to JD Vienna: LAW Melter Feed Property Correlations. 16 March 2005. 
CCN 132102. Memorandum, David Dodd/Bruce Kaiser to JD Vienna: Estimated Analytical Measurements Uncertainties of Selected HLW Analytes.

CCN 150795. Memorandum, JD Vienna to L Petkus: Halide, Chromate, and Phosphate Impacts on LAW Glass Salt Limits.

\subsection{Codes and Standards}

10 CFR 61.55, Licensing Requirements for Land Disposal of Radioactive Waste, Waste Classification. Code of Federal Regulations, as amended.

49 CFR 172.101, Purpose and Use of Hazardous Materials Table. Code of Federal Regulations, as amended.

\subsection{Other Documents}

Andre, L. 2004. Prototypic LAW Container and HLW Canister Glass Fill Test Results Report. TRR-PLT080, Rev. 0, Duratek, Inc., Columbia, MD.

ASTM. 2002. Standard Test Methods for Determining Chemical Durability of Nuclear, Hazardous, and Mixed Waste Glasses and Multiphase Glass Ceramics: The Product Consistency Test (PCT). ASTM C 1285-02, American Society for Testing and Materials, West Conshohocken, PA.

Deiner, G, M Brandys, TB Edwards, DS Dickey, KS Matlack, and IL Pegg. 2006. Test Plan: Pretreated Waste and Melter Feed Composition Variability Testing Using HLW and LAW Simulants, VSL06T1000-1. River Protection Project, Waste Treatment Plant, Richland, WA. 24590-101-TSA-W0000009-176-00001, Rev 00B.

DOE. 2000. Contract DE-AC27-01RV14136, as amended, U.S. Department of Energy, Richland, WA.

Eibling, RE, RF Schumacher, and EK Hansen. 2003. Development of Simulants To Support Mixing Tests for High Level Waste and Low Activity Waste, WSRC-TR-2003-00220, Rev. 0, Westinghouse Savannah River Company, Aiken, SC.

Matlack, KS, W Gong, and IL Pegg. 2003a. DuraMelter 100 Sub-Envelope Changeover Testing Using LAW Sub-Envelopes A1 and C1Feeds in Support of the LAW Pilot Melter, VSL-02R62N0-6, Rev. 0, Vitreous State Laboratory, The Catholic University of America, Washington, DC. 24590-101-TSAW000-0009-106-07, Rev. 00C.

Matlack, KS, W Gong, and IL Pegg. 2003b. DuraMelter 100 Sub-Envelope Changeover Testing Using LAW Sub-Envelope A2 and B1Feeds in Support of the LAW Pilot Melter, VSL-03R3410-1, Rev. 0, Vitreous State Laboratory, The Catholic University of America, Washington, DC. 24590-101-TSAW000-0009-144-04, Rev. 00A

Matlack, KS, W Gong, and IL Pegg. 2003c. Compositional Variation Tests on DuraMelter 100 with LAW Sub-Envelope B2Feed in Support of the LAW Pilot Melter, VSL-03R3410-2, Rev. 0, Vitreous State Laboratory, The Catholic University of America, Washington, DC. 24590-101-TSA-W000-0009-13504, Rev. 00B

Matlack, KS, W Gong, and IL Pegg. 2003d. DuraMelter 100 Sub-Envelope Changeover Testing Using LAW Sub-Envelope A3 and C2 Feeds in Support of the LAW Pilot Melter, VSL-03R3410-3, Rev. 0, Vitreous State Laboratory, The Catholic University of America, Washington, DC. 24590-101-TSAW000-0009-106-17, Rev. 00B.

Matlack, KS, W Gong, T Bardakci, N D’Angelo, M Brandys, WK Kot, and IL Pegg. 2005. Regulatory OffGas Emissions Testing on the DM1200 Melter System Using HLW and LAW Simulants, VSL-05R5830- 
1, Rev. 0, Vitreous State Laboratory, The Catholic University of America, Washington, D.C. - 24590101-TSA-W000-0009-166-00001.

Muller, IS, G Diener, I Joseph, and IL Pegg. 2004. Proposed Approach for Development of LAW Glass Formulation Correlation. VSL-04L4460-1, Rev. 0, Vitreous State Laboratory, The Catholic University of America, Washington, DC.

Muller, IS, H Gan, AC Buechele, and IL Pegg. 2002. Enhanced K-3 Refractory Corrosion with LAW AZ102 Glass Formulations, VSL-02S4600-1, Rev. 0, Vitreous State Laboratory, The Catholic University of America, Washington, DC.

Muller, IS, H Gan, IL Pegg, SK Cooley, and GF Piepel. 2005. Phase I ILAW PCT and VHT Model Development. VSL-04R4480-2, Rev. 0, Vitreous State Laboratory, The Catholic University of America, Washington, DC.

Piepel, GF, BG Amidan, A Heredia-Langner, DR Weier, and SK Cooley. 2005. Statistical Methods and Results for WTP IHLW and ILAW Compliance. WTP-RPT-072, Rev. 0, Battelle-Pacific Northwest Division, Richland, WA.

Piepel GF, Cooley SK, Muller I, Gan H, Joseph I, and Pegg IL. 2007. ILAW PCT, VHT, Viscosity and Electrical Conductivity Model Development. VSL-07R1230-1, Rev 0, Vitreous State laboratory, Catholic University of America, Washington DC.

Poloski, A, H Smith, G Smith, and T Calloway. 2004. Technical Basis for LAW Vitrification Stream Physical and Rheological Property Bounding Conditions. PNWD-3398, WTP-RPT-098, Rev. 0, Battelle-Pacific Northwest Division, Richland, WA.

Schumacher, RF. 2003. Characterization of HLW and LAW Glass Formers - Final Report, WSRC-TR2002-00282, Rev. 1 (SRT-RPP-2002-00146. Rev. 1), Westinghouse Savannah River Company, Aiken, $\mathrm{SC}$.

Schumacher, RF, EK Hansen, TM Jones, and JE Josephs. 2003. Evaluation of Wetting Agents to Mitigate Dusting of Glass Forming Chemicals During Delivery to the Melter Feed Preparation Vessel, WSRCTR-2003-00209, Rev. 0, Westinghouse Savannah River Company, Aiken, SC. 


\section{Appendix A-Inputs Used in Calculations}


Table A-1. Oxide Conversion Factors $\left(f_{i}\right)$ for Chemical Elements and Radionuclides and Specific Activities $\left(\boldsymbol{A}_{i}\right)$ for Radionuclides

\begin{tabular}{|c|c|c|c|c|c|c|}
\hline Element & Glass oxide & $f_{i}$ & Radionuclide & Glass oxide & $f_{i}$ & $A_{i}, \mathrm{Ci} / \mathrm{g}$ \\
\hline Ac & $\mathrm{Ac} 2 \mathrm{O} 3$ & NA & $59 \mathrm{Ni}$ & $59 \mathrm{NiO}$ & 1.2714800 & 7.982E-02 \\
\hline $\mathrm{Ag}$ & $\mathrm{Ag} 2 \mathrm{O}$ & 1.0741618 & $60 \mathrm{Co}$ & $60 \mathrm{CoO}$ & 1.2669102 & $1.131 \mathrm{E}+03$ \\
\hline $\mathrm{Al}$ & $\mathrm{Al} 2 \mathrm{O} 3$ & 1.8894637 & $63 \mathrm{Ni}$ & $63 \mathrm{NiO}$ & 1.2542412 & $5.738 \mathrm{E}+01$ \\
\hline $\mathrm{Am}$ & $\mathrm{Am} 2 \mathrm{O} 3$ & NA & $79 \mathrm{Se}$ & $79 \mathrm{SeO} 2$ & 1.4054638 & $6.969 \mathrm{E}-02$ \\
\hline As & As2O5 & 1.5338715 & $90 \mathrm{Sr}$ & $90 \mathrm{SrO}$ & 1.1779550 & $1.388 \mathrm{E}+02$ \\
\hline $\mathrm{B}$ & $\mathrm{B} 2 \mathrm{O} 3$ & 3.2198779 & $90 \mathrm{Y}$ & $90 \mathrm{Y} 2 \mathrm{O} 3$ & 1.2669393 & $5.437 \mathrm{E}+05$ \\
\hline $\mathrm{Ba}$ & $\mathrm{BaO}$ & 1.1165059 & $93 \mathrm{mNb}$ & $93 \mathrm{mNb} 2 \mathrm{O} 5$ & 1.4305248 & $2.386 \mathrm{E}+02$ \\
\hline $\mathrm{Be}$ & $\mathrm{BeO}$ & 2.7753081 & $93 \mathrm{Zr}$ & 93ZrO2 & 1.3444224 & $2.515 \mathrm{E}-03$ \\
\hline $\mathrm{Bi}$ & $\mathrm{Bi} 2 \mathrm{O} 3$ & 1.1148390 & 99Tc & $99 \mathrm{Tc} 2 \mathrm{O} 7$ & 1.5661615 & $1.711 \mathrm{E}-02$ \\
\hline $\mathrm{Ca}$ & $\mathrm{CaO}$ & 1.3992065 & $106 \mathrm{Ru}$ & $106 \mathrm{RuO} 2$ & 1.3018755 & $3.349 \mathrm{E}+03$ \\
\hline $\mathrm{Cd}$ & $\mathrm{CdO}$ & 1.1423295 & $113 \mathrm{mCd}$ & $113 \mathrm{mCdO}$ & 1.1417075 & $2.311 \mathrm{E}+02$ \\
\hline $\mathrm{Ce}$ & $\mathrm{Ce} 2 \mathrm{O} 3$ & 1.1712814 & $125 \mathrm{Sb}$ & $125 \mathrm{Sb} 2 \mathrm{O} 3$ & 1.1919928 & $1.037 \mathrm{E}+03$ \\
\hline $\mathrm{Cl}$ & $\mathrm{Cl}$ & 1.0000000 & $126 \mathrm{Sn}$ & $126 \mathrm{SnO} 2$ & 1.2539587 & $2.839 \mathrm{E}-02$ \\
\hline $\mathrm{Cm}$ & $\mathrm{Cm} 2 \mathrm{O} 3$ & NA & $129 \mathrm{I}$ & $129 \mathrm{I}$ & 1.0000000 & $1.768 \mathrm{E}-04$ \\
\hline Co & $\mathrm{CoO}$ & 1.2714836 & $134 \mathrm{Cs}$ & $134 \mathrm{Cs} 2 \mathrm{O}$ & 1.0596993 & $1.293 \mathrm{E}+03$ \\
\hline $\mathrm{Cr}$ & $\mathrm{Cr} 2 \mathrm{O} 3$ & 1.4615558 & $137 \mathrm{mBa}$ & $137 \mathrm{mBaO}$ & 1.1167839 & $5.382 \mathrm{E}+08$ \\
\hline $\mathrm{Cs}$ & $\mathrm{Cs} 2 \mathrm{O}$ & 1.0601909 & $137 \mathrm{Cs}$ & $137 \mathrm{Cs} 2 \mathrm{O}$ & 1.0583920 & $8.655 \mathrm{E}+01$ \\
\hline $\mathrm{Cu}$ & $\mathrm{CuO}$ & 1.2517767 & $151 \mathrm{Sm}$ & $151 \mathrm{Sm} 2 \mathrm{O} 3$ & 1.1589344 & $2.632 \mathrm{E}+01$ \\
\hline $\mathrm{Eu}$ & $\mathrm{Eu} 2 \mathrm{O} 3$ & NA & $152 \mathrm{Eu}$ & $152 \mathrm{Eu} 2 \mathrm{O} 3$ & 1.1578888 & $1.740 \mathrm{E}+02$ \\
\hline $\mathrm{F}$ & $\mathrm{F}$ & 1.0000000 & $154 \mathrm{Eu}$ & $154 \mathrm{Eu} 2 \mathrm{O} 3$ & 1.1558383 & $2.703 \mathrm{E}+02$ \\
\hline $\mathrm{Fe}$ & $\mathrm{Fe} 2 \mathrm{O} 3$ & 1.4297294 & $155 \mathrm{Eu}$ & $155 \mathrm{Eu} 2 \mathrm{O} 3$ & 1.1548329 & $4.762 \mathrm{E}+02$ \\
\hline $\mathrm{Gd}$ & $\mathrm{Gd} 2 \mathrm{O} 3$ & 1.1526175 & $226 \mathrm{Ra}$ & $226 \mathrm{RaO}$ & 1.0707860 & $9.885 \mathrm{E}-01$ \\
\hline $\mathrm{Hg}$ & $\mathrm{HgO}$ & 1.0797617 & 227Ac & $227 \mathrm{Ac} 2 \mathrm{O} 3$ & 1.1057099 & $7.232 \mathrm{E}+01$ \\
\hline I & I & NA & $228 \mathrm{Ra}$ & $228 \mathrm{RaO}$ & 1.0701728 & $2.727 \mathrm{E}+02$ \\
\hline $\mathrm{K}$ & $\mathrm{K} 2 \mathrm{O}$ & 1.2046048 & $229 \mathrm{Th}$ & $229 \mathrm{ThO} 2$ & 1.1397132 & $2.127 \mathrm{E}-01$ \\
\hline $\mathrm{La}$ & $\mathrm{La} 2 \mathrm{O} 3$ & 1.1727729 & $231 \mathrm{~Pa}$ & 231Pa2O5 & 1.1731267 & $4.723 \mathrm{E}-02$ \\
\hline $\mathrm{Li}$ & $\mathrm{Li} 2 \mathrm{O}$ & 2.1525285 & $232 \mathrm{Th}$ & $232 \mathrm{ThO} 2$ & 1.1379033 & $1.097 \mathrm{E}-07$ \\
\hline $\mathrm{Mg}$ & $\mathrm{MgO}$ & 1.6582761 & $232 \mathrm{U}$ & 232UO3 & 1.2068558 & $2.207 \mathrm{E}+01$ \\
\hline $\mathrm{Mn}$ & $\mathrm{MnO}$ & 1.2912262 & $233 \mathrm{U}$ & 233UO3 & 1.2059655 & $9.633 \mathrm{E}-03$ \\
\hline Mo & $\mathrm{MoO} 3$ & 1.5002939 & $234 \mathrm{U}$ & 234UO3 & 1.2050846 & $6.217 \mathrm{E}-03$ \\
\hline $\mathrm{Na}$ & $\mathrm{Na} 2 \mathrm{O}$ & 1.3479678 & $235 \mathrm{U}$ & $235 \mathrm{UO} 3$ & 1.2042094 & $2.161 \mathrm{E}-06$ \\
\hline $\mathrm{Nb}$ & $\mathrm{Nb} 2 \mathrm{O} 5$ & NA & $236 \mathrm{U}$ & 236UO3 & 1.2033426 & $6.468 \mathrm{E}-05$ \\
\hline $\mathrm{Nd}$ & $\mathrm{Nd} 2 \mathrm{O} 3$ & 1.1663831 & $237 \mathrm{~Np}$ & $237 \mathrm{NpO} 2$ & 1.1349887 & $7.047 \mathrm{E}-04$ \\
\hline $\mathrm{Ni}$ & $\mathrm{NiO}$ & 1.2725928 & $238 \mathrm{Pu}$ & $238 \mathrm{PuO} 2$ & 1.1344205 & $1.712 \mathrm{E}+01$ \\
\hline $\mathrm{Np}$ & $\mathrm{NpO} 2$ & NA & $238 \mathrm{U}$ & 238UO3 & 1.2016299 & $3.361 \mathrm{E}-07$ \\
\hline $\mathrm{P}$ & $\mathrm{P} 2 \mathrm{O} 5$ & 2.2913672 & $239 \mathrm{Pu}$ & $239 \mathrm{PuO} 2$ & 1.1338571 & 6.202E-02 \\
\hline $\mathrm{Pa}$ & $\mathrm{Pa} 2 \mathrm{O} 5$ & NA & $240 \mathrm{Pu}$ & $240 \mathrm{PuO} 2$ & 1.1332983 & $2.269 \mathrm{E}-01$ \\
\hline $\mathrm{Pb}$ & $\mathrm{PbO}$ & 1.0772172 & $241 \mathrm{Am}$ & $241 \mathrm{Am} 2 \mathrm{O} 3$ & 1.0995578 & $3.427 \mathrm{E}+00$ \\
\hline $\mathrm{Pd}$ & $\mathrm{PdO}$ & 1.1503420 & $241 \mathrm{Pu}$ & $241 \mathrm{PuO} 2$ & 1.1327437 & $1.030 \mathrm{E}+02$ \\
\hline $\operatorname{Pr}$ & $\mathrm{Pr} 2 \mathrm{O} 3$ & 1.1703179 & $242 \mathrm{Cm}$ & $242 \mathrm{Cm} 2 \mathrm{O} 3$ & 1.0991457 & $3.311 \mathrm{E}+03$ \\
\hline $\mathrm{Pu}$ & $\mathrm{PuO} 2$ & NA & $242 \mathrm{Pu}$ & $242 \mathrm{PuO} 2$ & 1.1321942 & $3.954 \mathrm{E}-03$ \\
\hline $\mathrm{Ra}$ & $\mathrm{RaO}$ & NA & $243 \mathrm{Am}$ & $243 \mathrm{Am} 2 \mathrm{O} 3$ & 1.0987369 & $1.997 \mathrm{E}-01$ \\
\hline $\mathrm{Rb}$ & $\mathrm{Rb} 2 \mathrm{O}$ & 1.0935990 & $243 \mathrm{Cm}$ & $243 \mathrm{Cm} 2 \mathrm{O} 3$ & 1.0987369 & $4.903 \mathrm{E}+01$ \\
\hline $\mathrm{Rh}$ & $\mathrm{Rh} 2 \mathrm{O} 3$ & 1.2332149 & $244 \mathrm{Cm}$ & $244 \mathrm{Cm} 2 \mathrm{O} 3$ & 1.0983316 & $8.093 \mathrm{E}+01$ \\
\hline
\end{tabular}




\begin{tabular}{|c|c|c||}
\hline Element & Glass oxide & $\boldsymbol{f}_{\boldsymbol{i}}$ \\
\hline $\mathrm{Ru}$ & $\mathrm{RuO} 2$ & 1.3166004 \\
\hline $\mathrm{S}$ & $\mathrm{SO} 3$ & 2.4968565 \\
\hline $\mathrm{Sb}$ & $\mathrm{Sb} 2 \mathrm{O} 3$ & 1.1971065 \\
\hline $\mathrm{Se}$ & $\mathrm{SeO} 2$ & 1.4052533 \\
\hline $\mathrm{Si}$ & $\mathrm{SiO} 2$ & 2.1393352 \\
\hline $\mathrm{Sm}$ & $\mathrm{Sm} 2 \mathrm{O} 3$ & $\mathrm{NA}$ \\
\hline $\mathrm{Sn}$ & $\mathrm{SnO} 2$ & $\mathrm{NA}$ \\
\hline $\mathrm{Sr}$ & $\mathrm{SrO}$ & 1.1825999 \\
\hline $\mathrm{Ta}$ & $\mathrm{Ta} 2 \mathrm{O} 5$ & 1.2210498 \\
\hline $\mathrm{Tc}$ & $\mathrm{Tc} 2 \mathrm{O} 7$ & $\mathrm{NA}$ \\
\hline $\mathrm{Te}$ & $\mathrm{TeO} 2$ & 1.2507743 \\
\hline $\mathrm{Th}$ & $\mathrm{ThO} 2$ & 1.1379032 \\
\hline $\mathrm{Ti}$ & $\mathrm{TiO} 2$ & 1.6683124 \\
\hline $\mathrm{Tl}$ & $\mathrm{T} 12 \mathrm{O}$ & 1.0391407 \\
\hline $\mathrm{U}$ & $\mathrm{UO} 3$ & 1.2016486 \\
\hline $\mathrm{V}$ & $\mathrm{V} 2 \mathrm{O} 5$ & 1.7851850 \\
\hline $\mathrm{W}$ & $\mathrm{WO} 3$ & 1.2610726 \\
\hline $\mathrm{Y}$ & $\mathrm{Y} 2 \mathrm{O} 3$ & 1.2699384 \\
\hline $\mathrm{Zn}$ & $\mathrm{ZnO}$ & 1.2446766 \\
\hline $\mathrm{Zr}$ & $\mathrm{ZrO} 2$ & 1.3507717 \\
\hline \hline
\end{tabular}

NA: not applicable (these components have radionuclides only) 
Table A-2. Minimum, CRV Analytical \%RSD, and CRV Mixing and Sampling \%RSD

\begin{tabular}{|c|c|c|c|c|}
\hline Element & MRQ mg/L & $\begin{array}{c}\text { Analytical High } \\
\text { \%RSD }\end{array}$ & $\begin{array}{c}\text { Analytical Low } \\
\% \text { RSD }\end{array}$ & $\begin{array}{c}\text { CRV mix/samp } \\
\text { \%RSD }\end{array}$ \\
\hline $\mathrm{Ac}$ & NA & NA & NA & NA \\
\hline $\mathrm{Ag}$ & 0.2 & 20 & 5 & $1.47 \%$ \\
\hline $\mathrm{Al}$ & 18 & 5 & 5 & $1.47 \%$ \\
\hline $\mathrm{Am}$ & NA & NA & NA & NA \\
\hline As & 2.8 & 25 & 10 & $1.47 \%$ \\
\hline $\mathrm{B}$ & 0.4 & 25 & 10 & $1.47 \%$ \\
\hline $\mathrm{Ba}$ & 0.4 & 15 & 5 & $1.47 \%$ \\
\hline $\mathrm{Be}$ & 0.03 & 25 & 5 & $1.47 \%$ \\
\hline $\mathrm{Bi}$ & 0.9 & 15 & 10 & $1.47 \%$ \\
\hline $\mathrm{Ca}$ & 2 & 15 & 5 & $1.47 \%$ \\
\hline $\mathrm{Cd}$ & 0.06 & 10 & 5 & $1.47 \%$ \\
\hline $\mathrm{Ce}$ & 2 & 25 & 10 & $1.47 \%$ \\
\hline $\mathrm{Cl}$ & 19 & 10 & 10 & $1.47 \%$ \\
\hline $\mathrm{Cm}$ & NA & NA & NA & NA \\
\hline $\mathrm{Co}$ & 0.1 & 25 & 10 & $1.47 \%$ \\
\hline $\mathrm{Cr}$ & 0.7 & 5 & 5 & $1.47 \%$ \\
\hline $\mathrm{Cs}$ & 0.1 & 15 & 10 & $1.47 \%$ \\
\hline $\mathrm{Cu}$ & 2 & 25 & 10 & $1.47 \%$ \\
\hline $\mathrm{Eu}$ & NA & NA & NA & NA \\
\hline $\mathrm{F}$ & 19 & 10 & 10 & $1.47 \%$ \\
\hline $\mathrm{Fe}$ & 2 & 5 & 5 & $1.47 \%$ \\
\hline $\mathrm{Gd}^{(\mathrm{a})}$ & 1 & 15 & 5 & $1.47 \%$ \\
\hline $\mathrm{Hg}$ & 0.001 & 10 & 5 & $1.47 \%$ \\
\hline $\mathrm{I}$ & NA & NA & NA & NA \\
\hline $\mathrm{K}$ & 10 & 5 & 5 & $1.47 \%$ \\
\hline $\mathrm{La}$ & 0.6 & 10 & 5 & $1.47 \%$ \\
\hline $\mathrm{Li}$ & 0.3 & 15 & 5 & $1.47 \%$ \\
\hline $\mathrm{Mg}$ & 9 & 25 & 10 & $1.47 \%$ \\
\hline $\mathrm{Mn}$ & 2 & 15 & 5 & $1.47 \%$ \\
\hline Mo & 3 & 10 & 5 & $1.47 \%$ \\
\hline $\mathrm{Na}$ & 200 & 10 & 10 & $1.47 \%$ \\
\hline $\mathrm{Nb}$ & NA & NA & NA & NA \\
\hline $\mathrm{Nd}$ & 1 & 15 & 5 & $1.47 \%$ \\
\hline $\mathrm{Ni}$ & 7 & 10 & 5 & $1.47 \%$ \\
\hline $\mathrm{Np}$ & NA & NA & NA & NA \\
\hline $\mathrm{P}$ & 12 & 15 & 10 & $1.47 \%$ \\
\hline $\mathrm{Pa}$ & NA & NA & NA & NA \\
\hline $\mathrm{Pb}$ & 0.9 & 15 & 15 & $1.47 \%$ \\
\hline $\mathrm{Pd}$ & 1 & 15 & 15 & $1.47 \%$ \\
\hline $\operatorname{Pr}$ & 1 & 15 & 10 & $1.47 \%$ \\
\hline $\mathrm{Pu}$ & NA & NA & NA & NA \\
\hline $\mathrm{Ra}$ & NA & NA & NA & NA \\
\hline $\mathrm{Rb}$ & 10 & 25 & 15 & $1.47 \%$ \\
\hline $\mathrm{Rh}$ & 0.004 & 20 & 5 & $1.47 \%$ \\
\hline $\mathrm{Ru}$ & 0.02 & 25 & 5 & $1.47 \%$ \\
\hline $\mathrm{S}$ & 10 & 10 & 5 & $1.47 \%$ \\
\hline
\end{tabular}




\begin{tabular}{|c|c|c|c|c|}
\hline Element & MRQ mg/L & $\begin{array}{c}\text { Analytical High } \\
\text { \%RSD }\end{array}$ & $\begin{array}{c}\text { Analytical Low } \\
\text { \%RSD }\end{array}$ & $\begin{array}{c}\text { CRV mix/samp } \\
\text { \%RSD }\end{array}$ \\
\hline $\mathrm{Sb}$ & 0.3 & 25 & 10 & $1.47 \%$ \\
\hline $\mathrm{Se}$ & 4 & 25 & 10 & $1.47 \%$ \\
\hline $\mathrm{Si}$ & 4 & 15 & 5 & $1.47 \%$ \\
\hline $\mathrm{Sm}$ & NA & NA & NA & NA \\
\hline $\mathrm{Sn}$ & NA & NA & NA & NA \\
\hline $\mathrm{Sr}$ & 0.01 & 5 & 5 & $1.47 \%$ \\
\hline $\mathrm{Ta}$ & 0.2 & 15 & 5 & $1.47 \%$ \\
\hline Tc & NA & NA & NA & NA \\
\hline $\mathrm{Te}$ & 1 & 25 & 10 & $1.47 \%$ \\
\hline $\mathrm{Th}^{(\mathrm{b})}$ & 2 & 25 & 10 & $1.47 \%$ \\
\hline $\mathrm{Ti}$ & 0.07 & 25 & 5 & $1.47 \%$ \\
\hline $\mathrm{Tl}$ & 0.02 & 25 & 10 & $1.47 \%$ \\
\hline $\mathrm{U}^{(\mathrm{a})}$ & 1 & 15 & 5 & $1.47 \%$ \\
\hline $\mathrm{V}$ & 0.07 & 15 & 5 & $1.47 \%$ \\
\hline $\mathrm{W}$ & 0.2 & 15 & 5 & $1.47 \%$ \\
\hline $\mathrm{Y}$ & 0.6 & 25 & 5 & $1.47 \%$ \\
\hline $\mathrm{Zn}$ & 4 & 25 & 5 & $1.47 \%$ \\
\hline $\mathrm{Zr}$ & 2 & 15 & 5 & $1.47 \%$ \\
\hline Radionuclide & MRQ mCi/L & $\begin{array}{c}\text { Analytical High } \\
\% \text { RSD }\end{array}$ & $\begin{array}{c}\text { Analytical Low } \\
\text { \%RSD }\end{array}$ & $\begin{array}{c}\text { CRV mix/samp } \\
\text { \%RSD } \\
\end{array}$ \\
\hline $59 \mathrm{Ni}$ & $7.982 \mathrm{E}-07$ & 10 & 10 & $1.47 \%$ \\
\hline $60 \mathrm{Co}$ & $1.131 \mathrm{E}-05$ & 5 & 5 & $1.47 \%$ \\
\hline $63 \mathrm{Ni}$ & $5.738 \mathrm{E}-02$ & 10 & 10 & $1.47 \%$ \\
\hline $79 \mathrm{Se}$ & $6.969 \mathrm{E}-05$ & 15 & 10 & $1.47 \%$ \\
\hline $90 \mathrm{Sr}$ & $1.388 \mathrm{E}-06$ & 5 & 5 & $1.47 \%$ \\
\hline $90 \mathrm{Y}^{(\mathrm{d})}$ & $1.388 \mathrm{E}-06$ & 5 & 5 & $1.47 \%$ \\
\hline $93 \mathrm{mNb}$ & $2.386 \mathrm{E}-04$ & 15 & 10 & $1.47 \%$ \\
\hline $93 \mathrm{Zr}$ & $2.515 \mathrm{E}-06$ & 10 & 10 & $1.47 \%$ \\
\hline 99Tc & $1.711 \mathrm{E}-06$ & 10 & 10 & $1.47 \%$ \\
\hline $106 \mathrm{Ru}^{(\mathrm{c})}$ & $2.009 \mathrm{E}-03$ & 15 & 10 & $1.47 \%$ \\
\hline $113 \mathrm{mCd}$ & $4.622 \mathrm{E}-05$ & 25 & 10 & $1.47 \%$ \\
\hline $125 \mathrm{Sb}$ & $3.111 \mathrm{E}-04$ & 25 & 5 & $1.47 \%$ \\
\hline $126 \mathrm{Sn}$ & $5.678 \mathrm{E}-06$ & 20 & 15 & $1.47 \%$ \\
\hline 129I & $1.768 \mathrm{E}-04$ & 15 & 10 & $1.47 \%$ \\
\hline $134 \mathrm{Cs}$ & $4.526 \mathrm{E}-06$ & 25 & 10 & $1.47 \%$ \\
\hline $137 \mathrm{mBa}^{(\mathrm{d})}$ & $1.731 \mathrm{E}-06$ & 15 & 5 & $1.47 \%$ \\
\hline $137 \mathrm{Cs}$ & $1.731 \mathrm{E}-06$ & 15 & 5 & $1.47 \%$ \\
\hline $151 \mathrm{Sm}$ & $5.264 \mathrm{E}-01$ & 20 & 10 & $1.47 \%$ \\
\hline $152 \mathrm{Eu}$ & $1.740 \mathrm{E}-06$ & 5 & 5 & $1.47 \%$ \\
\hline $154 \mathrm{Eu}$ & $2.703 \mathrm{E}-06$ & 5 & 5 & $1.47 \%$ \\
\hline $155 \mathrm{Eu}$ & $4.762 \mathrm{E}-05$ & 5 & 5 & $1.47 \%$ \\
\hline $226 \mathrm{Ra}$ & $9.885 \mathrm{E}-07$ & 25 & 10 & $1.47 \%$ \\
\hline 227Ac & $7.232 \mathrm{E}-07$ & 50 & 10 & $1.47 \%$ \\
\hline $228 \mathrm{Ra}$ & $2.727 \mathrm{E}-03$ & 50 & 25 & $1.47 \%$ \\
\hline $229 \mathrm{Th}$ & $6.381 \mathrm{E}-04$ & 50 & 50 & $1.47 \%$ \\
\hline $231 \mathrm{~Pa}$ & $1.417 \mathrm{E}-04$ & 50 & 50 & $1.47 \%$ \\
\hline $232 \mathrm{Th}$ & $3.291 \mathrm{E}-10$ & 25 & 10 & $1.47 \%$ \\
\hline
\end{tabular}




\begin{tabular}{|c|c|c|c|c||}
\hline Radionuclide & MRQ mCi/L & $\begin{array}{c}\text { Analytical High } \\
\text { \%RSD }\end{array}$ & $\begin{array}{c}\text { Analytical Low } \\
\text { \%RSD }\end{array}$ & $\begin{array}{c}\text { CRV mix/samp } \\
\text { \%RSD }\end{array}$ \\
\hline $232 \mathrm{U}$ & $6.621 \mathrm{E}-08$ & 25 & 5 & $1.47 \%$ \\
\hline $233 \mathrm{U}$ & $9.633 \mathrm{E}-07$ & 10 & 5 & $1.47 \%$ \\
\hline $234 \mathrm{U}$ & $6.217 \mathrm{E}-06$ & 5 & 5 & $1.47 \%$ \\
\hline $235 \mathrm{U}$ & $2.161 \mathrm{E}-07$ & 10 & 5 & $1.47 \%$ \\
\hline $236 \mathrm{U}$ & $6.468 \mathrm{E}-08$ & 10 & 5 & $1.47 \%$ \\
\hline $237 \mathrm{~Np}$ & $7.047 \mathrm{E}-07$ & 10 & 5 & $1.47 \%$ \\
\hline $238 \mathrm{Pu}$ & $1.712 \mathrm{E}-07$ & 5 & 5 & $1.47 \%$ \\
\hline $238 \mathrm{U}$ & $6.722 \mathrm{E}-09$ & 10 & 10 & $1.47 \%$ \\
\hline $239 \mathrm{Pu}$ & $6.202 \mathrm{E}-08$ & 5 & 5 & $1.47 \%$ \\
\hline $240 \mathrm{Pu}$ & $2.269 \mathrm{E}-09$ & 10 & 10 & $1.47 \%$ \\
\hline $241 \mathrm{Am}$ & $3.427 \mathrm{E}-06$ & 10 & 10 & $1.47 \%$ \\
\hline $241 \mathrm{Pu}$ & $1.030 \mathrm{E}-07$ & 15 & 15 & $1.47 \%$ \\
\hline $242 \mathrm{Cm}$ & $3.311 \mathrm{E}-06$ & 10 & 10 & $1.47 \%$ \\
\hline $242 \mathrm{Pu}$ & $3.954 \mathrm{E}-11$ & 10 & 10 & $1.47 \%$ \\
\hline $243 \mathrm{Am}$ & $3.994 \mathrm{E}-08$ & 15 & 15 & $1.47 \%$ \\
\hline $243 \mathrm{Cm}$ & $9.806 \mathrm{E}-07$ & 15 & 15 & $1.47 \%$ \\
\hline $244 \mathrm{Cm}$ & $2.428 \mathrm{E}-06$ & 15 & 15 & $1.47 \%$ \\
\hline
\end{tabular}

NA: not applicable (these components have radionuclides only)

Note Analytical High and Low \%RSD are from CCN 111456. CRV mixing and sampling \%RSD is from 24590-LAW-RPT-RT-11-001, Rev 0.

(a) Data not available in CCN 111456. The value for Nd was assumed.

(b) Data not available in CCN 111456. The value for Ce was assumed.

(c) Data not available in CCN 111456. The value for 106Ru given for HLW in CCN 132102 was assumed.

(d) Data for $90 \mathrm{Y}$ and $137 \mathrm{mBa}$ are not given in CCN 111456 because they are short-lived daughters of $90 \mathrm{Sr}$ and $137 \mathrm{Cs}$. The same $\%$ RSDs as for $90 \mathrm{Sr}$ and $137 \mathrm{Cs}$ were assumed. 
Table A-3. Decontamination Factor (DF) in $\ln (\mathrm{DF})^{(\mathrm{a})}$ and Nominal Retention Factor $\left(v_{i}\right)$

\begin{tabular}{|c|c|c|c|c|c|}
\hline Component & $\begin{array}{c}\ln (\mathrm{DF}), \\
\text { Min }\end{array}$ & $\begin{array}{l}\ln (\mathrm{DF}) \\
\text { Median }\end{array}$ & $\begin{array}{c}\ln (\mathrm{DF}), \\
\text { Max }\end{array}$ & Notes $^{(a)}$ & $v_{i}$, Nominal ${ }^{(b)}$ \\
\hline $\mathrm{Ac} 2 \mathrm{O} 3$ & 2.9601 & 6.8772 & 11.1239 & Non-volatile & 0.99721 \\
\hline $\mathrm{Ag} 2 \mathrm{O}$ & 1.8563 & 4.1940 & 6.4944 & Semi-volatile & 0.97803 \\
\hline $\mathrm{Al} 2 \mathrm{O} 3$ & 5.0764 & 7.0814 & 8.8901 & Non-volatile from data & 0.99888 \\
\hline $\mathrm{Am} 2 \mathrm{O} 3$ & 1.8563 & 4.1940 & 6.4944 & Semi-volatile & 0.97803 \\
\hline As2O5 & 0.0945 & 1.5296 & 4.2370 & Volatile & 0.77121 \\
\hline $\mathrm{B} 2 \mathrm{O} 3$ & 3.7080 & 4.5886 & 5.8519 & Semi-volatile from data & 0.98968 \\
\hline $\mathrm{BaO}$ & 2.9601 & 6.8772 & 11.1239 & Non-volatile & 0.99721 \\
\hline $\mathrm{BeO}$ & 2.9601 & 6.8772 & 11.1239 & Non-volatile & 0.99721 \\
\hline $\mathrm{Bi} 2 \mathrm{O} 3$ & 1.8563 & 4.1940 & 6.4944 & Semi-volatile & 0.97803 \\
\hline $\mathrm{CaO}$ & 5.2311 & 7.0825 & 8.6034 & Non-volatile from data & 0.99892 \\
\hline $\mathrm{CdO}$ & 2.9601 & 6.8772 & 11.1239 & Non-volatile & 0.99721 \\
\hline $\mathrm{Ce} 2 \mathrm{O} 3$ & 2.9601 & 6.8772 & 11.1239 & Non-volatile & 0.99721 \\
\hline $\mathrm{Cl}$ & 0.0979 & 0.7583 & 1.9095 & Volatile from data & 0.54407 \\
\hline $\mathrm{Cm} 2 \mathrm{O} 3$ & 2.9601 & 6.8772 & 11.1239 & Non-volatile & 0.99721 \\
\hline $\mathrm{CoO}$ & 2.9601 & 6.8772 & 11.1239 & Non-volatile & 0.99721 \\
\hline $\mathrm{Cr} 2 \mathrm{O} 3$ & 1.8563 & 3.0681 & 5.3033 & Semi-volatile from data & 0.95261 \\
\hline $\mathrm{Cs} 2 \mathrm{O}$ & 0.4700 & 2.3609 & 4.2370 & Volatile from data & 0.87902 \\
\hline $\mathrm{CuO}$ & 2.9601 & 6.8772 & 11.1239 & Non-volatile & 0.99721 \\
\hline $\mathrm{Eu} 2 \mathrm{O} 3$ & 2.9601 & 6.8772 & 11.1239 & Non-volatile & 0.99721 \\
\hline $\mathrm{F}$ & 0.1179 & 1.4682 & 2.4361 & Volatile from data & 0.72984 \\
\hline $\mathrm{Fe} 2 \mathrm{O} 3$ & 4.9381 & 6.6712 & 8.8984 & Non-volatile from data & 0.99848 \\
\hline $\mathrm{Gd} 2 \mathrm{O} 3$ & 2.9601 & 6.8772 & 11.1239 & Non-volatile & 0.99721 \\
\hline $\mathrm{HgO}$ & 0.0000 & 0.0000 & 0.0000 & Assumed & 0 \\
\hline $\mathrm{I}$ & 0.0945 & 0.5807 & 2.2660 & Volatile from data & 0.50961 \\
\hline $\mathrm{K} 2 \mathrm{O}$ & 2.0669 & 3.3844 & 5.5607 & Semi-volatile from data & 0.96423 \\
\hline $\mathrm{La} 2 \mathrm{O} 3$ & 2.9601 & 6.8772 & 11.1239 & Non-volatile & 0.99721 \\
\hline $\mathrm{Li} 2 \mathrm{O}$ & 3.4689 & 5.9870 & 7.2894 & Non-volatile from data & 0.99601 \\
\hline $\mathrm{MgO}$ & 7.2464 & 8.8618 & 11.0268 & Non-volatile from data & 0.99984 \\
\hline $\mathrm{MnO}$ & 2.9601 & 6.8772 & 11.1239 & Non-volatile & 0.99721 \\
\hline $\mathrm{MoO} 3$ & 1.8563 & 4.1940 & 6.4944 & Semi-volatile & 0.97803 \\
\hline $\mathrm{Na} 2 \mathrm{O}$ & 3.4874 & 4.8633 & 6.4944 & Semi-volatile from data & 0.99136 \\
\hline $\mathrm{Nb} 2 \mathrm{O} 5$ & 2.9601 & 6.8772 & 11.1239 & Non-volatile & 0.99721 \\
\hline $\mathrm{Nd} 2 \mathrm{O} 3$ & 2.9601 & 6.8772 & 11.1239 & Non-volatile & 0.99721 \\
\hline $\mathrm{NiO}$ & 3.9299 & 4.7875 & 6.3835 & Non-volatile from data & 0.99187 \\
\hline $\mathrm{NpO} 2$ & 2.9601 & 6.8772 & 11.1239 & Non-volatile & 0.99721 \\
\hline $\mathrm{P} 2 \mathrm{O} 5$ & 2.9601 & 5.1381 & 6.7822 & Non-volatile from data & 0.99169 \\
\hline $\mathrm{Pa} 2 \mathrm{O} 5$ & 2.9601 & 6.8772 & 11.1239 & Non-volatile & 0.99721 \\
\hline $\mathrm{PbO}$ & 3.2542 & 4.4716 & 6.2971 & Semi-volatile from data & 0.98796 \\
\hline $\mathrm{PdO}$ & 2.9601 & 6.8772 & 11.1239 & Non-volatile & 0.99721 \\
\hline $\mathrm{Pr} 2 \mathrm{O} 3$ & 2.9601 & 6.8772 & 11.1239 & Non-volatile & 0.99721 \\
\hline $\mathrm{PuO} 2$ & 2.9601 & 6.8772 & 11.1239 & Non-volatile & 0.99721 \\
\hline $\mathrm{RaO}$ & 0.0945 & 1.5296 & 4.2370 & Volatile & 0.77121 \\
\hline $\mathrm{Rb} 2 \mathrm{O}$ & 1.8563 & 4.1940 & 6.4944 & Semi-volatile & 0.97803 \\
\hline $\mathrm{Rh} 2 \mathrm{O} 3$ & 2.9601 & 6.8772 & 11.1239 & Non-volatile & 0.99721 \\
\hline $\mathrm{RuO2}$ & 1.8563 & 4.1940 & 6.4944 & Semi-volatile & 0.97803 \\
\hline $\mathrm{SO} 3$ & 0.6308 & 1.9694 & 3.2089 & Volatile from data & 0.84032 \\
\hline $\mathrm{Sb} 2 \mathrm{O} 3$ & 0.0945 & 1.5296 & 4.2370 & Volatile & 0.77121 \\
\hline
\end{tabular}




\begin{tabular}{|c|c|c|c|c|c|}
\hline Component & $\begin{array}{c}\ln (\mathrm{DF}), \\
\text { Min }\end{array}$ & $\begin{array}{l}\text { In(DF), } \\
\text { Median }\end{array}$ & $\begin{array}{c}\ln (\mathbf{D F}) \\
\mathbf{M a x}\end{array}$ & Notes $^{(\mathrm{a})}$ & $v_{i}$, Nominal ${ }^{(b)}$ \\
\hline $\mathrm{SeO} 2$ & 0.0945 & 1.5296 & 4.2370 & Volatile & 0.77121 \\
\hline $\mathrm{SiO} 2$ & 5.3471 & 7.5372 & 9.7527 & Non-volatile from data & 0.99926 \\
\hline $\mathrm{Sm} 2 \mathrm{O} 3$ & 2.9601 & 6.8772 & 11.1239 & Non-volatile & 0.99721 \\
\hline $\mathrm{SnO} 2$ & 2.9601 & 6.8772 & 11.1239 & Non-volatile & 0.99721 \\
\hline $\mathrm{SrO}$ & 2.9601 & 6.8772 & 11.1239 & Non-volatile & 0.99721 \\
\hline Ta2O5 & 2.9601 & 6.8772 & 11.1239 & Non-volatile & 0.99721 \\
\hline Tc2O7 & 0.0953 & 0.4700 & 1.6094 & Volatile from data & 0.43049 \\
\hline $\mathrm{TeO} 2$ & 0.0945 & 1.5296 & 4.2370 & Volatile & 0.77121 \\
\hline $\mathrm{ThO} 2$ & 2.9601 & 6.8772 & 11.1239 & Non-volatile & 0.99721 \\
\hline $\mathrm{TiO} 2$ & 4.6308 & 6.1247 & 8.0740 & Non-volatile from data & 0.99752 \\
\hline $\mathrm{T} 12 \mathrm{O}$ & 0.0945 & 1.5296 & 4.2370 & Volatile & 0.77121 \\
\hline $\mathrm{UO} 3$ & 2.9601 & 6.8772 & 11.1239 & Non-volatile & 0.99721 \\
\hline $\mathrm{V} 2 \mathrm{O} 5$ & 1.8563 & 4.1940 & 6.4944 & Semi-volatile & 0.97803 \\
\hline WO3 & 2.9601 & 6.8772 & 11.1239 & Non-volatile & 0.99721 \\
\hline $\mathrm{Y} 2 \mathrm{O} 3$ & 2.9601 & 6.8772 & 11.1239 & Non-volatile & 0.99721 \\
\hline $\mathrm{ZnO}$ & 4.7353 & 6.2383 & 7.8709 & Non-volatile from data & 0.99773 \\
\hline $\mathrm{ZrO} 2$ & 7.2204 & 8.7143 & 11.1239 & Non-volatile from data & 0.99982 \\
\hline
\end{tabular}

(a) 24590-LAW-RPT-RT-10-001, Rev. 0

(b) Obtained from 500,000 Monte Carlo simulations for $\ln (\mathrm{DF})$ and used for nominal glass composition calculation. 
Table A-4. GFC Compositions: Minimum, Most Likely, and Maximum Values Used for Composition Uncertainty Calculations in Monte Carlo Method

\begin{tabular}{|c|c|c|c|c|c|c|c|c|c|c|c|}
\hline \multicolumn{12}{|c|}{ Minimum } \\
\hline Comp & Kyanite & $\begin{array}{c}\text { Boric } \\
\text { Acid } \\
\end{array}$ & $\begin{array}{c}\text { Wollas- } \\
\text { tonite }\end{array}$ & Hematite & $\begin{array}{c}\mathbf{L i} \\
\text { Carbonate }\end{array}$ & Olivine & $\begin{array}{c}\mathrm{Na} \\
\text { Carbonate }\end{array}$ & Silica & Rutile & Zincite & Zircon \\
\hline $\mathrm{Ac} 2 \mathrm{O} 3$ & 0 & 0 & 0 & 0 & 0 & 0 & 0 & 0 & 0 & 0 & 0 \\
\hline Ag2O & 0 & 0 & 0 & 0 & 0 & 0 & 0 & 0 & 0 & 0 & 0 \\
\hline $\mathrm{Al} 2 \mathrm{O} 3$ & 0.54 & 0 & 0.0013 & 0.0099 & 0 & 0.0003 & 0 & 0.0004 & 0 & 0 & 0.001 \\
\hline $\mathrm{Am} 2 \mathrm{O} 3$ & 0 & 0 & 0 & 0 & 0 & 0 & 0 & 0 & 0 & 0 & 0 \\
\hline As2O5 & 0 & 0 & 0 & 0 & 0 & 0 & 0 & 0 & 0 & 0 & 0 \\
\hline $\mathrm{B} 2 \mathrm{O} 3$ & 0 & 0.5625 & 0 & 0 & 0 & 0 & 0 & 0 & 0 & 0 & 0 \\
\hline $\mathrm{BaO}$ & 0 & 0 & 0 & 0 & 0 & 0 & 0 & 0 & 0 & 0 & 0 \\
\hline $\mathrm{BeO}$ & 0 & 0 & 0 & 0 & 0 & 0 & 0 & 0 & 0 & 0 & 0 \\
\hline $\mathrm{Bi} 2 \mathrm{O} 3$ & 0 & 0 & 0 & 0 & 0 & 0 & 0 & 0 & 0 & 0 & 0 \\
\hline $\mathrm{CaO}$ & 0 & 0 & 0.4477 & 0 & 0 & 0 & 0 & 0 & 0 & 0 & 0 \\
\hline $\mathrm{CdO}$ & 0 & 0 & 0 & 0 & 0 & 0 & 0 & 0 & 0 & 0 & 0 \\
\hline $\mathrm{Ce} 2 \mathrm{O} 3$ & 0 & 0 & 0 & 0 & 0 & 0 & 0 & 0 & 0 & 0 & 0 \\
\hline $\mathrm{Cl}$ & 0 & 0 & 0 & 0 & 0 & 0 & 0 & 0 & 0 & 0 & 0 \\
\hline $\mathrm{Cm} 2 \mathrm{O} 3$ & 0 & 0 & 0 & 0 & 0 & 0 & 0 & 0 & 0 & 0 & 0 \\
\hline $\mathrm{CoO}$ & 0 & 0 & 0 & 0 & 0 & 0 & 0 & 0 & 0 & 0 & 0 \\
\hline $\mathrm{Cr} 2 \mathrm{O} 3$ & 0 & 0 & 0 & 0 & 0 & 0 & 0 & 0 & 0 & 0 & 0 \\
\hline $\mathrm{Cs} 2 \mathrm{O}$ & 0 & 0 & 0 & 0 & 0 & 0 & 0 & 0 & 0 & 0 & 0 \\
\hline $\mathrm{CuO}$ & 0 & 0 & 0 & 0 & 0 & 0 & 0 & 0 & 0 & 0 & 0 \\
\hline $\mathrm{Eu} 2 \mathrm{O} 3$ & 0 & 0 & 0 & 0 & 0 & 0 & 0 & 0 & 0 & 0 & 0 \\
\hline $\mathrm{F}$ & 0 & 0 & 0 & 0 & 0 & 0 & 0 & 0 & 0 & 0 & 0 \\
\hline $\mathrm{Fe} 2 \mathrm{O} 3$ & 0.0042 & 0 & 0.0029 & 0.9615 & 0 & 0.0468 & 0 & 0.0001 & 0 & 0 & 0.0006 \\
\hline $\mathrm{Gd} 2 \mathrm{O} 3$ & 0 & 0 & 0 & 0 & 0 & 0 & 0 & 0 & 0 & 0 & 0 \\
\hline $\mathrm{HgO}$ & 0 & 0 & 0 & 0 & 0 & 0 & 0 & 0 & 0 & 0 & 0 \\
\hline $\mathrm{I}$ & 0 & 0 & 0 & 0 & 0 & 0 & 0 & 0 & 0 & 0 & 0 \\
\hline $\mathrm{K} 2 \mathrm{O}$ & 0 & 0 & 0 & 0 & 0 & 0 & 0 & 0 & 0 & 0 & 0 \\
\hline $\mathrm{La} 2 \mathrm{O} 3$ & 0 & 0 & 0 & 0 & 0 & 0 & 0 & 0 & 0 & 0 & 0 \\
\hline $\mathrm{Li} 2 \mathrm{O}$ & 0 & 0 & 0 & 0 & 0.4 & 0 & 0 & 0 & 0 & 0 & 0 \\
\hline $\mathrm{MgO}$ & 0 & 0 & 0 & 0.0001 & 0 & 0.4634 & 0 & 0 & 0 & 0 & 0 \\
\hline $\mathrm{MnO}$ & 0 & 0 & 0.0009 & 0.0003 & 0 & 0 & 0 & 0 & 0 & 0 & 0 \\
\hline $\mathrm{MoO} 3$ & 0 & 0 & 0 & 0 & 0 & 0 & 0 & 0 & 0 & 0 & 0 \\
\hline $\mathrm{Na} 2 \mathrm{O}$ & 0 & 0 & 0 & 0 & 0 & 0 & 0.5831 & 0 & 0 & 0 & 0 \\
\hline $\mathrm{Nb} 2 \mathrm{O} 5$ & 0 & 0 & 0 & 0 & 0 & 0 & 0 & 0 & 0 & 0 & 0 \\
\hline $\mathrm{Nd} 2 \mathrm{O} 3$ & 0 & 0 & 0 & 0 & 0 & 0 & 0 & 0 & 0 & 0 & 0 \\
\hline $\mathrm{NiO}$ & 0 & 0 & 0 & 0 & 0 & 0.0022 & 0 & 0 & 0 & 0 & 0 \\
\hline $\mathrm{NpO} 2$ & 0 & 0 & 0 & 0 & 0 & 0 & 0 & 0 & 0 & 0 & 0 \\
\hline $\mathrm{P} 2 \mathrm{O} 5$ & 0 & 0 & 0 & 0.0018 & 0 & 0 & 0 & 0 & 0 & 0 & 0 \\
\hline $\mathrm{Pa} 2 \mathrm{O} 5$ & 0 & 0 & 0 & 0 & 0 & 0 & 0 & 0 & 0 & 0 & 0 \\
\hline $\mathrm{PbO}$ & 0 & 0 & 0 & 0 & 0 & 0 & 0 & 0 & 0 & 0 & 0 \\
\hline $\mathrm{PdO}$ & 0 & 0 & 0 & 0 & 0 & 0 & 0 & 0 & 0 & 0 & 0 \\
\hline Pr2O3 & 0 & 0 & 0 & 0 & 0 & 0 & 0 & 0 & 0 & 0 & 0 \\
\hline $\mathrm{PuO} 2$ & 0 & 0 & 0 & 0 & 0 & 0 & 0 & 0 & 0 & 0 & 0 \\
\hline $\mathrm{RaO}$ & 0 & 0 & 0 & 0 & 0 & 0 & 0 & 0 & 0 & 0 & 0 \\
\hline $\mathrm{Rb} 2 \mathrm{O}$ & 0 & 0 & 0 & 0 & 0 & 0 & 0 & 0 & 0 & 0 & 0 \\
\hline $\mathrm{Rh} 2 \mathrm{O} 3$ & 0 & 0 & 0 & 0 & 0 & 0 & 0 & 0 & 0 & 0 & 0 \\
\hline $\mathrm{RuO} 2$ & 0 & 0 & 0 & 0 & 0 & 0 & 0 & 0 & 0 & 0 & 0 \\
\hline
\end{tabular}




\begin{tabular}{|c|c|c|c|c|c|c|c|c|c|c|c|}
\hline \multicolumn{12}{|c|}{ Minimum } \\
\hline Comp & Kyanite & $\begin{array}{c}\text { Boric } \\
\text { Acid } \\
\end{array}$ & $\begin{array}{c}\text { Wollas- } \\
\text { tonite }\end{array}$ & Hematite & \begin{tabular}{|c|}
$\mathbf{L i}$ \\
Carbonate \\
\end{tabular} & Olivine & $\begin{array}{c}\mathrm{Na} \\
\text { Carbonate }\end{array}$ & Silica & Rutile & Zincite & Zircon \\
\hline $\mathrm{SO} 3$ & 0 & 0 & 0 & 0.0006 & 0 & 0 & 0 & 0 & 0 & 0 & 0 \\
\hline $\mathrm{Sb} 2 \mathrm{O} 3$ & 0 & 0 & 0 & 0 & 0 & 0 & 0 & 0 & 0 & 0 & 0 \\
\hline $\mathrm{SeO} 2$ & 0 & 0 & 0 & 0 & 0 & 0 & 0 & 0 & 0 & 0 & 0 \\
\hline $\mathrm{SiO} 2$ & 0.39 & 0 & 0.48 & 0.0084 & 0 & 0.4085 & 0 & 0.992 & 0 & 0 & 0.32 \\
\hline $\mathrm{Sm} 2 \mathrm{O} 3$ & 0 & 0 & 0 & 0 & 0 & 0 & 0 & 0 & 0 & 0 & 0 \\
\hline $\mathrm{SnO} 2$ & 0 & 0 & 0 & 0 & 0 & 0 & 0 & 0 & 0 & 0 & 0 \\
\hline $\mathrm{SrO}$ & 0 & 0 & 0 & 0 & 0 & 0 & 0 & 0 & 0 & 0 & 0 \\
\hline $\mathrm{Ta} 2 \mathrm{O} 5$ & 0 & 0 & 0 & 0 & 0 & 0 & 0 & 0 & 0 & 0 & 0 \\
\hline $\mathrm{Tc} 2 \mathrm{O} 7$ & 0 & 0 & 0 & 0 & 0 & 0 & 0 & 0 & 0 & 0 & 0 \\
\hline $\mathrm{TeO} 2$ & 0 & 0 & 0 & 0 & 0 & 0 & 0 & 0 & 0 & 0 & 0 \\
\hline $\mathrm{ThO} 2$ & 0 & 0 & 0 & 0 & 0 & 0 & 0 & 0 & 0 & 0 & 0 \\
\hline $\mathrm{TiO} 2$ & 0.005 & 0 & 0.0001 & 0 & 0 & 0 & 0 & 0 & 0.928 & 0 & 0.0007 \\
\hline $\mathrm{T} 12 \mathrm{O}$ & 0 & 0 & 0 & 0 & 0 & 0 & 0 & 0 & 0 & 0 & 0 \\
\hline UO3 & 0 & 0 & 0 & 0 & 0 & 0 & 0 & 0 & 0 & 0 & 0.0003 \\
\hline $\mathrm{V} 2 \mathrm{O} 5$ & 0 & 0 & 0 & 0 & 0 & 0 & 0 & 0 & 0 & 0 & 0 \\
\hline WO3 & 0 & 0 & 0 & 0 & 0 & 0 & 0 & 0 & 0 & 0 & 0 \\
\hline $\mathrm{Y} 2 \mathrm{O} 3$ & 0 & 0 & 0 & 0 & 0 & 0 & 0 & 0 & 0 & 0 & 0 \\
\hline $\mathrm{ZnO}$ & 0 & 0 & 0 & 0 & 0 & 0 & 0 & 0 & 0 & 0.993 & 0 \\
\hline $\mathrm{ZrO} 2$ & 0 & 0 & 0 & 0 & 0 & 0 & 0 & 0 & 0 & 0 & 0.65 \\
\hline
\end{tabular}

\begin{tabular}{|c|c|c|c|c|c|c|c|c|c|c|c|}
\hline \multicolumn{12}{|c|}{ Most Likely } \\
\hline Comp & Kyanite & $\begin{array}{l}\text { Boric } \\
\text { Acid }\end{array}$ & $\begin{array}{c}\text { Wollas- } \\
\text { tonite }\end{array}$ & Hematite & $\begin{array}{c}\mathbf{L i} \\
\text { Carbonate }\end{array}$ & Olivine & $\begin{array}{c}\mathrm{Na} \\
\text { Carbonate }\end{array}$ & Silica & Rutile & Zincite & Zircon \\
\hline $\mathrm{Ac} 2 \mathrm{O} 3$ & 0 & 0 & 0 & 0 & 0 & 0 & 0 & 0 & 0 & 0 & 0 \\
\hline $\mathrm{Ag} 2 \mathrm{O}$ & 0 & 0 & 0 & 0 & 0 & 0 & 0 & 0 & 0 & 0 & 0 \\
\hline $\mathrm{A} 12 \mathrm{O} 3$ & 0.5703 & 0 & 0.002 & 0.015 & 0 & 0.0019 & 0 & 0.0014 & 0.005 & 0 & 0.0025 \\
\hline $\mathrm{Am} 2 \mathrm{O} 3$ & 0 & 0 & 0 & 0 & 0 & 0 & 0 & 0 & 0 & 0 & 0 \\
\hline As2O5 & 0 & 0 & 0 & 0 & 0 & 0 & 0 & 0 & 0 & 0 & 0 \\
\hline $\mathrm{B} 2 \mathrm{O} 3$ & 0 & 0.5652 & 0 & 0 & 0 & 0 & 0 & 0 & 0 & 0 & 0 \\
\hline $\mathrm{BaO}$ & 0 & 0 & 0 & 0 & 0 & 0 & 0 & 0 & 0 & 0 & 0 \\
\hline $\mathrm{BeO}$ & 0 & 0 & 0 & 0 & 0 & 0 & 0 & 0 & 0 & 0 & 0 \\
\hline $\mathrm{Bi} 2 \mathrm{O} 3$ & 0 & 0 & 0 & 0 & 0 & 0 & 0 & 0 & 0 & 0 & 0 \\
\hline $\mathrm{CaO}$ & 0.0003 & 0 & 0.475 & 0.0004 & 0 & 0.0002 & 0 & 0.0001 & 0 & 0 & 0 \\
\hline $\mathrm{CdO}$ & 0 & 0 & 0 & 0 & 0 & 0 & 0 & 0 & 0 & 0.0001 & 0 \\
\hline $\mathrm{Ce} 2 \mathrm{O} 3$ & 0 & 0 & 0 & 0 & 0 & 0 & 0 & 0 & 0 & 0 & 0 \\
\hline $\mathrm{Cl}$ & 0 & 0 & 0 & 0 & 0.0001 & 0 & 0.0002 & 0 & 0 & 0 & 0 \\
\hline $\mathrm{Cm} 2 \mathrm{O} 3$ & 0 & 0 & 0 & 0 & 0 & 0 & 0 & 0 & 0 & 0 & 0 \\
\hline $\mathrm{CoO}$ & 0 & 0 & 0 & 0 & 0 & 0 & 0 & 0 & 0 & 0 & 0 \\
\hline $\mathrm{Cr} 2 \mathrm{O} 3$ & 0 & 0 & 0 & 0 & 0.0001 & 0.0013 & 0 & 0 & 0.0016 & 0 & 0 \\
\hline $\mathrm{Cs} 2 \mathrm{O}$ & 0 & 0 & 0 & 0 & 0 & 0 & 0 & 0 & 0 & 0 & 0 \\
\hline $\mathrm{CuO}$ & 0 & 0 & 0 & 0 & 0 & 0 & 0 & 0 & 0 & 0 & 0 \\
\hline $\mathrm{Eu} 2 \mathrm{O} 3$ & 0 & 0 & 0 & 0 & 0 & 0 & 0 & 0 & 0 & 0 & 0 \\
\hline $\mathrm{F}$ & 0 & 0 & 0 & 0 & 0 & 0 & 0 & 0 & 0 & 0 & 0 \\
\hline $\mathrm{Fe} 2 \mathrm{O} 3$ & 0.0078 & 0 & 0.004 & 0.97 & 0 & 0.0768 & 0 & 0.0002 & 0.007 & 0 & 0.0008 \\
\hline $\mathrm{Gd} 2 \mathrm{O} 3$ & 0 & 0 & 0 & 0 & 0 & 0 & 0 & 0 & 0 & 0 & 0 \\
\hline $\mathrm{HgO}$ & 0 & 0 & 0 & 0 & 0 & 0 & 0 & 0 & 0 & 0 & 0 \\
\hline I & 0 & 0 & 0 & 0 & 0 & 0 & 0 & 0 & 0 & 0 & 0 \\
\hline
\end{tabular}




\begin{tabular}{|c|c|c|c|c|c|c|c|c|c|c|c|}
\hline \multicolumn{12}{|c|}{ Most Likely } \\
\hline Comp & Kyanite & $\begin{array}{l}\text { Boric } \\
\text { Acid }\end{array}$ & $\begin{array}{c}\text { Wollas- } \\
\text { tonite }\end{array}$ & Hematite & $\begin{array}{c}\mathbf{L i} \\
\text { Carbonate }\end{array}$ & Olivine & $\begin{array}{c}\mathrm{Na} \\
\text { Carbonate }\end{array}$ & Silica & Rutile & Zincite & Zircon \\
\hline $\mathrm{K} 2 \mathrm{O}$ & 0 & 0 & 0 & 0 & 0 & 0 & 0 & 0 & 0 & 0 & 0 \\
\hline $\mathrm{La} 2 \mathrm{O} 3$ & 0 & 0 & 0 & 0 & 0 & 0 & 0 & 0 & 0 & 0 & 0 \\
\hline $\mathrm{Li} 2 \mathrm{O}$ & 0 & 0 & 0 & 0 & 0.402 & 0 & 0 & 0 & 0 & 0 & 0 \\
\hline $\mathrm{MgO}$ & 0.0001 & 0 & 0.001 & 0.001 & 0.0001 & 0.4801 & 0 & 0.0001 & 0 & 0 & 0 \\
\hline $\mathrm{MnO}$ & 0 & 0 & 0.001 & 0.0012 & 0 & 0 & 0 & 0 & 0 & 0 & 0 \\
\hline $\mathrm{MoO} 3$ & 0 & 0 & 0 & 0 & 0 & 0 & 0 & 0 & 0 & 0 & 0 \\
\hline $\mathrm{Na} 2 \mathrm{O}$ & 0.0042 & 0 & 0 & 0 & 0.0008 & 0.0003 & 0.5837 & 0.0002 & 0 & 0 & 0 \\
\hline $\mathrm{Nb} 2 \mathrm{O} 5$ & 0 & 0 & 0 & 0 & 0 & 0 & 0 & 0 & 0 & 0 & 0 \\
\hline $\mathrm{Nd} 2 \mathrm{O} 3$ & 0 & 0 & 0 & 0 & 0 & 0 & 0 & 0 & 0 & 0 & 0 \\
\hline $\mathrm{NiO}$ & 0 & 0 & 0 & 0 & 0 & 0.0037 & 0 & 0 & 0 & 0 & 0 \\
\hline $\mathrm{NpO} 2$ & 0 & 0 & 0 & 0 & 0 & 0 & 0 & 0 & 0 & 0 & 0 \\
\hline $\mathrm{P} 2 \mathrm{O} 5$ & 0 & 0 & 0 & 0.0027 & 0 & 0 & 0 & 0 & 0 & 0 & 0 \\
\hline $\mathrm{Pa} 2 \mathrm{O} 5$ & 0 & 0 & 0 & 0 & 0 & 0 & 0 & 0 & 0 & 0 & 0 \\
\hline $\mathrm{PbO}$ & 0 & 0 & 0 & 0 & 0 & 0 & 0 & 0 & 0 & 0 & 0 \\
\hline $\mathrm{PdO}$ & 0 & 0 & 0 & 0 & 0 & 0 & 0 & 0 & 0 & 0 & 0 \\
\hline Pr2O3 & 0 & 0 & 0 & 0 & 0 & 0 & 0 & 0 & 0 & 0 & 0 \\
\hline $\mathrm{PuO} 2$ & 0 & 0 & 0 & 0 & 0 & 0 & 0 & 0 & 0 & 0 & 0 \\
\hline $\mathrm{RaO}$ & 0 & 0 & 0 & 0 & 0 & 0 & 0 & 0 & 0 & 0 & 0 \\
\hline $\mathrm{Rb} 2 \mathrm{O}$ & 0 & 0 & 0 & 0 & 0 & 0 & 0 & 0 & 0 & 0 & 0 \\
\hline $\mathrm{Rh} 2 \mathrm{O} 3$ & 0 & 0 & 0 & 0 & 0 & 0 & 0 & 0 & 0 & 0 & 0 \\
\hline $\mathrm{RuO} 2$ & 0 & 0 & 0 & 0 & 0 & 0 & 0 & 0 & 0 & 0 & 0 \\
\hline SO3 & 0 & 0 & 0 & 0.0007 & 0.0003 & 0 & 0.0001 & 0 & 0 & 0 & 0 \\
\hline $\mathrm{Sb} 2 \mathrm{O} 3$ & 0 & 0 & 0 & 0 & 0 & 0 & 0 & 0 & 0 & 0 & 0 \\
\hline $\mathrm{SeO} 2$ & 0 & 0 & 0 & 0 & 0 & 0 & 0 & 0 & 0 & 0 & 0 \\
\hline $\mathrm{SiO} 2$ & 0.4067 & 0 & 0.51 & 0.0135 & 0 & 0.4252 & 0 & 0.997 & 0.022 & 0 & 0.3225 \\
\hline $\mathrm{Sm} 2 \mathrm{O} 3$ & 0 & 0 & 0 & 0 & 0 & 0 & 0 & 0 & 0 & 0 & 0 \\
\hline $\mathrm{SnO} 2$ & 0 & 0 & 0 & 0 & 0 & 0 & 0 & 0 & 0 & 0 & 0 \\
\hline $\mathrm{SrO}$ & 0 & 0 & 0 & 0 & 0 & 0 & 0 & 0 & 0 & 0 & 0 \\
\hline Ta2O5 & 0 & 0 & 0 & 0 & 0 & 0 & 0 & 0 & 0 & 0 & 0 \\
\hline Tc2O7 & 0 & 0 & 0 & 0 & 0 & 0 & 0 & 0 & 0 & 0 & 0 \\
\hline $\mathrm{TeO} 2$ & 0 & 0 & 0 & 0 & 0 & 0 & 0 & 0 & 0 & 0 & 0 \\
\hline ThO2 & 0 & 0 & 0 & 0 & 0 & 0 & 0 & 0 & 0 & 0 & 0 \\
\hline $\mathrm{TiO} 2$ & 0.0079 & 0 & 0.0002 & 0 & 0 & 0 & 0 & 0.0001 & 0.932 & 0 & 0.001 \\
\hline $\mathrm{T} 12 \mathrm{O}$ & 0 & 0 & 0 & 0 & 0 & 0 & 0 & 0 & 0 & 0 & 0 \\
\hline UO3 & 0 & 0 & 0 & 0 & 0 & 0 & 0 & 0 & 0 & 0 & 0.0004 \\
\hline $\mathrm{V} 2 \mathrm{O} 5$ & 0 & 0 & 0 & 0 & 0 & 0 & 0 & 0 & 0.0045 & 0 & 0 \\
\hline WO3 & 0 & 0 & 0 & 0 & 0 & 0 & 0 & 0 & 0 & 0 & 0 \\
\hline $\mathrm{Y} 2 \mathrm{O} 3$ & 0 & 0 & 0 & 0 & 0 & 0 & 0 & 0 & 0 & 0 & 0 \\
\hline $\mathrm{ZnO}$ & 0 & 0 & 0 & 0 & 0 & 0 & 0 & 0 & 0 & 0.999 & 0 \\
\hline $\mathrm{ZrO} 2$ & 0 & 0 & 0 & 0 & 0 & 0 & 0 & 0 & 0.019 & 0 & 0.66 \\
\hline
\end{tabular}

\begin{tabular}{|c|c|c|c|c|c|c|c|c|c|c|c|}
\hline \multicolumn{10}{|c|}{ Maximum } \\
\hline Comp & Kyanite & $\begin{array}{c}\text { Boric } \\
\text { Acid }\end{array}$ & $\begin{array}{c}\text { Wollas- } \\
\text { tonite }\end{array}$ & $\begin{array}{c}\text { Hema- } \\
\text { tite }\end{array}$ & $\begin{array}{c}\text { Li } \\
\text { Carbonate }\end{array}$ & Olivine & $\begin{array}{c}\text { Na } \\
\text { Carbonate }\end{array}$ & Silica & Rutile & Zincite & Zircon \\
\hline $\mathrm{Ac} 2 \mathrm{O} 3$ & 0 & 0 & 0 & 0 & 0 & 0 & 0 & 0 & 0 & 0 & 0 \\
\hline $\mathrm{Ag} 2 \mathrm{O}$ & 0 & 0 & 0 & 0 & 0 & 0 & 0 & 0 & 0 & 0 & 0 \\
\hline $\mathrm{A} 12 \mathrm{O} 3$ & 0.6 & 0 & 0.0027 & 0.0201 & 0 & 0.0078 & 0 & 0.004 & 0.0075 & 0 & 0.004 \\
\hline
\end{tabular}




\begin{tabular}{|c|c|c|c|c|c|c|c|c|c|c|c|}
\hline \multicolumn{12}{|c|}{ Maximum } \\
\hline Comp & Kyanite & $\begin{array}{l}\text { Boric } \\
\text { Acid }\end{array}$ & $\begin{array}{c}\text { Wollas- } \\
\text { tonite }\end{array}$ & $\begin{array}{c}\text { Hema- } \\
\text { tite }\end{array}$ & $\mid \begin{array}{c}\mathbf{L i} \\
\text { Carbonate }\end{array}$ & Olivine & $\begin{array}{c}\mathrm{Na} \\
\text { Carbonate }\end{array}$ & Silica & Rutile & Zincite & Zircon \\
\hline $\mathrm{Am} 2 \mathrm{O} 3$ & 0 & 0 & 0 & 0 & \begin{tabular}{l|}
0 \\
\end{tabular} & 0 & 0 & 0 & 0 & 0 & 0 \\
\hline As2O5 & 0 & 0 & 0 & 0 & 0 & 0 & 0 & 0 & 0 & 0 & 0 \\
\hline $\mathrm{B} 2 \mathrm{O} 3$ & 0 & 0.568 & 0 & 0 & 0 & 0 & 0 & 0 & 0 & 0 & 0 \\
\hline $\mathrm{BaO}$ & 0 & 0 & 0 & 0 & 0 & 0 & 0 & 0 & 0 & 0 & 0 \\
\hline $\mathrm{BeO}$ & 0 & 0 & 0 & 0 & 0 & 0 & 0 & 0 & 0 & 0 & 0 \\
\hline $\mathrm{Bi} 2 \mathrm{O} 3$ & 0 & 0 & 0 & 0 & 0 & 0 & 0 & 0 & 0 & 0 & 0 \\
\hline $\mathrm{CaO}$ & 0.0004 & 0 & 0.5023 & 0.0008 & 0.022 & 0.0003 & 0.0001 & 0.0002 & 0 & 0 & 0 \\
\hline $\mathrm{CdO}$ & 0 & 0 & 0 & 0 & 0 & 0 & 0 & 0 & 0 & 0.0002 & 0 \\
\hline $\mathrm{Ce} 2 \mathrm{O} 3$ & 0 & 0 & 0 & 0 & 0 & 0 & 0 & 0 & 0 & 0 & 0 \\
\hline $\mathrm{Cl}$ & 0 & 0 & 0 & 0 & 0.0001 & 0 & 0.0002 & 0 & 0 & 0 & 0 \\
\hline $\mathrm{Cm} 2 \mathrm{O} 3$ & 0 & 0 & 0 & 0 & 0 & 0 & 0 & 0 & 0 & 0 & 0 \\
\hline $\mathrm{CoO}$ & 0 & 0 & 0 & 0 & 0 & 0 & 0 & 0 & 0 & 0 & 0 \\
\hline $\mathrm{Cr} 2 \mathrm{O} 3$ & 0 & 0 & 0 & 0 & 0.0002 & 0.0078 & 0.0006 & 0 & 0.0075 & 0 & 0 \\
\hline $\mathrm{Cs} 2 \mathrm{O}$ & 0 & 0 & 0 & 0 & 0 & 0 & 0 & 0 & 0 & 0 & 0 \\
\hline $\mathrm{CuO}$ & 0 & 0 & 0 & 0 & 0 & 0 & 0 & 0 & 0 & 0 & 0 \\
\hline $\mathrm{Eu} 2 \mathrm{O} 3$ & 0 & 0 & 0 & 0 & 0 & 0 & 0 & 0 & 0 & 0 & 0 \\
\hline $\mathrm{F}$ & 0 & 0 & 0 & 0 & 0 & 0 & 0 & 0 & 0 & 0 & 0 \\
\hline $\mathrm{Fe} 2 \mathrm{O} 3$ & 0.01 & 0 & 0.0051 & 0.9785 & 0.0001 & 0.1068 & 0.0001 & 0.0004 & 0.025 & 0.0001 & 0.0009 \\
\hline $\mathrm{Gd} 2 \mathrm{O} 3$ & 0 & 0 & 0 & 0 & 0 & 0 & 0 & 0 & 0 & 0 & 0 \\
\hline $\mathrm{HgO}$ & 0 & 0 & 0 & 0 & 0 & 0 & 0 & 0 & 0 & 0 & 0 \\
\hline I & 0 & 0 & 0 & 0 & 0 & 0 & 0 & 0 & 0 & 0 & 0 \\
\hline $\mathrm{K} 2 \mathrm{O}$ & 0.0007 & 0 & 0 & 0 & 0.0001 & 0 & 0 & 0.0002 & 0 & 0 & 0 \\
\hline $\mathrm{La} 2 \mathrm{O} 3$ & 0 & 0 & 0 & 0 & 0 & 0 & 0 & 0 & 0 & 0 & 0 \\
\hline $\mathrm{Li2O}$ & 0 & 0 & 0 & 0 & 0.4044 & 0 & 0 & 0 & 0 & 0 & 0 \\
\hline $\mathrm{MgO}$ & 0.0004 & 0 & 0.001 & 0.0037 & 0.0002 & 0.4934 & 0.0001 & 0.0001 & 0 & 0 & 0 \\
\hline $\mathrm{MnO}$ & 0 & 0 & 0.0011 & 0.0039 & 0 & 0 & 0 & 0 & 0 & 0.0001 & 0 \\
\hline $\mathrm{MoO} 3$ & 0 & 0 & 0 & 0 & 0 & 0 & 0 & 0 & 0 & 0 & 0 \\
\hline $\mathrm{Na} 2 \mathrm{O}$ & 0.0042 & 0 & 0 & 0 & 0.0011 & 0.0004 & 0.5848 & 0.0002 & 0 & 0 & 0 \\
\hline $\mathrm{Nb} 2 \mathrm{O} 5$ & 0 & 0 & 0 & 0 & 0 & 0 & 0 & 0 & 0 & 0 & 0 \\
\hline $\mathrm{Nd} 2 \mathrm{O} 3$ & 0 & 0 & 0 & 0 & 0 & 0 & 0 & 0 & 0 & 0 & 0 \\
\hline $\mathrm{NiO}$ & 0 & 0 & 0 & 0 & 0 & 0.0052 & 0 & 0 & 0 & 0 & 0 \\
\hline $\mathrm{NpO} 2$ & 0 & 0 & 0 & 0 & 0 & 0 & 0 & 0 & 0 & 0 & 0 \\
\hline $\mathrm{P} 2 \mathrm{O} 5$ & 0 & 0 & 0 & 0.0054 & 0 & 0 & 0 & 0 & 0.0007 & 0 & 0 \\
\hline $\mathrm{Pa} 2 \mathrm{O} 5$ & 0 & 0 & 0 & 0 & 0 & 0 & 0 & 0 & 0 & 0 & 0 \\
\hline $\mathrm{PbO}$ & 0 & 0 & 0 & 0 & 0 & 0 & 0 & 0 & 0 & 0.0001 & 0 \\
\hline $\mathrm{PdO}$ & 0 & 0 & 0 & 0 & 0 & 0 & 0 & 0 & 0 & 0 & 0 \\
\hline Pr2O3 & 0 & 0 & 0 & 0 & 0 & 0 & 0 & 0 & 0 & 0 & 0 \\
\hline $\mathrm{PuO} 2$ & 0 & 0 & 0 & 0 & 0 & 0 & 0 & 0 & 0 & 0 & 0 \\
\hline $\mathrm{RaO}$ & 0 & 0 & 0 & 0 & 0 & 0 & 0 & 0 & 0 & 0 & 0 \\
\hline $\mathrm{Rb} 2 \mathrm{O}$ & 0 & 0 & 0 & 0 & 0 & 0 & 0 & 0 & 0 & 0 & 0 \\
\hline $\mathrm{Rh} 2 \mathrm{O} 3$ & 0 & 0 & 0 & 0 & 0 & 0 & 0 & 0 & 0 & 0 & 0 \\
\hline $\mathrm{RuO} 2$ & 0 & 0 & 0 & 0 & 0 & 0 & 0 & 0 & 0 & 0 & 0 \\
\hline $\mathrm{SO} 3$ & 0 & 0.0003 & 0 & 0.0009 & 0.0004 & 0 & 0.0002 & 0 & 0.0007 & 0 & 0 \\
\hline $\mathrm{Sb} 2 \mathrm{O} 3$ & 0 & 0 & 0 & 0 & 0 & 0 & 0 & 0 & 0 & 0 & 0 \\
\hline $\mathrm{SeO} 2$ & 0 & 0 & 0 & 0 & 0 & 0 & 0 & 0 & 0 & 0 & 0 \\
\hline $\mathrm{SiO} 2$ & 0.42 & 0 & 0.53 & 0.0186 & 0 & 0.4385 & 0 & 0.999 & 0.025 & 0 & 0.325 \\
\hline $\mathrm{Sm} 2 \mathrm{O} 3$ & 0 & 0 & 0 & 0 & 0 & 0 & 0 & 0 & 0 & 0 & 0 \\
\hline
\end{tabular}




\begin{tabular}{|c|c|c|c|c|c|c|c|c|c|c|c||}
\hline \hline & \multicolumn{10}{c|}{ Maximum } \\
\hline Comp & Kyanite & $\begin{array}{c}\text { Boric } \\
\text { Acid }\end{array}$ & $\begin{array}{c}\text { Wollas- } \\
\text { tonite }\end{array}$ & $\begin{array}{c}\text { Hema- } \\
\text { tite }\end{array}$ & $\begin{array}{c}\text { Li } \\
\text { Carbonate }\end{array}$ & Olivine & $\begin{array}{c}\text { Na } \\
\text { Carbonate }\end{array}$ & Silica & Rutile & Zincite & Zircon \\
\hline $\mathrm{SnO} 2$ & 0 & 0 & 0 & 0 & 0 & 0 & 0 & 0 & 0 & 0 & 0 \\
\hline $\mathrm{SrO}$ & 0 & 0 & 0 & 0 & 0 & 0 & 0 & 0 & 0 & 0 & 0 \\
\hline $\mathrm{Ta} 2 \mathrm{O} 5$ & 0 & 0 & 0 & 0 & 0 & 0 & 0 & 0 & 0 & 0 & 0 \\
\hline $\mathrm{Tc2O} 7$ & 0 & 0 & 0 & 0 & 0 & 0 & 0 & 0 & 0 & 0 & 0 \\
\hline $\mathrm{TeO} 2$ & 0 & 0 & 0 & 0 & 0 & 0 & 0 & 0 & 0 & 0 & 0 \\
\hline $\mathrm{ThO} 2$ & 0 & 0 & 0 & 0 & 0 & 0 & 0 & 0 & 0 & 0 & 0 \\
\hline $\mathrm{TiO} 2$ & 0.016 & 0 & 0.0003 & 0 & 0 & 0 & 0 & 0.0005 & 0.936 & 0 & 0.0014 \\
\hline $\mathrm{T} 12 \mathrm{O}$ & 0 & 0 & 0 & 0 & 0 & 0 & 0 & 0 & 0 & 0 & 0 \\
\hline $\mathrm{UO3}$ & 0 & 0 & 0 & 0 & 0 & 0 & 0 & 0 & 0 & 0 & 0.0008 \\
\hline $\mathrm{V} 2 \mathrm{O} 5$ & 0 & 0 & 0 & 0 & 0 & 0 & 0 & 0 & 0.0075 & 0 & 0 \\
\hline $\mathrm{WO} 3$ & 0 & 0 & 0 & 0 & 0 & 0 & 0 & 0 & 0 & 0 & 0 \\
\hline $\mathrm{Y} 2 \mathrm{O} 3$ & 0 & 0 & 0 & 0 & 0 & 0 & 0 & 0 & 0 & 0 & 0 \\
\hline $\mathrm{ZnO}$ & 0 & 0 & 0 & 0 & 0 & 0 & 0 & 0 & 0 & 0.9999 & 0 \\
\hline $\mathrm{ZrO} 2$ & 0 & 0 & 0 & 0 & 0 & 0 & 0 & 0 & 0.025 & 0 & 0.67 \\
\hline
\end{tabular}


Table A-5. GFC Compositions: Nominal Composition Used for Nominal Glass Composition Calculation Obtained by 50,000 Monte Carlo Simulations

\begin{tabular}{|c|c|c|c|c|c|c|}
\hline \multicolumn{7}{|c|}{ Nominal } \\
\hline Comp & Kyanite & $\begin{array}{l}\text { Boric } \\
\text { Acid }\end{array}$ & Wollastonite & Hematite & $\underset{\text { Carbonate }}{\mathbf{L i}}$ & Olivine \\
\hline $\mathrm{Ac} 2 \mathrm{O} 3$ & 0 & 0 & 0 & 0 & 0 & 0 \\
\hline Ag2O & 0 & 0 & 0 & 0 & 0 & 0 \\
\hline $\mathrm{A} 12 \mathrm{O} 3$ & $5.7022 \mathrm{E}-01$ & 0 & $2.0031 \mathrm{E}-03$ & $1.5000 \mathrm{E}-02$ & 0 & $2.6103 \mathrm{E}-03$ \\
\hline $\mathrm{Am} 2 \mathrm{O} 3$ & 0 & 0 & 0 & 0 & 0 & 0 \\
\hline As2O5 & 0 & 0 & 0 & 0 & 0 & 0 \\
\hline $\mathrm{B} 2 \mathrm{O} 3$ & 0 & $5.6522 \mathrm{E}-01$ & 0 & 0 & 0 & 0 \\
\hline $\mathrm{BaO}$ & 0 & 0 & 0 & 0 & 0 & 0 \\
\hline $\mathrm{BeO}$ & 0 & 0 & 0 & 0 & 0 & 0 \\
\hline $\mathrm{Bi} 2 \mathrm{O} 3$ & 0 & 0 & 0 & 0 & 0 & 0 \\
\hline $\mathrm{CaO}$ & $2.6660 \mathrm{E}-04$ & 0 & $4.7510 \mathrm{E}-01$ & $3.9931 \mathrm{E}-04$ & $3.6573 \mathrm{E}-03$ & $1.8367 \mathrm{E}-04$ \\
\hline $\mathrm{CdO}$ & 0 & 0 & 0 & 0 & 0 & 0 \\
\hline $\mathrm{Ce} 2 \mathrm{O} 3$ & 0 & 0 & 0 & 0 & 0 & 0 \\
\hline $\mathrm{Cl}$ & 0 & 0 & 0 & 0 & $8.3241 \mathrm{E}-05$ & 0 \\
\hline $\mathrm{Cm} 2 \mathrm{O} 3$ & 0 & 0 & 0 & 0 & 0 & 0 \\
\hline $\mathrm{CoO}$ & 0 & 0 & 0 & 0 & 0 & 0 \\
\hline $\mathrm{Cr} 2 \mathrm{O} 3$ & 0 & 0 & 0 & 0 & $1.0008 \mathrm{E}-04$ & $2.1723 \mathrm{E}-03$ \\
\hline $\mathrm{Cs} 2 \mathrm{O}$ & 0 & 0 & 0 & 0 & 0 & 0 \\
\hline $\mathrm{CuO}$ & 0 & 0 & 0 & 0 & 0 & 0 \\
\hline $\mathrm{Eu} 2 \mathrm{O} 3$ & 0 & 0 & 0 & 0 & 0 & 0 \\
\hline $\mathrm{F}$ & 0 & 0 & 0 & 0 & 0 & 0 \\
\hline $\mathrm{Fe} 2 \mathrm{O} 3$ & $7.5678 \mathrm{E}-03$ & 0 & $4.0029 \mathrm{E}-03$ & $9.7006 \mathrm{E}-01$ & $1.6695 \mathrm{E}-05$ & $7.6858 \mathrm{E}-02$ \\
\hline $\mathrm{Gd} 2 \mathrm{O} 3$ & 0 & 0 & 0 & 0 & 0 & 0 \\
\hline $\mathrm{HgO}$ & 0 & 0 & 0 & 0 & 0 & 0 \\
\hline $\mathrm{I}$ & 0 & 0 & 0 & 0 & 0 & 0 \\
\hline $\mathrm{K} 2 \mathrm{O}$ & $1.1645 \mathrm{E}-04$ & 0 & 0 & 0 & $1.6577 \mathrm{E}-05$ & 0 \\
\hline $\mathrm{La} 2 \mathrm{O} 3$ & 0 & 0 & 0 & 0 & 0 & 0 \\
\hline $\mathrm{Li} 2 \mathrm{O}$ & 0 & 0 & 0 & 0 & 0.402061902 & 0 \\
\hline $\mathrm{MgO}$ & $1.3317 \mathrm{E}-04$ & 0 & 8.3461E-04 & $1.2988 \mathrm{E}-03$ & $9.9860 \mathrm{E}-05$ & 4.7949E-01 \\
\hline $\mathrm{MnO}$ & 0 & 0 & $1.0001 \mathrm{E}-03$ & 1.4992E-03 & 0 & 0 \\
\hline $\mathrm{MoO} 3$ & 0 & 0 & 0 & 0 & 0 & 0 \\
\hline $\mathrm{Na} 2 \mathrm{O}$ & 3.4953E-03 & 0 & 0 & 0 & $7.1550 \mathrm{E}-04$ & $2.6723 \mathrm{E}-04$ \\
\hline $\mathrm{Nb} 2 \mathrm{O} 5$ & 0 & 0 & 0 & 0 & 0 & 0 \\
\hline $\mathrm{Nd} 2 \mathrm{O} 3$ & 0 & 0 & 0 & 0 & 0 & 0 \\
\hline $\mathrm{NiO}$ & 0 & 0 & 0 & 0 & 0 & $3.7037 \mathrm{E}-03$ \\
\hline $\mathrm{NpO} 2$ & 0 & 0 & 0 & 0 & 0 & 0 \\
\hline $\mathrm{P} 2 \mathrm{O} 5$ & 0 & 0 & 0 & $2.9962 \mathrm{E}-03$ & 0 & 0 \\
\hline $\mathrm{Pa} 2 \mathrm{O} 5$ & 0 & 0 & 0 & 0 & 0 & 0 \\
\hline $\mathrm{PbO}$ & 0 & 0 & 0 & 0 & 0 & 0 \\
\hline $\mathrm{PdO}$ & 0 & 0 & 0 & 0 & 0 & 0 \\
\hline $\operatorname{Pr} 2 \mathrm{O} 3$ & 0 & 0 & 0 & 0 & 0 & 0 \\
\hline $\mathrm{PuO} 2$ & 0 & 0 & 0 & 0 & 0 & 0 \\
\hline $\mathrm{RaO}$ & 0 & 0 & 0 & 0 & 0 & 0 \\
\hline $\mathrm{Rb} 2 \mathrm{O}$ & 0 & 0 & 0 & 0 & 0 & 0 \\
\hline $\mathrm{Rh} 2 \mathrm{O} 3$ & 0 & 0 & 0 & 0 & 0 & 0 \\
\hline $\mathrm{RuO} 2$ & 0 & 0 & 0 & 0 & 0 & 0 \\
\hline
\end{tabular}




\begin{tabular}{|c|c|c|c|c|c|c|}
\hline \multicolumn{7}{|c|}{ Nominal } \\
\hline Comp & Kyanite & $\begin{array}{l}\text { Boric } \\
\text { Acid }\end{array}$ & Wollastonite & Hematite & $\begin{array}{c}\mathbf{L i} \\
\text { Carbonate }\end{array}$ & Olivine \\
\hline $\mathrm{SO} 3$ & 0 & $4.9790 \mathrm{E}-05$ & 0 & 7.1674E-04 & $2.6638 \mathrm{E}-04$ & 0 \\
\hline $\mathrm{Sb} 2 \mathrm{O} 3$ & 0 & 0 & 0 & 0 & 0 & 0 \\
\hline $\mathrm{SeO} 2$ & 0 & 0 & 0 & 0 & 0 & 0 \\
\hline $\mathrm{SiO} 2$ & $4.0608 \mathrm{E}-01$ & 0 & $5.0821 \mathrm{E}-01$ & $1.3493 \mathrm{E}-02$ & 0 & $4.2466 \mathrm{E}-01$ \\
\hline $\mathrm{Sm} 2 \mathrm{O} 3$ & 0 & 0 & 0 & 0 & 0 & 0 \\
\hline $\mathrm{SnO} 2$ & 0 & 0 & 0 & 0 & 0 & 0 \\
\hline $\mathrm{SrO}$ & 0 & 0 & 0 & 0 & 0 & 0 \\
\hline Ta2O5 & 0 & 0 & 0 & 0 & 0 & 0 \\
\hline Tc2O7 & 0 & 0 & 0 & 0 & 0 & 0 \\
\hline $\mathrm{TeO} 2$ & 0 & 0 & 0 & 0 & 0 & 0 \\
\hline ThO2 & 0 & 0 & 0 & 0 & 0 & 0 \\
\hline $\mathrm{TiO} 2$ & $8.7694 \mathrm{E}-03$ & 0 & $1.9986 \mathrm{E}-04$ & 0 & 0 & 0 \\
\hline $\mathrm{T} 12 \mathrm{O}$ & 0 & 0 & 0 & 0 & 0 & 0 \\
\hline UO3 & 0 & 0 & 0 & 0 & 0 & 0 \\
\hline $\mathrm{V} 2 \mathrm{O} 5$ & 0 & 0 & 0 & 0 & 0 & 0 \\
\hline WO3 & 0 & 0 & 0 & 0 & 0 & 0 \\
\hline $\mathrm{Y} 2 \mathrm{O} 3$ & 0 & 0 & 0 & 0 & 0 & 0 \\
\hline $\mathrm{ZnO}$ & 0 & 0 & 0 & 0 & 0 & 0 \\
\hline $\mathrm{ZrO} 2$ & 0 & 0 & 0 & 0 & 0 & 0 \\
\hline
\end{tabular}

\begin{tabular}{|c|c|c|c|c|c|}
\hline \multicolumn{6}{|c|}{ Nominal (continued) } \\
\hline Comp & $\begin{array}{c}\mathrm{Na} \\
\text { Carbonate } \\
\end{array}$ & Silica & Rutile & Zincite & Zircon \\
\hline $\mathrm{Ac} 2 \mathrm{O} 3$ & 0 & 0 & 0 & 0 & 0 \\
\hline $\mathrm{Ag} 2 \mathrm{O}$ & 0 & 0 & 0 & 0 & 0 \\
\hline $\mathrm{Al} 2 \mathrm{O} 3$ & 0 & $1.6566 \mathrm{E}-03$ & 4.5844E-03 & 0 & $2.5022 \mathrm{E}-03$ \\
\hline $\mathrm{Am} 2 \mathrm{O} 3$ & 0 & 0 & 0 & 0 & 0 \\
\hline As2O5 & 0 & 0 & 0 & 0 & 0 \\
\hline $\mathrm{B} 2 \mathrm{O} 3$ & 0 & 0 & 0 & 0 & 0 \\
\hline $\mathrm{BaO}$ & 0 & 0 & 0 & 0 & 0 \\
\hline $\mathrm{BeO}$ & 0 & 0 & 0 & 0 & 0 \\
\hline $\mathrm{Bi} 2 \mathrm{O} 3$ & 0 & 0 & 0 & 0 & 0 \\
\hline $\mathrm{CaO}$ & $1.6584 \mathrm{E}-05$ & $1.0045 \mathrm{E}-04$ & 0 & 0 & 0 \\
\hline $\mathrm{CdO}$ & 0 & 0 & 0 & $1.0008 \mathrm{E}-04$ & 0 \\
\hline $\mathrm{Ce} 2 \mathrm{O} 3$ & 0 & 0 & 0 & 0 & 0 \\
\hline $\mathrm{Cl}$ & $1.6674 \mathrm{E}-04$ & 0 & 0 & 0 & 0 \\
\hline $\mathrm{Cm} 2 \mathrm{O} 3$ & 0 & 0 & 0 & 0 & 0 \\
\hline $\mathrm{CoO}$ & 0 & 0 & 0 & 0 & 0 \\
\hline $\mathrm{Cr} 2 \mathrm{O} 3$ & $1.0015 \mathrm{E}-04$ & 0 & $2.3093 \mathrm{E}-03$ & 0 & 0 \\
\hline $\mathrm{Cs} 2 \mathrm{O}$ & 0 & 0 & 0 & 0 & 0 \\
\hline $\mathrm{CuO}$ & 0 & 0 & 0 & 0 & 0 \\
\hline $\mathrm{Eu} 2 \mathrm{O} 3$ & 0 & 0 & 0 & 0 & 0 \\
\hline $\mathrm{F}$ & 0 & 0 & 0 & 0 & 0 \\
\hline $\mathrm{Fe} 2 \mathrm{O} 3$ & $1.6688 \mathrm{E}-05$ & $2.1680 \mathrm{E}-04$ & 8.8351E-03 & $1.6578 \mathrm{E}-05$ & 7.8329E-04 \\
\hline $\mathrm{Gd} 2 \mathrm{O} 3$ & 0 & 0 & 0 & 0 & 0 \\
\hline $\mathrm{HgO}$ & 0 & 0 & 0 & 0 & 0 \\
\hline $\mathrm{I}$ & 0 & 0 & 0 & 0 & 0 \\
\hline
\end{tabular}




\begin{tabular}{|c|c|c|c|c|c|}
\hline \multicolumn{6}{|c|}{ Nominal (continued) } \\
\hline Comp & $\begin{array}{c}\mathrm{Na} \\
\text { Carbonate }\end{array}$ & Silica & Rutile & Zincite & Zircon \\
\hline $\mathrm{K} 2 \mathrm{O}$ & 0 & $3.3482 \mathrm{E}-05$ & 0 & 0 & 0 \\
\hline $\mathrm{La} 2 \mathrm{O} 3$ & 0 & 0 & 0 & 0 & 0 \\
\hline $\mathrm{Li} 2 \mathrm{O}$ & 0 & 0 & 0 & 0 & 0 \\
\hline $\mathrm{MgO}$ & $1.6635 \mathrm{E}-05$ & $8.3341 \mathrm{E}-05$ & 0 & 0 & 0 \\
\hline $\mathrm{MnO}$ & 0 & 0 & 0 & $1.6592 \mathrm{E}-05$ & 0 \\
\hline $\mathrm{MoO} 3$ & 0 & 0 & 0 & 0 & 0 \\
\hline $\mathrm{Na} 2 \mathrm{O}$ & $5.8378 \mathrm{E}-01$ & $1.6693 \mathrm{E}-04$ & 0 & 0 & 0 \\
\hline $\mathrm{Nb} 2 \mathrm{O} 5$ & 0 & 0 & 0 & 0 & 0 \\
\hline $\mathrm{Nd} 2 \mathrm{O} 3$ & 0 & 0 & 0 & 0 & 0 \\
\hline $\mathrm{NiO}$ & 0 & 0 & 0 & 0 & 0 \\
\hline $\mathrm{NpO} 2$ & 0 & 0 & 0 & 0 & 0 \\
\hline $\mathrm{P} 2 \mathrm{O} 5$ & 0 & 0 & $1.1719 \mathrm{E}-04$ & 0 & 0 \\
\hline $\mathrm{Pa} 2 \mathrm{O} 5$ & 0 & 0 & 0 & 0 & 0 \\
\hline $\mathrm{PbO}$ & 0 & 0 & 0 & $1.6637 \mathrm{E}-05$ & 0 \\
\hline $\mathrm{PdO}$ & 0 & 0 & 0 & 0 & 0 \\
\hline Pr2O3 & 0 & 0 & 0 & 0 & 0 \\
\hline $\mathrm{PuO} 2$ & 0 & 0 & 0 & 0 & 0 \\
\hline $\mathrm{RaO}$ & 0 & 0 & 0 & 0 & 0 \\
\hline $\mathrm{Rb} 2 \mathrm{O}$ & 0 & 0 & 0 & 0 & 0 \\
\hline $\mathrm{Rh} 2 \mathrm{O} 3$ & 0 & 0 & 0 & 0 & 0 \\
\hline $\mathrm{RuO} 2$ & 0 & 0 & 0 & 0 & 0 \\
\hline $\mathrm{SO} 3$ & $1.0011 \mathrm{E}-04$ & 0 & $1.1701 \mathrm{E}-04$ & 0 & 0 \\
\hline $\mathrm{Sb} 2 \mathrm{O} 3$ & 0 & 0 & 0 & 0 & 0 \\
\hline $\mathrm{SeO} 2$ & 0 & 0 & 0 & 0 & 0 \\
\hline $\mathrm{SiO} 2$ & 0 & $9.9651 \mathrm{E}-01$ & $1.8817 \mathrm{E}-02$ & 0 & $3.2253 \mathrm{E}-01$ \\
\hline $\mathrm{Sm} 2 \mathrm{O} 3$ & 0 & 0 & 0 & 0 & 0 \\
\hline $\mathrm{SnO} 2$ & 0 & 0 & 0 & 0 & 0 \\
\hline $\mathrm{SrO}$ & 0 & 0 & 0 & 0 & 0 \\
\hline Ta2O5 & 0 & 0 & 0 & 0 & 0 \\
\hline $\mathrm{Tc} 2 \mathrm{O} 7$ & 0 & 0 & 0 & 0 & 0 \\
\hline $\mathrm{TeO} 2$ & 0 & 0 & 0 & 0 & 0 \\
\hline $\mathrm{ThO} 2$ & 0 & 0 & 0 & 0 & 0 \\
\hline $\mathrm{TiO} 2$ & 0 & $1.5000 \mathrm{E}-04$ & $9.3206 \mathrm{E}-01$ & 0 & $1.0169 \mathrm{E}-03$ \\
\hline $\mathrm{T} 12 \mathrm{O}$ & 0 & 0 & 0 & 0 & 0 \\
\hline $\mathrm{UO} 3$ & 0 & 0 & 0 & 0 & $4.5003 \mathrm{E}-04$ \\
\hline $\mathrm{V} 2 \mathrm{O} 5$ & 0 & 0 & $4.2517 \mathrm{E}-03$ & 0 & 0 \\
\hline WO3 & 0 & 0 & 0 & 0 & 0 \\
\hline $\mathrm{Y} 2 \mathrm{O} 3$ & 0 & 0 & 0 & 0 & 0 \\
\hline $\mathrm{ZnO}$ & 0 & 0 & 0 & $9.9815 \mathrm{E}-01$ & 0 \\
\hline $\mathrm{ZrO} 2$ & 0 & 0 & $1.6837 \mathrm{E}-02$ & 0 & $6.6004 \mathrm{E}-01$ \\
\hline
\end{tabular}


Table A-6. GFC Compositions: 11x11 Matrix of Nominal GFC Composition Used in Initial Calculation of GFC Masses from Target GFC Composition

\begin{tabular}{|c|c|c|c|c|c|c||}
\hline \hline Comp\GFC & Kyanite & $\begin{array}{c}\text { Boric } \\
\text { Acid }\end{array}$ & Wollastonite & Hematite & $\begin{array}{c}\text { Li } \\
\text { Carbonate }\end{array}$ & Olivine \\
\hline $\mathrm{A} 12 \mathrm{O} 3$ & $5.7022 \mathrm{E}-01$ & 0 & $2.0031 \mathrm{E}-03$ & $1.5000 \mathrm{E}-02$ & 0 & $2.6103 \mathrm{E}-03$ \\
\hline $\mathrm{B} 2 \mathrm{O} 3$ & 0 & $5.6522 \mathrm{E}-01$ & 0 & 0 & 0 & 0 \\
\hline $\mathrm{CaO}$ & $2.6660 \mathrm{E}-04$ & 0 & $4.7510 \mathrm{E}-01$ & $3.9931 \mathrm{E}-04$ & $3.6573 \mathrm{E}-03$ & $1.8367 \mathrm{E}-04$ \\
\hline $\mathrm{Fe} 2 \mathrm{O} 3$ & $7.5678 \mathrm{E}-03$ & 0 & $4.0029 \mathrm{E}-03$ & $9.7006 \mathrm{E}-01$ & $1.6695 \mathrm{E}-05$ & $7.6858 \mathrm{E}-02$ \\
\hline $\mathrm{Li} 2 \mathrm{O}$ & 0 & 0 & 0 & 0 & $4.0206 \mathrm{E}-01$ & 0 \\
\hline $\mathrm{MgO}$ & $1.3317 \mathrm{E}-04$ & 0 & $8.3461 \mathrm{E}-04$ & $1.2988 \mathrm{E}-03$ & $9.9860 \mathrm{E}-05$ & $4.7949 \mathrm{E}-01$ \\
\hline $\mathrm{Na} 2 \mathrm{O}$ & $3.4953 \mathrm{E}-03$ & 0 & 0 & 0 & $7.1550 \mathrm{E}-04$ & $2.6723 \mathrm{E}-04$ \\
\hline $\mathrm{SiO} 2$ & $4.0608 \mathrm{E}-01$ & 0 & $5.0821 \mathrm{E}-01$ & $1.3493 \mathrm{E}-02$ & 0 & $4.2466 \mathrm{E}-01$ \\
\hline $\mathrm{TiO} 2$ & $8.7694 \mathrm{E}-03$ & 0 & $1.9986 \mathrm{E}-04$ & 0 & 0 & 0 \\
\hline $\mathrm{ZnO}$ & 0 & 0 & 0 & 0 & 0 & 0 \\
\hline $\mathrm{ZrO} 2$ & 0 & 0 & 0 & 0 & 0 & 0 \\
\hline
\end{tabular}

\begin{tabular}{|c|c|c|c|c|c|}
\hline Comp $\backslash$ GFC & $\begin{array}{c}\text { Na } \\
\text { Carbonate }\end{array}$ & Silica & Rutile & Zincite & Zircon \\
\hline $\mathrm{Al2O} 3$ & 0 & $1.6566 \mathrm{E}-03$ & $4.5844 \mathrm{E}-03$ & 0 & $2.5022 \mathrm{E}-03$ \\
\hline $\mathrm{B} 2 \mathrm{O} 3$ & 0 & 0 & 0 & 0 & 0 \\
\hline $\mathrm{CaO}$ & $1.6584 \mathrm{E}-05$ & $1.0045 \mathrm{E}-04$ & 0 & 0 & 0 \\
\hline $\mathrm{Fe} 2 \mathrm{O} 3$ & $1.6688 \mathrm{E}-05$ & $2.1680 \mathrm{E}-04$ & $8.8351 \mathrm{E}-03$ & $1.6578 \mathrm{E}-05$ & $7.8329 \mathrm{E}-04$ \\
\hline $\mathrm{Li} 2 \mathrm{O}$ & 0 & 0 & 0 & 0 & 0 \\
\hline $\mathrm{MgO}$ & $1.6635 \mathrm{E}-05$ & $8.3341 \mathrm{E}-05$ & 0 & 0 & 0 \\
\hline $\mathrm{Na} 2 \mathrm{O}$ & $5.8378 \mathrm{E}-01$ & $1.6693 \mathrm{E}-04$ & 0 & 0 & 0 \\
\hline $\mathrm{SiO} 2$ & 0 & $9.9651 \mathrm{E}-01$ & $1.8817 \mathrm{E}-02$ & 0 & $3.2253 \mathrm{E}-01$ \\
\hline $\mathrm{TiO} 2$ & 0 & $1.5000 \mathrm{E}-04$ & $9.3206 \mathrm{E}-01$ & 0 & $1.0169 \mathrm{E}-03$ \\
\hline $\mathrm{ZnO}$ & 0 & 0 & 0 & $9.9815 \mathrm{E}-01$ & 0 \\
\hline $\mathrm{ZrO} 2$ & 0 & 0 & $5.7022 \mathrm{E}-01$ & 0 & $6.6004 \mathrm{E}-01$ \\
\hline
\end{tabular}


Table A-7. Variance-Covariance Matrices for PCT-B Model

\begin{tabular}{|c|c|c|c|c|c|c|c|c||}
\hline Term & Al2O3 & B2O3 & CaO & Fe2O3 & K2O & Li2O & MgO & Na2O \\
\hline $\mathrm{A} 2 \mathrm{O} 3$ & 4.5411 & -0.8535 & -0.0978 & 0.0909 & 0.9952 & -4.5759 & -0.0689 & -4.8201 \\
\hline $\mathrm{B} 2 \mathrm{O} 3$ & -0.8535 & 6.5050 & -0.4167 & -0.6563 & -0.0878 & 10.2294 & 11.4075 & -2.3603 \\
\hline $\mathrm{CaO}$ & -0.0978 & -0.4167 & 9.0851 & 8.3041 & 2.1673 & 6.1810 & 1.3799 & -5.4011 \\
\hline $\mathrm{Fe} 2 \mathrm{O} 3$ & 0.0909 & -0.6563 & 8.3041 & 10.3431 & 2.0919 & 3.0053 & 0.5102 & -7.1887 \\
\hline $\mathrm{K} 2 \mathrm{O}$ & 0.9952 & -0.0878 & 2.1673 & 2.0919 & 3.0456 & 0.4433 & 0.6721 & -5.0192 \\
\hline $\mathrm{Li} 2 \mathrm{O}$ & -4.5759 & 10.2294 & 6.1810 & 3.0053 & 0.4433 & 72.0621 & -0.5370 & 2.9757 \\
\hline $\mathrm{MgO}$ & -0.0689 & 11.4075 & 1.3799 & 0.5102 & 0.6721 & -0.5370 & 68.0494 & -1.9809 \\
\hline $\mathrm{Na} 2 \mathrm{O}$ & -4.8201 & -2.3603 & -5.4011 & -7.1887 & -5.0192 & 2.9757 & -1.9809 & 27.1863 \\
\hline $\mathrm{P} 2 \mathrm{O} 5$ & 0.6100 & 0.0070 & 1.5476 & 1.8056 & 1.3508 & -0.8300 & -0.1016 & -4.0699 \\
\hline $\mathrm{SiO} 2$ & -0.9005 & -1.0301 & -1.5567 & -1.7741 & -1.0531 & -1.5044 & -1.2803 & 4.9330 \\
\hline $\mathrm{ZrO} 2$ & 1.2709 & 0.5252 & -0.5915 & -0.6713 & 0.6179 & -3.7898 & 2.2079 & -6.7996 \\
\hline $\mathrm{Others}$ & 0.6941 & 0.1474 & 0.7187 & 1.4425 & 0.4403 & -2.8944 & -1.3257 & -4.6686 \\
\hline $\mathrm{CaO} * \mathrm{Li} 2 \mathrm{O}$ & 3.9237 & -5.0328 & -82.4567 & -50.8286 & -6.5335 & -198.0406 & -87.7450 & -26.7093 \\
\hline $\mathrm{B} 2 \mathrm{O} 3 * \mathrm{MgO}$ & 5.7135 & -125.6845 & 0.4841 & 10.4487 & 13.4220 & -18.4379 & -703.1255 & -33.3977 \\
\hline $\mathrm{B} 2 \mathrm{O} 3 * \mathrm{Li} 2 \mathrm{O}$ & 50.1661 & -109.6279 & -0.4991 & 20.5465 & 17.2896 & -538.7395 & 4.6201 & -49.6081 \\
\hline $\mathrm{Na} 2 \mathrm{O} * \mathrm{SiO} 2$ & 11.8034 & 4.2468 & 13.4194 & 17.4395 & 12.8827 & -6.2908 & -2.2819 & -67.5964 \\
\hline $\mathrm{CaO} \mathrm{Fe} 2 \mathrm{O} 3$ & 11.6489 & 7.9481 & -122.4661 & -130.7800 & -21.6787 & -107.5801 & -26.9959 & 33.8730 \\
\hline
\end{tabular}

\begin{tabular}{|c|c|c|c|c|c|c||}
\hline Term & P2O5 & $\mathbf{S i O 2}$ & $\mathbf{Z r O 2}$ & Others & $\mathbf{C a O}^{*} \mathbf{L i 2 O}$ & $\mathbf{B 2 O 3}^{*} \mathbf{M g O}$ \\
\hline $\mathrm{A} 2 \mathrm{O} 3$ & 0.6100 & -0.9005 & 1.2709 & 0.6941 & 3.9237 & 5.7135 \\
\hline $\mathrm{B} 2 \mathrm{O} 3$ & 0.0070 & -1.0301 & 0.5252 & 0.1474 & -5.0328 & -125.6845 \\
\hline $\mathrm{CaO}$ & 1.5476 & -1.5567 & -0.5915 & 0.7187 & -82.4567 & 0.4841 \\
\hline $\mathrm{Fe} 2 \mathrm{O} 3$ & 1.8056 & -1.7741 & -0.6713 & 1.4425 & -50.8286 & 10.4487 \\
\hline $\mathrm{K} 2 \mathrm{O}$ & 1.3508 & -1.0531 & 0.6179 & 0.4403 & -6.5335 & 13.4220 \\
\hline $\mathrm{Li2O}$ & -0.8300 & -1.5044 & -3.7898 & -2.8944 & -198.0406 & -18.4379 \\
\hline $\mathrm{MgO}$ & -0.1016 & -1.2803 & 2.2079 & -1.3257 & -87.7450 & -703.1255 \\
\hline $\mathrm{Na2O}$ & -4.0699 & 4.9330 & -6.7996 & -4.6686 & -26.7093 & -33.3977 \\
\hline $\mathrm{P} 2 \mathrm{O} 5$ & 7.9409 & -0.9021 & 0.5266 & 0.9485 & 17.4291 & 6.7145 \\
\hline $\mathrm{SiO} 2$ & -0.9021 & 1.2395 & -1.2130 & -1.0866 & 0.6220 & 0.4196 \\
\hline $\mathrm{ZrO} 2$ & 0.5266 & -1.2130 & 7.7654 & 0.9872 & 22.7654 & -6.3621 \\
\hline $\mathrm{Others}$ & 0.9485 & -1.0866 & 0.9872 & 3.4495 & 13.2488 & 18.5875 \\
\hline $\mathrm{CaO}$ Li2O & 17.4291 & 0.6220 & 22.7654 & 13.2488 & 2855.3392 & 1162.9848 \\
\hline $\mathrm{B} 2 \mathrm{O} 3 * \mathrm{MgO}$ & 6.7145 & 0.4196 & -6.3621 & 18.5875 & 1162.9848 & 8018.1830 \\
\hline $\mathrm{B} 2 \mathrm{O} 3 * \mathrm{Li} 2 \mathrm{O}$ & 9.8905 & 2.2332 & 20.6910 & 24.3367 & 343.3240 & 227.1726 \\
\hline $\mathrm{Na} 2 \mathrm{O} * \mathrm{SiO} 2$ & 10.5893 & -12.6902 & 16.5233 & 11.6207 & 86.3608 & 175.8912 \\
\hline $\mathrm{CaO} * \mathrm{Fe} 2 \mathrm{O} 3$ & -16.7213 & 12.3915 & 32.4518 & -3.4768 & 1009.9195 & 225.1001 \\
\hline
\end{tabular}

\begin{tabular}{||c|c|c|c||}
\hline Term & B2O3*Li2O $^{*}$ & $\mathbf{N a 2 O}^{*} \mathbf{S i O 2}$ & $\mathbf{C a O} * \mathbf{F e 2 O 3}$ \\
\hline $\mathrm{A} 12 \mathrm{O} 3$ & 50.1661 & 11.8034 & 11.6489 \\
\hline $\mathrm{B} 2 \mathrm{O} 3$ & -109.6279 & 4.2468 & 7.9481 \\
\hline $\mathrm{CaO}$ & -0.4991 & 13.4194 & -122.4661 \\
\hline $\mathrm{Fe} 2 \mathrm{O} 3$ & 20.5465 & 17.4395 & -130.7800 \\
\hline $\mathrm{K} 2 \mathrm{O}$ & 17.2896 & 12.8827 & -21.6787 \\
\hline $\mathrm{Li} 2 \mathrm{O}$ & -538.7395 & -6.2908 & -107.5801 \\
\hline $\mathrm{MgO}$ & 4.6201 & -2.2819 & -26.9959 \\
\hline
\end{tabular}




\begin{tabular}{||c|c|c|c||}
\hline \hline Term & B2O3*Li2O & Na2O*SiO2 & CaO*Fe2O3 \\
\hline $\mathrm{Na} 2 \mathrm{O}$ & -49.6081 & -67.5964 & 33.8730 \\
\hline $\mathrm{P} 2 \mathrm{O} 5$ & 9.8905 & 10.5893 & -16.7213 \\
\hline $\mathrm{SiO} 2$ & 2.2332 & -12.6902 & 12.3915 \\
\hline $\mathrm{ZrO} 2$ & 20.6910 & 16.5233 & 32.4518 \\
\hline $\mathrm{O}$ thers & 24.3367 & 11.6207 & -3.4768 \\
\hline $\mathrm{CaO} * \mathrm{Li} 2 \mathrm{O}$ & 343.3240 & 86.3608 & 1009.9195 \\
\hline $\mathrm{B} 2 \mathrm{O} 3 * \mathrm{MgO}$ & 227.1726 & 175.8912 & 225.1001 \\
\hline $\mathrm{B} 2 \mathrm{O} 3 * \mathrm{Li} 2 \mathrm{O}$ & 5204.8656 & 138.6761 & 301.8835 \\
\hline $\mathrm{Na} 2 \mathrm{O} * \mathrm{SiO} 2$ & 138.6761 & 172.0205 & -71.7517 \\
\hline $\mathrm{CaO} * \mathrm{Fe} 2 \mathrm{O} 3$ & 301.8835 & -71.7517 & 2124.8909 \\
\hline
\end{tabular}


Table A-8. Variance-Covariance Matrix for PCT-Na Model

\begin{tabular}{|c|c|c|c|c|c|c|c||}
\hline Term & $\mathbf{A l 2 0 3}$ & $\mathbf{B 2 O 3}$ & $\mathbf{C a O}$ & $\mathbf{F e 2 O 3}$ & $\mathbf{K 2 O}$ & $\mathbf{L i 2 O}$ & MgO \\
\hline $\mathrm{A} 12 \mathrm{O} 3$ & 2.6367 & -0.2222 & -0.7385 & -0.9214 & 0.3894 & 0.0726 & 0.0444 \\
\hline $\mathrm{B} 2 \mathrm{O} 3$ & -0.2222 & 7.6234 & -1.8619 & -1.2119 & 0.0080 & -2.1700 & 8.3156 \\
\hline $\mathrm{CaO}$ & -0.7385 & -1.8619 & 6.5491 & 5.5974 & -0.3900 & 4.5648 & 1.3215 \\
\hline $\mathrm{Fe} 2 \mathrm{O} 3$ & -0.9214 & -1.2119 & 5.5974 & 6.7804 & -0.7335 & 3.5350 & 0.5885 \\
\hline $\mathrm{K} 2 \mathrm{O}$ & 0.3894 & 0.0080 & -0.3900 & -0.7335 & 15.7842 & 0.2329 & 1.0913 \\
\hline $\mathrm{Li} 2 \mathrm{O}$ & 0.0726 & -2.1700 & 4.5648 & 3.5350 & 0.2329 & 12.5785 & 0.1544 \\
\hline $\mathrm{MgO}$ & 0.0444 & 8.3156 & 1.3215 & 0.5885 & 1.0913 & 0.1544 & 52.5669 \\
\hline $\mathrm{Na} 2 \mathrm{O}$ & -0.2025 & 2.8308 & -0.8383 & -0.5800 & -0.1269 & 0.0640 & -2.6874 \\
\hline $\mathrm{P} 2 \mathrm{O} 5$ & -0.0847 & -0.9891 & 0.7250 & 0.6211 & 0.6935 & -0.0688 & 0.1514 \\
\hline $\mathrm{SiO} 2$ & -0.0931 & -0.8349 & -0.3090 & -0.3470 & 0.0011 & -0.4073 & -1.0574 \\
\hline $\mathrm{ZrO} 2$ & 0.0893 & -0.2650 & -1.4150 & -1.8620 & 0.5222 & -1.8244 & 1.9660 \\
\hline $\mathrm{Others}$ & -0.1842 & -0.0865 & -0.0130 & 0.2671 & -0.9330 & -0.6020 & -0.9052 \\
\hline $\mathrm{CaO} * \mathrm{Li2O}$ & -2.8191 & 2.1879 & -70.6074 & -48.1835 & 7.4888 & -130.1176 & -66.8946 \\
\hline $\mathrm{CaO}$ Fe2O3 & 10.9332 & 22.0585 & -93.0576 & -98.1200 & 4.8711 & -59.0421 & -22.4845 \\
\hline $\mathrm{B} 2 \mathrm{O} 3 * \mathrm{MgO}$ & -5.5808 & -105.5970 & -7.7365 & -4.3021 & -8.5036 & -0.2581 & -540.0123 \\
\hline $\mathrm{B} 2 \mathrm{O} 3 * \mathrm{Na} 2 \mathrm{O}$ & 0.3251 & -40.8666 & 9.5918 & 4.2261 & -1.1662 & 9.1771 & 5.6624 \\
\hline $\mathrm{K} 2 \mathrm{O} * \mathrm{~K} 2 \mathrm{O}$ & -7.5665 & -13.1053 & 30.6658 & 30.2914 & -313.1547 & 24.6694 & -8.6805 \\
\hline
\end{tabular}

\begin{tabular}{|c|c|c|c|c|c||}
\hline Term & Na2O & P2O5 & SiO2 & ZrO2 & Others \\
\hline $\mathrm{A} 12 \mathrm{O} 3$ & -0.2025 & -0.0847 & -0.0931 & 0.0893 & -0.1842 \\
\hline $\mathrm{B} 2 \mathrm{O} 3$ & 2.8308 & -0.9891 & -0.8349 & -0.2650 & -0.0865 \\
\hline $\mathrm{CaO}$ & -0.8383 & 0.7250 & -0.3090 & -1.4150 & -0.0130 \\
\hline $\mathrm{Fe} 2 \mathrm{O} 3$ & -0.5800 & 0.6211 & -0.3470 & -1.8620 & 0.2671 \\
\hline $\mathrm{K} 2 \mathrm{O}$ & -0.1269 & 0.6935 & 0.0011 & 0.5222 & -0.9330 \\
\hline $\mathrm{Li} 2 \mathrm{O}$ & 0.0640 & -0.0688 & -0.4073 & -1.8244 & -0.6020 \\
\hline $\mathrm{MgO}$ & -2.6874 & 0.1514 & -1.0574 & 1.9660 & -0.9052 \\
\hline $\mathrm{Na} 2 \mathrm{O}$ & 2.8123 & -0.5161 & -0.4047 & -0.6056 & -0.2447 \\
\hline $\mathrm{P} 2 \mathrm{O} 5$ & -0.5161 & 5.7728 & -0.0060 & -0.2731 & 0.2061 \\
\hline $\mathrm{SiO} 2$ & -0.4047 & -0.0060 & 0.2645 & 0.0507 & -0.1846 \\
\hline $\mathrm{ZrO} 2$ & -0.6056 & -0.2731 & 0.0507 & 4.8825 & -0.1335 \\
\hline $\mathrm{Others}$ & -0.2447 & 0.2061 & -0.1846 & -0.1335 & 2.0567 \\
\hline $\mathrm{CaO}$ Li2O & 7.1486 & 9.1275 & 4.6965 & 11.8234 & 4.2279 \\
\hline $\mathrm{CaO} * \mathrm{Fe} 2 \mathrm{O} 3$ & 9.7084 & -10.6784 & 4.0376 & 30.3392 & -0.8944 \\
\hline $\mathrm{B} 2 \mathrm{O} 3 * \mathrm{MgO}$ & 22.8696 & -2.1734 & 10.8288 & -17.9346 & 5.6599 \\
\hline $\mathrm{B} 2 \mathrm{O} 3 * \mathrm{Na} 2 \mathrm{O}$ & -29.0184 & 7.2277 & 4.3856 & 4.3044 & 2.0542 \\
\hline $\mathrm{K} 2 \mathrm{O} * \mathrm{~K} 2 \mathrm{O}$ & -2.7077 & -4.3109 & -1.1330 & -21.3201 & 13.3522 \\
\hline
\end{tabular}

\begin{tabular}{|c|c|c|c|c|c||}
\hline Term & $\mathbf{C a O}$ *i2O & $\mathbf{C a O} * \mathbf{F e 2 O 3}$ & $\mathbf{B 2 O 3 * \mathbf { M g O }}$ & B2O3*Na2O & K2O*K2O \\
\hline $\mathrm{A} 12 \mathrm{O} 3$ & -2.8191 & 10.9332 & -5.5808 & 0.3251 & -7.5665 \\
\hline $\mathrm{B} 2 \mathrm{O} 3$ & 2.1879 & 22.0585 & -105.5970 & -40.8666 & -13.1053 \\
\hline $\mathrm{CaO}$ & -70.6074 & -93.0576 & -7.7365 & 9.5918 & 30.6658 \\
\hline $\mathrm{Fe} 2 \mathrm{O} 3$ & -48.1835 & -98.1200 & -4.3021 & 4.2261 & 30.2914 \\
\hline $\mathrm{K} 2 \mathrm{O}$ & 7.4888 & 4.8711 & -8.5036 & -1.1662 & -313.1547 \\
\hline $\mathrm{Li} 2 \mathrm{O}$ & -130.1176 & -59.0421 & -0.2581 & 9.1771 & 24.6694 \\
\hline $\mathrm{MgO}$ & -66.8946 & -22.4845 & -540.0123 & 5.6624 & -8.6805 \\
\hline
\end{tabular}




\begin{tabular}{|c|c|c|c|c|c||}
\hline Term & $\mathbf{C a O} * \mathbf{L i 2 O}$ & $\mathbf{C a O} * \mathbf{F e 2 O 3}$ & $\mathbf{B 2 O 3 * \mathbf { M g O }}$ & $\mathbf{B 2 O 3} * \mathbf{N a 2 O}$ & K2O*K2O \\
\hline $\mathrm{Na} 2 \mathrm{O}$ & 7.1486 & 9.7084 & 22.8696 & -29.0184 & -2.7077 \\
\hline $\mathrm{P} 2 \mathrm{O} 5$ & 9.1275 & -10.6784 & -2.1734 & 7.2277 & -4.3109 \\
\hline $\mathrm{SiO} 2$ & 4.6965 & 4.0376 & 10.8288 & 4.3856 & -1.1330 \\
\hline $\mathrm{ZrO} 2$ & 11.8234 & 30.3392 & -17.9346 & 4.3044 & -21.3201 \\
\hline $\mathrm{O}$ thers & 4.2279 & -0.8944 & 5.6599 & 2.0542 & 13.3522 \\
\hline $\mathrm{CaO} * \mathrm{Li} 2 \mathrm{O}$ & 2181.7928 & 819.1763 & 810.6713 & -25.9923 & -398.1906 \\
\hline $\mathrm{CaO} * \mathrm{Fe} 2 \mathrm{O} 3$ & 819.1763 & 1633.1939 & 203.0666 & -73.5093 & -408.6876 \\
\hline $\mathrm{B} 2 \mathrm{O} 3 * \mathrm{MgO}$ & 810.6713 & 203.0666 & 6060.0432 & 59.3798 & 202.3782 \\
\hline $\mathrm{B} 2 \mathrm{O} 3 * \mathrm{Na} 2 \mathrm{O}$ & -25.9923 & -73.5093 & 59.3798 & 361.3491 & 102.0262 \\
\hline $\mathrm{K} 2 \mathrm{O} * \mathrm{~K} 2 \mathrm{O}$ & -398.1906 & -408.6876 & 202.3782 & 102.0262 & 6928.8404 \\
\hline \hline
\end{tabular}


Table A-9. Variance-Covariance Matrix for VHT Model

\begin{tabular}{|c|c|c|c|c|c|c||}
\hline Term & $\mathbf{A l 2 O 3}$ & $\mathbf{B 2 O 3}$ & $\mathbf{C a O}$ & Fe2O3 & K2O & Li2O \\
\hline $\mathrm{A} 12 \mathrm{O} 3$ & 37.0274 & -6.1959 & -7.5969 & 0.8362 & -3.8661 & -21.7084 \\
\hline $\mathrm{B} 2 \mathrm{O} 3$ & -6.1959 & 35.0847 & 34.8292 & 1.0209 & -6.1880 & -37.0646 \\
\hline $\mathrm{CaO}$ & -7.5969 & 34.8292 & 89.2636 & -12.8816 & -23.1870 & -31.9473 \\
\hline $\mathrm{Fe} 2 \mathrm{O} 3$ & 0.8362 & 1.0209 & -12.8816 & 22.3018 & -11.4926 & -19.7243 \\
\hline $\mathrm{K} 2 \mathrm{O}$ & -3.8661 & -6.1880 & -23.1870 & -11.4926 & 114.6504 & 11.3336 \\
\hline $\mathrm{Li} 2 \mathrm{O}$ & -21.7084 & -37.0646 & -31.9473 & -19.7243 & 11.3336 & 402.6862 \\
\hline $\mathrm{MgO}$ & -7.1062 & -6.2560 & -14.3315 & -0.8794 & 33.6888 & -3.1993 \\
\hline $\mathrm{Na} 2 \mathrm{O}$ & -16.2542 & 6.5622 & 42.1681 & -19.7161 & -3.7296 & 150.0097 \\
\hline $\mathrm{SiO} 2$ & 0.7085 & -7.7598 & -12.6605 & 0.5479 & 0.5948 & -14.3494 \\
\hline $\mathrm{ZrO} 2$ & 4.4076 & -3.1717 & -4.0153 & 5.4465 & 3.7883 & -33.6196 \\
\hline $\mathrm{Others}$ & -2.6630 & -0.3724 & -11.9223 & 5.1363 & -0.2410 & -22.2422 \\
\hline$(\mathrm{K} 2 \mathrm{O}) 2 \mathrm{Na} 2 \mathrm{O}$ & 771.0153 & 163.3330 & 859.1075 & 1630.2301 & -10990.5144 & -4461.2830 \\
\hline$(\mathrm{Na} 2 \mathrm{O}) 3$ & 136.0406 & -21.6663 & -349.6870 & 195.3939 & 60.2046 & -1792.6212 \\
\hline $\mathrm{Li} 2 \mathrm{O} * \mathrm{Na} 2 \mathrm{O} * \mathrm{SiO} 2$ & 276.5747 & 673.4985 & 310.5460 & 424.0416 & 230.0304 & -6956.0025 \\
\hline $\mathrm{B} 2 \mathrm{O} 3 * \mathrm{CaO} * \mathrm{Na} 2 \mathrm{O}$ & 640.1299 & -3014.8798 & -6657.9092 & 1204.3237 & 1358.4667 & 1732.9326 \\
\hline
\end{tabular}

\begin{tabular}{|c|c|c|c|c|c|}
\hline Term & MgO & Na2O & SiO2 & ZrO2 & Others \\
\hline $\mathrm{A} 2 \mathrm{O} 3$ & -7.1062 & -16.2542 & 0.7085 & 4.4076 & -2.6630 \\
\hline $\mathrm{B} 2 \mathrm{O} 3$ & -6.2560 & 6.5622 & -7.7598 & -3.1717 & -0.3724 \\
\hline $\mathrm{CaO}$ & -14.3315 & 42.1681 & -12.6605 & -4.0153 & -11.9223 \\
\hline $\mathrm{Fe} 2 \mathrm{O} 3$ & -0.8794 & -19.7161 & 0.5479 & 5.4465 & 5.1363 \\
\hline $\mathrm{K} 2 \mathrm{O}$ & 33.6888 & -3.7296 & 0.5948 & 3.7883 & -0.2410 \\
\hline $\mathrm{Li} 2 \mathrm{O}$ & -3.1993 & 150.0097 & -14.3494 & -33.6196 & -22.2422 \\
\hline $\mathrm{MgO}$ & 64.6618 & -7.0818 & -0.4710 & 2.6589 & 0.9723 \\
\hline $\mathrm{Na} 2 \mathrm{O}$ & -7.0818 & 109.7369 & -15.6511 & -15.8112 & -16.6912 \\
\hline $\mathrm{SiO} 2$ & -0.4710 & -15.6511 & 5.2310 & 0.3491 & -0.6156 \\
\hline $\mathrm{ZrO} 2$ & 2.6589 & -15.8112 & 0.3491 & 57.6249 & -1.8627 \\
\hline $\mathrm{Others}$ & 0.9723 & -16.6912 & -0.6156 & -1.8627 & 28.6027 \\
\hline$(\mathrm{K} 2 \mathrm{O}) 2 * \mathrm{Na} 2 \mathrm{O}$ & -2212.0420 & -2639.7226 & 279.1963 & -614.7721 & 786.0088 \\
\hline$(\mathrm{Na} 2 \mathrm{O}) 3$ & 115.1066 & -1302.7253 & 164.8064 & 112.1162 & 195.0451 \\
\hline $\mathrm{Li2O} * \mathrm{Na} 2 \mathrm{O} * \mathrm{SiO} 2$ & 343.3545 & -2825.3603 & 197.3669 & 368.3748 & 561.4452 \\
\hline $\mathrm{B} 2 \mathrm{O} 3 * \mathrm{CaO} * \mathrm{Na} 2 \mathrm{O}$ & 1224.0790 & -4182.2868 & 1064.2436 & 527.1768 & 927.7819 \\
\hline
\end{tabular}

\begin{tabular}{|c|c|c|c|c||}
\hline Term & $\mathbf{( K 2 O ) 2 * N a 2 O}$ & $\mathbf{( N a 2 O ) 3}$ & $\mathbf{L i 2 O}$ *Na2O*SiO2 & B2O3*CaO*Na2O \\
\hline $\mathrm{A} 12 \mathrm{O} 3$ & 771.0153 & 136.0406 & 276.5747 & 640.1299 \\
\hline $\mathrm{B} 2 \mathrm{O} 3$ & 163.3330 & -21.6663 & 673.4985 & -3014.8798 \\
\hline $\mathrm{CaO}$ & 859.1075 & -349.6870 & 310.5460 & -6657.9092 \\
\hline $\mathrm{Fe} 2 \mathrm{O} 3$ & 1630.2301 & 195.3939 & 424.0416 & 1204.3237 \\
\hline $\mathrm{K} 2 \mathrm{O}$ & -10990.5144 & 60.2046 & 230.0304 & 1358.4667 \\
\hline $\mathrm{Li} 2 \mathrm{O}$ & -4461.2830 & -1792.6212 & -6956.0025 & 1732.9326 \\
\hline $\mathrm{MgO}$ & -2212.0420 & 115.1066 & 343.3545 & 1224.0790 \\
\hline $\mathrm{Na} 2 \mathrm{O}$ & -2639.7226 & -1302.7253 & -2825.3603 & -4182.2868 \\
\hline $\mathrm{SiO} 2$ & 279.1963 & 164.8064 & 197.3669 & 1064.2436 \\
\hline $\mathrm{ZrO} 2$ & -614.7721 & 112.1162 & 368.3748 & 527.1768 \\
\hline $\mathrm{Others}$ & 786.0088 & 195.0451 & 561.4452 & 927.7819 \\
\hline
\end{tabular}




\begin{tabular}{||c|c|c|c|c||}
\hline Term & $\mathbf{( K 2 O ) 2 * N a 2 O}$ & $\mathbf{( N a 2 O ) 3}$ & Li2O*Na2O*SiO2 & B2O3*CaO*Na2O \\
\hline$(\mathrm{K} 2 \mathrm{O}) 2 * \mathrm{Na} 2 \mathrm{O}$ & 1436442.3984 & 29221.3465 & 65274.7345 & 24923.3397 \\
\hline$(\mathrm{Na} 2 \mathrm{O}) 3$ & 29221.3465 & 17067.2975 & 37209.8730 & 40016.3557 \\
\hline $\mathrm{Li} 2 \mathrm{O} * \mathrm{Na} 2 \mathrm{O} * \mathrm{SiO} 2$ & 65274.7345 & 37209.8730 & 150236.7297 & -25688.2830 \\
\hline $\mathrm{B} 2 \mathrm{O} 3 * \mathrm{CaO} * \mathrm{Na} 2 \mathrm{O}$ & 24923.3397 & 40016.3557 & -25688.2830 & 598088.4681 \\
\hline
\end{tabular}


Table A-10. Variance-Covariance Matrix for Viscosity Model

\begin{tabular}{|c|c|c|c|c|c|c|}
\hline Term & Al2O3 & B2O3 & $\mathrm{CaO}$ & Fe2O3 & K2O & Li2O \\
\hline $\mathrm{A} 12 \mathrm{O} 3$ & 4.3931 & -4.2122 & -0.1233 & -0.0843 & 0.0498 & 4.6732 \\
\hline $\mathrm{B} 2 \mathrm{O} 3$ & -4.2122 & 47.1379 & -1.8275 & -2.2280 & -1.7454 & -3.3764 \\
\hline $\mathrm{CaO}$ & -0.1233 & -1.8275 & 0.9674 & 0.0108 & 0.1916 & -0.7363 \\
\hline $\mathrm{Fe} 2 \mathrm{O} 3$ & -0.0843 & -2.2280 & 0.0108 & 1.0795 & 0.0179 & 0.1230 \\
\hline $\mathrm{K} 2 \mathrm{O}$ & 0.0498 & -1.7454 & 0.1916 & 0.0179 & 0.8756 & 0.2793 \\
\hline $\mathrm{Li} 2 \mathrm{O}$ & 4.6732 & -3.3764 & -0.7363 & 0.1230 & 0.2793 & 20.7045 \\
\hline $\mathrm{MgO}$ & 0.6928 & -20.4729 & 1.9764 & 1.2104 & 2.5447 & -0.1117 \\
\hline $\mathrm{Na} 2 \mathrm{O}$ & -0.1107 & -1.9214 & 0.2159 & 0.0502 & 0.0852 & 0.7659 \\
\hline $\mathrm{P} 2 \mathrm{O} 5$ & -0.0789 & -0.5171 & 0.2320 & 0.1245 & 0.2515 & -0.3392 \\
\hline$\overline{\mathrm{SiO} 2}$ & -0.0429 & -2.2502 & -0.0453 & 0.0050 & 0.0266 & -0.4024 \\
\hline $\mathrm{ZrO} 2$ & -0.0615 & -2.1771 & 0.2763 & 0.1063 & -0.1280 & -0.8618 \\
\hline Others & -0.2520 & -1.2726 & 0.0602 & 0.2731 & -0.0457 & -1.0501 \\
\hline$(\mathrm{B} 2 \mathrm{O} 3) 2$ & 20.3262 & -249.5197 & 9.9237 & 12.3605 & 9.4277 & 13.5252 \\
\hline$(\mathrm{Li2O}) 2$ & 0.0997 & -12.1963 & 4.2240 & -0.1684 & -9.1920 & -93.4991 \\
\hline $\mathrm{Al} 2 \mathrm{O} 3 * \mathrm{Li} 2 \mathrm{O}$ & -75.9624 & 50.2923 & 2.8455 & 1.3714 & 5.7603 & -190.3501 \\
\hline$(\mathrm{MgO}) 2$ & -27.1251 & 390.6125 & -33.5639 & -21.9405 & -44.4567 & -8.3165 \\
\hline $\mathrm{A} 12 \mathrm{O} 3 /(\mathrm{T} / 1000) 2$ & -2.7928 & -0.0012 & 0.2130 & 0.2020 & 0.0001 & 0.0764 \\
\hline $\mathrm{CaO} /(\mathrm{T} / 1000) 2$ & 0.2113 & -0.0023 & -0.9869 & 0.1058 & 0.0003 & 0.4454 \\
\hline $\mathrm{Fe} 2 \mathrm{O} 3 /(\mathrm{T} / 1000) 2$ & 0.2016 & -0.0045 & 0.1043 & -1.1063 & -0.0008 & -0.2253 \\
\hline $\mathrm{Li} 2 \mathrm{O} /(\mathrm{T} / 1000) 2$ & 0.0822 & 0.0065 & 0.4475 & -0.2271 & -0.0005 & -4.8829 \\
\hline $\mathrm{MgO} /(\mathrm{T} / 1000) 2$ & 0.5041 & -0.0094 & -0.2921 & -0.0913 & 0.0014 & -0.0124 \\
\hline $\mathrm{Na} 2 \mathrm{O} /(\mathrm{T} / 1000) 2$ & 0.1874 & 0.0016 & -0.1692 & 0.0557 & -0.0009 & -1.0799 \\
\hline $\mathrm{P} 2 \mathrm{O} 5 /(\mathrm{T} / 1000) 2$ & -0.0002 & 0.0554 & -0.2028 & -0.1564 & -0.0020 & -0.2204 \\
\hline $\mathrm{SiO} 2 /(\mathrm{T} / 1000) 2$ & 0.2305 & 0.0005 & 0.1368 & 0.1083 & 0.0001 & 0.3919 \\
\hline $\mathrm{ZrO} 2 /(\mathrm{T} / 1000) 2$ & 0.2824 & 0.0072 & -0.3680 & -0.0435 & -0.0013 & 1.1774 \\
\hline Others/(T/1000)2 & 0.0521 & -0.0081 & 0.0177 & -0.1935 & 0.0019 & 0.2932 \\
\hline
\end{tabular}

\begin{tabular}{|c|c|c|c|c|c|c||}
\hline Term & MgO & Na2O & P2O5 & SiO2 & ZrO2 & Others \\
\hline $\mathrm{A} 2 \mathrm{O} 3$ & 0.6928 & -0.1107 & -0.0789 & -0.0429 & -0.0615 & -0.2520 \\
\hline $\mathrm{B} 2 \mathrm{O} 3$ & -20.4729 & -1.9214 & -0.5171 & -2.2502 & -2.1771 & -1.2726 \\
\hline $\mathrm{CaO}$ & 1.9764 & 0.2159 & 0.2320 & -0.0453 & 0.2763 & 0.0602 \\
\hline $\mathrm{Fe} 2 \mathrm{O} 3$ & 1.2104 & 0.0502 & 0.1245 & 0.0050 & 0.1063 & 0.2731 \\
\hline $\mathrm{K} 2 \mathrm{O}$ & 2.5447 & 0.0852 & 0.2515 & 0.0266 & -0.1280 & -0.0457 \\
\hline $\mathrm{Li2O}$ & -0.1117 & 0.7659 & -0.3392 & -0.4024 & -0.8618 & -1.0501 \\
\hline $\mathrm{MgO}$ & 30.4968 & 1.0138 & 0.2125 & 0.4123 & -0.5144 & 0.5974 \\
\hline $\mathrm{Na} 2 \mathrm{O}$ & 1.0138 & 0.4543 & 0.0486 & -0.0246 & -0.1311 & -0.0078 \\
\hline $\mathrm{P} 2 \mathrm{O} 5$ & 0.2125 & 0.0486 & 8.2711 & -0.0620 & -0.2324 & 0.1048 \\
\hline $\mathrm{SiO} 2$ & 0.4123 & -0.0246 & -0.0620 & 0.2754 & 0.0220 & -0.1523 \\
\hline $\mathrm{ZrO} 2$ & -0.5144 & -0.1311 & -0.2324 & 0.0220 & 4.3076 & -0.1032 \\
\hline $\mathrm{Others}$ & 0.5974 & -0.0078 & 0.1048 & -0.1523 & -0.1032 & 2.0486 \\
\hline$(\mathrm{B} 2 \mathrm{O} 3) 2$ & 107.9026 & 10.2913 & 2.7664 & 11.6977 & 11.0765 & 7.4392 \\
\hline$(\mathrm{Li} 2 \mathrm{O}) 2$ & -10.9375 & -0.4836 & 4.7339 & 2.5586 & 0.1008 & 1.5422 \\
\hline $\mathrm{A} 12 \mathrm{O} 3 * \mathrm{Li} 2 \mathrm{O}$ & 17.3764 & 3.3875 & 5.5647 & -0.1315 & -0.7979 & 11.7642 \\
\hline$(\mathrm{MgO}) 2$ & -534.4482 & -14.7794 & -7.7473 & -11.2139 & 21.0534 & -15.3621 \\
\hline $\mathrm{Al2O} 3 /(\mathrm{T} / 1000) 2$ & 0.5136 & 0.1879 & 0.0040 & 0.2319 & 0.2772 & 0.0446 \\
\hline $\mathrm{CaO} /(\mathrm{T} / 1000) 2$ & -0.2894 & -0.1686 & -0.2004 & 0.1368 & -0.3660 & 0.0170 \\
\hline $\mathrm{Fe} 2 \mathrm{O} 3 /(\mathrm{T} / 1000) 2$ & -0.1139 & 0.0560 & -0.1533 & 0.1090 & -0.0387 & -0.1942 \\
\hline \hline
\end{tabular}




\begin{tabular}{|c|c|c|c|c|c|c||}
\hline Term & MgO & Na2O & P2O5 & SiO2 & ZrO2 & Others \\
\hline $\mathrm{Li} 2 \mathrm{O} /(\mathrm{T} / 1000) 2$ & -0.0575 & -1.0790 & -0.2152 & 0.3947 & 1.1620 & 0.2724 \\
\hline $\mathrm{MgO} /(\mathrm{T} / 1000) 2$ & -4.2316 & -0.2458 & 0.3431 & 0.2332 & -0.5703 & 0.2492 \\
\hline $\mathrm{Na} 2 \mathrm{O} /(\mathrm{T} / 1000) 2$ & -0.2568 & -0.4355 & -0.0234 & 0.1449 & 0.2795 & 0.0955 \\
\hline $\mathrm{P} 2 \mathrm{O} 5 /(\mathrm{T} / 1000) 2$ & 0.3159 & -0.0256 & -9.6661 & 0.1036 & 0.2737 & -0.1465 \\
\hline $\mathrm{SiO} 2 /(\mathrm{T} / 1000) 2$ & 0.2358 & 0.1450 & 0.1060 & -0.1768 & 0.1657 & 0.2560 \\
\hline $\mathrm{ZrO} 2 /(\mathrm{T} / 1000) 2$ & -0.5962 & 0.2783 & 0.2752 & 0.1662 & -4.7238 & 0.1832 \\
\hline Others/(T/1000)2 & 0.2725 & 0.0950 & -0.1446 & 0.2553 & 0.1827 & -2.2841 \\
\hline
\end{tabular}

\begin{tabular}{|c|c|c|c|c|c|c|}
\hline Term & (B2O3)2 & (Li2O)2 & Al2O3*Li2O & (MgO)2 & $\begin{array}{c}\mathrm{Al2O3} / \\
(\mathrm{T} / 1000) 2\end{array}$ & $\begin{array}{c}\mathrm{CaO} / \\
(\mathrm{T} / 1000) 2\end{array}$ \\
\hline $\mathrm{Al} 2 \mathrm{O} 3$ & 20.3262 & 0.0997 & -75.9624 & -27.1251 & -2.7928 & 0.2113 \\
\hline $\mathrm{B} 2 \mathrm{O} 3$ & -249.5197 & -12.1963 & 50.2923 & 390.6125 & -0.0012 & -0.0023 \\
\hline $\mathrm{CaO}$ & 9.9237 & 4.2240 & 2.8455 & -33.5639 & 0.2130 & -0.9869 \\
\hline $\mathrm{Fe} 2 \mathrm{O} 3$ & 12.3605 & -0.1684 & 1.3714 & -21.9405 & 0.2020 & 0.1058 \\
\hline $\mathrm{K} 2 \mathrm{O}$ & 9.4277 & -9.1920 & 5.7603 & -44.4567 & 0.0001 & 0.0003 \\
\hline $\mathrm{Li} 2 \mathrm{O}$ & 13.5252 & -93.4991 & -190.3501 & -8.3165 & 0.0764 & 0.4454 \\
\hline $\mathrm{MgO}$ & 107.9026 & -10.9375 & 17.3764 & -534.4482 & 0.5136 & -0.2894 \\
\hline $\mathrm{Na} 2 \mathrm{O}$ & 10.2913 & -0.4836 & 3.3875 & -14.7794 & 0.1879 & -0.1686 \\
\hline $\mathrm{P} 2 \mathrm{O} 5$ & 2.7664 & 4.7339 & 5.5647 & -7.7473 & 0.0040 & -0.2004 \\
\hline $\mathrm{SiO} 2$ & 11.6977 & 2.5586 & -0.1315 & -11.2139 & 0.2319 & 0.1368 \\
\hline $\mathrm{ZrO} 2$ & 11.0765 & 0.1008 & -0.7979 & 21.0534 & 0.2772 & -0.3660 \\
\hline Others & 7.4392 & 1.5422 & 11.7642 & -15.3621 & 0.0446 & 0.0170 \\
\hline$(\mathrm{B} 2 \mathrm{O} 3) 2$ & 1334.1445 & 61.0130 & -199.7892 & -2044.9113 & -0.0209 & 0.0117 \\
\hline$(\mathrm{Li} 2 \mathrm{O}) 2$ & 61.0130 & 1865.1464 & -51.5337 & 113.7300 & 0.0292 & -0.0295 \\
\hline $\mathrm{A} 12 \mathrm{O} 3 * \mathrm{Li} 2 \mathrm{O}$ & -199.7892 & -51.5337 & 3142.4026 & -64.0502 & 0.0986 & 0.0783 \\
\hline$(\mathrm{MgO}) 2$ & -2044.9113 & 113.7300 & -64.0502 & 10718.1194 & -0.2344 & -0.1081 \\
\hline $\mathrm{A} 12 \mathrm{O} 3 /(\mathrm{T} / 1000) 2$ & -0.0209 & 0.0292 & 0.0986 & -0.2344 & 5.1453 & -0.3937 \\
\hline $\mathrm{CaO} /(\mathrm{T} / 1000) 2$ & 0.0117 & -0.0295 & 0.0783 & -0.1081 & -0.3937 & 1.8219 \\
\hline $\mathrm{Fe} 2 \mathrm{O} 3 /(\mathrm{T} / 1000) 2$ & 0.0219 & -0.0963 & 0.0713 & 0.4542 & -0.3688 & -0.1946 \\
\hline $\mathrm{Li} 2 \mathrm{O} /(\mathrm{T} / 1000) 2$ & -0.0139 & 0.2143 & -0.0200 & 0.8846 & -0.1387 & -0.8270 \\
\hline $\mathrm{MgO} /(\mathrm{T} / 1000) 2$ & 0.0437 & -0.0437 & -0.0298 & -1.3377 & -0.9292 & 0.5412 \\
\hline $\mathrm{Na} 2 \mathrm{O} /(\mathrm{T} / 1000) 2$ & 0.0009 & 0.0233 & -0.0073 & 0.2273 & -0.3424 & 0.3119 \\
\hline $\mathrm{P} 2 \mathrm{O} 5 /(\mathrm{T} / 1000) 2$ & -0.3035 & 0.0376 & 0.0266 & 0.5350 & -0.0127 & 0.3693 \\
\hline $\mathrm{SiO} 2 /(\mathrm{T} / 1000) 2$ & -0.0007 & 0.0171 & 0.0282 & -0.0353 & -0.4263 & -0.2516 \\
\hline $\mathrm{ZrO} 2 /(\mathrm{T} / 1000) 2$ & -0.0509 & -0.0321 & -0.2577 & 0.6372 & -0.5259 & 0.6740 \\
\hline Others/(T/1000)2 & 0.0410 & -0.0521 & -0.2877 & -0.5317 & -0.0898 & -0.0334 \\
\hline
\end{tabular}

\begin{tabular}{|c|c|c|c|c||}
\hline Term & $\begin{array}{c}\mathbf{F e 2 O 3} / \\
\mathbf{T} / \mathbf{1 0 0 0} \mathbf{2}\end{array}$ & $\begin{array}{c}\mathbf{L i 2 O} / \\
\mathbf{( T / 1 0 0 0 ) 2}\end{array}$ & $\begin{array}{c}\mathbf{M g O} / \\
\mathbf{T} / \mathbf{1 0 0 0}) 2\end{array}$ & $\begin{array}{c}\mathbf{N a 2 O} / \\
\mathbf{T} / \mathbf{1 0 0 0}) \mathbf{2}\end{array}$ \\
\hline $\mathrm{A} 12 \mathrm{O} 3$ & 0.2016 & 0.0822 & 0.5041 & 0.1874 \\
\hline $\mathrm{B} 2 \mathrm{O} 3$ & -0.0045 & 0.0065 & -0.0094 & 0.0016 \\
\hline $\mathrm{CaO}$ & 0.1043 & 0.4475 & -0.2921 & -0.1692 \\
\hline $\mathrm{Fe} 2 \mathrm{O} 3$ & -1.1063 & -0.2271 & -0.0913 & 0.0557 \\
\hline $\mathrm{K} 2 \mathrm{O}$ & -0.0008 & -0.0005 & 0.0014 & -0.0009 \\
\hline $\mathrm{Li} 2 \mathrm{O}$ & -0.2253 & -4.8829 & -0.0124 & -1.0799 \\
\hline $\mathrm{MgO}$ & -0.1139 & -0.0575 & -4.2316 & -0.2568 \\
\hline $\mathrm{Na} 2 \mathrm{O}$ & 0.0560 & -1.0790 & -0.2458 & -0.4355 \\
\hline $\mathrm{P} 2 \mathrm{O} 5$ & -0.1533 & -0.2152 & 0.3431 & -0.0234 \\
\hline
\end{tabular}




\begin{tabular}{|c|c|c|c|c|}
\hline Term & $\begin{array}{c}\mathrm{Fe} 2 \mathrm{O3} / \\
(\mathrm{T} / 1000) 2\end{array}$ & $\begin{array}{c}\mathrm{Li2O} / \\
(\mathrm{T} / 1000) 2\end{array}$ & $\begin{array}{c}\mathrm{MgO} / \\
(\mathrm{T} / 1000) 2 \\
\end{array}$ & $\begin{array}{c}\mathrm{Na} 2 \mathrm{O} / \\
(\mathrm{T} / 1000) 2\end{array}$ \\
\hline $\mathrm{SiO} 2$ & 0.1090 & 0.3947 & 0.2332 & 0.1449 \\
\hline $\mathrm{ZrO} 2$ & -0.0387 & 1.1620 & -0.5703 & 0.2795 \\
\hline Others & -0.1942 & 0.2724 & 0.2492 & 0.0955 \\
\hline$(\mathrm{B} 2 \mathrm{O} 3) 2$ & 0.0219 & -0.0139 & 0.0437 & 0.0009 \\
\hline$(\mathrm{Li} 2 \mathrm{O}) 2$ & -0.0963 & 0.2143 & -0.0437 & 0.0233 \\
\hline $\mathrm{A} 12 \mathrm{O} 3 * \mathrm{Li} 2 \mathrm{O}$ & 0.0713 & -0.0200 & -0.0298 & -0.0073 \\
\hline$(\mathrm{MgO}) 2$ & 0.4542 & 0.8846 & -1.3377 & 0.2273 \\
\hline $\mathrm{A} 12 \mathrm{O} 3 /(\mathrm{T} / 1000) 2$ & -0.3688 & -0.1387 & -0.9292 & -0.3424 \\
\hline $\mathrm{CaO} /(\mathrm{T} / 1000) 2$ & -0.1946 & -0.8270 & 0.5412 & 0.3119 \\
\hline $\mathrm{Fe} 2 \mathrm{O} 3 /(\mathrm{T} / 1000) 2$ & 2.0360 & 0.4119 & 0.1716 & -0.1034 \\
\hline $\mathrm{Li} 2 \mathrm{O} /(\mathrm{T} / 1000) 2$ & 0.4119 & 8.9724 & 0.0513 & 1.9851 \\
\hline $\mathrm{MgO} /(\mathrm{T} / 1000) 2$ & 0.1716 & 0.0513 & 7.9128 & 0.4583 \\
\hline $\mathrm{Na} 2 \mathrm{O} /(\mathrm{T} / 1000) 2$ & -0.1034 & 1.9851 & 0.4583 & 0.8025 \\
\hline $\mathrm{P} 2 \mathrm{O} 5 /(\mathrm{T} / 1000) 2$ & 0.2845 & 0.3957 & -0.6325 & 0.0422 \\
\hline $\mathrm{SiO} 2 /(\mathrm{T} / 1000) 2$ & -0.2002 & -0.7304 & -0.4320 & -0.2683 \\
\hline $\mathrm{ZrO} 2 /(\mathrm{T} / 1000) 2$ & 0.0786 & -2.1333 & 1.0470 & -0.5126 \\
\hline Others/(T/1000)2 & 0.3652 & -0.4870 & -0.4692 & -0.1727 \\
\hline
\end{tabular}

\begin{tabular}{|c|c|c|c|c|}
\hline Term & $\begin{array}{c}\mathrm{P2O5} / \\
(\mathrm{T} / \mathbf{1 0 0 0 ) 2}\end{array}$ & $\begin{array}{c}\mathrm{SiO2} / \\
(\mathrm{T} / \mathbf{1 0 0 0}) 2\end{array}$ & $\begin{array}{c}\mathrm{ZrO2} / \\
(\mathrm{T} / \mathbf{1 0 0 0}) 2\end{array}$ & $\begin{array}{c}\text { Others/ } \\
(\mathrm{T} / \mathbf{1 0 0 0 ) 2}\end{array}$ \\
\hline $\mathrm{Al} 2 \mathrm{O} 3$ & -0.0002 & 0.2305 & 0.2824 & 0.0521 \\
\hline $\mathrm{B} 2 \mathrm{O} 3$ & 0.0554 & 0.0005 & 0.0072 & -0.0081 \\
\hline $\mathrm{CaO}$ & -0.2028 & 0.1368 & -0.3680 & 0.0177 \\
\hline $\mathrm{Fe} 2 \mathrm{O} 3$ & -0.1564 & 0.1083 & -0.0435 & -0.1935 \\
\hline $\mathrm{K} 2 \mathrm{O}$ & -0.0020 & 0.0001 & -0.0013 & 0.0019 \\
\hline $\mathrm{Li2O}$ & -0.2204 & 0.3919 & 1.1774 & 0.2932 \\
\hline $\mathrm{MgO}$ & 0.3159 & 0.2358 & -0.5962 & 0.2725 \\
\hline $\mathrm{Na} 2 \mathrm{O}$ & -0.0256 & 0.1450 & 0.2783 & 0.0950 \\
\hline $\mathrm{P} 2 \mathrm{O} 5$ & -9.6661 & 0.1060 & 0.2752 & -0.1446 \\
\hline $\mathrm{SiO} 2$ & 0.1036 & -0.1768 & 0.1662 & 0.2553 \\
\hline $\mathrm{ZrO} 2$ & 0.2737 & 0.1657 & -4.7238 & 0.1827 \\
\hline Others & -0.1465 & 0.2560 & 0.1832 & -2.2841 \\
\hline$(\mathrm{B} 2 \mathrm{O} 3) 2$ & -0.3035 & -0.0007 & -0.0509 & 0.0410 \\
\hline$(\mathrm{Li} 2 \mathrm{O}) 2$ & 0.0376 & 0.0171 & -0.0321 & -0.0521 \\
\hline $\mathrm{Al} 2 \mathrm{O} 3 * \mathrm{Li} 2 \mathrm{O}$ & 0.0266 & 0.0282 & -0.2577 & -0.2877 \\
\hline$(\mathrm{MgO}) 2$ & 0.5350 & -0.0353 & 0.6372 & -0.5317 \\
\hline $\mathrm{A} 12 \mathrm{O} 3 /(\mathrm{T} / 1000) 2$ & -0.0127 & -0.4263 & -0.5259 & -0.0898 \\
\hline $\mathrm{CaO} /(\mathrm{T} / 1000) 2$ & 0.3693 & -0.2516 & 0.6740 & -0.0334 \\
\hline $\mathrm{Fe} 2 \mathrm{O} 3 /(\mathrm{T} / 1000) 2$ & 0.2845 & -0.2002 & 0.0786 & 0.3652 \\
\hline $\mathrm{Li} 2 \mathrm{O} /(\mathrm{T} / 1000) 2$ & 0.3957 & -0.7304 & -2.1333 & -0.4870 \\
\hline $\mathrm{MgO} /(\mathrm{T} / 1000) 2$ & -0.6325 & -0.4320 & 1.0470 & -0.4692 \\
\hline $\mathrm{Na} 2 \mathrm{O} /(\mathrm{T} / 1000) 2$ & 0.0422 & -0.2683 & -0.5126 & -0.1727 \\
\hline $\mathrm{P} 2 \mathrm{O} 5 /(\mathrm{T} / 1000) 2$ & 17.9128 & -0.1942 & -0.5139 & 0.2648 \\
\hline $\mathrm{SiO} 2 /(\mathrm{T} / 1000) 2$ & -0.1942 & 0.3259 & -0.3022 & -0.4711 \\
\hline $\mathrm{ZrO} 2 /(\mathrm{T} / 1000) 2$ & -0.5139 & -0.3022 & 8.7153 & -0.3605 \\
\hline Others/(T/1000)2 & 0.2648 & -0.4711 & -0.3605 & 4.2105 \\
\hline
\end{tabular}


Table A-11. Variance-Covariance Matrix for Electrical Conductivity Model

\begin{tabular}{|c|c|c|c|c|c|c|}
\hline Term & Al2O3 & B2O3 & $\mathrm{CaO}$ & $\mathrm{Fe} 2 \mathrm{O3}$ & $\mathrm{K2O}$ & Li2O \\
\hline $\mathrm{A} 12 \mathrm{O} 3$ & 6.4799 & -0.7687 & -0.5444 & -0.6502 & 0.3336 & 0.1030 \\
\hline $\mathrm{B} 2 \mathrm{O} 3$ & -0.7687 & 3.0753 & -0.2350 & 0.5775 & 0.2775 & -1.2268 \\
\hline $\mathrm{CaO}$ & -0.5444 & -0.2350 & 9.0967 & -0.8749 & -0.4213 & 4.9678 \\
\hline $\mathrm{Fe} 2 \mathrm{O} 3$ & -0.6502 & 0.5775 & -0.8749 & 2.7741 & -0.5565 & -0.6301 \\
\hline $\mathrm{K} 2 \mathrm{O}$ & 0.3336 & 0.2775 & -0.4213 & -0.5565 & 4.7674 & 0.0410 \\
\hline $\mathrm{Li} 2 \mathrm{O}$ & 0.1030 & -1.2268 & 4.9678 & -0.6301 & 0.0410 & 25.2917 \\
\hline $\mathrm{MgO}$ & -0.9935 & 0.3064 & -0.0479 & 0.1079 & 2.0530 & -0.8496 \\
\hline $\mathrm{Na} 2 \mathrm{O}$ & -0.3862 & -0.2836 & 2.2997 & -0.3634 & -0.2676 & 4.5557 \\
\hline $\mathrm{SiO} 2$ & -0.4047 & -0.5409 & -0.8098 & -0.2683 & -0.1665 & -1.3387 \\
\hline $\mathrm{ZrO} 2$ & -0.2125 & -1.1722 & 0.7554 & -0.0338 & -0.4077 & -2.5711 \\
\hline Others & -0.2443 & 0.5012 & -1.0702 & 0.6758 & -0.3242 & -1.8311 \\
\hline $\mathrm{CaO}^{*} \mathrm{Li} 2 \mathrm{O}$ & -1.2238 & 8.2817 & -97.2024 & 10.3567 & 9.9114 & -144.7756 \\
\hline $\mathrm{CaO} * \mathrm{Na} 2 \mathrm{O}$ & 0.6257 & 2.6594 & -37.2667 & 3.2215 & 4.5760 & -23.1400 \\
\hline $\mathrm{Li} 2 \mathrm{O} * \mathrm{Na} 2 \mathrm{O}$ & 0.7076 & 0.4980 & -3.8171 & 2.3793 & 1.5515 & -49.3728 \\
\hline $\mathrm{A} 12 \mathrm{O} 3 /(\mathrm{T} / 1000)$ & -7.5254 & 0.8973 & 0.4993 & 0.7818 & -0.3460 & -0.2022 \\
\hline $\mathrm{B} 2 \mathrm{O} 3 /(\mathrm{T} / 1000)$ & 0.8936 & -3.5307 & -0.3263 & -0.6165 & -0.2495 & 0.8258 \\
\hline $\mathrm{CaO} /(\mathrm{T} / 1000)$ & 0.5428 & -0.3195 & -2.6215 & 0.2754 & -0.4498 & 1.2059 \\
\hline $\mathrm{Fe} 2 \mathrm{O} 3 /(\mathrm{T} / 1000)$ & 0.7772 & -0.6154 & 0.2666 & -3.1503 & 0.7529 & -0.2586 \\
\hline $\mathrm{K} 2 \mathrm{O} /(\mathrm{T} / 1000)$ & -0.3493 & -0.2504 & -0.4489 & 0.7530 & -5.4297 & -0.9151 \\
\hline $\mathrm{Li} 2 \mathrm{O} /(\mathrm{T} / 1000)$ & -0.1538 & 0.8038 & 1.2660 & -0.2552 & -0.9205 & -13.1967 \\
\hline $\mathrm{MgO} /(\mathrm{T} / 1000)$ & 1.1952 & -0.2491 & -1.0073 & -0.0067 & -2.2522 & -0.5340 \\
\hline $\mathrm{Na} 2 \mathrm{O} /(\mathrm{T} / 1000)$ & 0.3837 & 0.1629 & -0.3799 & 0.1868 & 0.0067 & -2.8888 \\
\hline $\mathrm{SiO} 2 /(\mathrm{T} / 1000)$ & 0.4850 & 0.6685 & 0.4366 & 0.3658 & 0.2583 & 0.9848 \\
\hline $\mathrm{ZrO} 2 /(\mathrm{T} / 1000)$ & 0.2397 & 1.3326 & -0.8151 & 0.0439 & 0.4558 & 2.7148 \\
\hline Others/(T/1000) & 0.3050 & -0.4933 & 0.0014 & -0.6695 & 0.5157 & 0.5978 \\
\hline
\end{tabular}

\begin{tabular}{|c|c|c|c|c|c||}
\hline Term & MgO & Na2O & SiO2 & ZrO2 & Others \\
\hline $\mathrm{A} 12 \mathrm{O} 3$ & -0.9935 & -0.3862 & -0.4047 & -0.2125 & -0.2443 \\
\hline $\mathrm{B} 2 \mathrm{O} 3$ & 0.3064 & -0.2836 & -0.5409 & -1.1722 & 0.5012 \\
\hline $\mathrm{CaO}$ & -0.0479 & 2.2997 & -0.8098 & 0.7554 & -1.0702 \\
\hline $\mathrm{Fe} 2 \mathrm{O} 3$ & 0.1079 & -0.3634 & -0.2683 & -0.0338 & 0.6758 \\
\hline $\mathrm{K} 2 \mathrm{O}$ & 2.0530 & -0.2676 & -0.1665 & -0.4077 & -0.3242 \\
\hline $\mathrm{Li} 2 \mathrm{O}$ & -0.8496 & 4.5557 & -1.3387 & -2.5711 & -1.8311 \\
\hline $\mathrm{MgO}$ & 10.6342 & 0.2676 & -0.5761 & 0.8667 & -0.6353 \\
\hline $\mathrm{Na} 2 \mathrm{O}$ & 0.2676 & 1.6011 & -0.4465 & -0.5657 & -0.4966 \\
\hline $\mathrm{SiO} 2$ & -0.5761 & -0.4465 & 0.5453 & -0.1535 & -0.4958 \\
\hline $\mathrm{ZrO} 2$ & 0.8667 & -0.5657 & -0.1535 & 11.0901 & -0.5539 \\
\hline $\mathrm{Others}$ & -0.6353 & -0.4966 & -0.4958 & -0.5539 & 4.5320 \\
\hline $\mathrm{CaO} * \mathrm{Li2O}$ & 15.5091 & -27.7001 & 6.6834 & 0.0352 & 18.0251 \\
\hline $\mathrm{CaO} * \mathrm{Na} 2 \mathrm{O}$ & 4.3607 & -10.5266 & 2.2859 & -0.5814 & 5.4664 \\
\hline $\mathrm{Li} 2 \mathrm{O} * \mathrm{Na} 2 \mathrm{O}$ & 3.0783 & -4.2848 & 1.0436 & 2.1222 & 2.3364 \\
\hline $\mathrm{A} 12 \mathrm{O} 3 /(\mathrm{T} / 1000)$ & 1.2016 & 0.3729 & 0.4873 & 0.2378 & 0.3140 \\
\hline $\mathrm{B} 2 \mathrm{O} 3 /(\mathrm{T} / 1000)$ & -0.2525 & 0.1631 & 0.6690 & 1.3316 & -0.4931 \\
\hline $\mathrm{CaO} /(\mathrm{T} / 1000)$ & -0.9684 & -0.3947 & 0.4317 & -0.8125 & -0.0048 \\
\hline $\mathrm{Fe} 2 \mathrm{O} 3 /(\mathrm{T} / 1000)$ & -0.0089 & 0.1873 & 0.3662 & 0.0427 & -0.6668 \\
\hline $\mathrm{K} 2 \mathrm{O} /(\mathrm{T} / 1000)$ & -2.2564 & 0.0078 & 0.2585 & 0.4556 & 0.5178 \\
\hline $\mathrm{Li2O} /(\mathrm{T} / 1000)$ & -0.5100 & -2.8923 & 0.9836 & 2.7133 & 0.5798 \\
\hline \hline
\end{tabular}




\begin{tabular}{||c|c|c|c|c|c||}
\hline Term & MgO & Na2O & SiO2 & ZrO2 & Others \\
\hline $\mathrm{MgO} /(\mathrm{T} / 1000)$ & -12.2210 & -0.6549 & 0.7407 & -0.9862 & 0.9390 \\
\hline $\mathrm{Na} 2 \mathrm{O} /(\mathrm{T} / 1000)$ & -0.6470 & -1.1510 & 0.3650 & 0.6476 & 0.1982 \\
\hline $\mathrm{SiO} 2 /(\mathrm{T} / 1000)$ & 0.7382 & 0.3665 & -0.6023 & 0.1879 & 0.6645 \\
\hline $\mathrm{ZrO} 2 /(\mathrm{T} / 1000)$ & -0.9854 & 0.6460 & 0.1876 & -12.9040 & 0.6778 \\
\hline Others/(T/1000) & 0.9315 & 0.2048 & 0.6643 & 0.6765 & -5.0739 \\
\hline
\end{tabular}

\begin{tabular}{|c|c|c|c|c|c|}
\hline Term & $\mathrm{CaO} * \mathrm{Li2O}$ & $\mathrm{CaO} * \mathrm{Na} 2 \mathrm{O}$ & $\mathrm{Li2O} * \mathrm{Na} 20$ & $\begin{array}{c}\text { Al2O3/ } \\
\text { (T/1000) }\end{array}$ & $\begin{array}{r}\mathrm{B} 2 \mathrm{O3} / \\
(\mathrm{T} / \mathbf{1 0 0 0})\end{array}$ \\
\hline $\mathrm{Al} 2 \mathrm{O} 3$ & -1.2238 & 0.6257 & 0.7076 & -7.5254 & 0.8936 \\
\hline $\mathrm{B} 2 \mathrm{O} 3$ & 8.2817 & 2.6594 & 0.4980 & 0.8973 & -3.5307 \\
\hline $\mathrm{CaO}$ & -97.2024 & -37.2667 & -3.8171 & 0.4993 & -0.3263 \\
\hline $\mathrm{Fe} 2 \mathrm{O} 3$ & 10.3567 & 3.2215 & 2.3793 & 0.7818 & -0.6165 \\
\hline $\mathrm{K} 2 \mathrm{O}$ & 9.9114 & 4.5760 & 1.5515 & -0.3460 & -0.2495 \\
\hline $\mathrm{Li} 2 \mathrm{O}$ & -144.7756 & -23.1400 & -49.3728 & -0.2022 & 0.8258 \\
\hline $\mathrm{MgO}$ & 15.5091 & 4.3607 & 3.0783 & 1.2016 & -0.2525 \\
\hline $\mathrm{Na} 2 \mathrm{O}$ & -27.7001 & -10.5266 & -4.2848 & 0.3729 & 0.1631 \\
\hline $\mathrm{SiO} 2$ & 6.6834 & 2.2859 & 1.0436 & 0.4873 & 0.6690 \\
\hline $\mathrm{ZrO} 2$ & 0.0352 & -0.5814 & 2.1222 & 0.2378 & 1.3316 \\
\hline Others & 18.0251 & 5.4664 & 2.3364 & 0.3140 & -0.4931 \\
\hline $\mathrm{CaO} * \mathrm{Li} 2 \mathrm{O}$ & 1955.4791 & 445.9270 & 279.7517 & 0.8392 & -0.0833 \\
\hline $\mathrm{CaO} * \mathrm{Na} 2 \mathrm{O}$ & 445.9270 & 214.7187 & -20.8270 & 0.2132 & 0.0547 \\
\hline $\mathrm{Li} 2 \mathrm{O} * \mathrm{Na} 2 \mathrm{O}$ & 279.7517 & -20.8270 & 295.9502 & -0.0160 & -0.1174 \\
\hline $\mathrm{Al2O} /(\mathrm{T} / 1000)$ & 0.8392 & 0.2132 & -0.0160 & 10.2181 & -1.2142 \\
\hline $\mathrm{B} 2 \mathrm{O} 3 /(\mathrm{T} / 1000)$ & -0.0833 & 0.0547 & -0.1174 & -1.2142 & 4.7895 \\
\hline $\mathrm{CaO} /(\mathrm{T} / 1000)$ & 0.2714 & 0.0903 & -0.0290 & -0.7321 & 0.4311 \\
\hline $\mathrm{Fe} 2 \mathrm{O} 3 /(\mathrm{T} / 1000)$ & 0.2092 & 0.0305 & -0.0398 & -1.0621 & 0.8387 \\
\hline $\mathrm{K} 2 \mathrm{O} /(\mathrm{T} / 1000)$ & -0.0760 & -0.0100 & 0.0342 & 0.4675 & 0.3314 \\
\hline $\mathrm{Li} 2 \mathrm{O} /(\mathrm{T} / 1000)$ & -0.8599 & -0.2373 & -0.0166 & 0.2379 & -1.0927 \\
\hline $\mathrm{MgO} /(\mathrm{T} / 1000)$ & 0.5694 & 0.1969 & -0.0226 & -1.6484 & 0.3250 \\
\hline $\mathrm{Na} 2 \mathrm{O} /(\mathrm{T} / 1000)$ & -0.2141 & -0.0500 & -0.0316 & -0.5099 & -0.2228 \\
\hline $\mathrm{SiO} 2 /(\mathrm{T} / 1000)$ & -0.0733 & -0.0355 & 0.0541 & -0.6600 & -0.9084 \\
\hline $\mathrm{ZrO} 2 /(\mathrm{T} / 1000)$ & -0.0523 & 0.0289 & 0.0110 & -0.3207 & -1.7838 \\
\hline Others/(T/1000) & -0.0016 & -0.0585 & -0.0907 & -0.4295 & 0.6754 \\
\hline
\end{tabular}

\begin{tabular}{|c|c|c|c|c|c||}
\hline Term & $\begin{array}{c}\mathbf{C a O} / \\
\mathbf{T} / \mathbf{1 0 0 0})\end{array}$ & $\begin{array}{c}\mathbf{F e 2 O 3} / \\
\mathbf{( T / 1 0 0 0})\end{array}$ & $\begin{array}{c}\mathbf{K 2 O} / \\
\mathbf{( T / 1 0 0 0})\end{array}$ & $\begin{array}{c}\mathbf{L i 2 O} / \\
\mathbf{( T / 1 0 0 0})\end{array}$ & $\begin{array}{c}\mathbf{M g O} / \\
\mathbf{T} / \mathbf{1 0 0 0})\end{array}$ \\
\hline $\mathrm{Al} 2 \mathrm{O} 3$ & 0.5428 & 0.7772 & -0.3493 & -0.1538 & 1.1952 \\
\hline $\mathrm{B} 2 \mathrm{O} 3$ & -0.3195 & -0.6154 & -0.2504 & 0.8038 & -0.2491 \\
\hline $\mathrm{CaO}$ & -2.6215 & 0.2666 & -0.4489 & 1.2660 & -1.0073 \\
\hline $\mathrm{Fe} 2 \mathrm{O} 3$ & 0.2754 & -3.1503 & 0.7530 & -0.2552 & -0.0067 \\
\hline $\mathrm{K} 2 \mathrm{O}$ & -0.4498 & 0.7529 & -5.4297 & -0.9205 & -2.2522 \\
\hline $\mathrm{Li} 2 \mathrm{O}$ & 1.2059 & -0.2586 & -0.9151 & -13.1967 & -0.5340 \\
\hline $\mathrm{MgO}$ & -0.9684 & -0.0089 & -2.2564 & -0.5100 & -12.2210 \\
\hline $\mathrm{Na} 2 \mathrm{O}$ & -0.3947 & 0.1873 & 0.0078 & -2.8923 & -0.6549 \\
\hline $\mathrm{SiO} 2$ & 0.4317 & 0.3662 & 0.2585 & 0.9836 & 0.7407 \\
\hline $\mathrm{ZrO} 2$ & -0.8125 & 0.0427 & 0.4556 & 2.7133 & -0.9862 \\
\hline $\mathrm{Others}$ & -0.0048 & -0.6668 & 0.5178 & 0.5798 & 0.9390 \\
\hline $\mathrm{CaO}$ Li2O & 0.2714 & 0.2092 & -0.0760 & -0.8599 & 0.5694 \\
\hline $\mathrm{CaO} * \mathrm{Na} 2 \mathrm{O}$ & 0.0903 & 0.0305 & -0.0100 & -0.2373 & 0.1969 \\
\hline
\end{tabular}




\begin{tabular}{||c|c|c|c|c|c||}
\hline Term & $\begin{array}{c}\mathbf{C a O} / \\
\mathbf{T} / \mathbf{1 0 0 0})\end{array}$ & $\begin{array}{c}\mathbf{F e 2 O 3} / \\
\mathbf{( T / 1 0 0 0})\end{array}$ & $\begin{array}{c}\mathbf{K 2 O} / \\
\mathbf{( T / 1 0 0 0})\end{array}$ & $\begin{array}{c}\mathbf{L i 2 O} / \\
\mathbf{( T / 1 0 0 0})\end{array}$ & $\begin{array}{c}\mathbf{M g O} / \\
\mathbf{( T / 1 0 0 0})\end{array}$ \\
\hline $\mathrm{Li} 2 \mathrm{O} * \mathrm{Na} 2 \mathrm{O}$ & -0.0290 & -0.0398 & 0.0342 & -0.0166 & -0.0226 \\
\hline $\mathrm{A} 2 \mathrm{O} 3 /(\mathrm{T} / 1000)$ & -0.7321 & -1.0621 & 0.4675 & 0.2379 & -1.6484 \\
\hline $\mathrm{B} 2 \mathrm{O} 3 /(\mathrm{T} / 1000)$ & 0.4311 & 0.8387 & 0.3314 & -1.0927 & 0.3250 \\
\hline $\mathrm{CaO} /(\mathrm{T} / 1000)$ & 3.5331 & -0.3723 & 0.6086 & -1.6551 & 1.3049 \\
\hline $\mathrm{Fe} 2 \mathrm{O} 3 /(\mathrm{T} / 1000)$ & -0.3723 & 4.2851 & -1.0248 & 0.3279 & 0.0132 \\
\hline $\mathrm{K} 2 \mathrm{O} /(\mathrm{T} / 1000)$ & 0.6086 & -1.0248 & 7.3644 & 1.2568 & 3.0460 \\
\hline $\mathrm{Li} 2 \mathrm{O} /(\mathrm{T} / 1000)$ & -1.6551 & 0.3279 & 1.2568 & 17.9774 & 0.7249 \\
\hline $\mathrm{MgO} /(\mathrm{T} / 1000)$ & 1.3049 & 0.0132 & 3.0460 & 0.7249 & 16.5800 \\
\hline $\mathrm{Na} 2 \mathrm{O} /(\mathrm{T} / 1000)$ & 0.5282 & -0.2595 & -0.0097 & 3.9412 & 0.8847 \\
\hline $\mathrm{SiO} 2 /(\mathrm{T} / 1000)$ & -0.5827 & -0.4972 & -0.3498 & -1.3476 & -0.9958 \\
\hline $\mathrm{ZrO} 2 /(\mathrm{T} / 1000)$ & 1.1093 & -0.0539 & -0.6020 & -3.6868 & 1.3306 \\
\hline $\mathrm{Others} /(\mathrm{T} / 1000)$ & 0.0053 & 0.9181 & -0.6959 & -0.7680 & -1.2733 \\
\hline
\end{tabular}

\begin{tabular}{||c|c|c|c|c||}
\hline Term & $\begin{array}{c}\mathbf{N a 2 O} / \\
\mathbf{( T / 1 0 0 0 )}\end{array}$ & $\begin{array}{c}\mathbf{S i O 2 /} \\
\mathbf{( T / 1 0 0 0 )}\end{array}$ & $\begin{array}{c}\text { ZrO2/ } \\
\mathbf{( T / 1 0 0 0 )}\end{array}$ & $\begin{array}{c}\text { Others/ } \\
\mathbf{( T / 1 0 0 0 )}\end{array}$ \\
\hline $\mathrm{A} 12 \mathrm{O} 3$ & 0.3837 & 0.4850 & 0.2397 & 0.3050 \\
\hline $\mathrm{B} 2 \mathrm{O} 3$ & 0.1629 & 0.6685 & 1.3326 & -0.4933 \\
\hline $\mathrm{CaO}$ & -0.3799 & 0.4366 & -0.8151 & 0.0014 \\
\hline $\mathrm{Fe} 2 \mathrm{O} 3$ & 0.1868 & 0.3658 & 0.0439 & -0.6695 \\
\hline $\mathrm{K} 2 \mathrm{O}$ & 0.0067 & 0.2583 & 0.4558 & 0.5157 \\
\hline $\mathrm{Li} 2 \mathrm{O}$ & -2.8888 & 0.9848 & 2.7148 & 0.5978 \\
\hline $\mathrm{MgO}$ & -0.6470 & 0.7382 & -0.9854 & 0.9315 \\
\hline $\mathrm{Na} 2 \mathrm{O}$ & -1.1510 & 0.3665 & 0.6460 & 0.2048 \\
\hline $\mathrm{SiO} 2$ & 0.3650 & -0.6023 & 0.1876 & 0.6643 \\
\hline $\mathrm{ZrO} 2$ & 0.6476 & 0.1879 & -12.9040 & 0.6765 \\
\hline $\mathrm{Others}$ & 0.1982 & 0.6645 & 0.6778 & -5.0739 \\
\hline $\mathrm{CaO} * \mathrm{Li} 2 \mathrm{O}$ & -0.2141 & -0.0733 & -0.0523 & -0.0016 \\
\hline $\mathrm{CaO} * \mathrm{Na} 2 \mathrm{O}$ & -0.0500 & -0.0355 & 0.0289 & -0.0585 \\
\hline $\mathrm{Li2O} * \mathrm{Na} 2 \mathrm{O}$ & -0.0316 & 0.0541 & 0.0110 & -0.0907 \\
\hline $\mathrm{A} 2 \mathrm{O} 3 /(\mathrm{T} / 1000)$ & -0.5099 & -0.6600 & -0.3207 & -0.4295 \\
\hline $\mathrm{B} 2 \mathrm{O} 3 /(\mathrm{T} / 1000)$ & -0.2228 & -0.9084 & -1.7838 & 0.6754 \\
\hline $\mathrm{CaO} /(\mathrm{T} / 1000)$ & 0.5282 & -0.5827 & 1.1093 & 0.0053 \\
\hline $\mathrm{Fe} 2 \mathrm{O} 3 /(\mathrm{T} / 1000)$ & -0.2595 & -0.4972 & -0.0539 & 0.9181 \\
\hline $\mathrm{K} 2 \mathrm{O} /(\mathrm{T} / 1000)$ & -0.0097 & -0.3498 & -0.6020 & -0.6959 \\
\hline $\mathrm{Li} 2 \mathrm{O} /(\mathrm{T} / 1000)$ & 3.9412 & -1.3476 & -3.6868 & -0.7680 \\
\hline $\mathrm{MgO} /(\mathrm{T} / 1000)$ & 0.8847 & -0.9958 & 1.3306 & -1.2733 \\
\hline $\mathrm{Na} 2 \mathrm{O} /(\mathrm{T} / 1000)$ & 1.5664 & -0.4982 & -0.8797 & -0.2651 \\
\hline $\mathrm{SiO} 2 /(\mathrm{T} / 1000)$ & -0.4982 & 0.8185 & -0.2568 & -0.9051 \\
\hline $\mathrm{ZrO} /(\mathrm{T} / 1000)$ & -0.8797 & -0.2568 & 17.5140 & -0.9500 \\
\hline $\mathrm{Others/(T/1000)}$ & -0.2651 & -0.9051 & -0.9500 & 6.8928 \\
\hline \hline & & & & \\
\hline
\end{tabular}


Table A-12. Particle Density of GFC and Sucrose

\begin{tabular}{|c|c|}
\hline GFC or other additives $^{(\text {a) }}$ & Particle density, $\mathbf{g} / \mathbf{L}$ \\
\hline Kyanite & 3398.3 \\
\hline Boric Acid & 1509.3 \\
\hline Wollastonite & 2899.3 \\
\hline Hematite & 4747.9 \\
\hline Lithium Carbonate & 2109.6 \\
\hline Olivine & 2948.2 \\
\hline Sodium Carbonate & 2532.5 \\
\hline Silica & 2649.5 \\
\hline Rutile & 4647.8 \\
\hline Zincite & 5596.9 \\
\hline Zircon & 4701.4 \\
\hline Sucrose & 1549.0 \\
\hline
\end{tabular}




\section{Appendix B-Results of Example Calculations}


Table B-1. Composition of CRV Batches Used for Example Calculations in the Format as Reported by Analytical Laboratory

\begin{tabular}{|c|c|c|c|c|c|c|c|c|}
\hline $\begin{array}{c}\text { CRV Batch } \\
\text { ID }\end{array}$ & A10 & B10 & A11 & B11 & A12 & B12 & A13 & B13 \\
\hline \multicolumn{9}{|c|}{ Concentration of chemical elements, NOx, and TOC (mg/L) } \\
\hline \multicolumn{9}{|l|}{ Ac } \\
\hline $\mathrm{Ag}$ & 3.2305E-01 & $3.1876 \mathrm{E}-01$ & $3.1693 \mathrm{E}-01$ & $3.1782 \mathrm{E}-01$ & $3.1834 \mathrm{E}-01$ & 3.1077E-01 & $2.9757 \mathrm{E}-01$ & $2.8670 \mathrm{E}-01$ \\
\hline $\mathrm{Al}$ & $9.5241 \mathrm{E}+03$ & $9.6281 \mathrm{E}+03$ & $9.7247 \mathrm{E}+03$ & $9.8076 \mathrm{E}+03$ & $9.3131 \mathrm{E}+03$ & $8.9359 \mathrm{E}+03$ & $8.8641 \mathrm{E}+03$ & $9.0613 \mathrm{E}+03$ \\
\hline \multicolumn{9}{|l|}{ Am } \\
\hline As & $1.2149 \mathrm{E}+00$ & $1.2002 \mathrm{E}+00$ & $1.1706 \mathrm{E}+00$ & $1.1495 \mathrm{E}+00$ & $1.2373 \mathrm{E}+00$ & $1.3507 \mathrm{E}+00$ & $1.4016 \mathrm{E}+00$ & $1.4023 \mathrm{E}+00$ \\
\hline $\mathrm{B}$ & $1.5902 \mathrm{E}+01$ & $1.4783 \mathrm{E}+01$ & $1.6770 \mathrm{E}+01$ & $1.8207 \mathrm{E}+01$ & $1.9934 \mathrm{E}+01$ & $1.7651 \mathrm{E}+01$ & $1.6987 \mathrm{E}+01$ & $1.8055 \mathrm{E}+01$ \\
\hline $\mathrm{Ba}$ & 2.7294E-01 & $2.6936 \mathrm{E}-01$ & $2.6287 \mathrm{E}-01$ & $2.5781 \mathrm{E}-01$ & $2.7820 \mathrm{E}-01$ & $3.0466 \mathrm{E}-01$ & $3.1690 \mathrm{E}-01$ & 3.1742E-01 \\
\hline $\mathrm{Be}$ & 5.1924E-01 & 5.1343E-01 & $5.1434 \mathrm{E}-01$ & $5.2162 \mathrm{E}-01$ & 4.9923E-01 & $4.5208 \mathrm{E}-01$ & $4.0501 \mathrm{E}-01$ & 3.7599E-01 \\
\hline $\mathrm{Bi}$ & $4.7604 \mathrm{E}+00$ & $4.7009 \mathrm{E}+00$ & $4.5088 \mathrm{E}+00$ & $4.3350 \mathrm{E}+00$ & $5.0127 \mathrm{E}+00$ & $5.9918 \mathrm{E}+00$ & $6.5751 \mathrm{E}+00$ & $6.7408 \mathrm{E}+00$ \\
\hline $\mathrm{Ca}$ & $3.4621 \mathrm{E}+01$ & $3.4583 \mathrm{E}+01$ & $3.5197 \mathrm{E}+01$ & $3.6000 \mathrm{E}+01$ & $3.6148 \mathrm{E}+01$ & $3.6131 \mathrm{E}+01$ & $3.5519 \mathrm{E}+01$ & $3.4778 \mathrm{E}+01$ \\
\hline $\mathrm{Cd}$ & $8.0278 \mathrm{E}-01$ & 7.9314E-01 & $7.9400 \mathrm{E}-01$ & $8.0400 \mathrm{E}-01$ & 7.7727E-01 & 7.1447E-01 & 6.4969E-01 & 6.0903E-01 \\
\hline $\mathrm{Ce}$ & $2.5103 \mathrm{E}-01$ & $2.4742 \mathrm{E}-01$ & $2.3683 \mathrm{E}-01$ & $2.2634 \mathrm{E}-01$ & $2.6616 \mathrm{E}-01$ & $3.2413 \mathrm{E}-01$ & $3.5964 \mathrm{E}-01$ & 3.7044E-01 \\
\hline $\mathrm{Cl}$ & $2.7498 \mathrm{E}+03$ & $2.7515 \mathrm{E}+03$ & $2.7811 \mathrm{E}+03$ & $2.8086 \mathrm{E}+03$ & $2.8597 \mathrm{E}+03$ & $2.8983 \mathrm{E}+03$ & $2.9321 \mathrm{E}+03$ & $2.9578 \mathrm{E}+03$ \\
\hline \multicolumn{9}{|l|}{$\mathrm{Cm}$} \\
\hline $\mathrm{Co}$ & 3.9890E-01 & $3.9860 \mathrm{E}-01$ & $4.0135 \mathrm{E}-01$ & 4.0792E-01 & $4.0355 \mathrm{E}-01$ & $3.8477 \mathrm{E}-01$ & $3.6063 \mathrm{E}-01$ & 3.4353E-01 \\
\hline $\mathrm{Cr}$ & $6.4146 \mathrm{E}+02$ & $6.3532 \mathrm{E}+02$ & $6.1262 \mathrm{E}+02$ & $5.9230 \mathrm{E}+02$ & $6.7965 \mathrm{E}+02$ & $8.0756 \mathrm{E}+02$ & $8.8348 \mathrm{E}+02$ & $9.0450 \mathrm{E}+02$ \\
\hline $\mathrm{Cs}$ & $3.3451 \mathrm{E}-03$ & $3.2756 \mathrm{E}-03$ & $3.2623 \mathrm{E}-03$ & $3.2601 \mathrm{E}-03$ & $3.5517 \mathrm{E}-03$ & $3.7539 \mathrm{E}-03$ & $3.8581 \mathrm{E}-03$ & 3.8901E-03 \\
\hline $\mathrm{Cu}$ & 7.6645E-01 & $7.5758 \mathrm{E}-01$ & $7.5380 \mathrm{E}-01$ & 7.5817E-01 & 7.4824E-01 & 7.1557E-01 & $6.7271 \mathrm{E}-01$ & 6.4121E-01 \\
\hline \multicolumn{9}{|l|}{$\mathrm{Eu}$} \\
\hline $\mathrm{F}$ & $1.1429 \mathrm{E}+03$ & $1.1056 \mathrm{E}+03$ & $1.1532 \mathrm{E}+03$ & $1.1946 \mathrm{E}+03$ & $1.2303 \mathrm{E}+03$ & $1.1409 \mathrm{E}+03$ & $1.0823 \mathrm{E}+03$ & $1.0780 \mathrm{E}+03$ \\
\hline $\mathrm{Fe}$ & $1.2554 \mathrm{E}+01$ & $1.1624 \mathrm{E}+01$ & $1.3181 \mathrm{E}+01$ & $1.4209 \mathrm{E}+01$ & $1.5952 \mathrm{E}+01$ & $1.4716 \mathrm{E}+01$ & $1.4614 \mathrm{E}+01$ & $1.5634 \mathrm{E}+01$ \\
\hline $\mathrm{Gd}$ & $0.0000 \mathrm{E}+00$ & $0.0000 \mathrm{E}+00$ & $0.0000 \mathrm{E}+00$ & $0.0000 \mathrm{E}+00$ & $0.0000 \mathrm{E}+00$ & $0.0000 \mathrm{E}+00$ & $0.0000 \mathrm{E}+00$ & $0.0000 \mathrm{E}+00$ \\
\hline $\mathrm{Hg}$ & $9.8536 \mathrm{E}-02$ & 9.6952E-02 & $9.4184 \mathrm{E}-02$ & $9.1371 \mathrm{E}-02$ & $1.0619 \mathrm{E}-01$ & $1.2554 \mathrm{E}-01$ & $1.3778 \mathrm{E}-01$ & $1.4235 \mathrm{E}-01$ \\
\hline \multicolumn{9}{|l|}{ I } \\
\hline $\mathrm{K}$ & $1.3573 \mathrm{E}+04$ & $1.3413 \mathrm{E}+04$ & $1.3433 \mathrm{E}+04$ & $1.3613 \mathrm{E}+04$ & $1.3100 \mathrm{E}+04$ & $1.1955 \mathrm{E}+04$ & $1.0794 \mathrm{E}+04$ & $1.0073 \mathrm{E}+04$ \\
\hline $\mathrm{La}$ & 3.6882E-01 & 3.6881E-01 & $3.6526 \mathrm{E}-01$ & $3.6297 \mathrm{E}-01$ & $3.9379 \mathrm{E}-01$ & 4.3071E-01 & $4.4766 \mathrm{E}-01$ & 4.4886E-01 \\
\hline $\mathrm{Li}$ & 1.6135E-01 & $1.5949 \mathrm{E}-01$ & $1.5850 \mathrm{E}-01$ & $1.5924 \mathrm{E}-01$ & $1.5790 \mathrm{E}-01$ & $1.5222 \mathrm{E}-01$ & $1.4405 \mathrm{E}-01$ & 1.3779E-01 \\
\hline $\mathrm{Mg}$ & $9.6546 \mathrm{E}+00$ & $8.8701 \mathrm{E}+00$ & $1.3066 \mathrm{E}+01$ & $1.6327 \mathrm{E}+01$ & $2.0030 \mathrm{E}+01$ & $1.7710 \mathrm{E}+01$ & $1.8632 \mathrm{E}+01$ & $2.2824 \mathrm{E}+01$ \\
\hline $\mathrm{Mn}$ & $1.3040 \mathrm{E}+00$ & $1.2564 \mathrm{E}+00$ & $1.2967 \mathrm{E}+00$ & $1.3170 \mathrm{E}+00$ & $1.4302 \mathrm{E}+00$ & $1.4517 \mathrm{E}+00$ & $1.4757 \mathrm{E}+00$ & $1.5099 \mathrm{E}+00$ \\
\hline Mo & $9.7705 \mathrm{E}+00$ & $9.6510 \mathrm{E}+00$ & $9.4758 \mathrm{E}+00$ & $9.3783 \mathrm{E}+00$ & $9.8362 \mathrm{E}+00$ & $1.0339 \mathrm{E}+01$ & $1.0458 \mathrm{E}+01$ & $1.0344 \mathrm{E}+01$ \\
\hline $\mathrm{Na}$ & $1.5809 \mathrm{E}+05$ & $1.5863 \mathrm{E}+05$ & $1.5881 \mathrm{E}+05$ & $1.5942 \mathrm{E}+05$ & $1.5764 \mathrm{E}+05$ & $1.5695 \mathrm{E}+05$ & $1.5646 \mathrm{E}+05$ & $1.5670 \mathrm{E}+05$ \\
\hline \multicolumn{9}{|l|}{$\mathrm{Nb}$} \\
\hline $\mathrm{Nd}$ & $1.1961 \mathrm{E}+00$ & $1.1823 \mathrm{E}+00$ & $1.1758 \mathrm{E}+00$ & $1.1821 \mathrm{E}+00$ & $1.1691 \mathrm{E}+00$ & $1.1220 \mathrm{E}+00$ & $1.0578 \mathrm{E}+00$ & $1.0098 \mathrm{E}+00$ \\
\hline $\mathrm{Ni}$ & $2.5738 \mathrm{E}+01$ & $2.6017 \mathrm{E}+01$ & $2.6535 \mathrm{E}+01$ & $2.7270 \mathrm{E}+01$ & $2.6996 \mathrm{E}+01$ & $2.5584 \mathrm{E}+01$ & $2.3845 \mathrm{E}+01$ & $2.2669 \mathrm{E}+01$ \\
\hline \multicolumn{9}{|l|}{$\mathrm{Np}$} \\
\hline $\mathrm{P}$ & $9.0542 \mathrm{E}+02$ & $9.0200 \mathrm{E}+02$ & $8.9007 \mathrm{E}+02$ & $8.8407 \mathrm{E}+02$ & $9.4110 \mathrm{E}+02$ & $1.0127 \mathrm{E}+03$ & $1.0406 \mathrm{E}+03$ & $1.0363 \mathrm{E}+03$ \\
\hline \multicolumn{9}{|l|}{$\mathrm{Pa}$} \\
\hline $\mathrm{Pb}$ & $3.2157 \mathrm{E}+01$ & $3.2426 \mathrm{E}+01$ & $3.2954 \mathrm{E}+01$ & $3.3748 \mathrm{E}+01$ & $3.3607 \mathrm{E}+01$ & $3.2196 \mathrm{E}+01$ & $3.0294 \mathrm{E}+01$ & $2.8945 \mathrm{E}+01$ \\
\hline $\mathrm{Pd}$ & $7.3745 \mathrm{E}+00$ & $7.2921 \mathrm{E}+00$ & $7.3090 \mathrm{E}+00$ & $7.4173 \mathrm{E}+00$ & $7.0817 \mathrm{E}+00$ & $6.3838 \mathrm{E}+00$ & $5.6951 \mathrm{E}+00$ & $5.2745 \mathrm{E}+00$ \\
\hline $\operatorname{Pr}$ & 1.0387E-02 & $1.0271 \mathrm{E}-02$ & $1.0279 \mathrm{E}-02$ & $1.0413 \mathrm{E}-02$ & $1.0008 \mathrm{E}-02$ & $9.1333 \mathrm{E}-03$ & $8.2408 \mathrm{E}-03$ & 7.6813E-03 \\
\hline \multicolumn{9}{|l|}{$\mathrm{Pu}$} \\
\hline \multicolumn{9}{|l|}{$\mathrm{Ra}$} \\
\hline $\mathrm{Rb}$ & $1.5682 \mathrm{E}+00$ & $1.5504 \mathrm{E}+00$ & $1.5525 \mathrm{E}+00$ & $1.5737 \mathrm{E}+00$ & $1.5101 \mathrm{E}+00$ & $1.3734 \mathrm{E}+00$ & $1.2355 \mathrm{E}+00$ & $1.1499 \mathrm{E}+00$ \\
\hline $\mathrm{Rh}$ & $3.0812 \mathrm{E}+00$ & $3.0440 \mathrm{E}+00$ & $3.0564 \mathrm{E}+00$ & $3.1057 \mathrm{E}+00$ & $2.9610 \mathrm{E}+00$ & $2.6529 \mathrm{E}+00$ & $2.3556 \mathrm{E}+00$ & $2.1781 \mathrm{E}+00$ \\
\hline $\mathrm{Ru}$ & $1.3756 \mathrm{E}+01$ & $1.3463 \mathrm{E}+01$ & $1.3681 \mathrm{E}+01$ & $1.3985 \mathrm{E}+01$ & $1.3534 \mathrm{E}+01$ & $1.2020 \mathrm{E}+01$ & $1.0713 \mathrm{E}+01$ & $1.0049 \mathrm{E}+01$ \\
\hline $\mathrm{S}$ & $1.6951 \mathrm{E}+03$ & $1.6756 \mathrm{E}+03$ & $1.6216 \mathrm{E}+03$ & $1.5763 \mathrm{E}+03$ & $1.7646 \mathrm{E}+03$ & $2.0264 \mathrm{E}+03$ & $2.1729 \mathrm{E}+03$ & $2.2080 \mathrm{E}+03$ \\
\hline $\mathrm{Sb}$ & 3.3380E-01 & $3.3108 \mathrm{E}-01$ & $3.1960 \mathrm{E}-01$ & $3.0929 \mathrm{E}-01$ & $3.5546 \mathrm{E}-01$ & 4.2091E-01 & 4.5934E-01 & 4.6992E-01 \\
\hline
\end{tabular}




\begin{tabular}{|c|c|c|c|c|c|c|c|c|}
\hline $\begin{array}{c}\text { CRV Batch } \\
\text { ID }\end{array}$ & A10 & B10 & A11 & B11 & A12 & B12 & A13 & B13 \\
\hline $\mathrm{Se}$ & $2.2786 \mathrm{E}+00$ & $2.2364 \mathrm{E}+00$ & $2.2165 \mathrm{E}+00$ & $2027 \mathrm{E}+00$ & $2.3749 \mathrm{E}+00$ & $.5289 \mathrm{E}+00$ & $2.6034 \mathrm{E}+00$ & $2.6208 \mathrm{E}+\mathrm{C}$ \\
\hline $\mathrm{Si}$ & $4.7632 \mathrm{E}+02$ & $4.7764 \mathrm{E}+02$ & $4.8740 \mathrm{E}+02$ & $5.0008 \mathrm{E}+02$ & $4.9956 \mathrm{E}+02$ & $4.8809 \mathrm{E}+02$ & $4.6999 \mathrm{E}+02$ & $4.5543 \mathrm{E}+02$ \\
\hline \multicolumn{9}{|l|}{$\mathrm{Sm}$} \\
\hline \multicolumn{9}{|l|}{$\mathrm{Sn}$} \\
\hline $\mathrm{Sr}$ & -01 & -01 & -01 & 77E-01 & 3684E-01 & $1.6270 \mathrm{E}-01$ & 1.779 & $1.8226 \mathrm{H}$ \\
\hline $\mathrm{Ta}$ & $4.1030 \mathrm{E}-02$ & $4.0572 \mathrm{E}-02$ & $4.0675 \mathrm{E}-02$ & & $3.9381 \mathrm{E}-02$ & 5437E-02 & $3.1560 \mathrm{E}-02$ & $9201 \mathrm{E}-02$ \\
\hline \multicolumn{9}{|l|}{$\mathrm{Tc}$} \\
\hline $\mathrm{Te}$ & $\mathrm{E}-01$ & $\mathrm{E}-01$ & 2303E-01 & $1.2506 \mathrm{E}-01$ & 1982E-01 & $.0766 \mathrm{E}-01$ & $9.6045 \mathrm{E}-02$ & $9215 \mathrm{E}-02$ \\
\hline Th & $4.1376 \mathrm{E}+00$ & $4.1165 \mathrm{E}+00$ & $3.9978 \mathrm{E}+00$ & $3.8932 \mathrm{E}+00$ & $4.4317 \mathrm{E}+00$ & $5.1785 \mathrm{E}+00$ & $5.6073 \mathrm{E}+00$ & $5.7189 \mathrm{E}+00$ \\
\hline $\mathrm{Ti}$ & 2.693 & $E+00$ & $2.9230 \mathrm{E}+00$ & $3.2619 \mathrm{E}+00$ & $\mathrm{E}+00$ & $7 \mathrm{E}+00$ & 2.9682 & +00 \\
\hline $\mathrm{Tl}$ & $\mathrm{E}+00$ & $1.0628 \mathrm{E}+00$ & $1.0086 \mathrm{E}+00$ & 9.56 & $1.1563 \mathrm{E}+00$ & $1.4523 \mathrm{E}+00$ & 1.637 & \\
\hline $\mathrm{U}$ & $E+01$ & 3.69 & 3.650 & & & & & \\
\hline $\mathrm{V}$ & & & & & & & & \\
\hline W & & & & & & & +00 & \\
\hline Y & E-01 & E-01 & -01 & E-01 & -01 & $341 \mathrm{E}-01$ & 4.7795E-01 & -01 \\
\hline $\mathrm{Zn}$ & $1.1381 \mathrm{E}+01$ & $1.0442 \mathrm{E}+01$ & $1.2223 \mathrm{E}+01$ & $1.3509 \mathrm{E}+01$ & $1.4864 \mathrm{E}+01$ & $1.2703 \mathrm{E}+01$ & $1.2055 \mathrm{E}+01$ & $1.2989 \mathrm{E}+01$ \\
\hline $\mathrm{Zr}$ & $6.3441 \mathrm{E}+00$ & $6.2069 \mathrm{E}+00$ & $6.1977 \mathrm{E}+00$ & $6.1875 \mathrm{E}+00$ & $6.7302 \mathrm{E}+00$ & $7.1512 \mathrm{E}+00$ & $7.3830 \mathrm{E}+00$ & 7.477 \\
\hline $\mathrm{NO} 2$ & $2.8881 \mathrm{E}+04$ & 2.8526 & 2.80 & 2.7 & 2.90671 & $89 \mathrm{E}+04$ & 3.079 & +04 \\
\hline $\mathrm{NO} 3$ & $1 \mathrm{E}+04$ & $7.5263 \mathrm{E}+04$ & $7.3888 \mathrm{E}+04$ & 04 & 04 & $48 \mathrm{E}+04$ & 8.201 & +04 \\
\hline & & & $E+03$ & +03 & & & & \\
\hline \multicolumn{9}{|c|}{ Activity of radionuclides (mCi/L) } \\
\hline $59 \mathrm{Ni}$ & & & 3.83 & & -04 & & & \\
\hline $60 \mathrm{Co}$ & & -04 & & & & & -04 & \\
\hline $63 \mathrm{Ni}$ & -02 & $\mathrm{E}-02$ & $\mathrm{E}-02$ & $\mathrm{E}-02$ & -02 & -02 & $6 \mathrm{E}-02$ & 3.4 \\
\hline $79 \mathrm{Se}$ & $\mathrm{E}-03$ & $1.4641 \mathrm{E}-03$ & 1.43 & 1.4 & & $6 \mathrm{E}-03$ & $1.9459 \mathrm{E}-03$ & $1.9941 \mathrm{E}-03$ \\
\hline $90 \mathrm{Sr}$ & $6.2741 \mathrm{E}-01$ & $6.2600 \mathrm{E}-01$ & $6.2227 \mathrm{E}-01$ & $6.2320 \mathrm{E}-01$ & 6.48 & 6.6989E-01 & 6.6891E-01 & 6.57 \\
\hline $90 \mathrm{Y}$ & & & & & & -01 & -01 & \\
\hline $93 \mathrm{mNb}$ & $\mathrm{E}+00$ & & 1.42 & 1.6 & -00 & +00 & $\mathrm{E}+00$ & \\
\hline $93 \mathrm{Zr}$ & & & & & & $\mathrm{E}-03$ & $\mathrm{E}-03$ & \\
\hline $99 \mathrm{Tc}$ & & & & & & & & \\
\hline $\mathrm{Ru}$ & & 5.5 & -07 & & & -07 & & 9. \\
\hline $113 \mathrm{mCd}$ & -03 & E-03 & $4 \mathrm{E}-03$ & $\mathrm{E}-03$ & 03 & 7.7831E-03 & $36 \mathrm{E}-03$ & $7.9892 \mathrm{E}-03$ \\
\hline $125 \mathrm{Sb}$ & $1.7675 \mathrm{E}-03$ & $1.7450 \mathrm{E}-03$ & $1.6599 \mathrm{E}-03$ & $1.5789 \mathrm{E}-03$ & $1.8915 \mathrm{E}-03$ & $2.3525 \mathrm{E}-03$ & $2.6391 \mathrm{E}-03$ & $2.7302 \mathrm{E}-03$ \\
\hline $126 \mathrm{Sn}$ & $1.6010 \mathrm{E}-03$ & $1.5875 \mathrm{E}-03$ & $1.5700 \mathrm{E}-03$ & $1.5663 \mathrm{E}-03$ & $1.6133 \mathrm{E}-03$ & $1.6497 \mathrm{E}-03$ & $1.6347 \mathrm{E}-03$ & $1.6006 \mathrm{E}-03$ \\
\hline 129I & $1.1977 \mathrm{E}-04$ & $1.1663 \mathrm{E}-04$ & & $1.2111 \mathrm{E}$ & & $1.3057 \mathrm{E}-04$ & $1.3102 \mathrm{E}-04$ & 1.323 \\
\hline IJTes & 77 & 2. & & & & -07 & $8-07$ & \\
\hline $137 \mathrm{mBa}$ & $8+02$ & $8 \mathrm{E}+01$ & $\mathrm{E}+01$ & 9.7 & $1 \mathrm{E}+02$ & $3 \mathrm{E}+02$ & $15 \mathrm{E}+02$ & \\
\hline & & & & & & & & \\
\hline 15 & & & 1.7 & & -00 & +00 & +00 & 2.0 \\
\hline $152 \mathrm{Eu}$ & & -04 & E-04 & 2.9 & $52 \mathrm{E}-04$ & $3.7222 \mathrm{E}-04$ & -04 & 4.0214E-04 \\
\hline $154 \mathrm{Eu}$ & $6.1890 \mathrm{E}-03$ & $6.2121 \mathrm{E}-03$ & $6.2249 \mathrm{E}-03$ & $6.2813 \mathrm{E}-03$ & $6.4939 \mathrm{E}-03$ & $6.6298 \mathrm{E}-03$ & $6.5574 \mathrm{E}-03$ & $6.4188 \mathrm{E}-03$ \\
\hline $155 \mathrm{Eu}$ & $2.8626 \mathrm{E}-03$ & $2.8431 \mathrm{E}-03$ & $2.7833 \mathrm{E}-03$ & $2.7405 \mathrm{E}-03$ & $2.9790 \mathrm{E}-03$ & $3.2869 \mathrm{E}-03$ & 3.4331E-03 & $3.4448 \mathrm{E}-03$ \\
\hline $226 \mathrm{Ra}$ & $4.9255 \mathrm{E}-06$ & $4.8703 \mathrm{E}-06$ & $4.8787 \mathrm{E}-06$ & $4.9476 \mathrm{E}-06$ & $4.7358 \mathrm{E}-06$ & $4.2895 \mathrm{E}-06$ & $3.8438 \mathrm{E}-06$ & $3.5688 \mathrm{E}-06$ \\
\hline $227 \mathrm{Ac}$ & & E-06 & E- 06 & $4.5843 \mathrm{E}-06$ & $4.4161 \mathrm{E}-06$ & 416E-06 & $3.6568 \mathrm{E}-06$ & $3.4160 \mathrm{E}-06$ \\
\hline & & & & & & $1 \mathrm{E}-06$ & E-06 & $28 \mathrm{E}-06$ \\
\hline & & & $96 \mathrm{E}-07$ & $29 \mathrm{E}-07$ & $2.3619 \mathrm{E}-07$ & $2.9677 \mathrm{E}-07$ & 3.3477E-07 & $3.4712 \mathrm{E}-07$ \\
\hline & & & & & & $7 \mathrm{E}-05$ & 9.8907E-06 & $9.1930 \mathrm{E}-06$ \\
\hline $232 \mathrm{Th}$ & $4.5355 \mathrm{E}-07$ & $4.5126 \mathrm{E}-07$ & 4.3819E-07 & $4.2668 \mathrm{E}-07$ & $4.8569 \mathrm{E}-07$ & $5.6766 \mathrm{E}-07$ & $6.1470 \mathrm{E}-07$ & $6.2691 \mathrm{E}-07$ \\
\hline $232 \mathrm{U}$ & $6.2067 \mathrm{E}-07$ & 6.1294E-07 & $5.9278 \mathrm{E}-07$ & $5.7589 \mathrm{E}-07$ & $6.4246 \mathrm{E}-07$ & $7.3532 \mathrm{E}-07$ & 7.8636E-07 & $7.9729 \mathrm{E}-07$ \\
\hline $233 \mathrm{U}$ & $2.9000 \mathrm{E}-05$ & $2.8656 \mathrm{E}-05$ & $2.8130 \mathrm{E}-05$ & $2.7844 \mathrm{E}-05$ & $2.9132 \mathrm{E}-05$ & $3.0557 \mathrm{E}-05$ & $3.0847 \mathrm{E}-05$ & $3.0468 \mathrm{E}-0$ \\
\hline
\end{tabular}




\begin{tabular}{|c|c|c|c|c|c|c|c|c||}
\hline $\begin{array}{c}\text { CRV Batch } \\
\text { ID }\end{array}$ & $\mathbf{A 1 0}$ & $\mathbf{B 1 0}$ & $\mathbf{A 1 1}$ & $\mathbf{B 1 1}$ & $\mathbf{A 1 2}$ & B12 & A13 & B13 \\
\hline $234 \mathrm{U}$ & $1.6670 \mathrm{E}-05$ & $1.6479 \mathrm{E}-05$ & $1.6319 \mathrm{E}-05$ & $1.6323 \mathrm{E}-05$ & $1.6451 \mathrm{E}-05$ & $1.6288 \mathrm{E}-05$ & $1.5749 \mathrm{E}-05$ & $1.5231 \mathrm{E}-05$ \\
\hline $235 \mathrm{U}$ & $6.2943 \mathrm{E}-07$ & $6.2236 \mathrm{E}-07$ & $6.1586 \mathrm{E}-07$ & $6.1545 \mathrm{E}-07$ & $6.2306 \mathrm{E}-07$ & $6.2129 \mathrm{E}-07$ & $6.0405 \mathrm{E}-07$ & $5.8582 \mathrm{E}-07$ \\
\hline $236 \mathrm{U}$ & $1.1561 \mathrm{E}-06$ & $1.1428 \mathrm{E}-06$ & $1.1349 \mathrm{E}-06$ & $1.1392 \mathrm{E}-06$ & $1.1329 \mathrm{E}-06$ & $1.0975 \mathrm{E}-06$ & $1.0428 \mathrm{E}-06$ & $9.9951 \mathrm{E}-07$ \\
\hline $237 \mathrm{~Np}$ & $8.4642 \mathrm{E}-05$ & $8.4020 \mathrm{E}-05$ & $8.2274 \mathrm{E}-05$ & $8.1046 \mathrm{E}-05$ & $8.7794 \mathrm{E}-05$ & $9.6441 \mathrm{E}-05$ & $1.0047 \mathrm{E}-04$ & $1.0072 \mathrm{E}-04$ \\
\hline $238 \mathrm{Pu}$ & $4.4701 \mathrm{E}-05$ & $4.4148 \mathrm{E}-05$ & $4.2767 \mathrm{E}-05$ & $4.1646 \mathrm{E}-05$ & $4.6105 \mathrm{E}-05$ & $5.2261 \mathrm{E}-05$ & $5.5555 \mathrm{E}-05$ & $5.6181 \mathrm{E}-05$ \\
\hline $238 \mathrm{U}$ & $1.2434 \mathrm{E}-05$ & $1.2299 \mathrm{E}-05$ & $1.2165 \mathrm{E}-05$ & $1.2148 \mathrm{E}-05$ & $1.2353 \mathrm{E}-05$ & $1.2402 \mathrm{E}-05$ & $1.2120 \mathrm{E}-05$ & $1.1785 \mathrm{E}-05$ \\
\hline $239 \mathrm{Pu}$ & $5.2071 \mathrm{E}-04$ & $5.1421 \mathrm{E}-04$ & $4.9488 \mathrm{E}-04$ & $4.7790 \mathrm{E}-04$ & $5.4441 \mathrm{E}-04$ & $6.3936 \mathrm{E}-04$ & $6.9444 \mathrm{E}-04$ & $7.0885 \mathrm{E}-04$ \\
\hline $240 \mathrm{Pu}$ & $1.2698 \mathrm{E}-04$ & $1.2539 \mathrm{E}-04$ & $1.2057 \mathrm{E}-04$ & $1.1631 \mathrm{E}-04$ & $1.3298 \mathrm{E}-04$ & $1.5686 \mathrm{E}-04$ & $1.7081 \mathrm{E}-04$ & $1.7454 \mathrm{E}-04$ \\
\hline $241 \mathrm{Am}$ & $6.4277 \mathrm{E}-04$ & $6.3463 \mathrm{E}-04$ & $6.0647 \mathrm{E}-04$ & $5.8034 \mathrm{E}-04$ & $6.8138 \mathrm{E}-04$ & $8.2887 \mathrm{E}-04$ & $9.1864 \mathrm{E}-04$ & $9.4567 \mathrm{E}-04$ \\
\hline $241 \mathrm{Pu}$ & $1.4488 \mathrm{E}-03$ & $1.4300 \mathrm{E}-03$ & $1.3689 \mathrm{E}-03$ & $1.3131 \mathrm{E}-03$ & $1.5279 \mathrm{E}-03$ & $1.8401 \mathrm{E}-03$ & $2.0279 \mathrm{E}-03$ & $2.0826 \mathrm{E}-03$ \\
\hline $242 \mathrm{Cm}$ & $3.1290 \mathrm{E}-06$ & $3.1172 \mathrm{E}-06$ & $3.0237 \mathrm{E}-06$ & $2.9365 \mathrm{E}-06$ & $3.3395 \mathrm{E}-06$ & $3.9002 \mathrm{E}-06$ & $4.2271 \mathrm{E}-06$ & $4.3068 \mathrm{E}-06$ \\
\hline $242 \mathrm{Pu}$ & $1.4009 \mathrm{E}-08$ & $1.3834 \mathrm{E}-08$ & $1.3314 \mathrm{E}-08$ & $1.2858 \mathrm{E}-08$ & $1.4647 \mathrm{E}-08$ & $1.7200 \mathrm{E}-08$ & $1.8682 \mathrm{E}-08$ & $1.9069 \mathrm{E}-08$ \\
\hline $243 \mathrm{Am}$ & $1.0374 \mathrm{E}-07$ & $1.0249 \mathrm{E}-07$ & $9.9846 \mathrm{E}-08$ & $9.7911 \mathrm{E}-08$ & $1.0585 \mathrm{E}-07$ & $1.1629 \mathrm{E}-07$ & $1.2116 \mathrm{E}-07$ & $1.2143 \mathrm{E}-07$ \\
\hline $243 \mathrm{Cm}$ & $3.5947 \mathrm{E}-07$ & $3.6007 \mathrm{E}-07$ & $3.6058 \mathrm{E}-07$ & $3.6185 \mathrm{E}-07$ & $3.8048 \mathrm{E}-07$ & $3.9835 \mathrm{E}-07$ & $4.0151 \mathrm{E}-07$ & $3.9678 \mathrm{E}-07$ \\
\hline $244 \mathrm{Cm}$ & $7.3215 \mathrm{E}-06$ & $7.3351 \mathrm{E}-06$ & $7.3551 \mathrm{E}-06$ & $7.3929 \mathrm{E}-06$ & $7.7443 \mathrm{E}-06$ & $8.0520 \mathrm{E}-06$ & $8.0806 \mathrm{E}-06$ & $7.9685 \mathrm{E}-06$ \\
\hline
\end{tabular}

Empty cells represent no data for components with radionuclides only 
Table B-2. CRV Composition Converted to the Format Used in Glass Formulation for the $1^{\text {st }}$ Transfer Waste Transferred from the $A 11^{\text {th }} \mathrm{CRV}$

\begin{tabular}{|c|c|c|c|}
\hline Component & Value & Component & Value \\
\hline \multicolumn{2}{|c|}{ Glass oxide (mass fraction) } & \multicolumn{2}{|c|}{ NOx and TOC concentration $(\mathrm{g} / \mathrm{L})$} \\
\hline $\mathrm{Ac}_{2} \mathrm{O}_{3}$ & $2.6471 \mathrm{E}-13$ & $\mathrm{NO}_{2}$ & $2.7981 \mathrm{E}+01$ \\
\hline $\mathrm{Ag}_{2} \mathrm{O}$ & $1.3045 \mathrm{E}-06$ & $\mathrm{NO}_{3}$ & $7.3780 \mathrm{E}+01$ \\
\hline $\mathrm{Al}_{2} \mathrm{O}_{3}$ & 7.0410E-02 & TOC & $1.1356 \mathrm{E}+00$ \\
\hline $\mathrm{Am}_{2} \mathrm{O}_{3}$ & $7.4775 \mathrm{E}-10$ & \multicolumn{2}{|c|}{ Radionuclide specific activity (mCi/g oxides) } \\
\hline $\mathrm{As}_{2} \mathrm{O}_{5}$ & $6.8805 \mathrm{E}-06$ & $59 \mathrm{Ni}$ & $1.4685 \mathrm{E}-06$ \\
\hline $\mathrm{B}_{2} \mathrm{O}_{3}$ & $2.0692 \mathrm{E}-04$ & $60 \mathrm{Co}$ & $2.3378 \mathrm{E}-06$ \\
\hline $\mathrm{BaO}$ & $1.1246 \mathrm{E}-06$ & $63 \mathrm{Ni}$ & $1.3388 \mathrm{E}-04$ \\
\hline $\mathrm{BeO}$ & 5.4699E-06 & $79 \mathrm{Se}$ & $5.4909 \mathrm{E}-06$ \\
\hline $\mathrm{Bi}_{2} \mathrm{O}_{3}$ & $1.9262 \mathrm{E}-05$ & $90 \mathrm{Sr}$ & $2.3845 \mathrm{E}-03$ \\
\hline $\mathrm{CaO}$ & $1.8872 \mathrm{E}-04$ & $90 \mathrm{Y}$ & $2.3086 \mathrm{E}-03$ \\
\hline $\mathrm{CdO}$ & $3.4756 \mathrm{E}-06$ & $93 \mathrm{mNb}$ & $5.4502 \mathrm{E}-03$ \\
\hline $\mathrm{Ce}_{2} \mathrm{O}_{3}$ & $1.0629 \mathrm{E}-06$ & $93 \mathrm{Zr}$ & $3.5849 \mathrm{E}-05$ \\
\hline $\mathrm{Cl}$ & 1.0657E-02 & 99Tc & $2.2235 \mathrm{E}-04$ \\
\hline $\mathrm{Cm}_{2} \mathrm{O}_{3}$ & $4.1731 \mathrm{E}-13$ & $106 \mathrm{Ru}$ & $2.0408 \mathrm{E}-09$ \\
\hline $\mathrm{CoO}$ & $1.9555 \mathrm{E}-06$ & $113 \mathrm{mCd}$ & $2.6335 \mathrm{E}-05$ \\
\hline $\mathrm{Cr}_{2} \mathrm{O}_{3}$ & $3.4310 \mathrm{E}-03$ & $125 \mathrm{Sb}$ & $6.3608 \mathrm{E}-06$ \\
\hline $\mathrm{Cs}_{2} \mathrm{O}$ & $1.3254 \mathrm{E}-08$ & $126 \mathrm{Sn}$ & $6.0160 \mathrm{E}-06$ \\
\hline $\mathrm{CuO}$ & $3.6158 \mathrm{E}-06$ & $129 \mathrm{I}$ & $4.5629 \mathrm{E}-07$ \\
\hline $\mathrm{Eu}_{2} \mathrm{O}_{3}$ & $1.3553 \mathrm{E}-10$ & $134 \mathrm{Cs}$ & $1.0212 \mathrm{E}-09$ \\
\hline $\mathrm{F}$ & $4.4190 \mathrm{E}-03$ & $137 \mathrm{mBa}$ & $3.7691 \mathrm{E}-01$ \\
\hline $\mathrm{Fe}_{2} \mathrm{O}_{3}$ & $7.2215 \mathrm{E}-05$ & $137 \mathrm{Cs}$ & $2.1760 \mathrm{E}-04$ \\
\hline $\mathrm{Gd}_{2} \mathrm{O}_{3}$ & $0.0000 \mathrm{E}+00$ & $151 \mathrm{Sm}$ & $6.7836 \mathrm{E}-03$ \\
\hline $\mathrm{HgO}$ & $3.8970 \mathrm{E}-07$ & $152 \mathrm{Eu}$ & $1.1522 \mathrm{E}-06$ \\
\hline $\mathrm{I}$ & $2.5808 \mathrm{E}-06$ & $154 \mathrm{Eu}$ & $2.3853 \mathrm{E}-05$ \\
\hline $\mathrm{K}_{2} \mathrm{O}$ & $6.2008 \mathrm{E}-02$ & $155 \mathrm{Eu}$ & $1.0666 \mathrm{E}-05$ \\
\hline $\mathrm{La}_{2} \mathrm{O}_{3}$ & $1.6415 \mathrm{E}-06$ & $226 \mathrm{Ra}$ & $1.8695 \mathrm{E}-08$ \\
\hline $\mathrm{Li}_{2} \mathrm{O}$ & $1.3074 \mathrm{E}-06$ & $227 \mathrm{Ac}$ & $1.7313 \mathrm{E}-08$ \\
\hline $\mathrm{MgO}$ & 8.3024E-05 & $228 \mathrm{Ra}$ & $7.2680 \mathrm{E}-09$ \\
\hline $\mathrm{MnO}$ & $6.4159 \mathrm{E}-06$ & $229 \mathrm{Th}$ & $7.8921 \mathrm{E}-10$ \\
\hline $\mathrm{MoO}_{3}$ & $5.4477 \mathrm{E}-05$ & $231 \mathrm{~Pa}$ & 4.7880E-08 \\
\hline $\mathrm{Na}_{2} \mathrm{O}$ & $8.2030 \mathrm{E}-01$ & $232 \mathrm{Th}$ & $1.6791 \mathrm{E}-09$ \\
\hline $\mathrm{Nb}_{2} \mathrm{O}_{5}$ & $3.2676 \mathrm{E}-08$ & $232 \mathrm{U}$ & $2.2715 \mathrm{E}-09$ \\
\hline $\mathrm{Nd}_{2} \mathrm{O}_{3}$ & $5.2552 \mathrm{E}-06$ & $233 \mathrm{U}$ & $1.0779 \mathrm{E}-07$ \\
\hline $\mathrm{NiO}$ & $1.2940 \mathrm{E}-04$ & $234 \mathrm{U}$ & $6.2532 \mathrm{E}-08$ \\
\hline $\mathrm{NpO}_{2}$ & $5.0777 \mathrm{E}-07$ & $235 \mathrm{U}$ & $2.3599 \mathrm{E}-09$ \\
\hline $\mathrm{P}_{2} \mathrm{O}_{5}$ & 7.8152E-03 & $236 \mathrm{U}$ & 4.3489E-09 \\
\hline $\mathrm{Pa}_{2} \mathrm{O}_{5}$ & $1.1893 \mathrm{E}-09$ & $237 \mathrm{~Np}$ & $3.1527 \mathrm{E}-07$ \\
\hline $\mathrm{PbO}$ & $1.3603 \mathrm{E}-04$ & $238 \mathrm{Pu}$ & $1.6388 \mathrm{E}-07$ \\
\hline $\mathrm{PdO}$ & $3.2219 \mathrm{E}-05$ & $238 \mathrm{U}$ & 4.6617E-08 \\
\hline $\mathrm{Pr}_{2} \mathrm{O}_{3}$ & 4.6099E-08 & $239 \mathrm{Pu}$ & $1.8964 \mathrm{E}-06$ \\
\hline $\mathrm{PuO}_{2}$ & $3.7061 \mathrm{E}-08$ & $240 \mathrm{Pu}$ & $4.6204 \mathrm{E}-07$ \\
\hline $\mathrm{RaO}$ & $2.0280 \mathrm{E}-11$ & $241 \mathrm{Am}$ & $2.3240 \mathrm{E}-06$ \\
\hline $\mathrm{Rb}_{2} \mathrm{O}$ & $6.5061 \mathrm{E}-06$ & $241 \mathrm{Pu}$ & $5.2457 \mathrm{E}-06$ \\
\hline $\mathrm{Rh}_{2} \mathrm{O}_{3}$ & $1.4443 \mathrm{E}-05$ & $242 \mathrm{Cm}$ & $1.1587 \mathrm{E}-08$ \\
\hline
\end{tabular}




\begin{tabular}{|c|c|c|c|}
\hline Component & Value & Component & Value \\
\hline $\mathrm{RuO}_{2}$ & $6.9023 \mathrm{E}-05$ & $242 \mathrm{Pu}$ & $5.1020 \mathrm{E}-11$ \\
\hline $\mathrm{SO}_{3}$ & $1.5515 \mathrm{E}-02$ & $243 \mathrm{Am}$ & $3.8261 \mathrm{E}-10$ \\
\hline $\mathrm{Sb}_{2} \mathrm{O}_{3}$ & $1.4661 \mathrm{E}-06$ & $243 \mathrm{Cm}$ & $1.3817 \mathrm{E}-09$ \\
\hline $\mathrm{SeO}_{2}$ & $1.1936 \mathrm{E}-05$ & $244 \mathrm{Cm}$ & $2.8185 \mathrm{E}-08$ \\
\hline $\mathrm{SiO}_{2}$ & 3.9957E-03 & & \\
\hline $\mathrm{Sm}_{2} \mathrm{O}_{3}$ & $2.9870 \mathrm{E}-07$ & & \\
\hline $\mathrm{SnO}_{2}$ & $2.6572 \mathrm{E}-07$ & & \\
\hline $\mathrm{SrO}$ & 5.5799E-07 & & \\
\hline $\mathrm{Ta}_{2} \mathrm{O}_{5}$ & $1.9032 \mathrm{E}-07$ & & \\
\hline $\mathrm{Tc}_{2} \mathrm{O}_{7}$ & $2.0353 \mathrm{E}-05$ & & \\
\hline $\mathrm{TeO}_{2}$ & $5.8967 \mathrm{E}-07$ & & \\
\hline $\mathrm{ThO}_{2}$ & $1.7432 \mathrm{E}-05$ & & \\
\hline $\mathrm{TiO}_{2}$ & $1.8686 \mathrm{E}-05$ & & \\
\hline $\mathrm{Tl}_{2} \mathrm{O}$ & 4.0163E-06 & & \\
\hline $\mathrm{UO}_{3}$ & $1.6809 \mathrm{E}-04$ & & \\
\hline $\mathrm{V}_{2} \mathrm{O}_{5}$ & $2.5785 \mathrm{E}-06$ & & \\
\hline $\mathrm{WO}_{3}$ & $5.3711 \mathrm{E}-05$ & & \\
\hline $\mathrm{Y}_{2} \mathrm{O}_{3}$ & $2.9525 \mathrm{E}-06$ & & \\
\hline $\mathrm{ZnO}$ & $5.8300 \mathrm{E}-05$ & & \\
\hline $\mathrm{ZrO}_{2}$ & $3.2080 \mathrm{E}-05$ & & \\
\hline SUM & $1.0000 \mathrm{E}+00$ & & \\
\hline
\end{tabular}


Table B-3. Initial Composition, Adjusted Target Composition, Waste Contribution, and GFC Target Composition in the $A 101^{\text {th }}$ MFPV Batch

\begin{tabular}{|c|c|c|c|c|c|c|}
\hline Component & Initial target & $\begin{array}{l}\text { Initial Waste } \\
\text { contribution }\end{array}$ & $\begin{array}{c}\text { Initial GFC } \\
\text { target }\end{array}$ & $\begin{array}{c}\text { Adjusted } \\
\text { target }\end{array}$ & $\begin{array}{c}\text { Adjusted } \\
\text { Waste } \\
\text { contribution } \\
\end{array}$ & $\begin{array}{c}\text { Adjusted } \\
\text { GFC target }\end{array}$ \\
\hline $\mathrm{Ac}_{2} \mathrm{O}_{3}$ & $6.1720 \mathrm{E}-14$ & $6.1720 \mathrm{E}-14$ & & $6.1720 \mathrm{E}-14$ & $6.1720 \mathrm{E}-14$ & \\
\hline $\mathrm{Ag}_{2} \mathrm{O}$ & $3.0417 \mathrm{E}-07$ & $3.0417 \mathrm{E}-07$ & & $3.0417 \mathrm{E}-07$ & $3.0417 \mathrm{E}-07$ & \\
\hline $\mathrm{Al}_{2} \mathrm{O}_{3}$ & $6.1000 \mathrm{E}-02$ & $1.6417 \mathrm{E}-02$ & $4.4583 \mathrm{E}-02$ & $6.1000 \mathrm{E}-02$ & $1.6417 \mathrm{E}-02$ & 4.4583E-02 \\
\hline $\mathrm{Am}_{2} \mathrm{O}_{3}$ & $1.7435 \mathrm{E}-10$ & $1.7435 \mathrm{E}-10$ & & $1.7435 \mathrm{E}-10$ & $1.7435 \mathrm{E}-10$ & \\
\hline $\mathrm{As}_{2} \mathrm{O}_{5}$ & $1.6043 \mathrm{E}-06$ & $1.6043 \mathrm{E}-06$ & & 1.6043E-06 & $1.6043 \mathrm{E}-06$ & \\
\hline $\mathrm{B}_{2} \mathrm{O}_{3}$ & $1.0000 \mathrm{E}-01$ & 4.8247E-05 & 9.9952E-02 & $1.0000 \mathrm{E}-01$ & 4.8247E-05 & 9.9952E-02 \\
\hline $\mathrm{BaO}$ & $2.6223 \mathrm{E}-07$ & $2.6223 \mathrm{E}-07$ & & $2.6223 \mathrm{E}-07$ & $2.6223 \mathrm{E}-07$ & \\
\hline $\mathrm{BeO}$ & $1.2754 \mathrm{E}-06$ & $1.2754 \mathrm{E}-06$ & & $1.2754 \mathrm{E}-06$ & $1.2754 \mathrm{E}-06$ & \\
\hline $\mathrm{Bi}_{2} \mathrm{O}_{3}$ & 4.4912E-06 & 4.4912E-06 & & 4.4912E-06 & 4.4912E-06 & \\
\hline $\mathrm{CaO}$ & $2.4706 \mathrm{E}-02$ & $4.4002 \mathrm{E}-05$ & $2.4662 \mathrm{E}-02$ & $2.4706 \mathrm{E}-02$ & $4.4002 \mathrm{E}-05$ & $2.4662 \mathrm{E}-02$ \\
\hline $\mathrm{CdO}$ & $8.1040 \mathrm{E}-07$ & $8.1040 \mathrm{E}-07$ & & $8.1040 \mathrm{E}-07$ & $8.1040 \mathrm{E}-07$ & \\
\hline $\mathrm{Ce}_{2} \mathrm{O}_{3}$ & $2.4784 \mathrm{E}-07$ & $2.4784 \mathrm{E}-07$ & & $2.4784 \mathrm{E}-07$ & $2.4784 \mathrm{E}-07$ & \\
\hline $\mathrm{Cl}$ & $2.4848 \mathrm{E}-03$ & $2.4848 \mathrm{E}-03$ & & $2.4848 \mathrm{E}-03$ & $2.4848 \mathrm{E}-03$ & \\
\hline $\mathrm{Cm}_{2} \mathrm{O}_{3}$ & $9.7303 \mathrm{E}-14$ & $9.7303 \mathrm{E}-14$ & & $9.7303 \mathrm{E}-14$ & $9.7303 \mathrm{E}-14$ & \\
\hline $\mathrm{CoO}$ & $4.5595 \mathrm{E}-07$ & $4.5595 \mathrm{E}-07$ & & $4.5595 \mathrm{E}-07$ & $4.5595 \mathrm{E}-07$ & \\
\hline $\mathrm{Cr}_{2} \mathrm{O}_{3}$ & $8.0000 \mathrm{E}-04$ & $8.0000 \mathrm{E}-04$ & & $8.0000 \mathrm{E}-04$ & $8.0000 \mathrm{E}-04$ & \\
\hline $\mathrm{Cs}_{2} \mathrm{O}$ & 3.0903E-09 & 3.0903E-09 & & 3.0903E-09 & 3.0903E-09 & \\
\hline $\mathrm{CuO}$ & $8.4308 \mathrm{E}-07$ & $8.4308 \mathrm{E}-07$ & & $8.4308 \mathrm{E}-07$ & $8.4308 \mathrm{E}-07$ & \\
\hline $\mathrm{Eu}_{2} \mathrm{O}_{3}$ & $3.1602 \mathrm{E}-11$ & $3.1602 \mathrm{E}-11$ & & $3.1602 \mathrm{E}-11$ & $3.1602 \mathrm{E}-11$ & \\
\hline $\mathrm{F}$ & $1.0304 \mathrm{E}-03$ & $1.0304 \mathrm{E}-03$ & & $1.0304 \mathrm{E}-03$ & $1.0304 \mathrm{E}-03$ & \\
\hline $\mathrm{Fe}_{2} \mathrm{O}_{3}$ & $5.5000 \mathrm{E}-02$ & $1.6838 \mathrm{E}-05$ & $5.4983 \mathrm{E}-02$ & $5.5000 \mathrm{E}-02$ & $1.6838 \mathrm{E}-05$ & 5.4983E-02 \\
\hline $\mathrm{Gd}_{2} \mathrm{O}_{3}$ & $0.0000 \mathrm{E}+00$ & $0.0000 \mathrm{E}+00$ & & $0.0000 \mathrm{E}+00$ & $0.0000 \mathrm{E}+00$ & \\
\hline $\mathrm{HgO}$ & $9.0864 \mathrm{E}-08$ & $9.0864 \mathrm{E}-08$ & & 9.0864E-08 & $9.0864 \mathrm{E}-08$ & \\
\hline $\mathrm{I}$ & $6.0176 \mathrm{E}-07$ & $6.0176 \mathrm{E}-07$ & & $6.0176 \mathrm{E}-07$ & $6.0176 \mathrm{E}-07$ & \\
\hline $\mathrm{K}_{2} \mathrm{O}$ & $1.4458 \mathrm{E}-02$ & $1.4458 \mathrm{E}-02$ & & $1.4458 \mathrm{E}-02$ & $1.4458 \mathrm{E}-02$ & \\
\hline $\mathrm{La}_{2} \mathrm{O}_{3}$ & $3.8274 \mathrm{E}-07$ & $3.8274 \mathrm{E}-07$ & & $3.8274 \mathrm{E}-07$ & $3.8274 \mathrm{E}-07$ & \\
\hline $\mathrm{Li}_{2} \mathrm{O}$ & $3.0484 \mathrm{E}-07$ & $3.0484 \mathrm{E}-07$ & $0.0000 \mathrm{E}+00$ & $1.9003 E-03$ & $3.0484 \mathrm{E}-07$ & $1.9000 \mathrm{E}-03$ \\
\hline $\mathrm{MgO}$ & $1.4800 \mathrm{E}-02$ & $1.9358 \mathrm{E}-05$ & $1.4781 \mathrm{E}-02$ & $1.4800 \mathrm{E}-02$ & $1.9358 \mathrm{E}-05$ & $1.4781 \mathrm{E}-02$ \\
\hline $\mathrm{MnO}$ & $1.4960 \mathrm{E}-06$ & $1.4960 \mathrm{E}-06$ & & $1.4960 \mathrm{E}-06$ & $1.4960 \mathrm{E}-06$ & \\
\hline $\mathrm{MoO}_{3}$ & $1.2702 \mathrm{E}-05$ & $1.2702 \mathrm{E}-05$ & & $1.2702 \mathrm{E}-05$ & $1.2702 \mathrm{E}-05$ & \\
\hline $\mathrm{Na}_{2} \mathrm{O}$ & $1.9127 \mathrm{E}-01$ & $1.9127 \mathrm{E}-01$ & $0.0000 \mathrm{E}+00$ & $1.9127 \mathrm{E}-01$ & $1.9127 \mathrm{E}-01$ & $0.0000 \mathrm{E}+00$ \\
\hline $\mathrm{Nb}_{2} \mathrm{O}_{5}$ & $7.6190 \mathrm{E}-09$ & $7.6190 \mathrm{E}-09$ & & $7.6190 \mathrm{E}-09$ & $7.6190 \mathrm{E}-09$ & \\
\hline $\mathrm{Nd}_{2} \mathrm{O}_{3}$ & $1.2253 \mathrm{E}-06$ & $1.2253 \mathrm{E}-06$ & & $1.2253 \mathrm{E}-06$ & $1.2253 \mathrm{E}-06$ & \\
\hline $\mathrm{NiO}$ & $3.0172 \mathrm{E}-05$ & $3.0172 \mathrm{E}-05$ & & $3.0172 \mathrm{E}-05$ & $3.0172 \mathrm{E}-05$ & \\
\hline $\mathrm{NpO}_{2}$ & 1.1839E-07 & $1.1839 \mathrm{E}-07$ & & 1.1839E-07 & 1.1839E-07 & \\
\hline $\mathrm{P}_{2} \mathrm{O}_{5}$ & $1.8222 \mathrm{E}-03$ & $1.8222 \mathrm{E}-03$ & & 1.8222E-03 & $1.8222 \mathrm{E}-03$ & \\
\hline $\mathrm{Pa}_{2} \mathrm{O}_{5}$ & $2.7729 \mathrm{E}-10$ & $2.7729 \mathrm{E}-10$ & & $2.7729 \mathrm{E}-10$ & $2.7729 \mathrm{E}-10$ & \\
\hline $\mathrm{PbO}$ & $3.1717 \mathrm{E}-05$ & $3.1717 \mathrm{E}-05$ & & $3.1717 \mathrm{E}-05$ & $3.1717 \mathrm{E}-05$ & \\
\hline $\mathrm{PdO}$ & $7.5123 \mathrm{E}-06$ & $7.5123 \mathrm{E}-06$ & & $7.5123 \mathrm{E}-06$ & $7.5123 \mathrm{E}-06$ & \\
\hline $\mathrm{Pr}_{2} \mathrm{O}_{3}$ & $1.0749 \mathrm{E}-08$ & $1.0749 \mathrm{E}-08$ & & $1.0749 \mathrm{E}-08$ & $1.0749 \mathrm{E}-08$ & \\
\hline $\mathrm{PuO}_{2}$ & $8.6412 \mathrm{E}-09$ & $8.6412 \mathrm{E}-09$ & & 8.6412E-09 & $8.6412 \mathrm{E}-09$ & \\
\hline $\mathrm{RaO}$ & $4.7286 \mathrm{E}-12$ & $4.7286 \mathrm{E}-12$ & & $4.7286 \mathrm{E}-12$ & $4.7286 \mathrm{E}-12$ & \\
\hline $\mathrm{Rb}_{2} \mathrm{O}$ & $1.5170 \mathrm{E}-06$ & $1.5170 \mathrm{E}-06$ & & $1.5170 \mathrm{E}-06$ & $1.5170 \mathrm{E}-06$ & \\
\hline $\mathrm{Rh}_{2} \mathrm{O}_{3}$ & $3.3677 \mathrm{E}-06$ & $3.3677 \mathrm{E}-06$ & & $3.3677 \mathrm{E}-06$ & $3.3677 \mathrm{E}-06$ & \\
\hline $\mathrm{RuO}_{2}$ & $1.6094 \mathrm{E}-05$ & $1.6094 \mathrm{E}-05$ & & $1.6094 \mathrm{E}-05$ & $1.6094 \mathrm{E}-05$ & \\
\hline $\mathrm{SO}_{3}$ & $3.6176 \mathrm{E}-03$ & $3.6176 \mathrm{E}-03$ & & $3.6176 \mathrm{E}-03$ & $3.6176 \mathrm{E}-03$ & \\
\hline $\mathrm{Sb}_{2} \mathrm{O}_{3}$ & $3.4184 \mathrm{E}-07$ & $3.4184 \mathrm{E}-07$ & & $3.4184 \mathrm{E}-07$ & $3.4184 \mathrm{E}-07$ & \\
\hline $\mathrm{SeO}_{2}$ & $2.7830 \mathrm{E}-06$ & $2.7830 \mathrm{E}-06$ & & $2.7830 \mathrm{E}-06$ & $2.7830 \mathrm{E}-06$ & \\
\hline
\end{tabular}




\begin{tabular}{|c|c|c|c|c|c|c||}
\hline Component & Initial target & $\begin{array}{c}\text { Initial Waste } \\
\text { contribution }\end{array}$ & $\begin{array}{c}\text { Initial GFC } \\
\text { target }\end{array}$ & $\begin{array}{c}\text { Adjusted } \\
\text { Adjusted } \\
\text { target }\end{array}$ & $\begin{array}{c}\text { Waste } \\
\text { contribution }\end{array}$ & $\begin{array}{c}\text { Adjusted } \\
\text { GFC target }\end{array}$ \\
\hline $\mathrm{SiO}_{2}$ & $4.4983 \mathrm{E}-01$ & $9.3165 \mathrm{E}-04$ & $4.4890 \mathrm{E}-01$ & $\mathbf{4 . 4 7 9 3 E - 0 1}$ & $9.3165 \mathrm{E}-04$ & 4.4700E-01 \\
\hline $\mathrm{Sm}_{2} \mathrm{O}_{3}$ & $6.9647 \mathrm{E}-08$ & $6.9647 \mathrm{E}-08$ & & $6.9647 \mathrm{E}-08$ & $6.9647 \mathrm{E}-08$ & \\
\hline $\mathrm{SnO}_{2}$ & $6.1957 \mathrm{E}-08$ & $6.1957 \mathrm{E}-08$ & & $6.1957 \mathrm{E}-08$ & $6.1957 \mathrm{E}-08$ & \\
\hline $\mathrm{SrO}^{\mathrm{Ta}} \mathrm{O}_{5}$ & $1.3010 \mathrm{E}-07$ & $1.3010 \mathrm{E}-07$ & & $1.3010 \mathrm{E}-07$ & $1.3010 \mathrm{E}-07$ & \\
\hline $\mathrm{Tc}_{2} \mathrm{O}_{7}$ & $4.4375 \mathrm{E}-08$ & $4.4375 \mathrm{E}-08$ & & $4.4375 \mathrm{E}-08$ & $4.4375 \mathrm{E}-08$ & \\
\hline $\mathrm{TeO}_{2}$ & $1.37456 \mathrm{E}-06$ & $4.7456 \mathrm{E}-06$ & & $4.7456 \mathrm{E}-06$ & $4.7456 \mathrm{E}-06$ & \\
\hline $\mathrm{ThO}_{2}$ & $4.0645 \mathrm{E}-06$ & $1.3749 \mathrm{E}-07$ & & $1.3749 \mathrm{E}-07$ & $1.3749 \mathrm{E}-07$ & \\
\hline $\mathrm{TiO}_{2}$ & $1.4000 \mathrm{E}-02$ & $4.3545 \mathrm{E}-06$ & & $4.0645 \mathrm{E}-06$ & $4.0645 \mathrm{E}-06$ & \\
\hline $\mathrm{Tl}_{2} \mathrm{O}$ & $9.3647 \mathrm{E}-07$ & $9.3647 \mathrm{E}-07$ & & $9.3647 \mathrm{E}-07$ & $9.3647 \mathrm{E}-07$ & \\
\hline $\mathrm{UO}_{3}$ & $3.9192 \mathrm{E}-05$ & $3.9192 \mathrm{E}-05$ & & $3.9192 \mathrm{E}-05$ & $3.9192 \mathrm{E}-05$ & \\
\hline $\mathrm{V}_{2} \mathrm{O}_{5}$ & $6.0121 \mathrm{E}-07$ & $6.0121 \mathrm{E}-07$ & & $6.0121 \mathrm{E}-07$ & $6.0121 \mathrm{E}-07$ & \\
\hline $\mathrm{WO}_{3}$ & $1.2524 \mathrm{E}-05$ & $1.2524 \mathrm{E}-05$ & & $1.2524 \mathrm{E}-05$ & $1.2524 \mathrm{E}-05$ & \\
\hline $\mathrm{Y}_{2} \mathrm{O}_{3}$ & $6.8843 \mathrm{E}-07$ & $6.8843 \mathrm{E}-07$ & & $6.8843 \mathrm{E}-07$ & $6.8843 \mathrm{E}-07$ & \\
\hline $\mathrm{ZnO}$ & $3.5000 \mathrm{E}-02$ & $1.3594 \mathrm{E}-05$ & $3.4986 \mathrm{E}-02$ & $3.5000 \mathrm{E}-02$ & $1.3594 \mathrm{E}-05$ & $3.4986 \mathrm{E}-02$ \\
\hline $\mathrm{ZrO}_{2}$ & $3.0000 \mathrm{E}-02$ & $7.4799 \mathrm{E}-06$ & $2.9993 \mathrm{E}-02$ & $3.0000 \mathrm{E}-02$ & $7.4799 \mathrm{E}-06$ & $2.9993 \mathrm{E}-02$ \\
\hline $\mathrm{SUM}$ & 1.00000 & 0.23317 & 0.76683 & 1.00000 & 0.23317 & 0.76683 \\
\hline \hline
\end{tabular}

Empty cells represent non-GFC components.

$\mathrm{Li}_{2} \mathrm{O}$ and $\mathrm{SiO}_{2}$ concentrations (in bold) are only changes after adjustment. 
Table B-4a. Waste and Glass Compositions in Step 1 Calculation of the $A 101^{\text {th }}$ MFPV Batch before Adjustment

\begin{tabular}{|c|c|c|c|c|c|}
\hline Component & $\begin{array}{c}\text { Waste } \\
\text { Contribution } \\
\end{array}$ & $\begin{array}{c}\text { GFC } \\
\text { Contribution } \\
\end{array}$ & $\begin{array}{c}\text { Combined } \\
\text { Normalized } \\
\end{array}$ & $\begin{array}{c}\text { Glass After } \\
\text { Retention }\end{array}$ & $\begin{array}{c}\text { Final Glass } \\
\text { Normalized }\end{array}$ \\
\hline $\mathrm{Ac}_{2} \mathrm{O}_{3}$ & $6.1720 \mathrm{E}-14$ & & $6.1659 \mathrm{E}-14$ & $6.1487 \mathrm{E}-14$ & $6.1852 \mathrm{E}-14$ \\
\hline $\mathrm{Ag}_{2} \mathrm{O}$ & $3.0417 \mathrm{E}-07$ & & $3.0387 \mathrm{E}-07$ & $2.9719 \mathrm{E}-07$ & $2.9896 \mathrm{E}-07$ \\
\hline $\mathrm{Al}_{2} \mathrm{O}_{3}$ & $1.6417 \mathrm{E}-02$ & $4.4583 \mathrm{E}-02$ & $6.0940 \mathrm{E}-02$ & $6.0871 \mathrm{E}-02$ & $6.1232 \mathrm{E}-02$ \\
\hline $\mathrm{Am}_{2} \mathrm{O}_{3}$ & $1.7435 \mathrm{E}-10$ & & $1.7418 \mathrm{E}-10$ & $1.7035 \mathrm{E}-10$ & $1.7136 \mathrm{E}-10$ \\
\hline $\mathrm{As}_{2} \mathrm{O}_{5}$ & $1.6043 \mathrm{E}-06$ & & $1.6027 \mathrm{E}-06$ & $1.2360 \mathrm{E}-06$ & $1.2434 \mathrm{E}-06$ \\
\hline $\mathrm{B}_{2} \mathrm{O}_{3}$ & $4.8247 \mathrm{E}-05$ & $9.9952 \mathrm{E}-02$ & $9.9901 \mathrm{E}-02$ & $9.8870 \mathrm{E}-02$ & $9.9457 \mathrm{E}-02$ \\
\hline $\mathrm{BaO}$ & $2.6223 \mathrm{E}-07$ & & $2.6197 \mathrm{E}-07$ & $2.6124 \mathrm{E}-07$ & $2.6279 \mathrm{E}-07$ \\
\hline $\mathrm{BeO}$ & $1.2754 \mathrm{E}-06$ & & $1.2741 \mathrm{E}-06$ & $1.2706 \mathrm{E}-06$ & $1.2781 \mathrm{E}-06$ \\
\hline $\mathrm{Bi}_{2} \mathrm{O}_{3}$ & $4.4912 \mathrm{E}-06$ & & $4.4867 \mathrm{E}-06$ & $4.3882 \mathrm{E}-06$ & 4.4142E-06 \\
\hline $\mathrm{CaO}$ & $4.4002 \mathrm{E}-05$ & $2.4662 \mathrm{E}-02$ & $2.4682 \mathrm{E}-02$ & $2.4655 \mathrm{E}-02$ & $2.4801 \mathrm{E}-02$ \\
\hline $\mathrm{CdO}$ & $8.1040 \mathrm{E}-07$ & $3.5079 \mathrm{E}-06$ & $4.3141 \mathrm{E}-06$ & $4.3020 \mathrm{E}-06$ & $4.3275 \mathrm{E}-06$ \\
\hline $\mathrm{Ce}_{2} \mathrm{O}_{3}$ & $2.4784 \mathrm{E}-07$ & & $2.4760 \mathrm{E}-07$ & $2.4691 \mathrm{E}-07$ & $2.4837 \mathrm{E}-07$ \\
\hline $\mathrm{Cl}$ & $2.4848 \mathrm{E}-03$ & $0.0000 \mathrm{E}+00$ & $2.4824 \mathrm{E}-03$ & $1.3506 \mathrm{E}-03$ & $1.3586 \mathrm{E}-03$ \\
\hline $\mathrm{Cm}_{2} \mathrm{O}_{3}$ & $9.7303 \mathrm{E}-14$ & & $9.7207 \mathrm{E}-14$ & $9.6936 \mathrm{E}-14$ & $9.7511 \mathrm{E}-14$ \\
\hline $\mathrm{CoO}$ & $4.5595 \mathrm{E}-07$ & & $4.5550 \mathrm{E}-07$ & $4.5423 \mathrm{E}-07$ & 4.5692E-07 \\
\hline $\mathrm{Cr}_{2} \mathrm{O}_{3}$ & $8.0000 \mathrm{E}-04$ & $9.9042 \mathrm{E}-05$ & $8.9815 \mathrm{E}-04$ & $8.5559 \mathrm{E}-04$ & $8.6066 \mathrm{E}-04$ \\
\hline $\mathrm{Cs}_{2} \mathrm{O}$ & 3.0903E-09 & & 3.0872E-09 & $2.7137 \mathrm{E}-09$ & $2.7298 \mathrm{E}-09$ \\
\hline $\mathrm{CuO}$ & $8.4308 \mathrm{E}-07$ & & $8.4224 \mathrm{E}-07$ & 8.3989E-07 & $8.4487 \mathrm{E}-07$ \\
\hline $\mathrm{Eu}_{2} \mathrm{O}_{3}$ & $3.1602 \mathrm{E}-11$ & & $3.1570 \mathrm{E}-11$ & $3.1482 \mathrm{E}-11$ & $3.1669 \mathrm{E}-11$ \\
\hline $\mathrm{F}$ & $1.0304 \mathrm{E}-03$ & & $1.0293 \mathrm{E}-03$ & $7.5126 \mathrm{E}-04$ & 7.5572E-04 \\
\hline $\mathrm{Fe}_{2} \mathrm{O}_{3}$ & $1.6838 \mathrm{E}-05$ & 5.4983E-02 & $5.4946 \mathrm{E}-02$ & $5.4862 \mathrm{E}-02$ & $5.5187 \mathrm{E}-02$ \\
\hline $\mathrm{Gd}_{2} \mathrm{O}_{3}$ & $0.0000 \mathrm{E}+00$ & & $0.0000 \mathrm{E}+00$ & $0.0000 \mathrm{E}+00$ & $0.0000 \mathrm{E}+00$ \\
\hline $\mathrm{HgO}$ & $9.0864 \mathrm{E}-08$ & & $9.0774 \mathrm{E}-08$ & $0.0000 \mathrm{E}+00$ & $0.0000 \mathrm{E}+00$ \\
\hline $\mathrm{I}$ & $6.0176 \mathrm{E}-07$ & & $6.0116 \mathrm{E}-07$ & $3.0636 \mathrm{E}-07$ & $3.0818 \mathrm{E}-07$ \\
\hline $\mathrm{K}_{2} \mathrm{O}$ & $1.4458 \mathrm{E}-02$ & $2.0962 \mathrm{E}-05$ & $1.4465 \mathrm{E}-02$ & $1.3947 \mathrm{E}-02$ & $1.4030 \mathrm{E}-02$ \\
\hline $\mathrm{La}_{2} \mathrm{O}_{3}$ & $3.8274 \mathrm{E}-07$ & & $3.8236 \mathrm{E}-07$ & $3.8129 \mathrm{E}-07$ & $3.8356 \mathrm{E}-07$ \\
\hline $\mathrm{Li}_{2} \mathrm{O}$ & $3.0484 \mathrm{E}-07$ & $0.0000 \mathrm{E}+00$ & $3.0454 \mathrm{E}-07$ & $3.0332 \mathrm{E}-07$ & $3.0512 \mathrm{E}-07$ \\
\hline $\mathrm{MgO}$ & $1.9358 \mathrm{E}-05$ & $1.4781 \mathrm{E}-02$ & $1.4786 \mathrm{E}-02$ & $1.4783 \mathrm{E}-02$ & $1.4871 \mathrm{E}-02$ \\
\hline $\mathrm{MnO}$ & $1.4960 \mathrm{E}-06$ & $1.3210 \mathrm{E}-04$ & $1.3347 \mathrm{E}-04$ & $1.3309 \mathrm{E}-04$ & 1.3388E-04 \\
\hline $\mathrm{MoO}_{3}$ & $1.2702 \mathrm{E}-05$ & & $1.2690 \mathrm{E}-05$ & $1.2411 \mathrm{E}-05$ & 1.2484E-05 \\
\hline $\mathrm{Na}_{2} \mathrm{O}$ & $1.9127 \mathrm{E}-01$ & $3.3154 \mathrm{E}-04$ & $1.9141 \mathrm{E}-01$ & $1.8975 \mathrm{E}-01$ & $1.9088 \mathrm{E}-01$ \\
\hline $\mathrm{Nb}_{2} \mathrm{O}_{5}$ & 7.6190E-09 & & 7.6115E-09 & 7.5902E-09 & 7.6353E-09 \\
\hline $\mathrm{Nd}_{2} \mathrm{O}_{3}$ & $1.2253 \mathrm{E}-06$ & & $1.2241 \mathrm{E}-06$ & $1.2207 \mathrm{E}-06$ & 1.2279E-06 \\
\hline $\mathrm{NiO}$ & $3.0172 \mathrm{E}-05$ & $1.1299 \mathrm{E}-04$ & $1.4302 \mathrm{E}-04$ & $1.4186 \mathrm{E}-04$ & $1.4270 \mathrm{E}-04$ \\
\hline $\mathrm{NpO}_{2}$ & 1.1839E-07 & & $1.1828 \mathrm{E}-07$ & $1.1795 \mathrm{E}-07$ & $1.1865 \mathrm{E}-07$ \\
\hline $\mathrm{P}_{2} \mathrm{O}_{5}$ & $1.8222 \mathrm{E}-03$ & $1.6111 \mathrm{E}-04$ & $1.9814 \mathrm{E}-03$ & $1.9649 \mathrm{E}-03$ & $1.9766 \mathrm{E}-03$ \\
\hline $\mathrm{Pa}_{2} \mathrm{O}_{5}$ & $2.7729 \mathrm{E}-10$ & & $2.7702 \mathrm{E}-10$ & $2.7625 \mathrm{E}-10$ & $2.7789 \mathrm{E}-10$ \\
\hline $\mathrm{PbO}$ & $3.1717 \mathrm{E}-05$ & $5.8315 \mathrm{E}-07$ & $3.2269 \mathrm{E}-05$ & $3.1880 \mathrm{E}-05$ & 3.2069E-05 \\
\hline $\mathrm{PdO}$ & $7.5123 \mathrm{E}-06$ & & $7.5048 \mathrm{E}-06$ & 7.4839E-06 & 7.5283E-06 \\
\hline $\mathrm{Pr}_{2} \mathrm{O}_{3}$ & $1.0749 \mathrm{E}-08$ & & $1.0738 \mathrm{E}-08$ & $1.0708 \mathrm{E}-08$ & 1.0772E-08 \\
\hline $\mathrm{PuO}_{2}$ & 8.6412E-09 & & $8.6327 \mathrm{E}-09$ & $8.6086 \mathrm{E}-09$ & 8.6597E-09 \\
\hline $\mathrm{RaO}$ & $4.7286 \mathrm{E}-12$ & & 4.7239E-12 & $3.6431 \mathrm{E}-12$ & $3.6647 \mathrm{E}-12$ \\
\hline $\mathrm{Rb}_{2} \mathrm{O}$ & $1.5170 \mathrm{E}-06$ & & $1.5155 \mathrm{E}-06$ & $1.4822 \mathrm{E}-06$ & $1.4910 \mathrm{E}-06$ \\
\hline $\mathrm{Rh}_{2} \mathrm{O}_{3}$ & $3.3677 \mathrm{E}-06$ & & $3.3644 \mathrm{E}-06$ & $3.3550 \mathrm{E}-06$ & $3.3749 \mathrm{E}-06$ \\
\hline $\mathrm{RuO}_{2}$ & $1.6094 \mathrm{E}-05$ & & $1.6078 \mathrm{E}-05$ & $1.5725 \mathrm{E}-05$ & $1.5818 \mathrm{E}-05$ \\
\hline $\mathrm{SO}_{3}$ & $3.6176 \mathrm{E}-03$ & $4.8607 \mathrm{E}-05$ & $3.6626 \mathrm{E}-03$ & $3.0777 \mathrm{E}-03$ & $3.0960 \mathrm{E}-03$ \\
\hline $\mathrm{Sb}_{2} \mathrm{O}_{3}$ & $3.4184 \mathrm{E}-07$ & & $3.4150 \mathrm{E}-07$ & $2.6337 \mathrm{E}-07$ & 2.6493E-07 \\
\hline $\mathrm{SeO}_{2}$ & $2.7830 \mathrm{E}-06$ & & $2.7803 \mathrm{E}-06$ & $2.1442 \mathrm{E}-06$ & $2.1569 \mathrm{E}-06$ \\
\hline $\mathrm{SiO}_{2}$ & $9.3165 \mathrm{E}-04$ & 4.4890E-01 & 4.4939E-01 & $4.4905 \mathrm{E}-01$ & 4.5172E-01 \\
\hline
\end{tabular}




\begin{tabular}{|c|c|c|c|c|c|}
\hline Component & $\begin{array}{c}\text { Waste } \\
\text { Contribution } \\
\end{array}$ & $\begin{array}{c}\text { GFC } \\
\text { Contribution } \\
\end{array}$ & $\begin{array}{c}\text { Combined } \\
\text { Normalized } \\
\end{array}$ & $\begin{array}{c}\text { Glass After } \\
\text { Retention } \\
\end{array}$ & $\begin{array}{r}\text { Final Glass } \\
\text { Normalized } \\
\end{array}$ \\
\hline $\mathrm{Sm}_{2} \mathrm{O}_{3}$ & $6.9647 \mathrm{E}-08$ & & $6.9578 \mathrm{E}-08$ & $6.9384 \mathrm{E}-08$ & 6.9795E-08 \\
\hline $\mathrm{SnO}_{2}$ & $6.1957 \mathrm{E}-08$ & & $6.1896 \mathrm{E}-08$ & $6.1723 \mathrm{E}-08$ & $6.2090 \mathrm{E}-08$ \\
\hline $\mathrm{SrO}$ & $1.3010 \mathrm{E}-07$ & & $1.2997 \mathrm{E}-07$ & $1.2961 \mathrm{E}-07$ & $1.3038 \mathrm{E}-07$ \\
\hline $\mathrm{Ta}_{2} \mathrm{O}_{5}$ & 4.4375E-08 & & 4.4331E-08 & 4.4208E-08 & 4.4470E-08 \\
\hline $\mathrm{Tc}_{2} \mathrm{O}_{7}$ & $4.7456 \mathrm{E}-06$ & & 4.7409E-06 & $2.0409 \mathrm{E}-06$ & $2.0530 \mathrm{E}-06$ \\
\hline $\mathrm{TeO}_{2}$ & $1.3749 \mathrm{E}-07$ & & $1.3735 \mathrm{E}-07$ & $1.0593 \mathrm{E}-07$ & $1.0656 \mathrm{E}-07$ \\
\hline $\mathrm{ThO}_{2}$ & $4.0645 \mathrm{E}-06$ & & 4.0605E-06 & 4.0492E-06 & 4.0732E-06 \\
\hline $\mathrm{TiO}_{2}$ & $4.3570 \mathrm{E}-06$ & $1.3996 \mathrm{E}-02$ & $1.3986 \mathrm{E}-02$ & $1.3951 \mathrm{E}-02$ & $1.4034 \mathrm{E}-02$ \\
\hline $\mathrm{Tl}_{2} \mathrm{O}$ & $9.3647 \mathrm{E}-07$ & & $9.3554 \mathrm{E}-07$ & $7.2150 \mathrm{E}-07$ & $7.2578 \mathrm{E}-07$ \\
\hline $\mathrm{UO}_{3}$ & 3.9192E-05 & $2.0287 \mathrm{E}-05$ & $5.9420 \mathrm{E}-05$ & 5.9254E-05 & $5.9606 \mathrm{E}-05$ \\
\hline $\mathrm{V}_{2} \mathrm{O}_{5}$ & $6.0121 \mathrm{E}-07$ & $6.0333 \mathrm{E}-05$ & $6.0874 \mathrm{E}-05$ & $5.9536 \mathrm{E}-05$ & $5.9890 \mathrm{E}-05$ \\
\hline $\mathrm{WO}_{3}$ & $1.2524 \mathrm{E}-05$ & & $1.2511 \mathrm{E}-05$ & $1.2476 \mathrm{E}-05$ & $1.2550 \mathrm{E}-05$ \\
\hline $\mathrm{Y}_{2} \mathrm{O}_{3}$ & $6.8843 \mathrm{E}-07$ & & $6.8775 \mathrm{E}-07$ & $6.8583 \mathrm{E}-07$ & $6.8990 \mathrm{E}-07$ \\
\hline $\mathrm{ZnO}$ & $1.3594 \mathrm{E}-05$ & $3.4986 \mathrm{E}-02$ & $3.4965 \mathrm{E}-02$ & $3.4886 \mathrm{E}-02$ & $3.5093 \mathrm{E}-02$ \\
\hline $\mathrm{ZrO}_{2}$ & 7.4799E-06 & $2.9993 \mathrm{E}-02$ & $2.9970 \mathrm{E}-02$ & $2.9965 \mathrm{E}-02$ & $3.0143 \mathrm{E}-02$ \\
\hline SUM & 0.233165 & 0.767826 & 1.00000 & 0.99410 & 1.00000 \\
\hline \multicolumn{2}{|c|}{ Waste and GFC contributions } & $1.000991 \mathrm{E}+00$ & & & \\
\hline
\end{tabular}

Empty cells represent the components not present in any of the GFCs

Table B-4b. Waste and Glass Compositions in Step 1 Calculation of the $A 101^{\text {th }}$ MFPV Batch after Adjustment

\begin{tabular}{|c|c|c|c|c|c|}
\hline Component & $\begin{array}{c}\text { Waste } \\
\text { Contribution } \\
\end{array}$ & $\begin{array}{c}\text { GFC } \\
\text { Contribution } \\
\end{array}$ & $\begin{array}{c}\text { Combined } \\
\text { Normalized }\end{array}$ & $\begin{array}{c}\text { Glass After } \\
\text { Retention }\end{array}$ & $\begin{array}{l}\text { Final Glass } \\
\text { Normalized }\end{array}$ \\
\hline $\mathrm{Ac}_{2} \mathrm{O}_{3}$ & $6.1720 \mathrm{E}-14$ & & $6.1659 \mathrm{E}-14$ & $6.1487 \mathrm{E}-14$ & $6.1852 \mathrm{E}-14$ \\
\hline $\mathrm{Ag}_{2} \mathrm{O}$ & $3.0417 \mathrm{E}-07$ & & $3.0387 \mathrm{E}-07$ & $2.9719 \mathrm{E}-07$ & $2.9896 \mathrm{E}-07$ \\
\hline $\mathrm{Al}_{2} \mathrm{O}_{3}$ & $1.6417 \mathrm{E}-02$ & 4.4583E-02 & $6.0939 \mathrm{E}-02$ & $6.0871 \mathrm{E}-02$ & $6.1233 \mathrm{E}-02$ \\
\hline $\mathrm{Am}_{2} \mathrm{O}_{3}$ & $1.7435 \mathrm{E}-10$ & & $1.7418 \mathrm{E}-10$ & $1.7035 \mathrm{E}-10$ & $1.7136 \mathrm{E}-10$ \\
\hline $\mathrm{As}_{2} \mathrm{O}_{5}$ & $1.6043 \mathrm{E}-06$ & & $1.6027 \mathrm{E}-06$ & $1.2360 \mathrm{E}-06$ & $1.2434 \mathrm{E}-06$ \\
\hline $\mathrm{B}_{2} \mathrm{O}_{3}$ & $4.8247 \mathrm{E}-05$ & 9.9952E-02 & $9.9900 \mathrm{E}-02$ & $9.8869 \mathrm{E}-02$ & $9.9457 \mathrm{E}-02$ \\
\hline $\mathrm{BaO}$ & $2.6223 \mathrm{E}-07$ & & $2.6197 \mathrm{E}-07$ & $2.6124 \mathrm{E}-07$ & $2.6279 \mathrm{E}-07$ \\
\hline $\mathrm{BeO}$ & $1.2754 \mathrm{E}-06$ & & $1.2741 \mathrm{E}-06$ & $1.2706 \mathrm{E}-06$ & $1.2781 \mathrm{E}-06$ \\
\hline $\mathrm{Bi}_{2} \mathrm{O}_{3}$ & $4.4912 \mathrm{E}-06$ & & 4.4867E-06 & $4.3881 \mathrm{E}-06$ & 4.4142E-06 \\
\hline $\mathrm{CaO}$ & 4.4002E-05 & $2.4662 \mathrm{E}-02$ & $2.4682 \mathrm{E}-02$ & $2.4655 \mathrm{E}-02$ & $2.4801 \mathrm{E}-02$ \\
\hline $\mathrm{CdO}$ & $8.1040 \mathrm{E}-07$ & $3.5079 \mathrm{E}-06$ & $4.3140 \mathrm{E}-06$ & $4.3020 \mathrm{E}-06$ & $4.3275 \mathrm{E}-06$ \\
\hline $\mathrm{Ce}_{2} \mathrm{O}_{3}$ & $2.4784 \mathrm{E}-07$ & & $2.4759 \mathrm{E}-07$ & $2.4690 \mathrm{E}-07$ & $2.4837 \mathrm{E}-07$ \\
\hline $\mathrm{Cl}$ & $2.4848 \mathrm{E}-03$ & $3.9337 \mathrm{E}-07$ & $2.4827 \mathrm{E}-03$ & $1.3508 \mathrm{E}-03$ & $1.3588 \mathrm{E}-03$ \\
\hline $\mathrm{Cm}_{2} \mathrm{O}_{3}$ & $9.7303 \mathrm{E}-14$ & & $9.7206 \mathrm{E}-14$ & $9.6935 \mathrm{E}-14$ & $9.7511 \mathrm{E}-14$ \\
\hline $\mathrm{CoO}$ & $4.5595 \mathrm{E}-07$ & & 4.5549E-07 & $4.5422 \mathrm{E}-07$ & 4.5692E-07 \\
\hline $\mathrm{Cr}_{2} \mathrm{O}_{3}$ & $8.0000 \mathrm{E}-04$ & $9.9514 \mathrm{E}-05$ & 8.9862E-04 & $8.5603 \mathrm{E}-04$ & 8.6112E-04 \\
\hline $\mathrm{Cs}_{2} \mathrm{O}$ & $3.0903 \mathrm{E}-09$ & & 3.0872E-09 & $2.7137 \mathrm{E}-09$ & $2.7298 \mathrm{E}-09$ \\
\hline $\mathrm{CuO}$ & $8.4308 \mathrm{E}-07$ & & $8.4224 \mathrm{E}-07$ & $8.3989 \mathrm{E}-07$ & 8.4487E-07 \\
\hline $\mathrm{Eu}_{2} \mathrm{O}_{3}$ & $3.1602 \mathrm{E}-11$ & & $3.1570 \mathrm{E}-11$ & $3.1482 \mathrm{E}-11$ & $3.1669 \mathrm{E}-11$ \\
\hline $\mathrm{F}$ & $1.0304 \mathrm{E}-03$ & & $1.0293 \mathrm{E}-03$ & $7.5126 \mathrm{E}-04$ & 7.5572E-04 \\
\hline $\mathrm{Fe}_{2} \mathrm{O}_{3}$ & $1.6838 \mathrm{E}-05$ & $5.4983 \mathrm{E}-02$ & $5.4945 \mathrm{E}-02$ & $5.4862 \mathrm{E}-02$ & $5.5188 \mathrm{E}-02$ \\
\hline $\mathrm{Gd}_{2} \mathrm{O}_{3}$ & $0.0000 \mathrm{E}+00$ & & $0.0000 \mathrm{E}+00$ & $0.0000 \mathrm{E}+00$ & $0.0000 \mathrm{E}+00$ \\
\hline $\mathrm{HgO}$ & $9.0864 \mathrm{E}-08$ & & $9.0773 \mathrm{E}-08$ & $0.0000 \mathrm{E}+00$ & $0.0000 \mathrm{E}+00$ \\
\hline $\mathrm{I}$ & $6.0176 \mathrm{E}-07$ & & $6.0116 \mathrm{E}-07$ & $3.0636 \mathrm{E}-07$ & $3.0818 \mathrm{E}-07$ \\
\hline $\mathrm{K}_{2} \mathrm{O}$ & $1.4458 \mathrm{E}-02$ & $2.0978 \mathrm{E}-05$ & $1.4465 \mathrm{E}-02$ & $1.3947 \mathrm{E}-02$ & $1.4030 \mathrm{E}-02$ \\
\hline $\mathrm{La}_{2} \mathrm{O}_{3}$ & $3.8274 \mathrm{E}-07$ & & $3.8236 \mathrm{E}-07$ & $3.8129 \mathrm{E}-07$ & $3.8356 \mathrm{E}-07$ \\
\hline $\mathrm{Li}_{2} \mathrm{O}$ & $3.0484 \mathrm{E}-07$ & $1.9000 \mathrm{E}-03$ & $1.8984 \mathrm{E}-03$ & $1.8908 \mathrm{E}-03$ & $1.9021 \mathrm{E}-03$ \\
\hline $\mathrm{MgO}$ & $1.9358 \mathrm{E}-05$ & $1.4781 \mathrm{E}-02$ & $1.4786 \mathrm{E}-02$ & $1.4783 \mathrm{E}-02$ & $1.4871 \mathrm{E}-02$ \\
\hline
\end{tabular}




\begin{tabular}{|c|c|c|c|c|c|}
\hline Component & $\begin{array}{c}\text { Waste } \\
\text { Contribution } \\
\end{array}$ & $\begin{array}{c}\text { GFC } \\
\text { Contribution } \\
\end{array}$ & $\begin{array}{c}\text { Combined } \\
\text { Normalized } \\
\end{array}$ & $\begin{array}{c}\text { Glass After } \\
\text { Retention }\end{array}$ & $\begin{array}{l}\text { Final Glass } \\
\text { Normalized } \\
\end{array}$ \\
\hline $\mathrm{MnO}$ & $1.4960 \mathrm{E}-06$ & $1.3207 \mathrm{E}-04$ & $1.3343 \mathrm{E}-04$ & $1.3306 \mathrm{E}-04$ & $1.3385 \mathrm{E}-04$ \\
\hline $\mathrm{MoO}_{3}$ & $1.2702 \mathrm{E}-05$ & & $1.2689 \mathrm{E}-05$ & $1.2411 \mathrm{E}-05$ & $1.2484 \mathrm{E}-05$ \\
\hline $\mathrm{Na}_{2} \mathrm{O}$ & $1.9127 \mathrm{E}-01$ & $3.3462 \mathrm{E}-04$ & $1.9141 \mathrm{E}-01$ & $1.8976 \mathrm{E}-01$ & $1.9088 \mathrm{E}-01$ \\
\hline $\mathrm{Nb}_{2} \mathrm{O}_{5}$ & 7.6190E-09 & & 7.6114E-09 & 7.5902E-09 & 7.6353E-09 \\
\hline $\mathrm{Nd}_{2} \mathrm{O}_{3}$ & $1.2253 \mathrm{E}-06$ & & $1.2241 \mathrm{E}-06$ & $1.2207 \mathrm{E}-06$ & $1.2279 \mathrm{E}-06$ \\
\hline $\mathrm{NiO}$ & $3.0172 \mathrm{E}-05$ & $1.1299 \mathrm{E}-04$ & $1.4302 \mathrm{E}-04$ & $1.4186 \mathrm{E}-04$ & $1.4270 \mathrm{E}-04$ \\
\hline $\mathrm{NpO}_{2}$ & 1.1839E-07 & & $1.1828 \mathrm{E}-07$ & $1.1795 \mathrm{E}-07$ & $1.1865 \mathrm{E}-07$ \\
\hline $\mathrm{P}_{2} \mathrm{O}_{5}$ & $1.8222 \mathrm{E}-03$ & $1.6111 \mathrm{E}-04$ & $1.9814 \mathrm{E}-03$ & $1.9649 \mathrm{E}-03$ & $1.9766 \mathrm{E}-03$ \\
\hline $\mathrm{Pa}_{2} \mathrm{O}_{5}$ & $2.7729 \mathrm{E}-10$ & & $2.7702 \mathrm{E}-10$ & $2.7625 \mathrm{E}-10$ & $2.7789 \mathrm{E}-10$ \\
\hline $\mathrm{PbO}$ & $3.1717 \mathrm{E}-05$ & $5.8315 \mathrm{E}-07$ & $3.2268 \mathrm{E}-05$ & $3.1880 \mathrm{E}-05$ & $3.2069 \mathrm{E}-05$ \\
\hline $\mathrm{PdO}$ & $7.5123 \mathrm{E}-06$ & & $7.5048 \mathrm{E}-06$ & 7.4839E-06 & $7.5283 \mathrm{E}-06$ \\
\hline $\mathrm{Pr}_{2} \mathrm{O}_{3}$ & 1.0749E-08 & & $1.0738 \mathrm{E}-08$ & $1.0708 \mathrm{E}-08$ & $1.0772 \mathrm{E}-08$ \\
\hline $\mathrm{PuO}_{2}$ & 8.6412E-09 & & $8.6326 \mathrm{E}-09$ & $8.6085 \mathrm{E}-09$ & $8.6597 \mathrm{E}-09$ \\
\hline $\mathrm{RaO}$ & $4.7286 \mathrm{E}-12$ & & $4.7239 \mathrm{E}-12$ & $3.6431 \mathrm{E}-12$ & $3.6647 \mathrm{E}-12$ \\
\hline $\mathrm{Rb}_{2} \mathrm{O}$ & $1.5170 \mathrm{E}-06$ & & $1.5155 \mathrm{E}-06$ & $1.4822 \mathrm{E}-06$ & $1.4910 \mathrm{E}-06$ \\
\hline $\mathrm{Rh}_{2} \mathrm{O}_{3}$ & $3.3677 \mathrm{E}-06$ & & $3.3643 \mathrm{E}-06$ & $3.3550 \mathrm{E}-06$ & $3.3749 \mathrm{E}-06$ \\
\hline $\mathrm{RuO}_{2}$ & $1.6094 \mathrm{E}-05$ & & $1.6078 \mathrm{E}-05$ & $1.5725 \mathrm{E}-05$ & $1.5818 \mathrm{E}-05$ \\
\hline $\mathrm{SO}_{3}$ & $3.6176 \mathrm{E}-03$ & $4.9866 \mathrm{E}-05$ & $3.6638 \mathrm{E}-03$ & $3.0788 \mathrm{E}-03$ & $3.0971 \mathrm{E}-03$ \\
\hline $\mathrm{Sb}_{2} \mathrm{O}_{3}$ & $3.4184 \mathrm{E}-07$ & & $3.4150 \mathrm{E}-07$ & $2.6336 \mathrm{E}-07$ & $2.6493 \mathrm{E}-07$ \\
\hline $\mathrm{SeO}_{2}$ & $2.7830 \mathrm{E}-06$ & & $2.7802 \mathrm{E}-06$ & $2.1441 \mathrm{E}-06$ & $2.1569 \mathrm{E}-06$ \\
\hline $\mathrm{SiO}_{2}$ & $9.3165 \mathrm{E}-04$ & $4.4700 \mathrm{E}-01$ & $4.4748 \mathrm{E}-01$ & $4.4715 \mathrm{E}-01$ & $4.4981 \mathrm{E}-01$ \\
\hline $\mathrm{Sm}_{2} \mathrm{O}_{3}$ & 6.9647E-08 & & $6.9577 \mathrm{E}-08$ & $6.9383 \mathrm{E}-08$ & $6.9795 \mathrm{E}-08$ \\
\hline $\mathrm{SnO}_{2}$ & $6.1957 \mathrm{E}-08$ & & $6.1896 \mathrm{E}-08$ & $6.1723 \mathrm{E}-08$ & $6.2090 \mathrm{E}-08$ \\
\hline $\mathrm{SrO}$ & $1.3010 \mathrm{E}-07$ & & $1.2997 \mathrm{E}-07$ & $1.2961 \mathrm{E}-07$ & $1.3038 \mathrm{E}-07$ \\
\hline $\mathrm{Ta}_{2} \mathrm{O}_{5}$ & 4.4375E-08 & & $4.4331 \mathrm{E}-08$ & 4.4207E-08 & 4.4470E-08 \\
\hline $\mathrm{Tc}_{2} \mathrm{O}_{7}$ & $4.7456 \mathrm{E}-06$ & & 4.7409E-06 & $2.0409 \mathrm{E}-06$ & $2.0530 \mathrm{E}-06$ \\
\hline $\mathrm{TeO}_{2}$ & $1.3749 \mathrm{E}-07$ & & $1.3735 \mathrm{E}-07$ & $1.0593 \mathrm{E}-07$ & $1.0656 \mathrm{E}-07$ \\
\hline $\mathrm{ThO}_{2}$ & $4.0645 \mathrm{E}-06$ & & $4.0605 \mathrm{E}-06$ & 4.0492E-06 & 4.0732E-06 \\
\hline $\mathrm{TiO}_{2}$ & $4.3570 \mathrm{E}-06$ & $1.3996 \mathrm{E}-02$ & $1.3986 \mathrm{E}-02$ & $1.3951 \mathrm{E}-02$ & $1.4034 \mathrm{E}-02$ \\
\hline $\mathrm{Tl}_{2} \mathrm{O}$ & $9.3647 \mathrm{E}-07$ & & $9.3554 \mathrm{E}-07$ & $7.2150 \mathrm{E}-07$ & $7.2578 \mathrm{E}-07$ \\
\hline $\mathrm{UO}_{3}$ & $3.9192 \mathrm{E}-05$ & $2.0287 \mathrm{E}-05$ & $5.9420 \mathrm{E}-05$ & $5.9254 \mathrm{E}-05$ & $5.9606 \mathrm{E}-05$ \\
\hline $\mathrm{V}_{2} \mathrm{O}_{5}$ & $6.0121 \mathrm{E}-07$ & $6.0334 \mathrm{E}-05$ & $6.0875 \mathrm{E}-05$ & $5.9537 \mathrm{E}-05$ & $5.9891 \mathrm{E}-05$ \\
\hline $\mathrm{WO}_{3}$ & $1.2524 \mathrm{E}-05$ & & $1.2511 \mathrm{E}-05$ & $1.2476 \mathrm{E}-05$ & $1.2550 \mathrm{E}-05$ \\
\hline $\mathrm{Y}_{2} \mathrm{O}_{3}$ & $6.8843 \mathrm{E}-07$ & & $6.8774 \mathrm{E}-07$ & $6.8583 \mathrm{E}-07$ & $6.8990 \mathrm{E}-07$ \\
\hline $\mathrm{ZnO}$ & $1.3594 \mathrm{E}-05$ & $3.4986 \mathrm{E}-02$ & $3.4965 \mathrm{E}-02$ & $3.4886 \mathrm{E}-02$ & $3.5093 \mathrm{E}-02$ \\
\hline $\mathrm{ZrO}_{2}$ & 7.4799E-06 & $2.9993 \mathrm{E}-02$ & $2.9970 \mathrm{E}-02$ & $2.9965 \mathrm{E}-02$ & $3.0143 \mathrm{E}-02$ \\
\hline SUM & 0.233165 & 0.767831 & 1.00000 & 0.994096 & 1.000000 \\
\hline \multicolumn{2}{|c|}{ Waste and GFC contributions } & $1.000996 \mathrm{E}+00$ & & & \\
\hline
\end{tabular}

Empty cells represent the components not present in any of the GFCs 
Table B-5a. Radionuclides Activities in Step 1 Calculation the $A 101^{\text {th }}$ MFPV Batch before Adjustment

\begin{tabular}{|c|c|c|c|}
\hline Radionuclide & $\begin{array}{c}\text { Before Retention } \\
\mathrm{mCi} / \mathrm{g} \text { glass }\end{array}$ & $\begin{array}{c}\text { After Retention } \\
\text { mCi/g glass }\end{array}$ & $\begin{array}{c}\mathrm{SD} \\
\mathrm{mCi} / \mathrm{g} \text { glass } \\
\end{array}$ \\
\hline $59 \mathrm{Ni}$ & $3.42061 \mathrm{E}-07$ & $3.41293 \mathrm{E}-07$ & $2.44481 \mathrm{E}-08$ \\
\hline $60 \mathrm{Co}$ & 5.44554E-07 & $5.46256 \mathrm{E}-07$ & $2.81398 \mathrm{E}-08$ \\
\hline $63 \mathrm{Ni}$ & $3.11851 \mathrm{E}-05$ & $3.11150 \mathrm{E}-05$ & $2.21133 \mathrm{E}-06$ \\
\hline $79 \mathrm{Se}$ & $1.27903 \mathrm{E}-06$ & 9.92253E-07 & $2.25001 \mathrm{E}-07$ \\
\hline $90 \mathrm{Sr}$ & 5.55430E-04 & $5.57167 \mathrm{E}-04$ & $2.87069 \mathrm{E}-05$ \\
\hline $90 \mathrm{Y}$ & $5.37760 \mathrm{E}-04$ & 5.39441E-04 & $2.78000 \mathrm{E}-05$ \\
\hline $93 \mathrm{mNb}$ & $1.26953 \mathrm{E}-03$ & $1.27350 \mathrm{E}-03$ & $9.29833 \mathrm{E}-05$ \\
\hline $93 \mathrm{Zr}$ & $8.35053 \mathrm{E}-06$ & $8.39856 \mathrm{E}-06$ & $6.02715 \mathrm{E}-07$ \\
\hline $99 \mathrm{Tc}$ & 5.17932E-05 & $2.24287 \mathrm{E}-05$ & 7.82282E-06 \\
\hline $106 \mathrm{Ru}$ & $4.75383 \mathrm{E}-10$ & 4.67697E-10 & 4.60344E-11 \\
\hline $113 \mathrm{mCd}$ & $6.13426 \mathrm{E}-06$ & $6.15343 \mathrm{E}-06$ & $4.37393 \mathrm{E}-07$ \\
\hline $125 \mathrm{Sb}$ & $1.48165 \mathrm{E}-06$ & $1.14945 \mathrm{E}-06$ & $2.53761 \mathrm{E}-07$ \\
\hline $126 \mathrm{Sn}$ & $1.40134 \mathrm{E}-06$ & $1.40573 \mathrm{E}-06$ & $1.35855 \mathrm{E}-07$ \\
\hline 129I & $1.06286 \mathrm{E}-07$ & 5.44856E-08 & $1.94087 \mathrm{E}-08$ \\
\hline $134 \mathrm{Cs}$ & $2.37865 \mathrm{E}-10$ & $2.10328 \mathrm{E}-10$ & $3.83314 \mathrm{E}-11$ \\
\hline $137 \mathrm{mBa}$ & $8.77954 \mathrm{E}-02$ & 8.80699E-02 & $4.59182 \mathrm{E}-03$ \\
\hline $137 \mathrm{Cs}$ & $5.06870 \mathrm{E}-05$ & 4.48192E-05 & $5.15875 \mathrm{E}-06$ \\
\hline $151 \mathrm{Sm}$ & $1.58014 \mathrm{E}-03$ & $1.58508 \mathrm{E}-03$ & $1.97595 \mathrm{E}-04$ \\
\hline $152 \mathrm{Eu}$ & $2.68392 \mathrm{E}-07$ & $2.69231 \mathrm{E}-07$ & $1.37499 \mathrm{E}-08$ \\
\hline $154 \mathrm{Eu}$ & $5.55628 \mathrm{E}-06$ & 5.57364E-06 & 2.87399E-07 \\
\hline $155 \mathrm{Eu}$ & $2.48438 \mathrm{E}-06$ & $2.49215 \mathrm{E}-06$ & $1.27901 \mathrm{E}-07$ \\
\hline $226 \mathrm{Ra}$ & 4.35473E-09 & 3.37834E-09 & $8.70663 \mathrm{E}-10$ \\
\hline $227 \mathrm{Ac}$ & $4.03288 \mathrm{E}-09$ & 4.04549E-09 & $2.92393 \mathrm{E}-10$ \\
\hline $228 \mathrm{Ra}$ & 1.69296E-09 & $1.31337 \mathrm{E}-09$ & $4.91951 \mathrm{E}-10$ \\
\hline $229 \mathrm{Th}$ & $1.83835 \mathrm{E}-10$ & $1.84409 \mathrm{E}-10$ & $5.41429 \mathrm{E}-11$ \\
\hline $231 \mathrm{~Pa}$ & $1.11528 \mathrm{E}-08$ & $1.11877 \mathrm{E}-08$ & $3.21593 \mathrm{E}-09$ \\
\hline $232 \mathrm{Th}$ & 3.91129E-10 & 3.92351E-10 & $2.80536 \mathrm{E}-11$ \\
\hline $232 \mathrm{U}$ & 5.29112E-10 & $5.30766 \mathrm{E}-10$ & $2.75495 \mathrm{E}-11$ \\
\hline $233 \mathrm{U}$ & $2.51086 \mathrm{E}-08$ & $2.51871 \mathrm{E}-08$ & $1.29041 \mathrm{E}-09$ \\
\hline $234 \mathrm{U}$ & $1.45659 \mathrm{E}-08$ & $1.46114 \mathrm{E}-08$ & $7.45308 \mathrm{E}-10$ \\
\hline $235 \mathrm{U}$ & $5.49713 \mathrm{E}-10$ & $5.51431 \mathrm{E}-10$ & $3.95082 \mathrm{E}-11$ \\
\hline $236 \mathrm{U}$ & 1.01302E-09 & $1.01618 \mathrm{E}-09$ & $5.20845 \mathrm{E}-11$ \\
\hline $237 \mathrm{~Np}$ & 7.34369E-08 & 7.36664E-08 & $3.83442 \mathrm{E}-09$ \\
\hline $238 \mathrm{Pu}$ & 3.81740E-08 & 3.82933E-08 & $1.97530 \mathrm{E}-09$ \\
\hline $238 \mathrm{U}$ & $1.08587 \mathrm{E}-08$ & $1.08927 \mathrm{E}-08$ & $7.68048 \mathrm{E}-10$ \\
\hline $239 \mathrm{Pu}$ & $4.41730 \mathrm{E}-07$ & $4.43110 \mathrm{E}-07$ & $2.31630 \mathrm{E}-08$ \\
\hline $240 \mathrm{Pu}$ & 1.07624E-07 & $1.07961 \mathrm{E}-07$ & 7.76704E-09 \\
\hline $241 \mathrm{Am}$ & 5.41329E-07 & 5.32577E-07 & 4.01454E-08 \\
\hline $241 \mathrm{Pu}$ & $1.22191 \mathrm{E}-06$ & $1.22573 \mathrm{E}-06$ & $1.17456 \mathrm{E}-07$ \\
\hline $242 \mathrm{Cm}$ & 2.69892E-09 & $2.70736 \mathrm{E}-09$ & $1.96260 \mathrm{E}-10$ \\
\hline $242 \mathrm{Pu}$ & $1.18844 \mathrm{E}-11$ & $1.19216 \mathrm{E}-11$ & $8.47851 \mathrm{E}-13$ \\
\hline $243 \mathrm{Am}$ & 8.91223E-11 & $8.76813 \mathrm{E}-11$ & $8.65084 \mathrm{E}-12$ \\
\hline $243 \mathrm{Cm}$ & $3.21852 \mathrm{E}-10$ & $3.22858 \mathrm{E}-10$ & $3.12534 \mathrm{E}-11$ \\
\hline $244 \mathrm{Cm}$ & $6.56516 \mathrm{E}-09$ & $6.58568 \mathrm{E}-09$ & $6.33379 \mathrm{E}-10$ \\
\hline Total TRU ${ }^{(a)}$ & $1.20928 \mathrm{E}-06$ & $1.20262 \mathrm{E}-06$ & $4.71965 \mathrm{E}-08$ \\
\hline
\end{tabular}

(a) Total TRU measured by total alpha counting from LAW 1a sample will be used during plant operation. Sum of activities from TRU radionuclides is used in example calculation. 
Table B-5b. Radionuclides Activities in Step 1 Calculation the $A 101^{\text {th }}$ MFPV Batch after Adjustment

\begin{tabular}{|c|c|c|c|}
\hline Radionuclide & $\begin{array}{c}\text { Before Retention } \\
\text { mCi/g glass }\end{array}$ & $\begin{array}{c}\text { After Retention } \\
\mathrm{mCi} / \mathrm{g} \text { glass }\end{array}$ & $\begin{array}{c}\text { SD } \\
\mathrm{mCi} / \mathrm{g} \text { glass }\end{array}$ \\
\hline $59 \mathrm{Ni}$ & 3.42059E-07 & $3.41293 \mathrm{E}-07$ & $2.43342 \mathrm{E}-08$ \\
\hline $60 \mathrm{Co}$ & $5.44551 \mathrm{E}-07$ & $5.46257 \mathrm{E}-07$ & $2.80463 \mathrm{E}-08$ \\
\hline $63 \mathrm{Ni}$ & $3.11849 \mathrm{E}-05$ & $3.11151 \mathrm{E}-05$ & $2.23726 \mathrm{E}-06$ \\
\hline $79 \mathrm{Se}$ & $1.27902 \mathrm{E}-06$ & 9.92254E-07 & 2.22039E-07 \\
\hline $90 \mathrm{Sr}$ & $5.55428 \mathrm{E}-04$ & 5.57167E-04 & $2.90332 \mathrm{E}-05$ \\
\hline $90 \mathrm{Y}$ & $5.37757 \mathrm{E}-04$ & $5.39441 \mathrm{E}-04$ & $2.77737 \mathrm{E}-05$ \\
\hline $93 \mathrm{mNb}$ & $1.26952 \mathrm{E}-03$ & $1.27350 \mathrm{E}-03$ & $9.17426 \mathrm{E}-05$ \\
\hline $93 \mathrm{Zr}$ & 8.35049E-06 & 8.39857E-06 & $6.04429 \mathrm{E}-07$ \\
\hline $99 \mathrm{Tc}$ & 5.17929E-05 & $2.24288 \mathrm{E}-05$ & 7.66743E-06 \\
\hline $106 \mathrm{Ru}$ & $4.75381 \mathrm{E}-10$ & $4.67698 \mathrm{E}-10$ & 4.62192E-11 \\
\hline $113 \mathrm{mCd}$ & $6.13423 \mathrm{E}-06$ & $6.15344 \mathrm{E}-06$ & $4.50918 \mathrm{E}-07$ \\
\hline $125 \mathrm{Sb}$ & $1.48165 \mathrm{E}-06$ & $1.14945 \mathrm{E}-06$ & $2.48851 \mathrm{E}-07$ \\
\hline $126 \mathrm{Sn}$ & $1.40134 \mathrm{E}-06$ & $1.40573 \mathrm{E}-06$ & $1.35899 \mathrm{E}-07$ \\
\hline $129 \mathrm{I}$ & $1.06285 \mathrm{E}-07$ & 5.44857E-08 & $1.89869 \mathrm{E}-08$ \\
\hline $134 \mathrm{Cs}$ & $2.37863 \mathrm{E}-10$ & $2.10328 \mathrm{E}-10$ & $3.83694 \mathrm{E}-11$ \\
\hline $137 \mathrm{mBa}$ & $8.77950 \mathrm{E}-02$ & $8.80700 \mathrm{E}-02$ & $4.54325 \mathrm{E}-03$ \\
\hline $137 \mathrm{Cs}$ & $5.06867 \mathrm{E}-05$ & 4.48192E-05 & $5.11592 \mathrm{E}-06$ \\
\hline $151 \mathrm{Sm}$ & $1.58014 \mathrm{E}-03$ & $1.58509 \mathrm{E}-03$ & $1.95506 \mathrm{E}-04$ \\
\hline $152 \mathrm{Eu}$ & $2.68391 \mathrm{E}-07$ & $2.69232 \mathrm{E}-07$ & $1.37589 \mathrm{E}-08$ \\
\hline $154 \mathrm{Eu}$ & $5.55625 \mathrm{E}-06$ & $5.57365 \mathrm{E}-06$ & $2.89269 \mathrm{E}-07$ \\
\hline $155 \mathrm{Eu}$ & $2.48437 \mathrm{E}-06$ & $2.49215 \mathrm{E}-06$ & $1.28703 \mathrm{E}-07$ \\
\hline $226 \mathrm{Ra}$ & 4.35471E-09 & 3.37834E-09 & $8.99466 \mathrm{E}-10$ \\
\hline 227Ac & $4.03286 \mathrm{E}-09$ & 4.04549E-09 & $2.89147 \mathrm{E}-10$ \\
\hline $228 \mathrm{Ra}$ & 1.69295E-09 & $1.31337 \mathrm{E}-09$ & $4.86878 \mathrm{E}-10$ \\
\hline $229 \mathrm{Th}$ & $1.83834 \mathrm{E}-10$ & $1.84409 \mathrm{E}-10$ & $5.31553 \mathrm{E}-11$ \\
\hline $231 \mathrm{~Pa}$ & $1.11527 \mathrm{E}-08$ & $1.11877 \mathrm{E}-08$ & $3.25948 \mathrm{E}-09$ \\
\hline $232 \mathrm{Th}$ & $3.91127 \mathrm{E}-10$ & 3.92352E-10 & $2.78769 \mathrm{E}-11$ \\
\hline $232 \mathrm{U}$ & 5.29109E-10 & 5.30767E-10 & $2.75775 \mathrm{E}-11$ \\
\hline $233 \mathrm{U}$ & $2.51085 \mathrm{E}-08$ & $2.51871 \mathrm{E}-08$ & $1.30522 \mathrm{E}-09$ \\
\hline $234 \mathrm{U}$ & $1.45658 \mathrm{E}-08$ & $1.46114 \mathrm{E}-08$ & 7.46527E-10 \\
\hline $235 \mathrm{U}$ & $5.49710 \mathrm{E}-10$ & 5.51432E-10 & $4.05786 \mathrm{E}-11$ \\
\hline $236 \mathrm{U}$ & 1.01301E-09 & $1.01618 \mathrm{E}-09$ & $5.20458 \mathrm{E}-11$ \\
\hline $237 \mathrm{~Np}$ & 7.34365E-08 & 7.36665E-08 & 3.81045E-09 \\
\hline $238 \mathrm{Pu}$ & $3.81738 \mathrm{E}-08$ & $3.82934 \mathrm{E}-08$ & $1.97868 \mathrm{E}-09$ \\
\hline $238 \mathrm{U}$ & $1.08587 \mathrm{E}-08$ & $1.08927 \mathrm{E}-08$ & $7.68151 \mathrm{E}-10$ \\
\hline $239 \mathrm{Pu}$ & 4.41727E-07 & $4.43111 \mathrm{E}-07$ & $2.26847 \mathrm{E}-08$ \\
\hline $240 \mathrm{Pu}$ & $1.07624 \mathrm{E}-07$ & $1.07961 \mathrm{E}-07$ & 7.61149E-09 \\
\hline 241Am & $5.41326 \mathrm{E}-07$ & 5.32578E-07 & $3.99840 \mathrm{E}-08$ \\
\hline $241 \mathrm{Pu}$ & $1.22190 \mathrm{E}-06$ & $1.22573 \mathrm{E}-06$ & $1.16798 \mathrm{E}-07$ \\
\hline $242 \mathrm{Cm}$ & 2.69891E-09 & $2.70736 \mathrm{E}-09$ & $1.95381 \mathrm{E}-10$ \\
\hline $242 \mathrm{Pu}$ & $1.18843 \mathrm{E}-11$ & $1.19216 \mathrm{E}-11$ & $8.62480 \mathrm{E}-13$ \\
\hline $243 \mathrm{Am}$ & $8.91218 \mathrm{E}-11$ & $8.76815 \mathrm{E}-11$ & $8.50568 \mathrm{E}-12$ \\
\hline $243 \mathrm{Cm}$ & $3.21850 \mathrm{E}-10$ & $3.22859 \mathrm{E}-10$ & $3.09946 \mathrm{E}-11$ \\
\hline $244 \mathrm{Cm}$ & $6.56513 \mathrm{E}-09$ & 6.58569E-09 & $6.43148 \mathrm{E}-10$ \\
\hline Total TRU ${ }^{(\mathrm{a})}$ & $1.20928 \mathrm{E}-06$ & $1.20262 \mathrm{E}-06$ & $4.67985 \mathrm{E}-08$ \\
\hline
\end{tabular}

(a) Total TRU measured by total alpha counting from LAW 1a sample will be used during plant operation. Sum of activities from TRU radionuclides is used in example calculation. 
Table B-6. Waste and Glass Compositions in Step 3 Calculation the $\boldsymbol{A 1 0 1}^{\text {th }}$ MFPV Batch

\begin{tabular}{|c|c|c|c|c|c|}
\hline Component & $\begin{array}{c}\text { Waste } \\
\text { contribution } \\
\text { (Step 3) }\end{array}$ & $\begin{array}{c}\text { GFC } \\
\text { contribution } \\
\text { (Step 3) }\end{array}$ & $\begin{array}{c}\text { Combined } \\
\text { normalized } \\
\text { (Step 3) }\end{array}$ & $\begin{array}{c}\text { After applying } \\
\text { retention } \\
\text { factors }\end{array}$ & $\begin{array}{c}\text { Final } \\
\text { normalized }\end{array}$ \\
\hline $\mathrm{Ac} 2 \mathrm{O} 3$ & $6.1658 \mathrm{E}-14$ & & $6.1658 \mathrm{E}-14$ & $6.1486 \mathrm{E}-14$ & $6.1851 \mathrm{E}-14$ \\
\hline $\mathrm{Ag} 2 \mathrm{O}$ & $3.0386 \mathrm{E}-07$ & & $3.0386 \mathrm{E}-07$ & 2.9719E-07 & $2.9895 \mathrm{E}-07$ \\
\hline $\mathrm{Al} 2 \mathrm{O} 3$ & $1.6401 \mathrm{E}-02$ & 4.4555E-02 & $6.0956 \mathrm{E}-02$ & 6.0887E-02 & $6.1249 \mathrm{E}-02$ \\
\hline $\mathrm{Am} 2 \mathrm{O} 3$ & $1.7417 \mathrm{E}-10$ & & $1.7417 \mathrm{E}-10$ & $1.7035 \mathrm{E}-10$ & $1.7136 \mathrm{E}-10$ \\
\hline As2O5 & $1.6027 \mathrm{E}-06$ & & $1.6027 \mathrm{E}-06$ & $1.2360 \mathrm{E}-06$ & $1.2433 \mathrm{E}-06$ \\
\hline $\mathrm{B} 2 \mathrm{O} 3$ & $4.8198 \mathrm{E}-05$ & $9.9834 \mathrm{E}-02$ & $9.9883 \mathrm{E}-02$ & $9.8852 \mathrm{E}-02$ & $9.9439 \mathrm{E}-02$ \\
\hline $\mathrm{BaO}$ & $2.6197 \mathrm{E}-07$ & & $2.6197 \mathrm{E}-07$ & $2.6123 \mathrm{E}-07$ & $2.6279 \mathrm{E}-07$ \\
\hline $\mathrm{BeO}$ & $1.2741 \mathrm{E}-06$ & & $1.2741 \mathrm{E}-06$ & $1.2706 \mathrm{E}-06$ & $1.2781 \mathrm{E}-06$ \\
\hline $\mathrm{Bi} 2 \mathrm{O} 3$ & $4.4867 \mathrm{E}-06$ & & 4.4867E-06 & $4.3881 \mathrm{E}-06$ & 4.4142E-06 \\
\hline $\mathrm{CaO}$ & $4.3958 \mathrm{E}-05$ & $2.4645 \mathrm{E}-02$ & $2.4689 \mathrm{E}-02$ & $2.4662 \mathrm{E}-02$ & $2.4809 \mathrm{E}-02$ \\
\hline $\mathrm{CdO}$ & $8.0958 \mathrm{E}-07$ & $3.5025 \mathrm{E}-06$ & $4.3120 \mathrm{E}-06$ & $4.3000 \mathrm{E}-06$ & 4.3255E-06 \\
\hline $\mathrm{Ce} 2 \mathrm{O} 3$ & $2.4759 \mathrm{E}-07$ & & $2.4759 \mathrm{E}-07$ & $2.4690 \mathrm{E}-07$ & $2.4837 \mathrm{E}-07$ \\
\hline $\mathrm{Cl}$ & $2.4823 \mathrm{E}-03$ & $3.9374 \mathrm{E}-07$ & $2.4827 \mathrm{E}-03$ & $1.3508 \mathrm{E}-03$ & $1.3588 \mathrm{E}-03$ \\
\hline $\mathrm{Cm} 2 \mathrm{O} 3$ & $9.7205 \mathrm{E}-14$ & & $9.7205 \mathrm{E}-14$ & $9.6934 \mathrm{E}-14$ & $9.7510 \mathrm{E}-14$ \\
\hline $\mathrm{CoO}$ & 4.5549E-07 & & 4.5549E-07 & 4.5422E-07 & 4.5692E-07 \\
\hline $\mathrm{Cr} 2 \mathrm{O} 3$ & 7.9919E-04 & $9.9401 \mathrm{E}-05$ & $8.9860 \mathrm{E}-04$ & $8.5601 \mathrm{E}-04$ & 8.6109E-04 \\
\hline $\mathrm{Cs} 2 \mathrm{O}$ & $3.0872 \mathrm{E}-09$ & & $3.0872 \mathrm{E}-09$ & 2.7137E-09 & $2.7298 \mathrm{E}-09$ \\
\hline $\mathrm{CuO}$ & $8.4223 \mathrm{E}-07$ & & 8.4223E-07 & $8.3988 \mathrm{E}-07$ & 8.4486E-07 \\
\hline $\mathrm{Eu} 2 \mathrm{O} 3$ & $3.1570 \mathrm{E}-11$ & & $3.1570 \mathrm{E}-11$ & $3.1482 \mathrm{E}-11$ & $3.1669 \mathrm{E}-11$ \\
\hline $\mathrm{F}$ & $1.0293 \mathrm{E}-03$ & & $1.0293 \mathrm{E}-03$ & $7.5125 \mathrm{E}-04$ & $7.5571 \mathrm{E}-04$ \\
\hline $\mathrm{Fe} 2 \mathrm{O} 3$ & $1.6821 \mathrm{E}-05$ & $5.4913 \mathrm{E}-02$ & $5.4930 \mathrm{E}-02$ & $5.4847 \mathrm{E}-02$ & $5.5172 \mathrm{E}-02$ \\
\hline $\mathrm{Gd} 2 \mathrm{O} 3$ & $0.0000 \mathrm{E}+00$ & & $0.0000 \mathrm{E}+00$ & $0.0000 \mathrm{E}+00$ & $0.0000 \mathrm{E}+00$ \\
\hline $\mathrm{HgO}$ & $9.0772 \mathrm{E}-08$ & & $9.0772 \mathrm{E}-08$ & $0.0000 \mathrm{E}+00$ & $0.0000 \mathrm{E}+00$ \\
\hline $\mathrm{I}$ & $6.0115 \mathrm{E}-07$ & & $6.0115 \mathrm{E}-07$ & $3.0635 \mathrm{E}-07$ & $3.0817 \mathrm{E}-07$ \\
\hline $\mathrm{K} 2 \mathrm{O}$ & $1.4444 \mathrm{E}-02$ & $2.0961 \mathrm{E}-05$ & $1.4465 \mathrm{E}-02$ & $1.3947 \mathrm{E}-02$ & $1.4030 \mathrm{E}-02$ \\
\hline $\mathrm{La} 2 \mathrm{O} 3$ & $3.8235 \mathrm{E}-07$ & & $3.8235 \mathrm{E}-07$ & $3.8129 \mathrm{E}-07$ & $3.8355 \mathrm{E}-07$ \\
\hline $\mathrm{Li} 2 \mathrm{O}$ & $3.0453 \mathrm{E}-07$ & $1.9018 \mathrm{E}-03$ & $1.9021 \mathrm{E}-03$ & $1.8945 \mathrm{E}-03$ & $1.9057 \mathrm{E}-03$ \\
\hline $\mathrm{MgO}$ & $1.9339 \mathrm{E}-05$ & $1.4761 \mathrm{E}-02$ & $1.4780 \mathrm{E}-02$ & $1.4778 \mathrm{E}-02$ & $1.4866 \mathrm{E}-02$ \\
\hline $\mathrm{MnO}$ & $1.4945 \mathrm{E}-06$ & $1.3193 \mathrm{E}-04$ & $1.3342 \mathrm{E}-04$ & $1.3305 \mathrm{E}-04$ & $1.3384 \mathrm{E}-04$ \\
\hline $\mathrm{MoO} 3$ & $1.2689 \mathrm{E}-05$ & & $1.2689 \mathrm{E}-05$ & $1.2411 \mathrm{E}-05$ & $1.2484 \mathrm{E}-05$ \\
\hline $\mathrm{Na} 2 \mathrm{O}$ & $1.9107 \mathrm{E}-01$ & $3.3440 \mathrm{E}-04$ & $1.9141 \mathrm{E}-01$ & $1.8975 \mathrm{E}-01$ & $1.9088 \mathrm{E}-01$ \\
\hline $\mathrm{Nb} 2 \mathrm{O} 5$ & 7.6113E-09 & & 7.6113E-09 & 7.5901E-09 & 7.6352E-09 \\
\hline $\mathrm{Nd} 2 \mathrm{O} 3$ & $1.2241 \mathrm{E}-06$ & & $1.2241 \mathrm{E}-06$ & $1.2207 \mathrm{E}-06$ & $1.2279 \mathrm{E}-06$ \\
\hline $\mathrm{NiO}$ & $3.0141 \mathrm{E}-05$ & $1.1284 \mathrm{E}-04$ & $1.4298 \mathrm{E}-04$ & $1.4182 \mathrm{E}-04$ & $1.4266 \mathrm{E}-04$ \\
\hline $\mathrm{NpO} 2$ & $1.1828 \mathrm{E}-07$ & & $1.1828 \mathrm{E}-07$ & $1.1795 \mathrm{E}-07$ & $1.1865 \mathrm{E}-07$ \\
\hline $\mathrm{P} 2 \mathrm{O} 5$ & $1.8204 \mathrm{E}-03$ & $1.6091 \mathrm{E}-04$ & $1.9813 \mathrm{E}-03$ & $1.9648 \mathrm{E}-03$ & $1.9765 \mathrm{E}-03$ \\
\hline $\mathrm{Pa} 2 \mathrm{O} 5$ & $2.7702 \mathrm{E}-10$ & & $2.7702 \mathrm{E}-10$ & $2.7624 \mathrm{E}-10$ & $2.7788 \mathrm{E}-10$ \\
\hline $\mathrm{PbO}$ & $3.1686 \mathrm{E}-05$ & $5.8224 \mathrm{E}-07$ & $3.2268 \mathrm{E}-05$ & $3.1879 \mathrm{E}-05$ & $3.2069 \mathrm{E}-05$ \\
\hline $\mathrm{PdO}$ & 7.5047E-06 & & $7.5047 \mathrm{E}-06$ & $7.4838 \mathrm{E}-06$ & 7.5282E-06 \\
\hline Pr2O3 & $1.0738 \mathrm{E}-08$ & & $1.0738 \mathrm{E}-08$ & $1.0708 \mathrm{E}-08$ & $1.0771 \mathrm{E}-08$ \\
\hline $\mathrm{PuO} 2$ & $8.6325 \mathrm{E}-09$ & & 8.6325E-09 & 8.6084E-09 & 8.6596E-09 \\
\hline $\mathrm{RaO}$ & $4.7238 \mathrm{E}-12$ & & $4.7238 \mathrm{E}-12$ & $3.6430 \mathrm{E}-12$ & $3.6647 \mathrm{E}-12$ \\
\hline $\mathrm{Rb} 2 \mathrm{O}$ & $1.5155 \mathrm{E}-06$ & & $1.5155 \mathrm{E}-06$ & $1.4822 \mathrm{E}-06$ & $1.4910 \mathrm{E}-06$ \\
\hline $\mathrm{Rh} 2 \mathrm{O} 3$ & $3.3643 \mathrm{E}-06$ & & $3.3643 \mathrm{E}-06$ & $3.3549 \mathrm{E}-06$ & $3.3748 \mathrm{E}-06$ \\
\hline $\mathrm{RuO} 2$ & $1.6078 \mathrm{E}-05$ & & $1.6078 \mathrm{E}-05$ & $1.5724 \mathrm{E}-05$ & $1.5818 \mathrm{E}-05$ \\
\hline $\mathrm{SO} 3$ & $3.6140 \mathrm{E}-03$ & 4.9807E-05 & $3.6638 \mathrm{E}-03$ & $3.0787 \mathrm{E}-03$ & $3.0970 \mathrm{E}-03$ \\
\hline $\mathrm{Sb} 2 \mathrm{O} 3$ & $3.4149 \mathrm{E}-07$ & & $3.4149 \mathrm{E}-07$ & $2.6336 \mathrm{E}-07$ & $2.6493 \mathrm{E}-07$ \\
\hline
\end{tabular}




\begin{tabular}{|c|c|c|c|c|c|}
\hline Component & $\begin{array}{c}\text { Waste } \\
\text { contribution } \\
\text { (Step 3) } \\
\end{array}$ & $\begin{array}{c}\text { GFC } \\
\text { contribution } \\
\text { (Step 3) } \\
\end{array}$ & $\begin{array}{c}\text { Combined } \\
\text { normalized } \\
\text { (Step 3) } \\
\end{array}$ & $\begin{array}{c}\text { After applying } \\
\text { retention } \\
\text { factors }\end{array}$ & $\begin{array}{c}\text { Final } \\
\text { normalized }\end{array}$ \\
\hline $\mathrm{SeO} 2$ & $2.7802 \mathrm{E}-06$ & & $2.7802 \mathrm{E}-06$ & $2.1441 \mathrm{E}-06$ & $2.1569 \mathrm{E}-06$ \\
\hline $\mathrm{SiO} 2$ & $9.3071 \mathrm{E}-04$ & $4.4659 \mathrm{E}-01$ & $4.4752 \mathrm{E}-01$ & 4.4719E-01 & 4.4984E-01 \\
\hline $\mathrm{Sm} 2 \mathrm{O} 3$ & $6.9576 \mathrm{E}-08$ & & $6.9576 \mathrm{E}-08$ & $6.9382 \mathrm{E}-08$ & $6.9794 \mathrm{E}-08$ \\
\hline $\mathrm{SnO} 2$ & $6.1895 \mathrm{E}-08$ & & $6.1895 \mathrm{E}-08$ & 6.1722E-08 & $6.2089 \mathrm{E}-08$ \\
\hline $\mathrm{SrO}$ & $1.2997 \mathrm{E}-07$ & & $1.2997 \mathrm{E}-07$ & $1.2961 \mathrm{E}-07$ & $1.3038 \mathrm{E}-07$ \\
\hline $\mathrm{Ta} 2 \mathrm{O} 5$ & 4.4330E-08 & & 4.4330E-08 & 4.4207E-08 & 4.4469E-08 \\
\hline $\mathrm{Tc} 2 \mathrm{O} 7$ & 4.7408E-06 & & $4.7408 \mathrm{E}-06$ & $2.0409 \mathrm{E}-06$ & $2.0530 \mathrm{E}-06$ \\
\hline $\mathrm{TeO} 2$ & $1.3735 \mathrm{E}-07$ & & $1.3735 \mathrm{E}-07$ & $1.0593 \mathrm{E}-07$ & $1.0656 \mathrm{E}-07$ \\
\hline ThO2 & $4.0605 \mathrm{E}-06$ & & $4.0605 \mathrm{E}-06$ & 4.0491E-06 & $4.0732 \mathrm{E}-06$ \\
\hline $\mathrm{TiO} 2$ & $4.3526 \mathrm{E}-06$ & $1.3986 \mathrm{E}-02$ & $1.3990 \mathrm{E}-02$ & $1.3955 \mathrm{E}-02$ & $1.4038 \mathrm{E}-02$ \\
\hline $\mathrm{T} 12 \mathrm{O}$ & $9.3553 \mathrm{E}-07$ & & $9.3553 \mathrm{E}-07$ & $7.2149 \mathrm{E}-07$ & $7.2577 \mathrm{E}-07$ \\
\hline $\mathrm{UO} 3$ & $3.9153 \mathrm{E}-05$ & $2.0263 \mathrm{E}-05$ & $5.9415 \mathrm{E}-05$ & $5.9250 \mathrm{E}-05$ & $5.9602 \mathrm{E}-05$ \\
\hline $\mathrm{V} 2 \mathrm{O} 5$ & $6.0060 \mathrm{E}-07$ & $6.0290 \mathrm{E}-05$ & $6.0891 \mathrm{E}-05$ & $5.9553 \mathrm{E}-05$ & $5.9907 \mathrm{E}-05$ \\
\hline WO3 & $1.2511 \mathrm{E}-05$ & & $1.2511 \mathrm{E}-05$ & $1.2476 \mathrm{E}-05$ & $1.2550 \mathrm{E}-05$ \\
\hline $\mathrm{Y} 2 \mathrm{O} 3$ & $6.8774 \mathrm{E}-07$ & & $6.8774 \mathrm{E}-07$ & 6.8582E-07 & $6.8989 \mathrm{E}-07$ \\
\hline $\mathrm{ZnO}$ & $1.3580 \mathrm{E}-05$ & $3.4932 \mathrm{E}-02$ & $3.4945 \mathrm{E}-02$ & $3.4866 \mathrm{E}-02$ & $3.5073 \mathrm{E}-02$ \\
\hline $\mathrm{ZrO} 2$ & 7.4724E-06 & $2.9957 \mathrm{E}-02$ & $2.9965 \mathrm{E}-02$ & 2.9959E-02 & $3.0137 \mathrm{E}-02$ \\
\hline SUM & 0.23293 & 0.76707 & 1.00000 & 0.99410 & 1.00000 \\
\hline \multicolumn{2}{|c|}{ Waste and GFC contributions } & $1.00000 \mathrm{E}+00$ & & & \\
\hline
\end{tabular}

Empty cells represent the components not present in any of the GFCs. 
Table B-7. Radionuclides Activities in Step 3 Calculation the $A 101^{\text {th }}$ MFPV Batch

\begin{tabular}{|c|c|c|c|}
\hline Radionuclide & $\begin{array}{c}\text { Before retention } \\
\text { (Step 3) } \\
\text { mCi/g glass } \\
\end{array}$ & $\begin{array}{c}\text { After retention } \\
\text { (Step 3) } \\
\text { mCi/g glass } \\
\end{array}$ & $\begin{array}{c}\text { SD } \\
\mathrm{mCi} / \mathrm{g} \text { glass }\end{array}$ \\
\hline $59 \mathrm{Ni}$ & $3.4205 \mathrm{E}-07$ & $3.4129 \mathrm{E}-07$ & $2.4466 \mathrm{E}-08$ \\
\hline $60 \mathrm{Co}$ & $5.4454 \mathrm{E}-07$ & $5.4625 \mathrm{E}-07$ & $2.8064 \mathrm{E}-08$ \\
\hline $63 \mathrm{Ni}$ & $3.1185 \mathrm{E}-05$ & $3.1115 \mathrm{E}-05$ & $2.2279 \mathrm{E}-06$ \\
\hline $79 \mathrm{Se}$ & $1.2790 \mathrm{E}-06$ & $9.9224 \mathrm{E}-07$ & $2.1499 \mathrm{E}-07$ \\
\hline $90 \mathrm{Sr}$ & 5.5542E-04 & $5.5716 \mathrm{E}-04$ & $2.8693 \mathrm{E}-05$ \\
\hline $90 \mathrm{Y}$ & $5.3775 \mathrm{E}-04$ & $5.3943 \mathrm{E}-04$ & $2.8171 \mathrm{E}-05$ \\
\hline $93 \mathrm{mNb}$ & $1.2695 \mathrm{E}-03$ & $1.2735 \mathrm{E}-03$ & $9.0349 \mathrm{E}-05$ \\
\hline $93 \mathrm{Zr}$ & $8.3504 \mathrm{E}-06$ & $8.3985 \mathrm{E}-06$ & $5.9083 \mathrm{E}-07$ \\
\hline 99Tc & 5.1792E-05 & $2.2428 \mathrm{E}-05$ & $7.5227 \mathrm{E}-06$ \\
\hline $106 \mathrm{Ru}$ & $4.7537 \mathrm{E}-10$ & 4.6769E-10 & $4.5578 \mathrm{E}-11$ \\
\hline $113 \mathrm{mCd}$ & $6.1342 \mathrm{E}-06$ & $6.1534 \mathrm{E}-06$ & $4.4645 \mathrm{E}-07$ \\
\hline $125 \mathrm{Sb}$ & $1.4816 \mathrm{E}-06$ & $1.1494 \mathrm{E}-06$ & $2.5101 \mathrm{E}-07$ \\
\hline $126 \mathrm{Sn}$ & $1.4013 \mathrm{E}-06$ & $1.4057 \mathrm{E}-06$ & $1.3679 \mathrm{E}-07$ \\
\hline 129I & $1.0628 \mathrm{E}-07$ & $5.4485 \mathrm{E}-08$ & $1.9243 \mathrm{E}-08$ \\
\hline $134 \mathrm{Cs}$ & $2.3786 \mathrm{E}-10$ & $2.1033 \mathrm{E}-10$ & $3.8551 \mathrm{E}-11$ \\
\hline $137 \mathrm{mBa}$ & $8.7794 \mathrm{E}-02$ & 8.8069E-02 & $4.5725 \mathrm{E}-03$ \\
\hline $137 \mathrm{Cs}$ & $5.0686 \mathrm{E}-05$ & $4.4819 \mathrm{E}-05$ & $5.0779 \mathrm{E}-06$ \\
\hline $151 \mathrm{Sm}$ & $1.5801 \mathrm{E}-03$ & $1.5851 \mathrm{E}-03$ & $1.9667 \mathrm{E}-04$ \\
\hline $152 \mathrm{Eu}$ & $2.6839 \mathrm{E}-07$ & $2.6923 \mathrm{E}-07$ & $1.3796 \mathrm{E}-08$ \\
\hline $154 \mathrm{Eu}$ & $5.5562 \mathrm{E}-06$ & $5.5736 \mathrm{E}-06$ & $2.8811 \mathrm{E}-07$ \\
\hline $155 \mathrm{Eu}$ & $2.4843 \mathrm{E}-06$ & $2.4921 \mathrm{E}-06$ & $1.2616 \mathrm{E}-07$ \\
\hline $226 \mathrm{Ra}$ & $4.3547 \mathrm{E}-09$ & $3.3783 \mathrm{E}-09$ & $8.9244 \mathrm{E}-10$ \\
\hline 227Ac & 4.0328E-09 & 4.0454E-09 & $2.9183 \mathrm{E}-10$ \\
\hline $228 \mathrm{Ra}$ & 1.6929E-09 & $1.3134 \mathrm{E}-09$ & $4.8513 \mathrm{E}-10$ \\
\hline 229Th & $1.8383 \mathrm{E}-10$ & $1.8441 \mathrm{E}-10$ & $5.4186 \mathrm{E}-11$ \\
\hline $231 \mathrm{~Pa}$ & $1.1153 \mathrm{E}-08$ & $1.1188 \mathrm{E}-08$ & $3.3445 \mathrm{E}-09$ \\
\hline $232 \mathrm{Th}$ & $3.9112 \mathrm{E}-10$ & $3.9235 \mathrm{E}-10$ & $2.8481 \mathrm{E}-11$ \\
\hline $232 \mathrm{U}$ & $5.2910 \mathrm{E}-10$ & $5.3076 \mathrm{E}-10$ & $2.7295 \mathrm{E}-11$ \\
\hline $233 \mathrm{U}$ & $2.5108 \mathrm{E}-08$ & $2.5187 \mathrm{E}-08$ & $1.2978 \mathrm{E}-09$ \\
\hline $234 \mathrm{U}$ & $1.4566 \mathrm{E}-08$ & $1.4611 \mathrm{E}-08$ & $7.5277 \mathrm{E}-10$ \\
\hline $235 \mathrm{U}$ & $5.4970 \mathrm{E}-10$ & $5.5142 \mathrm{E}-10$ & $3.9628 \mathrm{E}-11$ \\
\hline $236 \mathrm{U}$ & $1.0130 \mathrm{E}-09$ & $1.0162 \mathrm{E}-09$ & $5.2242 \mathrm{E}-11$ \\
\hline $237 \mathrm{~Np}$ & $7.3436 \mathrm{E}-08$ & $7.3666 \mathrm{E}-08$ & $3.7579 \mathrm{E}-09$ \\
\hline $238 \mathrm{Pu}$ & $3.8173 \mathrm{E}-08$ & 3.8293E-08 & $1.9700 \mathrm{E}-09$ \\
\hline $238 \mathrm{U}$ & $1.0859 \mathrm{E}-08$ & $1.0893 \mathrm{E}-08$ & $7.8669 \mathrm{E}-10$ \\
\hline $239 \mathrm{Pu}$ & 4.4172E-07 & $4.4311 \mathrm{E}-07$ & $2.3118 \mathrm{E}-08$ \\
\hline $240 \mathrm{Pu}$ & $1.0762 \mathrm{E}-07$ & $1.0796 \mathrm{E}-07$ & $7.6493 \mathrm{E}-09$ \\
\hline $241 \mathrm{Am}$ & 5.4132E-07 & $5.3257 \mathrm{E}-07$ & $4.0675 \mathrm{E}-08$ \\
\hline $241 \mathrm{Pu}$ & $1.2219 \mathrm{E}-06$ & $1.2257 \mathrm{E}-06$ & $1.1890 \mathrm{E}-07$ \\
\hline $242 \mathrm{Cm}$ & $2.6989 \mathrm{E}-09$ & $2.7073 \mathrm{E}-09$ & $1.9515 \mathrm{E}-10$ \\
\hline $242 \mathrm{Pu}$ & $1.1884 \mathrm{E}-11$ & $1.1921 \mathrm{E}-11$ & $8.4942 \mathrm{E}-13$ \\
\hline $243 \mathrm{Am}$ & $8.9121 \mathrm{E}-11$ & $8.7680 \mathrm{E}-11$ & $8.6280 \mathrm{E}-12$ \\
\hline $243 \mathrm{Cm}$ & $3.2185 \mathrm{E}-10$ & $3.2285 \mathrm{E}-10$ & $3.0759 \mathrm{E}-11$ \\
\hline $244 \mathrm{Cm}$ & $6.5650 \mathrm{E}-09$ & $6.5856 \mathrm{E}-09$ & $6.3814 \mathrm{E}-10$ \\
\hline Total TRU ${ }^{(\mathrm{a})}$ & $1.20926 \mathrm{E}-06$ & $1.2026 \mathrm{E}-06$ & $4.7601 \mathrm{E}-08$ \\
\hline
\end{tabular}

(a) Total TRU measured by total alpha counting from LAW 1a sample will be used during plant operation. Sum of activities from TRU radionuclides is used in example calculation. 
Table B-8. Input and Results of Algorithm Calculations for 10 Example MFPV Batches

\begin{tabular}{|c|c|c|c|c|}
\hline MFPV Batch & MFPV-A101 & MFPV-B101 & MFPV-A102 & MFPV-B102 \\
\hline \multicolumn{5}{|l|}{ Input } \\
\hline Source CRV $(d)$ & CRV-A11 & CRV-A11 & CRV-A11 & CRV-B11 \\
\hline CRV transfer \# $(m)$ & 1 & 2 & 3 & 1 \\
\hline CRV volume before calculation, $\mathrm{L}$ & 48709.0 & 39822.6 & 31002.5 & 48852.0 \\
\hline MFPV heel volume, $\mathrm{L}$ & 6712 & 6651 & 6538 & 6443 \\
\hline Sampling line flush water volume, $\mathrm{L}$ & 71.2 & NA & NA & 108.6 \\
\hline CRV-MFPV line flush water volume, $\mathrm{L}$ & NA & 24.6 & 24.6 & NA \\
\hline Calculated dilution factor & 0.99854 & 0.99792 & 0.99713 & 0.99778 \\
\hline Total mass of glass oxides in CRV waste, $\mathrm{g} / \mathrm{L}$ & 260.583 & 260.421 & 260.215 & 261.535 \\
\hline \multicolumn{5}{|l|}{ Step 1 Calculation } \\
\hline Minimum $\mathrm{Na}_{2} \mathrm{O}$ loading from formulation rules & $19.13 \%$ & $19.13 \%$ & $19.13 \%$ & $19.86 \%$ \\
\hline Limiting rule or component & $\mathrm{Cr} 2 \mathrm{O} 3$ & $\mathrm{Cr} 2 \mathrm{O} 3$ & $\mathrm{Cr} 2 \mathrm{O} 3$ & $\mathrm{Cr} 2 \mathrm{O} 3$ \\
\hline Initial waste loading & $23.317 \%$ & $23.317 \%$ & $23.317 \%$ & $24.223 \%$ \\
\hline g oxides/L waste & 1117.59 & 1116.89 & 1116.01 & 1079.70 \\
\hline g glass $/ \mathrm{L}$ waste & 1111.00 & 1110.30 & 1109.43 & 1073.17 \\
\hline Manual adjustment of GFC component - & $+0.19 \mathrm{wt} \% \mathrm{Li} 2 \mathrm{O}$ & $+0.18 w \mathrm{w} \% \mathrm{Li} 2 \mathrm{O}$ & $+0.21 \mathrm{wt} \% \mathrm{Li} 2 \mathrm{O}$ & None \\
\hline Target waste transfer volume, $\mathrm{L}$ & 8696.7 & 8671.3 & 8820.5 & 8955.6 \\
\hline GFC volume, L & 3273.5 & 3261.2 & 3316.8 & 3211.4 \\
\hline Dust control water volume, $\mathrm{L}$ & 330.2 & 329.0 & 334.6 & 323.9 \\
\hline Sucrose volume, L & 200.8 & 200.1 & 203.4 & 204.4 \\
\hline CRV-MFPV line flush volume, $\mathrm{L}$ & 37.5 & 66.2 & 37.5 & 40.5 \\
\hline Sampling line flush volume, $\mathrm{L}$ & 175.3 & 247.2 & 175.3 & 247.2 \\
\hline Dilution water volume, $\mathrm{L}$ & 0.0 & 0.0 & 0.0 & 0.0 \\
\hline Calculated MFPV working volume, $\mathrm{L}$ & 19426.0 & 19426.0 & 19426.0 & 19426.0 \\
\hline Target Na Molarity, M & 7.870 & 7.870 & 7.870 & 8.164 \\
\hline Dilution water volume, $\mathrm{L}$ & -1617.5 & -1718.6 & -1648.1 & -1977.5 \\
\hline Na Molarity of CRV waste, M & 6.898 & 6.893 & 6.888 & 6.919 \\
\hline (Target) Kyanite mass, $\mathrm{kg}$ & 729.90 & 727.31 & 739.25 & 714.34 \\
\hline Boric Acid, kg & 1718.73 & 1712.64 & 1740.75 & 1709.80 \\
\hline Wollastonite, $\mathrm{kg}$ & 502.47 & 500.70 & 508.87 & 444.60 \\
\hline Hematite, $\mathrm{kg}$ & 517.23 & 515.39 & 523.85 & 514.87 \\
\hline Li Carbonate, $\mathrm{kg}$ & 45.93 & 43.36 & 50.51 & 0.00 \\
\hline Olivine, $\mathrm{kg}$ & 296.51 & 295.46 & 300.31 & 294.98 \\
\hline $\mathrm{Na}$ Carbonate, $\mathrm{kg}$ & 0.00 & 0.00 & 0.00 & 0.00 \\
\hline Silica, kg & 3528.27 & 3516.74 & 3571.88 & 3507.22 \\
\hline Rutile, $\mathrm{kg}$ & 137.92 & 137.43 & 139.69 & 137.33 \\
\hline Zincite, $\mathrm{kg}$ & 340.67 & 339.47 & 345.04 & 338.90 \\
\hline Zircon, $\mathrm{kg}$ & 438.13 & 436.58 & 443.74 & 435.87 \\
\hline Sucrose, $\mathrm{kg}$ & 311.09 & 309.99 & 315.08 & 316.61 \\
\hline Total, $\mathrm{kg}$ & 8566.83 & 8535.08 & 8678.96 & 8414.52 \\
\hline Glass mass per L feed before retention, $\mathrm{g} / \mathrm{L}$ & 765.2 & 758.9 & 764.6 & 745.5 \\
\hline Glass mass per L feed after retention, $\mathrm{g} / \mathrm{L}$ & 760.7 & 754.4 & 760.0 & 741.0 \\
\hline Final waste loading, before retention & $23.293 \%$ & $23.293 \%$ & $23.293 \%$ & $24.199 \%$ \\
\hline Glass mass per batch, before retention, $\mathrm{kg}$ & 9729.0 & 9694.5 & 9853.6 & 9678.9 \\
\hline Glass mass per batch, after retention, $\mathrm{kg}$ & 9671.5 & 9637.3 & 9795.4 & 9620.3 \\
\hline \multicolumn{5}{|l|}{ Step 2 Calculation } \\
\hline Actual waste transfer volume assumed, $\mathrm{L}$ & 8957.6 & 8844.7 & 8908.7 & 9134.7 \\
\hline CRV-MFPV line flush volume, $\mathrm{L}$ & 37.5 & 66.2 & 37.5 & 40.5 \\
\hline GFC volume, L & 3371.8 & 3326.4 & 3349.9 & 3275.7 \\
\hline
\end{tabular}




\begin{tabular}{|c|c|c|c|c|}
\hline MFPV Batch & MFPV-A101 & MFPV-B101 & MFPV-A102 & MFPV-B102 \\
\hline Dust control water volume, $\mathrm{L}$ & 340.1 & 335.6 & 337.9 & 330.4 \\
\hline Sucrose volume, L & 206.9 & 204.1 & 205.4 & 208.5 \\
\hline Sampling line flush volume, $\mathrm{L}$ & 175.3 & 247.2 & 175.3 & 247.2 \\
\hline Dilution water volume, $\mathrm{L}$ & 0.0 & 0.0 & 0.0 & 0.0 \\
\hline Calculated MFPV working volume, $\mathrm{L}$ & 19801.1 & 19675.2 & 19552.7 & 19679.9 \\
\hline Difference in volume, $\mathrm{L}$ & 375.1 & 249.2 & 126.7 & 253.9 \\
\hline Dilution water volume, L & -1659.7 & -1746.7 & -1662.4 & -2011.3 \\
\hline (Calculated) Kyanite mass, $\mathrm{kg}$ & 751.80 & 741.86 & 746.64 & 728.63 \\
\hline Boric Acid, $\mathrm{kg}$ & 1770.30 & 1746.90 & 1758.15 & 1744.00 \\
\hline Wollastonite, $\mathrm{kg}$ & 517.54 & 510.72 & 513.96 & 453.49 \\
\hline Hematite, $\mathrm{kg}$ & 532.74 & 525.70 & 529.09 & 525.17 \\
\hline Li Carbonate, $\mathrm{kg}$ & 47.31 & 44.23 & 51.02 & 0.00 \\
\hline Olivine, $\mathrm{kg}$ & 305.40 & 301.37 & 303.31 & 300.88 \\
\hline $\mathrm{Na}$ Carbonate, $\mathrm{kg}$ & 0.00 & 0.00 & 0.00 & 0.00 \\
\hline Silica, kg & 3634.13 & 3587.08 & 3607.58 & 3577.37 \\
\hline Rutile, $\mathrm{kg}$ & 142.06 & 140.18 & 141.09 & 140.08 \\
\hline Zincite, $\mathrm{kg}$ & 350.89 & 346.26 & 348.49 & 345.68 \\
\hline Zircon, $\mathrm{kg}$ & 451.28 & 445.31 & 448.18 & 444.59 \\
\hline Sucrose, $\mathrm{kg}$ & 320.43 & 316.19 & 318.23 & 322.94 \\
\hline Total, $\mathrm{kg}$ & 8823.88 & 8705.79 & 8765.71 & 8582.82 \\
\hline \multicolumn{5}{|l|}{ Step 3 Calculation } \\
\hline (Assumed as actual) Kyanite mass, kg & 752.1 & 742.0 & 747.1 & 728.7 \\
\hline Boric Acid, kg & 1770.0 & 1747.1 & 1758.3 & 1744.1 \\
\hline Wollastonite, $\mathrm{kg}$ & 517.7 & 510.7 & 514.1 & 453.2 \\
\hline Hematite, $\mathrm{kg}$ & 532.6 & 525.6 & 529.1 & 525.2 \\
\hline Li Carbonate, $\mathrm{kg}$ & 47.4 & 44.2 & 50.9 & 0.0 \\
\hline Olivine, $\mathrm{kg}$ & 305.3 & 301.4 & 303.2 & 300.8 \\
\hline $\mathrm{Na}$ Carbonate, $\mathrm{kg}$ & 0.0 & 0.0 & 0.0 & 0.0 \\
\hline Silica, kg & 3634.4 & 3587.5 & 3607.3 & 3577.3 \\
\hline Rutile, $\mathrm{kg}$ & 142.1 & 140.3 & 141.1 & 140.1 \\
\hline Zincite, $\mathrm{kg}$ & 350.7 & 346.1 & 348.4 & 345.7 \\
\hline Zircon, $\mathrm{kg}$ & 451.2 & 445.3 & 448.2 & 444.6 \\
\hline Sucrose, $\mathrm{kg}$ & 320.3 & 316.2 & 318.3 & 322.5 \\
\hline Total, $\mathrm{kg}$ & 8823.8 & 8706.4 & 8766.0 & 8582.2 \\
\hline Transfer waste volume, $\mathrm{L}$ & 8957.6 & 8844.7 & 8908.7 & 9134.7 \\
\hline Dust control water volume, $\mathrm{L}$ & 340.1 & 335.6 & 337.9 & 330.4 \\
\hline CRV-MFPV line flush volume, $\mathrm{L}$ & 37.5 & 66.2 & 37.5 & 40.5 \\
\hline Sampling line flush volume, $\mathrm{L}$ & 175.3 & 247.2 & 175.3 & 247.2 \\
\hline Dilution water volume, $\mathrm{L}$ & 0.0 & 0.0 & 0.0 & 0.0 \\
\hline GFC volume, $\mathrm{L}$ & 3371.7 & 3326.7 & 3350.0 & 3275.6 \\
\hline Sucrose volume, L & 206.8 & 204.1 & 205.5 & 208.2 \\
\hline Calculated MFPV working volume, $\mathrm{L}$ & 19801.0 & 19675.5 & 19552.8 & 19679.6 \\
\hline Glass mass per $\mathrm{L}$ feed before retention, $\mathrm{g} / \mathrm{L}$ & 765.6 & 759.3 & 764.7 & 745.8 \\
\hline Glass mass per L feed after retention, $\mathrm{g} / \mathrm{L}$ & 761.1 & 754.8 & 760.2 & 741.3 \\
\hline Mass of waste oxides per batch, $\mathrm{kg}$ & $2,334.2$ & $2,303.3$ & $2,318.2$ & $2,389.0$ \\
\hline Mass of GFC oxides per batch, $\mathrm{kg}$ & $7,686.8$ & $7,585.6$ & $7,634.1$ & $7,483.2$ \\
\hline Waste loading for Step 3 & $23.293 \%$ & $23.292 \%$ & $23.293 \%$ & $24.200 \%$ \\
\hline Mass of glass before retention, $\mathrm{kg}$ & 10,021 & 9,889 & 9,952 & 9,872 \\
\hline Mass of glass after retention, $\mathrm{kg}$ & 9,962 & 9,831 & 9,894 & 9,812 \\
\hline
\end{tabular}




\begin{tabular}{|c|c|c|c|c|}
\hline MFPV Batch & MFPV-A103 & MFPV-B103 & MFPV-A104 & MFPV-B104 \\
\hline \multicolumn{5}{|l|}{ Input } \\
\hline Source CRV $(d)$ & CRV-B11 & CRV-B11 & CRV-A12 & CRV-A12 \\
\hline CRV transfer \# $(m)$ & 2 & 3 & 1 & 2 \\
\hline CRV volume before calculation, $\mathrm{L}$ & 39825.9 & 30843.3 & 49049 & 40610.0 \\
\hline MFPV heel volume, L & 6582 & 6488 & 6515 & 6441 \\
\hline Sampling line flush water volume, $\mathrm{L}$ & NA & NA & 71.2 & NA \\
\hline CRV-MFPV line flush water volume, $\mathrm{L}$ & 25.0 & 25.0 & NA & 24.6 \\
\hline Calculated dilution factor & 0.99716 & 0.99635 & 0.99855 & 0.99795 \\
\hline Total mass of glass oxides in CRV waste, $\mathrm{g} / \mathrm{L}$ & 261.373 & 261.160 & 258.620 & 258.465 \\
\hline \multicolumn{5}{|l|}{ Step 1 Calculation } \\
\hline Minimum $\mathrm{Na}_{2} \mathrm{O}$ loading from formulation rules & $19.86 \%$ & $19.86 \%$ & $17.11 \%$ & $17.11 \%$ \\
\hline Limiting rule or component & $\mathrm{Cr} 2 \mathrm{O} 3$ & $\mathrm{Cr} 2 \mathrm{O} 3$ & $\mathrm{Cr} 2 \mathrm{O} 3$ & $\mathrm{Cr} 2 \mathrm{O} 3$ \\
\hline Initial waste loading & $24.223 \%$ & $24.223 \%$ & $20.858 \%$ & $20.858 \%$ \\
\hline g oxides/L waste & 1079.03 & 1078.16 & 1239.88 & 1239.14 \\
\hline g glass/L waste & 1072.50 & 1071.63 & 1232.95 & 1232.21 \\
\hline Manual adjustment of GFC component & None & None & $+0.22 \mathrm{wt} \% \mathrm{Li} 2 \mathrm{O}$ & $+0.21 \mathrm{wt} \% \mathrm{Li} 2 \mathrm{O}$ \\
\hline Target waste transfer volume, $\mathrm{L}$ & 8918.4 & 8927.6 & 8467.8 & 8452.3 \\
\hline GFC volume, L & 3196.1 & 3196.8 & 3657.4 & 3647.7 \\
\hline Dust control water volume, $\mathrm{L}$ & 322.4 & 322.4 & 369.7 & 368.7 \\
\hline Sucrose volume, L & 203.4 & 203.5 & 203.4 & 202.9 \\
\hline CRV-MFPV line flush volume, $\mathrm{L}$ & 28.4 & 40.5 & 37.5 & 66.2 \\
\hline Sampling line flush volume, $\mathrm{L}$ & 175.3 & 247.2 & 175.3 & 247.2 \\
\hline Dilution water volume, L & 0.0 & 0.0 & 0.0 & 0.0 \\
\hline Calculated MFPV working volume, L & 19426.0 & 19426.0 & 19426.0 & 19426.0 \\
\hline Target Na Molarity, M & 8.164 & 8.164 & 7.061 & 7.061 \\
\hline Dilution water volume, $\mathrm{L}$ & -1890.9 & -1982.6 & -839.7 & -943.9 \\
\hline Na Molarity of CRV waste, M & 6.915 & 6.909 & 6.847 & 6.843 \\
\hline (Target) Kyanite mass, $\mathrm{kg}$ & 710.93 & 711.09 & 829.17 & 827.15 \\
\hline Boric Acid, $\mathrm{kg}$ & 1701.65 & 1702.02 & 1856.57 & 1852.06 \\
\hline Wollastonite, $\mathrm{kg}$ & 442.48 & 442.57 & 793.31 & 791.40 \\
\hline Hematite, $\mathrm{kg}$ & 512.42 & 512.53 & 557.42 & 556.07 \\
\hline Li Carbonate, $\mathrm{kg}$ & 0.00 & 0.00 & 155.79 & 152.80 \\
\hline Olivine, $\mathrm{kg}$ & 293.57 & 293.63 & 319.72 & 318.94 \\
\hline $\mathrm{Na}$ Carbonate, $\mathrm{kg}$ & 0.00 & 0.00 & 0.00 & 0.00 \\
\hline Silica, kg & 3490.50 & 3491.25 & 3740.06 & 3732.01 \\
\hline Rutile, $\mathrm{kg}$ & 136.68 & 136.71 & 148.56 & 148.20 \\
\hline Zincite, $\mathrm{kg}$ & 337.29 & 337.36 & 367.99 & 367.10 \\
\hline Zircon, $\mathrm{kg}$ & 433.80 & 433.89 & 473.30 & 472.15 \\
\hline Sucrose, $\mathrm{kg}$ & 315.10 & 315.16 & 314.99 & 314.23 \\
\hline Total, $\mathrm{kg}$ & 8374.41 & 8376.21 & 9556.89 & 9532.10 \\
\hline Glass mass per L feed before retention, $\mathrm{g} / \mathrm{L}$ & 750.0 & 744.7 & 814.0 & 807.4 \\
\hline Glass mass per L feed after retention, $\mathrm{g} / \mathrm{L}$ & 745.4 & 740.2 & 809.5 & 802.9 \\
\hline Final Waste loading, before retention & $24.199 \%$ & $24.199 \%$ & $20.837 \%$ & $20.837 \%$ \\
\hline Glass mass per batch, before retention, $\mathrm{kg}$ & 9632.7 & 9634.8 & 10510.1 & 10484.5 \\
\hline Glass mass per batch, after retention, $\mathrm{kg}$ & 9574.4 & 9576.5 & 10451.3 & 10425.9 \\
\hline \multicolumn{5}{|l|}{ Step 2 Calculation } \\
\hline Actual waste transfer volume assumed, $\mathrm{L}$ & 9007.6 & 8838.3 & 8510.2 & 8410.1 \\
\hline CRV-MFPV line flush volume, $\mathrm{L}$ & 28.4 & 40.5 & 37.5 & 66.2 \\
\hline GFC volume, L & 3228.1 & 3164.8 & 3675.7 & 3629.4 \\
\hline Dust control water volume, $\mathrm{L}$ & 325.6 & 319.2 & 371.5 & 366.9 \\
\hline
\end{tabular}




\begin{tabular}{|c|c|c|c|c|}
\hline MFPV Batch & MFPV-A103 & MFPV-B103 & MFPV-A104 & MFPV-B104 \\
\hline Sucrose volume, $\mathrm{L}$ & 205.5 & 201.4 & 204.4 & 201.8 \\
\hline Sampling line flush volume, $\mathrm{L}$ & 175.3 & 247.2 & 175.3 & 247.2 \\
\hline Dilution water volume, $\mathrm{L}$ & 0.0 & 0.0 & 0.0 & 0.0 \\
\hline Calculated MFPV working volume, $\mathrm{L}$ & 19552.4 & 19299.5 & 19489.5 & 19362.7 \\
\hline Difference in volume, $\mathrm{L}$ & 126.4 & -126.5 & 63.5 & -63.3 \\
\hline Dilution water volume, $\mathrm{L}$ & -1907.8 & -1965.6 & -842.9 & -940.7 \\
\hline (Calculated) Kyanite mass, $\mathrm{kg}$ & 718.04 & 703.97 & 833.32 & 823.02 \\
\hline Boric Acid, kg & 1718.67 & 1684.99 & 1865.86 & 1842.80 \\
\hline Wollastonite, $\mathrm{kg}$ & 446.90 & 438.15 & 797.28 & 787.45 \\
\hline Hematite, $\mathrm{kg}$ & 517.54 & 507.40 & 560.21 & 553.29 \\
\hline Li Carbonate, $\mathrm{kg}$ & 0.00 & 0.00 & 156.57 & 152.04 \\
\hline Olivine, $\mathrm{kg}$ & 296.51 & 290.70 & 321.32 & 317.35 \\
\hline $\mathrm{Na}$ Carbonate, $\mathrm{kg}$ & 0.00 & 0.00 & 0.00 & 0.00 \\
\hline Silica, $\mathrm{kg}$ & 3525.40 & 3456.33 & 3758.77 & 3713.37 \\
\hline Rutile, $\mathrm{kg}$ & 138.04 & 135.34 & 149.30 & 147.46 \\
\hline Zincite, $\mathrm{kg}$ & 340.66 & 333.99 & 369.83 & 365.27 \\
\hline Zircon, $\mathrm{kg}$ & 438.13 & 429.55 & 475.67 & 469.79 \\
\hline Sucrose, $\mathrm{kg}$ & 318.25 & 312.01 & 316.57 & 312.66 \\
\hline Total, $\mathrm{kg}$ & 8458.14 & 8292.43 & 9604.70 & 9484.48 \\
\hline \multicolumn{5}{|l|}{ Step 3 Calculation } \\
\hline (Assumed as actual) Kyanite mass, $\mathrm{kg}$ & 718.1 & 703.7 & 833.1 & 822.9 \\
\hline Boric Acid, kg & 1718.6 & 1685.0 & 1866.2 & 1842.6 \\
\hline Wollastonite, $\mathrm{kg}$ & 446.5 & 437.9 & 797.3 & 787.3 \\
\hline Hematite, $\mathrm{kg}$ & 517.5 & 507.3 & 560.1 & 553.3 \\
\hline Li Carbonate, $\mathrm{kg}$ & 0.0 & 0.0 & 156.4 & 152.0 \\
\hline Olivine, $\mathrm{kg}$ & 296.3 & 290.7 & 321.3 & 317.4 \\
\hline $\mathrm{Na}$ Carbonate, $\mathrm{kg}$ & 0.0 & 0.0 & 0.0 & 0.0 \\
\hline Silica, $\mathrm{kg}$ & 3524.9 & 3455.7 & 3758.9 & 3713.0 \\
\hline Rutile, $\mathrm{kg}$ & 138.0 & 135.3 & 149.2 & 147.4 \\
\hline Zincite, $\mathrm{kg}$ & 340.5 & 334.1 & 369.9 & 365.3 \\
\hline Zircon, $\mathrm{kg}$ & 437.9 & 429.5 & 475.7 & 469.8 \\
\hline Sucrose, $\mathrm{kg}$ & 318.6 & 312.0 & 316.4 & 312.4 \\
\hline Total, kg & 8456.9 & 8291.2 & 9604.5 & 9483.4 \\
\hline Transfer waste volume, $\mathrm{L}$ & 9007.6 & 8838.3 & 8510.2 & 8410.1 \\
\hline Dust control water volume, $\mathrm{L}$ & 325.6 & 319.2 & 371.5 & 366.9 \\
\hline CRV-MFPV line flush volume, $\mathrm{L}$ & 28.4 & 40.5 & 37.5 & 66.2 \\
\hline Sampling line flush volume, $\mathrm{L}$ & 175.3 & 247.2 & 175.3 & 247.2 \\
\hline Dilution water volume, $\mathrm{L}$ & 0.0 & 0.0 & 0.0 & 0.0 \\
\hline GFC volume, $\mathrm{L}$ & 3227.6 & 3164.4 & 3675.8 & 3629.1 \\
\hline Sucrose volume, $\mathrm{L}$ & 205.7 & 201.4 & 204.3 & 201.7 \\
\hline Calculated MFPV working volume, $\mathrm{L}$ & 19552.1 & 19299.0 & 19489.5 & 19362.2 \\
\hline Glass mass per $\mathrm{L}$ feed before retention, $\mathrm{g} / \mathrm{L}$ & 750.0 & 744.5 & 814.1 & 807.3 \\
\hline Glass mass per $\mathrm{L}$ feed after retention, $\mathrm{g} / \mathrm{L}$ & 745.5 & 739.9 & 809.5 & 802.8 \\
\hline Mass of waste oxides per batch, $\mathrm{kg}$ & $2,354.3$ & $2,308.2$ & $2,200.9$ & $2,173.7$ \\
\hline Mass of GFC oxides per batch, $\mathrm{kg}$ & $7,373.1$ & $7,229.0$ & $8,361.7$ & $8,257.7$ \\
\hline Waste loading for Step 3 & $24.203 \%$ & $24.202 \%$ & $20.837 \%$ & $20.838 \%$ \\
\hline Mass of glass before retention, $\mathrm{kg}$ & 9,727 & 9,537 & 10,563 & 10,431 \\
\hline Mass of glass after retention, $\mathrm{kg}$ & 9,669 & 9,479 & 10,503 & 10,373 \\
\hline
\end{tabular}




\begin{tabular}{|c|c|c|}
\hline MFPV Batch & MFPV-A105 & MFPV-B105 \\
\hline \multicolumn{3}{|l|}{ Input } \\
\hline Source CRV $(d)$ & CRV-A12 & CRV-A12 \\
\hline CRV transfer \# $(m)$ & 3 & 4 \\
\hline CRV volume before calculation, $\mathrm{L}$ & 32224.5 & 23771.1 \\
\hline MFPV heel volume, L & 6530 & 6405 \\
\hline Sampling line flush water volume, $\mathrm{L}$ & NA & NA \\
\hline CRV-MFPV line flush water volume, L & 24.6 & 24.6 \\
\hline Calculated dilution factor & 0.99719 & 0.99615 \\
\hline Total mass of glass oxides in CRV waste, $\mathrm{g} / \mathrm{L}$ & 258.268 & 257.999 \\
\hline \multicolumn{3}{|l|}{ Step 1 Calculation } \\
\hline Minimum $\mathrm{Na}_{2} \mathrm{O}$ loading from formulation rules & $17.11 \%$ & $17.11 \%$ \\
\hline Limiting rule or component & $\mathrm{Cr} 2 \mathrm{O} 3$ & $\mathrm{Cr} 2 \mathrm{O} 3$ \\
\hline Initial waste loading & $20.858 \%$ & $20.858 \%$ \\
\hline g oxides/L waste & 1238.19 & 1236.90 \\
\hline g glass $/ \mathrm{L}$ waste & 1231.27 & 1229.99 \\
\hline Manual adjustment of GFC component & $+0.23 \mathrm{wt}^{2} \% \mathrm{Li} 2 \mathrm{O}$ & $+0.23 \mathrm{wt} \% \mathrm{Li} 2 \mathrm{O}$ \\
\hline Target waste transfer volume, $\mathrm{L}$ & 8461.1 & 8480.2 \\
\hline GFC volume, $\mathrm{L}$ & 3650.3 & 3654.8 \\
\hline Dust control water volume, $\mathrm{L}$ & 368.9 & 369.4 \\
\hline Sucrose volume, L & 202.9 & 203.2 \\
\hline CRV-MFPV line flush volume, $\mathrm{L}$ & 37.5 & 66.2 \\
\hline Sampling line flush volume, $\mathrm{L}$ & 175.3 & 247.2 \\
\hline Dilution water volume, $\mathrm{L}$ & 0.0 & 0.0 \\
\hline Calculated MFPV working volume, L & 19426.0 & 19426.0 \\
\hline Target Na Molarity, M & 7.061 & 7.061 \\
\hline Dilution water volume, $\mathrm{L}$ & -849.9 & -960.3 \\
\hline Na Molarity of CRV waste, M & 6.838 & 6.830 \\
\hline (Target) Kyanite mass, kg & 827.38 & 828.39 \\
\hline Boric Acid, kg & 1852.56 & 1854.82 \\
\hline Wollastonite, $\mathrm{kg}$ & 791.58 & 792.54 \\
\hline Hematite, $\mathrm{kg}$ & 556.22 & 556.90 \\
\hline Li Carbonate, $\mathrm{kg}$ & 158.06 & 158.25 \\
\hline Olivine, $\mathrm{kg}$ & 319.03 & 319.42 \\
\hline $\mathrm{Na}$ Carbonate, $\mathrm{kg}$ & 0.00 & 0.00 \\
\hline Silica, $\mathrm{kg}$ & 3730.94 & 3735.49 \\
\hline Rutile, $\mathrm{kg}$ & 148.24 & 148.42 \\
\hline Zincite, $\mathrm{kg}$ & 367.20 & 367.65 \\
\hline Zircon, $\mathrm{kg}$ & 472.28 & 472.85 \\
\hline Sucrose, $\mathrm{kg}$ & 314.31 & 314.70 \\
\hline Total, $\mathrm{kg}$ & 9537.79 & 9549.42 \\
\hline Glass mass per L feed before retention, $\mathrm{g} / \mathrm{L}$ & 813.2 & 806.4 \\
\hline Glass mass per L feed after retention, $\mathrm{g} / \mathrm{L}$ & 808.7 & 801.9 \\
\hline Final Waste loading, before retention & $20.837 \%$ & $20.837 \%$ \\
\hline Glass mass per batch, before retention, $\mathrm{kg}$ & 10487.4 & 10500.2 \\
\hline Glass mass per batch, after retention, $\mathrm{kg}$ & 10428.7 & 10441.4 \\
\hline \multicolumn{3}{|l|}{ Step 2 Calculation } \\
\hline Actual waste transfer volume assumed, $\mathrm{L}$ & 8478.0 & 8488.7 \\
\hline CRV-MFPV line flush volume, $\mathrm{L}$ & 37.5 & 66.2 \\
\hline GFC volume, L & 3657.6 & 3658.4 \\
\hline Dust control water volume, $\mathrm{L}$ & 369.7 & 369.8 \\
\hline
\end{tabular}




\begin{tabular}{|c|c|c|}
\hline MFPV Batch & MFPV-A105 & MFPV-B105 \\
\hline Sucrose volume, L & 203.3 & 203.4 \\
\hline Sampling line flush volume, $\mathrm{L}$ & 175.3 & 247.2 \\
\hline Dilution water volume, L & 0.0 & 0.0 \\
\hline Calculated MFPV working volume, $\mathrm{L}$ & 19451.4 & 19438.7 \\
\hline Difference in volume, $\mathrm{L}$ & 25.4 & 12.7 \\
\hline Dilution water volume, $\mathrm{L}$ & -851.2 & -960.9 \\
\hline (Calculated) Kyanite mass, $\mathrm{kg}$ & 829.04 & 829.22 \\
\hline Boric Acid, $\mathrm{kg}$ & 1856.27 & 1856.67 \\
\hline Wollastonite, $\mathrm{kg}$ & 793.16 & 793.33 \\
\hline Hematite, $\mathrm{kg}$ & 557.33 & 557.45 \\
\hline Li Carbonate, $\mathrm{kg}$ & 158.37 & 158.41 \\
\hline Olivine, $\mathrm{kg}$ & 319.67 & 319.74 \\
\hline $\mathrm{Na}$ Carbonate, $\mathrm{kg}$ & 0.00 & 0.00 \\
\hline Silica, $\mathrm{kg}$ & 3738.41 & 3739.22 \\
\hline Rutile, $\mathrm{kg}$ & 148.53 & 148.57 \\
\hline Zincite, $\mathrm{kg}$ & 367.93 & 368.01 \\
\hline Zircon, kg & 473.22 & 473.32 \\
\hline Sucrose, $\mathrm{kg}$ & 314.94 & 315.01 \\
\hline Total, $\mathrm{kg}$ & 9556.87 & 9558.96 \\
\hline \multicolumn{3}{|l|}{ Step 3 Calculation } \\
\hline (Assumed as actual) Kyanite mass, $\mathrm{kg}$ & 829.4 & 829.3 \\
\hline Boric Acid, kg & 1855.9 & 1856.7 \\
\hline Wollastonite, $\mathrm{kg}$ & 793.3 & 793.4 \\
\hline Hematite, $\mathrm{kg}$ & 557.2 & 557.5 \\
\hline Li Carbonate, $\mathrm{kg}$ & 158.3 & 158.3 \\
\hline Olivine, $\mathrm{kg}$ & 319.8 & 319.8 \\
\hline $\mathrm{Na}$ Carbonate, $\mathrm{kg}$ & 0.0 & 0.0 \\
\hline Silica, $\mathrm{kg}$ & 3738.7 & 3739.3 \\
\hline Rutile, $\mathrm{kg}$ & 148.6 & 148.6 \\
\hline Zincite, $\mathrm{kg}$ & 367.8 & 368.0 \\
\hline Zircon, $\mathrm{kg}$ & 473.2 & 473.2 \\
\hline Sucrose, $\mathrm{kg}$ & 315.0 & 315.1 \\
\hline Total, kg & 9557.2 & 9559.2 \\
\hline Transfer waste volume, $\mathrm{L}$ & 8478.0 & 8488.7 \\
\hline Dust control water volume, $\mathrm{L}$ & 369.7 & 369.8 \\
\hline CRV-MFPV line flush volume, $\mathrm{L}$ & 37.5 & 66.2 \\
\hline Sampling line flush volume, $\mathrm{L}$ & 175.3 & 247.2 \\
\hline Dilution water volume, $\mathrm{L}$ & 0.0 & 0.0 \\
\hline GFC volume, L & 3657.6 & 3658.5 \\
\hline Sucrose volume, $\mathrm{L}$ & 203.4 & 203.4 \\
\hline Calculated MFPV working volume, $\mathrm{L}$ & 19451.4 & 19438.8 \\
\hline Glass mass per L feed before retention, $\mathrm{g} / \mathrm{L}$ & 813.3 & 806.4 \\
\hline Glass mass per L feed after retention, $\mathrm{g} / \mathrm{L}$ & 808.7 & 801.9 \\
\hline Mass of waste oxides per batch, $\mathrm{kg}$ & $2,189.6$ & $2,190.1$ \\
\hline Mass of GFC oxides per batch, $\mathrm{kg}$ & $8,319.2$ & $8,320.8$ \\
\hline Waste loading for Step 3 & $20.836 \%$ & $20.836 \%$ \\
\hline Mass of glass before retention, $\mathrm{kg}$ & 10,509 & 10,511 \\
\hline Mass of glass after retention, $\mathrm{kg}$ & 10,450 & 10,452 \\
\hline
\end{tabular}


Table B-9. Waste and Final Glass Compositions and SD for Glass Composition in 10 Example MFPV Batches

\begin{tabular}{|c|c|c|c|c|c|c|}
\hline \multirow{2}{*}{$\begin{array}{l}\text { Batch } \\
\text { Comp }\end{array}$} & \multicolumn{3}{|c|}{ MFPV-A101 } & \multicolumn{3}{|c|}{ MFPV-B101 } \\
\hline & Waste & Glass & Glass SD & Waste & Glass & Glass SD \\
\hline $\mathrm{Ac} 2 \mathrm{O} 3$ & $2.6471 \mathrm{E}-13$ & $6.1851 \mathrm{E}-14$ & $4.4618 \mathrm{E}-15$ & $2.6471 \mathrm{E}-13$ & $6.1849 \mathrm{E}-14$ & $4.4677 \mathrm{E}-15$ \\
\hline $\mathrm{Ag} 2 \mathrm{O}$ & $1.3045 \mathrm{E}-06$ & $2.9895 \mathrm{E}-07$ & $3.6975 \mathrm{E}-08$ & $1.3045 \mathrm{E}-06$ & 2.9894E-07 & $3.7303 \mathrm{E}-08$ \\
\hline $\mathrm{A} 12 \mathrm{O} 3$ & $7.0410 \mathrm{E}-02$ & $6.1249 \mathrm{E}-02$ & $1.1848 \mathrm{E}-03$ & $7.0410 \mathrm{E}-02$ & $6.1238 \mathrm{E}-02$ & $1.2159 \mathrm{E}-03$ \\
\hline $\mathrm{Am} 2 \mathrm{O} 3$ & $7.4775 \mathrm{E}-10$ & $1.7136 \mathrm{E}-10$ & $1.3066 \mathrm{E}-11$ & $7.4775 \mathrm{E}-10$ & $1.7135 \mathrm{E}-10$ & $1.2692 \mathrm{E}-11$ \\
\hline As2O5 & $6.8805 \mathrm{E}-06$ & $1.2433 \mathrm{E}-06$ & $3.2541 \mathrm{E}-07$ & $6.8805 \mathrm{E}-06$ & $1.2433 \mathrm{E}-06$ & $3.2158 \mathrm{E}-07$ \\
\hline $\mathrm{B} 2 \mathrm{O} 3$ & $2.0692 \mathrm{E}-04$ & 9.9439E-02 & $1.6440 \mathrm{E}-03$ & $2.0692 \mathrm{E}-04$ & $9.9463 \mathrm{E}-02$ & $1.6529 \mathrm{E}-03$ \\
\hline $\mathrm{BaO}$ & $1.1246 \mathrm{E}-06$ & $2.6279 \mathrm{E}-07$ & $2.5200 \mathrm{E}-08$ & $1.1246 \mathrm{E}-06$ & $2.6278 \mathrm{E}-07$ & $2.5305 \mathrm{E}-08$ \\
\hline $\mathrm{BeO}$ & 5.4699E-06 & $1.2781 \mathrm{E}-06$ & 6.6004E-08 & $5.4699 \mathrm{E}-06$ & $1.2780 \mathrm{E}-06$ & $6.5164 \mathrm{E}-08$ \\
\hline $\mathrm{Bi} 2 \mathrm{O} 3$ & $1.9262 \mathrm{E}-05$ & 4.4142E-06 & $3.2805 \mathrm{E}-07$ & $1.9262 \mathrm{E}-05$ & 4.4140E-06 & 4.2971E-07 \\
\hline $\mathrm{CaO}$ & $1.8872 \mathrm{E}-04$ & $2.4809 \mathrm{E}-02$ & $6.6487 \mathrm{E}-04$ & $1.8872 \mathrm{E}-04$ & $2.4799 \mathrm{E}-02$ & 6.5394E-04 \\
\hline $\mathrm{CdO}$ & $3.4756 \mathrm{E}-06$ & 4.3255E-06 & $1.3246 \mathrm{E}-06$ & $3.4756 \mathrm{E}-06$ & 4.3257E-06 & $1.3349 \mathrm{E}-06$ \\
\hline $\mathrm{Ce} 2 \mathrm{O} 3$ & $1.0629 \mathrm{E}-06$ & $2.4837 \mathrm{E}-07$ & $3.6910 \mathrm{E}-08$ & $1.0629 \mathrm{E}-06$ & $2.4836 \mathrm{E}-07$ & $3.6792 \mathrm{E}-08$ \\
\hline $\mathrm{Cl}$ & $1.0657 \mathrm{E}-02$ & $1.3588 \mathrm{E}-03$ & 3.7987E-04 & $1.0657 \mathrm{E}-02$ & $1.3587 \mathrm{E}-03$ & $3.8397 \mathrm{E}-04$ \\
\hline $\mathrm{Cm} 2 \mathrm{O} 3$ & $4.1731 \mathrm{E}-13$ & $9.7510 \mathrm{E}-14$ & $8.8478 \mathrm{E}-15$ & 4.1731E-13 & $9.7506 \mathrm{E}-14$ & $8.6969 \mathrm{E}-15$ \\
\hline $\mathrm{CoO}$ & $1.9555 \mathrm{E}-06$ & $4.5692 \mathrm{E}-07$ & $6.8675 \mathrm{E}-08$ & $1.9555 \mathrm{E}-06$ & $4.5690 \mathrm{E}-07$ & $6.9227 \mathrm{E}-08$ \\
\hline $\mathrm{Cr} 2 \mathrm{O} 3$ & $3.4310 \mathrm{E}-03$ & 8.6109E-04 & $6.3918 \mathrm{E}-05$ & $3.4310 \mathrm{E}-03$ & 8.6108E-04 & $6.2643 \mathrm{E}-05$ \\
\hline $\mathrm{Cs} 2 \mathrm{O}$ & $1.3254 \mathrm{E}-08$ & $2.7298 \mathrm{E}-09$ & $3.8148 \mathrm{E}-10$ & $1.3254 \mathrm{E}-08$ & $2.7297 \mathrm{E}-09$ & $3.8097 \mathrm{E}-10$ \\
\hline $\mathrm{CuO}$ & $3.6158 \mathrm{E}-06$ & $8.4486 \mathrm{E}-07$ & $1.2826 \mathrm{E}-07$ & $3.6158 \mathrm{E}-06$ & 8.4483E-07 & $1.2615 \mathrm{E}-07$ \\
\hline $\mathrm{Eu} 2 \mathrm{O} 3$ & $1.3553 \mathrm{E}-10$ & $3.1669 \mathrm{E}-11$ & $1.5183 \mathrm{E}-12$ & $1.3553 \mathrm{E}-10$ & $3.1667 \mathrm{E}-11$ & $1.5058 \mathrm{E}-12$ \\
\hline $\mathrm{F}$ & 4.4190E-03 & $7.5571 \mathrm{E}-04$ & $1.3883 \mathrm{E}-04$ & 4.4190E-03 & $7.5568 \mathrm{E}-04$ & $1.3835 \mathrm{E}-04$ \\
\hline $\mathrm{Fe} 2 \mathrm{O} 3$ & $7.2215 \mathrm{E}-05$ & 5.5172E-02 & $9.7216 \mathrm{E}-04$ & 7.2215E-05 & $5.5175 \mathrm{E}-02$ & $9.7787 \mathrm{E}-04$ \\
\hline $\mathrm{Gd} 2 \mathrm{O} 3$ & $0.0000 \mathrm{E}+00$ & $0.0000 \mathrm{E}+00$ & $0.0000 \mathrm{E}+00$ & $0.0000 \mathrm{E}+00$ & $0.0000 \mathrm{E}+00$ & $0.0000 \mathrm{E}+00$ \\
\hline $\mathrm{HgO}$ & $3.8970 \mathrm{E}-07$ & $0.0000 \mathrm{E}+00$ & $0.0000 \mathrm{E}+00$ & $3.8970 \mathrm{E}-07$ & $0.0000 \mathrm{E}+00$ & $0.0000 \mathrm{E}+00$ \\
\hline $\mathrm{I}$ & $2.5808 \mathrm{E}-06$ & $3.0817 \mathrm{E}-07$ & $1.0885 \mathrm{E}-07$ & $2.5808 \mathrm{E}-06$ & $3.0816 \mathrm{E}-07$ & $1.0893 \mathrm{E}-07$ \\
\hline $\mathrm{K} 2 \mathrm{O}$ & $6.2008 \mathrm{E}-02$ & $1.4030 \mathrm{E}-02$ & $7.8322 \mathrm{E}-04$ & $6.2008 \mathrm{E}-02$ & $1.4029 \mathrm{E}-02$ & $7.9140 \mathrm{E}-04$ \\
\hline $\mathrm{La} 2 \mathrm{O} 3$ & $1.6415 \mathrm{E}-06$ & $3.8355 \mathrm{E}-07$ & $2.7446 \mathrm{E}-08$ & $1.6415 \mathrm{E}-06$ & $3.8354 \mathrm{E}-07$ & $2.7598 \mathrm{E}-08$ \\
\hline $\mathrm{Li} 2 \mathrm{O}$ & $1.3074 \mathrm{E}-06$ & $1.9057 \mathrm{E}-03$ & $3.1946 \mathrm{E}-05$ & $1.3074 \mathrm{E}-06$ & $1.8008 \mathrm{E}-03$ & $3.0298 \mathrm{E}-05$ \\
\hline $\mathrm{MgO}$ & 8.3024E-05 & $1.4866 \mathrm{E}-02$ & $2.9267 \mathrm{E}-04$ & $8.3024 \mathrm{E}-05$ & $1.4872 \mathrm{E}-02$ & $2.9269 \mathrm{E}-04$ \\
\hline $\mathrm{MnO}$ & $6.4159 \mathrm{E}-06$ & $1.3384 \mathrm{E}-04$ & $3.4375 \mathrm{E}-05$ & $6.4159 \mathrm{E}-06$ & $1.3382 \mathrm{E}-04$ & $3.4246 \mathrm{E}-05$ \\
\hline $\mathrm{MoO} 3$ & $5.4477 \mathrm{E}-05$ & $1.2484 \mathrm{E}-05$ & $9.3488 \mathrm{E}-07$ & $5.4477 \mathrm{E}-05$ & $1.2484 \mathrm{E}-05$ & $9.3213 \mathrm{E}-07$ \\
\hline $\mathrm{Na} 2 \mathrm{O}$ & $8.2030 \mathrm{E}-01$ & $1.9088 \mathrm{E}-01$ & 1.1599E-02 & $8.2030 \mathrm{E}-01$ & $1.9087 \mathrm{E}-01$ & $1.1644 \mathrm{E}-02$ \\
\hline $\mathrm{Nb} 2 \mathrm{O} 5$ & $3.2676 \mathrm{E}-08$ & 7.6352E-09 & $5.4174 \mathrm{E}-10$ & $3.2676 \mathrm{E}-08$ & 7.6349E-09 & $5.4752 \mathrm{E}-10$ \\
\hline $\mathrm{Nd} 2 \mathrm{O} 3$ & $5.2552 \mathrm{E}-06$ & $1.2279 \mathrm{E}-06$ & $1.2103 \mathrm{E}-07$ & 5.2552E-06 & $1.2279 \mathrm{E}-06$ & $1.2054 \mathrm{E}-07$ \\
\hline $\mathrm{NiO}$ & $1.2940 \mathrm{E}-04$ & $1.4266 \mathrm{E}-04$ & $1.7514 \mathrm{E}-05$ & $1.2940 \mathrm{E}-04$ & $1.4270 \mathrm{E}-04$ & $1.7210 \mathrm{E}-05$ \\
\hline $\mathrm{NpO} 2$ & $5.0777 \mathrm{E}-07$ & $1.1865 \mathrm{E}-07$ & $6.0525 \mathrm{E}-09$ & $5.0777 \mathrm{E}-07$ & $1.1864 \mathrm{E}-07$ & 5.9732E-09 \\
\hline $\mathrm{P} 2 \mathrm{O} 5$ & $7.8152 \mathrm{E}-03$ & $1.9765 \mathrm{E}-03$ & $1.3468 \mathrm{E}-04$ & 7.8152E-03 & $1.9764 \mathrm{E}-03$ & $1.3627 \mathrm{E}-04$ \\
\hline $\mathrm{Pa} 2 \mathrm{O} 5$ & $1.1893 \mathrm{E}-09$ & $2.7788 \mathrm{E}-10$ & $8.3073 \mathrm{E}-11$ & $1.1893 \mathrm{E}-09$ & $2.7787 \mathrm{E}-10$ & $8.1826 \mathrm{E}-11$ \\
\hline $\mathrm{PbO}$ & $1.3603 \mathrm{E}-04$ & 3.2069E-05 & $3.1069 \mathrm{E}-06$ & $1.3603 \mathrm{E}-04$ & $3.2067 \mathrm{E}-05$ & $3.0737 \mathrm{E}-06$ \\
\hline $\mathrm{PdO}$ & $3.2219 \mathrm{E}-05$ & $7.5282 \mathrm{E}-06$ & $7.2562 \mathrm{E}-07$ & $3.2219 \mathrm{E}-05$ & $7.5279 \mathrm{E}-06$ & $7.2577 \mathrm{E}-07$ \\
\hline $\operatorname{Pr} 2 \mathrm{O} 3$ & 4.6099E-08 & $1.0771 \mathrm{E}-08$ & $1.0262 \mathrm{E}-09$ & 4.6099E-08 & $1.0771 \mathrm{E}-08$ & $1.0562 \mathrm{E}-09$ \\
\hline $\mathrm{PuO} 2$ & $3.7061 \mathrm{E}-08$ & $8.6596 \mathrm{E}-09$ & $4.4231 \mathrm{E}-10$ & $3.7061 \mathrm{E}-08$ & $8.6592 \mathrm{E}-09$ & $4.4179 \mathrm{E}-10$ \\
\hline $\mathrm{RaO}$ & $2.0280 \mathrm{E}-11$ & $3.6647 \mathrm{E}-12$ & $9.6776 \mathrm{E}-13$ & $2.0280 \mathrm{E}-11$ & $3.6645 \mathrm{E}-12$ & $9.6176 \mathrm{E}-13$ \\
\hline $\mathrm{Rb} 2 \mathrm{O}$ & $6.5061 \mathrm{E}-06$ & $1.4910 \mathrm{E}-06$ & $2.2412 \mathrm{E}-07$ & $6.5061 \mathrm{E}-06$ & $1.4909 \mathrm{E}-06$ & $2.2499 \mathrm{E}-07$ \\
\hline $\mathrm{Rh} 2 \mathrm{O} 3$ & $1.4443 \mathrm{E}-05$ & $3.3748 \mathrm{E}-06$ & $1.7223 \mathrm{E}-07$ & $1.4443 \mathrm{E}-05$ & $3.3747 \mathrm{E}-06$ & $1.7546 \mathrm{E}-07$ \\
\hline $\mathrm{RuO} 2$ & $6.9023 \mathrm{E}-05$ & $1.5818 \mathrm{E}-05$ & $8.8424 \mathrm{E}-07$ & $6.9023 \mathrm{E}-05$ & $1.5817 \mathrm{E}-05$ & 8.7594E-07 \\
\hline $\mathrm{SO} 3$ & $1.5515 \mathrm{E}-02$ & $3.0970 \mathrm{E}-03$ & $3.3241 \mathrm{E}-04$ & $1.5515 \mathrm{E}-02$ & $3.0968 \mathrm{E}-03$ & $3.2700 \mathrm{E}-04$ \\
\hline $\mathrm{Sb} 2 \mathrm{O} 3$ & $1.4661 \mathrm{E}-06$ & $2.6493 \mathrm{E}-07$ & 7.0143E-08 & $1.4661 \mathrm{E}-06$ & $2.6491 \mathrm{E}-07$ & $6.8393 \mathrm{E}-08$ \\
\hline
\end{tabular}




\begin{tabular}{|c|c|c|c|c|c|c|}
\hline \multirow{2}{*}{$\begin{array}{c}\text { Batch } \\
\mathrm{SeO} 2 \\
\end{array}$} & \multicolumn{3}{|c|}{ MFPV-A101 } & \multicolumn{3}{|c|}{ MFPV-B101 } \\
\hline & $1.1936 \mathrm{E}-05$ & $2.1569 \mathrm{E}-06$ & $5.4927 \mathrm{E}-07$ & $1.1936 \mathrm{E}-05$ & $2.1568 \mathrm{E}-06$ & $5.6620 \mathrm{E}-07$ \\
\hline $\mathrm{SiO} 2$ & 3.9957E-03 & 4.4984E-01 & $7.2343 \mathrm{E}-03$ & $3.9957 \mathrm{E}-03$ & 4.4993E-01 & $7.2505 \mathrm{E}-03$ \\
\hline $\mathrm{Sm} 2 \mathrm{O} 3$ & $2.9870 \mathrm{E}-07$ & 6.9794E-08 & 8.6608E-09 & $2.9870 \mathrm{E}-07$ & 6.9792E-08 & $8.5223 \mathrm{E}-09$ \\
\hline $\mathrm{SnO} 2$ & $2.6572 \mathrm{E}-07$ & 6.2089E-08 & $6.0421 \mathrm{E}-09$ & $2.6572 \mathrm{E}-07$ & $6.2086 \mathrm{E}-08$ & $5.9870 \mathrm{E}-09$ \\
\hline $\mathrm{SrO}$ & 5.5799E-07 & $1.3038 \mathrm{E}-07$ & 6.7076E-09 & $5.5799 \mathrm{E}-07$ & $1.3037 \mathrm{E}-07$ & 6.6832E-09 \\
\hline $\mathrm{Ta} 2 \mathrm{O} 5$ & $1.9032 \mathrm{E}-07$ & 4.4469E-08 & 4.2870E-09 & $1.9032 \mathrm{E}-07$ & $4.4468 \mathrm{E}-08$ & $4.2755 \mathrm{E}-09$ \\
\hline Tc2O7 & $2.0353 \mathrm{E}-05$ & $2.0530 \mathrm{E}-06$ & 6.8859E-07 & $2.0353 \mathrm{E}-05$ & $2.0529 \mathrm{E}-06$ & $7.0596 \mathrm{E}-07$ \\
\hline $\mathrm{TeO} 2$ & $5.8967 \mathrm{E}-07$ & $1.0656 \mathrm{E}-07$ & $2.7969 \mathrm{E}-08$ & $5.8967 \mathrm{E}-07$ & $1.0655 \mathrm{E}-07$ & $2.8249 \mathrm{E}-08$ \\
\hline $\mathrm{ThO} 2$ & $1.7432 \mathrm{E}-05$ & $4.0732 \mathrm{E}-06$ & $6.1610 \mathrm{E}-07$ & $1.7432 \mathrm{E}-05$ & $4.0730 \mathrm{E}-06$ & $6.0225 \mathrm{E}-07$ \\
\hline $\mathrm{TiO} 2$ & $1.8686 \mathrm{E}-05$ & $1.4038 \mathrm{E}-02$ & 2.7022E-04 & $1.8686 \mathrm{E}-05$ & $1.4045 \mathrm{E}-02$ & $2.7154 \mathrm{E}-04$ \\
\hline $\mathrm{T} 12 \mathrm{O}$ & 4.0163E-06 & 7.2577E-07 & $1.6305 \mathrm{E}-07$ & $4.0163 \mathrm{E}-06$ & 7.2574E-07 & $1.6131 \mathrm{E}-07$ \\
\hline UO3 & $1.6809 \mathrm{E}-04$ & $5.9602 \mathrm{E}-05$ & 4.3474E-06 & $1.6809 \mathrm{E}-04$ & 5.9602E-05 & $4.3436 \mathrm{E}-06$ \\
\hline $\mathrm{V} 2 \mathrm{O} 5$ & $2.5785 \mathrm{E}-06$ & 5.9907E-05 & $1.9505 \mathrm{E}-05$ & $2.5785 \mathrm{E}-06$ & 5.9937E-05 & $1.9800 \mathrm{E}-05$ \\
\hline WO3 & $5.3711 \mathrm{E}-05$ & $1.2550 \mathrm{E}-05$ & $6.4042 \mathrm{E}-07$ & $5.3711 \mathrm{E}-05$ & $1.2550 \mathrm{E}-05$ & $6.4478 \mathrm{E}-07$ \\
\hline Y2O3 & $2.9525 \mathrm{E}-06$ & $6.8989 \mathrm{E}-07$ & $1.0319 \mathrm{E}-07$ & $2.9525 \mathrm{E}-06$ & $6.8986 \mathrm{E}-07$ & $1.0619 \mathrm{E}-07$ \\
\hline $\mathrm{ZnO}$ & $5.8300 \mathrm{E}-05$ & $3.5073 \mathrm{E}-02$ & $5.6709 \mathrm{E}-04$ & $5.8300 \mathrm{E}-05$ & $3.5075 \mathrm{E}-02$ & $5.7030 \mathrm{E}-04$ \\
\hline $\mathrm{ZrO} 2$ & $3.2080 \mathrm{E}-05$ & $3.0137 \mathrm{E}-02$ & $5.1482 \mathrm{E}-04$ & $3.2080 \mathrm{E}-05$ & $3.0141 \mathrm{E}-02$ & $5.1925 \mathrm{E}-04$ \\
\hline SUM & $1.0000 \mathrm{E}+00$ & $1.0000 \mathrm{E}+00$ & NA & $1.0000 \mathrm{E}+00$ & $1.0000 \mathrm{E}+00$ & NA \\
\hline $\operatorname{Rad}$ & mCi/g oxides & $\mathrm{mCi} / \mathrm{g}$ glass & $\mathrm{mCi} / \mathrm{g}$ glass & mCi/g oxides & $\mathrm{mCi} / \mathrm{g}$ glass & $\mathrm{mCi} / \mathrm{g}$ glass \\
\hline $59 \mathrm{Ni}$ & $1.4685 \mathrm{E}-06$ & $3.4129 \mathrm{E}-07$ & $2.4466 \mathrm{E}-08$ & $1.4685 \mathrm{E}-06$ & $3.4128 \mathrm{E}-07$ & $2.4552 \mathrm{E}-08$ \\
\hline $60 \mathrm{Co}$ & $2.3378 \mathrm{E}-06$ & $5.4625 \mathrm{E}-07$ & 2.8064E-08 & $2.3378 \mathrm{E}-06$ & $5.4623 \mathrm{E}-07$ & $2.8103 \mathrm{E}-08$ \\
\hline $63 \mathrm{Ni}$ & $1.3388 \mathrm{E}-04$ & $3.1115 \mathrm{E}-05$ & $2.2279 \mathrm{E}-06$ & $1.3388 \mathrm{E}-04$ & $3.1113 \mathrm{E}-05$ & $2.2151 \mathrm{E}-06$ \\
\hline 79Se & $5.4909 \mathrm{E}-06$ & $9.9224 \mathrm{E}-07$ & 2.1499E-07 & 5.4909E-06 & $9.9220 \mathrm{E}-07$ & $2.2354 \mathrm{E}-07$ \\
\hline $90 \mathrm{Sr}$ & $2.3845 \mathrm{E}-03$ & $5.5716 \mathrm{E}-04$ & 2.8693E-05 & $2.3845 \mathrm{E}-03$ & $5.5714 \mathrm{E}-04$ & $2.8694 \mathrm{E}-05$ \\
\hline $90 \mathrm{Y}$ & $2.3086 \mathrm{E}-03$ & $5.3943 \mathrm{E}-04$ & $2.8171 \mathrm{E}-05$ & $2.3086 \mathrm{E}-03$ & 5.3941E-04 & $2.7870 \mathrm{E}-05$ \\
\hline $93 \mathrm{mNb}$ & $5.4502 \mathrm{E}-03$ & $1.2735 \mathrm{E}-03$ & $9.0349 \mathrm{E}-05$ & $5.4502 \mathrm{E}-03$ & $1.2734 \mathrm{E}-03$ & $9.1322 \mathrm{E}-05$ \\
\hline $93 \mathrm{Zr}$ & $3.5849 \mathrm{E}-05$ & $8.3985 \mathrm{E}-06$ & $5.9083 \mathrm{E}-07$ & $3.5849 \mathrm{E}-05$ & $8.3981 \mathrm{E}-06$ & $6.0551 \mathrm{E}-07$ \\
\hline $99 \mathrm{Tc}$ & $2.2235 \mathrm{E}-04$ & $2.2428 \mathrm{E}-05$ & $7.5227 \mathrm{E}-06$ & $2.2235 \mathrm{E}-04$ & $2.2428 \mathrm{E}-05$ & $7.7125 \mathrm{E}-06$ \\
\hline $106 \mathrm{Ru}$ & $2.0408 \mathrm{E}-09$ & 4.6769E-10 & $4.5578 \mathrm{E}-11$ & $2.0408 \mathrm{E}-09$ & 4.6767E-10 & $4.6015 \mathrm{E}-11$ \\
\hline $113 \mathrm{mCd}$ & $2.6335 \mathrm{E}-05$ & $6.1534 \mathrm{E}-06$ & 4.4645E-07 & $2.6335 \mathrm{E}-05$ & $6.1531 \mathrm{E}-06$ & 4.4787E-07 \\
\hline $125 \mathrm{Sb}$ & $6.3608 \mathrm{E}-06$ & $1.1494 \mathrm{E}-06$ & $2.5101 \mathrm{E}-07$ & $6.3608 \mathrm{E}-06$ & $1.1494 \mathrm{E}-06$ & $2.4814 \mathrm{E}-07$ \\
\hline $126 \mathrm{Sn}$ & $6.0160 \mathrm{E}-06$ & $1.4057 \mathrm{E}-06$ & $1.3679 \mathrm{E}-07$ & $6.0160 \mathrm{E}-06$ & $1.4057 \mathrm{E}-06$ & $1.3555 \mathrm{E}-07$ \\
\hline $129 \mathrm{I}$ & $4.5629 \mathrm{E}-07$ & $5.4485 \mathrm{E}-08$ & $1.9243 \mathrm{E}-08$ & 4.5629E-07 & 5.4483E-08 & $1.9260 \mathrm{E}-08$ \\
\hline $134 \mathrm{Cs}$ & $1.0212 \mathrm{E}-09$ & $2.1033 \mathrm{E}-10$ & $3.8551 \mathrm{E}-11$ & $1.0212 \mathrm{E}-09$ & $2.1032 \mathrm{E}-10$ & $3.8364 \mathrm{E}-11$ \\
\hline $137 \mathrm{mBa}$ & 3.7691E-01 & 8.8069E-02 & $4.5725 \mathrm{E}-03$ & $3.7691 \mathrm{E}-01$ & $8.8065 \mathrm{E}-02$ & 4.5349E-03 \\
\hline $137 \mathrm{Cs}$ & $2.1760 \mathrm{E}-04$ & $4.4819 \mathrm{E}-05$ & $5.0779 \mathrm{E}-06$ & $2.1760 \mathrm{E}-04$ & $4.4817 \mathrm{E}-05$ & $5.0869 \mathrm{E}-06$ \\
\hline $151 \mathrm{Sm}$ & $6.7836 \mathrm{E}-03$ & $1.5851 \mathrm{E}-03$ & $1.9667 \mathrm{E}-04$ & $6.7836 \mathrm{E}-03$ & $1.5850 \mathrm{E}-03$ & $1.9355 \mathrm{E}-04$ \\
\hline $152 \mathrm{Eu}$ & $1.1522 \mathrm{E}-06$ & $2.6923 \mathrm{E}-07$ & $1.3796 \mathrm{E}-08$ & $1.1522 \mathrm{E}-06$ & 2.6922E-07 & $1.3696 \mathrm{E}-08$ \\
\hline $154 \mathrm{Eu}$ & $2.3853 \mathrm{E}-05$ & $5.5736 \mathrm{E}-06$ & $2.8811 \mathrm{E}-07$ & $2.3853 \mathrm{E}-05$ & 5.5734E-06 & $2.8500 \mathrm{E}-07$ \\
\hline $155 \mathrm{Eu}$ & $1.0666 \mathrm{E}-05$ & $2.4921 \mathrm{E}-06$ & $1.2616 \mathrm{E}-07$ & $1.0666 \mathrm{E}-05$ & $2.4920 \mathrm{E}-06$ & $1.2843 \mathrm{E}-07$ \\
\hline $226 \mathrm{Ra}$ & $1.8695 \mathrm{E}-08$ & 3.3783E-09 & $8.9244 \mathrm{E}-10$ & $1.8695 \mathrm{E}-08$ & 3.3782E-09 & $8.8703 \mathrm{E}-10$ \\
\hline $227 \mathrm{Ac}$ & $1.7313 \mathrm{E}-08$ & 4.0454E-09 & $2.9183 \mathrm{E}-10$ & $1.7313 \mathrm{E}-08$ & 4.0453E-09 & $2.9222 \mathrm{E}-10$ \\
\hline $228 \mathrm{Ra}$ & $7.2680 \mathrm{E}-09$ & $1.3134 \mathrm{E}-09$ & $4.8513 \mathrm{E}-10$ & $7.2680 \mathrm{E}-09$ & 1.3133E-09 & $4.6909 \mathrm{E}-10$ \\
\hline $229 \mathrm{Th}$ & $7.8921 \mathrm{E}-10$ & $1.8441 \mathrm{E}-10$ & $5.4186 \mathrm{E}-11$ & $7.8921 \mathrm{E}-10$ & $1.8440 \mathrm{E}-10$ & $5.4131 \mathrm{E}-11$ \\
\hline $231 \mathrm{~Pa}$ & $4.7880 \mathrm{E}-08$ & $1.1188 \mathrm{E}-08$ & $3.3445 \mathrm{E}-09$ & 4.7880E-08 & $1.1187 \mathrm{E}-08$ & $3.2943 \mathrm{E}-09$ \\
\hline $232 \mathrm{Th}$ & $1.6791 \mathrm{E}-09$ & $3.9235 \mathrm{E}-10$ & $2.8481 \mathrm{E}-11$ & $1.6791 \mathrm{E}-09$ & $3.9233 \mathrm{E}-10$ & $2.7921 \mathrm{E}-11$ \\
\hline $232 \mathrm{U}$ & $2.2715 \mathrm{E}-09$ & $5.3076 \mathrm{E}-10$ & $2.7295 \mathrm{E}-11$ & $2.2715 \mathrm{E}-09$ & $5.3074 \mathrm{E}-10$ & $2.7301 \mathrm{E}-11$ \\
\hline $233 \mathrm{U}$ & $1.0779 \mathrm{E}-07$ & $2.5187 \mathrm{E}-08$ & $1.2978 \mathrm{E}-09$ & $1.0779 \mathrm{E}-07$ & $2.5186 \mathrm{E}-08$ & $1.3053 \mathrm{E}-09$ \\
\hline $234 \mathrm{U}$ & $6.2532 \mathrm{E}-08$ & $1.4611 \mathrm{E}-08$ & $7.5277 \mathrm{E}-10$ & $6.2532 \mathrm{E}-08$ & 1.4611E-08 & $7.5550 \mathrm{E}-10$ \\
\hline $235 \mathrm{U}$ & 2.3599E-09 & $5.5142 \mathrm{E}-10$ & $3.9628 \mathrm{E}-11$ & $2.3599 \mathrm{E}-09$ & $5.5140 \mathrm{E}-10$ & $3.8998 \mathrm{E}-11$ \\
\hline
\end{tabular}




\begin{tabular}{|c|c|c|c|c|c|c||}
\hline Batch & \multicolumn{3}{|c|}{ MFPV-A101 } & \multicolumn{3}{c||}{ MFPV-B101 } \\
\hline $236 \mathrm{U}$ & $4.3489 \mathrm{E}-09$ & $1.0162 \mathrm{E}-09$ & $5.2242 \mathrm{E}-11$ & $4.3489 \mathrm{E}-09$ & $1.0161 \mathrm{E}-09$ & $5.1606 \mathrm{E}-11$ \\
\hline $237 \mathrm{~Np}$ & $3.1527 \mathrm{E}-07$ & $7.3666 \mathrm{E}-08$ & $3.7579 \mathrm{E}-09$ & $3.1527 \mathrm{E}-07$ & $7.3663 \mathrm{E}-08$ & $3.7087 \mathrm{E}-09$ \\
\hline $238 \mathrm{Pu}$ & $1.6388 \mathrm{E}-07$ & $3.8293 \mathrm{E}-08$ & $1.9700 \mathrm{E}-09$ & $1.6388 \mathrm{E}-07$ & $3.8291 \mathrm{E}-08$ & $1.9492 \mathrm{E}-09$ \\
\hline $238 \mathrm{U}$ & $4.6617 \mathrm{E}-08$ & $1.0893 \mathrm{E}-08$ & $7.8669 \mathrm{E}-10$ & $4.6617 \mathrm{E}-08$ & $1.0892 \mathrm{E}-08$ & $7.8698 \mathrm{E}-10$ \\
\hline $239 \mathrm{Pu}$ & $1.8964 \mathrm{E}-06$ & $4.4311 \mathrm{E}-07$ & $2.3118 \mathrm{E}-08$ & $1.8964 \mathrm{E}-06$ & $4.4309 \mathrm{E}-07$ & $2.3021 \mathrm{E}-08$ \\
\hline $240 \mathrm{Pu}$ & $4.6204 \mathrm{E}-07$ & $1.0796 \mathrm{E}-07$ & $7.6493 \mathrm{E}-09$ & $4.6204 \mathrm{E}-07$ & $1.0796 \mathrm{E}-07$ & $7.8820 \mathrm{E}-09$ \\
\hline $241 \mathrm{Am}$ & $2.3240 \mathrm{E}-06$ & $5.3257 \mathrm{E}-07$ & $4.0675 \mathrm{E}-08$ & $2.3240 \mathrm{E}-06$ & $5.3255 \mathrm{E}-07$ & $3.9518 \mathrm{E}-08$ \\
\hline $241 \mathrm{Pu}$ & $5.2457 \mathrm{E}-06$ & $1.2257 \mathrm{E}-06$ & $1.1890 \mathrm{E}-07$ & $5.2457 \mathrm{E}-06$ & $1.2257 \mathrm{E}-06$ & $1.1808 \mathrm{E}-07$ \\
\hline $242 \mathrm{Cm}$ & $1.1587 \mathrm{E}-08$ & $2.7073 \mathrm{E}-09$ & $1.9515 \mathrm{E}-10$ & $1.1587 \mathrm{E}-08$ & $2.7072 \mathrm{E}-09$ & $1.9353 \mathrm{E}-10$ \\
\hline $242 \mathrm{Pu}$ & $5.1020 \mathrm{E}-11$ & $1.1921 \mathrm{E}-11$ & $8.4942 \mathrm{E}-13$ & $5.1020 \mathrm{E}-11$ & $1.1921 \mathrm{E}-11$ & $8.4990 \mathrm{E}-13$ \\
\hline $243 \mathrm{Am}$ & $3.8261 \mathrm{E}-10$ & $8.7680 \mathrm{E}-11$ & $8.6280 \mathrm{E}-12$ & $3.8261 \mathrm{E}-10$ & $8.7677 \mathrm{E}-11$ & $8.5247 \mathrm{E}-12$ \\
\hline $243 \mathrm{Cm}$ & $1.3817 \mathrm{E}-09$ & $3.2285 \mathrm{E}-10$ & $3.0759 \mathrm{E}-11$ & $1.3817 \mathrm{E}-09$ & $3.2284 \mathrm{E}-10$ & $3.1243 \mathrm{E}-11$ \\
\hline $244 \mathrm{Cm}$ & $2.8185 \mathrm{E}-08$ & $6.5856 \mathrm{E}-09$ & $6.3814 \mathrm{E}-10$ & $2.8185 \mathrm{E}-08$ & $6.5853 \mathrm{E}-09$ & $6.2770 \mathrm{E}-10$ \\
\hline $\mathrm{TRU}^{(\mathrm{a})}$ & $5.1915 \mathrm{E}-06$ & $1.2026 \mathrm{E}-06$ & $4.7601 \mathrm{E}-08$ & $5.1915 \mathrm{E}-06$ & $1.2026 \mathrm{E}-06$ & $4.6602 \mathrm{E}-08$ \\
\hline
\end{tabular}

\begin{tabular}{|c|c|c|c|c|c|c|}
\hline \multirow{2}{*}{$\begin{array}{l}\text { Batch } \\
\text { Comp }\end{array}$} & \multicolumn{3}{|c|}{ MFPV-A102 } & \multicolumn{3}{|c|}{ MFPV-B102 } \\
\hline & Waste & Glass & Glass SD & Waste & Glass & Glass SD \\
\hline $\mathrm{Ac} 2 \mathrm{O} 3$ & $2.6471 \mathrm{E}-13$ & $6.1851 \mathrm{E}-14$ & $4.4240 \mathrm{E}-15$ & $2.6740 \mathrm{E}-13$ & 6.4922E-14 & $4.6356 \mathrm{E}-15$ \\
\hline $\mathrm{Ag} 2 \mathrm{O}$ & $1.3045 \mathrm{E}-06$ & $2.9895 \mathrm{E}-07$ & $3.6630 \mathrm{E}-08$ & $1.3024 \mathrm{E}-06$ & $3.1013 \mathrm{E}-07$ & $3.8242 \mathrm{E}-08$ \\
\hline $\mathrm{A} 12 \mathrm{O} 3$ & $7.0410 \mathrm{E}-02$ & $6.1258 \mathrm{E}-02$ & $1.1936 \mathrm{E}-03$ & 7.0698E-02 & $6.1248 \mathrm{E}-02$ & $1.2034 \mathrm{E}-03$ \\
\hline $\mathrm{Am} 2 \mathrm{O} 3$ & $7.4775 \mathrm{E}-10$ & $1.7136 \mathrm{E}-10$ & $1.2879 \mathrm{E}-11$ & $7.1244 \mathrm{E}-10$ & $1.6965 \mathrm{E}-10$ & $1.2354 \mathrm{E}-11$ \\
\hline As2O5 & $6.8805 \mathrm{E}-06$ & $1.2433 \mathrm{E}-06$ & $3.2701 \mathrm{E}-07$ & $6.7267 \mathrm{E}-06$ & $1.2631 \mathrm{E}-06$ & $3.2675 \mathrm{E}-07$ \\
\hline $\mathrm{B} 2 \mathrm{O} 3$ & $2.0692 \mathrm{E}-04$ & 9.9463E-02 & $1.6993 \mathrm{E}-03$ & $2.2365 \mathrm{E}-04$ & $9.9481 \mathrm{E}-02$ & $1.6928 \mathrm{E}-03$ \\
\hline $\mathrm{BaO}$ & $1.1246 \mathrm{E}-06$ & $2.6278 \mathrm{E}-07$ & $2.5250 \mathrm{E}-08$ & $1.0982 \mathrm{E}-06$ & $2.6663 \mathrm{E}-07$ & $2.5366 \mathrm{E}-08$ \\
\hline $\mathrm{BeO}$ & $5.4699 \mathrm{E}-06$ & $1.2781 \mathrm{E}-06$ & $6.5620 \mathrm{E}-08$ & $5.5230 \mathrm{E}-06$ & $1.3409 \mathrm{E}-06$ & $6.7622 \mathrm{E}-08$ \\
\hline $\mathrm{Bi} 2 \mathrm{O} 3$ & $1.9262 \mathrm{E}-05$ & 4.4141E-06 & $4.3670 \mathrm{E}-07$ & $1.8438 \mathrm{E}-05$ & 4.3904E-06 & $4.3051 \mathrm{E}-07$ \\
\hline $\mathrm{CaO}$ & $1.8872 \mathrm{E}-04$ & $2.4808 \mathrm{E}-02$ & $6.6220 \mathrm{E}-04$ & $1.9217 \mathrm{E}-04$ & $2.2049 \mathrm{E}-02$ & $5.9266 \mathrm{E}-04$ \\
\hline $\mathrm{CdO}$ & $3.4756 \mathrm{E}-06$ & $4.3266 \mathrm{E}-06$ & 1.3389E-06 & $3.5039 \mathrm{E}-06$ & $4.3668 \mathrm{E}-06$ & $1.3459 \mathrm{E}-06$ \\
\hline $\mathrm{Ce} 2 \mathrm{O} 3$ & $1.0629 \mathrm{E}-06$ & $2.4836 \mathrm{E}-07$ & $3.7648 \mathrm{E}-08$ & $1.0114 \mathrm{E}-06$ & $2.4556 \mathrm{E}-07$ & $3.7339 \mathrm{E}-08$ \\
\hline $\mathrm{Cl}$ & $1.0657 \mathrm{E}-02$ & $1.3588 \mathrm{E}-03$ & 3.7904E-04 & $1.0715 \mathrm{E}-02$ & $1.4194 \mathrm{E}-03$ & $3.9320 \mathrm{E}-04$ \\
\hline $\mathrm{Cm} 2 \mathrm{O} 3$ & $4.1731 \mathrm{E}-13$ & $9.7509 \mathrm{E}-14$ & $8.7175 \mathrm{E}-15$ & $4.1743 \mathrm{E}-13$ & $1.0135 \mathrm{E}-13$ & $9.0067 \mathrm{E}-15$ \\
\hline $\mathrm{CoO}$ & $1.9555 \mathrm{E}-06$ & $4.5691 \mathrm{E}-07$ & $6.9188 \mathrm{E}-08$ & $1.9787 \mathrm{E}-06$ & $4.8042 \mathrm{E}-07$ & $7.3463 \mathrm{E}-08$ \\
\hline $\mathrm{Cr} 2 \mathrm{O} 3$ & $3.4310 \mathrm{E}-03$ & $8.6112 \mathrm{E}-04$ & $6.2236 \mathrm{E}-05$ & $3.3027 \mathrm{E}-03$ & $8.6084 \mathrm{E}-04$ & $6.2073 \mathrm{E}-05$ \\
\hline $\mathrm{Cs} 2 \mathrm{O}$ & $1.3254 \mathrm{E}-08$ & $2.7298 \mathrm{E}-09$ & $3.9018 \mathrm{E}-10$ & $1.3186 \mathrm{E}-08$ & $2.8220 \mathrm{E}-09$ & $3.9365 \mathrm{E}-10$ \\
\hline $\mathrm{CuO}$ & $3.6158 \mathrm{E}-06$ & $8.4486 \mathrm{E}-07$ & $1.2772 \mathrm{E}-07$ & $3.6207 \mathrm{E}-06$ & $8.7908 \mathrm{E}-07$ & $1.3050 \mathrm{E}-07$ \\
\hline $\mathrm{Eu} 2 \mathrm{O} 3$ & $1.3553 \mathrm{E}-10$ & $3.1668 \mathrm{E}-11$ & $1.5164 \mathrm{E}-12$ & $1.3527 \mathrm{E}-10$ & $3.2843 \mathrm{E}-11$ & $1.5164 \mathrm{E}-12$ \\
\hline $\mathrm{F}$ & 4.4190E-03 & $7.5570 \mathrm{E}-04$ & $1.4036 \mathrm{E}-04$ & $4.5576 \mathrm{E}-03$ & 8.0986E-04 & $1.4457 \mathrm{E}-04$ \\
\hline $\mathrm{Fe} 2 \mathrm{O} 3$ & 7.2215E-05 & $5.5187 \mathrm{E}-02$ & 1.0094E-03 & 7.7503E-05 & $5.5200 \mathrm{E}-02$ & $9.9525 \mathrm{E}-04$ \\
\hline $\mathrm{Gd} 2 \mathrm{O} 3$ & $0.0000 \mathrm{E}+00$ & $0.0000 \mathrm{E}+00$ & $0.0000 \mathrm{E}+00$ & $0.0000 \mathrm{E}+00$ & $0.0000 \mathrm{E}+00$ & $0.0000 \mathrm{E}+00$ \\
\hline $\mathrm{HgO}$ & $3.8970 \mathrm{E}-07$ & $0.0000 \mathrm{E}+00$ & $0.0000 \mathrm{E}+00$ & 3.7639E-07 & $0.0000 \mathrm{E}+00$ & $0.0000 \mathrm{E}+0 \mathrm{C}$ \\
\hline $\mathrm{I}$ & $2.5808 \mathrm{E}-06$ & $3.0817 \mathrm{E}-07$ & $1.0769 \mathrm{E}-07$ & $2.6133 \mathrm{E}-06$ & $3.2425 \mathrm{E}-07$ & $1.1542 \mathrm{E}-07$ \\
\hline $\mathrm{K} 2 \mathrm{O}$ & $6.2008 \mathrm{E}-02$ & $1.4030 \mathrm{E}-02$ & $7.8154 \mathrm{E}-04$ & $6.2561 \mathrm{E}-02$ & $1.4707 \mathrm{E}-02$ & $7.9214 \mathrm{E}-04$ \\
\hline $\mathrm{La} 2 \mathrm{O} 3$ & $1.6415 \mathrm{E}-06$ & $3.8355 \mathrm{E}-07$ & $2.7083 \mathrm{E}-08$ & $1.6240 \mathrm{E}-06$ & 3.9429E-07 & $2.8096 \mathrm{E}-08$ \\
\hline $\mathrm{Li} 2 \mathrm{O}$ & $1.3074 \mathrm{E}-06$ & $2.0606 \mathrm{E}-03$ & $2.9626 \mathrm{E}-08$ & $1.3077 \mathrm{E}-06$ & $3.1711 \mathrm{E}-07$ & $3.0795 \mathrm{E}-08$ \\
\hline $\mathrm{MgO}$ & $8.3024 \mathrm{E}-05$ & $1.4865 \mathrm{E}-02$ & $3.1126 \mathrm{E}-04$ & $1.0329 \mathrm{E}-04$ & $1.4870 \mathrm{E}-02$ & $2.9847 \mathrm{E}-04$ \\
\hline $\mathrm{MnO}$ & $6.4159 \mathrm{E}-06$ & $1.3386 \mathrm{E}-04$ & $3.3890 \mathrm{E}-05$ & $6.4877 \mathrm{E}-06$ & $1.2824 \mathrm{E}-04$ & $3.4054 \mathrm{E}-05$ \\
\hline $\mathrm{MoO} 3$ & 5.4477E-05 & $1.2484 \mathrm{E}-05$ & $9.2987 \mathrm{E}-07$ & 5.3679E-05 & $1.2782 \mathrm{E}-05$ & $9.3840 \mathrm{E}-07$ \\
\hline $\mathrm{Na} 2 \mathrm{O}$ & 8.2030E-01 & $1.9088 \mathrm{E}-01$ & $1.1898 \mathrm{E}-02$ & 8.1983E-01 & $1.9821 \mathrm{E}-01$ & $1.1843 \mathrm{E}-02$ \\
\hline $\mathrm{Nb} 2 \mathrm{O} 5$ & $3.2676 \mathrm{E}-08$ & $7.6351 \mathrm{E}-09$ & $5.4216 \mathrm{E}-10$ & $3.6608 \mathrm{E}-08$ & 8.8881E-09 & $6.2388 \mathrm{E}-10$ \\
\hline $\mathrm{Nd} 2 \mathrm{O} 3$ & $5.2552 \mathrm{E}-06$ & $1.2279 \mathrm{E}-06$ & $1.1623 \mathrm{E}-07$ & $5.2602 \mathrm{E}-06$ & $1.2771 \mathrm{E}-06$ & $1.2297 \mathrm{E}-07$ \\
\hline
\end{tabular}




\begin{tabular}{|c|c|c|c|c|c|c|}
\hline \multirow{2}{*}{$\begin{array}{l}\text { Batch } \\
\text { Comp }\end{array}$} & \multicolumn{3}{|c|}{ MFPV-A102 } & \multicolumn{3}{|c|}{ MFPV-B102 } \\
\hline & Waste & Glass & Glass SD & Waste & Glass & Glass SD \\
\hline $\mathrm{NiO}$ & $1.2940 \mathrm{E}-04$ & $1.4265 \mathrm{E}-04$ & $1.7495 \mathrm{E}-05$ & $1.3240 \mathrm{E}-04$ & $1.4459 \mathrm{E}-04$ & $1.7361 \mathrm{E}-05$ \\
\hline $\mathrm{NpO} 2$ & $5.0777 \mathrm{E}-07$ & $1.1864 \mathrm{E}-07$ & 6.1051E-09 & 4.9799E-07 & $1.2091 \mathrm{E}-07$ & $6.0622 \mathrm{E}-09$ \\
\hline $\mathrm{P} 2 \mathrm{O} 5$ & $7.8152 \mathrm{E}-03$ & $1.9765 \mathrm{E}-03$ & $1.3206 \mathrm{E}-04$ & 7.7283E-03 & $2.0267 \mathrm{E}-03$ & $1.3424 \mathrm{E}-04$ \\
\hline $\mathrm{Pa} 2 \mathrm{O} 5$ & 1.1893E-09 & $2.7788 \mathrm{E}-10$ & $8.0908 \mathrm{E}-11$ & 1.2004E-09 & $2.9145 \mathrm{E}-10$ & $8.6102 \mathrm{E}-11$ \\
\hline $\mathrm{PbO}$ & $1.3603 \mathrm{E}-04$ & $3.2068 \mathrm{E}-05$ & $3.0726 \mathrm{E}-06$ & $1.3869 \mathrm{E}-04$ & $3.3940 \mathrm{E}-05$ & $3.1635 \mathrm{E}-06$ \\
\hline $\mathrm{PdO}$ & $3.2219 \mathrm{E}-05$ & $7.5281 \mathrm{E}-06$ & $7.1533 \mathrm{E}-07$ & $3.2552 \mathrm{E}-05$ & $7.9033 \mathrm{E}-06$ & $7.5353 \mathrm{E}-07$ \\
\hline $\mathrm{Pr} 2 \mathrm{O} 3$ & 4.6099E-08 & $1.0771 \mathrm{E}-08$ & $1.0426 \mathrm{E}-09$ & $4.6495 \mathrm{E}-08$ & $1.1289 \mathrm{E}-08$ & $1.0893 \mathrm{E}-09$ \\
\hline $\mathrm{PuO} 2$ & $3.7061 \mathrm{E}-08$ & 8.6595E-09 & $4.3550 \mathrm{E}-10$ & $3.5629 \mathrm{E}-08$ & 8.6503E-09 & $4.3045 \mathrm{E}-10$ \\
\hline $\mathrm{RaO}$ & $2.0280 \mathrm{E}-11$ & $3.6646 \mathrm{E}-12$ & $9.4955 \mathrm{E}-13$ & $2.0474 \mathrm{E}-11$ & $3.8444 \mathrm{E}-12$ & $9.9596 \mathrm{E}-13$ \\
\hline $\mathrm{Rb} 2 \mathrm{O}$ & $6.5061 \mathrm{E}-06$ & $1.4910 \mathrm{E}-06$ & $2.2768 \mathrm{E}-07$ & $6.5656 \mathrm{E}-06$ & $1.5634 \mathrm{E}-06$ & $2.3705 \mathrm{E}-07$ \\
\hline $\mathrm{Rh} 2 \mathrm{O} 3$ & $1.4443 \mathrm{E}-05$ & $3.3748 \mathrm{E}-06$ & $1.7150 \mathrm{E}-07$ & $1.4612 \mathrm{E}-05$ & $3.5476 \mathrm{E}-06$ & $1.7370 \mathrm{E}-07$ \\
\hline $\mathrm{RuO} 2$ & $6.9023 \mathrm{E}-05$ & $1.5818 \mathrm{E}-05$ & $8.7436 \mathrm{E}-07$ & $7.0248 \mathrm{E}-05$ & $1.6728 \mathrm{E}-05$ & $9.0363 \mathrm{E}-07$ \\
\hline $\mathrm{SO} 3$ & $1.5515 \mathrm{E}-02$ & $3.0971 \mathrm{E}-03$ & $3.2703 \mathrm{E}-04$ & $1.5015 \mathrm{E}-02$ & $3.1131 \mathrm{E}-03$ & $3.2978 \mathrm{E}-04$ \\
\hline $\mathrm{Sb} 2 \mathrm{O} 3$ & $1.4661 \mathrm{E}-06$ & 2.6492E-07 & $6.9841 \mathrm{E}-08$ & $1.4126 \mathrm{E}-06$ & $2.6523 \mathrm{E}-07$ & $6.9954 \mathrm{E}-08$ \\
\hline $\mathrm{SeO} 2$ & $1.1936 \mathrm{E}-05$ & $2.1568 \mathrm{E}-06$ & $5.5768 \mathrm{E}-07$ & $1.1809 \mathrm{E}-05$ & $2.2173 \mathrm{E}-06$ & $5.8492 \mathrm{E}-07$ \\
\hline $\mathrm{SiO} 2$ & $3.9957 \mathrm{E}-03$ & $4.4963 \mathrm{E}-01$ & $7.4306 \mathrm{E}-03$ & $4.0816 \mathrm{E}-03$ & $4.4621 \mathrm{E}-01$ & $7.3342 \mathrm{E}-03$ \\
\hline $\mathrm{Sm} 2 \mathrm{O} 3$ & $2.9870 \mathrm{E}-07$ & 6.9794E-08 & 8.6323E-09 & $2.9247 \mathrm{E}-07$ & $7.1008 \mathrm{E}-08$ & $8.8608 \mathrm{E}-09$ \\
\hline $\mathrm{SnO} 2$ & 2.6572E-07 & $6.2088 \mathrm{E}-08$ & 5.9532E-09 & $2.6393 \mathrm{E}-07$ & $6.4080 \mathrm{E}-08$ & $6.0201 \mathrm{E}-09$ \\
\hline $\mathrm{SrO}$ & 5.5799E-07 & $1.3038 \mathrm{E}-07$ & $6.6736 \mathrm{E}-09$ & $5.3587 \mathrm{E}-07$ & $1.3011 \mathrm{E}-07$ & $6.4827 \mathrm{E}-09$ \\
\hline $\mathrm{Ta} 2 \mathrm{O} 5$ & $1.9032 \mathrm{E}-07$ & 4.4469E-08 & 4.3624E-09 & $1.9233 \mathrm{E}-07$ & 4.6697E-08 & $4.5210 \mathrm{E}-09$ \\
\hline $\mathrm{Tc} 2 \mathrm{O} 7$ & $2.0353 \mathrm{E}-05$ & $2.0530 \mathrm{E}-06$ & $7.0272 \mathrm{E}-07$ & $2.0004 \mathrm{E}-05$ & $2.0966 \mathrm{E}-06$ & $7.2215 \mathrm{E}-07$ \\
\hline $\mathrm{TeO} 2$ & 5.8967E-07 & $1.0655 \mathrm{E}-07$ & 2.7582E-08 & $5.9678 \mathrm{E}-07$ & $1.1206 \mathrm{E}-07$ & $2.9476 \mathrm{E}-08$ \\
\hline ThO2 & $1.7432 \mathrm{E}-05$ & $4.0731 \mathrm{E}-06$ & $6.1216 \mathrm{E}-07$ & $1.6901 \mathrm{E}-05$ & 4.1035E-06 & $6.2896 \mathrm{E}-07$ \\
\hline $\mathrm{TiO} 2$ & $1.8686 \mathrm{E}-05$ & $1.4036 \mathrm{E}-02$ & $2.9117 \mathrm{E}-04$ & $2.0761 \mathrm{E}-05$ & $1.4039 \mathrm{E}-02$ & $2.7890 \mathrm{E}-04$ \\
\hline $\mathrm{T} 12 \mathrm{O}$ & 4.0163E-06 & $7.2576 \mathrm{E}-07$ & $1.6314 \mathrm{E}-07$ & $3.7920 \mathrm{E}-06$ & $7.1201 \mathrm{E}-07$ & $1.5873 \mathrm{E}-07$ \\
\hline UO3 & $1.6809 \mathrm{E}-04$ & $5.9605 \mathrm{E}-05$ & $4.3369 \mathrm{E}-06$ & $1.6711 \mathrm{E}-04$ & $6.0908 \mathrm{E}-05$ & $4.3598 \mathrm{E}-06$ \\
\hline $\mathrm{V} 2 \mathrm{O} 5$ & $2.5785 \mathrm{E}-06$ & $5.9896 \mathrm{E}-05$ & $1.9533 \mathrm{E}-05$ & $2.5796 \mathrm{E}-06$ & $5.9985 \mathrm{E}-05$ & $1.9858 \mathrm{E}-05$ \\
\hline WO3 & $5.3711 \mathrm{E}-05$ & $1.2550 \mathrm{E}-05$ & $6.3908 \mathrm{E}-07$ & $5.4213 \mathrm{E}-05$ & $1.3163 \mathrm{E}-05$ & $6.5499 \mathrm{E}-07$ \\
\hline $\mathrm{Y} 2 \mathrm{O} 3$ & $2.9525 \mathrm{E}-06$ & $6.8988 \mathrm{E}-07$ & $1.0333 \mathrm{E}-07$ & $2.9811 \mathrm{E}-06$ & $7.2380 \mathrm{E}-07$ & $1.0962 \mathrm{E}-07$ \\
\hline $\mathrm{ZnO}$ & $5.8300 \mathrm{E}-05$ & $3.5084 \mathrm{E}-02$ & $6.0051 \mathrm{E}-04$ & $6.4149 \mathrm{E}-05$ & $3.5101 \mathrm{E}-02$ & $5.8286 \mathrm{E}-04$ \\
\hline $\mathrm{ZrO} 2$ & $3.2080 \mathrm{E}-05$ & $3.0144 \mathrm{E}-02$ & $5.3508 \mathrm{E}-04$ & $3.1886 \mathrm{E}-05$ & 3.0149E-02 & $5.2964 \mathrm{E}-04$ \\
\hline SUM & $1.0000 \mathrm{E}+00$ & $1.0000 \mathrm{E}+00$ & NA & $1.0000 \mathrm{E}+00$ & $1.0000 \mathrm{E}+00$ & $\mathrm{NA}$ \\
\hline $\operatorname{Rad}$ & mCi/g oxides & $\mathrm{mCi} / \mathrm{g}$ glass & $\mathrm{mCi} / \mathrm{g}$ glass & mCi/g oxides & $\mathrm{mCi} / \mathrm{g}$ glass & $\mathrm{mCi} / \mathrm{g}$ glass \\
\hline $59 \mathrm{Ni}$ & $1.4685 \mathrm{E}-06$ & $3.4129 \mathrm{E}-07$ & $2.4381 \mathrm{E}-08$ & $1.4789 \mathrm{E}-06$ & $3.5714 \mathrm{E}-07$ & $2.5044 \mathrm{E}-08$ \\
\hline $60 \mathrm{Co}$ & $2.3378 \mathrm{E}-06$ & $5.4625 \mathrm{E}-07$ & $2.7714 \mathrm{E}-08$ & $2.2972 \mathrm{E}-06$ & $5.5775 \mathrm{E}-07$ & $2.7855 \mathrm{E}-08$ \\
\hline $63 \mathrm{Ni}$ & $1.3388 \mathrm{E}-04$ & $3.1114 \mathrm{E}-05$ & $2.2207 \mathrm{E}-06$ & $1.3482 \mathrm{E}-04$ & $3.2558 \mathrm{E}-05$ & $2.3334 \mathrm{E}-06$ \\
\hline $79 \mathrm{Se}$ & $5.4909 \mathrm{E}-06$ & 9.9223E-07 & $2.1759 \mathrm{E}-07$ & $5.3564 \mathrm{E}-06$ & $1.0058 \mathrm{E}-06$ & $2.2629 \mathrm{E}-07$ \\
\hline $90 \mathrm{Sr}$ & $2.3845 \mathrm{E}-03$ & $5.5716 \mathrm{E}-04$ & $2.8511 \mathrm{E}-05$ & $2.3776 \mathrm{E}-03$ & 5.7725E-04 & $2.8863 \mathrm{E}-05$ \\
\hline $90 \mathrm{Y}$ & $2.3086 \mathrm{E}-03$ & $5.3943 \mathrm{E}-04$ & $2.7343 \mathrm{E}-05$ & $2.3019 \mathrm{E}-03$ & $5.5889 \mathrm{E}-04$ & $2.7862 \mathrm{E}-05$ \\
\hline $93 \mathrm{mNb}$ & $5.4502 \mathrm{E}-03$ & $1.2735 \mathrm{E}-03$ & $9.0429 \mathrm{E}-05$ & $6.1059 \mathrm{E}-03$ & $1.4825 \mathrm{E}-03$ & $1.0405 \mathrm{E}-04$ \\
\hline $93 \mathrm{Zr}$ & 3.5849E-05 & $8.3984 \mathrm{E}-06$ & $6.0061 \mathrm{E}-07$ & $3.5560 \mathrm{E}-05$ & $8.6562 \mathrm{E}-06$ & $6.1624 \mathrm{E}-07$ \\
\hline $99 \mathrm{Tc}$ & $2.2235 \mathrm{E}-04$ & $2.2428 \mathrm{E}-05$ & $7.6771 \mathrm{E}-06$ & $2.1854 \mathrm{E}-04$ & $2.2905 \mathrm{E}-05$ & $7.8893 \mathrm{E}-06$ \\
\hline $106 \mathrm{Ru}$ & $2.0408 \mathrm{E}-09$ & 4.6769E-10 & $4.5622 \mathrm{E}-11$ & $1.9323 \mathrm{E}-09$ & 4.6012E-10 & $4.5378 \mathrm{E}-11$ \\
\hline $113 \mathrm{mCd}$ & $2.6335 \mathrm{E}-05$ & $6.1533 \mathrm{E}-06$ & 4.3848E-07 & $2.5788 \mathrm{E}-05$ & $6.2612 \mathrm{E}-06$ & 4.4408E-07 \\
\hline $125 \mathrm{Sb}$ & $6.3608 \mathrm{E}-06$ & $1.1494 \mathrm{E}-06$ & $2.4858 \mathrm{E}-07$ & $6.0235 \mathrm{E}-06$ & $1.1310 \mathrm{E}-06$ & $2.4590 \mathrm{E}-07$ \\
\hline $126 \mathrm{Sn}$ & $6.0160 \mathrm{E}-06$ & $1.4057 \mathrm{E}-06$ & $1.3478 \mathrm{E}-07$ & $5.9755 \mathrm{E}-06$ & $1.4508 \mathrm{E}-06$ & $1.3630 \mathrm{E}-07$ \\
\hline 129I & 4.5629E-07 & $5.4485 \mathrm{E}-08$ & $1.9040 \mathrm{E}-08$ & $4.6203 \mathrm{E}-07$ & 5.7327E-08 & $2.0405 \mathrm{E}-08$ \\
\hline $134 \mathrm{Cs}$ & $1.0212 \mathrm{E}-09$ & $2.1032 \mathrm{E}-10$ & $3.8400 \mathrm{E}-11$ & $1.0053 \mathrm{E}-09$ & $2.1515 \mathrm{E}-10$ & $3.8679 \mathrm{E}-11$ \\
\hline $137 \mathrm{mBa}$ & $3.7691 \mathrm{E}-01$ & 8.8068E-02 & 4.5095E-03 & $3.7197 \mathrm{E}-01$ & $9.0310 \mathrm{E}-02$ & $4.5263 \mathrm{E}-03$ \\
\hline
\end{tabular}




\begin{tabular}{|c|c|c|c|c|c|c|}
\hline \multirow{2}{*}{$\begin{array}{l}\text { Batch } \\
\text { Comp } \\
\end{array}$} & \multicolumn{3}{|c|}{ MFPV-A102 } & \multicolumn{3}{|c|}{ MFPV-B102 } \\
\hline & Waste & Glass & Glass SD & Waste & Glass & Glass SD \\
\hline $137 \mathrm{Cs}$ & $2.1760 \mathrm{E}-04$ & 4.4818E-05 & 5.1433E-06 & $2.1567 \mathrm{E}-04$ & 4.6158E-05 & $5.2306 \mathrm{E}-06$ \\
\hline $151 \mathrm{Sm}$ & $6.7836 \mathrm{E}-03$ & $1.5851 \mathrm{E}-03$ & $1.9604 \mathrm{E}-04$ & $6.6420 \mathrm{E}-03$ & $1.6126 \mathrm{E}-03$ & $2.0123 \mathrm{E}-04$ \\
\hline $152 \mathrm{Eu}$ & $1.1522 \mathrm{E}-06$ & 2.6923E-07 & $1.3818 \mathrm{E}-08$ & $1.1188 \mathrm{E}-06$ & $2.7163 \mathrm{E}-07$ & $1.3429 \mathrm{E}-08$ \\
\hline $154 \mathrm{Eu}$ & $2.3853 \mathrm{E}-05$ & $5.5735 \mathrm{E}-06$ & $2.8692 \mathrm{E}-07$ & $2.3964 \mathrm{E}-05$ & 5.8182E-06 & $2.8938 \mathrm{E}-07$ \\
\hline $155 \mathrm{Eu}$ & $1.0666 \mathrm{E}-05$ & $2.4921 \mathrm{E}-06$ & $1.2826 \mathrm{E}-07$ & $1.0455 \mathrm{E}-05$ & $2.5385 \mathrm{E}-06$ & $1.2765 \mathrm{E}-07$ \\
\hline $226 \mathrm{Ra}$ & $1.8695 \mathrm{E}-08$ & 3.3783E-09 & $8.7573 \mathrm{E}-10$ & $1.8876 \mathrm{E}-08$ & 3.5442E-09 & $9.1856 \mathrm{E}-10$ \\
\hline $227 \mathrm{Ac}$ & $1.7313 \mathrm{E}-08$ & 4.0454E-09 & $2.8936 \mathrm{E}-10$ & $1.7489 \mathrm{E}-08$ & 4.2463E-09 & $3.0319 \mathrm{E}-10$ \\
\hline $228 \mathrm{Ra}$ & $7.2680 \mathrm{E}-09$ & 1.3133E-09 & $4.8118 \mathrm{E}-10$ & $7.0340 \mathrm{E}-09$ & $1.3208 \mathrm{E}-09$ & $4.8744 \mathrm{E}-10$ \\
\hline $229 \mathrm{Th}$ & $7.8921 \mathrm{E}-10$ & $1.8441 \mathrm{E}-10$ & $5.4340 \mathrm{E}-11$ & $7.4506 \mathrm{E}-10$ & $1.8089 \mathrm{E}-10$ & $5.3882 \mathrm{E}-11$ \\
\hline $231 \mathrm{~Pa}$ & $4.7880 \mathrm{E}-08$ & $1.1187 \mathrm{E}-08$ & 3.2573E-09 & 4.8329E-08 & $1.1734 \mathrm{E}-08$ & $3.4665 \mathrm{E}-09$ \\
\hline $232 \mathrm{Th}$ & $1.6791 \mathrm{E}-09$ & 3.9234E-10 & $2.8064 \mathrm{E}-11$ & $1.6278 \mathrm{E}-09$ & $3.9522 \mathrm{E}-10$ & $2.7719 \mathrm{E}-11$ \\
\hline $232 \mathrm{U}$ & $2.2715 \mathrm{E}-09$ & $5.3075 \mathrm{E}-10$ & $2.6793 \mathrm{E}-11$ & 2.1971E-09 & $5.3343 \mathrm{E}-10$ & $2.6865 \mathrm{E}-11$ \\
\hline $233 \mathrm{U}$ & $1.0779 \mathrm{E}-07$ & $2.5187 \mathrm{E}-08$ & $1.2873 \mathrm{E}-09$ & $1.0623 \mathrm{E}-07$ & $2.5791 \mathrm{E}-08$ & $1.2837 \mathrm{E}-09$ \\
\hline $234 \mathrm{U}$ & $6.2532 \mathrm{E}-08$ & $1.4611 \mathrm{E}-08$ & $7.4307 \mathrm{E}-10$ & $6.2275 \mathrm{E}-08$ & $1.5120 \mathrm{E}-08$ & $7.4798 \mathrm{E}-10$ \\
\hline $235 \mathrm{U}$ & $2.3599 \mathrm{E}-09$ & 5.5142E-10 & $3.9166 \mathrm{E}-11$ & $2.3480 \mathrm{E}-09$ & $5.7007 \mathrm{E}-10$ & 4.0122E-11 \\
\hline $236 \mathrm{U}$ & 4.3489E-09 & 1.0162E-09 & 5.1979E-11 & 4.3462E-09 & $1.0552 \mathrm{E}-09$ & $5.3158 \mathrm{E}-11$ \\
\hline $237 \mathrm{~Np}$ & $3.1527 \mathrm{E}-07$ & 7.3665E-08 & $3.7906 \mathrm{E}-09$ & $3.0920 \mathrm{E}-07$ & $7.5070 \mathrm{E}-08$ & $3.7639 \mathrm{E}-09$ \\
\hline $238 \mathrm{Pu}$ & $1.6388 \mathrm{E}-07$ & 3.8293E-08 & $1.9529 \mathrm{E}-09$ & $1.5888 \mathrm{E}-07$ & $3.8575 \mathrm{E}-08$ & $1.9345 \mathrm{E}-09$ \\
\hline $238 \mathrm{U}$ & 4.6617E-08 & 1.0892E-08 & $7.7040 \mathrm{E}-10$ & 4.6347E-08 & $1.1253 \mathrm{E}-08$ & $7.8816 \mathrm{E}-10$ \\
\hline $239 \mathrm{Pu}$ & $1.8964 \mathrm{E}-06$ & $4.4310 \mathrm{E}-07$ & $2.2728 \mathrm{E}-08$ & $1.8232 \mathrm{E}-06$ & 4.4266E-07 & $2.2485 \mathrm{E}-08$ \\
\hline $240 \mathrm{Pu}$ & 4.6204E-07 & $1.0796 \mathrm{E}-07$ & 7.7615E-09 & 4.4373E-07 & $1.0773 \mathrm{E}-07$ & 7.5949E-09 \\
\hline 241Am & $2.3240 \mathrm{E}-06$ & 5.3257E-07 & 4.0096E-08 & $2.2141 \mathrm{E}-06$ & $5.2721 \mathrm{E}-07$ & $3.8456 \mathrm{E}-08$ \\
\hline $241 \mathrm{Pu}$ & $5.2457 \mathrm{E}-06$ & $1.2257 \mathrm{E}-06$ & $1.1761 \mathrm{E}-07$ & $5.0095 \mathrm{E}-06$ & $1.2163 \mathrm{E}-06$ & $1.1734 \mathrm{E}-07$ \\
\hline $242 \mathrm{Cm}$ & $1.1587 \mathrm{E}-08$ & $2.7073 \mathrm{E}-09$ & $1.9200 \mathrm{E}-10$ & $1.1203 \mathrm{E}-08$ & $2.7200 \mathrm{E}-09$ & $1.9226 \mathrm{E}-10$ \\
\hline $242 \mathrm{Pu}$ & $5.1020 \mathrm{E}-11$ & $1.1921 \mathrm{E}-11$ & $8.6059 \mathrm{E}-13$ & $4.9053 \mathrm{E}-11$ & $1.1910 \mathrm{E}-11$ & $8.4938 \mathrm{E}-13$ \\
\hline $243 \mathrm{Am}$ & $3.8261 \mathrm{E}-10$ & $8.7680 \mathrm{E}-11$ & $8.5834 \mathrm{E}-12$ & $3.7354 \mathrm{E}-10$ & 8.8948E-11 & $8.6311 \mathrm{E}-12$ \\
\hline $243 \mathrm{Cm}$ & $1.3817 \mathrm{E}-09$ & $3.2285 \mathrm{E}-10$ & $3.0922 \mathrm{E}-11$ & $1.3805 \mathrm{E}-09$ & $3.3517 \mathrm{E}-10$ & $3.1916 \mathrm{E}-11$ \\
\hline $244 \mathrm{Cm}$ & $2.8185 \mathrm{E}-08$ & $6.5855 \mathrm{E}-09$ & $6.2971 \mathrm{E}-10$ & $2.8205 \mathrm{E}-08$ & $6.8478 \mathrm{E}-09$ & $6.5068 \mathrm{E}-10$ \\
\hline $\mathrm{TRU}^{(\mathrm{a})}$ & $5.1915 \mathrm{E}-06$ & $1.2026 \mathrm{E}-06$ & 4.6937E-08 & 4.9791E-06 & $1.1985 \mathrm{E}-06$ & 4.5392E-08 \\
\hline
\end{tabular}

\begin{tabular}{|c|c|c|c|c|c|c||}
\hline Batch & \multicolumn{3}{|c|}{ MFPV-A103 } & \multicolumn{3}{c||}{ MFPV-B103 } \\
\hline Comp & Waste & Glass & Glass SD & Waste & Glass & Glass SD \\
\hline $\mathrm{Ac} 2 \mathrm{O} 3$ & $2.6740 \mathrm{E}-13$ & $6.4931 \mathrm{E}-14$ & $4.5957 \mathrm{E}-15$ & $2.6740 \mathrm{E}-13$ & $6.4929 \mathrm{E}-14$ & $4.6407 \mathrm{E}-15$ \\
\hline $\mathrm{Ag} 2 \mathrm{O}$ & $1.3024 \mathrm{E}-06$ & $3.1018 \mathrm{E}-07$ & $3.7915 \mathrm{E}-08$ & $1.3024 \mathrm{E}-06$ & $3.1017 \mathrm{E}-07$ & $3.7954 \mathrm{E}-08$ \\
\hline $\mathrm{A} 2 \mathrm{O} 3$ & $7.0698 \mathrm{E}-02$ & $6.1256 \mathrm{E}-02$ & $1.1870 \mathrm{E}-03$ & $7.0698 \mathrm{E}-02$ & $6.1234 \mathrm{E}-02$ & $1.1977 \mathrm{E}-03$ \\
\hline $\mathrm{Am} 2 \mathrm{O} 3$ & $7.1244 \mathrm{E}-10$ & $1.6967 \mathrm{E}-10$ & $1.2511 \mathrm{E}-11$ & $7.1244 \mathrm{E}-10$ & $1.6966 \mathrm{E}-10$ & $1.2443 \mathrm{E}-11$ \\
\hline $\mathrm{As} 2 \mathrm{O} 5$ & $6.7267 \mathrm{E}-06$ & $1.2632 \mathrm{E}-06$ & $3.3367 \mathrm{E}-07$ & $6.7267 \mathrm{E}-06$ & $1.2632 \mathrm{E}-06$ & $3.3067 \mathrm{E}-07$ \\
\hline $\mathrm{B} 2 \mathrm{O} 3$ & $2.2365 \mathrm{E}-04$ & $9.9485 \mathrm{E}-02$ & $1.7345 \mathrm{E}-03$ & $2.2365 \mathrm{E}-04$ & $9.9486 \mathrm{E}-02$ & $1.7133 \mathrm{E}-03$ \\
\hline $\mathrm{BaO}$ & $1.0982 \mathrm{E}-06$ & $2.6666 \mathrm{E}-07$ & $2.5723 \mathrm{E}-08$ & $1.0982 \mathrm{E}-06$ & $2.6665 \mathrm{E}-07$ & $2.5114 \mathrm{E}-08$ \\
\hline $\mathrm{BeO}$ & $5.5230 \mathrm{E}-06$ & $1.3411 \mathrm{E}-06$ & $6.8656 \mathrm{E}-08$ & $5.5230 \mathrm{E}-06$ & $1.3411 \mathrm{E}-06$ & $6.7289 \mathrm{E}-08$ \\
\hline $\mathrm{Bi} 2 \mathrm{O} 3$ & $1.8438 \mathrm{E}-05$ & $4.3910 \mathrm{E}-06$ & $4.3178 \mathrm{E}-07$ & $1.8438 \mathrm{E}-05$ & $4.3909 \mathrm{E}-06$ & $4.3376 \mathrm{E}-07$ \\
\hline $\mathrm{CaO}$ & $1.9217 \mathrm{E}-04$ & $2.2047 \mathrm{E}-02$ & $6.1012 \mathrm{E}-04$ & $1.9217 \mathrm{E}-04$ & $2.2053 \mathrm{E}-02$ & $5.8708 \mathrm{E}-04$ \\
\hline $\mathrm{CdO}$ & $3.5039 \mathrm{E}-06$ & $4.3655 \mathrm{E}-06$ & $1.3183 \mathrm{E}-06$ & $3.5039 \mathrm{E}-06$ & $4.3682 \mathrm{E}-06$ & $1.3274 \mathrm{E}-06$ \\
\hline $\mathrm{Ce} 2 \mathrm{O} 3$ & $1.0114 \mathrm{E}-06$ & $2.4560 \mathrm{E}-07$ & $3.6437 \mathrm{E}-08$ & $1.0114 \mathrm{E}-06$ & $2.4559 \mathrm{E}-07$ & $3.6668 \mathrm{E}-08$ \\
\hline $\mathrm{Cl}$ & $1.0715 \mathrm{E}-02$ & $1.4196 \mathrm{E}-03$ & $3.9952 \mathrm{E}-04$ & $1.0715 \mathrm{E}-02$ & $1.4195 \mathrm{E}-03$ & $4.0160 \mathrm{E}-04$ \\
\hline $\mathrm{Cm} 2 \mathrm{O} 3$ & $4.1743 \mathrm{E}-13$ & $1.0136 \mathrm{E}-13$ & $9.2382 \mathrm{E}-15$ & $4.1743 \mathrm{E}-13$ & $1.0136 \mathrm{E}-13$ & $8.9366 \mathrm{E}-15$ \\
\hline $\mathrm{CoO}$ & $1.9787 \mathrm{E}-06$ & $4.8049 \mathrm{E}-07$ & $7.1121 \mathrm{E}-08$ & $1.9787 \mathrm{E}-06$ & $4.8047 \mathrm{E}-07$ & $7.2648 \mathrm{E}-08$ \\
\hline $\mathrm{Cr} 2 \mathrm{O} 3$ & $3.3027 \mathrm{E}-03$ & $8.6092 \mathrm{E}-04$ & $6.2664 \mathrm{E}-05$ & $3.3027 \mathrm{E}-03$ & $8.6093 \mathrm{E}-04$ & $6.2423 \mathrm{E}-05$ \\
\hline $\mathrm{Cs} 2 \mathrm{O}$ & $1.3186 \mathrm{E}-08$ & $2.8224 \mathrm{E}-09$ & $3.8786 \mathrm{E}-10$ & $1.3186 \mathrm{E}-08$ & $2.8223 \mathrm{E}-09$ & $3.9286 \mathrm{E}-10$ \\
\hline \hline
\end{tabular}




\begin{tabular}{|c|c|c|c|c|c|c|}
\hline \multirow{2}{*}{$\begin{array}{l}\text { Batch } \\
\text { Comp }\end{array}$} & \multicolumn{3}{|c|}{ MFPV-A103 } & \multicolumn{3}{|c|}{ MFPV-B103 } \\
\hline & Waste & Glass & Glass SD & Waste & Glass & Glass SD \\
\hline $\mathrm{CuO}$ & $3.6207 \mathrm{E}-06$ & $8.7920 \mathrm{E}-07$ & $1.3222 \mathrm{E}-07$ & $3.6207 \mathrm{E}-06$ & $8.7917 \mathrm{E}-07$ & $1.3366 \mathrm{E}-07$ \\
\hline $\mathrm{Eu} 2 \mathrm{O} 3$ & $1.3527 \mathrm{E}-10$ & $3.2847 \mathrm{E}-11$ & $1.5411 \mathrm{E}-12$ & $1.3527 \mathrm{E}-10$ & $3.2846 \mathrm{E}-11$ & $1.5343 \mathrm{E}-12$ \\
\hline $\mathrm{F}$ & $4.5576 \mathrm{E}-03$ & 8.0997E-04 & $1.4885 \mathrm{E}-04$ & $4.5576 \mathrm{E}-03$ & $8.0995 \mathrm{E}-04$ & $1.5030 \mathrm{E}-04$ \\
\hline $\mathrm{Fe} 2 \mathrm{O} 3$ & $7.7503 \mathrm{E}-05$ & $5.5200 \mathrm{E}-02$ & $1.0275 \mathrm{E}-03$ & $7.7503 \mathrm{E}-05$ & $5.5193 \mathrm{E}-02$ & $9.9704 \mathrm{E}-04$ \\
\hline $\mathrm{Gd} 2 \mathrm{O} 3$ & $0.0000 \mathrm{E}+00$ & $0.0000 \mathrm{E}+00$ & $0.0000 \mathrm{E}+00$ & $0.0000 \mathrm{E}+00$ & $0.0000 \mathrm{E}+00$ & $0.0000 \mathrm{E}+00$ \\
\hline $\mathrm{HgO}$ & 3.7639E-07 & $0.0000 \mathrm{E}+00$ & $0.0000 \mathrm{E}+00$ & $3.7639 \mathrm{E}-07$ & $0.0000 \mathrm{E}+00$ & $0.0000 \mathrm{E}+00$ \\
\hline $\mathrm{I}$ & $2.6133 \mathrm{E}-06$ & $3.2429 \mathrm{E}-07$ & $1.1365 \mathrm{E}-07$ & $2.6133 \mathrm{E}-06$ & $3.2428 \mathrm{E}-07$ & $1.1332 \mathrm{E}-07$ \\
\hline $\mathrm{K} 2 \mathrm{O}$ & $6.2561 \mathrm{E}-02$ & $1.4709 \mathrm{E}-02$ & $8.0871 \mathrm{E}-04$ & $6.2561 \mathrm{E}-02$ & $1.4708 \mathrm{E}-02$ & $8.1803 \mathrm{E}-04$ \\
\hline $\mathrm{La} 2 \mathrm{O} 3$ & $1.6240 \mathrm{E}-06$ & $3.9435 \mathrm{E}-07$ & $2.7943 \mathrm{E}-08$ & $1.6240 \mathrm{E}-06$ & 3.9433E-07 & $2.7730 \mathrm{E}-08$ \\
\hline $\mathrm{Li} 2 \mathrm{O}$ & $1.3077 \mathrm{E}-06$ & $3.1715 \mathrm{E}-07$ & $3.0378 \mathrm{E}-08$ & $1.3077 \mathrm{E}-06$ & $3.1714 \mathrm{E}-07$ & $3.0504 \mathrm{E}-08$ \\
\hline $\mathrm{MgO}$ & $1.0329 \mathrm{E}-04$ & $1.4865 \mathrm{E}-02$ & $3.1747 \mathrm{E}-04$ & $1.0329 \mathrm{E}-04$ & $1.4875 \mathrm{E}-02$ & $2.9831 \mathrm{E}-04$ \\
\hline $\mathrm{MnO}$ & $6.4877 \mathrm{E}-06$ & $1.2823 \mathrm{E}-04$ & $3.4265 \mathrm{E}-05$ & $6.4877 \mathrm{E}-06$ & $1.2824 \mathrm{E}-04$ & $3.4467 \mathrm{E}-05$ \\
\hline $\mathrm{MoO} 3$ & $5.3679 \mathrm{E}-05$ & $1.2784 \mathrm{E}-05$ & $9.4620 \mathrm{E}-07$ & $5.3679 \mathrm{E}-05$ & $1.2784 \mathrm{E}-05$ & $9.4419 \mathrm{E}-07$ \\
\hline $\mathrm{Na} 2 \mathrm{O}$ & $8.1983 \mathrm{E}-01$ & $1.9823 \mathrm{E}-01$ & $1.2101 \mathrm{E}-02$ & $8.1983 \mathrm{E}-01$ & $1.9823 \mathrm{E}-01$ & $1.1902 \mathrm{E}-02$ \\
\hline $\mathrm{Nb2O5}$ & $3.6608 \mathrm{E}-08$ & $8.8893 \mathrm{E}-09$ & $6.3816 \mathrm{E}-10$ & $3.6608 \mathrm{E}-08$ & $8.8890 \mathrm{E}-09$ & $6.1775 \mathrm{E}-10$ \\
\hline $\mathrm{Nd} 2 \mathrm{O} 3$ & $5.2602 \mathrm{E}-06$ & $1.2773 \mathrm{E}-06$ & $1.2272 \mathrm{E}-07$ & $5.2602 \mathrm{E}-06$ & $1.2773 \mathrm{E}-06$ & $1.2300 \mathrm{E}-07$ \\
\hline $\mathrm{NiO}$ & $1.3240 \mathrm{E}-04$ & $1.4456 \mathrm{E}-04$ & $1.7411 \mathrm{E}-05$ & $1.3240 \mathrm{E}-04$ & $1.4463 \mathrm{E}-04$ & $1.7633 \mathrm{E}-05$ \\
\hline $\mathrm{NpO} 2$ & 4.9799E-07 & $1.2092 \mathrm{E}-07$ & $6.0096 \mathrm{E}-09$ & $4.9799 \mathrm{E}-07$ & $1.2092 \mathrm{E}-07$ & $6.0643 \mathrm{E}-09$ \\
\hline $\mathrm{P} 2 \mathrm{O} 5$ & $7.7283 \mathrm{E}-03$ & $2.0269 \mathrm{E}-03$ & $1.3736 \mathrm{E}-04$ & $7.7283 \mathrm{E}-03$ & $2.0268 \mathrm{E}-03$ & $1.3494 \mathrm{E}-04$ \\
\hline $\mathrm{Pa} 2 \mathrm{O} 5$ & $1.2004 \mathrm{E}-09$ & $2.9149 \mathrm{E}-10$ & $8.5504 \mathrm{E}-11$ & $1.2004 \mathrm{E}-09$ & $2.9148 \mathrm{E}-10$ & $8.4903 \mathrm{E}-11$ \\
\hline $\mathrm{PbO}$ & $1.3869 \mathrm{E}-04$ & $3.3944 \mathrm{E}-05$ & $3.2233 \mathrm{E}-06$ & $1.3869 \mathrm{E}-04$ & $3.3944 \mathrm{E}-05$ & $3.2462 \mathrm{E}-06$ \\
\hline $\mathrm{PdO}$ & $3.2552 \mathrm{E}-05$ & $7.9044 \mathrm{E}-06$ & $7.5982 \mathrm{E}-07$ & $3.2552 \mathrm{E}-05$ & 7.9042E-06 & $7.6054 \mathrm{E}-07$ \\
\hline Pr2O3 & $4.6495 \mathrm{E}-08$ & $1.1290 \mathrm{E}-08$ & $1.0692 \mathrm{E}-09$ & $4.6495 \mathrm{E}-08$ & $1.1290 \mathrm{E}-08$ & $1.0884 \mathrm{E}-09$ \\
\hline $\mathrm{PuO} 2$ & $3.5629 \mathrm{E}-08$ & $8.6515 \mathrm{E}-09$ & $4.2148 \mathrm{E}-10$ & $3.5629 \mathrm{E}-08$ & $8.6512 \mathrm{E}-09$ & $4.3118 \mathrm{E}-10$ \\
\hline $\mathrm{RaO}$ & $2.0474 \mathrm{E}-11$ & $3.8449 \mathrm{E}-12$ & $9.8428 \mathrm{E}-13$ & $2.0474 \mathrm{E}-11$ & $3.8448 \mathrm{E}-12$ & $1.0113 \mathrm{E}-12$ \\
\hline $\mathrm{Rb} 2 \mathrm{O}$ & $6.5656 \mathrm{E}-06$ & $1.5636 \mathrm{E}-06$ & $2.3321 \mathrm{E}-07$ & $6.5656 \mathrm{E}-06$ & $1.5636 \mathrm{E}-06$ & $2.3411 \mathrm{E}-07$ \\
\hline $\mathrm{Rh} 2 \mathrm{O} 3$ & $1.4612 \mathrm{E}-05$ & $3.5481 \mathrm{E}-06$ & $1.7823 \mathrm{E}-07$ & $1.4612 \mathrm{E}-05$ & $3.5479 \mathrm{E}-06$ & $1.7806 \mathrm{E}-07$ \\
\hline $\mathrm{RuO} 2$ & $7.0248 \mathrm{E}-05$ & $1.6730 \mathrm{E}-05$ & $8.9515 \mathrm{E}-07$ & $7.0248 \mathrm{E}-05$ & $1.6729 \mathrm{E}-05$ & $8.9104 \mathrm{E}-07$ \\
\hline $\mathrm{SO} 3$ & $1.5015 \mathrm{E}-02$ & $3.1135 \mathrm{E}-03$ & $3.2608 \mathrm{E}-04$ & $1.5015 \mathrm{E}-02$ & $3.1134 \mathrm{E}-03$ & $3.3010 \mathrm{E}-04$ \\
\hline $\mathrm{Sb} 2 \mathrm{O} 3$ & $1.4126 \mathrm{E}-06$ & $2.6527 \mathrm{E}-07$ & $6.9087 \mathrm{E}-08$ & $1.4126 \mathrm{E}-06$ & $2.6526 \mathrm{E}-07$ & $6.9581 \mathrm{E}-08$ \\
\hline $\mathrm{SeO} 2$ & $1.1809 \mathrm{E}-05$ & $2.2176 \mathrm{E}-06$ & $5.9038 \mathrm{E}-07$ & $1.1809 \mathrm{E}-05$ & $2.2175 \mathrm{E}-06$ & $5.7091 \mathrm{E}-07$ \\
\hline $\mathrm{SiO} 2$ & $4.0816 \mathrm{E}-03$ & $4.4620 \mathrm{E}-01$ & $7.5408 \mathrm{E}-03$ & $4.0816 \mathrm{E}-03$ & $4.4618 \mathrm{E}-01$ & $7.4256 \mathrm{E}-03$ \\
\hline $\mathrm{Sm} 2 \mathrm{O} 3$ & $2.9247 \mathrm{E}-07$ & $7.1018 \mathrm{E}-08$ & $8.7455 \mathrm{E}-09$ & $2.9247 \mathrm{E}-07$ & $7.1015 \mathrm{E}-08$ & $8.7248 \mathrm{E}-09$ \\
\hline $\mathrm{SnO} 2$ & $2.6393 \mathrm{E}-07$ & $6.4089 \mathrm{E}-08$ & $6.2305 \mathrm{E}-09$ & $2.6393 \mathrm{E}-07$ & $6.4087 \mathrm{E}-08$ & $6.1163 \mathrm{E}-09$ \\
\hline $\mathrm{SrO}$ & $5.3587 \mathrm{E}-07$ & $1.3012 \mathrm{E}-07$ & $6.6038 \mathrm{E}-09$ & $5.3587 \mathrm{E}-07$ & $1.3012 \mathrm{E}-07$ & $6.5344 \mathrm{E}-09$ \\
\hline Ta2O5 & $1.9233 \mathrm{E}-07$ & $4.6704 \mathrm{E}-08$ & $4.5199 \mathrm{E}-09$ & $1.9233 \mathrm{E}-07$ & $4.6702 \mathrm{E}-08$ & $4.5111 \mathrm{E}-09$ \\
\hline Tc2O7 & $2.0004 \mathrm{E}-05$ & $2.0969 \mathrm{E}-06$ & $7.2888 \mathrm{E}-07$ & $2.0004 \mathrm{E}-05$ & $2.0968 \mathrm{E}-06$ & $7.2127 \mathrm{E}-07$ \\
\hline $\mathrm{TeO} 2$ & $5.9678 \mathrm{E}-07$ & $1.1207 \mathrm{E}-07$ & $2.9351 \mathrm{E}-08$ & $5.9678 \mathrm{E}-07$ & $1.1207 \mathrm{E}-07$ & $2.8946 \mathrm{E}-08$ \\
\hline $\mathrm{ThO} 2$ & $1.6901 \mathrm{E}-05$ & $4.1040 \mathrm{E}-06$ & $6.1329 \mathrm{E}-07$ & $1.6901 \mathrm{E}-05$ & $4.1039 \mathrm{E}-06$ & $6.1137 \mathrm{E}-07$ \\
\hline $\mathrm{TiO} 2$ & $2.0761 \mathrm{E}-05$ & $1.4035 \mathrm{E}-02$ & $2.9892 \mathrm{E}-04$ & $2.0761 \mathrm{E}-05$ & $1.4034 \mathrm{E}-02$ & $2.7812 \mathrm{E}-04$ \\
\hline $\mathrm{T} 12 \mathrm{O}$ & $3.7920 \mathrm{E}-06$ & $7.1211 \mathrm{E}-07$ & $1.5700 \mathrm{E}-07$ & $3.7920 \mathrm{E}-06$ & $7.1209 \mathrm{E}-07$ & $1.6042 \mathrm{E}-07$ \\
\hline UO3 & $1.6711 \mathrm{E}-04$ & $6.0905 \mathrm{E}-05$ & $4.3418 \mathrm{E}-06$ & $1.6711 \mathrm{E}-04$ & $6.0911 \mathrm{E}-05$ & $4.4644 \mathrm{E}-06$ \\
\hline V2O5 & $2.5796 \mathrm{E}-06$ & $5.9966 \mathrm{E}-05$ & $1.9328 \mathrm{E}-05$ & $2.5796 \mathrm{E}-06$ & $5.9965 \mathrm{E}-05$ & $1.9830 \mathrm{E}-05$ \\
\hline WO3 & $5.4213 \mathrm{E}-05$ & $1.3164 \mathrm{E}-05$ & $6.5957 \mathrm{E}-07$ & $5.4213 \mathrm{E}-05$ & $1.3164 \mathrm{E}-05$ & $6.5170 \mathrm{E}-07$ \\
\hline $\mathrm{Y} 2 \mathrm{O} 3$ & $2.9811 \mathrm{E}-06$ & $7.2390 \mathrm{E}-07$ & $1.0969 \mathrm{E}-07$ & $2.9811 \mathrm{E}-06$ & $7.2387 \mathrm{E}-07$ & $1.0888 \mathrm{E}-07$ \\
\hline $\mathrm{ZnO}$ & $6.4149 \mathrm{E}-05$ & $3.5088 \mathrm{E}-02$ & $6.1239 \mathrm{E}-04$ & $6.4149 \mathrm{E}-05$ & $3.5115 \mathrm{E}-02$ & $5.8989 \mathrm{E}-04$ \\
\hline $\mathrm{ZrO} 2$ & $3.1886 \mathrm{E}-05$ & $3.0136 \mathrm{E}-02$ & $5.5535 \mathrm{E}-04$ & $3.1886 \mathrm{E}-05$ & $3.0148 \mathrm{E}-02$ & $5.3327 \mathrm{E}-04$ \\
\hline SUM & $1.0000 \mathrm{E}+00$ & $1.0000 \mathrm{E}+00$ & NA & $1.0000 \mathrm{E}+00$ & $1.0000 \mathrm{E}+00$ & NA \\
\hline- & -- & -- & -- & -- & -- & -- \\
\hline
\end{tabular}




\begin{tabular}{|c|c|c|c|c|c|c|}
\hline \multirow{2}{*}{$\begin{array}{l}\text { Batch } \\
\text { Comp }\end{array}$} & \multicolumn{3}{|c|}{ MFPV-A103 } & \multicolumn{3}{|c|}{ MFPV-B103 } \\
\hline & Waste & Glass & Glass SD & Waste & Glass & Glass SD \\
\hline $\operatorname{Rad}$ & mCi/g oxides & $\mathrm{mCi} / \mathrm{g}$ glass & $\mathrm{mCi} / \mathrm{g}$ glass & mCi/g oxides & $\mathrm{mCi} / \mathrm{g}$ glass & $\mathrm{mCi} / \mathrm{g}$ glass \\
\hline $59 \mathrm{Ni}$ & $1.4789 \mathrm{E}-06$ & $3.5718 \mathrm{E}-07$ & $2.4950 \mathrm{E}-08$ & $1.4789 \mathrm{E}-06$ & $3.5717 \mathrm{E}-07$ & $2.5943 \mathrm{E}-08$ \\
\hline $60 \mathrm{Co}$ & $2.2972 \mathrm{E}-06$ & $5.5782 \mathrm{E}-07$ & 2.7979E-08 & 2.2972E-06 & 5.5781E-07 & $2.7968 \mathrm{E}-08$ \\
\hline $63 \mathrm{Ni}$ & $1.3482 \mathrm{E}-04$ & $3.2563 \mathrm{E}-05$ & $2.3171 \mathrm{E}-06$ & $1.3482 \mathrm{E}-04$ & $3.2561 \mathrm{E}-05$ & $2.3373 \mathrm{E}-06$ \\
\hline $79 \mathrm{Se}$ & $5.3564 \mathrm{E}-06$ & $1.0059 \mathrm{E}-06$ & 2.3292E-07 & $5.3564 \mathrm{E}-06$ & $1.0059 \mathrm{E}-06$ & $2.2122 \mathrm{E}-07$ \\
\hline $90 \mathrm{Sr}$ & $2.3776 \mathrm{E}-03$ & $5.7733 \mathrm{E}-04$ & $2.9206 \mathrm{E}-05$ & $2.3776 \mathrm{E}-03$ & 5.7731E-04 & $2.8873 \mathrm{E}-05$ \\
\hline $90 \mathrm{Y}$ & $2.3019 \mathrm{E}-03$ & $5.5897 \mathrm{E}-04$ & $2.8412 \mathrm{E}-05$ & $2.3019 \mathrm{E}-03$ & $5.5895 \mathrm{E}-04$ & $2.8005 \mathrm{E}-05$ \\
\hline $93 \mathrm{mNb}$ & 6.1059E-03 & $1.4827 \mathrm{E}-03$ & $1.0644 \mathrm{E}-04$ & $6.1059 \mathrm{E}-03$ & $1.4826 \mathrm{E}-03$ & $1.0304 \mathrm{E}-04$ \\
\hline $93 \mathrm{Zr}$ & $3.5560 \mathrm{E}-05$ & $8.6574 \mathrm{E}-06$ & $6.2592 \mathrm{E}-07$ & $3.5560 \mathrm{E}-05$ & $8.6571 \mathrm{E}-06$ & $6.0974 \mathrm{E}-07$ \\
\hline $99 \mathrm{Tc}$ & $2.1854 \mathrm{E}-04$ & $2.2908 \mathrm{E}-05$ & $7.9628 \mathrm{E}-06$ & $2.1854 \mathrm{E}-04$ & $2.2908 \mathrm{E}-05$ & $7.8797 \mathrm{E}-06$ \\
\hline $106 \mathrm{Ru}$ & $1.9323 \mathrm{E}-09$ & $4.6018 \mathrm{E}-10$ & $4.5902 \mathrm{E}-11$ & $1.9323 \mathrm{E}-09$ & 4.6017E-10 & $4.5806 \mathrm{E}-11$ \\
\hline $113 \mathrm{mCd}$ & $2.5788 \mathrm{E}-05$ & $6.2620 \mathrm{E}-06$ & 4.4870E-07 & $2.5788 \mathrm{E}-05$ & $6.2618 \mathrm{E}-06$ & 4.4687E-07 \\
\hline $125 \mathrm{Sb}$ & $6.0235 \mathrm{E}-06$ & $1.1312 \mathrm{E}-06$ & $2.4573 \mathrm{E}-07$ & $6.0235 \mathrm{E}-06$ & $1.1311 \mathrm{E}-06$ & $2.4545 \mathrm{E}-07$ \\
\hline $126 \mathrm{Sn}$ & $5.9755 \mathrm{E}-06$ & $1.4510 \mathrm{E}-06$ & $1.4106 \mathrm{E}-07$ & $5.9755 \mathrm{E}-06$ & $1.4509 \mathrm{E}-06$ & $1.3847 \mathrm{E}-07$ \\
\hline 129I & 4.6203E-07 & $5.7335 \mathrm{E}-08$ & 2.0094E-08 & 4.6203E-07 & 5.7333E-08 & $2.0034 \mathrm{E}-08$ \\
\hline $134 \mathrm{Cs}$ & $1.0053 \mathrm{E}-09$ & $2.1518 \mathrm{E}-10$ & $3.8947 \mathrm{E}-11$ & $1.0053 \mathrm{E}-09$ & $2.1518 \mathrm{E}-10$ & $3.8712 \mathrm{E}-11$ \\
\hline $137 \mathrm{mBa}$ & $3.7197 \mathrm{E}-01$ & $9.0323 \mathrm{E}-02$ & 4.5793E-03 & $3.7197 \mathrm{E}-01$ & $9.0320 \mathrm{E}-02$ & $4.5024 \mathrm{E}-03$ \\
\hline $137 \mathrm{Cs}$ & $2.1567 \mathrm{E}-04$ & 4.6164E-05 & 5.1394E-06 & $2.1567 \mathrm{E}-04$ & 4.6162E-05 & $5.1760 \mathrm{E}-06$ \\
\hline $151 \mathrm{Sm}$ & $6.6420 \mathrm{E}-03$ & $1.6128 \mathrm{E}-03$ & $1.9861 \mathrm{E}-04$ & $6.6420 \mathrm{E}-03$ & $1.6128 \mathrm{E}-03$ & $1.9814 \mathrm{E}-04$ \\
\hline $152 \mathrm{Eu}$ & $1.1188 \mathrm{E}-06$ & $2.7167 \mathrm{E}-07$ & $1.3676 \mathrm{E}-08$ & $1.1188 \mathrm{E}-06$ & $2.7166 \mathrm{E}-07$ & $1.3574 \mathrm{E}-08$ \\
\hline $154 \mathrm{Eu}$ & $2.3964 \mathrm{E}-05$ & $5.8190 \mathrm{E}-06$ & $2.9357 \mathrm{E}-07$ & $2.3964 \mathrm{E}-05$ & 5.8188E-06 & $2.9317 \mathrm{E}-07$ \\
\hline $155 \mathrm{Eu}$ & $1.0455 \mathrm{E}-05$ & $2.5388 \mathrm{E}-06$ & $1.2894 \mathrm{E}-07$ & $1.0455 \mathrm{E}-05$ & $2.5387 \mathrm{E}-06$ & $1.2730 \mathrm{E}-07$ \\
\hline $226 \mathrm{Ra}$ & $1.8876 \mathrm{E}-08$ & 3.5447E-09 & $9.0779 \mathrm{E}-10$ & $1.8876 \mathrm{E}-08$ & $3.5446 \mathrm{E}-09$ & $9.3277 \mathrm{E}-10$ \\
\hline 227Ac & $1.7489 \mathrm{E}-08$ & 4.2468E-09 & $3.0058 \mathrm{E}-10$ & $1.7489 \mathrm{E}-08$ & 4.2467E-09 & $3.0353 \mathrm{E}-10$ \\
\hline $228 \mathrm{Ra}$ & $7.0340 \mathrm{E}-09$ & 1.3209E-09 & 4.8487E-10 & $7.0340 \mathrm{E}-09$ & 1.3209E-09 & $4.7817 \mathrm{E}-10$ \\
\hline 229Th & $7.4506 \mathrm{E}-10$ & $1.8092 \mathrm{E}-10$ & $5.3394 \mathrm{E}-11$ & $7.4506 \mathrm{E}-10$ & $1.8091 \mathrm{E}-10$ & $5.2534 \mathrm{E}-11$ \\
\hline $231 \mathrm{~Pa}$ & 4.8329E-08 & $1.1735 \mathrm{E}-08$ & $3.4424 \mathrm{E}-09$ & 4.8329E-08 & $1.1735 \mathrm{E}-08$ & $3.4182 \mathrm{E}-09$ \\
\hline $232 \mathrm{Th}$ & $1.6278 \mathrm{E}-09$ & $3.9528 \mathrm{E}-10$ & $2.8214 \mathrm{E}-11$ & $1.6278 \mathrm{E}-09$ & $3.9527 \mathrm{E}-10$ & $2.8149 \mathrm{E}-11$ \\
\hline $232 \mathrm{U}$ & 2.1971E-09 & $5.3350 \mathrm{E}-10$ & $2.6588 \mathrm{E}-11$ & $2.1971 \mathrm{E}-09$ & $5.3348 \mathrm{E}-10$ & $2.6529 \mathrm{E}-11$ \\
\hline $233 \mathrm{U}$ & $1.0623 \mathrm{E}-07$ & $2.5794 \mathrm{E}-08$ & 1.3004E-09 & $1.0623 \mathrm{E}-07$ & $2.5793 \mathrm{E}-08$ & $1.3111 \mathrm{E}-09$ \\
\hline $234 \mathrm{U}$ & $6.2275 \mathrm{E}-08$ & $1.5122 \mathrm{E}-08$ & $7.5314 \mathrm{E}-10$ & $6.2275 \mathrm{E}-08$ & $1.5121 \mathrm{E}-08$ & $7.5846 \mathrm{E}-10$ \\
\hline $235 \mathrm{U}$ & $2.3480 \mathrm{E}-09$ & $5.7015 \mathrm{E}-10$ & $4.0290 \mathrm{E}-11$ & $2.3480 \mathrm{E}-09$ & $5.7013 \mathrm{E}-10$ & $4.0075 \mathrm{E}-11$ \\
\hline $236 \mathrm{U}$ & 4.3462E-09 & $1.0554 \mathrm{E}-09$ & $5.3087 \mathrm{E}-11$ & 4.3462E-09 & $1.0553 \mathrm{E}-09$ & $5.3930 \mathrm{E}-11$ \\
\hline $237 \mathrm{~Np}$ & $3.0920 \mathrm{E}-07$ & 7.5081E-08 & 3.7313E-09 & $3.0920 \mathrm{E}-07$ & $7.5078 \mathrm{E}-08$ & $3.7653 \mathrm{E}-09$ \\
\hline $238 \mathrm{Pu}$ & $1.5888 \mathrm{E}-07$ & $3.8580 \mathrm{E}-08$ & $1.9520 \mathrm{E}-09$ & $1.5888 \mathrm{E}-07$ & $3.8579 \mathrm{E}-08$ & $1.9337 \mathrm{E}-09$ \\
\hline $238 \mathrm{U}$ & 4.6347E-08 & $1.1254 \mathrm{E}-08$ & $8.0587 \mathrm{E}-10$ & 4.6347E-08 & $1.1254 \mathrm{E}-08$ & $8.0691 \mathrm{E}-10$ \\
\hline $239 \mathrm{Pu}$ & $1.8232 \mathrm{E}-06$ & 4.4273E-07 & 2.1979E-08 & $1.8232 \mathrm{E}-06$ & $4.4271 \mathrm{E}-07$ & $2.2474 \mathrm{E}-08$ \\
\hline $240 \mathrm{Pu}$ & 4.4373E-07 & $1.0775 \mathrm{E}-07$ & 7.6832E-09 & 4.4373E-07 & $1.0775 \mathrm{E}-07$ & $7.7549 \mathrm{E}-09$ \\
\hline $241 \mathrm{Am}$ & $2.2141 \mathrm{E}-06$ & $5.2729 \mathrm{E}-07$ & 3.8954E-08 & $2.2141 \mathrm{E}-06$ & $5.2727 \mathrm{E}-07$ & $3.8737 \mathrm{E}-08$ \\
\hline $241 \mathrm{Pu}$ & $5.0095 \mathrm{E}-06$ & $1.2164 \mathrm{E}-06$ & $1.1569 \mathrm{E}-07$ & $5.0095 \mathrm{E}-06$ & $1.2164 \mathrm{E}-06$ & $1.1718 \mathrm{E}-07$ \\
\hline $242 \mathrm{Cm}$ & $1.1203 \mathrm{E}-08$ & 2.7204E-09 & $1.9353 \mathrm{E}-10$ & $1.1203 \mathrm{E}-08$ & 2.7203E-09 & $1.9470 \mathrm{E}-10$ \\
\hline $242 \mathrm{Pu}$ & 4.9053E-11 & $1.1911 \mathrm{E}-11$ & $8.4618 \mathrm{E}-13$ & $4.9053 \mathrm{E}-11$ & $1.1911 \mathrm{E}-11$ & $8.3352 \mathrm{E}-13$ \\
\hline $243 \mathrm{Am}$ & $3.7354 \mathrm{E}-10$ & $8.8960 \mathrm{E}-11$ & $8.5566 \mathrm{E}-12$ & $3.7354 \mathrm{E}-10$ & $8.8957 \mathrm{E}-11$ & $8.7726 \mathrm{E}-12$ \\
\hline $243 \mathrm{Cm}$ & $1.3805 \mathrm{E}-09$ & $3.3522 \mathrm{E}-10$ & $3.2252 \mathrm{E}-11$ & $1.3805 \mathrm{E}-09$ & $3.3521 \mathrm{E}-10$ & $3.2275 \mathrm{E}-11$ \\
\hline $244 \mathrm{Cm}$ & $2.8205 \mathrm{E}-08$ & 6.8487E-09 & $6.6742 \mathrm{E}-10$ & $2.8205 \mathrm{E}-08$ & $6.8485 \mathrm{E}-09$ & $6.4471 \mathrm{E}-10$ \\
\hline $\mathrm{TRU}^{(\mathrm{a})}$ & 4.9791E-06 & 1.1987E-06 & $4.5582 \mathrm{E}-08$ & 4.9791E-06 & $1.1987 \mathrm{E}-06$ & $4.5652 \mathrm{E}-08$ \\
\hline
\end{tabular}




\begin{tabular}{|c|c|c|c|c|c|c|}
\hline \multirow{2}{*}{$\begin{array}{l}\text { Batch } \\
\text { Comp }\end{array}$} & \multicolumn{3}{|c|}{ MFPV-A104 } & \multicolumn{3}{|c|}{ MFPV-B104 } \\
\hline & Waste & Glass & Glass SD & Waste & Glass & Glass SD \\
\hline $\mathrm{Ac} 2 \mathrm{O} 3$ & $2.6069 \mathrm{E}-13$ & 5.4473E-14 & $3.9173 \mathrm{E}-15$ & $2.6069 \mathrm{E}-13$ & $5.4476 \mathrm{E}-14$ & $3.9660 \mathrm{E}-15$ \\
\hline Ag2O & $1.3203 \mathrm{E}-06$ & $2.7058 \mathrm{E}-07$ & $3.4282 \mathrm{E}-08$ & $1.3203 \mathrm{E}-06$ & $2.7059 \mathrm{E}-07$ & $3.4365 \mathrm{E}-08$ \\
\hline $\mathrm{A} 12 \mathrm{O} 3$ & $6.7942 \mathrm{E}-02$ & $6.1199 \mathrm{E}-02$ & $1.1292 \mathrm{E}-03$ & $6.7942 \mathrm{E}-02$ & $6.1208 \mathrm{E}-02$ & $1.1380 \mathrm{E}-03$ \\
\hline $\mathrm{Am} 2 \mathrm{O} 3$ & $8.4636 \mathrm{E}-10$ & $1.7345 \mathrm{E}-10$ & $1.2992 \mathrm{E}-11$ & $8.4636 \mathrm{E}-10$ & $1.7346 \mathrm{E}-10$ & $1.3061 \mathrm{E}-11$ \\
\hline As2O5 & $7.3276 \mathrm{E}-06$ & $1.1841 \mathrm{E}-06$ & $3.1191 \mathrm{E}-07$ & $7.3276 \mathrm{E}-06$ & $1.1842 \mathrm{E}-06$ & $3.0992 \mathrm{E}-07$ \\
\hline $\mathrm{B} 2 \mathrm{O} 3$ & $2.4782 \mathrm{E}-04$ & $9.9440 \mathrm{E}-02$ & $1.5195 \mathrm{E}-03$ & $2.4782 \mathrm{E}-04$ & $9.9417 \mathrm{E}-02$ & $1.5210 \mathrm{E}-03$ \\
\hline $\mathrm{BaO}$ & $1.1993 \mathrm{E}-06$ & $2.5060 \mathrm{E}-07$ & $2.4631 \mathrm{E}-08$ & 1.1993E-06 & $2.5062 \mathrm{E}-07$ & $2.4463 \mathrm{E}-08$ \\
\hline $\mathrm{BeO}$ & $5.3496 \mathrm{E}-06$ & $1.1178 \mathrm{E}-06$ & $5.8228 \mathrm{E}-08$ & $5.3496 \mathrm{E}-06$ & $1.1179 \mathrm{E}-06$ & 5.8997E-08 \\
\hline $\mathrm{Bi} 2 \mathrm{O} 3$ & $2.1577 \mathrm{E}-05$ & 4.4219E-06 & $3.3355 \mathrm{E}-07$ & $2.1577 \mathrm{E}-05$ & $4.4222 \mathrm{E}-06$ & $3.3314 \mathrm{E}-07$ \\
\hline $\mathrm{CaO}$ & $1.9529 \mathrm{E}-04$ & $3.6204 \mathrm{E}-02$ & $9.1150 \mathrm{E}-04$ & $1.9529 \mathrm{E}-04$ & $3.6199 \mathrm{E}-02$ & $9.2816 \mathrm{E}-04$ \\
\hline $\mathrm{CdO}$ & $3.4282 \mathrm{E}-06$ & $4.2310 \mathrm{E}-06$ & $1.3141 \mathrm{E}-06$ & $3.4282 \mathrm{E}-06$ & $4.2310 \mathrm{E}-06$ & $1.3038 \mathrm{E}-06$ \\
\hline $\mathrm{Ce} 2 \mathrm{O} 3$ & $1.2037 \mathrm{E}-06$ & $2.5151 \mathrm{E}-07$ & $3.8542 \mathrm{E}-08$ & $1.2037 \mathrm{E}-06$ & $2.5153 \mathrm{E}-07$ & 3.7404E-08 \\
\hline $\mathrm{Cl}$ & $1.1041 \mathrm{E}-02$ & $1.2594 \mathrm{E}-03$ & $3.5262 \mathrm{E}-04$ & $1.1041 \mathrm{E}-02$ & $1.2595 \mathrm{E}-03$ & 3.6159E-04 \\
\hline $\mathrm{Cm} 2 \mathrm{O} 3$ & $4.4300 \mathrm{E}-13$ & $9.2568 \mathrm{E}-14$ & $8.4361 \mathrm{E}-15$ & $4.4300 \mathrm{E}-13$ & $9.2574 \mathrm{E}-14$ & $8.4852 \mathrm{E}-15$ \\
\hline $\mathrm{CoO}$ & $1.9811 \mathrm{E}-06$ & $4.1397 \mathrm{E}-07$ & $6.2376 \mathrm{E}-08$ & $1.9811 \mathrm{E}-06$ & $4.1400 \mathrm{E}-07$ & $6.2922 \mathrm{E}-08$ \\
\hline $\mathrm{Cr} 2 \mathrm{O} 3$ & $3.8354 \mathrm{E}-03$ & $8.6155 \mathrm{E}-04$ & $6.3488 \mathrm{E}-05$ & $3.8354 \mathrm{E}-03$ & $8.6161 \mathrm{E}-04$ & $6.3665 \mathrm{E}-05$ \\
\hline $\mathrm{Cs} 2 \mathrm{O}$ & $1.4539 \mathrm{E}-08$ & $2.6779 \mathrm{E}-09$ & $3.7874 \mathrm{E}-10$ & $1.4539 \mathrm{E}-08$ & $2.6781 \mathrm{E}-09$ & $3.7880 \mathrm{E}-10$ \\
\hline $\mathrm{CuO}$ & $3.6164 \mathrm{E}-06$ & $7.5567 \mathrm{E}-07$ & $1.1419 \mathrm{E}-07$ & $3.6164 \mathrm{E}-06$ & $7.5572 \mathrm{E}-07$ & $1.1277 \mathrm{E}-07$ \\
\hline $\mathrm{Eu} 2 \mathrm{O} 3$ & $1.4350 \mathrm{E}-10$ & $2.9985 \mathrm{E}-11$ & $1.4790 \mathrm{E}-12$ & $1.4350 \mathrm{E}-10$ & $2.9987 \mathrm{E}-11$ & $1.4922 \mathrm{E}-12$ \\
\hline $\mathrm{F}$ & $4.7503 \mathrm{E}-03$ & $7.2647 \mathrm{E}-04$ & $1.3278 \mathrm{E}-04$ & $4.7503 \mathrm{E}-03$ & $7.2651 \mathrm{E}-04$ & $1.3171 \mathrm{E}-04$ \\
\hline $\mathrm{Fe} 2 \mathrm{O} 3$ & $8.8061 \mathrm{E}-05$ & $5.5158 \mathrm{E}-02$ & $8.9652 \mathrm{E}-04$ & $8.8061 \mathrm{E}-05$ & $5.5173 \mathrm{E}-02$ & 8.9744E-04 \\
\hline $\mathrm{Gd} 2 \mathrm{O} 3$ & $0.0000 \mathrm{E}+00$ & $0.0000 \mathrm{E}+00$ & $0.0000 \mathrm{E}+00$ & $0.0000 \mathrm{E}+00$ & $0.0000 \mathrm{E}+00$ & $0.0000 \mathrm{E}+00$ \\
\hline $\mathrm{HgO}$ & $4.4272 \mathrm{E}-07$ & $0.0000 \mathrm{E}+00$ & $0.0000 \mathrm{E}+00$ & 4.4272E-07 & $0.0000 \mathrm{E}+00$ & $0.0000 \mathrm{E}+00$ \\
\hline $\mathrm{I}$ & $2.8276 \mathrm{E}-06$ & $3.0194 \mathrm{E}-07$ & $1.0638 \mathrm{E}-07$ & $2.8276 \mathrm{E}-06$ & $3.0196 \mathrm{E}-07$ & $1.0607 \mathrm{E}-07$ \\
\hline $\mathrm{K} 2 \mathrm{O}$ & $6.0931 \mathrm{E}-02$ & $1.2332 \mathrm{E}-02$ & $7.0467 \mathrm{E}-04$ & $6.0931 \mathrm{E}-02$ & $1.2332 \mathrm{E}-02$ & $7.0837 \mathrm{E}-04$ \\
\hline La2O3 & $1.7831 \mathrm{E}-06$ & $3.7260 \mathrm{E}-07$ & $2.7248 \mathrm{E}-08$ & $1.7831 \mathrm{E}-06$ & $3.7262 \mathrm{E}-07$ & $2.7227 \mathrm{E}-08$ \\
\hline $\mathrm{Li} 2 \mathrm{O}$ & $1.3123 \mathrm{E}-06$ & $5.9632 \mathrm{E}-03$ & $9.0520 \mathrm{E}-05$ & $1.3123 \mathrm{E}-06$ & $5.8683 \mathrm{E}-03$ & $8.9571 \mathrm{E}-05$ \\
\hline $\mathrm{MgO}$ & $1.2825 \mathrm{E}-04$ & $1.4867 \mathrm{E}-02$ & $2.8001 \mathrm{E}-04$ & $1.2825 \mathrm{E}-04$ & $1.4871 \mathrm{E}-02$ & $2.8223 \mathrm{E}-04$ \\
\hline $\mathrm{MnO}$ & $7.1305 \mathrm{E}-06$ & $1.5750 \mathrm{E}-04$ & $3.4441 \mathrm{E}-05$ & $7.1305 \mathrm{E}-06$ & $1.5751 \mathrm{E}-04$ & $3.4185 \mathrm{E}-05$ \\
\hline $\mathrm{MoO} 3$ & $5.6978 \mathrm{E}-05$ & $1.1677 \mathrm{E}-05$ & $8.7961 \mathrm{E}-07$ & $5.6978 \mathrm{E}-05$ & $1.1678 \mathrm{E}-05$ & $8.8018 \mathrm{E}-07$ \\
\hline $\mathrm{Na} 2 \mathrm{O}$ & $8.2044 \mathrm{E}-01$ & $1.7078 \mathrm{E}-01$ & $1.0814 \mathrm{E}-02$ & 8.2044E-01 & $1.7079 \mathrm{E}-01$ & $1.0880 \mathrm{E}-02$ \\
\hline $\mathrm{Nb} 2 \mathrm{O} 5$ & $4.1829 \mathrm{E}-08$ & 8.7404E-09 & $6.3346 \mathrm{E}-10$ & 4.1829E-08 & $8.7410 \mathrm{E}-09$ & $6.4170 \mathrm{E}-10$ \\
\hline $\mathrm{Nd} 2 \mathrm{O} 3$ & $5.2652 \mathrm{E}-06$ & $1.1002 \mathrm{E}-06$ & $1.0792 \mathrm{E}-07$ & $5.2652 \mathrm{E}-06$ & $1.1003 \mathrm{E}-06$ & $1.0654 \mathrm{E}-07$ \\
\hline $\mathrm{NiO}$ & $1.3264 \mathrm{E}-04$ & $1.3994 \mathrm{E}-04$ & $1.7382 \mathrm{E}-05$ & $1.3264 \mathrm{E}-04$ & $1.3998 \mathrm{E}-04$ & $1.7624 \mathrm{E}-05$ \\
\hline $\mathrm{NpO} 2$ & $5.4596 \mathrm{E}-07$ & $1.1408 \mathrm{E}-07$ & $5.9200 \mathrm{E}-09$ & $5.4596 \mathrm{E}-07$ & $1.1409 \mathrm{E}-07$ & $6.0532 \mathrm{E}-09$ \\
\hline $\mathrm{P} 2 \mathrm{O} 5$ & $8.3260 \mathrm{E}-03$ & $1.8902 \mathrm{E}-03$ & $1.3047 \mathrm{E}-04$ & $8.3260 \mathrm{E}-03$ & $1.8904 \mathrm{E}-03$ & $1.3017 \mathrm{E}-04$ \\
\hline $\mathrm{Pa} 2 \mathrm{O} 5$ & $1.1641 \mathrm{E}-09$ & $2.4326 \mathrm{E}-10$ & $7.0643 \mathrm{E}-11$ & $1.1641 \mathrm{E}-09$ & $2.4327 \mathrm{E}-10$ & $7.1190 \mathrm{E}-11$ \\
\hline $\mathrm{PbO}$ & $1.3978 \mathrm{E}-04$ & $2.9515 \mathrm{E}-05$ & $2.8390 \mathrm{E}-06$ & $1.3978 \mathrm{E}-04$ & $2.9517 \mathrm{E}-05$ & $2.8714 \mathrm{E}-06$ \\
\hline $\mathrm{PdO}$ & $3.1454 \mathrm{E}-05$ & $6.5724 \mathrm{E}-06$ & $6.3309 \mathrm{E}-07$ & $3.1454 \mathrm{E}-05$ & $6.5728 \mathrm{E}-06$ & $6.4007 \mathrm{E}-07$ \\
\hline Pr2O3 & $4.5224 \mathrm{E}-08$ & 9.4499E-09 & $9.1880 \mathrm{E}-10$ & 4.5224E-08 & $9.4504 \mathrm{E}-09$ & $9.4052 \mathrm{E}-10$ \\
\hline $\mathrm{PuO} 2$ & $4.1086 \mathrm{E}-08$ & $8.5853 \mathrm{E}-09$ & $4.4880 \mathrm{E}-10$ & $4.1086 \mathrm{E}-08$ & $8.5858 \mathrm{E}-09$ & $4.4680 \mathrm{E}-10$ \\
\hline $\mathrm{RaO}$ & $1.9838 \mathrm{E}-11$ & $3.2059 \mathrm{E}-12$ & $8.5059 \mathrm{E}-13$ & $1.9838 \mathrm{E}-11$ & $3.2061 \mathrm{E}-12$ & $8.4421 \mathrm{E}-13$ \\
\hline $\mathrm{Rb} 2 \mathrm{O}$ & $6.3763 \mathrm{E}-06$ & $1.3067 \mathrm{E}-06$ & $2.0005 \mathrm{E}-07$ & $6.3763 \mathrm{E}-06$ & $1.3068 \mathrm{E}-06$ & $1.9951 \mathrm{E}-07$ \\
\hline Rh2O3 & $1.4099 \mathrm{E}-05$ & $2.9461 \mathrm{E}-06$ & $1.5848 \mathrm{E}-07$ & $1.4099 \mathrm{E}-05$ & $2.9462 \mathrm{E}-06$ & $1.5591 \mathrm{E}-07$ \\
\hline $\mathrm{RuO} 2$ & $6.8799 \mathrm{E}-05$ & $1.4100 \mathrm{E}-05$ & 7.9094E-07 & 6.8799E-05 & $1.4100 \mathrm{E}-05$ & $7.9690 \mathrm{E}-07$ \\
\hline SO3 & $1.7012 \mathrm{E}-02$ & $3.0397 \mathrm{E}-03$ & $3.2351 \mathrm{E}-04$ & $1.7012 \mathrm{E}-02$ & $3.0398 \mathrm{E}-03$ & $3.2952 \mathrm{E}-04$ \\
\hline $\mathrm{Sb} 2 \mathrm{O} 3$ & $1.6430 \mathrm{E}-06$ & $2.6550 \mathrm{E}-07$ & $6.9311 \mathrm{E}-08$ & $1.6430 \mathrm{E}-06$ & $2.6552 \mathrm{E}-07$ & $7.0728 \mathrm{E}-08$ \\
\hline $\mathrm{SeO} 2$ & $1.2886 \mathrm{E}-05$ & $2.0823 \mathrm{E}-06$ & $5.4779 \mathrm{E}-07$ & $1.2886 \mathrm{E}-05$ & $2.0824 \mathrm{E}-06$ & $5.4606 \mathrm{E}-07$ \\
\hline $\mathrm{SiO} 2$ & $4.1264 \mathrm{E}-03$ & $4.5652 \mathrm{E}-01$ & $6.7067 \mathrm{E}-03$ & 4.1264E-03 & $4.5660 \mathrm{E}-01$ & $6.7079 \mathrm{E}-03$ \\
\hline $\mathrm{Sm} 2 \mathrm{O} 3$ & $3.1663 \mathrm{E}-07$ & $6.6162 \mathrm{E}-08$ & $8.2984 \mathrm{E}-09$ & $3.1663 \mathrm{E}-07$ & $6.6166 \mathrm{E}-08$ & $8.2202 \mathrm{E}-09$ \\
\hline $\mathrm{SnO} 2$ & $2.7513 \mathrm{E}-07$ & $5.7491 \mathrm{E}-08$ & $5.6494 \mathrm{E}-09$ & $2.7513 \mathrm{E}-07$ & 5.7494E-08 & $5.6208 \mathrm{E}-09$ \\
\hline $\mathrm{SrO}$ & $6.2482 \mathrm{E}-07$ & $1.3056 \mathrm{E}-07$ & $6.9338 \mathrm{E}-09$ & $6.2482 \mathrm{E}-07$ & $1.3057 \mathrm{E}-07$ & $6.9003 \mathrm{E}-09$ \\
\hline
\end{tabular}




\begin{tabular}{|c|c|c|c|c|c|c|}
\hline Batch & \multicolumn{3}{|c|}{ MFPV-A104 } & \multicolumn{3}{|c|}{ MFPV-B104 } \\
\hline Comp & Waste & Glass & Glass SD & Waste & Glass & Glass SD \\
\hline Ta2O5 & $1.8567 \mathrm{E}-07$ & $3.8796 \mathrm{E}-08$ & $3.7549 \mathrm{E}-09$ & $1.8567 \mathrm{E}-07$ & $3.8799 \mathrm{E}-08$ & $3.7709 \mathrm{E}-09$ \\
\hline Tc2O7 & $2.2483 \mathrm{E}-05$ & $2.0281 \mathrm{E}-06$ & $6.9992 \mathrm{E}-07$ & $2.2483 \mathrm{E}-05$ & $2.0282 \mathrm{E}-06$ & $6.8930 \mathrm{E}-07$ \\
\hline $\mathrm{TeO} 2$ & $5.7866 \mathrm{E}-07$ & $9.3511 \mathrm{E}-08$ & $2.4345 \mathrm{E}-08$ & $5.7866 \mathrm{E}-07$ & $9.3517 \mathrm{E}-08$ & $2.4833 \mathrm{E}-08$ \\
\hline ThO2 & $1.9471 \mathrm{E}-05$ & $4.0685 \mathrm{E}-06$ & $6.1222 \mathrm{E}-07$ & $1.9471 \mathrm{E}-05$ & $4.0688 \mathrm{E}-06$ & $6.1981 \mathrm{E}-07$ \\
\hline $\mathrm{TiO} 2$ & $2.3466 \mathrm{E}-05$ & $1.4020 \mathrm{E}-02$ & $2.6267 \mathrm{E}-04$ & $2.3466 \mathrm{E}-05$ & $1.4025 \mathrm{E}-02$ & $2.6294 \mathrm{E}-04$ \\
\hline $\mathrm{T} 12 \mathrm{O}$ & 4.6394E-06 & 7.4974E-07 & $1.6795 \mathrm{E}-07$ & 4.6394E-06 & $7.4978 \mathrm{E}-07$ & $1.7196 \mathrm{E}-07$ \\
\hline UO3 & $1.7197 \mathrm{E}-04$ & $5.6260 \mathrm{E}-05$ & $4.3158 \mathrm{E}-06$ & $1.7197 \mathrm{E}-04$ & $5.6263 \mathrm{E}-05$ & $4.3535 \mathrm{E}-06$ \\
\hline $\mathrm{V} 2 \mathrm{O} 5$ & $2.6061 \mathrm{E}-06$ & $5.9602 \mathrm{E}-05$ & $1.9535 \mathrm{E}-05$ & $2.6061 \mathrm{E}-06$ & $5.9623 \mathrm{E}-05$ & $1.9444 \mathrm{E}-05$ \\
\hline WO3 & $5.2582 \mathrm{E}-05$ & $1.0987 \mathrm{E}-05$ & $5.7995 \mathrm{E}-07$ & $5.2582 \mathrm{E}-05$ & $1.0988 \mathrm{E}-05$ & $5.8282 \mathrm{E}-07$ \\
\hline $\mathrm{Y} 2 \mathrm{O} 3$ & $2.8879 \mathrm{E}-06$ & $6.0344 \mathrm{E}-07$ & $9.2608 \mathrm{E}-08$ & $2.8879 \mathrm{E}-06$ & $6.0348 \mathrm{E}-07$ & $8.9960 \mathrm{E}-08$ \\
\hline $\mathrm{ZnO}$ & 7.1434E-05 & $3.5087 \mathrm{E}-02$ & $5.1791 \mathrm{E}-04$ & 7.1434E-05 & $3.5086 \mathrm{E}-02$ & $5.2092 \mathrm{E}-04$ \\
\hline $\mathrm{ZrO} 2$ & $3.5101 \mathrm{E}-05$ & $3.0134 \mathrm{E}-02$ & $4.7472 \mathrm{E}-04$ & $3.5101 \mathrm{E}-05$ & $3.0135 \mathrm{E}-02$ & $4.7826 \mathrm{E}-04$ \\
\hline SUM & $1.0000 \mathrm{E}+00$ & $1.0000 \mathrm{E}+00$ & NA & $1.0000 \mathrm{E}+00$ & $1.0000 \mathrm{E}+00$ & NA \\
\hline Rad & mCi/g oxides & $\mathrm{mCi} / \mathrm{g}$ glass & $\mathrm{mCi} / \mathrm{g}$ glass & mCi/g oxides & $\mathrm{mCi} / \mathrm{g}$ glass & $\mathrm{mCi} / \mathrm{g}$ glass \\
\hline $59 \mathrm{Ni}$ & $1.5307 \mathrm{E}-06$ & $3.1814 \mathrm{E}-07$ & $2.3301 \mathrm{E}-08$ & $1.5307 \mathrm{E}-06$ & $3.1816 \mathrm{E}-07$ & $2.2969 \mathrm{E}-08$ \\
\hline $60 \mathrm{Co}$ & $2.4750 \mathrm{E}-06$ & $5.1717 \mathrm{E}-07$ & $2.7427 \mathrm{E}-08$ & $2.4750 \mathrm{E}-06$ & $5.1720 \mathrm{E}-07$ & $2.7062 \mathrm{E}-08$ \\
\hline $63 \mathrm{Ni}$ & $1.3947 \mathrm{E}-04$ & $2.8987 \mathrm{E}-05$ & $2.1038 \mathrm{E}-06$ & $\begin{array}{c}1.3947 \mathrm{E}-04 \\
\end{array}$ & $2.8988 \mathrm{E}-05$ & $2.1027 \mathrm{E}-06$ \\
\hline $79 \mathrm{Se}$ & $6.1299 \mathrm{E}-06$ & $9.9059 \mathrm{E}-07$ & $2.2389 \mathrm{E}-07$ & $6.1299 \mathrm{E}-06$ & $9.9065 \mathrm{E}-07$ & $2.1825 \mathrm{E}-07$ \\
\hline $90 \mathrm{Sr}$ & $2.5024 \mathrm{E}-03$ & $5.2290 \mathrm{E}-04$ & $2.7580 \mathrm{E}-05$ & $2.5024 \mathrm{E}-03$ & $5.2293 \mathrm{E}-04$ & $2.7240 \mathrm{E}-05$ \\
\hline $90 \mathrm{Y}$ & $2.4228 \mathrm{E}-03$ & $5.0627 \mathrm{E}-04$ & $2.6566 \mathrm{E}-05$ & $2.4228 \mathrm{E}-03$ & $5.0630 \mathrm{E}-04$ & $2.6690 \mathrm{E}-05$ \\
\hline $93 \mathrm{mNb}$ & $6.9767 \mathrm{E}-03$ & $1.4578 \mathrm{E}-03$ & $1.0566 \mathrm{E}-04$ & $6.9767 \mathrm{E}-03$ & $1.4579 \mathrm{E}-03$ & $1.0702 \mathrm{E}-04$ \\
\hline $93 \mathrm{Zr}$ & $3.6778 \mathrm{E}-05$ & $7.7052 \mathrm{E}-06$ & $5.5564 \mathrm{E}-07$ & $3.6778 \mathrm{E}-05$ & $7.7057 \mathrm{E}-06$ & $5.5761 \mathrm{E}-07$ \\
\hline 99Tc & $2.4562 \mathrm{E}-04$ & $2.2156 \mathrm{E}-05$ & $7.6464 \mathrm{E}-06$ & $2.4562 \mathrm{E}-04$ & $2.2158 \mathrm{E}-05$ & $7.5305 \mathrm{E}-06$ \\
\hline $106 \mathrm{Ru}$ & $2.3905 \mathrm{E}-09$ & $4.8990 \mathrm{E}-10$ & $4.8430 \mathrm{E}-11$ & $2.3905 \mathrm{E}-09$ & $4.8993 \mathrm{E}-10$ & $4.8072 \mathrm{E}-11$ \\
\hline $113 \mathrm{mCd}$ & $2.7854 \mathrm{E}-05$ & $5.8202 \mathrm{E}-06$ & $4.1964 \mathrm{E}-07$ & $2.7854 \mathrm{E}-05$ & $5.8206 \mathrm{E}-06$ & $4.2743 \mathrm{E}-07$ \\
\hline $125 \mathrm{Sb}$ & $7.3031 \mathrm{E}-06$ & $1.1802 \mathrm{E}-06$ & $2.5729 \mathrm{E}-07$ & $7.3031 \mathrm{E}-06$ & $1.1803 \mathrm{E}-06$ & $2.6495 \mathrm{E}-07$ \\
\hline $126 \mathrm{Sn}$ & $6.2291 \mathrm{E}-06$ & $1.3016 \mathrm{E}-06$ & $1.2789 \mathrm{E}-07$ & $6.2291 \mathrm{E}-06$ & $1.3017 \mathrm{E}-06$ & $1.2726 \mathrm{E}-07$ \\
\hline $129 \mathrm{I}$ & $4.9991 \mathrm{E}-07$ & $5.3383 \mathrm{E}-08$ & $1.8805 \mathrm{E}-08$ & $4.9991 \mathrm{E}-07$ & $5.3386 \mathrm{E}-08$ & $1.8752 \mathrm{E}-08$ \\
\hline $134 \mathrm{Cs}$ & $1.1544 \mathrm{E}-09$ & $2.1263 \mathrm{E}-10$ & $3.9233 \mathrm{E}-11$ & $1.1544 \mathrm{E}-09$ & $2.1264 \mathrm{E}-10$ & $3.8682 \mathrm{E}-11$ \\
\hline $137 \mathrm{mBa}$ & $4.1280 \mathrm{E}-01$ & $8.6257 \mathrm{E}-02$ & $4.5805 \mathrm{E}-03$ & $4.1280 \mathrm{E}-01$ & $8.6262 \mathrm{E}-02$ & $4.5056 \mathrm{E}-03$ \\
\hline $137 \mathrm{Cs}$ & $2.4114 \mathrm{E}-04$ & $4.4416 \mathrm{E}-05$ & $5.1322 \mathrm{E}-06$ & $2.4114 \mathrm{E}-04$ & 4.4419E-05 & $5.1507 \mathrm{E}-06$ \\
\hline $151 \mathrm{Sm}$ & $7.1909 \mathrm{E}-03$ & $1.5026 \mathrm{E}-03$ & $1.8846 \mathrm{E}-04$ & $7.1909 \mathrm{E}-03$ & $1.5027 \mathrm{E}-03$ & $1.8668 \mathrm{E}-04$ \\
\hline $152 \mathrm{Eu}$ & $1.2607 \mathrm{E}-06$ & $2.6343 \mathrm{E}-07$ & $1.3825 \mathrm{E}-08$ & $1.2607 \mathrm{E}-06$ & $2.6345 \mathrm{E}-07$ & $1.3933 \mathrm{E}-08$ \\
\hline 154Eu & $2.5073 \mathrm{E}-05$ & $5.2393 \mathrm{E}-06$ & $2.7680 \mathrm{E}-07$ & $2.5073 \mathrm{E}-05$ & $5.2396 \mathrm{E}-06$ & $2.8035 \mathrm{E}-07$ \\
\hline $155 \mathrm{Eu}$ & $1.1502 \mathrm{E}-05$ & $2.4035 \mathrm{E}-06$ & $1.2720 \mathrm{E}-07$ & $1.1502 \mathrm{E}-05$ & $2.4036 \mathrm{E}-06$ & $1.2751 \mathrm{E}-07$ \\
\hline $226 \mathrm{Ra}$ & $1.8285 \mathrm{E}-08$ & $2.9549 \mathrm{E}-09$ & $7.8436 \mathrm{E}-10$ & $1.8285 \mathrm{E}-08$ & $2.9551 \mathrm{E}-09$ & $7.7849 \mathrm{E}-10$ \\
\hline $227 \mathrm{Ac}$ & $1.7051 \mathrm{E}-08$ & $3.5629 \mathrm{E}-09$ & $2.5624 \mathrm{E}-10$ & $1.7051 \mathrm{E}-08$ & $3.5631 \mathrm{E}-09$ & $2.5940 \mathrm{E}-10$ \\
\hline $228 \mathrm{Ra}$ & $7.8728 \mathrm{E}-09$ & $1.2723 \mathrm{E}-09$ & $4.6811 \mathrm{E}-10$ & $7.8728 \mathrm{E}-09$ & $1.2723 \mathrm{E}-09$ & $4.6840 \mathrm{E}-10$ \\
\hline $229 \mathrm{Th}$ & $9.1195 \mathrm{E}-10$ & $1.9056 \mathrm{E}-10$ & $5.5717 \mathrm{E}-11$ & $9.1195 \mathrm{E}-10$ & $1.9057 \mathrm{E}-10$ & $5.6504 \mathrm{E}-11$ \\
\hline $231 \mathrm{~Pa}$ & $4.6868 \mathrm{E}-08$ & $9.7935 \mathrm{E}-09$ & $2.8441 \mathrm{E}-09$ & $4.6868 \mathrm{E}-08$ & $9.7941 \mathrm{E}-09$ & $2.8661 \mathrm{E}-09$ \\
\hline $232 \mathrm{Th}$ & $1.8753 \mathrm{E}-09$ & $3.9186 \mathrm{E}-10$ & $2.8661 \mathrm{E}-11$ & $1.8753 \mathrm{E}-09$ & $3.9188 \mathrm{E}-10$ & $2.8805 \mathrm{E}-11$ \\
\hline $232 \mathrm{U}$ & $2.4806 \mathrm{E}-09$ & $5.1834 \mathrm{E}-10$ & $2.7752 \mathrm{E}-11$ & $2.4806 \mathrm{E}-09$ & $5.1837 \mathrm{E}-10$ & $2.7158 \mathrm{E}-11$ \\
\hline $233 \mathrm{U}$ & $1.1248 \mathrm{E}-07$ & $2.3503 \mathrm{E}-08$ & $1.2553 \mathrm{E}-09$ & $1.1248 \mathrm{E}-07$ & $2.3505 \mathrm{E}-08$ & $1.2484 \mathrm{E}-09$ \\
\hline $234 \mathrm{U}$ & $6.3517 \mathrm{E}-08$ & $1.3272 \mathrm{E}-08$ & $6.9921 \mathrm{E}-10$ & $6.3517 \mathrm{E}-08$ & $1.3273 \mathrm{E}-08$ & $6.8822 \mathrm{E}-10$ \\
\hline $235 \mathrm{U}$ & $2.4057 \mathrm{E}-09$ & $5.0268 \mathrm{E}-10$ & $3.6360 \mathrm{E}-11$ & $2.4057 \mathrm{E}-09$ & $5.0271 \mathrm{E}-10$ & $3.6928 \mathrm{E}-11$ \\
\hline $236 \mathrm{U}$ & $4.3742 \mathrm{E}-09$ & $9.1402 \mathrm{E}-10$ & $4.8272 \mathrm{E}-11$ & $4.3742 \mathrm{E}-09$ & $9.1408 \mathrm{E}-10$ & $4.8524 \mathrm{E}-11$ \\
\hline $237 \mathrm{~Np}$ & $3.3898 \mathrm{E}-07$ & 7.0831E-08 & $3.6757 \mathrm{E}-09$ & $3.3898 \mathrm{E}-07$ & $7.0836 \mathrm{E}-08$ & $3.7583 \mathrm{E}-09$ \\
\hline $238 \mathrm{Pu}$ & $1.7801 \mathrm{E}-07$ & $3.7197 \mathrm{E}-08$ & $1.9659 \mathrm{E}-09$ & $1.7801 \mathrm{E}-07$ & $3.7200 \mathrm{E}-08$ & $1.9699 \mathrm{E}-09$ \\
\hline $238 \mathrm{U}$ & $4.7697 \mathrm{E}-08$ & $9.9666 \mathrm{E}-09$ & $7.2863 \mathrm{E}-10$ & $4.7697 \mathrm{E}-08$ & $9.9672 \mathrm{E}-09$ & $7.1880 \mathrm{E}-10$ \\
\hline $239 \mathrm{Pu}$ & $2.1020 \mathrm{E}-06$ & $4.3923 \mathrm{E}-07$ & $2.3404 \mathrm{E}-08$ & $2.1020 \mathrm{E}-06$ & $4.3925 \mathrm{E}-07$ & $2.3308 \mathrm{E}-08$ \\
\hline $240 \mathrm{Pu}$ & $5.1345 \mathrm{E}-07$ & $1.0729 \mathrm{E}-07$ & $7.8636 \mathrm{E}-09$ & $5.1345 \mathrm{E}-07$ & $1.0729 \mathrm{E}-07$ & $7.7731 \mathrm{E}-09$ \\
\hline $241 \mathrm{Am}$ & $2.6309 \mathrm{E}-06$ & $5.3916 \mathrm{E}-07$ & $4.0444 \mathrm{E}-08$ & $2.6309 \mathrm{E}-06$ & $5.3919 \mathrm{E}-07$ & $4.0661 \mathrm{E}-08$ \\
\hline $241 \mathrm{Pu}$ & $5.8995 \mathrm{E}-06$ & $1.2327 \mathrm{E}-06$ & $1.2178 \mathrm{E}-07$ & $5.8995 \mathrm{E}-06$ & $1.2328 \mathrm{E}-06$ & $1.1882 \mathrm{E}-07$ \\
\hline
\end{tabular}




\begin{tabular}{||c|c|c|c|c|c|c||}
\hline Batch & \multicolumn{3}{|c|}{ MFPV-A104 } & \multicolumn{3}{c||}{ MFPV-B104 } \\
\hline Comp & Waste & Glass & Glass SD & Waste & Glass & Glass SD \\
\hline $242 \mathrm{Cm}$ & $1.2894 \mathrm{E}-08$ & $2.6943 \mathrm{E}-09$ & $1.9515 \mathrm{E}-10$ & $1.2894 \mathrm{E}-08$ & $2.6945 \mathrm{E}-09$ & $1.9644 \mathrm{E}-10$ \\
\hline $242 \mathrm{Pu}$ & $5.6551 \mathrm{E}-11$ & $1.1817 \mathrm{E}-11$ & $8.5003 \mathrm{E}-13$ & $5.6551 \mathrm{E}-11$ & $1.1817 \mathrm{E}-11$ & $8.4354 \mathrm{E}-13$ \\
\hline $243 \mathrm{Am}$ & $4.0871 \mathrm{E}-10$ & $8.3760 \mathrm{E}-11$ & $8.2557 \mathrm{E}-12$ & $4.0871 \mathrm{E}-10$ & $8.3765 \mathrm{E}-11$ & $8.3359 \mathrm{E}-12$ \\
\hline $243 \mathrm{Cm}$ & $1.4691 \mathrm{E}-09$ & $3.0697 \mathrm{E}-10$ & $3.0467 \mathrm{E}-11$ & $1.4691 \mathrm{E}-09$ & $3.0699 \mathrm{E}-10$ & $2.9851 \mathrm{E}-11$ \\
\hline $244 \mathrm{Cm}$ & $2.9901 \mathrm{E}-08$ & $6.2480 \mathrm{E}-09$ & $6.0807 \mathrm{E}-10$ & $2.9901 \mathrm{E}-08$ & $6.2484 \mathrm{E}-09$ & $6.1139 \mathrm{E}-10$ \\
\hline $\mathrm{TRU}^{(\mathrm{a})}$ & $5.7951 \mathrm{E}-06$ & $1.2004 \mathrm{E}-06$ & $4.7572 \mathrm{E}-08$ & $5.7951 \mathrm{E}-06$ & $1.2004 \mathrm{E}-06$ & $4.7701 \mathrm{E}-08$ \\
\hline \hline
\end{tabular}

\begin{tabular}{|c|c|c|c|c|c|c|}
\hline \multirow{2}{*}{$\begin{array}{l}\text { Batch } \\
\text { Comp }\end{array}$} & \multicolumn{3}{|c|}{ "MFPV-A105 } & \multicolumn{3}{|c|}{ MFPV-B105 } \\
\hline & Waste & Glass & Glass SD & Waste & Glass & Glass SD \\
\hline $\mathrm{Ac} 2 \mathrm{O} 3$ & $2.6069 \mathrm{E}-13$ & $5.4470 \mathrm{E}-14$ & $3.8698 \mathrm{E}-15$ & $2.6069 \mathrm{E}-13$ & $5.4472 \mathrm{E}-14$ & $4.0206 \mathrm{E}-15$ \\
\hline Ag2O & $1.3203 \mathrm{E}-06$ & $2.7056 \mathrm{E}-07$ & $3.3173 \mathrm{E}-08$ & $1.3203 \mathrm{E}-06$ & $2.7057 \mathrm{E}-07$ & $3.3327 \mathrm{E}-08$ \\
\hline $\mathrm{Al} 2 \mathrm{O} 3$ & $6.7942 \mathrm{E}-02$ & $6.1228 \mathrm{E}-02$ & $1.1549 \mathrm{E}-03$ & $6.7942 \mathrm{E}-02$ & $6.1214 \mathrm{E}-02$ & $1.1615 \mathrm{E}-03$ \\
\hline $\mathrm{Am} 2 \mathrm{O} 3$ & $8.4636 \mathrm{E}-10$ & $1.7344 \mathrm{E}-10$ & $1.3385 \mathrm{E}-11$ & $8.4636 \mathrm{E}-10$ & $1.7345 \mathrm{E}-10$ & $1.3194 \mathrm{E}-11$ \\
\hline As2O5 & $7.3276 \mathrm{E}-06$ & $1.1841 \mathrm{E}-06$ & $3.1191 \mathrm{E}-07$ & $7.3276 \mathrm{E}-06$ & $1.1841 \mathrm{E}-06$ & $3.0656 \mathrm{E}-07$ \\
\hline $\mathrm{B} 2 \mathrm{O} 3$ & $2.4782 \mathrm{E}-04$ & $9.9397 \mathrm{E}-02$ & $1.5247 \mathrm{E}-03$ & $2.4782 \mathrm{E}-04$ & $9.9421 \mathrm{E}-02$ & $1.5328 \mathrm{E}-03$ \\
\hline $\mathrm{BaO}$ & $1.1993 \mathrm{E}-06$ & $2.5059 \mathrm{E}-07$ & $2.4581 \mathrm{E}-08$ & $1.1993 \mathrm{E}-06$ & $2.5060 \mathrm{E}-07$ & $2.4512 \mathrm{E}-08$ \\
\hline $\mathrm{BeO}$ & $5.3496 \mathrm{E}-06$ & $1.1178 \mathrm{E}-06$ & $5.9319 \mathrm{E}-08$ & $5.3496 \mathrm{E}-06$ & $1.1178 \mathrm{E}-06$ & $5.8426 \mathrm{E}-08$ \\
\hline Bi2O3 & $2.1577 \mathrm{E}-05$ & $4.4217 \mathrm{E}-06$ & $3.3662 \mathrm{E}-07$ & $2.1577 \mathrm{E}-05$ & $4.4218 \mathrm{E}-06$ & $3.3860 \mathrm{E}-07$ \\
\hline $\mathrm{CaO}$ & $1.9529 \mathrm{E}-04$ & $3.6208 \mathrm{E}-02$ & $9.2537 \mathrm{E}-04$ & $1.9529 \mathrm{E}-04$ & $3.6205 \mathrm{E}-02$ & $9.1751 \mathrm{E}-04$ \\
\hline $\mathrm{CdO}$ & $3.4282 \mathrm{E}-06$ & 4.2289E-06 & $1.3071 \mathrm{E}-06$ & $3.4282 \mathrm{E}-06$ & $4.2302 \mathrm{E}-06$ & $1.3551 \mathrm{E}-06$ \\
\hline $\mathrm{Ce} 2 \mathrm{O} 3$ & $1.2037 \mathrm{E}-06$ & $2.5150 \mathrm{E}-07$ & $3.7919 \mathrm{E}-08$ & $1.2037 \mathrm{E}-06$ & $2.5151 \mathrm{E}-07$ & $3.7441 \mathrm{E}-08$ \\
\hline $\mathrm{Cl}$ & $1.1041 \mathrm{E}-02$ & $1.2594 \mathrm{E}-03$ & $3.5639 \mathrm{E}-04$ & $1.1041 \mathrm{E}-02$ & $1.2594 \mathrm{E}-03$ & $3.5059 \mathrm{E}-04$ \\
\hline $\mathrm{Cm} 2 \mathrm{O} 3$ & $4.4300 \mathrm{E}-13$ & $9.2563 \mathrm{E}-14$ & $8.4632 \mathrm{E}-15$ & $4.4300 \mathrm{E}-13$ & $9.2566 \mathrm{E}-14$ & $8.4016 \mathrm{E}-15$ \\
\hline $\mathrm{CoO}$ & $1.9811 \mathrm{E}-06$ & $4.1395 \mathrm{E}-07$ & $6.2749 \mathrm{E}-08$ & $1.9811 \mathrm{E}-06$ & $4.1396 \mathrm{E}-07$ & $6.2742 \mathrm{E}-08$ \\
\hline $\mathrm{Cr} 2 \mathrm{O} 3$ & $3.8354 \mathrm{E}-03$ & $8.6160 \mathrm{E}-04$ & $6.4201 \mathrm{E}-05$ & $3.8354 \mathrm{E}-03$ & $8.6160 \mathrm{E}-04$ & $6.4330 \mathrm{E}-05$ \\
\hline $\mathrm{Cs} 2 \mathrm{O}$ & $1.4539 \mathrm{E}-08$ & $2.6778 \mathrm{E}-09$ & $3.7663 \mathrm{E}-10$ & $1.4539 \mathrm{E}-08$ & $2.6778 \mathrm{E}-09$ & $3.7761 \mathrm{E}-10$ \\
\hline $\mathrm{CuO}$ & $3.6164 \mathrm{E}-06$ & $7.5563 \mathrm{E}-07$ & $1.1425 \mathrm{E}-07$ & $3.6164 \mathrm{E}-06$ & $7.5565 \mathrm{E}-07$ & $1.1423 \mathrm{E}-07$ \\
\hline $\mathrm{Eu} 2 \mathrm{O} 3$ & $1.4350 \mathrm{E}-10$ & $2.9984 \mathrm{E}-11$ & $1.4957 \mathrm{E}-12$ & $1.4350 \mathrm{E}-10$ & $2.9985 \mathrm{E}-11$ & $1.4914 \mathrm{E}-12$ \\
\hline $\mathrm{F}$ & $4.7503 \mathrm{E}-03$ & 7.2643E-04 & $1.3079 \mathrm{E}-04$ & $4.7503 \mathrm{E}-03$ & $7.2645 \mathrm{E}-04$ & $1.3488 \mathrm{E}-04$ \\
\hline $\mathrm{Fe} 2 \mathrm{O} 3$ & $8.8061 \mathrm{E}-05$ & $5.5155 \mathrm{E}-02$ & $9.0840 \mathrm{E}-04$ & $8.8061 \mathrm{E}-05$ & $5.5172 \mathrm{E}-02$ & $9.0906 \mathrm{E}-04$ \\
\hline $\mathrm{Gd} 2 \mathrm{O} 3$ & $0.0000 \mathrm{E}+00$ & $0.0000 \mathrm{E}+00$ & $0.0000 \mathrm{E}+00$ & $0.0000 \mathrm{E}+00$ & $0.0000 \mathrm{E}+00$ & $0.0000 \mathrm{E}+00$ \\
\hline $\mathrm{HgO}$ & $4.4272 \mathrm{E}-07$ & $0.0000 \mathrm{E}+00$ & $0.0000 \mathrm{E}+00$ & 4.4272E-07 & $0.0000 \mathrm{E}+00$ & $0.0000 \mathrm{E}+00$ \\
\hline $\mathrm{I}$ & $2.8276 \mathrm{E}-06$ & $3.0192 \mathrm{E}-07$ & $1.0656 \mathrm{E}-07$ & $2.8276 \mathrm{E}-06$ & $3.0193 \mathrm{E}-07$ & $1.0759 \mathrm{E}-07$ \\
\hline $\mathrm{K} 2 \mathrm{O}$ & $6.0931 \mathrm{E}-02$ & $1.2331 \mathrm{E}-02$ & $7.1516 \mathrm{E}-04$ & $6.0931 \mathrm{E}-02$ & $1.2331 \mathrm{E}-02$ & $7.0908 \mathrm{E}-04$ \\
\hline $\mathrm{La} 2 \mathrm{O} 3$ & $1.7831 \mathrm{E}-06$ & $3.7258 \mathrm{E}-07$ & $2.7474 \mathrm{E}-08$ & $1.7831 \mathrm{E}-06$ & $3.7259 \mathrm{E}-07$ & $2.7217 \mathrm{E}-08$ \\
\hline $\mathrm{Li} 2 \mathrm{O}$ & $1.3123 \mathrm{E}-06$ & $6.0665 \mathrm{E}-03$ & $9.3054 \mathrm{E}-05$ & $1.3123 \mathrm{E}-06$ & $6.0654 \mathrm{E}-03$ & $9.3042 \mathrm{E}-05$ \\
\hline $\mathrm{MgO}$ & $1.2825 \mathrm{E}-04$ & $1.4873 \mathrm{E}-02$ & $2.8018 \mathrm{E}-04$ & $1.2825 \mathrm{E}-04$ & $1.4870 \mathrm{E}-02$ & $2.8561 \mathrm{E}-04$ \\
\hline $\mathrm{MnO}$ & $7.1305 \mathrm{E}-06$ & $1.5750 \mathrm{E}-04$ & $3.4488 \mathrm{E}-05$ & $7.1305 \mathrm{E}-06$ & $1.5752 \mathrm{E}-04$ & $3.3935 \mathrm{E}-05$ \\
\hline $\mathrm{MoO} 3$ & $5.6978 \mathrm{E}-05$ & $1.1676 \mathrm{E}-05$ & $8.7802 \mathrm{E}-07$ & $5.6978 \mathrm{E}-05$ & $1.1677 \mathrm{E}-05$ & $8.9308 \mathrm{E}-07$ \\
\hline $\mathrm{Na} 2 \mathrm{O}$ & $8.2044 \mathrm{E}-01$ & $1.7077 \mathrm{E}-01$ & $1.0974 \mathrm{E}-02$ & $8.2044 \mathrm{E}-01$ & $1.7078 \mathrm{E}-01$ & $1.0920 \mathrm{E}-02$ \\
\hline $\mathrm{Nb} 2 \mathrm{O} 5$ & $4.1829 \mathrm{E}-08$ & $8.7400 \mathrm{E}-09$ & $6.3905 \mathrm{E}-10$ & 4.1829E-08 & $8.7402 \mathrm{E}-09$ & $6.2807 \mathrm{E}-10$ \\
\hline $\mathrm{Nd} 2 \mathrm{O} 3$ & $5.2652 \mathrm{E}-06$ & $1.1001 \mathrm{E}-06$ & $1.0730 \mathrm{E}-07$ & $5.2652 \mathrm{E}-06$ & $1.1002 \mathrm{E}-06$ & $1.0774 \mathrm{E}-07$ \\
\hline $\mathrm{NiO}$ & $1.3264 \mathrm{E}-04$ & $1.3999 \mathrm{E}-04$ & $1.7159 \mathrm{E}-05$ & $1.3264 \mathrm{E}-04$ & $1.3997 \mathrm{E}-04$ & $1.7483 \mathrm{E}-05$ \\
\hline $\mathrm{NpO} 2$ & $5.4596 \mathrm{E}-07$ & $1.1408 \mathrm{E}-07$ & $6.0724 \mathrm{E}-09$ & $5.4596 \mathrm{E}-07$ & $1.1408 \mathrm{E}-07$ & $6.0258 \mathrm{E}-09$ \\
\hline $\mathrm{P} 2 \mathrm{O} 5$ & $8.3260 \mathrm{E}-03$ & $1.8901 \mathrm{E}-03$ & $1.3173 \mathrm{E}-04$ & $8.3260 \mathrm{E}-03$ & $1.8902 \mathrm{E}-03$ & $1.3071 \mathrm{E}-04$ \\
\hline $\mathrm{Pa} 2 \mathrm{O} 5$ & $1.1641 \mathrm{E}-09$ & $2.4324 \mathrm{E}-10$ & $7.0953 \mathrm{E}-11$ & $1.1641 \mathrm{E}-09$ & $2.4325 \mathrm{E}-10$ & $6.9884 \mathrm{E}-11$ \\
\hline $\mathrm{PbO}$ & $1.3978 \mathrm{E}-04$ & $2.9513 \mathrm{E}-05$ & $2.8883 \mathrm{E}-06$ & $1.3978 \mathrm{E}-04$ & $2.9514 \mathrm{E}-05$ & $2.8464 \mathrm{E}-06$ \\
\hline $\mathrm{PdO}$ & $3.1454 \mathrm{E}-05$ & $6.5721 \mathrm{E}-06$ & $6.4438 \mathrm{E}-07$ & $3.1454 \mathrm{E}-05$ & $6.5723 \mathrm{E}-06$ & $6.5060 \mathrm{E}-07$ \\
\hline Pr2O3 & $4.5224 \mathrm{E}-08$ & 9.4494E-09 & $9.1877 \mathrm{E}-10$ & 4.5224E-08 & $9.4496 \mathrm{E}-09$ & $9.2966 \mathrm{E}-10$ \\
\hline $\mathrm{PuO} 2$ & $4.1086 \mathrm{E}-08$ & $8.5848 \mathrm{E}-09$ & $4.5169 \mathrm{E}-10$ & $4.1086 \mathrm{E}-08$ & $8.5850 \mathrm{E}-09$ & $4.5051 \mathrm{E}-10$ \\
\hline $\mathrm{RaO}$ & $1.9838 \mathrm{E}-11$ & $3.2057 \mathrm{E}-12$ & $8.4332 \mathrm{E}-13$ & $1.9838 \mathrm{E}-11$ & $3.2058 \mathrm{E}-12$ & $8.3855 \mathrm{E}-13$ \\
\hline $\mathrm{Rb} 2 \mathrm{O}$ & $6.3763 \mathrm{E}-06$ & $1.3067 \mathrm{E}-06$ & $2.0310 \mathrm{E}-07$ & $6.3763 \mathrm{E}-06$ & $1.3067 \mathrm{E}-06$ & $2.0269 \mathrm{E}-07$ \\
\hline $\mathrm{Rh} 2 \mathrm{O} 3$ & $1.4099 \mathrm{E}-05$ & $2.9459 \mathrm{E}-06$ & $1.5751 \mathrm{E}-07$ & $1.4099 \mathrm{E}-05$ & $2.9460 \mathrm{E}-06$ & $1.5599 \mathrm{E}-07$ \\
\hline
\end{tabular}




\begin{tabular}{|c|c|c|c|c|c|c|}
\hline Batch & \multicolumn{3}{|c|}{ MFPV-A105 } & \multicolumn{3}{|c|}{ MFPV-B105 } \\
\hline $\mathrm{RuO} 2$ & $6.8799 \mathrm{E}-05$ & $1.4099 \mathrm{E}-05$ & $8.0260 \mathrm{E}-07$ & $6.8799 \mathrm{E}-05$ & $1.4099 \mathrm{E}-05$ & $7.9533 \mathrm{E}-07$ \\
\hline $\mathrm{SO} 3$ & $1.7012 \mathrm{E}-02$ & $3.0396 \mathrm{E}-03$ & $3.3040 \mathrm{E}-04$ & $1.7012 \mathrm{E}-02$ & $3.0397 \mathrm{E}-03$ & $3.2811 \mathrm{E}-04$ \\
\hline $\mathrm{Sb} 2 \mathrm{O} 3$ & $1.6430 \mathrm{E}-06$ & $2.6549 \mathrm{E}-07$ & $6.8122 \mathrm{E}-08$ & $1.6430 \mathrm{E}-06$ & $2.6550 \mathrm{E}-07$ & $6.9184 \mathrm{E}-08$ \\
\hline $\mathrm{SeO} 2$ & $1.2886 \mathrm{E}-05$ & $2.0822 \mathrm{E}-06$ & $5.4109 \mathrm{E}-07$ & $1.2886 \mathrm{E}-05$ & $2.0823 \mathrm{E}-06$ & $5.4847 \mathrm{E}-07$ \\
\hline $\mathrm{SiO} 2$ & $4.1264 \mathrm{E}-03$ & $4.5645 \mathrm{E}-01$ & 6.8064E-03 & 4.1264E-03 & $4.5642 \mathrm{E}-01$ & $6.7679 \mathrm{E}-03$ \\
\hline Sm2O3 & $3.1663 \mathrm{E}-07$ & $6.6159 \mathrm{E}-08$ & $8.2170 \mathrm{E}-09$ & $3.1663 \mathrm{E}-07$ & $6.6161 \mathrm{E}-08$ & $8.2647 \mathrm{E}-09$ \\
\hline $\mathrm{SnO} 2$ & $2.7513 \mathrm{E}-07$ & $5.7488 \mathrm{E}-08$ & $5.6875 \mathrm{E}-09$ & $2.7513 \mathrm{E}-07$ & $5.7489 \mathrm{E}-08$ & $5.4666 \mathrm{E}-09$ \\
\hline $\mathrm{SrO}$ & $6.2482 \mathrm{E}-07$ & $1.3055 \mathrm{E}-07$ & $6.9183 \mathrm{E}-09$ & $6.2482 \mathrm{E}-07$ & $1.3056 \mathrm{E}-07$ & $7.0290 \mathrm{E}-09$ \\
\hline Ta2O5 & $1.8567 \mathrm{E}-07$ & $3.8794 \mathrm{E}-08$ & $3.7738 \mathrm{E}-09$ & $1.8567 \mathrm{E}-07$ & $3.8795 \mathrm{E}-08$ & $3.7724 \mathrm{E}-09$ \\
\hline Tc2O7 & $2.2483 \mathrm{E}-05$ & $2.0280 \mathrm{E}-06$ & $7.0237 \mathrm{E}-07$ & $2.2483 \mathrm{E}-05$ & $2.0280 \mathrm{E}-06$ & $7.1015 \mathrm{E}-07$ \\
\hline $\mathrm{TeO} 2$ & $5.7866 \mathrm{E}-07$ & $9.3506 \mathrm{E}-08$ & $2.4451 \mathrm{E}-08$ & $5.7866 \mathrm{E}-07$ & $9.3508 \mathrm{E}-08$ & $2.4459 \mathrm{E}-08$ \\
\hline ThO2 & $1.9471 \mathrm{E}-05$ & $4.0683 \mathrm{E}-06$ & $6.2478 \mathrm{E}-07$ & $1.9471 \mathrm{E}-05$ & $4.0684 \mathrm{E}-06$ & $6.1782 \mathrm{E}-07$ \\
\hline $\mathrm{TiO} 2$ & $2.3466 \mathrm{E}-05$ & $1.4035 \mathrm{E}-02$ & $2.6315 \mathrm{E}-04$ & $2.3466 \mathrm{E}-05$ & $1.4032 \mathrm{E}-02$ & $2.6081 \mathrm{E}-04$ \\
\hline $\mathrm{T} 12 \mathrm{O}$ & 4.6394E-06 & $7.4970 \mathrm{E}-07$ & $1.7091 \mathrm{E}-07$ & 4.6394E-06 & $7.4972 \mathrm{E}-07$ & $1.7009 \mathrm{E}-07$ \\
\hline UO3 & 1.7197E-04 & $5.6255 \mathrm{E}-05$ & $4.2621 \mathrm{E}-06$ & $1.7197 \mathrm{E}-04$ & $5.6252 \mathrm{E}-05$ & $4.4123 \mathrm{E}-06$ \\
\hline $\mathrm{V} 2 \mathrm{O} 5$ & $2.6061 \mathrm{E}-06$ & $5.9665 \mathrm{E}-05$ & $1.9326 \mathrm{E}-05$ & $2.6061 \mathrm{E}-06$ & $5.9654 \mathrm{E}-05$ & $1.9310 \mathrm{E}-05$ \\
\hline WO3 & $5.2582 \mathrm{E}-05$ & $1.0987 \mathrm{E}-05$ & $5.8697 \mathrm{E}-07$ & $5.2582 \mathrm{E}-05$ & $1.0987 \mathrm{E}-05$ & $5.8396 \mathrm{E}-07$ \\
\hline $\mathrm{Y} 2 \mathrm{O} 3$ & $2.8879 \mathrm{E}-06$ & $6.0341 \mathrm{E}-07$ & $9.2319 \mathrm{E}-08$ & $2.8879 \mathrm{E}-06$ & $6.0342 \mathrm{E}-07$ & $9.1466 \mathrm{E}-08$ \\
\hline $\mathrm{ZnO}$ & 7.1434E-05 & $3.5066 \mathrm{E}-02$ & $5.2701 \mathrm{E}-04$ & $7.1434 \mathrm{E}-05$ & $3.5078 \mathrm{E}-02$ & $5.2460 \mathrm{E}-04$ \\
\hline $\mathrm{ZrO} 2$ & $3.5101 \mathrm{E}-05$ & $3.0129 \mathrm{E}-02$ & $4.8220 \mathrm{E}-04$ & $3.5101 \mathrm{E}-05$ & $3.0124 \mathrm{E}-02$ & $4.8240 \mathrm{E}-04$ \\
\hline SUM & $1.0000 \mathrm{E}+00$ & $1.0000 \mathrm{E}+00$ & NA & $1.0000 \mathrm{E}+00$ & $1.0000 \mathrm{E}+00$ & NA \\
\hline Rad & mCi/g oxides & mCi/g glass & mCi/g glass & mCi/g oxides & $\mathrm{mCi} / \mathrm{g}$ glass & $\mathrm{mCi} / \mathrm{g}$ glass \\
\hline $59 \mathrm{Ni}$ & $1.5307 \mathrm{E}-06$ & $3.1813 \mathrm{E}-07$ & $2.3048 \mathrm{E}-08$ & $1.5307 \mathrm{E}-06$ & $3.1813 \mathrm{E}-07$ & $2.2984 \mathrm{E}-08$ \\
\hline $60 \mathrm{Co}$ & $2.4750 \mathrm{E}-06$ & $5.1714 \mathrm{E}-07$ & $2.7714 \mathrm{E}-08$ & $2.4750 \mathrm{E}-06$ & $5.1715 \mathrm{E}-07$ & $2.7558 \mathrm{E}-08$ \\
\hline $63 \mathrm{Ni}$ & $1.3947 \mathrm{E}-04$ & $2.8985 \mathrm{E}-05$ & $2.1300 \mathrm{E}-06$ & $1.3947 \mathrm{E}-04$ & $2.8986 \mathrm{E}-05$ & $2.1102 \mathrm{E}-06$ \\
\hline $79 \mathrm{Se}$ & $6.1299 \mathrm{E}-06$ & $9.9054 \mathrm{E}-07$ & $2.2134 \mathrm{E}-07$ & $6.1299 \mathrm{E}-06$ & $9.9056 \mathrm{E}-07$ & $2.2394 \mathrm{E}-07$ \\
\hline $90 \mathrm{Sr}$ & $2.5024 \mathrm{E}-03$ & $5.2287 \mathrm{E}-04$ & $2.8170 \mathrm{E}-05$ & $2.5024 \mathrm{E}-03$ & $5.2289 \mathrm{E}-04$ & $2.7653 \mathrm{E}-05$ \\
\hline $90 \mathrm{Y}$ & $2.4228 \mathrm{E}-03$ & $5.0624 \mathrm{E}-04$ & $2.6755 \mathrm{E}-05$ & $2.4228 \mathrm{E}-03$ & $5.0625 \mathrm{E}-04$ & $2.6853 \mathrm{E}-05$ \\
\hline $93 \mathrm{mNb}$ & $6.9767 \mathrm{E}-03$ & $1.4578 \mathrm{E}-03$ & $1.0659 \mathrm{E}-04$ & $6.9767 \mathrm{E}-03$ & $1.4578 \mathrm{E}-03$ & $1.0476 \mathrm{E}-04$ \\
\hline $93 \mathrm{Zr}$ & $3.6778 \mathrm{E}-05$ & 7.7048E-06 & $5.6813 \mathrm{E}-07$ & $3.6778 \mathrm{E}-05$ & $7.7050 \mathrm{E}-06$ & $5.6191 \mathrm{E}-07$ \\
\hline 99Tc & $2.4562 \mathrm{E}-04$ & $2.2155 \mathrm{E}-05$ & 7.6732E-06 & $2.4562 \mathrm{E}-04$ & $2.2156 \mathrm{E}-05$ & $7.7583 \mathrm{E}-06$ \\
\hline $106 \mathrm{Ru}$ & $2.3905 \mathrm{E}-09$ & $4.8987 \mathrm{E}-10$ & $4.9403 \mathrm{E}-11$ & $2.3905 \mathrm{E}-09$ & $4.8988 \mathrm{E}-10$ & $4.8736 \mathrm{E}-11$ \\
\hline $113 \mathrm{mCd}$ & $2.7854 \mathrm{E}-05$ & $5.8199 \mathrm{E}-06$ & $4.2593 \mathrm{E}-07$ & $2.7854 \mathrm{E}-05$ & $5.8200 \mathrm{E}-06$ & $4.2591 \mathrm{E}-07$ \\
\hline $125 \mathrm{Sb}$ & $7.3031 \mathrm{E}-06$ & $1.1801 \mathrm{E}-06$ & $2.5570 \mathrm{E}-07$ & $7.3031 \mathrm{E}-06$ & $1.1802 \mathrm{E}-06$ & $2.5894 \mathrm{E}-07$ \\
\hline $126 \mathrm{Sn}$ & $6.2291 \mathrm{E}-06$ & $1.3015 \mathrm{E}-06$ & $1.2877 \mathrm{E}-07$ & $6.2291 \mathrm{E}-06$ & $1.3016 \mathrm{E}-06$ & $1.2377 \mathrm{E}-07$ \\
\hline 129I & $4.9991 \mathrm{E}-07$ & $5.3380 \mathrm{E}-08$ & $1.8839 \mathrm{E}-08$ & $4.9991 \mathrm{E}-07$ & $5.3381 \mathrm{E}-08$ & $1.9022 \mathrm{E}-08$ \\
\hline $134 \mathrm{Cs}$ & $1.1544 \mathrm{E}-09$ & $2.1262 \mathrm{E}-10$ & $3.8515 \mathrm{E}-11$ & $1.1544 \mathrm{E}-09$ & $2.1262 \mathrm{E}-10$ & $3.8517 \mathrm{E}-11$ \\
\hline $137 \mathrm{mBa}$ & $4.1280 \mathrm{E}-01$ & $8.6253 \mathrm{E}-02$ & $4.5871 \mathrm{E}-03$ & $4.1280 \mathrm{E}-01$ & $8.6255 \mathrm{E}-02$ & $4.6330 \mathrm{E}-03$ \\
\hline $137 \mathrm{Cs}$ & $2.4114 \mathrm{E}-04$ & $4.4414 \mathrm{E}-05$ & $5.1120 \mathrm{E}-06$ & $2.4114 \mathrm{E}-04$ & $4.4415 \mathrm{E}-05$ & $5.0396 \mathrm{E}-06$ \\
\hline $151 \mathrm{Sm}$ & $7.1909 \mathrm{E}-03$ & $1.5025 \mathrm{E}-03$ & $1.8661 \mathrm{E}-04$ & $7.1909 \mathrm{E}-03$ & $1.5025 \mathrm{E}-03$ & $1.8770 \mathrm{E}-04$ \\
\hline $152 \mathrm{Eu}$ & $1.2607 \mathrm{E}-06$ & $2.6342 \mathrm{E}-07$ & $1.4145 \mathrm{E}-08$ & $1.2607 \mathrm{E}-06$ & $2.6342 \mathrm{E}-07$ & $1.3848 \mathrm{E}-08$ \\
\hline $154 \mathrm{Eu}$ & $2.5073 \mathrm{E}-05$ & $5.2390 \mathrm{E}-06$ & $2.8045 \mathrm{E}-07$ & $2.5073 \mathrm{E}-05$ & $5.2391 \mathrm{E}-06$ & $2.7930 \mathrm{E}-07$ \\
\hline $155 \mathrm{Eu}$ & $1.1502 \mathrm{E}-05$ & $2.4033 \mathrm{E}-06$ & $1.2771 \mathrm{E}-07$ & $1.1502 \mathrm{E}-05$ & $2.4034 \mathrm{E}-06$ & $1.2741 \mathrm{E}-07$ \\
\hline $226 \mathrm{Ra}$ & $1.8285 \mathrm{E}-08$ & $2.9547 \mathrm{E}-09$ & $7.7770 \mathrm{E}-10$ & $1.8285 \mathrm{E}-08$ & $2.9548 \mathrm{E}-09$ & $7.7328 \mathrm{E}-10$ \\
\hline $227 \mathrm{Ac}$ & $1.7051 \mathrm{E}-08$ & $3.5627 \mathrm{E}-09$ & $2.5311 \mathrm{E}-10$ & $1.7051 \mathrm{E}-08$ & $3.5628 \mathrm{E}-09$ & $2.6297 \mathrm{E}-10$ \\
\hline $228 \mathrm{Ra}$ & $7.8728 \mathrm{E}-09$ & $1.2722 \mathrm{E}-09$ & $4.6196 \mathrm{E}-10$ & $7.8728 \mathrm{E}-09$ & $1.2722 \mathrm{E}-09$ & $4.6660 \mathrm{E}-10$ \\
\hline $229 \mathrm{Th}$ & $9.1195 \mathrm{E}-10$ & $1.9055 \mathrm{E}-10$ & $5.6422 \mathrm{E}-11$ & $9.1195 \mathrm{E}-10$ & $1.9055 \mathrm{E}-10$ & $5.5476 \mathrm{E}-11$ \\
\hline $231 \mathrm{~Pa}$ & $4.6868 \mathrm{E}-08$ & $9.7930 \mathrm{E}-09$ & $2.8566 \mathrm{E}-09$ & $4.6868 \mathrm{E}-08$ & $9.7932 \mathrm{E}-09$ & $2.8135 \mathrm{E}-09$ \\
\hline $232 \mathrm{Th}$ & $1.8753 \mathrm{E}-09$ & $3.9184 \mathrm{E}-10$ & $2.8498 \mathrm{E}-11$ & $1.8753 \mathrm{E}-09$ & $3.9185 \mathrm{E}-10$ & $2.8900 \mathrm{E}-11$ \\
\hline $232 \mathrm{U}$ & $2.4806 \mathrm{E}-09$ & $5.1831 \mathrm{E}-10$ & $2.7431 \mathrm{E}-11$ & $2.4806 \mathrm{E}-09$ & $5.1832 \mathrm{E}-10$ & $2.7885 \mathrm{E}-11$ \\
\hline $233 \mathrm{U}$ & $1.1248 \mathrm{E}-07$ & $2.3502 \mathrm{E}-08$ & $1.2426 \mathrm{E}-09$ & $1.1248 \mathrm{E}-07$ & $2.3503 \mathrm{E}-08$ & $1.2553 \mathrm{E}-09$ \\
\hline $234 \mathrm{U}$ & $6.3517 \mathrm{E}-08$ & $1.3272 \mathrm{E}-08$ & $7.0281 \mathrm{E}-10$ & $6.3517 \mathrm{E}-08$ & $1.3272 \mathrm{E}-08$ & $7.0440 \mathrm{E}-10$ \\
\hline $235 \mathrm{U}$ & $2.4057 \mathrm{E}-09$ & $5.0266 \mathrm{E}-10$ & $3.6747 \mathrm{E}-11$ & $2.4057 \mathrm{E}-09$ & $5.0267 \mathrm{E}-10$ & $3.7005 \mathrm{E}-11$ \\
\hline $236 \mathrm{U}$ & $4.3742 \mathrm{E}-09$ & $9.1398 \mathrm{E}-10$ & $4.9163 \mathrm{E}-11$ & $4.3742 \mathrm{E}-09$ & $9.1400 \mathrm{E}-10$ & $4.8761 \mathrm{E}-11$ \\
\hline
\end{tabular}




\begin{tabular}{||c|c|c|c|c|c|c||}
\hline \hline Batch & \multicolumn{3}{|c|}{ MFPV-A105 } & \multicolumn{3}{c||}{ MFPV-B105 } \\
\hline $237 \mathrm{~Np}$ & $3.3898 \mathrm{E}-07$ & $7.0828 \mathrm{E}-08$ & $3.7703 \mathrm{E}-09$ & $3.3898 \mathrm{E}-07$ & $7.0830 \mathrm{E}-08$ & $3.7413 \mathrm{E}-09$ \\
\hline $238 \mathrm{Pu}$ & $1.7801 \mathrm{E}-07$ & $3.7195 \mathrm{E}-08$ & $1.9758 \mathrm{E}-09$ & $1.7801 \mathrm{E}-07$ & $3.7196 \mathrm{E}-08$ & $1.9527 \mathrm{E}-09$ \\
\hline $238 \mathrm{U}$ & $4.7697 \mathrm{E}-08$ & $9.9661 \mathrm{E}-09$ & $7.2694 \mathrm{E}-10$ & $4.7697 \mathrm{E}-08$ & $9.9663 \mathrm{E}-09$ & $7.3322 \mathrm{E}-10$ \\
\hline $239 \mathrm{Pu}$ & $2.1020 \mathrm{E}-06$ & $4.3920 \mathrm{E}-07$ & $2.3563 \mathrm{E}-08$ & $2.1020 \mathrm{E}-06$ & $4.3921 \mathrm{E}-07$ & $2.3466 \mathrm{E}-08$ \\
\hline $240 \mathrm{Pu}$ & $5.1345 \mathrm{E}-07$ & $1.0728 \mathrm{E}-07$ & $7.8167 \mathrm{E}-09$ & $5.1345 \mathrm{E}-07$ & $1.0728 \mathrm{E}-07$ & $8.0058 \mathrm{E}-09$ \\
\hline $241 \mathrm{Am}$ & $2.6309 \mathrm{E}-06$ & $5.3913 \mathrm{E}-07$ & $4.1673 \mathrm{E}-08$ & $2.6309 \mathrm{E}-06$ & $5.3915 \mathrm{E}-07$ & $4.1075 \mathrm{E}-08$ \\
\hline $241 \mathrm{Pu}$ & $5.8995 \mathrm{E}-06$ & $1.2327 \mathrm{E}-06$ & $1.2064 \mathrm{E}-07$ & $5.8995 \mathrm{E}-06$ & $1.2327 \mathrm{E}-06$ & $1.1828 \mathrm{E}-07$ \\
\hline $242 \mathrm{Cm}$ & $1.2894 \mathrm{E}-08$ & $2.6942 \mathrm{E}-09$ & $1.9468 \mathrm{E}-10$ & $1.2894 \mathrm{E}-08$ & $2.6942 \mathrm{E}-09$ & $1.9477 \mathrm{E}-10$ \\
\hline $242 \mathrm{Pu}$ & $5.6551 \mathrm{E}-11$ & $1.1816 \mathrm{E}-11$ & $8.6061 \mathrm{E}-13$ & $5.6551 \mathrm{E}-11$ & $1.1816 \mathrm{E}-11$ & $8.5975 \mathrm{E}-13$ \\
\hline $243 \mathrm{Am}$ & $4.0871 \mathrm{E}-10$ & $8.3755 \mathrm{E}-11$ & $8.3714 \mathrm{E}-12$ & $4.0871 \mathrm{E}-10$ & $8.3757 \mathrm{E}-11$ & $8.4701 \mathrm{E}-12$ \\
\hline $243 \mathrm{Cm}$ & $1.4691 \mathrm{E}-09$ & $3.0695 \mathrm{E}-10$ & $3.0239 \mathrm{E}-11$ & $1.4691 \mathrm{E}-09$ & $3.0696 \mathrm{E}-10$ & $3.0187 \mathrm{E}-11$ \\
\hline $244 \mathrm{Cm}$ & $2.9901 \mathrm{E}-08$ & $6.2477 \mathrm{E}-09$ & $6.1082 \mathrm{E}-10$ & $2.9901 \mathrm{E}-08$ & $6.2479 \mathrm{E}-09$ & $6.0591 \mathrm{E}-10$ \\
\hline TRU ${ }^{(a)}$ & $5.7951 \mathrm{E}-06$ & $1.2003 \mathrm{E}-06$ & $4.8698 \mathrm{E}-08$ & $5.7951 \mathrm{E}-06$ & $1.2003 \mathrm{E}-06$ & $4.8167 \mathrm{E}-08$ \\
\hline
\end{tabular}


Table B-10. Results of Glass Properties and Constraint Quantities for 10 Example MFPV Batches

\begin{tabular}{|c|c|c|c|c|c|}
\hline Properties/Constraints & MFPV-A101 & MFPV-B101 & MFPV-A102 & MFPV-B102 & MFPV-A103 \\
\hline \multicolumn{6}{|c|}{$P^{\text {prop }}$} \\
\hline $\ln \left(r_{B}\right)$ & 0.0540 & 0.0492 & 0.0634 & 0.1408 & 0.1412 \\
\hline $\ln \left(r_{N a}\right)$ & -0.0579 & -0.0618 & -0.0506 & 0.0009 & 0.0012 \\
\hline $\ln (D)$ & 2.6105 & 2.5922 & 2.6358 & 2.8623 & 2.8656 \\
\hline $\ln \left(\eta_{1100}\right), u$ & 4.6076 & 4.6131 & 4.5985 & 4.5922 & 4.5920 \\
\hline $\ln \left(\eta_{1150}\right), l$ & 4.1117 & 4.1168 & 4.1032 & 4.0990 & 4.0987 \\
\hline $\ln \left(\eta_{1150}\right), u$ & 4.1117 & 4.1168 & 4.1032 & 4.0990 & 4.0987 \\
\hline $\ln \left(\varepsilon_{1100}\right), l$ & -1.0551 & -1.0561 & -1.0537 & -0.9829 & -0.9826 \\
\hline $\ln \left(\varepsilon_{1200}\right), u$ & -0.7026 & -0.7033 & -0.7014 & -0.6374 & -0.6371 \\
\hline \multicolumn{6}{|c|}{$U_{\text {pred }}^{\text {prop }}$} \\
\hline $\ln \left(r_{B}\right)$ & 0.1537 & 0.1545 & 0.1526 & 0.1640 & 0.1640 \\
\hline $\ln \left(r_{N a}\right)$ & 0.1651 & 0.1656 & 0.1643 & 0.1765 & 0.1765 \\
\hline $\ln (D)$ & 0.6303 & 0.6339 & 0.6250 & 0.6563 & 0.6562 \\
\hline $\ln \left(\eta_{1100}\right), u$ & 0.0326 & 0.0327 & 0.0324 & 0.0353 & 0.0353 \\
\hline $\ln \left(\eta_{1150}\right), l$ & 0.0328 & 0.0329 & 0.0326 & 0.0355 & 0.0355 \\
\hline $\ln \left(\eta_{1150}\right), u$ & 0.0328 & 0.0329 & 0.0326 & 0.0355 & 0.0355 \\
\hline $\ln \left(\varepsilon_{1100}\right), l$ & 0.0321 & 0.0322 & 0.0320 & 0.0353 & 0.0354 \\
\hline $\ln \left(\varepsilon_{1200}\right), u$ & 0.0327 & 0.0328 & 0.0325 & 0.0359 & 0.0359 \\
\hline \multicolumn{6}{|c|}{$U_{\text {comp }}^{\text {prop }}$} \\
\hline $\ln \left(r_{B}\right)$ & 0.3366 & 0.3516 & 0.3458 & 0.3496 & 0.3745 \\
\hline $\ln \left(r_{N a}\right)$ & 0.2852 & 0.2982 & 0.2944 & 0.2895 & 0.3088 \\
\hline $\ln (D)$ & 1.2035 & 1.2679 & 1.2219 & 1.3583 & 1.4372 \\
\hline $\ln \left(\eta_{1100}\right), u$ & 0.2523 & 0.2409 & 0.2618 & 0.2573 & 0.2597 \\
\hline $\ln \left(\eta_{1150}\right), l$ & 0.2254 & 0.2348 & 0.2337 & 0.2327 & 0.2467 \\
\hline $\ln \left(\eta_{1150}\right), u$ & 0.2333 & 0.2224 & 0.2415 & 0.2375 & 0.2396 \\
\hline $\ln \left(\varepsilon_{1100}\right), l$ & 0.1766 & 0.1689 & 0.1865 & 0.1788 & 0.1814 \\
\hline $\ln \left(\varepsilon_{1200}\right), u$ & 0.1528 & 0.1606 & 0.1618 & 0.1564 & 0.1686 \\
\hline \multicolumn{6}{|c|}{$B_{u c c i, l c c i}^{p r o p}$} \\
\hline $\ln \left(r_{B}\right)$ & 0.5443 & 0.5553 & 0.5619 & 0.6544 & 0.6796 \\
\hline $\ln \left(r_{N a}\right)$ & 0.3924 & 0.4020 & 0.4081 & 0.4669 & 0.4865 \\
\hline $\ln (D)$ & 4.4442 & 4.4940 & 4.4828 & 4.8770 & 4.9590 \\
\hline $\ln \left(\eta_{1100}\right), u$ & 4.8925 & 4.8867 & 4.8927 & 4.8848 & 4.8869 \\
\hline $\ln \left(\eta_{1150}\right), l$ & 3.8536 & 3.8491 & 3.8369 & 3.8308 & 3.8166 \\
\hline $\ln \left(\eta_{1150}\right), u$ & 4.3779 & 4.3721 & 4.3773 & 4.3720 & 4.3738 \\
\hline $\ln \left(\varepsilon_{1100}\right), l$ & -1.2638 & -1.2572 & -1.2722 & -1.1971 & -1.1993 \\
\hline $\ln \left(\varepsilon_{1200}\right), u$ & -0.5172 & -0.5099 & -0.5071 & -0.4451 & -0.4327 \\
\hline \multicolumn{6}{|c|}{ Model validity single component constraints } \\
\hline $\mathrm{Al}_{2} \mathrm{O}_{3}$ & 0.06125 & 0.06124 & 0.06126 & 0.06125 & 0.06126 \\
\hline $\mathrm{Cl}$ & 0.00136 & 0.00136 & 0.00136 & 0.00142 & 0.00142 \\
\hline $\mathrm{Cr}_{2} \mathrm{O}_{3}$ & 0.00086 & 0.00086 & 0.00086 & 0.00086 & 0.00086 \\
\hline $\mathrm{F}$ & 0.00076 & 0.00076 & 0.00076 & 0.00081 & 0.00081 \\
\hline $\mathrm{P}_{2} \mathrm{O}_{5}$ & 0.00198 & 0.00198 & 0.00198 & 0.00203 & 0.00203 \\
\hline $\mathrm{SiO}_{2}$ & 0.44984 & 0.44993 & 0.44963 & 0.44621 & 0.44620 \\
\hline
\end{tabular}




\begin{tabular}{|c|c|c|c|c|c|}
\hline Properties/Constraints & MFPV-A101 & MFPV-B101 & MFPV-A102 & MFPV-B102 & MFPV-A103 \\
\hline Sum of Minors & 0.00051 & 0.00051 & 0.00051 & 0.00051 & 0.00051 \\
\hline \multicolumn{6}{|c|}{ Model validity PCT constraints } \\
\hline$P^{p c t B}(\ln [\mathrm{g} / \mathrm{L}])$ & 0.0540 & 0.0492 & 0.0634 & 0.1408 & 0.1412 \\
\hline$P^{p c t N a}(\ln [\mathrm{g} / \mathrm{L}])$ & -0.0579 & -0.0618 & -0.0506 & 0.0009 & 0.0012 \\
\hline \multicolumn{6}{|c|}{ Model validity multiple component constraints } \\
\hline $\mathrm{Li}_{2} \mathrm{O}$ & 0.00191 & 0.00180 & 0.00206 & 0.00000 & 0.00000 \\
\hline $\mathrm{Cr}_{2} \mathrm{O} 3$ & 0.00086 & 0.00086 & 0.00086 & 0.00086 & 0.00086 \\
\hline $\mathrm{Na}_{2} \mathrm{O}$ & 0.19088 & 0.19087 & 0.19088 & 0.19821 & 0.19823 \\
\hline $\mathrm{Li}_{2} \mathrm{O}$ & 0.00191 & 0.00180 & 0.00206 & 0.00000 & 0.00000 \\
\hline $\mathrm{Na}_{2} \mathrm{O}$ & 0.19088 & 0.19087 & 0.19088 & 0.19821 & 0.19823 \\
\hline $\mathrm{Li}_{2} \mathrm{O}$ & 0.00191 & 0.00180 & 0.00206 & 0.00000 & 0.00000 \\
\hline $\mathrm{Na}_{2} \mathrm{O}$ & 0.19088 & 0.19087 & 0.19088 & 0.19821 & 0.19823 \\
\hline \multicolumn{6}{|l|}{ Lower limit } \\
\hline function of $\mathrm{Na}_{2} \mathrm{O}$ & -0.05336 & -0.05336 & -0.05336 & -0.05720 & -0.05722 \\
\hline function of $\mathrm{P}_{2} \mathrm{O}_{5}$ & -0.00138 & -0.00138 & -0.00138 & -0.00137 & -0.00137 \\
\hline function of $\mathrm{CaO}$ & 0.08877 & 0.08878 & 0.08877 & 0.09292 & 0.09292 \\
\hline function of $\mathrm{CaO}$ & 0.00000 & 0.00000 & 0.00000 & 0.00000 & 0.00000 \\
\hline function of $\mathrm{SO}_{3}$ & 0.03645 & 0.03645 & 0.03645 & 0.03615 & 0.03614 \\
\hline function of $\mathrm{SO}_{3}$ & -0.02079 & -0.02079 & -0.02079 & -0.02068 & -0.02068 \\
\hline function of $\mathrm{SiO}_{2}$ & 0.00469 & 0.00457 & 0.00498 & 0.00952 & 0.00953 \\
\hline \multicolumn{6}{|l|}{ Upper limit } \\
\hline function of $\mathrm{Na}_{2} \mathrm{O}$ & 0.02851 & 0.02851 & 0.02851 & 0.02643 & 0.02642 \\
\hline function of $\mathrm{P}_{2} \mathrm{O}_{5}$ & 0.00234 & 0.00234 & 0.00234 & 0.00235 & 0.00235 \\
\hline function of $\mathrm{CaO}$ & 0.28177 & 0.28178 & 0.28177 & 0.28592 & 0.28592 \\
\hline function of $\mathrm{CaO}$ & 0.03953 & 0.03952 & 0.03952 & 0.03827 & 0.03826 \\
\hline function of $\mathrm{SO}_{3}$ & 0.25785 & 0.25785 & 0.25785 & 0.25755 & 0.25754 \\
\hline function of $\mathrm{SO}_{3}$ & 0.05081 & 0.05081 & 0.05081 & 0.05092 & 0.05092 \\
\hline function of $\mathrm{SiO}_{2}$ & 0.20729 & 0.20717 & 0.20758 & 0.21212 & 0.21213 \\
\hline \multicolumn{6}{|c|}{ Waste $\mathrm{Na}_{2} \mathrm{O}$ loading constraint } \\
\hline $\begin{array}{c}\text { oxidein } \\
g_{\mathrm{Na} a_{2} \mathrm{O}(w), j}^{\mathrm{MFPV} 3} \text { (a) }\end{array}$ & 0.181 & 0.181 & 0.181 & 0.188 & 0.188 \\
\hline \multicolumn{6}{|c|}{ Radionuclide Concentration Constraints } \\
\hline 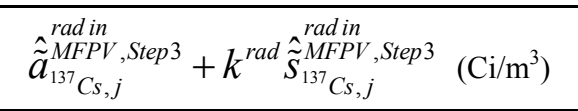 & 0.150 & 0.150 & 0.150 & 0.155 & 0.154 \\
\hline $\begin{array}{ccc}\text { rad in } & \begin{array}{r}\text { radSF in } \\
S F_{L L, j}^{M F P V, S t e p 3}+k^{\text {rad }} S_{L L, j}^{M F P V, S t e p 3}\end{array}\left(\mathrm{Ci} / \mathrm{m}^{3}\right) \\
\end{array}$ & 1.678 & 1.678 & 1.677 & 1.733 & 1.736 \\
\hline $\begin{array}{cc}\text { rad in } & \text { radSF in } \\
S F_{L L, j}^{M F P V, \text { Step 3 }}+k^{\text {rad }} S_{L L, j}^{M F P V, \text { Step } 3} & \end{array}$ & 0.04843 & 0.04877 & 0.04871 & 0.04959 & 0.04972 \\
\hline $\begin{array}{cc}\text { rad in } & \text { radSF in } \\
S F_{S L, j}^{M F P V, S t e p 3}+k^{\text {rad }} S_{S L, j}^{M F P V, \text { Step 3 }} & \end{array}$ & 0.00039 & 0.00039 & 0.00039 & 0.00041 & 0.00041 \\
\hline
\end{tabular}

\begin{tabular}{|c|c|c|c|c|c|c|}
\hline Properties/Constraints & MFPV-B103 & MFPV-A104 & MFPV-B104 & MFPV-A105 & MFPV-B105 \\
\hline \multicolumn{7}{|c||}{$P^{\text {prop }}$} \\
\hline $\ln \left(r_{B}\right)$ & 0.1422 & -0.1863 & -0.1915 & -0.1829 & -0.1819 \\
\hline $\ln \left(r_{N a}\right)$ & 0.0021 & -0.2200 & -0.2241 & -0.2170 & -0.2163 \\
\hline
\end{tabular}




\begin{tabular}{|c|c|c|c|c|c|}
\hline Properties/Constraints & MFPV-B103 & MFPV-A104 & MFPV-B104 & MFPV-A105 & MFPV-B105 \\
\hline $\ln (D)$ & 2.8639 & 1.9768 & 1.9632 & 1.9922 & 1.9923 \\
\hline $\ln \left(\eta_{1100}\right), u$ & 4.5914 & 4.6402 & 4.6453 & 4.6356 & 4.6349 \\
\hline $\ln \left(\eta_{1150}\right), l$ & 4.0982 & 4.1344 & 4.1391 & 4.1301 & 4.1294 \\
\hline $\ln \left(\eta_{1150}\right), u$ & 4.0982 & 4.1344 & 4.1391 & 4.1301 & 4.1294 \\
\hline $\ln \left(\varepsilon_{1100}\right), l$ & -0.9826 & -1.2526 & -1.2538 & -1.2515 & -1.2514 \\
\hline $\ln \left(\varepsilon_{1200}\right), u$ & -0.6371 & -0.8745 & -0.8755 & -0.8736 & -0.8734 \\
\hline \multicolumn{6}{|c|}{$U_{\text {pred }}^{\text {prop }}$} \\
\hline $\ln \left(r_{B}\right)$ & 0.1640 & 0.1478 & 0.1482 & 0.1472 & 0.1471 \\
\hline $\ln \left(r_{N a}\right)$ & 0.1765 & 0.1510 & 0.1513 & 0.1505 & 0.1505 \\
\hline $\ln (D)$ & 0.6562 & 0.6211 & 0.6240 & 0.6179 & 0.6178 \\
\hline $\ln \left(\eta_{1100}\right), u$ & 0.0353 & 0.0293 & 0.0294 & 0.0292 & 0.0292 \\
\hline $\ln \left(\eta_{1150}\right), l$ & 0.0355 & 0.0295 & 0.0296 & 0.0294 & 0.0294 \\
\hline $\ln \left(\eta_{1150}\right), u$ & 0.0355 & 0.0295 & 0.0296 & 0.0294 & 0.0294 \\
\hline $\ln \left(\varepsilon_{1100}\right), l$ & 0.0353 & 0.0298 & 0.0299 & 0.0297 & 0.0297 \\
\hline $\ln \left(\varepsilon_{1200}\right), u$ & 0.0359 & 0.0303 & 0.0304 & 0.0302 & 0.0302 \\
\hline \multicolumn{6}{|c|}{$U_{\text {comp }}^{\text {prop }}$} \\
\hline $\ln \left(r_{B}\right)$ & 0.3660 & 0.2941 & 0.3012 & 0.3048 & 0.2973 \\
\hline $\ln \left(r_{N a}\right)$ & 0.3023 & 0.2658 & 0.2724 & 0.2751 & 0.2689 \\
\hline $\ln (D)$ & 1.4159 & 0.8537 & 0.8734 & 0.8787 & 0.8667 \\
\hline $\ln \left(\eta_{1100}\right), u$ & 0.2575 & 0.2319 & 0.2221 & 0.2282 & 0.2352 \\
\hline $\ln \left(\eta_{1150}\right), l$ & 0.2425 & 0.2084 & 0.2123 & 0.2148 & 0.2101 \\
\hline $\ln \left(\eta_{1150}\right), u$ & 0.2378 & 0.2131 & 0.2052 & 0.2098 & 0.2168 \\
\hline $\ln \left(\varepsilon_{1100}\right), l$ & 0.1789 & 0.1701 & 0.1641 & 0.1689 & 0.1719 \\
\hline $\ln \left(\varepsilon_{1200}\right), u$ & 0.1645 & 0.1480 & 0.1521 & 0.1539 & 0.1519 \\
\hline \multicolumn{6}{|c|}{$B_{u c c i, l c c i}^{\text {prop }}$} \\
\hline $\ln \left(r_{B}\right)$ & 0.6722 & 0.2556 & 0.2579 & 0.2690 & 0.2626 \\
\hline $\ln \left(r_{N a}\right)$ & 0.4809 & 0.1967 & 0.1996 & 0.2086 & 0.2030 \\
\hline $\ln (D)$ & 4.9359 & 3.4515 & 3.4606 & 3.4888 & 3.4768 \\
\hline $\ln \left(\eta_{1100}\right), u$ & 4.8841 & 4.9014 & 4.8968 & 4.8931 & 4.8993 \\
\hline $\ln \left(\eta_{1150}\right), l$ & 3.8202 & 3.8964 & 3.8973 & 3.8859 & 3.8899 \\
\hline $\ln \left(\eta_{1150}\right), u$ & 4.3715 & 4.3770 & 4.3739 & 4.3694 & 4.3757 \\
\hline $\ln \left(\varepsilon_{1100}\right), l$ & -1.1969 & -1.4526 & -1.4478 & -1.4501 & -1.4529 \\
\hline $\ln \left(\varepsilon_{1200}\right), u$ & -0.4367 & -0.6962 & -0.6929 & -0.6895 & -0.6913 \\
\hline \multicolumn{6}{|c|}{ Model validity single component constraints } \\
\hline $\mathrm{Al}_{2} \mathrm{O}_{3}$ & 0.06123 & 0.06120 & 0.06121 & 0.06123 & 0.06121 \\
\hline $\mathrm{Cl}$ & 0.00142 & 0.00126 & 0.00126 & 0.00126 & 0.00126 \\
\hline $\mathrm{Cr}_{2} \mathrm{O}_{3}$ & 0.00086 & 0.00086 & 0.00086 & 0.00086 & 0.00086 \\
\hline $\mathrm{F}$ & 0.00081 & 0.00073 & 0.00073 & 0.00073 & 0.00073 \\
\hline $\mathrm{P}_{2} \mathrm{O}_{5}$ & 0.00203 & 0.00189 & 0.00189 & 0.00189 & 0.00189 \\
\hline $\mathrm{SiO}_{2}$ & 0.44618 & 0.45652 & 0.45660 & 0.45645 & 0.45642 \\
\hline Sum of Minors & 0.00051 & 0.00052 & 0.00052 & 0.00052 & 0.00052 \\
\hline \multicolumn{6}{|c|}{ Model validity PCT constraints } \\
\hline$P^{p c t B}(\ln [\mathrm{g} / \mathrm{L}])$ & 0.1422 & -0.1863 & -0.1915 & -0.1829 & -0.1819 \\
\hline$P^{p c t N a}(\ln [\mathrm{g} / \mathrm{L}])$ & 0.0021 & -0.2200 & -0.2241 & -0.2170 & -0.2163 \\
\hline
\end{tabular}




\begin{tabular}{|c|c|c|c|c|c|}
\hline Properties/Constraints & MFPV-B103 & MFPV-A104 & MFPV-B104 & MFPV-A105 & MFPV-B105 \\
\hline \multicolumn{6}{|c|}{ Model validity multiple component constraints } \\
\hline $\mathrm{Li}_{2} \mathrm{O}$ & 0.00000 & 0.00596 & 0.00587 & 0.00607 & 0.00607 \\
\hline $\mathrm{Cr}_{2} \mathrm{O} 3$ & 0.00086 & 0.00086 & 0.00086 & 0.00086 & 0.00086 \\
\hline $\mathrm{Na}_{2} \mathrm{O}$ & 0.19823 & 0.17078 & 0.17079 & 0.17077 & 0.17078 \\
\hline $\mathrm{Li}_{2} \mathrm{O}$ & 0.00000 & 0.00596 & 0.00587 & 0.00607 & 0.00607 \\
\hline $\mathrm{Na}_{2} \mathrm{O}$ & 0.19823 & 0.17078 & 0.17079 & 0.17077 & 0.17078 \\
\hline $\mathrm{Li}_{2} \mathrm{O}$ & 0.00000 & 0.00596 & 0.00587 & 0.00607 & 0.00607 \\
\hline $\mathrm{Na}_{2} \mathrm{O}$ & 0.19823 & 0.17078 & 0.17079 & 0.17077 & 0.17078 \\
\hline \multicolumn{6}{|l|}{ Lower limit } \\
\hline function of $\mathrm{Na}_{2} \mathrm{O}$ & -0.05721 & -0.04284 & -0.04284 & -0.04283 & -0.04284 \\
\hline function of $\mathrm{P}_{2} \mathrm{O}_{5}$ & -0.00137 & -0.00140 & -0.00140 & -0.00140 & -0.00140 \\
\hline function of $\mathrm{CaO}$ & 0.09291 & 0.07162 & 0.07163 & 0.07161 & 0.07162 \\
\hline function of $\mathrm{CaO}$ & 0.00000 & 0.00000 & 0.00000 & 0.00000 & 0.00000 \\
\hline function of $\mathrm{SO}_{3}$ & 0.03614 & 0.03753 & 0.03752 & 0.03753 & 0.03753 \\
\hline function of $\mathrm{SO}_{3}$ & -0.02068 & -0.02116 & -0.02116 & -0.02116 & -0.02116 \\
\hline function of $\mathrm{SiO}_{2}$ & 0.00955 & -0.00418 & -0.00428 & -0.00408 & -0.00404 \\
\hline \multicolumn{6}{|l|}{ Upper limit } \\
\hline function of $\mathrm{Na}_{2} \mathrm{O}$ & 0.02642 & 0.03421 & 0.03421 & 0.03422 & 0.03422 \\
\hline function of $\mathrm{P}_{2} \mathrm{O}_{5}$ & 0.00235 & 0.00231 & 0.00231 & 0.00231 & 0.00231 \\
\hline function of $\mathrm{CaO}$ & 0.28591 & 0.26462 & 0.26463 & 0.26461 & 0.26462 \\
\hline function of $\mathrm{CaO}$ & 0.03827 & 0.04473 & 0.04472 & 0.04473 & 0.04473 \\
\hline function of $\mathrm{SO}_{3}$ & 0.25754 & 0.25893 & 0.25892 & 0.25893 & 0.25893 \\
\hline function of $\mathrm{SO}_{3}$ & 0.05092 & 0.05044 & 0.05044 & 0.05044 & 0.05044 \\
\hline function of $\mathrm{SiO}_{2}$ & 0.21215 & 0.19842 & 0.19832 & 0.19852 & 0.19856 \\
\hline \multicolumn{6}{|c|}{ Waste $\mathrm{Na}_{2} \mathrm{O}$ loading constraint } \\
\hline $\begin{array}{c}\text { oxidein } \\
g_{\mathrm{Na}_{2} \mathrm{O}(w), \mathrm{Step} 3}^{M F(\text { a) }} \\
\end{array}$ & 0.188 & 0.162 & 0.162 & 0.162 & 0.162 \\
\hline \multicolumn{6}{|c|}{ Radionuclide Concentration Constraints } \\
\hline $\begin{array}{l}\text { radin } \\
\hat{\tilde{a}}_{137 C P V, \text { Step } 3}^{M F a d i n} \\
k^{\text {rad }} \hat{\tilde{S}}_{137 C S, j}^{M F P V, \text { Step } 3}\left(\mathrm{Ci} / \mathrm{m}^{3}\right)\end{array}$ & 0.154 & 0.149 & 0.149 & 0.149 & 0.149 \\
\hline 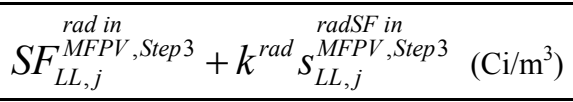 & 1.734 & 1.578 & 1.576 & 1.581 & 1.578 \\
\hline 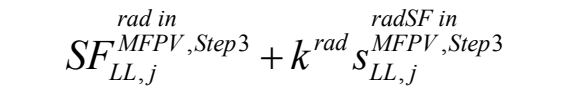 & 0.04957 & 0.04835 & 0.04814 & 0.04840 & 0.04855 \\
\hline$\underset{S F_{S L, j}^{M F P V, S t e p 3}+k^{\text {rad in }}}{\text { rad }} S_{S L, j}^{\text {radSF in }}$ & 0.00041 & 0.00037 & 0.00037 & 0.00037 & 0.00037 \\
\hline
\end{tabular}

(a) It was assumed that the waste in the $A 11^{\text {th }}, B 11^{\text {th }}$, and $A 12^{\text {th }}$ CRV were designated as Envelope A and had the fraction of sodium that is classified as waste sodium $\left(\omega_{A 11}\right)$ was $95 \%$. 


\section{Appendix C-Summary of Data Requirements}


Table C-1. Assumptions to be Reviewed Before Final Algorithm is Complete

\begin{tabular}{|c|c|c|}
\hline Description & Current Assumptions & Status \\
\hline 1. Glass property models & $\begin{array}{l}\text { Models for PCT, VHT, viscosity, and electrical conductivity are } \\
\text { from Piepel et al. 2007. Model coefficients are listed in Tables } 5 \\
\text { through } 8 \text {. Model forms are given by Equations }(19),(22),(23) \text {, } \\
\text { and (24). Model variance-covariance matrices are in Tables A-7 } \\
\text { through A-11and glass component concentration and property } \\
\text { ranges for model validity are given in Tables } 11 \text { through } 13 \text {. }\end{array}$ & $\begin{array}{l}\text { No specific verification or testing needs are associated } \\
\text { with the use of these models. }\end{array}$ \\
\hline $\begin{array}{l}\text { 2. GFC composition, } \\
\text { uncertainty in GFC } \\
\text { composition, and GFC } \\
\text { particle density }\end{array}$ & $\begin{array}{l}\text { The minimum, most likely, and maximum component mass } \\
\text { fraction values are given in Table A-4. Particle densities are given } \\
\text { in Table A-12. Data listed in Table A-4 were used to define the } \\
\text { uncertainty for the GFC composition based on PERT distribution. } \\
\text { The nominal GFC composition in Table A-5 was obtained by } \\
\text { Monte Carlo simulations and used for nominal glass composition } \\
\text { calculation. These data are based on the initial GFC vendor } \\
\text { certifications obtained during characterization testing (Schumacher } \\
\text { 2003). }\end{array}$ & $\begin{array}{l}\text { Eventually the algorithm will use data for the specific } \\
\text { materials used in each MFPV batch. } \\
\text { A decision needs be made on how to obtain these data for } \\
\text { each material. Two possible options are: (1) use the } \\
\text { vendor certifications supplied by the vendors for each } \\
\text { material, or (2) measure the composition and particle } \\
\text { density at WTP. }\end{array}$ \\
\hline $\begin{array}{l}\text { 3. Melter retention factors } \\
\text { and uncertainty of melt } \\
\text { retention factors }\end{array}$ & $\begin{array}{l}\text { Table A-3 lists the preliminary melter retention factors expressed } \\
\text { as } \ln (\mathrm{DF}) \text { in terms of minimum, most likely, and maximum values } \\
\text { for uncertainty expression by PERT distribution (24590-LAW- } \\
\text { RPT-RT-11-001, Rev 0). }\end{array}$ & $\begin{array}{l}\text { The melter retention factors and recycle effects should be } \\
\text { updated as more data become available and may need to be } \\
\text { expressed as a function of glass and feed compositions for } \\
\text { selected components. }\end{array}$ \\
\hline $\begin{array}{l}\text { 4. RSD in chemical and } \\
\text { radiological analyses of } \\
\text { CRV batches }\end{array}$ & $\begin{array}{l}\text { Table A-2 lists constants and uncertainty values used in the } \\
\text { calculations showing how the algorithm works. These values were } \\
\text { based on CCN } 111456 \text {. Other assumptions for components not } \\
\text { listed in CCN } 111456 \text { are summarized in Table A-2. }\end{array}$ & $\begin{array}{l}\text { A plan should be developed and implemented to establish a } \\
\text { maximum acceptable analytical uncertainty before } \\
\text { methods validation in order to demonstrate that the } \\
\text { methods meet an established requirement. }\end{array}$ \\
\hline $\begin{array}{l}\text { 5. RSD in mixing/sampling } \\
\text { and RSD for bias correction } \\
\text { of mixing and sampling in } \\
\text { CRV batches }\end{array}$ & $\begin{array}{l}\text { RSD in mixing/sampling is assumed as } 1.47 \% \text { for all components } \\
\text { (Table A-2) without bias correction as recommended by } 24590- \\
\text { LAW-RPT-RT-11-001, Rev } 0 \text {. }\end{array}$ & $\begin{array}{l}\text { A plan should be developed and implemented to establish a } \\
\text { maximum acceptable mixing/sampling uncertainty before } \\
\text { methods validation in order to demonstrate that the } \\
\text { methods meet an established requirement. }\end{array}$ \\
\hline $\begin{array}{l}\text { 6. CRV and MFPV } \\
\text { volumes }\end{array}$ & $\begin{array}{l}\text { CRV volumes are from 24590-LAW-M6C-LCP-00001, Rev } 1 \text { and } \\
\text { MFPV volumes are from 24590-LAW-M6C-LFP-00001, Rev } 1 \text { as } \\
\text { given in Table } 1 .\end{array}$ & $\begin{array}{l}\text { The vessel volumes will be updated upon any design } \\
\text { change. }\end{array}$ \\
\hline
\end{tabular}




\begin{tabular}{|c|c|c|}
\hline Description & Current Assumptions & Status \\
\hline $\begin{array}{l}\text { 7. SD in GFC mass } \\
\text { measurement }\end{array}$ & $\begin{array}{l}\text { Appendix E discusses the method obtaining the SD values based on } \\
\text { the load cell data and weigh hopper information. For the purpose } \\
\text { of this preliminary algorithm it was assumed that the Mettler } \\
\text { Toledo's Centerlign Weigh Module model } 744 \text { (for } 250 \mathrm{lb} \\
\text { capacity) and } 745 \text { (for } 500 \mathrm{lb} \text { capacity) are used. }\end{array}$ & $\begin{array}{l}\text { The calculation process should be updated as necessary } \\
\text { once the equipments are finalized. }\end{array}$ \\
\hline $\begin{array}{l}\text { 8. SD in waste transfer } \\
\text { volume measurement }\end{array}$ & $\begin{array}{l}\text { Appendix D discusses the approach taken to obtain the SD values } \\
\text { for waste transfer volume measurement based on a recommended } \\
\text { value of } 1.41 \text { inches for the level measurement uncertainty given in } \\
24590 \text {-LAW-RPT-RT-11-001, Rev } 0 \text {. }\end{array}$ & $\begin{array}{l}\text { The level measurement uncertainty used in the algorithm } \\
\text { should be compared to the uncertainty from actual plant } \\
\text { equipment to verify proper representation in the algorithm. }\end{array}$ \\
\hline $\begin{array}{l}\text { 9. Dust control water } \\
\text { volume estimate }\end{array}$ & $\begin{array}{l}\text { Equation (58) specifies } 4 \text { wt\% water addition based on } 24590- \\
\text { LAW-M4C-20-00002, Rev } 0 .\end{array}$ & $\begin{array}{l}\text { The validity of the Equation ( } 58) \text { may need to be tested to } \\
\text { meet engineering requirements. }\end{array}$ \\
\hline $\begin{array}{l}\text { 10. Line flush water } \\
\text { volumes }\end{array}$ & $\begin{array}{l}\text { Line flush and wash water volumes applicable to ILAW algorithm } \\
\text { are summarized in Table } 14 \text {. These values are based on project } \\
\text { line flush volume guidance. }\end{array}$ & $\begin{array}{l}\text { Line flush volumes will be updated as relevant engineering } \\
\text { documents and operating procedures are modified. }\end{array}$ \\
\hline $\begin{array}{l}\text { 11. Sucrose volume } \\
\text { calculation }\end{array}$ & $\begin{array}{l}\text { Equation (34) prescribes the amount of sucrose to add to HLW and } \\
\text { LAW melter feed based on the concentrations of organic carbon, } \\
\text { nitrate, and nitrite in the feed. This relationship was empirically } \\
\text { derived from pilot melter testing and is used to avoid melter upsets } \\
\text { due to over oxidation of multivalent elements (Matlack 2005). No } \\
\text { attempt to optimize reductant addition to improve melting } \\
\text { parameters (such as volatility, metal reduction, and feed processing } \\
\text { rate) has yet been performed. }\end{array}$ & $\begin{array}{l}\text { No testing or verification is required until optimization is } \\
\text { needed. }\end{array}$ \\
\hline $\begin{array}{l}\text { 12. Confidence level in } \\
\text { satisfying various } \\
\text { constraints }\end{array}$ & $\begin{array}{l}90 \% \text { confidence level is used for all properties as discussed in } \\
\text { Section } 4.3 .4 \text {. }\end{array}$ & $\begin{array}{l}\text { No testing or verification is required. Values may need to } \\
\text { be updated by project management decision. }\end{array}$ \\
\hline $\begin{array}{l}\text { 13. Software for } \\
\text { implementing the algorithm } \\
\text { described in this report }\end{array}$ & $\begin{array}{l}\text { The calculations described in this report have been demonstrated } \\
\text { using an Excel }{ }^{\mathrm{TM}} \text { with a RiskAMPTM add-in. However, the use of } \\
\text { that system will likely not suit the requirements of plant operation. } \\
\text { No software has yet been developed. }\end{array}$ & $\begin{array}{l}\text { Software development, validation, and verification will be } \\
\text { required prior to implementation of this algorithm. }\end{array}$ \\
\hline
\end{tabular}




\begin{tabular}{|l|l|l|}
\hline \multicolumn{1}{|c|}{ Description } & \multicolumn{1}{c|}{ Current Assumptions } & \multicolumn{1}{c|}{ Status } \\
\hline $\begin{array}{l}\text { 15. Methods/software to be } \\
\text { used for statistical process } \\
\text { control (SPC) }\end{array}$ & $\begin{array}{l}\text { Statistical process control is a useful tool that should be } \\
\text { incorporated into the formulation decision making as described in } \\
\text { Sections 5.2, 6.2, and 6.4. As SPC software to meet the } \\
\text { highlighted purposes is a common, of the shelf, product and it was } \\
\text { not developed as part of the algorithm equations. However, to } \\
\text { meet the functions described, such software must be selected and } \\
\text { integrated into the algorithm. }\end{array}$ & $\begin{array}{l}\text { No testing or verification is envisioned outside of software } \\
\text { selection, validation, and verification activities. The } \\
\text { notification values will be set by management decision. }\end{array}$ \\
& & \\
\hline
\end{tabular}


Table C-2. Data and Inputs Required During Operations: 1. Inputs Required on an Every Batch Basis

\begin{tabular}{|c|c|c|}
\hline Symbol & Brief Description & Anticipated Source \\
\hline$c_{i d}^{\text {element in }}$ & Concentration of the $i^{\text {th }}$ analyte in the $d^{\text {th }}$ CRV batch $(\mathrm{mg} / \mathrm{L})$ & Analytical laboratory \\
\hline$M_{k j}^{G F C \text { in }}$,measured & Measured mass of $k^{\text {th }}$ GFC added to the $j^{\text {th }}$ MFPV batch (g) & LAW operator \\
\hline $\begin{array}{c}\text { heel } \\
V_{j}^{M F P V}\end{array}$ & MFPV heel volume in the $j^{\text {th }}$ MFPV batch (L) & LAW operator \\
\hline $\begin{array}{l}\text { waste } \\
V_{j}^{M F P V}\end{array}$ & volume of waste transferred from CRV to the $j^{\text {th }}$ MFPV (L) & LAW operator \\
\hline $\begin{array}{c}\text { dust } \\
V_{j}^{M F P V, \text { mesured }}\end{array}$ & $\begin{array}{l}\text { measured volume of water added to control GFC dusting in the } j^{\text {th }} \\
\text { MFPV batch (L) }\end{array}$ & LAW operator \\
\hline $\begin{array}{c}\text { transflush } \\
V_{j}^{M F P V, \text { measured }} \\
\end{array}$ & $\begin{array}{l}\text { measured volume of water used to flush the CRV-MFPV transfer } \\
\text { line in the } j^{\text {th }} \text { MFPV batch (L) }\end{array}$ & LAW operator \\
\hline $\begin{array}{c}\text { sampflush } \\
V_{j}^{M F P V}, \text { measured }\end{array}$ & $\begin{array}{l}\text { measured volume of water used to flush the MFPV sampling line in } \\
\text { the } j^{\text {th }} \text { MFPV batch (L) }\end{array}$ & LAW operator \\
\hline $\begin{array}{c}\text { dilute } \\
V_{j}^{M F P V, \text { measured }}\end{array}$ & $\begin{array}{l}\text { measured volume of dilution water added to maintain satisfactory } \\
\text { melter-feed rheological properties in the } j^{\text {th }} \text { MFPV batch (L) }\end{array}$ & LAW operator \\
\hline Envelop & Type of LAW, A, B, or C & LAW operator \\
\hline$\omega_{d}$ & $\begin{array}{l}\text { Fraction of the sodium in the } d^{\text {th }} \mathrm{CRV} \text { batch that is classified as } \\
\text { waste sodium (unitless) }\end{array}$ & LAW operator \\
\hline
\end{tabular}

Table C-3. Data and Inputs Required During Operations: 2. Inputs Required Only When Process Changes are Made

\begin{tabular}{|l|l|l||}
\hline Symbol & Brief Description & Anticipated Source \\
\hline No symbol & Parameters for statistical process monitoring & LAW operations manager \\
\hline $\begin{array}{c}\text { dust } \\
V_{j}^{M F P V}\end{array}$ & $\begin{array}{l}\text { volume of water added to control GFC dusting in the } j^{\text {th }} \text { MFPV } \\
\text { batch (L) }\end{array}$ & LAW operations manager \\
\hline $\begin{array}{c}\text { oxides in } \\
m_{i k}^{G F C}\end{array}$ & $\begin{array}{l}\text { Mass fraction of the } i^{\text {th }} \text { glass oxide in the } k^{\text {th }} \text { GFC (g oxide per g } \\
\text { GFC including volatiles) }\end{array}$ & $\begin{array}{l}\text { GFC vendor or analytical } \\
\text { laboratory }\end{array}$ \\
\hline $\begin{array}{c}\text { transflush } \\
V_{j}^{M F P V}\end{array}$ & $\begin{array}{l}\text { Volume of water used to flush the CRV-MFPV transfer line in the } \\
j^{\text {th }} \text { MFPV batch (L) }\end{array}$ & LAW operations manager \\
\hline $\begin{array}{c}\text { sampflush } \\
V_{j}^{M F P V}\end{array}$ & $\begin{array}{l}\text { Volume of water used to flush the MFPV sampling line in the } j^{\text {th }} \\
\text { MFPV batch (L) }\end{array}$ & LAW operations manager \\
\hline $\begin{array}{l}\text { CL\% } \% 100(1-\alpha) \\
\text { RSD in } \\
\text { element in } \\
c_{i d}^{C R V}\end{array}$ & $\begin{array}{l}\text { Level of confidence in meeting predicted property constraints, may } \\
\text { be different for different properties }\end{array}$ & LAW operations manager \\
\hline \hline
\end{tabular}




\section{Appendix D-Uncertainties for Waste Transfer Volume Measurements}




\section{Appendix D-Uncertainties for Waste Transfer Volume Measurements}

The MFPV and CRV vessel volumes will be obtained from the radar level measurements. The volume of waste transferred from CRV to MFPV $\left(V_{j}^{\text {waste }}\right.$ MFV $)$ is determined based on the volume change in MFPV (24590-LAW-3YD-LFP-00001, Rev 2), i.e.,

$$
V_{j}^{\stackrel{\text { waste }}{M F P V}}=\Delta V_{j}^{M F P V}
$$

where $\quad \begin{gathered}\text { waste } \\ \text { MFPV }\end{gathered}=$ measured volume of the waste transferred from the CRV to the $j^{\text {th }}$ MFPV (L).

$$
\Delta V_{j}^{M F P V}=\text { volume change in the } j^{\text {th }} \text { MFPV after waste transfer from the CRV (L) }
$$

The SD for MFPV volume measurement is calculated from the SD for MFPV level measurement:

$$
s^{M F P V V}=\pi\left(\frac{D^{M F P V}}{2}\right)^{2} s^{M F P V \text { level }}
$$

where $\quad s^{M F P V V}=$ SD for MFPV volume measurement (L)

$$
\begin{aligned}
D^{M F P V} & =\text { inside diameter of MFPV vessel }(\mathrm{cm}) \\
s^{\text {MFPV level }} & =\text { SD for MFPV level measurement (L) }
\end{aligned}
$$

The SD for waste transfer is calculated from error propagation of two volume measurements:

$$
s_{j}^{\text {waste }}=\sqrt{2} s^{M F P V V}
$$

where $s_{j}^{\text {waste }}$ MFPV is SD for measured volume of the waste transferred from the CRV to the $j^{\text {th }}$ MFPV (L), which is a constant for all MFPV batches.

Table D-1 summarizes the calculation of SD for MFPV volume change. Table D-1 also includes the results of the same calculation for CRV volume for reference.

Table D-1. Calculation of SD for MFPV and CRV Volume Changes

\begin{tabular}{|l|c|c|l||}
\hline \multicolumn{1}{|c|}{ Item } & MFPV & CRV & \multicolumn{1}{c||}{ Notes } \\
\hline $\begin{array}{l}\text { Inside diameter of } \\
\text { vessel, ft }\end{array}$ & $\begin{array}{c}11 \\
(335.28 \mathrm{~cm})\end{array}$ & $\begin{array}{c}14 \\
(426.72 \mathrm{~cm})\end{array}$ & $\begin{array}{l}\text { 24590-LAW-M6C-LFP-00001, Rev. 1 } \\
\text { 24590-LAW-M6C-LCP-00001, Rev. 1 }\end{array}$ \\
\hline $\begin{array}{l}\text { Level measurement } \\
\text { SD, inch }\end{array}$ & $\begin{array}{c}1.41 \\
(3.581 \mathrm{~cm})\end{array}$ & $\begin{array}{c}1.41 \\
(3.581 \mathrm{~cm})\end{array}$ & 24590-LAW-RPT-RT-11-001, Rev 0 \\
\hline $\begin{array}{l}\text { Volume measurement } \\
\text { SD, L }\end{array}$ & 316.2 & 512.2 & Calculated from level measurement SD \\
\hline Volume change SD, L & 447.2 & 724.3 & $\begin{array}{l}\text { Corresponding to two volume } \\
\text { measurements }\end{array}$ \\
\hline
\end{tabular}




\section{Appendix E-Uncertainties for GFC Mass Measurements}




\section{Appendix E-Uncertainties for GFC Mass Measurements}

Measurements of GFC masses will be done using the load cells in the weigh hopper. According to 24590-BOF-3YD-GFR-00001, Rev 0, the weighing of GFCs will be done in 5 weigh hoppers. Four of these 5 weigh hoppers have a capacity of $10 \mathrm{ft}^{3}$ and one hopper $3 \mathrm{ft}^{3}$. As summarized in Table E- 1 four GFCs (hematite, olivine, rutile, and zircon) use $3 \mathrm{ft}^{3}$ hopper and the rest uses the $10 \mathrm{ft}^{3}$ hopper.

The exact models for load cells are not finalized, but the product from one of the candidate vendors was assumed for the purpose of this preliminary algorithm. The calculation process should be updated as necessary once the equipments are finalized. The mass capacity that can be measured in each hopper depends on bulk density of each GFC. TableE-2 summarizes the bulk density of GFC for ILAW production, which was obtained from Schumacher (2003). Based on volume capacity of each hopper and average and maximum density of GFC, the mass of each GFC per each hopper measurement is calculated in Table E-1. Table E-1 shows that the maximum expected mass is $1011 \mathrm{lb}$ for the $10 \mathrm{ft}^{3}$ hopper (Kyanite) and $465 \mathrm{lb}$ for $3 \mathrm{ft}^{3}$ hopper (Zircon). Each weigh hopper consists of three load cells of equal capacity and the final mass of each measurement is obtained by summing up three load cell readings. Then, based on maximum weight capacity reacquired given in Table E-1 and the models available for the selected candidate vendor assumed in this report, it was assumed that the $10 \mathrm{ft}^{3}$ hopper uses three $500 \mathrm{lb}$ capacity load cell models and $3 \mathrm{ft}^{3}$ hopper three $250 \mathrm{lb}$ models to provide 1500 and $750 \mathrm{lb}$ capacity weigh hoppers as summarized in Table E- $1 .^{(19)}$

Table E-1. Weight Capacity of Weigh Hoppers

\begin{tabular}{|c|c|c|c|c||}
\hline GFC/Sucrose & $\begin{array}{c}\text { Weigh } \\
\text { hopper } \\
\text { volume, ft }\end{array}$ & $\begin{array}{c}\text { Weight } \\
\text { capacity (Av } \\
\text { bulk density } \\
\text { base), lb }\end{array}$ & $\begin{array}{c}\text { Max Weight } \\
\text { capacity (Max } \\
\text { bulk density } \\
\text { base), lb }\end{array}$ & $\begin{array}{c}\text { Assumed } \\
\text { weight capacity } \\
\text { of weigh } \\
\text { hopper, lb }\end{array}$ \\
\hline Kyanite & 10 & 886.5 & 1011 & 1500 \\
\hline Boric Acid & 10 & 569.0 & 590 & 1500 \\
\hline Wollastonite & 10 & 676.5 & 768 & 1500 \\
\hline Hematite & 3 & 377.3 & 422.7 & 750 \\
\hline Li Carbonate & 10 & 670.0 & 722 & 1500 \\
\hline Olivine & 3 & 288.6 & 293.7 & 750 \\
\hline Na Carbonate & 10 & 669.0 & 675 & 1500 \\
\hline Silica & 10 & 790.0 & 889 & 1500 \\
\hline Rutile & 3 & 368.3 & 405.6 & 750 \\
\hline Zincite & 10 & 543.0 & 661 & 1500 \\
\hline Zircon & 3 & 415.2 & 464.7 & 750 \\
\hline Sucrose & 10 & 550.5 & 559 & 1500 \\
\hline
\end{tabular}

Table E-2. Bulk Density of GFCs and Sucrose

\begin{tabular}{|c|c|c|c||}
\hline GFC/Sucrose & Min & Max & Average \\
\hline Kyanite & 76.2 & 101.1 & 88.65 \\
\hline Boric Acid & 54.8 & 59 & 56.9 \\
\hline Wollastonite & 58.5 & 76.8 & 67.65 \\
\hline
\end{tabular}

${ }^{(19)}$ For the purpose of this preliminary algorithm it was assumed that the Mettler Toledo's Centerlign Weigh Module model 744 (for $250 \mathrm{lb}$ capacity) and 745 (for $500 \mathrm{lb}$ capacity) are used. 


\begin{tabular}{||c|c|c|c||}
\hline \hline GFC/Sucrose & Min & Max & Average \\
\hline Hematite & 110.6 & 140.9 & 125.75 \\
\hline Li Carbonate & 61.8 & 72.2 & 67 \\
\hline Olivine & 94.5 & 97.9 & 96.2 \\
\hline Na Carbonate & 66.3 & 67.5 & 66.9 \\
\hline Silica & 69.1 & 88.9 & 79 \\
\hline Rutile & 110.3 & 135.2 & 122.75 \\
\hline Zincite & 42.5 & 66.1 & 54.3 \\
\hline Zircon & 121.9 & 154.9 & 138.4 \\
\hline Sucrose & 54.2 & 55.9 & 55.05 \\
\hline
\end{tabular}

A brief review of the example MFPV batch formulations shows that the required mass of most GFCs would require multiple measurements to measure each GFC for a single MFPV batch. Therefore, the uncertainty related to the mass of each GFC added to the MFPV are calculated using the error propagation method described in Piepel et al. (2005) (Section 3.4.1.1).

First the SD is calculated for each weigh hopper using ${ }^{(20)}$ :

$$
s_{\text {weigh }}^{W H}=\sqrt{3\left(\frac{2}{3} S P C_{C E}^{2}+S P C_{N R}^{2}\right)}
$$

where $\quad S_{\text {weigh }}^{W H}=$ standard deviation for weigh hopper weight measurement $(\mathrm{kg})$

$$
\begin{aligned}
& S P C_{C E}=\begin{array}{l}
\text { specification for combined error (CE) as given in the data sheet for each load cell. } \\
\text { Includes linearity and hysteresis errors. (kg) }
\end{array} \\
& S P C_{N R}=\begin{array}{l}
\text { specification for non-repeatability (NR) as given in the data sheet for each load cell } \\
(\mathrm{kg})
\end{array}
\end{aligned}
$$

The $S P C_{C E}$ and $S P C_{N R}$ values are obtained by multiplying the combined error or non-repeatability error given in percent of full scale output (\%FSO) by the full scale of each load cell.

The SD for weighing each GFC depends on the number of weighing required for each MFPV batch. For Step 3 of glass formulation algorithm, the SD for weighing is given as:

$$
\begin{gathered}
s_{k}^{G F C V}=\sqrt{n_{k j}^{G F P V}{ }^{M F C \text { weigh }}\left[\left(s_{\text {weigh }}^{\text {WH }}\right)^{2}+\left(s_{\text {control }}^{\text {WH }}\right)^{2}\right]} \text { for Step } 1 \\
s_{k}^{\text {GFPV mass }}=s_{\text {weigh }}^{\text {WH }} \sqrt{n_{k j}^{G F C \text { weigh }}} \text { for Step } 3
\end{gathered}
$$

where $\quad s_{k j}^{G F C P \text { mass }}=$ standard deviation of weighing the $k^{\text {th }}$ GFC in the $j^{\text {th }}$ MFPV batch

$$
n_{k j}^{G F C V}=\text { number of weighing required for the } k^{\text {th }} \text { GFC in the } j^{\text {th }} \text { MFPV batch }
$$

${ }^{(20)}$ Reichmuth A. 2000. Estimating Weighing Uncertainty from Balance Data Sheet Specifications, Mettler Toledo, Columbus, OH. (available at www.mt.com) 


$$
\begin{aligned}
S_{\text {weigh }}^{W H} & =\text { standard deviation for weigh hopper weight measurement }(\mathrm{kg}) \\
S_{\text {control }}^{W H} & =\begin{array}{l}
\text { standard deviation for target mass control in weigh hopper weight measurement } \\
(\mathrm{kg})(\text { to be obtained after testing the plant equipment installed) }
\end{array}
\end{aligned}
$$

For Step 3, the $n_{k j}^{G F C \text { weigh }}$ is the actual number, however, for Step 1 the number of weighing is calculated based on the weighing mass capacity of weigh hopper as below:

$$
n_{k j}^{G F P V}=\operatorname{truncate}\left(\frac{M_{k j}^{\text {MFPV }} \text {,target,Step } 1}{M_{k}^{\text {GFC cass }}}\right)+1
$$

where

$$
\begin{aligned}
& n_{k j}^{G F C \text { weigh }}=\text { number of weighing required for the } k^{\text {th }} \text { GFC in the } j^{\text {th }} \text { MFPV batch }
\end{aligned}
$$

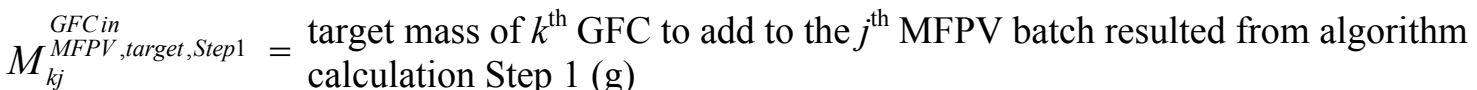

$$
\begin{aligned}
& \text { GFCmass } \\
& M_{k}^{\text {GHC capa }}=\text { mass capacity of the weigh hopper for the } k^{\text {th }} \text { GFC }
\end{aligned}
$$




\section{Appendix F-GFC and Sucrose Volume Contributions}




\section{Appendix F-GFC and Sucrose Volume Contributions}

The calculation of volume contribution from GFCs in Equation (56) assumes ideal mixing between waste slurry and GFC particles, i.e.

$$
V^{\text {slurry }}=V^{\text {water }}+\sum_{k=1}^{n} \frac{M_{k}^{G F C}}{\rho_{k}^{G F C}}
$$

where $\quad V^{\text {slurry }}=$ calculated volume of slurry (L)

$V^{\text {water }}=$ volume of water $(\mathrm{L})$

$M_{k}^{G F C}=$ mass of the $k^{\text {th }}$ GFC $(\mathrm{g})$

$\rho_{k}^{G F C}=$ density of the $k^{\text {th }}$ GFC $(\mathrm{g} / \mathrm{L})($ Table F-1)

However, the actual slurry volume will be different from that calculated based on ideal mixing because: (1) dissolution of water soluble materials tends to decrease the volume of slurry and (2) entrapment of small bubbles on the surface of solid particles would increase the slurry volume.

To evaluate the difference between calculated and actual slurry volumes, existing data on measured density of slurry feeds was evaluated. Table F-2 includes the feed recipes for GFCs, sucrose, and spiking chemicals in terms of added masses per 1 liter of waste simulant and target density of waste simulant and measured density of slurry feed. The waste oxide loading in glass for each feed is also included in Table F-2 for information. The target density of waste simulant and measured density of slurry feed data are used to obtain the "measured" volume of slurry feed.

$$
V^{\text {slurry }}=\frac{\rho^{\text {waste simul }} \times 1 \mathrm{~L}+\sum_{k=1}^{n} M_{k}^{\text {additives }}}{\rho^{\text {feed }}}
$$

The "calculated" volume of slurry feed is from Equation (F-1).

$$
V^{\text {slurry }}=1 \mathrm{~L}(\text { waste simulant })+\sum_{k=1}^{n} \frac{M_{k}^{\text {additives }}}{\rho_{k}}
$$

slurry
where $\quad V^{\text {meas }}=$ "measured" slurry volume obtained from target density of waste simulant and
measured density of slurry feed $(\mathrm{L})$

$\rho^{\text {waste simul }}=$ target density of waste simulant $(\mathrm{g} / \mathrm{L})$

$M_{k}^{\text {additives }}=\begin{aligned} & \text { mass of the } k^{\text {th }} \text { additive (GFCs, sucrose, and spiking chemicals) per } 1 \mathrm{~L} \text { of waste } \\ & \text { simulant }(\mathrm{g})\end{aligned}$

$\rho^{\text {feed }}=$ measured density of slurry feed $(\mathrm{g} / \mathrm{L})$

$V^{\text {slurry }}=$ "calculated" slurry volume based on ideal mixing between waste simulant and

$\rho_{k}=$ density of the $k^{\text {th }}$ additive (GFCs, sucrose, and spiking chemicals) (g/L) (Table F-1) 
Table F-2 shows the "measured" and "calculated" volumes of slurry feed and their relative percent difference for each feed. The difference ranged from $-1.5 \%$ (underestimation) to $3.3 \%$ (overestimation) with more feeds overestimating, which suggest that within limited data the deviation of calculated slurry feed volume from actual is relatively small. As discussed in Section 5.2, the allowable volume increase before the "High Operator Response" was 3,331 L. A half of this 3,331 L was used for allowable feed volume increase caused by accidentally increased waste transfer volume leaving the room for calculation errors. The GFC volume contribution is expected to be the main source of error in calculating the total feed volume. The room of 1,666 L corresponds to $12.9 \%$ of the MFPV batch volume $(12,870 \mathrm{~L})$, which sufficiently higher than the range of differences between -1.5 and $3.3 \%$.

Table F-1. Particle Density of GFCs, Sucrose and Spiking Chemicals

\begin{tabular}{|c|c|}
\hline GFC or other additives $^{(\mathrm{a})}$ & Particle density, g/L \\
\hline Kyanite & 3398.3 \\
\hline Boric Acid & 1509.3 \\
\hline Wollastonite & 2899.3 \\
\hline Hematite & 4747.9 \\
\hline Lithium Carbonate & 2109.6 \\
\hline Olivine & 2948.2 \\
\hline Sodium Carbonate & 2532.5 \\
\hline Silica & 2649.5 \\
\hline Rutile & 4647.8 \\
\hline Zincite & 5596.9 \\
\hline Zircon & 4701.4 \\
\hline Sucrose & 1549.0 \\
\hline $\mathrm{Na}_{2} \mathrm{SO}_{4}$ (spiking chemical) & 2680.0 \\
\hline $\mathrm{NaCl}^{\text {(spiking chemical) }}$ & 2165.0 \\
\hline $\mathrm{NaF}^{\text {(spiking chemical) }}$ & 2780.0 \\
\hline $\mathrm{KI}$ (spiking chemical) & 3670.0 \\
\hline
\end{tabular}

(a) Densities of GFCs and sucrose are as given in Table A-12. Densities of spiking chemicals were obtained from Alfa Aesar $\AA$ brochure. 
Table F-2. Data Collected for Various Slurry Feeds and Estimated Slurry Feed Volumes

\begin{tabular}{|c|c|c|c|c|c|c|c|c|c|}
\hline Feed ID & $\begin{array}{c}\text { 3M Na } \\
\text { LAW } \\
\end{array}$ & $\begin{array}{l}8 \mathrm{Ma} \\
\mathrm{NaNO}_{3}\end{array}$ & $\begin{array}{c}\text { Envelope } \\
\text { A1 } \\
\end{array}$ & $\begin{array}{c}\text { Envelope } \\
\text { C1 } \\
\end{array}$ & $\begin{array}{c}\text { Envelope } \\
\text { A2 } \\
\end{array}$ & $\begin{array}{c}\text { Envelope } \\
\text { B1 } \\
\end{array}$ & $\begin{array}{c}\text { Envelope } \\
\text { B2 } \\
\end{array}$ & $\begin{array}{c}\text { Envelope } \\
\text { A3 } \\
\end{array}$ & $\begin{array}{c}\text { Envelope } \\
\text { C2 } \\
\end{array}$ \\
\hline GFC and other chemicals ${ }^{(\mathrm{a})} \backslash$ Data source & \multicolumn{2}{|c|}{ Eibling et al. 2003} & \multicolumn{2}{|c|}{ Matlack et al. 2003a } & \multicolumn{2}{|c|}{ Matlack et al. 2003b } & $\begin{array}{l}\text { Matlack et } \\
\text { al. 2003c }\end{array}$ & \multicolumn{2}{|c|}{ Matlack et al. 2003d } \\
\hline Kyanite & 35.67 & 95.12 & 35.84 & 145.92 & 99.98 & 156.10 & 148.9 & 67.53 & 128.48 \\
\hline Boric Acid & 87.65 & 233.74 & 200.17 & 233.04 & 238.52 & 282.85 & 252.9 & 233.43 & 224.71 \\
\hline Wollastonite & 21.16 & 56.42 & 52.48 & 138.63 & 59.77 & 236.73 & 211.7 & 139.26 & 205.71 \\
\hline $\mathrm{Fe}_{2} \mathrm{O}_{3}$ & 27.21 & 72.55 & 81.90 & 63.38 & 72.18 & 75.82 & 67.9 & 66.79 & 43.65 \\
\hline Li Carbonate & - & - & - & 80.79 & - & 170.61 & 152.4 & 80.93 & 107.74 \\
\hline Olivine & 15.50 & 41.33 & 52.09 & 40.98 & 41.46 & 95.57 & 85.2 & 38.29 & 41.53 \\
\hline Na Carbonate & - & - & - & - & - & - & 61.1 & - & - \\
\hline $\mathrm{SiO}_{2}$ & 183.63 & 489.68 & 470.39 & 431.63 & 490.66 & 516.51 & 460.2 & 465.38 & 427.26 \\
\hline Rutile & 10.52 & 28.05 & 25.95 & 15.51 & 28.82 & 23.52 & 21.0 & 15.46 & 14.79 \\
\hline $\mathrm{ZnO}$ & 14.99 & 39.97 & 36.88 & 39.61 & 40.18 & 76.96 & 69.0 & 39.85 & 53.00 \\
\hline $\mathrm{ZrSiO}_{4}$ & 22.67 & 60.45 & 55.63 & 58.50 & 61.07 & 75.89 & 68.0 & 58.88 & 59.64 \\
\hline Sucrose & - & - & 78.50 & 4.65 & 83.66 & 24.55 & 8.0 & 63.85 & 23.66 \\
\hline $\mathrm{Na}_{2} \mathrm{SO}_{4}$ (spiking chemical) & - & - & 0.85 & 1.74 & 1.47 & 5.60 & 5.0 & 1.30 & 2.25 \\
\hline $\mathrm{NaCl}$ (spiking chemical) & - & - & 12.93 & 1.54 & 5.08 & 0.24 & 0.1 & 9.01 & 4.51 \\
\hline NaF (spiking chemical) & - & - & 0.02 & 1.55 & 1.71 & 0.46 & 0.1 & 0.30 & 0.54 \\
\hline KI (spiking chemical) & - & - & - & - & 1.78 & 2.08 & 1.9 & 1.69 & 1.72 \\
\hline Target density of waste simulant, $\mathrm{g} / \mathrm{L}$ & 1157.6 & 1390 & 1358.94 & 1256.95 & 1381.06 & 1125.48 & 1065.09 & 1292.43 & 1245.07 \\
\hline Measured density of slurry feed, g/L & 1382.0 & 1713.0 & 1714.3 & 1673.3 & 1730.0 & 1705.0 & $1690.0^{(\mathrm{b})}$ & 1692.5 & 1692.5 \\
\hline Waste oxide loading in glass, wt $\%$ & - & - & 26.04 & 15.62 & 24.54 & 6.71 & 4.01 & 18.84 & 13.95 \\
\hline \multicolumn{10}{|c|}{ Estimated Slurry Volumes } \\
\hline Based on measured slurry density, L & 1.141 & 1.466 & 1.436 & 1.503 & 1.507 & 1.683 & 1.585 & 1.521 & 1.527 \\
\hline Calculated from GFCs/chemicals densities, $\mathrm{L}$ & 1.166 & 1.442 & 1.455 & 1.501 & 1.507 & 1.693 & 1.637 & 1.533 & 1.537 \\
\hline RPD between "measured" and "calculated", \% & 2.2 & -1.5 & 1.3 & -0.1 & 0.0 & 0.6 & 3.3 & 0.8 & 0.7 \\
\hline
\end{tabular}

"-" represents empty data field

RPD: relative percent difference, ([calculated] - [measured])/[measured]

(a) Given as g per $1 \mathrm{~L}$ waste simulant for GFC, sucrose, and spiking chemicals.

(b) For Envelop B2 feed, target value is given because measured data is not available. 


\section{Appendix G-PERT Distribution}




\title{
Appendix G-PERT Distribution
}

\author{
oxides in
}

For GFC composition $\left(m_{i k}^{G F C}\right)$, values outside of 0 and 1 are not physically meaningful. This precludes the use of normal distribution for some GFC compositions which can yield a significant fraction of the distribution outside of this range. As an example, silica sand has a most likely (or mean) $\mathrm{SiO}_{2}$ concentration of 0.997 , minimum of 0.992 , and maximum of 0.999 (Table A-4). The SD value was estimated as 0.0015 as described in Piepel et al. (2005). Figure G-1 shows an example normal

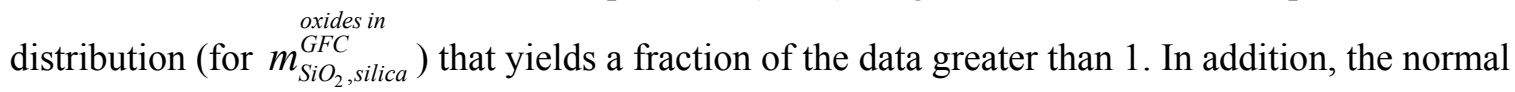
distribution gives a symmetric distribution for skewed data.

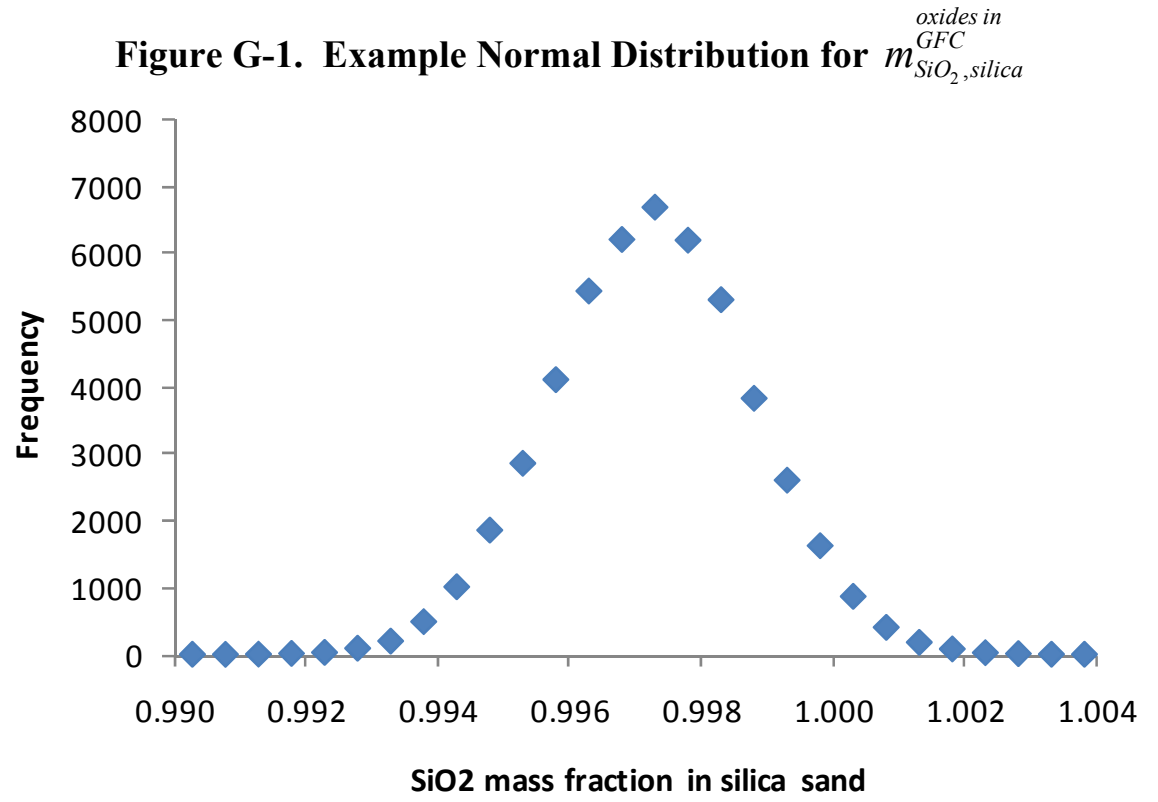

To address these concerns a PERT distribution was selected for use in the formulation algorithm. Figure

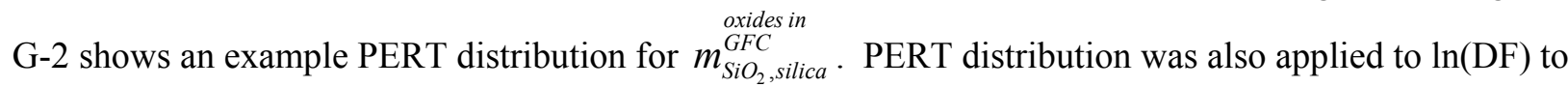
calculate the retention factor $\left(v_{i}\right)$.

The following description borrowed heavily from RiskAmp ${ }^{\circledR}$ software; exact quotes are italicized in this section. The PERT distribution uses the minimum, most likely, maximum, and potentially a scale parameter. Depending on the values provided, the PERT distribution can provide a close fit to the normal or lognormal distributions. Like the triangular distribution, the PERT distribution emphasizes the "most likely" value over the minimum and maximum estimates. However, unlike the triangular distribution the PERT distribution constructs a smooth curve which places progressively more emphasis on values around (near) the most likely value, in favor of values around the edges. Figure G-3 shows examples of the PERT distribution with symmetric and asymmetric "most likely" or median values. 
Figure G-2. Example PERT Distribution for $\begin{gathered}\text { oxides in } \\ m_{\mathrm{SiO}_{2}, \text { silica }}^{G F C}\end{gathered}$

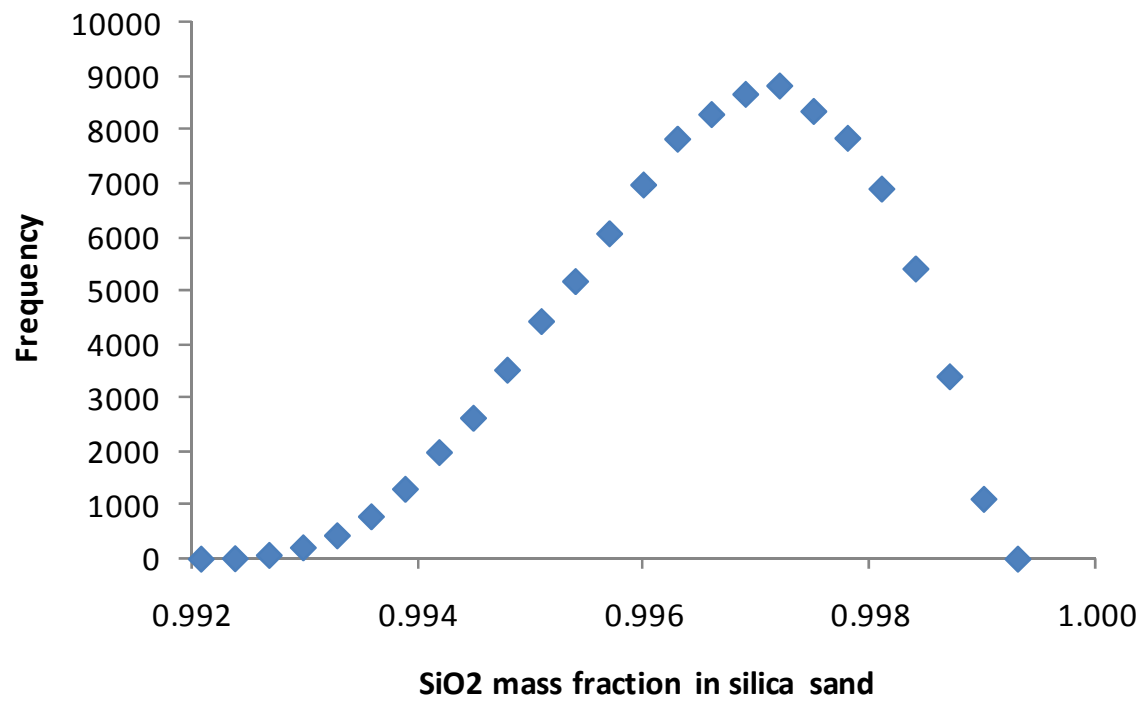

Figure G-3. Examples of the PERT distribution

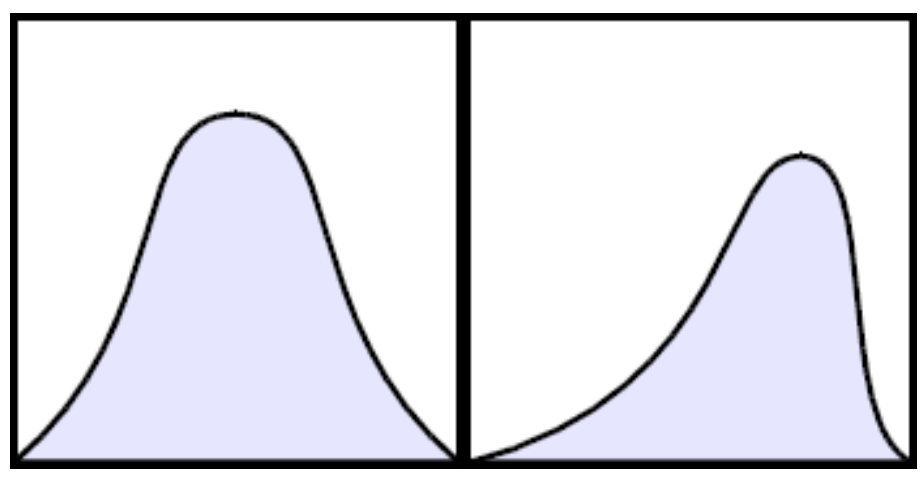

The PERT distribution is given by the following function:

$$
F(x)=\left\{\begin{array}{ll}
B_{x}(v, w) / B(v, w) & \rightarrow 0 \leq x \leq 1 \\
0 & \rightarrow \text { otherwise }
\end{array}\right\}
$$

where

$$
B(v, w) \equiv \int_{0}^{1} t^{v-1}(1-t)^{w-1} d t \text { and } B_{x}(v, w) \equiv \int_{0}^{x} t^{\nu-1}(1-t)^{w-1} d t
$$

The PERT distribution uses the mode or most likely parameter to generate the shape parameters $v$ and $w$. An additional scale parameter $\lambda$ scales the height of the distribution; the default value for this parameter is 4. 
In the PERT distribution, the mean $(\mu)$ is calculated

$$
\mu=\frac{x_{\min }+x_{\max }+\lambda x_{\bmod e}}{\lambda+2}
$$

and used to calculate the $v$ and $w$ shape parameters

$$
v=\frac{\left(\mu-x_{\min }\right)\left(2 x_{\bmod e}-x_{\min }-x_{\max }\right)}{\left(x_{\bmod e}-\mu\right)\left(x_{\max }-x_{\min }\right)} \text { and } w=\frac{v\left(x_{\max }-\mu\right)}{\mu-x_{\min }}
$$

which are used, with the minimum and maximum scale parameters, to sample the beta distribution. For more information and a more detailed analysis, see for example, Vose 2000. The PERT distribution gives realistic responses that strongly favor the "expected value" and smoothly vary to the range of measured values without exceeding the minimum or maximum. In order to implement the PERT distribution the required values are the minimum, maximum, and most likely value (or mode). The scaling factor $(\lambda)$ can be used to adjust the height to width of the distribution, but, are not used in this report and will not be discussed in this context. 